(Aus dem physiologischen Institut der Universität Halle a. S.)

\title{
Beitrag \\ zur Kenntnis von organischen Nahrungsstoffen mit spezifischer Wirkung.
}

Von

Emil Abderhalden und Y. Schaumann.

Mit Tafel I bis V.

(Eingegangen 10. Juli 1918.)

Inhaltsverzeichnis.

A. Allgemeiner Teil.

Seite

I. Einleitung . . . . . . . . . . . . . . . . . . 5

II. Die alimentäre Dystrophie (Polyneuritis) verschiedener Tierarten, im besonderen die der Tauben . . . . . . . . . . . .

III. Ist die alimentäre Dystrophie bzw. die Beriberi des Menschen auf die Wirkung eines exogenen oder endogenen Giftes zurückzuführen? . . 58

IV. Die Eutonine . . . . . . . . . . . . . . . . . . . . . . 67

V. Einfluss des mit Alkohol aus hydrolysierter Hefe hergestellten Extraktes und ferner der aus diesem gewonnenen hochwertigen Eutonin-Präparate auf die Wirkung von Hefefermenten: . . . . . . . . . . 88

VI. Die Muttersubstanzen der Eutonine ... . . . . . . . . . . . . . 92

VII. Versuche mit Aminosäuren . . . . . . . . . . . . . . 114

VIII. Versuche mit vollständig abgebauten, Inkrete liefernden Organen (Optonen) . . . . . . . . . . . . . . . . . 119

IX. Prüfung der Sera von einseitig mit geschliffenem Reis ernährten Tauben auf Abwehrfermente . . . . . . . . . . . . 121

X. Versuche mit einer Reihe durch Hydrolyse von Bierhefe gewonnener Abbanprodukte . . . . . . . . . . . . . . . . 125

XI. Schlusswort. . . . . . . . . . . . . . . 149

\section{B. Experimenteller Teil.}

I. Versuche mit ausgezogenen Graupen . . . . . . . . . . . . . . . 158

II. Versuche mit getrockneten Kartoffeln . . . . . . . . . . . . 159

III. Versuche über einseitige Ernährung an Ratten . . . . . . . . . . . 159

IV. Versuche über einseitige Ernährung an Sperlingen . . . . . . . 160

V. Versuche mit Oxalsäure (Versuch Nr. 1 und 2) . . . . . . . . . 160

VI. Versuch mit Rindergalle (Nr. 3) . . . . . . . . . . . . . . 161

VII. Hefepräparat A. Darstellung und Tierversuche (Nr. 4 und 5) . . . . 162 
VIII. Versuche mit Präparaten aus hydrolysierter Bierhefe und Reiskleie . 1. Alkoholische Extrakte. Darstellung und Versuche (Nr. 6-8). .

2. Aceton-Niederschlag aus dem alkoholischen Auszuge von Hefehydrolysat. Darstellung und Tierversuche (Nr. 9 und 10) . .

3. Versuche mit dem aus bydrolysierter Hefe gewonnenen AcetonNiederschlage und mit dem aus einer alkoholischen Lösung desselben durch Quecksilberchlorid gefällten, dann durch Schwefelwasserstoff zerlegten Niederschlage (Nr. 11). . . . . . . . . .

IX. Versuche mit Rinderblut (Nr. 12) . . . . . . . . . . . . 172

X. Versuche mit Hühner- und Taubenblut . . . . . . . . . . . 174

XI. Versuche mit Aminosäuren (Nr. 13-16) . . . . . . . . . . . . 175

XII. Versuche mit dem Phosphatid aus Weizenkleie (Nr. 17 A, B u. C). 177

XIII. Nukleoproteid aus Hefe. Darstellung, Untersuchung und Tierversuche (Nr. 18 und 19) . . . . . . . . . . . . . . . . 179

XIV. Filtrat von dem Nukleoproteid aus Hefe. Untersuchung und Tierversuche .................... . . 185

XV. Rückstand der mit verdünntem Ammoniak ausgezogenen Hefe. Tierversuche (Nr. 20 und 21) . . . . . . . . . . . . . . . . . . 186

XVI. Nuklein aus Hefe. Darstellung, Untersuchung und Tierversuche . . 188

XVII. Von dem Hefe-Nukleoproteid durch Finwirkung von Pepsin-Salzsäure hei $37^{\circ}$ abgespaltene Eiweisskomponente. Darstellung, Untersuchung und Tierversuche . . . . . . . . . . . . . . . . . . . . . 189

XVIII. Versuch mit Sojabohnen (Nr. 22) . . . . . . . . . . . 190

XIX. Versuche mit Präparaten aus Sojabohnen. Darstellung, Untersuchung und Tierversuche . . . . . . . . . . . . . . . 191

XX. Versuche mit Präparaten aus gemahlenen gelben Erbsen. Darstellung, Untersuchung und Tierversuche (Nr. 23 und 24) . . . . . . . .

XXI. Versuche mit vollständig abgebauten, Inkrete liefernden Organen (Optonen ans Corpus luteum, Thymus, Thyreoidea, Testes u. Hypophyse)

XXII. Prüfung der Sera von einseitig mit geschliffenem Reis ernährten Tauben auf Abwehrfermente: 1. Bereitung der Substrate; 2. Gewinnung des Taubenserums; 3. Methodik des Dialysierverfahrens; 4. Prüfung der Dialysate; 5. Versuchstiere; 6. Ernährung der Versuchstauben; 7. Ergebnisse ...............

XXIII. Untersuchung von Taubenkot bei einseitiger Fütterung mit Reis und bei Ernährung mit gemischtem Taubenfutter: 1. Bestimmung von Wasser, Stickstoff, Asche und Phosphorsäure; 2. Prüfung auf Oxalsäure; 3. Prüfung anf die Anwesenheit anderer organischer Gifte .

XXIV. Untersuchung des Proteins aus geschliffenem Reis . . . . . . 203

XXV. Analysen:

1. Gelbe Erbsen . . . . . . . . . . . . . . . . . . 204

2. Pepsin-Salzsäureauszug aus gemahlenen gelben Krbsen. . . . 205

3. Rückstand des mit Alkohol und Pepsin-Salzsäure ausgezogenen Erbsenmehls .............. 205

4. Bierhefe, getrocknet. Qualität Nr. I . . . . . . . . . 206

5. Bierhefe, getrocknet. Qualität Nr. II . . . . . . . 207 
Beitrag zur Kenntnis von organischen Nahrungsstoffen mit spezif. Wirkung.

6. Nukleoproteid aus Hefe:

A. Durch Zentrifugieren ausgewaschenes Präparat. . . . . . 207

B. Nach dem Wegelin'schen Verfahren vollkommen ausgewaschenes Präparat . . . . . . . . . . . . 207

7. Nuklein aus Hefe . . . . . . . . . . . . . . 208

8. Durch künstliche Verdauung (mit Pepsin-Salzsāure) aus dem HefeNukleoproteid abgespaltene Eiweisskomponente . . . . . . 209

9. Geschliffener Reis . . . . . . . . . . . . . 210

1. Sorte A . . . . . . . . . . . . . . . . 210

2. Sorte B . . . . . . . . . . . . . . . 211

3. Sorte C . . . . . . . . . . . . . 211

10. Sojabohnen ................. . . . 212

11. Präparate aus Sojabohnen . . . . . . . . . . . 212

XXVI. Darstellung von Abbauprodukten aus hydrolysierter Hefe sowie deren chemische und physiologische Untersuchung ${ }^{1)}$. . . . . . 214

1. Tertiârer Aceton-Niederschlag . . . . . . . . . . . 216

Schema der genetischen Beziehungen der einzelnen Präparate zueinander . . . . . . . . . . . . . 217

Präparat I A . . . . . . . . . . . . . . . 216

". I A 1 . . . . . . . . . . . . . . . . . 218

I A $2 \ldots \ldots \ldots \ldots$

I N $5 \ldots \ldots \ldots . \ldots 218$

I R 1 . . . . . . . . . . . . . . 221

I R $4 \ldots \ldots \ldots \ldots \ldots$

I $\mathrm{B} 3 \mathrm{a} \ldots \ldots \ldots \ldots$

I R $6 \ldots \ldots 227$

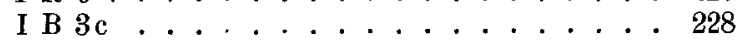

I B 2 . . . . . . . . . . . . . 229

I R $3 \ldots \ldots \ldots 230$

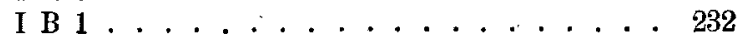

2. In absolutem Alkohol des Handels ( $99 \%$ igem) unlöslicher Anteil des Aceton-Niederschlages . . . . . . . . . . . 232

A. Quecksilbersulfat-Niederschlag .......... 232

B. Kupfersulfat-Natriumbisulfit-Niederschlag . . . . . . . 234

C. Quecksilberchlorid-Niederschlag . . . . . . . . 235

3. In Aceton löslicher Anteil des konzentrierten, aus hydrolysierter

Hefe dargestellten alkoholischen Auszuges. . . . . . . 235

Schema der genetischen Beziehungen der einzelnen Präparate zueinander ................ 236

Präparat III R .............. 287

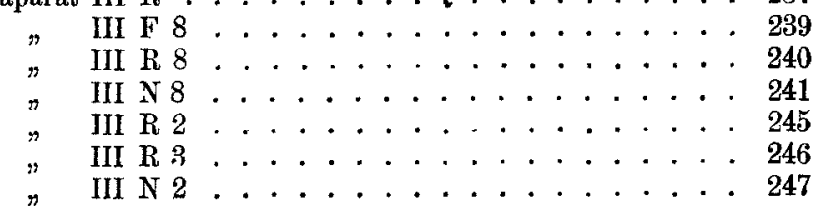

1) Ein alphabetisch geordnetes Verzeichnis der sämtlichen Präparate und Zwischenprodukte findet sich auf Seite 271. 
Emil Abderhalden und H. Schaumann:

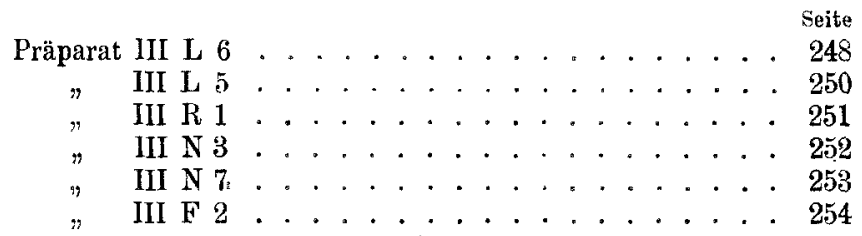

4. Tierversuche mit den aus hydrolysierter Hefe gewonnenen Abbauprodukten ${ }^{1}$ ) . . . . . . . . . . . . . . . 255

I. Tertiärer Aceton-Niederschlag (Nr. 24 und 25) . . . . 255

Präparat I A . . . . . . . . . . . . . 256

$\quad$ I A $1 \ldots \ldots \ldots . \ldots . \ldots 258$

" I A 2................. . . 258

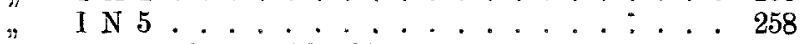

" I R 1 (Versuch Nr. 26) . . . . . . . . . 259

\# I R 2............... . 260

" I R 3................ 260

$" \quad \mathrm{I}$ R $6 \ldots \ldots \ldots . \ldots . \ldots 261$

" I B 1 ............... 261

$" \quad$ I B 2 . . . . . . . . . . . . . 262

" I B 3 c . . . . . . . . . . . . . . . . . . . 262

II. In absolutem Alkohol unlöslicher Rückstand der Aceton-

Niederscbläge (Versuch Nr. 27-29) . . . . . . . . . 262

III. In Aceton löslicher Anteil des konzentrierten, primären alkoholischen Auszuges aus hydrolysierter Hefe . . . . . 266

Präparat III R . . . . . . . . . . . . 266

III N $4 \ldots \ldots \ldots$

III F 8 . . . . . . . . . . . . . . 266

III R $8 \ldots \ldots \ldots \ldots$

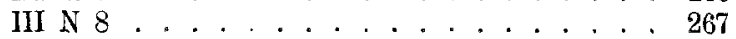

III R 2 . . . . . . . . . . . . . 267

III R 2 (salzsaures Salz) . . . . . . . . 268

III R 3 . . . . . . . . . . . . . . . . . 269

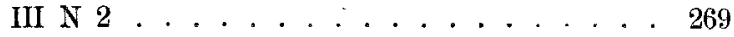

III L $6 \ldots \ldots \ldots 9$

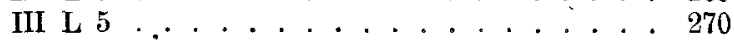

III N $3 \ldots \ldots \ldots$

III N $7 \ldots \ldots . \ldots . \ldots 270$

III F $7 \ldots \ldots \ldots \ldots$

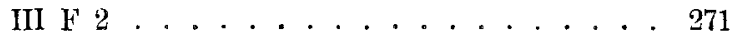

Verzeichnis der aus hydrolysierter Hefe gewonnenen Abbauprodukte in alphabetischer Reihenfolge . . . . . . . . 271

Verzeichnis der Tierversuche mit den aus hydrolysierter Hefe gewonnenen Abbauprodukten in alphabetischer Reihenfolge 272

XXVII. Photographien von Versuchstieren vgl. Tafel I-III.

XXVIII. Mikrophotographien der Kristallformen verschiedener A bbauprodukte der Hefe vgl. Tafel IV und V.

XXIX. Erläuterungen zu den Lichtbildern Nr. 1-37 . . . . . . . 272

XXX. Erläuterungen zu den Mikrophotographien Nr. 38-54. . . . . . 273

1) Ein alpbabetisch geordnetes Verzeichnis dieser Tierversuche findet sich auf Seite 272 . 


\section{A. Allgemeiner Teil.}

\section{Einleitung.}

Zahlreiche Forschungen der letzten Jahre haben Ergebnisse gezeitigt, die zu der Fragestellung führten, ob neben den bekannten organischen Nahrungsstoffen und ihren Bausteinen und den bekanntenorganischen noch Stoffe in der gewöhnlichen Nahrung vorhanden sind, an deren Vorhandensein sich der normale Ablauf der Stoffwechselprozesse knüpft. Wir haben beide unabhängig voneinander auf diesem Gebiete geforscht und haben uns dann vereinigt, um die gemeinsamen Erfahrungen zur Durchführung neuer Versuche zu verwerten. Die folgende Arbeit ist das Ergebnis dieser gemeinsamen Studien. Thr Endziel war, die wirksamen Stoffe nach ibrer Zusammensetzung und ihrem Bau kennen zu lernen und ihre Wirkung im einzelnen und zusammen genau zu verfolgen. Dieses Ziel konnten wir in Anbetracht der grossen Schwierigkeiten in der Beschaffung der Ausgangsmaterialien, der Versuchstiere und vor allem auch ihres Futters nicht in allen Teilen erreichen ${ }^{1}$ ). Immerhin glauben wir das ganze Problem in mehreren Teilen gefördert zu haben. Mit dem Endziele der Erkennung jener eigenartigen Stoffe, die für besondere Wirkungen verantwortlich gemacht werden, war das Bestreben verknüpft, einen tieferen Einblick in die feineren Stoffwechselvorgänge zu gewinnen; haben doch immer mehr Beobachtungen der letzten Jahre gezeigt, dass diese nicht"in so einfachen Bahnen verlaufen, wie es allgemein dargestellt worden ist. Gleichzeitig ist zu erwarten, dass jeder Fortschritt auf diesem Gebiete der Stoffwechselforschung befruchtend auf die Erkenntnis der Störungen des Stoffwechsels einwirken wird.

Wir möchten mit der folgenden Mitteilung nicht nur unsere Ergebnisse zur Kenntnis geben, sondern vielmehr den Versuch unternehmen, abzugrenzen, welchen Stand die ganze Forschung erreicht hat. Es lässt sich dann klar erkennen, welche Wege einzuschlagen sind, um die ganzen mannigfaltigen Probleme weiterhin mit Erfolg anzugreifen. Zahlreiche Forscher haben sich dem interessanten Forschungsgebiete zugewandt. Fast jede Zeitschrift bringt Beiträge zu der so wichtigen Frage der noch unbekannten Nahrungsstoffe. Die Ziele, die verfolgt werden, sind verschiedene. Die einen Forscher er-

1) Weitere Untersuchungen sind im Gange. 
streben die Gewinnung und Erkennung der wirksamen Stoffe, andere haben durch Tierversuche wichtige Beiträge zu der Frage der Möglichkeit der vollwertigen Ernährung von wachsenden und erwachsenen Individuen mit den bekannten, möglichst reinen Nahrungsstoffen mit und ohne Zusatz bestimmter Stoffe, wie Kleie, Hefe, Malzextrakt, geringen Mengen von Milch, frischen Gemüsen, Fruchtsäften usw., angestellt. Einen schon recht breiten Raum nehmen Mitteilungen über klinische Beobachtungen ein, die auf das Fehlen der noch unbekannten Stoffe zurückgeführt werden. Dieser Anteil an der ganzen Forschung ist naturgemäss der schwächste. Solange die Stoffe nicht bekannt sind und nicht einwandfrei bewiesen war, dass ganz geringe Mengen bestimmter Stoffe zur Aufrechterhaltung des Stoffwechsels und bestimmter Funktionen notwendig sind, und vor allem auch der Angriffspunkt der fraglichen Stoffe gar nicht festgelegt ist, ist möglichste Zurückhaltung in Erklärungsversuchen pathologischer Erscheinungen geboten.

Bei der Übersicht über die bis jetzt vorliegenden Versuche haben wir nur dann eine kritische Stellung zu den vorliegenden Ergebnissen und Schlussfolgerungen genommen, wo es in Anbetracht der erreichten Erkenntnis auf Grund der vorliegenden Tatsachen geboten erscheint. Dagegen haben wir mit Absicht überall da eine bestimmte Stellungnahme unterlassen, wo wir nicht festen Boden unter den Füssen hatten. Es liegen in der einschlägigen Literatur eine Reihe von Feststellungen vor, die eigenartig erscheinen, und bei denen man den Eindruck hat, dass sie nicht über jeden Zweifel erhaben sind. Wir haben sie trotzdem mitgeteilt, weil auf diesem Gebiete jede Beobachtung von Bedeutung sein kann.

Die ältere hierher gehörige Literatur ist von uns nur insoweit angeführt und berücksichtigt worden, als es für unsere Zwecke erforderlich erschien. Die neuere Literatur ist, soweit sie uns unter den gegenwärtigen Verhältnissen zugänglich war, überall da, wo sich Berührungspunkte mit unserer eigenen Arbeit ergaben, mit in den Kreis der Betrachtung einbezogen ${ }^{1}$ ).

1) Ausführliche Verzeichnisse über die ältere Literatur bis 1915 finden sich bei H. Schaumann, Die Ätiologie der Beriberi I und II und Neuere Érgebnisse der Beriberi-Forschung. Arch. f. Schiffs- u. Tropenhygiene Bd. 15 Beib. 8. 1910. Ebenda Bd. 18 Beih. 6. 1914. Bd. 19 S. 139. 1915. Eine recht gute Übersicht über die ganzen Probleme und die zugehörige Literatur gibt die nach der Ab- 
Die neúeren auf diesem Sondergebiet liegenden Forschungen sind auf das engste mit solchen verknüpft, welche zur Klärung der Ätiologie des Skorbuts, vor allem aber der B eriberi seit etwa zwei Dezennien im Gange sind. Als Beriberi (japan. Kakke) bezeichnet man bekanntlich eine besonders in Ostasien heimische Krankheit, der dort seit langer Zeit viele Tausende von Menschenleben jährlich zum Opfer gefallen sind. Diese grosse Mortalität hat begreiflicherweise seit langem die Aufmerksamkeit der Behörden in ausserordentlich hohem Maasse in Anspruch genommen und zu Vorbeugungs- und Schutzmaassregeln aller Art Veranlassung gegeben. Bis in die neueste Zeit waren diese Bemühungen indessen erfolglos, und erst die Forschungsergebnisse der letztvergangenen Jahre sind imstande gewesen, erfolgreiche Gegenmasssregeln zu zeitigen. Gekennzeichnet ist die Beriberi durch eine Reihe von klinischen Erscheinungen (Ödeme, Dilatation des Herzens, Lähmung der Beine und Arme, starke Abmagerung u. a. m.), die alle auf Degeneration peripherer Nerven, welehe in schweren Fällen auch auf das Rückenmark übergreift, zurückgeführt werden. Je nach dem Vorwalten dieser verschiedenen Symptome unterscheidet man auch verschiedene Formen (rudimentäre, hydropische, atrophische, kardiovaskuläre Form). Auf eine nähere Beschreibung der Epidemiologie, der pathologischen Anatomie und Therapie der Krankheit soll hier nicht eingegangen werden ${ }^{1}$ ). Dagegen beansprucht die Ätiologie der Beriberi für den vorliegenden $Z$ weck eine weitergehende Besprechung. Die Beriberi galt lange Zeit hindurch allgemein als eine Infektions-

fassung dieser Arbeit in unsere Hände gelangte zusammenfassende Arbeit von Wilhelm Stepp: Einseitige Ernährung und ihre Bedeutung für die Pathologie. Ergebnisse der inneren Medizin und Kinderheilkunde Bd. 15 S. 257. 1917. Ferner sei auf die ebenfalls nach Abschluss unserer Arbeit zu unserer Kenntnis gelangte wichtige experimentelle Arbeit von L. Langstein und F. Edelstein: Die Rolle der Ergänzungsstoffe bei der Ernährung wachsender Tiere. Ernährungsversuche an jungen wachsenden Ratten. Zeitschrift für Kinderheilkunde Bd. 16 S. 305.1917 u. Bd. 17 S. 255. 1918, aufmerksam gemacht. In den beiden zuletzt genannten Veröffentlichungen ist auch die neuere Literatur weitgehend berücksichtigt. Während der Drucklegung der Arbeit erschien ferner eine ausgezeichnete kritische Würdigung des bisher vorliegenden Materials auf diesem Forschungsgebiete von Franz Hofmeister: Über qualitativ unzureichende Ernährung. Ergebnisse der Physiologie XVI. Jahrg. S. 1 und S. 510. 1918.

1) Vgl. z. B. K. Miura, Beriberi. Suppl. zu H. Nothnagels spezielle Pathol. u. Ther. Alfred Hölder, Wien und Leipzig. 1913. 
krankheit. Ihr häufiges Auftreten als Massenerkrankung bildete die Hauptstütze für diese Auffassung, obschon es trotz der mannigfachsten Nachforschungen und Versuche nie gelungen ist, einen für Beriberi spezifischen Erreger aufzufinden. Das vorwiegende und nicht selten sich zu erschreckenden Massenerkrankungen steigernde Auftreten der Krankheit bei den Völkern, deren fast ausschliessliche oder doch bei weitem vorwiegende Nabrung aus geschliffenem Reis besteht, hatte wiederholt den Verdacht wachgerufen, dass zwischen dieser Art der Enährung und dem Auftreten der Krankheit vielleicht nahe Beziehungen beständen. Diese Vermutung, welcher lange Zeit hindurch eine Begründung fehlte, gewann erst durch die Entdeckung der Hühnerpolyneuritis durch Eijkman ${ }^{1}$ ) einen festen Stätzpunkt. Eijkman fand nämlich, dass Hühner bei einseitiger Fütterung mit geschliffenem Reis innerhalb von etwa 60 Tagen fast durchweg an einer durch Lähmung der Beine und Flügel gekennzeichneten Krankheit zugrunde gingen. Starke Abmagerung sowie Atemnot und Cyanose im vorgeschrittenen Stadium waren die Begleiterscheinungen der Krankleit. Bei der Untersuchung der peripheren Nerven der Beine und Flügel fand Eijkman eine zuweilen sehr weitgehende Degeneration. Er nannte die Krankheit deshalb Polyneuritis gallinarum. In einzelnen Fällen fanden sich bei den an Polyneuritis eingegangenen Hühnern auch Dilatation des Herzens sowie erhebliche Mengen von Herzbeutelflüssigkeit. Dieser Befund sowie das Entstehen der Krankheit nach einseitiger Fütterung mit geschliffenem Reis veranlassten Eijkman zu der Annahme, dass es sich bei der Hübnerpolyneuritis um eine der menschlichen Beriberi analoge oder doch sehr ähnliche Krankheit handle. Die Entdeckung der Hühnerpolyneuritis ist, wie wir sehen werden, für die Bekämpfung der Beriberi von der grössten Wichtigkeit geworden. Si e hat jedoch darüber hinaus für die Physiologie der Ernährung eine weitgehende Bedeutung erlangt, weil erst durch sie ein neuer Weg zu experimentellen Forschungen auf dem Gebieteder Physiologie und Pathologie der Ernährung geschaffen wurde. Eijkman fand weiter, dass Hühner, die mit

1) C. Eijkman, Ein Versuch zur Bekämpfung von Beriberi. Virchow's Arch. Bd. 149 S. 187. 1897. Eine Beriberi-ähnliche Erkrankung der Hühner: Ebenda Bd. 148 S. 529. 1897. 
ungeschliffenem Reis, d. h. solchem, bei welchem die Fruchthüllen (das Perikarp) nicht von dem Samenkorn (Endosperm) entfernt worden waren, gefüttert wurden, gesund blieben. Auch liess sich die Krankheit durch Zusatz von Reiskleje zu geschliffenem Reis sowohl heilen wie auch verhüten. Durch weitere Versuche von Eijkman sowie von Grijns ${ }^{1}$ ) wurde dann noch festgestellt, dass auch andere von ihren Fruchthüllen befreite Getreidearten bei eiuseitiger Verfütterung an Hühner die Erscheinungen der Polyneuritis nach sich zogen. Ferner fanden diese Forscher, dass an sich bekömmliche Nahrungsmittel, wie zum Beispiel Fleisch, nach längerem Erhitzen in Autoklaven auf $110^{\circ} \mathrm{C}$. als ausschliessliche Nahrung ebenfalls zu Hühnerpolyneuritis führten. Axel Holst und Fröhlich haben dann später ähnliche Versuche mit Tauben und Meerschweinchen angestellt und hierbei eine Anzahl anderer Nahrungsmittel aufgefunden, die bei einseitiger Verfütterung an Ta uben ebensowohl zu Lähmungen und anderen Erscheinungen führten, die denen der Hühnerpolyneuritis teilweise glichen, teils aber von ihnen abwichen. Vor allem aber baben Axel Holst und Fröhlich das Verdienst, festgestellt zu baben, dass ein und dasselbe insuffiziente Nahrungsmittel bei verschiedenen Tierarten zu ganz verschiedenen Krankheitsbildern führen kann. Die genannten Forscher fanden nämlich, dass einseitige Verfütterung von geschälten Getreidekörnern (Weizen, Hafer, Gerste und Roggen), die bei Tauben zu Polyneuritis führte, bei Meerschweinchen eine dem menseblichen Skorbut, besonders dem Kinderskorbut (Möller-Bar$10 \mathrm{w}$ 'sche Krankheit) sehr ähnliche Erkrankung bewirkte.

Von einem von uns ( $\mathrm{Sc}$ hauman $\mathrm{n}$ ) sind dann derartige Versuche mit Tauben und einer Reihe von Säugetieren (Hunden, Katzen, Kaninchen, Meerschweinchen sowie einem Affen und einem Ziegenbock) ausgeführt worden. Ausgedehnte, uber mehrere Jahre sich erstreckende Versuche an Ratten sind ferner von Abderhalden durchgeführt worden. Es gelang bei allen diesen Tierarten, durch ein-

1) G. Grijns, Over Polyneuritis gallinarum. I. u. II. Geneesk. Tijdsehr. vor Neederl. Indie 1901 und 1909 (Bd. 49).

2) Axel Holst und Theodor Fröhlich, Über experimentellen Skorbut. Ein Beitrag zur Lehre von dem Einfluss einer einseitigen Nahrung. Zeitschr. f. Hygiene u. Infektionskrankh. Bd. 72 S. 1. 1912; vgl. auch Bd. 75 S. 334. 1913. 
seitige Verfütterung verschiedener insuffizienter Nahrungsmittel typische Lähmungen hervorzurufen. Das Krankheitsbild wechselte aber sehr bei den verschiedenen. Tierarten. Bei diesen Versuchen wurde eine neue Reihe besonders wirksamer Produkte aufgefunden, die nicht nur vorbeugend wirkten, sondern auch die Heilung kranker Tiere in überraschend kurzer Zeit herbeizufuhren vermochten. Es war durch die hierbei befolgte Methodik gleichzeitig ein Mittel gegeben, um irgendwelche Stoffe relativ schnell und sicher auf ihre Wirksamkeit prüfen zu können. Alle die erwähnten Stoffe zeichneten sich durch einen besonders hohen Gehalt an organischen Phosphorverbindungen aus, während andererseits diejenigen Nahrungsmittel, die nach einseitiger Verfütterung am schnellsten Polyneuritis bei den Versuchstieren im Gefolge hatten, einen verhältnismässig sehr geringen Gehalt an organisch gebundener Phosphorsäure aufwiesen. In aussergewöhnlich hohem Maasse war dies bei geschliffenem Reis der Fall. $\mathrm{Zu}$ den in besonders hohem Maasse heilend und vorbeugend wirkenden Stoffen gehört vor allem die Bierhefe. Bei den von Beriberikranken stammenden Harnen und Fäces war der Phosphor- (und Stickstoff-) Gehalt so stark herabgesetzt, dass dieser Umstand auf eine grosse Phosphorverarmung des Organismus schliessen liess. Diese Befunde veranlassten Schaumann, die Ergebnisse seiner Tierversuche dahin zusammenzufassen, dass die auf alimentärer Basis entstandene Polyneuritis eine Stoffwechselkrankheit wäre, welche auf den Mangel der Nahrung an gewissen, noch näher zu bestimmenden Phosphorverbindungen zurückzuführen sei. Bei vielen Versuchen an Menschen in den ostasiatischen Ländern hat man später gefunden, dass der Phosphorgehalt des Reises ein guter und zuverlässiger Wertmesser für dessen Bekömmlichkeit ist, und dass Reissorten mit einem unter $0,4 \%$ liegenden $\mathrm{P}_{2} \mathrm{O}_{5}$-Gehalt als ausschliessliches oder "vorwiegendes Nahrungsmittel fast ausnahmslos, Beriberierkrankungen nach sich ziehen. Vielfach ist dieser Zusammenhang als ein "zufälliger" bezeichnet worden. Der Phosphorgehalt des Reises an sich sollte danach bedeutungslos sein und nur einen Anbalt für die mehr oder minder beriberiwidrigen Eigenschaften der betreffenden Reissorten bieten.

Im weiteren Verlauf der Nachforschungen hatten versehiedene Forscher gefunden, dass auch die alkoholischen Auszüge der Reiskleie (sogenannte Phosphatid-Fraktion) heilend und vorbeugend bei der Hühnerpolyneuritis 
wirkten. Fank ${ }^{1}$ ) gelang es dann, durch Phosphorwolframsäure aus hydrolysiertem alkoholischem Reiskleieextrakt eine Substanz zu fällen, die nach weiterer Reinigung in Mengen von $0,05 \mathrm{~g}$ die bei der Taubenpolyneuritis auftretenden nervösen Störungen in kurzer Zeit zu beseitigen vermochte. Auf Grund einer Elementaranalyse stellte Funk für diese Substanz, die er als rein und einheitlich bezeichnete, die Formel $\mathrm{C}_{17} \mathrm{H}_{18} \mathrm{O}_{4} \mathrm{~N}\left(\mathrm{HNO}_{3}\right)$ auf. Als Bezeichnung wählte er den Namen "Vitamin". Im Anscbluss an die an sich zweifellos sehr wichtige Auffindung dieser Substanz entwickelte $\mathrm{Fu} \mathrm{k}^{2}$ ) dann seine bekannte "Vitamin"-Theorie. Sie versucht, eine ganze Reihe von Krankheiten, die er als "Avitaminosen" bezeichnete, auf den Mangel der Nahrung an spezifischen "Vitaminen", wie Beriberi-, Skorbut-, Pellagra-, Rachitis-Vitamin, zurückzuführen.

Mit dem Namen "Vitamin" ist dann heuerdings in recht umfangreicher Weise operiert worden. Es erscheint beinahe so, als ob die mit diesem Namen verknüpften recht vielversprechenden und dehnbaren, dafür aber entsprechend unklaren Vorstellungen einem solchen Vorgehen Vorschub geleistet hätten. Die Bezeichnung "Vitamin" soll offenbar andeuten, dass es sich hier um einen besonders lebens= wichtigen St off handelt. Demgegenüber möchten wir darauf hinweisen, dass dies beim sogenannten "Vitamin" nicht mehr und nicht minder der Fall ist als bei einer Anzahl anderer ebenso unentbehrlicher Nahrungsbestandteilen. Von organischen Verbindungen dieser Art sei hier das Tryptophan angeführt, dessen Anwesenheit im Eiweiss der Nahrung ebenso lebenswichtig ist wie die des "Vitamins," Es bandelt sich auch beim Tryptophan um relativ sehr geringe Mengen, deren Aufnahme mit dem Nahrungseiweiss eine unerlässliche Vorbedingung für die Verwertung der übrigen Aminosäuren ist. Als Repräsentanten von anorganischen, für den Fortbestand des Organismus unbedingt notwendigen Nahrungsstoffen könnten auch der Sauerstoff neben Wasser und bestimmten Mineralstoffen genannt werden!

Über die chemische Zusammensetzung des "Vitamins" wissen wir noch nichts. Es sind bislang nur einige empirische Formeln ver-

1) C. Funk, On the chemical nature of the substance which cures Polyneuritis in birds, induced by a diet of polished rice. Journ. of Physiol vol. 43 p. 395. 1911.

2) C. Funk, Über die physiologische Bedeutung gewisser, bislang unbekannter Nahrungsbestandteile, der Vitamine. Ergebnisse der Physiologie Bd.13 S. 126. 1913. 
öfentlicht worden. Sie sind zurzeit noch keineswegs sichergestellt. Die von $\mathrm{Funk}$ angegebene Formel ist von verschiedenen Seiten angezweifelt worden, und die relativ hohen Gaben $(0,05 \mathrm{~g})$, die er zur Beseitigung der Lähmungen und anderer nervöser Störungen bei Polyneuritis-Tauben anwandte, deuten darauf hin, dass Funk's "Vitamin" offenbar keine reine und einheitliche chemische Verbindung war, wie $\mathrm{Funk}$ dies auch nenerdings zugegeben hat.

Spezifische "Vitamine", wie Beriberi-, Skorbut-, Pellagra-, Vitamin“ usw., sind bislang nie dargestellt worden. Sie sind durchaus hypothetisch.

Die einzigen bisher erwiesenen Tatsachen sind:

1. dass aus Reiskleie, Hefe und noch einigen anderen natürlichvorkommenden Stoffen pflanzlichen und tie. rischen Ursprungs Substanzen gewonnen worden sind, welchedieim Gefolgederalimentären Dystrophie (Polyneuritis bei Tieren) auftretenden nervösen Störungen Paralysen und Paresen der Beine und Flügel, Opisthotonus, Konvulsionen) in der Regel schnell und schonbei Verwendung sehrkleiner Gabenzu beseitigen vermögen. Dagegen bleiben alle anderen im Gefolge der alimentären Dystrophie auftretenden Ausfallerscheinungen trotz Zufuhr der genannten Substanzen ("Vitamine") im wesentlichen bestehen, wie dies später eingehend erörtert werden soll;

2. dass die Zufuhr dieser Substanzen ("Vitamine“) in mässigem Umfange den Stoffwechsel anregt. Diese Anregung ist aber nur eine recht beschränte und einseitige. Sie ist keineswegs sowohl qualitativ wie quantitativ mit derjenigen zu vergleichen, welche die Ausgangsmaterialien (Reiskleie, Hefe usw.) auszuüben vermögen, aus denen die "antineuritisch" wirkenden Substanzen ("Vitamine") dargestellt worden sind.

Wir beschränken uns hier auf diese prinzipiellen Feststellungen und verweisen im übrigen auf die spätere eingehende Besprechung: (S. 45) der hier in Betracht kommenden Verhältnisse.

Es seien schliesslich noch die bei der menschlichen Beriberi mit verschiedenen Arten der Ernährung gemachten Erfahrungen kurz wiedergegeben, weil diese ein besonders anschauliches Bild von der 
Beitrag zur Kenntnis von organischen Nahrungsstoffen mit spezif. Wirkung. 13

praktischen Bedeutung der hierher gehörigen Forschungen geben.

Eijkman's Entdeckung der Hühnerpolyneuritis hatte zunächst die Folge, dass Vorderman ${ }^{1}$ ), der hierdurch gegebenen Anregung folgend, Erhebungen über das Auftreten von Beriberi bei vorwiegender Ernährung einerseits mit geschliffenem, andererseits mit ungeschliffenem Reis anstellte. Sie wurden an Gefangenen gemacht, deren Ernährungsweise sicherer zu kontrollieren war, als dies sonst möglich ist. Vorderman fand, dass von 96530 Gefangenen, die mit ungeschliffenem Reis beköstigt worden waren, nur 9 , d. i. $0,009 \%$, an Beriberi erkrankten, während von 150226 mit geschliffenem Reis verpflegten Sträflingen 420 , d. i. $2,79 \%$, von Beriberi befallen wurden.

$\mathrm{Hulsh}$ off $\mathrm{Pol}^{2}$ ) machte ähnliche Erfahrungen bei Beköstigung mit geschliffenem und ungeschliffenem Reis in dem unter seiner Leitung stehenden Krankenhause. Auch fand $\mathrm{Hulsh}$ off $\mathrm{Pol}$, dass Katjang-idjoe (Phaseolus radiatus), eine in Ostasien und Afrika vielfach gezogene Bohnenart, eine ausgesprochene vorbeugende und heilende Wirkung gegen Beriberi innewohnt.

In Britisch-Indien war Braddo $\mathbf{n}^{3}$ ) ein Vorkämpfer für die Verwendung ungeschliffenen statt des geschliffenen Reises als Nahrungsmittel. Er nabm hierbei freilich zu der Intoxikationstheorie seine Zuflucht, indem er in dem geschliffenen und längere Zeit gelagerten Reis ein Beriberi hervorrufendes Gift vermutete. Fletcher ${ }^{4}$ ), Fraser und Stanton ${ }^{5}$ ) sowie Ellis ${ }^{6}$ ) stellten dann durch sorgsame Versuche, die teils an Insassen von Irrenhäusern, teils an freien Arbeitern angestellt wurden, in überzeugender Weise fest, dass bei

1) A. G. Vorderman, Onderzoek naar het raband tusschen den aard der rijstvoeding in de gevangenissen on Java en Madoera en het voorkomen van BeriBeri onder de geinternereden. Batavia 1897.

2) D. J. Hulshoff $\mathrm{Pol}$, Katjang-idjo, un nouveau médicament contre le Béri-Béri. Janus 1902.

3) W. L. Braddon, The cause and prevention of Beri-Beri. Brit. Med. Journ. 1909 p. 1007.

4) W. Fletcher, Rice and Beri-Beri. Lancet 29. Juni 1907 Nr. 4074 p. 1776 und Journ. of Tropic Med. and Hyg. vol. 12 p. 127.

5) H. ${ }^{\mathrm{s}} \mathrm{Fraser}$ and A. T. Stanton, An inquiry concerning the etiology of Beri-Beri. Lancet vol. 76 Nr. 4459 p. 451. 1909. - Dieselben, White rice as a causative agent of Beri-Beri. Lancet 1909 p. 406 .

6) W. Gilmore Ellis, Uncured rice as a cause of Beri-Beri. Brit. Med. Journ. 1909 Nr. 2544 p. 935. 
vorwiegender Beköstigung mit ungeschliffenem Reis Beriberifälle nur äusserst selten vorkommen, während die vorwiegende Ernährung mit geschliffenem Reis eine grosse Zahl von Erkrankungen an Beriberi nach sich zieht.

In Japan machte man die Erfahrung, dass ein teilweiser Ersatz des geschliffenen Reises durch Gerste bei der Beköstigung des Heeres einen erstaunlichen Rückgang der Beriberi zur Folge hatte. Die Morbiditätsziffer für diese Krankheit hatte vorher $236,7 \%$ und die Mortalitätsziffer $6 \%$ betragen. Diese Zahlen wurden durch die erwähnte Veränderung der Nahrung innerhalb von kurzer Zeit auf 2,8\% bzw. 0,047\% herabgedrückt. Die in der japanisehen Marine nur durch Veränderung der Kost erzielten günstigen Erfolge redeten eine ebenso beredte Sprache zugunsten des Ersatzes von geschliffenem Reis durch Gerste wie die bei dem Heere gemachten Erfahrungen. A uf den Philippinen ist die Beriberibekämpfung durch $\mathrm{He}$ ise ${ }^{5}$ ) in sehr energischer und erfolgreicher Weise nach denselben Grundsätzen betrieben worden. Überall, wo es gelang, die dort angestrebte allgemeine "Re is reform", d. h. den Ersatz von geschliffenem Reis durch ungeschliffenen strenge durchzuführen, verschwand die Seuche in kurzer Zeit. Auf die von Strong und Crowella ${ }^{2}$ unter Beobachtung der weitgehendsten Kautelen an Gefangenen ausgeführten Versuche kann hier nur hingewiesen werden. Diese Versuche bestätigendurchweg, dass dievorwiegendeBeköstigung mit geschliffenem Reis Beriberifälle zur Folge hat. Sie bleiben aus, wenn der geschliffene Reis bei sonst gleicher Kost durch ungeschliffenen Reis ersetzt wird.

Nächst den vorstehenden, zur Aufklärung der Ätiologie der Beriberi unternommenen Forschungen seien hier diejenigen von Axel Holst ${ }^{3}$ ) und seinen Mitarbeitern Fröhlichs) und

1) V. G. Heiser, Practical experience with Beri-Beri and unpolished rice. Philipp. Journ. of Science vol. 6 Nr. 3. 1911 und Journ. of the Americ. Med. Assoc. 29. April 1911. - Derselbe, Beri-Beri Governamental aid in its eradication. Med. Record 16. März 1912.

2) P. P. Strong and B. C. Crowell, The etiology of Beri-Beri. Philipp. Journ. of Science vol. 7 p. 271.1912.

3) A. Holst, Experimentelle Untersuchungen über den Skorbut. Verhandl. d. Nord. Kongr. f. innere Med. 1909 S. 328. - A. Holst und T. Fröhlich, Über experimentellen Skorbut. Zeitschr. f. Hyg. u. Infektionskrankh. Bd. 72. 1912.

4) T. Fröhlich, Experimentelle Untersuchungen über den inlantilen Skorbut. Zeitschr. f. Hyg. u. Infektionskrankh. Bd. 72 S. 155. 1912. 
Beitrag zur Kenntnis von organischen Nahrungsstoffen mit spezif. Wirkung. 15

Fürst ${ }^{1}$ ) erwähnt, welche die Ätiologie des Skorbuts zum Gegenstande hatten. Bei diesen Versuchen wurden folgende wichtige Feststellungen gemacht:

Ernährt man Meerschweinchen mit bestimmten Nahrungsmitteln (Getreide, Brot u. a. m.) einseitig, so gehen die Versuchstiere durchweg an einer skorbutartigen Krankheit zugrunde. Bei den so verendeten Tieren ergaben die Sektionen ausgesprochene Hämorrhagien in den Muskeln, dem Unterhautzellgewebe, der Schleimhaut des Magens, den Nieren, der Milz und den Lungen; ferner Atrophie der Knochensubstanz (Rarifikation und Brüchigkeit der Knochen) und gelockerte Zähne. Unter 65 Versuchstieren, welche die soeben genannten pathologisch-anatomischen Veränderungen aufwiesen, fanden sich nur zwei, die ausserdem ausgeprägte Polyneuritis (Degeneration peripherer Nerven) zeigten. Bei einseitiger Fütterung von Meersehweinchen mit bestimmten anderen Nahrungsmitteln (Weisskohl, Karotten, Löwenzahn u. a. m.) bliehen die Versuchstiere gesund. Wie schon gesagt, zog die einseitige Fütterung mit gewöhnlichem, trockenem Hafer und ebensolcher Gerste bei Meerschweinchen Skorbut nach sich. Liess man aber Hafer und Gerste genau derselben Qualität vorher keimen und verfütterte siedann erst an Meerschweinchen, so blieben diesevon Skorbutverschont. Das Trocknen der gekeimten Getreidearten, auch wenn dieses bei einer $37^{\circ}$ C. nicht übersteigenden Temperatur geschah, genügteaberschon, um diesamenihrerantiskorbutischen Eigenschaften wieder zu berauben. Durch wiederholtes Keimen der bei niedriger Temperatur getrockneten Samen erlangten diese allerdings die antiskorbutischen Eigenschaften wieder ${ }^{2}$ ). Auszüge aus Löwenzahn, Karotten und anderen frischen Vegetabilien hatten ebenfalls antiskorbutische Wirkung, verloren diese aber schon

1) V. Fürst, Weitere Beiträge zur Ätiologie des experimentellen Skorbuts des Meerschweinchens. Zeitschr. f. Hyg. u. Infektionskrankh. Bd. 72 S. 121. 1912. Derselbe, Untersuchungen über die Ursachen des Skorbuts. Ein Mittel gegen diese Krankheit. Verhandt. d. Nord. Kongr. f. innere Med. 1909 S. 349.

2) Vgl. hierzu auch die Beobachtungen von E. Well und G. Mouriquand, Vergleichende Meerschweinchenfütterungsrersuche mit ungeschälter Gerste im Ruhestadium oder im Keimungsstadium. Internat. agrar.-techn. Rundschau Bd. 8 S. 248. 1917. Ref. Physiol. Zentralbl. Bd. 33 S. 429. 1918. - Im ersteren Fall lebten die Tiere 29-30 Tage, im letzeren bis 106 Tage. Ausgedehnte Versuche des einen von uns (Abderhalden) führten zum gleichen Ergebnis. 
nach kurzer Zeit beim Aufbewahren. Alle jene Nahrungsmittel, welche einseitig verfüttert bei Meerschweinchen zu Skorbut führten, enthielten von den Hauptuährstoffen - Eiweiss, Kohlehydraten, Fett und mineralischen Bestandteilen - genügende Mengen, so dass eine Unterernährung mit Rücksicht auf diese Nährstoffe nicht in Betracht kam. Axel Holst und seine Mitarbeiter fassten die Ergebnisse ihrer Versuche dahin zusammen, dass allgemeine Unterernährung, Infektionsmöglichkeit, Mangel an Fermenten und Azidose bei der Pathogenese des Meerschweinchenskorbuts ausgeschlossen waren. Es konnte sich bei dieser Krankheit nur um den Mangel der sie erzeugenden Nabrungsmittel an bestimmten, bisher unbekannten und sehr labilen chemischen Verbindungen handeln.

Axel Holst fand ferner, dass Schweine, welche einseitig mit geschliffenem Reis ernährt wurden, nach einiger Zeit an einer $\mathrm{Misch}$ form von Skorbut und Polyneuritis erkrankten. Es fand sich hier neben den bei Meerschweinchen beobachteten pathologischanatomischen Veränderungen auch eine ausgesprochene Degeneration peripherer Nerven, welche zu Lähmungen geführt hatten.

Fürst's Versuche ergaben u. a., dass einseitige Ernährung mit getrockneten Erbsen, bei welchen Tauben und Kaninchen sehr gut gediehen, bei Meerschweinchen Skorbut hervorzurufen pflegt, und Axel Holst und Fröhlich fanden, dass Bierhefe keine antiskorbutischen Eigenschaften besitzt. Dies ist sehr bemerkenswertin Anbetracht des Umstandes, dass Bierhefe ein vorzügliches und schon in kleinen Gaben sehr wirksames Mittel gegen diealimentäre Dystrophie (Polyneuritis) der Tauben, Hühner, Hunde, Kaninchen und anderer Tierarten ist.

Ähnliche Beobachtungen hat der eine von uns (Abderhalden) an Hand langjähriger, noch nicht mitgeteilter Versuche gemacht. Sie hatten den Zweck, festzustellen, wie lange bestimmte Tierarten mit einem einzigen Nahrungsmittel leben können. Vor allem wurden Getreidearten, Mais, Bohnen, Erbsen verfüttert. Es zeigte sich, dass ein bestimmtes Nahrungsmittel für eine Tierart ganz ungenügend war, d. h. bald zum Tode führte, während es für eine andere lange Zeit genügte. Besonders interessant ist die Feststellung, dass die Fruchtbarkeit. der Ratten erlischt, wenn man sie ausschliesslich mit Getreide- 
Beitrag zur Kenntnis von organischen Nahrungsstoffen mit spezif. Wirkung. 17

arteu, Erbsen, Bohnen, Mais füttert. Zusatz geringer Mengen von Spinat, Kohl, kurz frischem Gemüse beeinflusste das Befinden der Tiere ganz ausserordentlich. Der eine von uns (A bderhalden) wird über diese Versuche noch besonders berichten.

Casimir $\mathrm{Funk}^{1}$ ) hat neuerdings Versuche mit ausschliesslicher Haferfütterung bei Meerschweinchen und Kaninchen ausgeführt. Beide Tierarten erkrankten, jedóch sind die Erscheinungen versehieden. Auch scheint die Ursache der Erkrankung nicht einheitlich zu sein. Bei Kaninchen erwies sich nämlich die Zufuhr von $\mathrm{NaHCO}_{3}$ günstig, während bei Meersehweinchen ein Erfolg nicht nachweisbar war.

E. B. Hart, J. G. Halpin und E. V. Me Coll $\mathrm{um}^{2}$ ) berichten, dass junge Hühner, die etwa die Hälfte ihres Normalgewichtes erreicht haben, bei einer reinen Korn- resp. Kornmehlnahrung unter Zusatz von $\mathrm{CaCO}_{3}$ regelrecht wachsen können und auch fruchtbare Eier legen, während Schweine und Ratten gegenüber der gleichen Art der Ernährung empfindlich sind und ihre Fruchtbarkeit verlieren.

Fasst man die vorstehend mitgeteilten Ergebnisse zusammen, so ergeben sich aus ihnen folgende Verhältnisse:

1. Ein und dasselbe Nahrungsmittel kann für eine bestimmte Tierart suffizient, dagegen für eine andere Tierart insuffizient sein.

2. Hefe, welche ein vorzügliches Heil-und Vorbeugungsmittelgegen die alimentäre Dystrophie (Polyneuritis) einer Reihe von Tierarten ist, versagt als Heil- und Vorbeugungsmittel gegen Meerschweinchenskorbut.

3. Ein und dasselbe insuffiziente Nahrungsmittel kann bei verschiedenen Tierarten ganz verschiedene Ausfallerscheinungen und Krankbeitsbilder hervorrufen.

Die hieraus zu ziehenden Schlussfolgerungen wären:

1. Jeder Organismus reagiert in einer besonderen

1) Casimir Funk, Die Natur der durch ausschliessliche Haferfütterung bei Meerschweinchen und Kaninchen auftretenden Erkrankungen. Journ. of Biol. Chem. vol. 25 p. 409. 1916. Ref. Chem. Zentralbl. 1917 Bd. 1 S. 117.

2) E. B. Hart, J. G. Halpin und E. V. Mc Collum, Das Verhalten junger Hähner bei ausschliesslicher Ernährung mit Getreidekörnern. Journ. of Biol. Chem. vol. 29 p. 57. 1916. Ref. Chem. Zentralbl. 1917 Nr. 2 S. 760.

Pflüger's Arehiv für Physiologie. Bd. 179. 
und ihm mehr oder weniger eigentümlichen Art auf die Einflüsse eines und desselben insuffizienten Nabrungsmittels.

2. Die Insuffizienz von $\mathrm{Nahrungsmit}$ el nim allgemeinen kann begründeterweise nicht auf das Fehlen eines einzigen (nicht zu den Hauptnähstoffen gehörigen) uneatbehrlichen Nahrungsbestandteils (z. B. "Vitamin") zurückgefüht werden, sondern es kommt hierbei eine Mehrabl derartiger Stoffe in Frage, deren chemische und physiologische Eigenschaften recht verschiedenartig seinkönnen. - Die Insuffizienzeinerbestimmten Nahrung kann ebensowohl durch das Fehlen eines einzelnen wie auch durch das einer Mehrzahl von derartigen unentbehrlichen Nahrungsbestandteilen veranlasst werden.

Was den ersten Satz angeht, so weisen nicht nur weiter voneinanderstehende Tierarten (Geflügel, Meerschweinchen, Kaninchen, Schweine, Hunde, Katzen, Affen u. a. m.), sondern auch einander bei weitem näherstehende Tierarten (z. B. Hühner und Tauben) wesentlich voneinander abweichende Krankheitsbilder bei gleicher insuffizienter Ernäbrungsweise auf. Und weiter beobachtet man, wie wir später näher ausführen werden, bei verschiedenen Individuen derselben Tierart, die mit einem und demselben insuffizienten Nahrungsmittel gefüttert werden, voneinander recht abweichende Ausfallerscheinungen und Symptome. Es ist daher a uch keineswegs verwunderlich, dass der Mensch auf derartige Einflusse in einer ihm eigentumlichen Weise, die ebenfalls individuelle Modifikationen a ufeisen kanu, antwortet.

Was den zweiten Satz betrifft, so beweist der Umstand, dass Hefe und Erbsen, die gegen die alimentäre Dystrophie (Polyneuritis) einer ganzen Reihe von Tierarten wirksam, dagegen gegen Meerschweinchen-Skorbut unwirksam sind, dass die in einem und dem anderen Falle wirksamen Substanzen voneinander verschieden sein müssen. Dass sich die Wirksamkeit der gegen alimentäre Bystrophie (Polyneuritis) erprobten, natürlich vorkommenden Stoffe (z. B. der Hefe) nicht auf einen einzigen in ihnen enthaltenen Bestandteil („Vitamin“) zurückfübren lässt, sondern als die Kollektivwirkung 
Beitrag zur Kenntnis von organischen Nahrungsstoffen mit spezif. Wirkung. 19

einer Mehrzahl von Stoffen aufzufassen sind, soll später gezeigt werden.

Weiter sind hier noch die Versuche von $S$ te $\mathrm{pp}^{1}$ ) zu bespreclen. Step p stellte fest, dass bestimmte ursprünglich für Mäuse suffiziente Nahrungsmittel (Protamol u. a. m.) durch genügend langes Ausziehen mit Alkohol und Äther insuffizient wurden. Die mit diesem ausgezogenen Nahrungsmittel ernährten Mäuse gingen alle innerhalb von wenigen Wocben zugrunde. Stepp stellte hierbei fest, dass es sich bei den Stoffen, deren Abwesenheit in der Nahrung den Tod der Versuchstiere nach sich zog, nicht um das bei der Extraktion zusammen mit anderen Stoffen entfernte Cholesterin und auch nicht um Lecithin (Handelsware Merck) handeln konnte. Der Zusatz dieser Stoffe zu den extrahierten Nahrungsmitteln änderte an deren Insuffizienz nichts und vermochte die Versuchstiere weder am Leben zu erhalten, noch deren Lebensdauer zu verlängern. Dagegen wurden die extrahierten Nahrungsmittel dann wieder suffizient, went man ihnen die durch Exuraktion und Abdampfen bei niedriger Temperatur gewonnenen Alkohol-Ätherextrakte (sogenannte Lipoid-Fraktion) wieder zusetzte. Die mit diesem Gemisch ernährten Mäuse blieben gesund und am Leben. Step p suchte die hier wirksamen Substanzen unter den Lipoiden und vermutet, dass es sich um bestimmte Phosphatide handeln könnte, auf deren Entfernung bei der Extraktion die Unzulänglichkeit der extrahierten Nahrung zurückzuführen sei.

Auf Grund späterer Versuche ${ }^{2}$ ), bei denen einem insuffizienten Nahrungsmittel (geschliffener, mit Wasser ausgezogener Reis) einerseits Reiskleiepräparate (Orypan-Präparate), andererseits die mit $96 \%$ igem Alkohol aus Eidotter ausziehbaren Stoffe zugesetzt waren, gelangte Stepp zu folgenden Schlüssen:

"Lipoidfreie Nahrung kann nur durch Zusatz von Lipoiden, sitaminfreie Nahrung nur durch Vitamin wieder zu einer vollwertigen Nahrung ergänzt werden. Es können dagegen in Kreuzversuchen die

1) W. Stepp, Experimentelle Untersuchungen über die Bedeutung der Lipoide für die Ernährung. Zeitschr. f. Biol. Bd. 57 S. 135. 1911. - Der selbe, Weitere Untersuchungen über die Unentbehrlichkeit der Lipoide für das Leben. Zeitschr. f. Biol. Bd. 59 S. 366 . 1912. - Der sel be , Fortgesetzte Untersuchungen über die Unentbehrlichkeit der Lipoide für das Leben. Zeitschr. f. Biol. Bd. 62 S. 405.1913.

2) W. Stepp, Ist die durch Lipoidhunger bedingte Ernährungskrankbeit identisch mit Beriberi? Zeitschr. f. Biol. Bd. 66 S. 339. 1916. 
akzessorischen Nährstoffe, Lipoid und Vitainin, nicht miteinander vertauscht werden. Es handelt sich also bei diesen Ernährungskrankheiten, worin wir uns an das zurzeit vorliegende Tatsachenmaterial balten wollen, um verschiedenartige Störungen."

Bei einer anderen Reihe von Versuchen ${ }^{1}$ ) verwandte S tepp gemahlenen Hundekuchen, welcher sich als sebr geeignetes Mäusefutter erwiesen" hatte. Wurde das Hundekuchenmehl mit Alkohol gründlich ausgezogen, so wurde es für Mäuse insuffizient. Alle mit dem so extrahierten Mehl ernährten Mäuse gingen innerhalb von 5 Wochen ein. Zusatz von alkoholischem Eigelbextrakt hatte einen nur relativ günstigen Einfluss. Von fünf Versucbsmäusen waren nur noch zwei nach 50 Tagen am Leben und munter. Durch Extrahieren von Ejdotter mit Aceton, hierauf mit Alkohol und Abdampfen der betreffenden Lösungsmittel wurden ein primäres Aceton- und ein sekundäres Alkoholextrakt dargestellt. Eine Mischung dieser beiden Extrakte erwies sich als geeignet, um extrahierten Hundekuchen wieder zu einem suffizienten Mäusefutter zı ergänzen. Das primäre Acetonextrakt allein war dagegen weniger wirksam als die Mischung von diesem mit dem alkoholischen Extrakt. Auch Ätherextrakt als Zusatz zu extrahiertem Hundekuchenmehl hatte insofern einen günstigen Einfluss, als es das Leben der Versuchsmäuse erheblich verlängerte. Eine Kombination von Lipoiden [Ovolecithin, Kephalin und Zerebron mit Orypansirup $\left.{ }^{2}\right)$ ] vermochte die aus einer ursprünglich suffizienten Nahrung durch Alkohol extrahierten lebenswichtigen Bestandteile zu ersetzen, wenn auch nicht in ganz vollkommener Weise. Die sogenannten Lipoide sowie der Orypansirup für sich allein erwiesen sich dagegen als völlig unwirksam.

Diese Beobachtungen zeigen wiederum, wie verwickelt das hier vorliegende Problem und wie unbegründet die Hypothese ist, maṇ könne durch die Annahme einer einzigen hierbei in Frage kommenden Substanz ("Vitamin") die grosse Mannigfaltigkeit der Erscheinungen erklären $\left.{ }^{3}\right)$.

Wir möchten zu diesen für die hier in Frage kommenden Ver-

1) W. Stepp, Die Lipoide als unentbehrliche Bestandteile der Nahrung. Zeitschr. f. Biol. Bd. 66 S. 365.1916.

2) Orypansirup ist ein von der Gesellschaft für chemische Industrie in Basel hergestelltes Reiskleiepräparat.

3) Vgl, hierzu auch Cooper, Biochem. Journ. Bd. 8 S. 347. 1914. 
Beitrag zur Kenntnis von organischen Nahrungsstoffen mit spezif. Wirkung. 21

hältnisse sehr wichtigen Versuchen bemerken, dass es sich bei den von Stepp gebrauchten Bezeichnungen "Lipoide" und "Vitamine" um Ausdrücke handelt, die klaren und präzisen Vorstellungen nicht entsprechen. Unter dem Sammelausdruck "Lipoide" fasst man bekanntlich eine ganze Reihe ihrer chemischen Konstitution nach sebr heterogenen Substanzen (Fette, Phosphatide, Sterine u. a. m.) zusammen. Maassgebend für die Zugehörigkeit zu dieser Gruppe ist ja mehr die Löslichkeit der betreffenden Substanzen in bestimmten Lösungsmitteln (Aceton, Alkohol, Äther, Chloroform, Tetrachlorkohlenstoff usw.), als es die sonstigen physikalischen und chemischen Eigenschaften der zu den "Lipoiden" gerechneten Stoffe sind. Bei dér Unkenntnis, die gegenwärtig noch bei vielen dieser Substanzen mit Rücksicht auf ihren chemischen Aufbau herrseht, muss zugegeben werden, dass diese Bezeichnung vorläufig in der Biologie kaum zu entbehren ist; nur muss man sich klar darüber sein, mit wie unklaren Begriffen man hierbei operiert. Nicht weniger trifft dies auf den Ausdruck "Vitamin" $\mathrm{zu}$, wie wir bereits an anderer Stelle (S. $11 \mathrm{u}$. ff.) erörtert haben. Besonders schwierig gestaltet sich aber die Deutung derartiger Versuche, wenn Reiskleiepräparate, wie Orypan, d. h. Präparate unbekannter Zusammensetzung, als Zugaben verwandt und als "Vitamin“ angesprochen werden. Viel zu wenig beachtet ist auch der Umstand, dass beim Extrahieren mit den erwähnten Reagenzien zahlreiche Stoffe mitgelöst werden, die an und für sich in reinem Zustande in ihnen gar nicht löslich sind. Man kann sich leicht davon überzeugen, dass aus der gleichen Muttersubstanz durch einfache Extraktion dargestellte Produkte nicht identisch in ihrer Zusammensetzung zu sein brauchen.

Sehr wichtig für die hier in Betracht kommenden Verhältnisse ist ferner das Verhalten der verschiedenen Aminosäuren des Nahrungseiweisses. Versuche von Hopkins und Will cock $\mathrm{ck}^{\mathfrak{l}}$ ) und diejenigen von Abderhalden ${ }^{2}$ ) haben gelehrt, dass bestimmte Aminosäuren

1) C. G. Willcock u. F. Gow land Hopkins, The importance of individual aminoacids in metabolism. Journ. of Physiol. vol. 85 p. 88.1907.

2) E. Abderhalden, Weiterer Beitrag zur Frage nach der Verwertung von tiefabgebautem Eiweiss im tierischen Organismus. Zeitschr. f. physiol. Chem. Bd. 57 S. 348. 1908. Fütterungsversuche mit vollständig abgebauten Nahrungsstoffen. Ebenda Bd. 77 S. 22. 1912. Weitere Versuche über die synthetischen Fähigkeiten des Organismus des Hundes. Ebenda Bd. 83 S. 444. 1913. Weitere Studien über den Stickstoffstoffwechsel. Ebenda Bd. 96 S. 1. 1915. 
fertig gebildet mit dem Nahrungseiweiss aufgenommen werden müssen, weil der tierische Organismus sie weder zu bilden vermag, noch auch auf die Dauer entbehren kann. Zu dieser Klasse von Aminosäuren gehört vor allem das T ryptophan. Füttert man zum Beispiel Hunde mit einer einzigen Eiweissart, die alle unentbehrlichen Aminosäuren enthält, wie z. B. Kasein, so gedeiht das Versuchstier hierbei vorzüglich. Zerlegt man dieses Eiweiss vollständig in seine einzelnen Bausteine (Aminosäuren), so gelingt es mit einer bestimmten Menge dieses Gemisches ebenfalls, Hunde im Stickstoffgleichgewicht zu erhalten. Entfernt man jedoch das Tryptophan aus diesem Aminosäurengemisch, so gelingt es nicht mehr, den Stickstoflstoffwechsel im Gleichgewicht zu halten. Es wird mehr Stickstoff ausgeschieden, als zugeführt wird. Dieser Umstand fübrt natürlich bald zu einer grossen Abnahme des Körpergewichts und schliesslich zum Tode. Ausser dem Tryptophan gehören auch die beiden zyklischen Aminosäuren $\mathrm{T}$ y rosin und Phenylanin zu den unentbehrlichen Aminosäuren, d. b. zu solchen, die der tierische Organismus nicht aufzubauen vermag, wohl aber können beide sich offenbar vertreten. Von den aliphatischen Aminosäuren scheint Lysin sich ebenso zu verhalten. Die schwierigen, zeitraubenden und kostspieligen Versuche auf diesem Gebiete des Eiweissstoffwechsels sind noch keineswegs abgeschlossen, und es ist deshalb wohl möglich, dass weitere Forschungen noch für manche andere Aminosäure ihre Unersetzbarkeit erweisen. Je de $\mathrm{n}$ falls ge nügen aber die bislang vorliegenden Ergebnisse, um darzutun, dass die Insuffizienzeines bestimmten Nahrungsmittels oderder Nahrung überhaupt ebensowobldurch das Fehlenvoneiner derunentbehrlichen Aminosäuren. oder von mehreren solchen bedingt sein kann als durch den Mangel an anderen, nicht zu den Hauptuährstoffen gehörigen Nahrungsbestandteilen.

Zum Schluss seien hier noch die Versuche besprochen, welche die Wachstumshemmung junger Tiere durch das Fehlen bestimmter Nahrungskomponenten und die Förderung des Wachst ums durch den Zusatz bestimmter Stoffe zum Gegenstand hatten.

F. G. Hopkins ${ }^{1}$ fand, dass junge Ratten, welche mit einem

1) F. Gowland Hopkins, Feeding experiments illustrating the importance of accessary factors in normal dietaries. Journ. of Physiol. vol. 44 p. 425.1912 . - 
Beitrag zur Kenntnis von organischen Nahrungsstoffen mit spezif. Wirkung. 23

Gemisch von Kasein, Kohlehydraten, Fett und Salzen gefüttert wurden, bald auf hörten zu wachsen. Fügte er aber diesem Gemisch eine sehr geringe Menge Milch $(2,5-\check{c} \mathrm{ccm})$ oder eine sehr geringe Menge eines aus alkoholischem Hefeauszug durch Ausziehen mit Äther gewonnenen Extrakts hinzu, so setzte das vorher unterdrückte Wachstum sofort wieder ein. Bei Zugabe des ätherischen Hefeextrakts erfolgte das Wachsen der jungen Ratten in besonders starkem Maasse.

Besonders umfassende Untersuchungen in dieser Richtung haben Thomas B. Osborne und Lafayette Mendel ${ }^{1}$ ) ausgeführt. In ibrer neuesten Mitteilung finden sie, dass Laktalbumin dem Kasein in bezug auf Wachstumsförderung bei weitem überlegen ist. Wurde dem Kasein Cystin zugesetzt, danu erreichte es den Wert des Laktalbumins! Kasein ist an und für sich arm an Cystin.

M c. Collum und Davis ${ }^{2}$ ) fütterten junge Ratten mit sorgfältig gereinigten Nährstoffen. Die Tiere hörten bei dieser Nahrung sehr bald auf zu wachsen. Das Wachstum setzte aber sofort wieder ein, wenn derselben Nahrung, die eine Unterdrủckung des Wachstums im Gefolge gebabt batte, Butterfett oder Ätherextrakt aus getrockneten Fischhoden oder Ätherextrakt aus Schweinenieren hinzugefügt wurde. Zusätze von Olivenöl oder Baumwollsamenöl erwiesen sich dagègen als wirkungslos ${ }^{3}$ ).

Vgl. auch W. D. Halliburton und J. C. Drummond, Der Nährwert von Margarine und Butterersatzmitteln in Beziehung zu ihrem Gehalt an der fettlöslichen akzessorischen Wachstumssubstanz. Journ. of Physiol. vol. 51 p. 235. 1917. Ref. Chem. Zentralbl. 1917 Bd. 1 S. 212.

2) Thomas B. Osborne und Lafayette Mendel unter Mitarbeit von Edna L. Ferry und Alfred J. Wakeman, Fin quantitativer Vergleich ron Kasein, Laktalbumin und Edestin bezüglich des Wachstums. Journ. of Biol. Chem. vol. 26 p. 1. 1916. Ref. Chem. Zentralbl. 1917 Bd. 1 S. 592. - Vgl. auch ebenda vol. 20 p. 351 und vol. 22 p. 241. 1915. - Ferner: Der relative Wert gewisser Eiweissarten und Eiweisspräparate als Zulagen zu Korngluten. Journ. of Biol. Chem. vol. 29 p. 69. 1917. Ref. Chem. Zentralbl. 1917 Bd. 2 S. 760.

3) C. V. Mc Collum und M. Davis, Ernährung mit gereinigten Nährsubstanzen. Journ. of Biol. Chem. vol. 20 p. 641-658. Ref. Chem. Zentralbl. 1915 Bd. 2 S. 667.

1) Vgl. hierzu auch Casimir Funk u. Archibald Bruce Macallum, Studien über das Wachstum. III. Vergleich der Werte von Speck und Butterfett für das Wachstum. Journ. of Biol. Chem. vol. 27 p. 51. 1916. Ref. Chem. Zentralbl. 1917 Bd. 1 S. 968. - Vgl. ferner II. Mitt. Ebenda vol. 33 p. 413. 1916. Ref. Chem. Zentralbl. 1916 Bd. 1 S. 716. 
Dieselben Autoren ${ }^{\mathbf{1}}$ ) beobachteten, dass man die Wachstumfördernde Substanz in Olivenöl überführen konnte, wenn man dieses mit einer aus Butterfett dargestellten Seifenlösung schüttelte. Dieser Umstand spricht dagegen, dass es sich bei dem wachstumfördernden Prinzip um eine gegen Alkalien sehr empfindliche Substanz bandelt, wie es die Aminobasen aus Reiskleie oder Hefe sind, welche die nervösen Störungen bei der alimentären Dystrophie (Polyneuritis) der Tiere leicht und schnell zu beseitigen vermögen. Drummond ${ }^{2}$ ) berichtet, er babe in Milchzucker eine wachstumfördernde Substanz beobachtet. Durch öfter wiederholtes Auflösen und Wiederausfällen des Milchzuckers liess sich dieser von der betreffenden Substanz, die in Alkohol löslich und gegen Erhitzen bis zu $100^{\circ}$ beständig war, entfernen. E $\left(d^{3} y^{3}\right)$ konnte durch Fällung des in Wasser löslichen Anteils eines alkoholischen Extrakts aus Schafpankreas mit Lloyd's Reagens oder Phosphorwolframsäure und Zerlegung dieser Niederschläge eine Substanz gewinnell, welche das Wachstum junger Mäuse anregte. Den Angaben des Verfahrens zufolge handelte es sich bei dieser Substanz weder um einen Eiweisskörper, noch um ein Aminosäuregemisch von besonders hoher biologischer Wertigkeit, noch auch um einen fettartigen Stoff.

Me. Collum, Simmronds und Pitz ${ }^{4}$ ) unterscheiden zwei wachstumfördernde Substanzen: eine in Fett lösliche Substanz A, wie sie im Butterfett enthalten ist, und eine wasserlösliche Substanz B,

1) C. V. M c Coll um und M. Davis, Beobachtungen über Isolierung einer das Wachstum fördernden Substanz aus Butteriett. Journ. of Biol. Chem. vol. 19 p. 245. 1914. Ref. Chem. Zentralbl. 1915 Bd. 1 S. 905.

2) J. C. Drummond, Das Wachstum der Ratten bei künstlichen Kostsätzen, die Laktose enthalten. Biochem. Journ. Bd. 10 S. 89. 1916. Ref. Chem. Zentralbl. 1916 Bd. 2 S. 1176. - Vgl. auch Thomas Burr Osborne und Lafayette Benedict Mendel, Das Wachstum von Ratten bei Kostsätzen aus isolierten Nährsubstanzen. Biochem. Journ. Bd. 10 S. 584. 1916.

3) W. H. Eddy, Die Isolierung einer wachstumfördernden Substanz aus Schafpankreas. Journ. of Biol. Chem. vol. 27 p. 113. 1916. Ref. Chem. Zentralbl. 1914 Bd. 1 S. 962.

4) C. V. Mc Collum, N. Simmronds und W. Pitz, Die Beziehungen zwischen den nicht identifizierten Nahrungsfaktoren, dem fettlöslichen A und dem wasserlöslichen B zu den wachstumfördernden Eigenschaften der Milch. Journ. of Biol. Chem, vol. 27 p. 33. 1916. Ref. Chem. Zentralbl. 1917 Bd. 1 S. 963. Ferner: Die Natur der fehlenden Ernährungsfaktoren beim Haferkorn. Ebenda vol. 29 p. 341. 1917. Ref. Chem. Zentralbl. 1917 Bd. 2 S. 761. 
Beitrag zur Kenntnis von organischen Nahrungsstoffen mit spezif. Wirkung. 25

die durch Ausziehen von Weizenkeimlingen mit Alkohol in diesen übergeht. Ein Kostsatz, bei dem eine säugende Ratte abmagerte und die von ibr gesäugten Jungen Wachstumstillstand aufwiesen, wurde dureh Zusatz der Substanzen A und B suffizient. Die Gewichtsabnahme des Muttertieres hörte auf, und die jungen Ratten begannen wieder kräftig zu wachsen. Die Autoren schlossen hieraus, dass der tierische Organismus die wachstumfördernden Substanzen sich nicht auf autosynthetischem Wege zu beschaffen vermag, sondern dass ihm diese mit der Nahrung zugeführt werden müssen, und dass diese Substanzen in die Milch übergehen.

Is ovesco $0^{1}$ ) hat aus versehiedenen tierischen Organen und auch aus Lebertran Substanzen (Lipoide) isoliert, welche bei jungen Kaninchen nach täglicher Einspritzung unter die Haut von sehr kleinen Gaben (5-10 $\mathrm{mg}$ pro $\mathrm{kg}$ Kaninchen) wachstumfördernd wirkten. Bei ausgewachsenen Tieren äusserte sich die Wirkung dieser Präparate durch allgemeine Zunahme des Körpergewichtes sowie in einigen Fällen auch durch Hypertrophie bestimmter Organe und andere abnorme Erscheinungen (Erhöhung der Pulsfrequenz, Steigerung der Schweissabsonderung u. a. m.). So bewirkte die aus dem Ovarium gewonnene Lipoidfraktion ausser Wachstumförderung bei jungen Kaninchen eine Hypertrophie der Gebärmutter. Die aus Hoden extrahierten Lipoide wirkten wachstumfördernd auf junge Kaninchen und veranlassten eine bedeutende Gewichtszunahme bei erwachsenen. Ausserdem erregten sie sowohl bei Menschen wie bei Tieren in hohem Grade die Libido sexualis. Eine aus der Rindenschicht der Nebennieren isolierte Substanz regte die Nierentätigkeit an. Die mit ihr behandelten Kaninchen unterschieden sich auch durch einen viel dichteren und üppigeren Pelz von den Kontrolltieren. Die aus dem

1) H. Is ovesco, Action d'un lipoide extrait de l'ovaire sar l'organisme. Compt. rend. de la Soc. de Biologie t. 75 p. 393 . 1913. - Derselbe, Action physiologique d'un lipoide extrait du testicule. Compt. rend. de la Soc. de Biol. t. 75 p. 445. 1913. - Derselbe, Sur les propriétés d'un lipoide extrait de la partie corticale des capsules surrénales. Compt. rend. de la Soc. de Biol. t. 75 p. 510. 1913. Derselbe, Propriétés physiologiques d'un lipoide extrait du pancréas. Compt. rend. de la Soc. de Biol. t. 75 p. 681 . 1913. - Derselbe, Propriétés physiologiques d'un lipoide extrait de la partie médullaire des capsules surrénales: Compt. rend." de la Soc. de Biol. t. 75 p. 548. 1913. - Derselbe, Sur les lécithides contenus dans l'huile de foie de morte. Compt. rend. de la Soc. de Biol. t. 76 p. 34.1914. 
Pankreas ${ }^{1}$ ) dargestellten Lipoide bewirkten Gewichtszunahme bei Menschen und Kaninchen und nach längerer Anwendung bei Jetzteren Hypotrophie der Leber. Das von Is ovesco gewählte Darstellungsverfahren lässt darauf schliessen, dass es sich bei diesen Lipoiden in der Hauptsache um Phosphatide handelte. Als solches bezeichnet Isovesco ausdrücklich ein ans Lebertran gewonnenes Präparat, Dieses konnte in sehr geringer Menge (0,2 $\mathrm{g}$ aus 1 Liter Lebertran) isoliert werden. Es wirkte schon in sehr geringen Gaben wachstumanregend auf junge Kaninchen.

Wulzen ${ }^{2}$ ) fand, dass die Häufigkeit der Teilung von Planarien sowie die Wachstumsgeschwindigkeit dieser Würmer dureh Verfütterung von Hypophysen-Substanz gesteigert wird. Hierbei waren mit Runcksicht auf die Häufgkeit der Teilung alle Teile der Drüse gleichwertig. Das Wachstum dagegen wurde nur von der Pars glandularis und Pars intermedia der Hypophyse angeregt.

Schliesslich gehört in den Rahmen dieser Forschungen das von Gudernatsch ${ }^{3}$ ) angeregte Gebiet des Studiums der Wirkung von Inkreten auf Kaulquappen. Romeis ${ }^{4}$ ) und andere Forscher haben die Beobachtungen von Gudernatsch, wonach Schildrüsensubstanz die Entwicklung von Kanlquappen stark beschleunigt und Thymussubstanz sie stark verlangsamt bis aufhebt, bestätigt. $\mathrm{Abder}$ halden ${ }^{5}$ ) verwandte statt der Organe selbst die durch Fermente aus ihnen gewonnenen Abbauprodukte. Das Ziel war, zu prüfen, ob die wirksamen Prinzipien durch Fermentwirkung unwirksam werden. Es

1) Vgl. hierzu auch Walter H. Eddy, Die Isolierung einer wachstumfördernden Substanz aus Schafpankreas. Journ. of Biol. Chem. vol. 27 p. 119. 1916. Ref. Chem. Zentralbl. 1917 Bd. 1 S. 962.

2) R. Wulzen, Die Hypophyse. Ihre Wirkung auf Wachstum und Teilung der Planarien. Journ. of Biol. Chem. vol. 25 p. 625. 1916. Ref. Chem. Zentralbl. 1917 Bu. 1 S. 329.

3) J. F. Gudernatsch, Feeding experiments on tadpoles. Arch. f. Entwicklungsmechanik der Organismen Bd. 35 S.456. 1913.

4) Benno Romeis, Experimentelle Untersuchungen über die Wirkung innersekretorischer Organe. Areh. f. Entwicklungsmechanik der Organismen Bd. 40 S. 571 , 1914 und Zeitschr. f. experimentelle Medizin Bd. 6 S. 101, 1918 (hier sind auch die abrigen Arbeiten des Autors genannt).

5) Emil, Abderhalden, Studien über die von den einzelnen Organen hervorgebrachten Substanzen mit spezifischer Wirkung. Pflüger's Arch. Bd. 162 S. 99. 1915 . 
war dies nicht der Fall. Auf Grund dieser Tatsache war es nun möglich, die Inkrete der einzelnen Organe in Kombination zu prüfen. Der eine von uns (Abderhalden) hat seine Studien auf diesem Gebiete stark ausgedehnt und auf andere Tierarten übertragen. Es wird in Bälde über die erhaltenen Resultate berichtet. Jedenfalls stösst man in den einzelnen Organen auf Stoffe, die ganz spezifische Wirkungen entfalten.

Die vorstehende gedrängte Übersicht über die auf diesem Sondergebiete bislang vorliegenden Forschungsergebnisse und Beobachtungen dürften. wohl ein Bild von der grossen Mannigfaltigkeit der Erscheinungen geben. Zugleich ergibt sich aber wohl aus dieser Zusammenstellung, wie ausserordentlich verwickelt und schwer zu enträtseln die hier vorliegenden Probleme sind und wie viele weitklaffende Lücken noch zu schliessen sind, bevor es möglich sein wird, die Gesamtheit der Erscheinungen in einem System zusammenzufassen, welches sich auf ein hierzu ausreichendes Tatsachenfundament aufbaut.

\section{Die alimentäre Dystrophie (Polyneuritis) versehiedener Mier- arten, im besonderen die der Tauben.}

Von verschiedenen Seiten ist bereits darauf hingewiesen, dass die Bezeichnung "Neuritis" bzw. "Polyneuritis" für die bei Tieren infolge von Nährschäden auftretende mit Nervendegeneration eiuhergehende Krankheit keine zutreffende ist. Es handelt sich bei den hier in Betracht kommenden Veränderungen der Nervensubstanz ja nicht um einen entzündlichen Vorgang, sondern um eine ohne Entzündung sich abspielende Veränderung des Nervengewebes. Wir haben deshalb für diese Erkrankung die Bezeichnung "alimentäre Neurodystrophie“ gewählt. Es sei schon hier hervorgehoben, dass die Erscheinungen von seiten des Nervengewebes nur einen Teil der Folgen darstellen, die im Gefolge insuffizienter Nahrung auftreten. Es ist im einzelnen schwer zu entscheiden, welche Erscheinungen primärer und welche sekundärer Natur sind. So findet man sebr häufig einen ausserordentlich weitgehenden Schwund der Muskeln. Man kann den gesamten Zustand vorläufig am besten als a li mentäre D y strophie auffassen. Diesen Namen werden wir hier in der Folge an Stelle der Bezeichnung "Polyneuritis" gebrauchen.

Die experimentelle alimentäre Dystrophie lässt sich, wie die vorliegenden zahlreichen Versuchsergebnisse zeigen, bei einer ganzen 
Reihe von Tierarten hervorrufen. Am längsten bekannt ist die von Eijkman entdeckte alimentäre Dystrophie der Hühner (Polyneuritis gallinarum). Hühner sind auch wohl bis auf die neueste Zeit am meisten zu derartigen Versuchen verwandt worden. Axel Holst und Fröhlich ${ }^{1}$ ) benutzten zu ihren Experimenten als erste Tauben, die manche Vorzüge vor Hühnern haben. Sie sind leichter in den Laboratoriumsräumen unterzubringen und daher bequem zu beobachten. Ihre Beschaffung und Erhaltung sind auch weniger kostspielig. Vor allem aber zeichnen sich Tauben vor anderen Geflügelarten durch grosse Widerstandsfähigkeit und Zähigkeit aus. Von einem von uns (Schaumann) ist dann eine grössere Anzahl von Säugetieren: Hunde, Katzen, Kaninchen, Ratten, Mäuse, Meerschweinchen sowie ein Affe und ein Ziegenbock zu derartigen Versuchen herangezogen worden. Wie schon erwähnt, hat Axel $\mathrm{Holst}^{2}$ ) bei einer weiteren Versuchsreihe neben Meersehweinchen auch Schweine verwandt, bei denen nach einseitiger Fütterung mit geschliffenem Reis eine Mischform von alimentärer Dystrophie und Skorbut auftrat. Von Vogelarten sind auch noch Enten von $\mathrm{Külz}^{3}$ ), Papageien von $\mathrm{Fink} \mathrm{k}^{4}$ ) und Reisvögel (Spermestes oryzivora) von 0 ttow ${ }^{5}$ ) und $0 l s \in n^{6}$ ) zu Nährschädenexperimenten benutzt worden. Von Shiga und $\mathrm{Kusama}{ }^{7}$ ) sowie $\mathrm{Gibsen}{ }^{8}$ ) und einigen anderen Forschern ist dann noch mit Affen in grösserem Maassstabe experimentiert worden. Bei

1) A. Holst and O.Fröhlich, Experimental studies relating to Ship-Beriberi and Scurvy. Journ. of Hygiene vol. 7 Nr. 5. 1907.

2) A. Holst, The etiology of Beri-Beri. Transactions of the Society of Tropical Med. and Hyg. vol. 5 p. 76.1911.

3) L. Külz, Über Beriberi bei Enten. Arch. f. Schiffs- u. Tropen-Hyg. 1912 Nr. 2 S. 193.

4) G. L. Fin $k$, Beriberi and white rice: an experiment with parrots. Journ. of Trop. Med. and Hyg. vol. 15. 1910. Ref. Zentralb]. f. Bakteriol. usw. Bd. 49 S. 364.1911.

5) W. M: O t tow, Testing storage and preparation of unpolished rice. Natuurk. Tijdschr. v. Nederl. Indie Bd. 74 S. 143. 1915.

6) 0.01 s en, Incugural-Dissertation. Freiburg i. B. 1916.

7) K. Shiga und Sh. Kusama, Über die kakke-(beri-beri-)ähnliche Krankheit der Tiere. (Studien über das Wesen der Kakke.) Arch. f. Schiffs- u. TropenHyg. Bd. 15 Beitr. 3. 1911.

8) R. B. Gibsen, The protective power of normal human milk against Polyneuritis gallinarum and Bexi-Beri. The Philipp. Journ. of Science B. vol. 8 p. 702. 1914 (s. a. vol. 9 p. 119). 
allen diesen Tierarten tritt nach längerer insuffizienter Ernährung alimentäre Dystrophie auf. Über Versuche mit Sperlingen und weitere Versuche mit Ratten soll in der Folge berichtet werden.

Pathogenese. Die Erkrankung an alimentärer Dystrophie ist stets auf längere Zeit durchgeführte Fütterung mit insuffizienten Nahrungsmitteln oder in seltenen Fällen auf allgemeine Inanition zurückzuführen. Hierbei ist aber wohl zu berücksichtigen, dass der Begriff "Insuffizienz" ein relativer ist, d. h. es kann eine bestimmte Nahrung für eine bestimmte Tierart oder mehrere solche suffizient, für andere Tierarten dagegen insuffizient sein: So ist zum Beispiel Mais ein für Tauben und wohl auch für Hühner suffizientes, dagegen für Kaninchen, Schweine und Ratten insuffizientes Nahrungsmittel. Getrocknete gelbe Erbsen sind für Kaninchen suffizient, für Meerschweinchen insuffizient. Geschliffener Reis ist für alle Säugetiere und Vogelarten, mit denen bislang Versuche angestellt sind, insuffizient. Als für Geflügel insuffizient sind, soweit die bisherigen Erfahrungen gehen, noch zu nennen alle von den Fruchthäuten und der Aleuronschicht befreiten Getreidesamen, kleiefreies Weizen-, Hafer- und Gerstenmehl sowie hieraus hergestelltes Gebäck und Kartoffeln, besonders präservierte. Es ist wahrscheinlich, dass aussej" den genannten noch eine grössere Anzahl anderer Bodenerzeugnisse für Tiere eine unzureichende Nahrung ist. Für Menschen sind (ausser geschliffenem Reis und kleiearmem Weizenbrot) sowohl Sago wie die Maniokwurzel (Kassode) insuffizient. Die vorwiegende Ernäbrung mit diesen Nahrungsmitteln führt, wie die Erfahrung erwiesen hat, leicht zu Beriberi.

Von Haus aus suffiziente Nahrungsmittel können durch allerlei mit der Herrichtung für den Handel verknüpfte oder zur Erhöhung der Haltbarkeit voryenommenen Eingriffe insuffizient werden. Auch eine unzweckmässige Behandlung bei der Zubereitung in der Küche kann dies nach sich ziehen. Langes Lagern bewirkt ein Insuffizientwerden, zum Beispiel bei Hülsenfrüchten. Sie werden hierbei häufig so hart, dass sie sich überhaupt nicht mehr weich kochen lassen.' Es wird dann gerne durch Zusatz von Soda nachgeholfen, wodurch noch weitere unentbehrliche Nahrungsbestandteile zerstört werden. Reis und andere Zerealien verhalten sich bei zu langem Lagern ähnlich. Ferner kann durch zuweitgehendes Entfernen der Fruchthäute und der Aleuronschicht (Kleie) Insuffizienz veranlasst sein, wie beim Reis und bei allen Getreidearten, wie Hafer, Gerste, Roggen und in be- 
sonders hohem Grade auch beim Weizen. Manipulationen, bei denen häufig lebenswichtige Nahrungsbestandteile entfernt werden, sind das Waschen oder Wässern (zum Beispiel beim Reis) sowie anhaltendes Kochen, hauptsächlich dann, wenn das Kochwasser weggegossen wird. Brưhen ist $\mathrm{da}$, wo es angängig ist, zum Beispiel bei Gemüsen, viel empfehlenswerter. Das bei der Herstellung von Konserven übliche Erhitzen in Autoklaven auf Temperaturen uber $100^{\circ} \mathrm{C}$. ist besonders gefährlich. Auch Fleisch verliert hierbei lebenswichtige Nahrungsbestandteile und wird insuffizient. Erhitzt man Fleisch mit 20\% iger Sodalösung 2-3 Stunden lang auf $120-130^{\circ} \mathrm{C}$., so wird es in hohem Maasse insuffizient. Hunde, die mit so denaturiertem Fleisch ernährt werden, erkranken regelmässig nach 3-4 Wochen an alimentärer Dystrophie. Salzfleisch (Pökelfleiseh) wird, wenn es lange in der Pökellake gelegen hat, für Menschen und Hunde (wahrscheinlich für andere fleischfressende Tiere ebensowohl) insuffizient. In der Lake finden sich dann allerlei Abbauprodukte von organischen Phosphorrerbindungen (Trimethylamin, Purinbasen) und ausserdem Kristalle von Magnesium-Ammoniumphosphat. Auch das Trocknen in der Sonne oder in Trockenöfen kann schon schädigend wirken. Präservierte Kartoffeln verlieren beim Trocknen nicht unerbebliche Mengen von labilen lebenswichtigen Nabrungsbestandteilen. Auch beim Heu liegen derartige Beobachtungen vor: Gras, welches auf einem an Nährsalzen armen Boden gewachseu war, wurde in frischem Zustande vom Vieh gut vertragen, dagegen erkrankte dieses an einer als "Stallmangel" bezeichneten Krankheit, wenn es in den Wintermonaten mit Heu gefüttert wurde, welches durch Trocknen aus ebendemselben Grase bereitet war. Der "Stallmangel" äussert sich besonders durch Knochenveränderungen und Lecksucht ${ }^{1}$ ).

Die vorstehend geschilderten Veränderungen von Nahrungsmitteln haben $_{8}$ soweit es sich um solche für Menschen handelt, für die Schiffslygiene eine besonders grosse Bedeutung, weil sie leicht bei langen Reisen Frkrankungen an Schiffsberiberi veranlassen. Diese Krankheit, welche auf Segelschiffen häufig einen grossen Teil der Mannschaft er-

1) Genanere und eingehende Mitteilungen über die hier besprochenen Verhältnisse finden sich in H. S chauman $\mathrm{n}$, Die Ätiologie der Beriberi I u. II (s. S. 6) und mit Rüclssicht auf den Reis in W. Schüffner und W. A. Kuenen, Über den Einfluss der Behandlung des Reises anf die Beriberi usw. Arch. f. Schiffsu. Tropenhyg. Bd, 16 S. 7. 1912. 
Beitrag zur Kenntnis von organischen Nahrungsstoffen mit spezif. Wirkung. 31

greift und nicht selten zum Tode führt, verschwindet regelmässig mit geradezu überraschender Schnelligkeit, sobald die Kranken mit frischen Lebensmitteln beköstigt werden. Der Proviant, welcher die Krankheit verursacht hat, sieht dabei fast immer recht gut aus, und ein einfacher Augenschein würde kaum vermuten lassen, wie wenig geeignet er zur Ernährung ist. Verfüttert man ihn jedoch an Tiere, so ruft er auch bei diesen nicht selten alimentäre Dystrophie hervor ${ }^{1}$ ).

Man nahm früher an, dass vollständige Nahrungsentziehung bei Geflügel nicht zu alimentärer Dystrophie führt. Später haben Ch a mberlain und Vedder ${ }^{2}$ ) Fälle beobachtet, in denen Hühner, welche nur Wasser bekamen, an alimentärer Dystrophie (Polyneuritis) erkrankten. Bei der Untersuchung so verendeter Hühner fanden die genannten Autoren unzweideutig Nervendegeneration. Diese Ergebnisse sind in der Folge von Chamberlain, Bloombergh, Kilbourne und Eijkman ${ }^{4}$ ) bestätigt worden. Fijkman sowie Derks${ }^{5}$ ) sahen bei Hühnern, welche nur etwas Hefe oder Reiskleie bekamen, in übrigen aber hungerten, vor dem Tode keine Symptome von alimentärer Dystrophie auftreten. In den Nerven der so zugrunde gegangenen Tiere fanden sich nur geringe degenerative Veränderungen.

Bei unseren Versuchen mit Graupen, die vorher mit Wasser gut ausgezogen waren (S. 158) sowie mit getrockneten und dann gekochten

1) Alle diese Feststellungen zeigen, wie unzureichend es is t, wenn nahrungsmittel-chemische Untersuchungen für sich über den biologischen Wert eines Nahrungsmittels entscheiden sollen. Abgesehen davon, dass schon die Feststellung der Ausnutzbarkeit Versuche am Organismus erfordert, sind wir zur Zeit zur Prüfung der Suffizienz ganz auf Tierversuche angewiesen. Jedes Nahrungsmittel-Untersuchungsinstitut muss in Zukunft anf Tierversuche eîngerichtet und die Ausbildung der Nahrungsmittelchemiker entsprechend ergänzt werden.

Emil Abderhalden.

2) W. P. Chamberlain and C.A. Vedder, A second contribution to the etiology of Beri-Beri. The Philipp. Journ. of Science B. vol. 6 p. 395.1911.

3) Chamberlain, Bloombergh and Kilbourne, Influence of rice diet and of inanition on the production of multiple neuritis of fowls and the bearing there of on the etiology of Beri-Beri. The Philipp. Journ. of Science B. vol. 6 p. 177.1911.

4) C. Eijkman, Über den Einfluss der Ernährung und der Nahrungsentziehung auf die Erkrankung an Polyneuritis gallinarum. Virchow's Arch. f. pathol. Anat. u. Physiol. u. f. klin. Med. Bd. 222 S. 301. 1916.

5) The J. G. Derks, Bijdrage tot de Polyneuritis gallinarum in verband met het Beriberivraagstuck. Inaug.-Dissert., Utrecht 1916. 
Kartoffeln (S. 159) erkrankte nur eine Minderzahl der Versuchstiere an den für alimentäre Dystrophie als typisch betrachteten nervösen Störungen. Die Mehrzahl der Versuchstiere ging unter starker Abmagerung zugrunde, ohne dass es zu den genannten Erscheinungen kam. Über Ödeme der Füsse, welche bei einer der mit Kartoffeln ernährten Tauben auftraten, soll ebenso wie über Versuche mit Sperlingen und neuere Experimente mit Ratten an anderer Stelle berichtet werden.

Klinische Erscheinungen. Eine allgemein bei alimentärer Dystrophie der Tiere auftretende Erscheinung ist die Abnabme der Fresslust. Am Anfange der Versuche pflegen die Tiere die insuffiziente Nahrung gern und in reichlicher Menge aufaunehmen. Zuweilen nimmt ihr Körpergewicht hierbei noch zu. Allmählich nimmt die Fresslust aber ab und sinkt schliesslich auf ein Minimum berab. Eines der beim Abbau von Hefe gewounenen Präparate, der in Alkohol un]ösliche Anteil des Acetonniederschlages (S. 262), schien, soweit die beiden mit diesem Präparate angestellten Versuche einen bindenden Schluss zulassen, eine ausgesprochene, appetitanregende Wirkung auf die Versuchstauben zu üben, ohne dass es indessen die Abmagerung und das Auftreten von Paresen am Schlusse des Versuches zu verhindern vermochte. Die tägliche spontane Aufnahme von geschliffenem Reis betrug bei diesen Versuchen durchschnittlich etwa $20 \mathrm{~g} \mathrm{bzw}$. $16 \mathrm{~g}$ (s. S. 262 u. ff.). Diese Mengen genügen bei geringer Hefezufuhr $(0,5 \mathrm{~g}$ pro Tag und Taube), um Tauben auf Gewichtskonstanz zu erhalten, wie der Versuch Nr. 27 (S. 264) mit einer der zu den Versuchen mit dem genannten Hefepräparat benutzten Tauben zeigt. Wir werden hierauf zurückkommen.

Eine zweite, so gut wie durchstehende Begleiterscheinung der alimentären Dystrophie ist die Abmagerung der Versuchstiere, die in der Regel sehr bedentend ist. Bei Tauben beträgt die Gewichtsabnahme haufig über $50 \%$. Man hat diese Abmagerung vielfach als eine Nebenerseheinung bezeichnet, die mit dem eigentlichen Wesen der alimentären Dystrophie nichts zu schaffen habe. Bei unseren zahlreichen Versuchen mit den verschiedensten Tierarten ist uns kein einziger Fall vorgekommen, in dem nicht eine erhebliche Gewichtsabnahme, dem Auftreten nervöser Störungen (Lähmungen, Opistbotonus, Krämpfe u. dgl.) vorausgegangen wäre. Dagegen kommt es bekanntlich nicht selten vor, dass insuffizient ernährte Hühner und 
Beitrag zur Kenntnis von organischen Nahrungsstoffen mit spezif. Wirkung. 33

Tauben sterben, ohne dass es überhaupt zu Störungen nervöser Art kommt. Fälle, in denen nervöse Störnngen auftraten, ohne das̀s die Abmagerung erheblich war, haben auch wir, wie wohl jeder auf diesem Gebiete Erfabrene, beobachtet, aber sie sind relativ seltene Ausnahmen. Man kann der Abmagerung wohl bis zu einem gewissen Grade durch Zugabe bestimmter Stoffe zu einem insuffizienten Nahrungsmittel sowie durch Zwangsfütterung entgegenwirken. Im ersteren Falle führt man offenbar dem insuffizienten Nahrungsmittel Stoffe zu, welche dessen Insuffizienz teilweise und zwar nach einer bestimniten Richtung hin aufheben. Die Insuffizienz von Nahrungsmitteln ist wohl, wie dies an anderer Stelle erörtert werden soll, in der Regel, wenn nicht durchweg, durch den Mangel an einer Mehrzahl von Stoffen bedingt, und es erscheint als verfehlt, eine solche Unzulänglichkeit auf das Fehlen eines einzigen Körpers („Vitamin“) zurückzuführen. Bei der Zwangsfütterung sucht man ja auf künstliche Weise der unzureichenden Nahrungsaufnahme und Abmagerung entgegenzuwirken: Diese ist aber doch bauptsächlich durch eine im Gefolge der Krankheit so gut wie durchweg auftretende Verweigerung der spontanen Nabrungsaufnahme bedingt. Es erscheint uns daher nicht als berechtigt, eine solche durchstehende Erscheinung von dem allgemeinen Krankheitsbilde loszutrennen. Bei der Segelschiff-Beriberi ist übrigens die Appetitlosigkeit, welche von den Seeleuten als "Abgegessensein" bezeichnet wird, ein bekanntes, dem Ausbruche der Krankheit häufig vorhergehendes Symptom. Wohl zu beachten sind aber hier zwei Umstände: Einmal magern Tauben fast durchweg schon in den ersten Tagen nach Beginn der Fütterung mit einem insuffizienten Nahrungsmittel (zum Beispielgeschliffenem Reis) sehr stark ab und $z$ war zu einer Zeit, in der sie dieses Nahrungsmittel noch gerne und in reichlichen Mengen fressen. Von einer ungenügenden Zufuhr kann hier noch keine Rède sein. Es gelingt auch nur ausnahmsweise, die Tiere auf Gewichtskonstanz zu erhalten, wenn man ihnen selbst sehr grosse Mengen der insuffizienten Nahrung einflösst. Diese ist aber nur ganz frei von allen den hier in Betracht kommenden Nahrungsbestandteilen, wenn man Mischungen von gereinigten Hauptnährstoffen (Kolehydraten, Eiweiss, Fett und anorganischen Salzen) verfüttert. Solche Genische werden jedoch erfahrungsgemäss von Tieren nur sehr kurze Zeit 
hindurch spontan aufgenommen und bei Zwaugsfütterung nach.wenigen Tagen durch Erbrechen wieder ausgeschieden. Von den natürlich vorkommenden Nabrungsmitteln enthält aber selbst der geschliffene Reis immer noch kleine Mengen von den hier in Frage kommenden Nahrungsbestandteilen. Es erscheint uns aus diesen Gründen nicht gerechtfertigt, wenn man die so gut wie immer vorkommende Abmagerung in der. Weise, wie es geschehen ist, von der Zugehörigkeit zu dem allgemeinen Krankheitsbilde der alimentären Dystrophie ausschliessen will. Sämtliche bislang erprobte natürlich vorkommenden Stoffe und aus ihnen hergestellte. Präparate, welche die nervösen Störungen bei der alimentären. Dystrophie zu beseitigen vermögen, wirken auch gleichzeitig appetitanregend und bewirken daher auch zuweilen eine meistens geringe Zunahıe des Körpergewichtes. Eine Unterscheidung der "trophischen" und "antineuritisehen" Wirkung erseleint daher auch undurchführbar.

Eine der wichtigsten und vielfach als allein typisch angesehenen Erscheinungen der alimentären Dystrophie (Polyneuritis) sind die in späterem Verlauf der Krankheit auftretenden $A$ us fallerscheinungen und Störungen nervöser Art: Paralysen und Paresen der Beine und. Flügel, Opisthotonus, Streckkrämpfe, Konvulsionen. Vielfach sind die Erseheinungen ähnlich denen, die man nach Verletzungdes Kleinhirns oder nach Zerstörung der Bogengänge des Vestibularapparates beobachtet. Es wäre von Interesse, diese Organe und die zugehörenden Nervenbahnen bei erkrankten Tieren zu untersuchen. Die Erscheinungen treten meistens ganz plötzlich, aber durchaus nicht immer auf. Bei Hühnern und besonders bei Tauben kommt es nicht selten vor, dass sie plötzlich und ohne Voranzeichen des nahen Torles sterben. Bei derartig eingegangenen Tierenfindet mandann häuig trotzdem ausgesprochene Waller'sche Degeneration der peripheren Nerven, ohne dass vor dem Tode irgendwelche Lähmuggen oder andere auf nervöse Störungen deutende Erscheinungen bemerkbar gewesen wären. Andererseits können Lähmungen schwerster Art, besonders bei Hunden und auch bei anderen Säugetieren; bestanden haben, ohnedass nennenswerte Veränderungen in den peripheren Nervenfasern nachuweisen sind. Bemerkenswert ist; dass die nervösen Störungen bei jeder : Tierart 
Beitrag zur Kenntuis von organischen Nahrungsstoffen mit spezif. Wirkung. 35

einen mehr oder minder eigenartigen Charakter annehmen. Zuweilen äusseru sie sich nur durch Paralysen oder Paresen wie bei Affen, in anderen Fällen, wie z. B. bei Kaninchen, gesellen sich zu den Lähmungen der Extremitäten heftige Krampfanfälle. Die alimentäre Dystrophie der Hühner verläuft anders als wie die.der Tauben, und diejenige der Sperlinge zeigt, wie später erörtert werden soll, wiederum ein anderes Bild.

Von klinischen Symptomen sind bei der alimentären Dystrophie der Tauben noch zu erwähnen: grüner, dünnflüssiger Stuhl, besonders nach längexer Fütterung mit einem insuffizienten Nahrungsmittel. Die grüne Farbe ist durch starke Sekretion von Galle veranlasst. Ferner Lähmung des Kropfes, so dass eine Stagnation der aufgenommenen Nahrung eintritt. Verdauungsstörungen, besonders Enteritis, sind nicht selten und führen ebenfalls zuweilen zum Tode, ehe es zu nervösen Störungen kommt. Die Herztätigkeit ist im vorgeschrittenen Stadium der Kraukheit oft beschleunigt, wäbrend die Körpertemperatur meistens einen starken Abfall zeigt. Bei gesunden Tauben liegt die Körpertemperatur zwischen 40 und $41^{\circ} \mathrm{C}$. Im Verlaufe der alimentären Dystrophie sinkt die Temperatur langsam, zuweilen bis unter $36^{\circ} \mathrm{C}$. Tauben, die eine so niedrige Körpertemperatur aufweisen, gehen auch bei Anwendung der wirksamsten Präparate in der Regel ein. Befinden sich mehrere Tauben in vorgerückterem Stadinm der Erkrankung in demselben Käfig, so drängen sie sich oft bei kühler Witterung, anscheiuend um sich gegenseitig zu erwärmen, dicht aneinander.

Wie bei Hühnern, so beobachtet man auch bei Taüben grosse individuelle Unterseh iede. Diese äussern sich zunächst durch den Zeitraum, der verstreicht, bis die Tiere erkranken. Selbstverstäudlich hängt diese Inkubationsdauer von der Art des verfütterten, insuffizienten Nahrungsmittels bzw, von der Qualität des als Nahrung verwandten geschliffenen Reises in erster Linie ab. Aber auch bei ganz gleichartiger Ernährung machen sich grosse individuelle Schwankungen geltend. In allgemeinen währt die Inkubation bei Verwendung von geschliffenem Reis 30-40 Tage. Tauben, die ein hohes Körpergewicht aufweisen, pflegen in der Regel entsprechend später zu erkranken. Am widerstandsfähigsten sind Feldtauben und Bastarde von sogenannten Pagadetten, die sich durch den besonders kräftig gebauten Schnabel, stark entwickelten Höcker über den Nasenlöchern und weiten Schlund 
auszeichmen. Duukelgefärbte Tauben widerstehen Nährschäden in der Regel länger als weisse. Die individuellen Unterschiede finden aber vor allem einen sehr auffallenden Ausdruck in dem Krankheitsbilde selbst. Man kana hier drei verschiedene Typen unterscheiden:

Ty pus I. Die Tauben magern sehr stark, oft bis zum Skelett, ab. Nervöse Störungen fehlen. Die Körpertemperatur nimmt im späteren Verlauf des Versuches stark ab und beträgt selten über $37^{\circ} \mathrm{C}$., sinkt aber hin und wieder unter $36^{\circ} \mathrm{C}$. Der Tod tritt oft plötzlich und unerwartet, zuweilen nach relativ kurzem komatösem Zustande ein.

Ty pus II. Die Tauben magern ebenfalls stark ab, jedoch in der Regel nicht so stark wie bei Typus I. Es treten dann Paresen der Beine, zuweilen auch der Flügel auf, bei letzteren seltener und in der Regel weniger schwer. Die Lähmungen der Beine nehmen allmäblich zu und steigern sich bis zur völligen Unfähigkeit der Tauben, sich zu erheben und zu laufen (Photographien Nr. 2 und 11). Wird die Nahrung nicht in geeigneter Weise verändert oder eine wirksame Therapie eingeleitet, so gehen die Tiere meistens plötzlich ein. Opisthotonus, Krämpfe und andere derartige nervöse Störungen fehlen. Langsame Rekonvaleszenz, bei der die Lähmungen noch relativ lange bestehen bleiben, ist häufig. Bei unseren Versuchen wiesen junge Tauben besonders häufig diesen Typus auf.

Als Beispiel für die bei diesem Typus häufig vorkommende langsame Wiederherstellung sei die zu dem Versuche 5 mit Präparat I A (S. 257) verwandte Taube aufgefuhrt. Die Photographie Nr. 13 ist nach neuntägiger Behandlung der Taube mit sehr energisch wirkenden Mitteln, die in anderen Fällen eine sebr schnelle Heilung nach sich zogen, aufgenommen. Wie man auf dem Bilde erkennen kann, ist das rechte Bein der Taube nach vorn, das linke nach hinten vollkommen ausgestreckt. In eine solche Stellung würde eine gesunde Taube kaum: $\mathrm{zu}$ bringen sein und noch weniger darin verharren. Auch hier handelt es sich um ein junges, etwa 3 Monate altes Tier.

Ty pus III. Allgemeine Abmagerung, aber nicht so stark wie bei Typus I. Die Tiere weisen nach längerer Fütterung mit geschliffenem Reis die nachstehend geschilderten Vorläufer der typischen Erkrankung auf. Plötzlich treten dann Paresen der Beine und Flügel sowie meistens gleichzeitig Opisthotonus und Strecklkrampf der Beine nach vorn auf (Photographien Nr. 4 und 6). Hierbei zeigen die so erkrankten Tauben (wahrseheinlich infolge Verlegung des Schwer- 
punktes durch den stark zurückgezogenen Hals und Kopf nach hinten) das Bestreben, sich rückwärts zu bewegen. Sie überschlagen sich dabei leicht oder fallen zur Seite, wodurch in der Regel heftige Konvulsionen ausgelöst werden. Die Tieren schlagen hierbei heftig mit den Flügeln und drehen sich im Kreise. Bei den Tauben, welche diesen Typus aufweisen, lassen sich zuweilen, wenn der Opisthotonus, wie es häufig vorkommt, zeitweilig schwindet, durch kurzes Berähren des Rückens starke Reflexbewegungen auslösen, wie sie die Augenblicksphotographien Nr. 27 und 28 wiedergeben. Bei Anwendung von wirksamen Hefe-, Reiskleie- und anderen derartigen Präparaten schwinden 'die für Typus III charakteristischen nervösen Erscheinungen meistens schnell, zuweilen, wenn auch nur ausnahmsweise, bei intramuskulärer Einspritzung starkwirkender Lösungen sogar schon innerhalb einer Stunde.

Der allgemeine Verlauf von dem Zeitpunkt, an dem die insuffiziente Ernährung einsetzt, an bis zur vollkommenen Entwicklung der alimentären Dystrophie pflegt folgender zu sein:

$\mathrm{Zu}$ Anfang fressen die Tauben noch reichliche Mengen der insuffizienten Nahrung, magern aber hierbei schon erheblich ab. Allmählich lässt die Fresslust nach, und die Tauben erscheinen weniger munter als vorher. Diese psychische Depression nimmt immer mehr zu. Die Tiere sitzen im weiteren Verlaufe mit eingezogenem Kopf und gesträubtem Gefieder auf der Sprungstange (Photographie Nr. 1). Nicht selten beobachtet man bei ihnen ein eigentümliches Zittern. Während des noch weiter vorgeschrittenen Stadiums der Krankheit pflegen sich die Tauben nicht mehr auf die Sprungstange zu setzen, sondern sitzen zusammengekauert in einer Ecke des Käfigs. Die Pflege des Gefieders lässt sichtlich nach, und der Kot wird dünnflüssig und nimmt eine grüne Farbe an (Gallenfarbstoff). Die Nahrungsaufnahme ist nur minimal und dabei sehr unregelmässig, d. b. die Tauben fressen einen Tag oder mehrere Tage lang hintereinander wenig oder überhaupt nichts, um dann wieder auf einmal grössere Mengen des Futters aufzunehmen. Zuweilen scheint in diesem Stadium das Gefieder sehr locker zu sitzen. Die Tauben verlieren dann, wenn sie umherflattern, leicht eine grössere Menge von Federn. Die letzterwähinten Prodromalsymptome lassen auf das nahe bevorstehende Auftreten von nervösen Störungen, wie sie für Typus II und III bezeichnend sind, schliessen. Bei Typus I kommt es vor, dass die Versuchstauben 
bis ganz kurz vor dem Tode noch hehende umherzulaufen vermögen. Besonders oft haben wir dies bei Tauben beobachtet, die Nukleinsäure aus Hefe (Boehringer) oder Phytin als Zugaben zu geschliffenem rohem Reis bekommen hatten.

Bei $\mathrm{Hunden}$ pflegen die Lähmungserscheinungen bei Fütterung mit denaturiertem Fleisch nach starker Abmagerung plötzlich aufzutreten. Sie sind am ausgesprochendsten an den Hinterbeinen, die ihren Dienst nicht selten ganz versagen. Der ganze Körper des Tieres erscheint steif. Bei Anwendung heilkräftiger Mittel (Hefe, Stierhoden, Reiskleieextrakt) verschwinden die Lähmungen in der Regel schnell, manchmal schon nach Verlauf von 6-8 Stunden. Zuweilen stellen sich kurz vor dem Tode Krampfanfälle ein.

Katzen verhalten sich ähnlich wie Hunde; nur scheint der Verauf der Krankheit ein akuterer und die Wiederherstellung schwieriger zu sein.

Bei Kaninchen stellen sich nach längerer Fütterung mit Mais starke Abmagerung und Lähmungen der Beine ein, die von in Intervallen einsetzenden heftigen Konvulsionen begleitet sind. Iie Tiere laufen noch längere Zeit, nachdem die Paresen durch vollwertige Ernährung in der Hauptsache beseitigt 'sind, auf den ganzen Vorderfüssen, statt auf den Zehen, wie gesunde Kaninchen. Das Fell wird durch teilweises Ausfallen der Haare oft rauh.

Bei Affen gelingt es nicht leicht und auch nicht immer, durch einseitige Frnährung mit geschliffenem Reis alimentäre Dystrophie hervorzurufen. Man gelangt, soweit unsere Erfahrung geht, eher zum Ziel, wenn man den geschliffenen Reis vor der Verfütterung noch ein paarmal mit reichlichen Mengen kalten Wassers ausziebt und dann wieder trocknet. Auch hier geht starke Abmagerung dem Auftreten anderer Ausfallerseheinungen voraus.

Ratten sind im allgemeinen sehr widerstandsfäbig gegen Nälırschäden. Sie erkranken bei einseitiger insuffizienter Ernährung meistens erst nach längerer Zeit. Die Lăhmungen sind selten sehr ausgesprochen. Es scheint so, als ob die Ratte, welche ja auf die verschiedenartigste und häufig auch auf eine sehr einseitige Nahrung angewiesen ist, sich diesen Verhältnissen in besonders hohem Maasse angepasst hat. Regelmässig zeigen sich Veränderungen am Fell und an der Haut. Die Haare fallen aus. Die Haut ist gegen Parasiten weniger widerstandsfähig. Trotz sorgfältigster Pflege zeigen sich bald mehr oder 
Beitrag zur Kenntnis von organischen Nahrungsstoffen mit spezif. Wirkung. 39

weniger abnorne Veränderungen. Sehr häufig findet sich 'Conjunctivitis.

Bei einem $\mathrm{Zi}$ egen bock gelang es, durch sechs Monate hindurch mit kurzen Unterbrechungen fortgesetzte Fütterung mit Mais und geschliffenem Reis eine chronische Lähmung, die sich durch schwere Lähmung der Beine, besonders der Vorderbeine, äusserte, hervorzurufen.

Über neue, von uns angestelite Versuche mit Ratten und Sperlingen soll noch, wie. schon gesagt, am Schluss berichtet werden.

Pat hologisch-anatomische Veränderungen. Am besten erforscht sind die bei der alimentären Dystrophie der Hühner auftretenden pathologisch-anatomischen Veränderungen. Eijkman fand schon bei seinen ersten Untersuchungen, dass sowohl die sensiblen wie die motorischen Bahnen peripherer Nerven von Hühnern bei Polyneuritis gallinarum Degeneration aufweisen. Diese trat in den Nervenstämmen bündelweise auf und bot das Bild der nicht entzündlichen atrophischen Degeneration dar, wie sie nach dem Durchschneiden eines Nerven an dem vom Zentrum getrennten Stück auftritt. Im Rückenmark wies Eij.kman ${ }^{1}$ ) Atrophie von Ganglienzellen in den Vorderhörnern nach. Auch die von den degenerierten Nerven bedienten Muskeln waren insofern verändert, als sich in einem Teil der quergestreiften Fasern durch Osmiumsäure eine grosse Zahl féiner Fetttröpfchen nachweisen liess. Shiga und Kusama ${ }^{2}$ ) fanden sowohl bei $\mathrm{Hühnern}$ wie auch bei $\mathrm{T}$ a uben, die an alimentärer Dystrophie eingegangen waren, bei der makroskopischen Untersuchung allgemeine Atrophie, Stauung, Hydroperikard und gelegentlich auch Anásarka. An histologischen Veränderungen fanden sich eine nach dem Kopf zu abnehmende einfache Degeneration der peripheren Nerven und des Rückenmarks, Fragmentation der Herz- und Skelettmuskeln. Herzbeutelflüssigkeit fand sich regelmässig in grösseren Mengen. Die Konsistenz des Gehirns war erheblich herabgesetzt.

1) C. Eijkman, Eine beriberi-äbnliche Krankheit der Hühner. Virchow's Arch. Bd. 148 S.523. 1897. - Derselbe, Polyneuritis bij hoenders, nieuwe bijdrage tot de aetiologie der ziekte. Geneesk. Tijdschr. vor Nederl. Indie 1896.

2) K. Shiga und Sh. Kusama, Über die kakke-(beriberi-)ähnliche Krankheit der Tiere (Studien über das Wesen der Kakke). Arch. f. Scbiffs- u. TropenHyg. Bd. 15 Beih. 3. 1911. 
Vedder und Clark ${ }^{1}$ ) fassen die Ergebnisse ihrer pathologischanatomischen Untersuchungen dahin zusammen, dass es sich bei der alimentären Dystrophie der Hühner nicht um die Degeneration einer grösseren oder geringeren Anzahl peripherer Nerven allein, sondern um. eine mehr oder minder ausgesprochene degenerative Veränderung des gesamten Nervensystems einschliesslich des Rückenmarks handle, wie dies auch von $D u ̈ \mathrm{rk}^{2}$ ) bei der menschlichen Beriberi festgestellt worden sei: Zuweilen fanden diese Forseher Veränderungen am Herz (leichtes Ödem, Pigmentzunahme, beginnende parenchymatöse odẹ mukoide Degeneration). Bei sehr ausgesprochenen Fällen konnten sie in allen Nervenfasern des $\mathrm{N}$. vagus degenerative, wenn auch nicht sehr fortgeschrittene Veränderungen nachweisen.' Es waren jedoch keine Wechselbeziehungen zwischen dem Grad dieser Degeneration einerseits und den pathologischen Veränderungen des Herzens oder dem Grade der nervösen. Störungen vor dem Tode nachweishar. Dagegen bestanden enge Bezielıungen zwischen den nachweisbaren degenerativen Veränderungen im N. ischiadicus und der Paralyse der Beine.

Bei Tauben, die an alimentärer Dystrophie eingegangen waren, fand Axel Holst (l. c.) in der Regel mässig grosse, aber deutlich ausgesprochene Ödeme unter der Haut der Beine und Füsse, in einigen wenigen Fällen allgemeines Anasarka. Zuweilen wurden nur an dem oberen Teil der Extremitäten oder an der Kehle oder am Kopfe Schwellungen gefunden, in anderen Fällen fehlten Ödeme ganz. Vereinzelt wurie Hydroperikardium und sehr selten Ascites angetroffen.

Bei unseren mit einseitiger Kartoffelfütterung an Tauben angestellten Versuchen stellten sich bei einem der Versuchstiere neben Lähmungen starke Ödeme der Füsse ein. Die am 12. April 1917 aufgenommene Photographie Nr. 34 zeigt die Füsse dieser Taube während der Zeit del stärksten Schwellung. Ein Vergleich mit den auf Photographie Nr. 33 wiedergegebenen normalen Füssen einer gesunden Taube veranschaulicht den Grad der Ödeme besser. Diese gingen nur allmählich nach Verabreichung gemischten Taubenfutters

1) E. B. Vedder and E. A. Clark, A study of polyneuritis gallinarum. A fifth contribution to the etiology of Beriberi. The Philipp. Journ. of Science B. vol. 7 p. 423.1911.

2) H. Dürck, Untersuchungen über die pathologische Anatomie der Beriberi. Gustav Fischer, Jena 1908. 
Beitrag zur Kenntnis von organischen Nahrungsstoffen mit spezif. Wirkung. 41

und einer Tagesgabe von $1 \mathrm{~g}$ Hefe zurück, und zwar zuerst am rechten Fusse. Die am 19. April 1917 aufgenommene Ph otog r a phie Nr. 35 lässt den Uuterschied zwischen den beiden Füssen deutlich hervortreten. Am rechten Fusse _ist da, wo die Zehen zusammenlaufen, auf dem Rücken des Fusses noch eine deutliche Schwellung bemerkbar, während die Zehen selbst fast wieder normal sind. Der linke Fuss dagegen schwoll sehr langsam $a b$, und war erst nach etwa 2 Monaten wieder normal, wie die am 26. Juni 1917 gemachte A a fnah me Nr. 36 zeigt.

Richter ${ }^{1}$ ) fasste die Ergebnisse seiner Nervenuntersuchungen bei Tauben, die an alimentärer Dystrophie eingegangen waren, folgendermaașsen zusammen: Hyperämie, Hämorrhagien im Nervengewebe, Degeneration der Nervenzellen, und zwar besonders im linken Horn des Rückenmarks, Vakuolenbildung in der motorischen Gruppe des Corpus bigeminum. Segawa ${ }^{2}$ ) stellte seine Versuche mit 36 Hühnern und fünf Tauben an und gelangte mit Rücksicht auf die pathologisch-anatomischen Veränderungen bei den an alimentärer Dystrophie verendeten Versuchstieren zu nachstehenden Ergebnissen: Die wichtigste Veränderung ist die Degeneration der peripheren Nerven.

Die anderen Befunde, nämlich Dilatation beider Ventrikel, allgemeine venöse Stauung, Hydroperikardium, Degeneration des von der gesehädigten Nervenfaser versorgten Muskels, Degeneration der Ganglienzellen der Vorderhörner des Rüekenmarks, Verfettung der Media der kleinen Arterienäste usw., sind meist als sekundäre Folgeerscheinungen aufzufassen.

Bei der alimentären Dystrophie der $\mathrm{Hunde}$ waren die bislang festgestellten Veränderungen der Nerven, trotzdem die Tiere vor dem Tode schwer gelähmt waren, im allgemeinen sehr wenig ausgesprochen. Typisch degenerierte Fasern fanden sich nur. vereinzelt. Schaumstruktur wurde öfter gefunden.

Ähnlich liegen die Verhältnisse bei Katzen. Es muss aber betont werden, dass es sich sowohl bei Hunden wie auch bei Katzen un eine geringe Zahl derartiger Untersuchungen handelt.

1) H. Richter, Experimentelle Beriberi-Erkrankung bei Tauben. Wiener Med. Wochenschr.1914Nr.36. Ref. Arch. f. Schiffs- u. Tropen-Hyg. Bd.19 S. 614. 1915.

2) M. Segawa, Über das Wesen der experimentellen Polyneuritis der Hühnel' und Tauben. Virchow's Arch. f. pathol. Anatomie u. Physiol. u. f. klin. Med. Bd. 15 S. 404. 1914. 
Bei Kaninchen, die einseitig mit Mais gefüttert wurden, ist eine sehr auffallende Veränderung die der Knochen (Rarifikation, Osteoporose), welche zuweilen so dünn wie Papier werden. Ausser Schaumstruktur wurden in den Nerven der an alimentärer Dystrophie verendeten Tiere keine Veränderungen gefunden, obwohl die. Tiere ebenfalls vor dem Tode häufig schwer gelähmt waren.

Affen erkranken nicht leicht an alimentärer Dystrophie. Hieraus erklären sich wohl auch die zahlreichen Misserfolge. Bei zwei infolge alimentärer Dystrophie verendeten Affen fanden Shiga und Kusama Anasarka, Hydroperikard, Atelektase und Ödeme der Lunge sowie Dilatation und Hypertrophie des Herzens. Letztere Veränderung ist bekanntlich eines der charakteristischen Merkmale der hydrophischen Beriberi. Bei einem von einem von uns (Schaumann) mit einem Affen angestellten Versuche fanden sich in den Nerven des unter Auftreten von Paresen eingegangenen Tieres keine typischen Veränderungen. Normale Fasern waren allerdings auch nur in geringer Zahl zu finden. Die überwiegende Menge zeigte Schaumstruktur.

Im yanzen: sind, soweit es sich um alimentäre Dystrophie von Säugetieren handelt, die pathologisch-anatomischen Veränderungen nur in sehr mässigem Umfange Gegenstand der Forschung gewesen, während dieses Gebiet bei der menschlichen Beriberi von einer ganzen Reihe hervorragender Forseher, neuerdings besonders von Dürck ${ }^{1}$ ). sehr gründlich und eingehend bearbeitet worden ist.

Prophylaxe und Therapie. Ausser durch Fütterung mit vollwertiger Nahrung lässt sich die alimentäre Dystrophie, auch wenn die inșuffiziente Ernährung, welche zur Erkrankung geführt hat, beibehalten wird, durch eine ganze Reihe von Zugaben heilen bzw. verbindern. Von den bekannten wirksamen, natürlich vorkommenden Stoffen kommt der Hefe an Wirksamkeit die erste Stelle zu. Sie hat sich nicht nur gegen die alimentäre Dystrophie von Hähnern und Tauben, sondern auch gegen die von Säugetieren, und zwar sowohl von fleisch- wie pflanzenfressenden, als sehr wirksam erwiesen (Hunde, Kaninchen, Ziegen). Bei Tauben, die einseitig mit geschliffenem Reis gefüttert wurden, genügte meistens schon eine Tagesgabe von

1) H. Dürck, Untersuchungen über die pathologische Anatomie der Beriberi. Gustav Fischer, Jena 1908. 
0,5 g getrockneter Bierhefe ${ }^{1}$ ), um die Versuchstiere nicht nur gesund, sondern auch auf Gewichtskonstanz zu erhalten. An Wirksamkeit steht der Bierhefe an nächsten die Reiskleie. Es folgen dann die Kleie von Gerste, Roggen, Hafer und Weizen. Eine hervorragende Wirksamkeit kommt auch der bereits erwähnten $\mathrm{K}$ atjangidj oe (Phaseolus radiatus), einer in Ostasien heimischen Bohnenart, $\mathrm{zu}_{\text {; }}$ Erbsen stehen dieser Bohnenart nach, sind aber ebenso wie Linsen immer noch recht wirksam. Bei Hunden erwiesen sich relativ geringe Gaben von entfettetem Stierhoden als äusserst wirksam. Bei Tauben war mit Stierhoden-Therapie ebenfalls eine Wirkung zu erzielen, doch schien diese der bei Hunden beobachteten erheblich nachzustehen. Eid otter ist nach den Versuchen von $\mathrm{C}$ o o per gegen die alimentäre Dystrophie der Tauben auch sehr wirksam. Alle die vorgenannten Stoffe wirkennicht nurheilend, sondern auch vorbeugend.

Ausser diesen Stoffen hat man eine ganze Reihe von anorganischen und organischen chemischen Verbindungen auf ihre Wirksamkeit geprüft. Von diesen kommt der $\mathrm{Nukleinsäure} \mathrm{aus} \mathrm{Hefe,}$ wenn sie sorgsam bereitet ist, zweifellos eine Wirkung gegen die im Gefolge der alimentären Dystrophie auftretenden nervösen. Störungen $\mathrm{zu}$, die sie bei erstmaliger Anwendung vollkommen $\mathrm{zu}$ beseitigen vermag. Merkwürdigerweise aber versagt die Hefenukleinsäure bei wiederholter Anwendung. Wir werden hierauf bei Besprechung der Wirksamkeit des Hefenukleoproteins sowie des Hefenukleins (S. 98 u. ff.) zurückkommen. Funk's ${ }^{2}$ ) Angaben zufolge soll auch der Thymus Nukleinsäure eine solche vorübergehende Wirksamkeit zukommen. Von anderen hierher gehörigen Verbindungen sind noch $\mathrm{Purin}-\mathrm{u}$ d Pyrimidinbasen zu nennen, bei" deren Anwendung Funk eine Wirkung gesehen haben will. Cooper gibt an, er habe auch bei Chinin- und Cinchoningaben eine vorübergehende günstige Beeinflussung der nervồsen Störungen beobachtet.

In der jüngst vergangenen Zeit sind von Robert E. Willia m s${ }^{3}$ )

1) Vgl. hierzu auch A the rt on Seide11, Der Vitamingehalt von Branereihefe. Journ. of Biol Chem. vol. 29 p. 145. 1917. Ref. Chem. Zentralbl. 1917Bd. 2 S. 819.

2) C. Funk, Further experimental studies on Beriberi. The action of certain purine and pyrimidine-derivates. Journ. of Physiol. vol. $45 \mathrm{Nr}$. 6. 1913.

3) Robert $R$. Williams, Structure of antineuritic hydroxypyridines. Proc. of the Soc. for exper. Biol. and Ned. vol. 14 p. 25. 1916. - Dersell.e, Die 
Versuche mit Derivaten der Nikotinsâure und des Pyridins angestellt worden. Von ersteren bewirkten dem Autor zufolge nur eine geringe Besserung Trigonellin, Nikotinsäuremethylester, p-Oxynikotinsäure. Am besten, aber ebenfalls nur vorübergehend, wirlite der Nikotinsäuremethylester. Durch Einwirkung von Phosphorpentoxyd oder Eisessig auf Oxynikutinsäure können undefinierte Kondensationsprodukte gewonnen werden, welche wirksamer waren. Von einer grösseren Anzahl von Pyridinderivaten erwiesen sich als wirksam gegen die bei alimentärer Dystrophie auftretenden nervösen Störungen $\alpha$-Oxypyridin, 2, 4, 6-Trioxypyridin und 2, 3, 4-Trioxypyridin. Die Wirkung dieser Körper war auffallend inkonstant und ging bei längerem Aufbewahren der Substanzen verloren [s. auch S. 86 u. ff.] ${ }^{1}$ ).

Williams schreibt diese Unbeständigkeit mit Rücksicht auf die Wirksamkeit einer inneren Umlagerung im Molekül der betreffenden Verbindungen zu. Auf diese Verhältnisse werden wir an anderer Stelle zurückkommen (S. 87).

Als wirksam haben sich auch Extrakte erwiesen, welche aus versehiedenen natürlich vorkommenden Substanzen gewonnen werden können. Sowohl salzsaures wie alkoholisches Extrakt aus Reiskleie, ferner alkoholisches Hefeextrakt sowie auch wässeriges durch Kochen oder durch Einwirkung von Pepsinsalzsäure aus Katjang idjoe (Phaseolus radiatus) gewonnenes Extrakt erwiesen sich als recht wirksam, um die bei alimentärer Dystrophie auftretenden nervösen Störungen zu beseitigen. Gleichzeitig wirken diese Extrakte anregend auf den Stoffwechsel, wie dies noch an der Hand von Beispielen gezeigt werden soll (s. S. 45 u. ff.). Es muss aber betont werden, dass kein einzigesdieser Präparate es an Stärke und Vielseitigkeit der Wirkung mit den

chemische Natur der Vitamine. I. Journ. of Biol. Chem. vol. 25 p. 437. 1916. Ref. Chem. Zentralbl. 1917 Bd. 1. S. 101. - Derselbe, Die Chemie der Vitamine. The Philipp. Journ, of Science A. vol. 11 p. 49. 1916. Ref. Chem. Zentralbl. 1917 Bd. 1 S. 251.

1) Vgl. auch die Arbeiten von Carl Voegtlin, Die Bedeutung der Vitamine in Beziehung zur Ernährung in Gesundheit und Krankheit. Journ. Washington Read. of Science vol. 6 p. 575. 1916. - C. Voegtlin und G. F. White, Journ. Pharm. Therap, vol. 9 p. 155. 1916. - Ferner: Arthur Harden u. Sylvester Salomon Zilva, Die angeblichen antineuritischen Eigenschaften von $\boldsymbol{\alpha}$-Hydroxypyridin und Adenin. Biochem. Journ. Bd. 11 S. 172. 1917. Ref. Chem. ZentralbI. 1917 Bd. 2 S. 819. 
Beitrag zur Kenntnis von organischen Nahrungsstoffen mit spezif. Wirkung. 45

Muttersubstanzen (Hefe, Reiskleie usw.) aufnehmen kann, aus denen sie dargestellt werden.

Was die als "Vit a min" bezeichneten, bislang dargestellten Substanzen angeht, so handelt es sich bei diesen offenbar meistens um unreine Produkte und nicht um einheitliche chemische Verbindungen. Im besonderen sind die von Funk beschriebenen "Vitamine" nicht

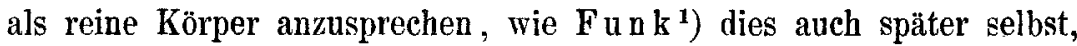
wenn auch nicht in klarer und eindeutiger Weise; zugegeben hat. Die Wirkung dieser Präparate ist ja eine überraschende, insofern als relativ kleine Gaben in relativ kurzer Zeit die im Gefolge der alimentären Dystrophie auftretenden nervösen Störungen in der Regel $\mathrm{zu}$ beseitigen vermögen. Es muss aber auch hier hervorgehoben werden, dass die Wirkung der sogenannten "Vitamine sich in der Hauptsache hierauf beschränkt. Den Einfluss, den sie auf den Stoffwechsel üben, ist keineswegs mit demjenigen $\mathrm{zu}$ verglejchen, welcher den Ausgangsprodukten (Hefe, Reiskleie usw.) zukommt. "Vitamin" allein als Zusatz zu einem insuffizienten Nahrungsmittel, wie zum Beispiel geschliffenen Reis, vermag die so ernährten Versuchstiere nicht am Leben zu erhalten. Sie gehen alle nach längerer derartiger Fütterung mit "Vitamin"-Zufuhr unter starker Abmagerung und zuweilen auch unter Auftreten nervöser Störungen zugrunde. Allerdings tritt der Tod meistens erst nach erheblich längerer Zeit ein als bei der Fütterung mit geschliffenem Reis allein. Es ergibt sich aus diesem Verhalten der Versuchstiere, dass "Vitamin" wohl eine günstige Wirkung auf den Stoffwechsel zu üben vermag, dass diese aber eine zu einseitige ist, als dass man die Wirkung der natürlich vorkommenden Stoffe, aus denen die betreffenden "Vitamine" stammen, auf die Wirksamkeit des "Vitamins" allein zurückführen dürfte. Die Einwirkung des "Vitamins" auf den Stoffwechsel des Taubenorganismus soll $u$. a. im Absehnitt IV eingehend (S. 72 u. ff.) behandelt werden.

St of fwechsel. Die Zahl der Stoffwechselversuche, welche mit Rücksicht auf die hier in Betracht kommenden Gesichtspunkte bislang ausgeführt worden sind, ist leider recht gering. Es ist dies um so bedauerlicher, als derartige Versuche am geeignetsten erscheinen, um

1) C. Funk, Results of studies on vitamines and deficiency diseases during the years 1913-1915. Biochem. Bullet. vol. 4 p. 304 (352). 1915. 
auch auf diesem Gebiete weitere Klärung und einen tieferen Einblick in die durch insuffiziente Ernährung veraulassten Stoffwechselstörungen zu ermöglichen. Wir geben nachstehend eine tahellarische Zusammenstellung der von einem von uns (Schaumann) schon früher veröffentlichten Ergebnisse von Stoff wechselversuchen ${ }^{1}$ ) wieder. An diese Übersicht sollen dann einige erläuternde und kritische Bemerkungen geknüpt werden. Auch bei dieser Art von Stoffwechselversuchen ist es, um zuverlässige Schlusse aus den erhaltenen Ergebnissen ziehen zu könen, durchauserforderlich, sie möglichst lange durchzuführen.

Zum besseren Verständnis der nachstehenden Tabellen sei folgendes bemerkt:

Die in Tabelle 1 und 2 aufgeführten Tauben wurden sämtlich erst nach längerer Beobachtung und Fütterung mit vollwertigem gemischten Taubenfutter zu den Versuchen verwandt. Die Ergebnisse zeigen, dass es nicht gelingt, Tauben mit den aus Hefe und Reiskleie gewonnenen Extrakten allein auf Gewichtskonstanz zu erhalten. Dies ist erst dann, wenigstens annähernd, möglich, wenn man die betreffenden Extrakte dem Rückstande, dem sie entzogen worden sind, wieder zusetzt und diese Mischung als Zugabe verwendet. Bei Verwendung von alkoholischem Reiskleieextrakt in Tagesgaben, welche $1,5-2,09 \mathrm{~g}$ frischer Reiskleie entsprechen, gingen alle die hierzu benutzten Versuchstauben nach starker Abmagerung und nach Auftreten von Lähmungen ein. Tagesgaben von 1,5-2 g frischer Reiskleie, als solche gegeben, genügen aber, um Tauben gesund und annähernd auf Gewichtskonstanz zu erhalten. Hieraus sowie aus dem Ergebnis des unter Nr. 4 aufgeführten Versuches ergibt sich ferner, dass es nicht gelingt, mit Alkohol auch bei viermaliger aufeinanderfolgender Extraktion und bei anschliessendem Ausziehen mit salzsaurem Wasser der Reiskleie alle die hier in Betracht kommenden wirksamen Bestandteile zu entziehen. Hefe verhält sich ebenso. Mit einem sehr weitgehend gereinigten "Vitamin" aus Reiskleie gelang es nicht, zwei Versuchstauben gesund und am Leben zu erhalten. Eine dieser Tauben ging sehr schnell ein, die andere lebte 63 Tage und hatte während dieses

1) H. Schaumann, Die Ätiologie der Beriberi. II. Arch. f. Schiffs- u. Tropen-Hyg. Bd. 18 S. 10-121. 1914. 
Beitrag zur Kenntnis von organischen Nahrungsstoffen mit spezif. Wirkung. 47

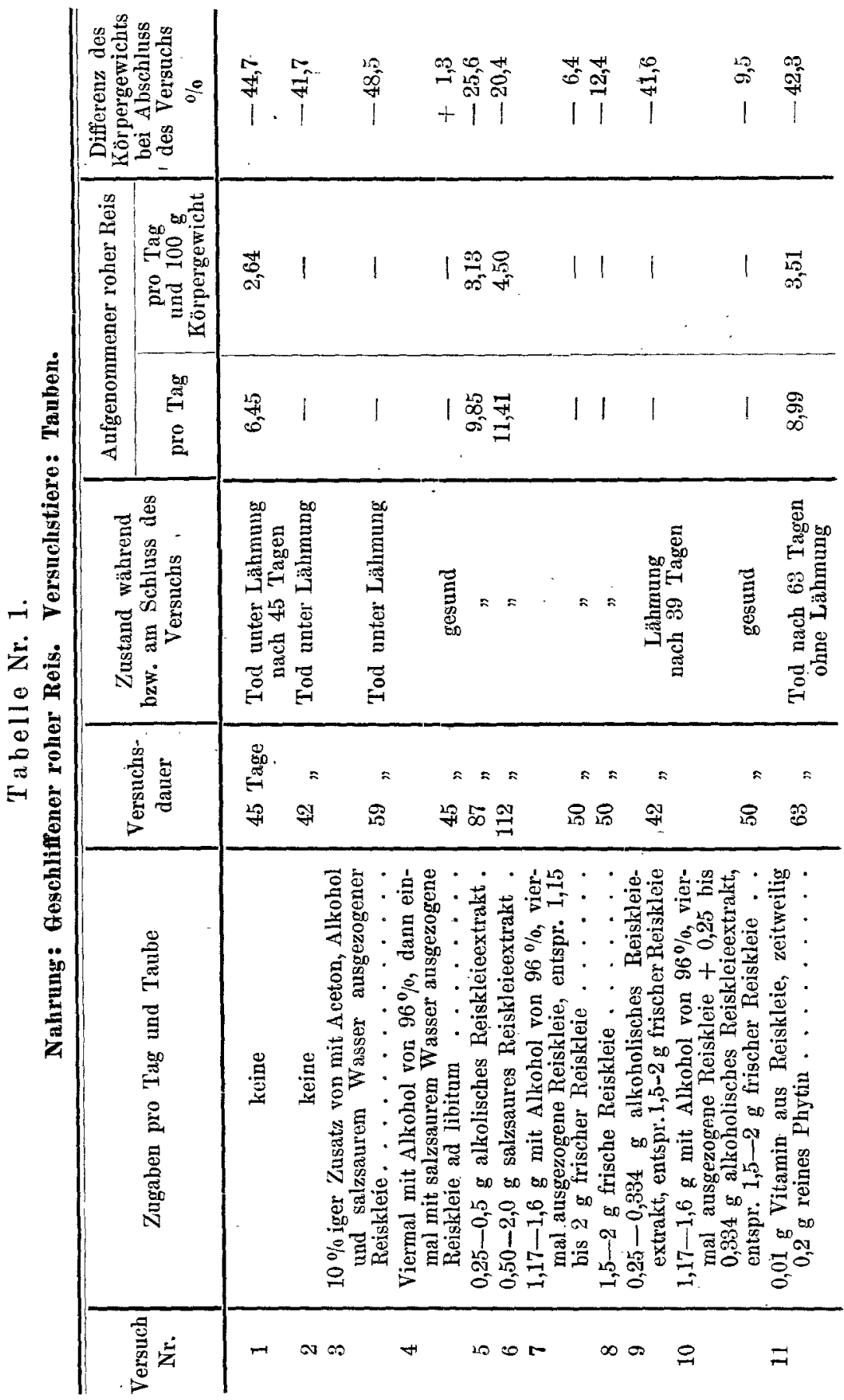


Emil Abderhalden und H. Schaumann:

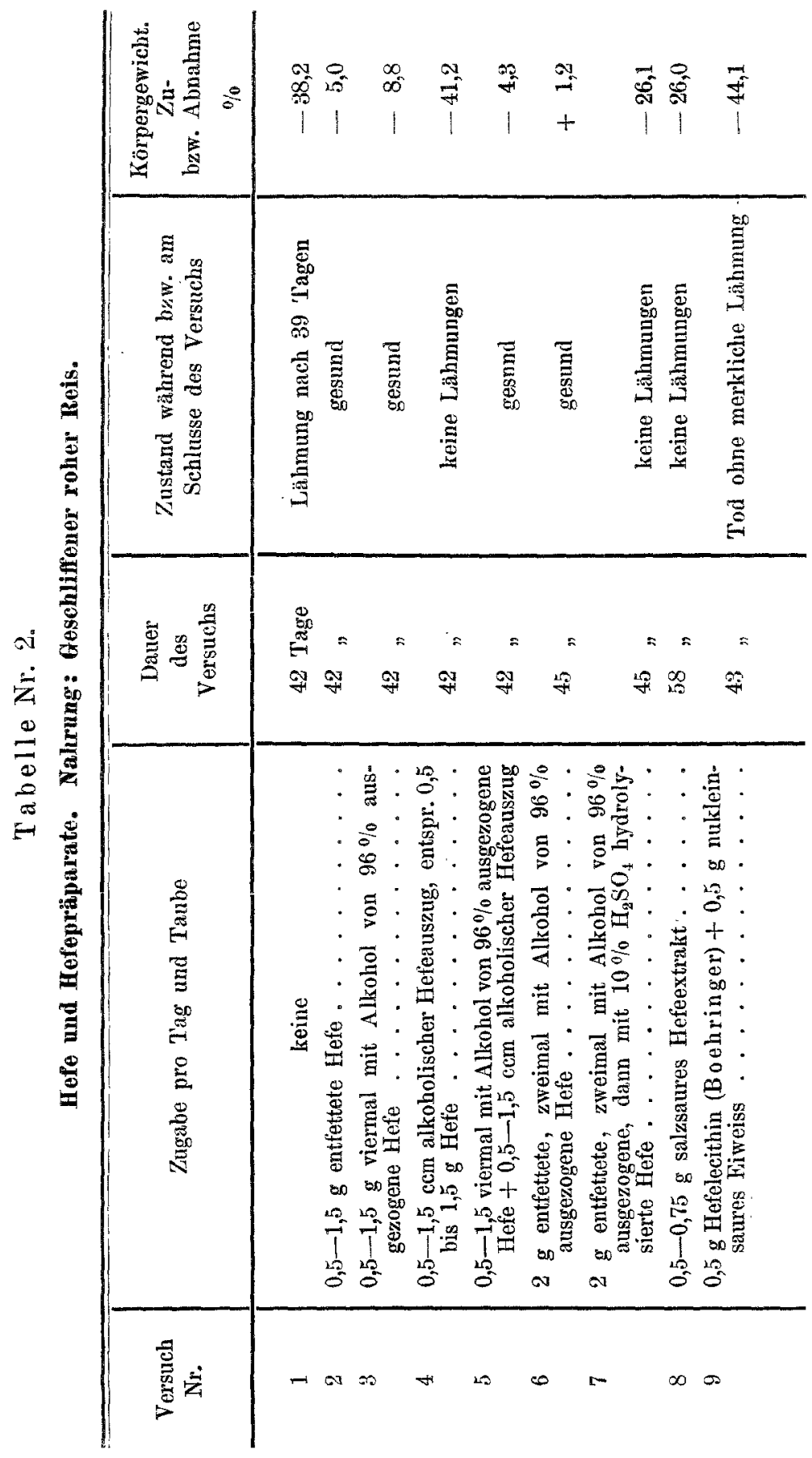


Beitrag zur Kenntnis von organischen Nahrungsstoffen mit spezif. Wirkung. 49

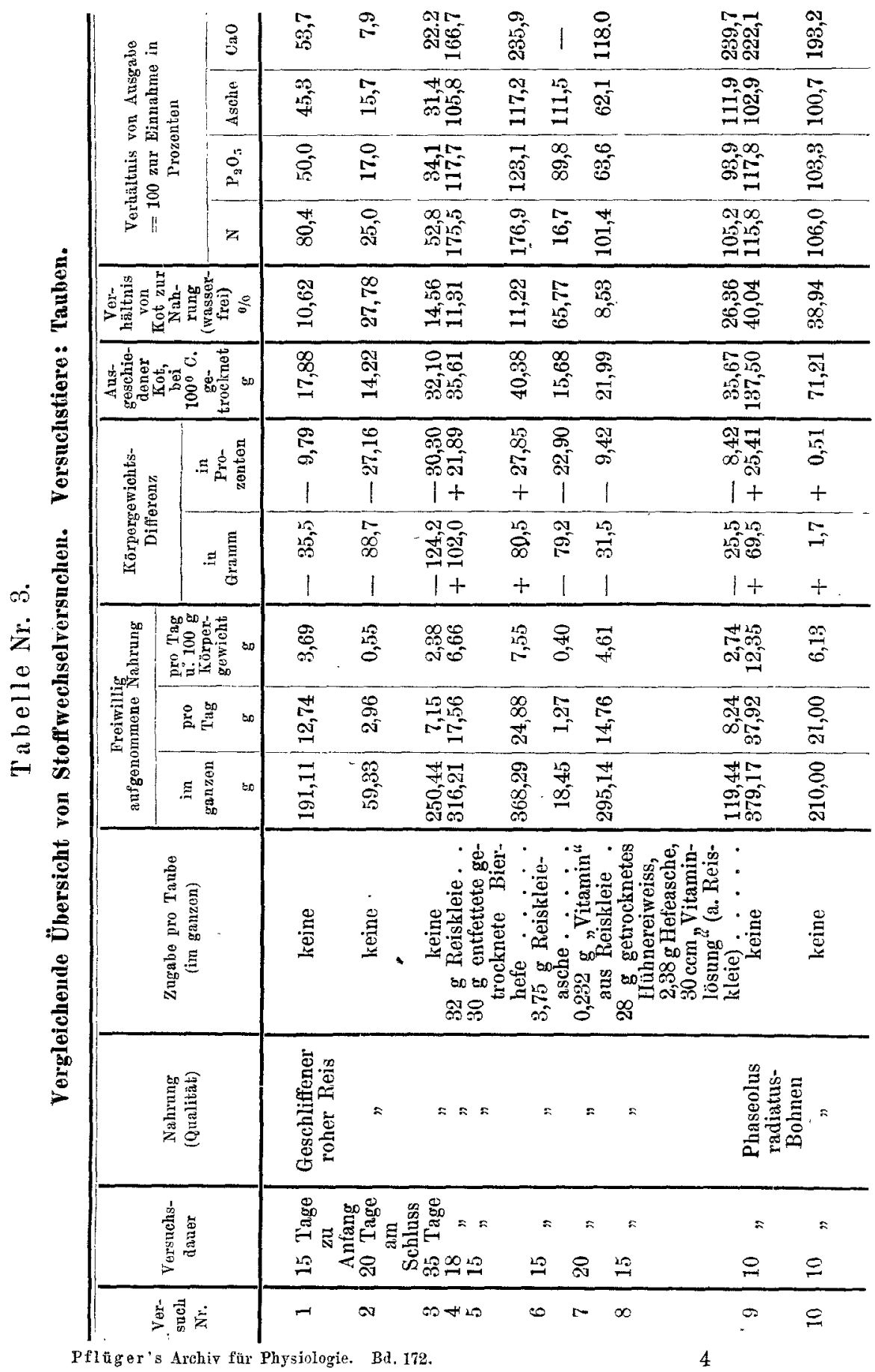


Beitrag zur Kenntnis von organischen Nahrungsstoffen mit spezif. Wirkung. 51

Zeitraumes $42,3 \%$ des Körpergewichtes, welches sie bei Beginn des Versuches aufwies, eingebüsst.

Tabelle Nr. 2 zeigt, dass Hefe sich Lösungsmitteln wie Alkohol und verdünnter Salzsäure gegenüber ähnlich verhielt wie Reiskleie. Es gelingt hier ebensowenig, der Hefe die Stoffe vollkommen zu entziehen, welche die alimentäre Dystrophie der Tauben zu heilen bzw. ihr vorzubeugen vermögen. Auch beim nicht lange ausgedehnten Hydrolysieren mit $10 \%$ iger Schwefelsäure blieben noch immer nennenswerte Mengen dieser Stoffe im Rückstande. Bemerkenswert ist allerdings, dass das alkoholische Extrakt aus Hefe nicht unerheblich wirksamer ist als das aus Reiskleie.

Bei den Tabellen Nr. 3 und 4 sind folgende Umstände zu beachten: Um individuelle Unterschiede möglichst auszuschliessen, wurde versucht, die hier angeführten Stoffwechselversuche mit einem und demselben Taubenpaare durehzuführen. Dies gelang auch bei den fünf zuerst aufgeführten Versuchev. Eine der Versuchstauben ging dann aber bei einem weiteren Versuche ein. Das erste Taubenpaar nusste daher durch ein zweites, möglichst gleichartiges ersetzt werden, mit dem dann alle weiteren Versuche durchgefährt werden konnten. Jede der Tauben war in einem besonderen Käfig untergebracht, welcher durch seine Konstruktion Verluste an Nahrung wie auch an Kot völlig ausschloss. Alle vier zu diesen Versuchen verwandten Tauben waren kräftige und gesunde Tiere. Zu sämtlichen Versuchen wurde dieselbe Qualität Reis als Nahrung verwandt.

Die in den Tabellen aufgeführten Zahlen sind das arithmetische Mittel der bei beiden Tauben ermittelten Werte, welche fast durchweg auch untereinander sehr gut übereinstimmten. Als Getränk erhielten die Tauben während der ganzen Versuchsreihe, deren Gang nachstehend beschrieben ist, nur destilliertes Wasser. Mit Rücksicht auf alle weiteren Einzelheiten sei auf die Originalveröffentlichung hingewiesen. Der Gang der ganzen Serie war folgender:

Bei dem ersten Versuche Nr. 1 wurden beide Tauben im ganzen 35 Tage lang nur mit geschliffenem rohen Reis gefüttert. Die Ergebnisse während der ersten 10 Tage und während der nächstfolgenden 15 Tage sind unter Nr. 1 und 2 gesondert aufgeführt, während unter Nr. 3 die Ergebnisse der gesamten Periode von 35 Tagen zusammengefasst sind. Die stark abgemagerten Tauben érhielten nun unter Beibehaltung derselben Nahrung (geschliffener, roher Reis) 
täglich je $2 \mathrm{~g}$ Reiskleje, bis das Körpergewicht nicht mehr zunahm (Versuch Nr. 4). Sie erbolten sich hierbei zusehends, und die Stoffwechselbilanz, die vorher stark negativ gewesen war, wurde ausgesprochen positiv. Beide Tauben bekamen hierauf in unmittelbarem Anschluss an den Versuch Nr. 4 bei derselben Ernährung täglich je $2 \mathrm{~g}$ getrocknete, entfettete Bierhefe (Versuch Nr. 5) mit dem Erfolge, dass von den Tauben eine schliesslich das ursprüngliche Körpergewicht wieder erreicht und die andere dieses sogar überschritten batte. Die beiden wieder sehr woblgenährten und munteren Tauben erhielten nunmehr in direktem Anschluss an den vorhergehenden Versuch (Nr. 5) als tägliche Zugabe 0,25 g Reiskleieasche (entsprechend 2,67 g Reiskleie) mit einem $\mathrm{P}_{2} \mathrm{O}_{5}$-Gehalt von $32,18 \%$. Beide Tauben magerten hierbei wieder stark ab. Die N-Bilanz wurde stark negativ. Auch die $\mathrm{P}_{2} \mathrm{O}_{5}$ - Bilanz wiestrotzderstarken $\mathrm{Zufuhr}$ vonanorganischen Phosphaten ein Defizit auf, während die Aschebilanz positiv blieb. Es wurde nun in unmittelbarer Folge neben $2 \mathrm{~g} g \mathrm{ge}$ trocknetem Hühnereiweis $0,25 \mathrm{~g}$ Hefeasche gereicht. Hierbei erkrankte eine der Tauben an typischer alimentärer Dystrophie und ging trotz. der versuchten Heilungsversuche ein. Das erste Taubenpaar wurde daher durch ein zweites, möglichst gleichartiges ersetzt. Mit diesem wurden dann alle weiteren Stoffwechselversuche durchgeführt. Bei dem ersten mit diesem neuen Taubenpaare angestellten Versuche bekamen die Tiere neben der aus geschliffenem rohen Reis bestehenden Nahrung eine Tagesgabe von je $0,0116 \mathrm{~g}$ eines sehr weit gereinigten und bei einer Reihe von Versuchen in Gaben von $0,01 \mathrm{~g}$ als sehr wirksam befundenen "Vitamins" aus Reiskleie (Versuch Nr. 7). Die Versuchstauben magerten hierbei ab. Die $\mathrm{N}$ - und $\mathrm{CaO} \cdot \mathrm{Bilanz}$ waren schwach positiv, die $\mathrm{P}_{2} \mathrm{O}_{5}$ - und Aschebilanz dagegen wiesen ein grosses Manko auf. Ein weiterer, direkt an den vorigen angeschlossener Versuch (Nr. 8), bei welchem als Zugabe je $2 \mathrm{~g}$ getrocknetes Hühnereiweis, $0,17 \mathrm{~g}$ Hefeasche sowie $2 \mathrm{~cm}$ einer sehr wirksamen "Vitaminlösung" pro Tag gegeben wurden, hatte das Ergehnis, dass die Versuchstauben ein kleines Plus bei der $\mathrm{N}$ - und Aschebilanz aufwiesen. Dabèi blieb aber das $\mathrm{P}_{2} \mathrm{O}_{5}$. Defizit, wenn auch in erheblich geringerem Grade als bei der Zufuhr von "Vitamin" allein (als Zugabe) bestehen, und die Tauben magerten weiter ab. Die in unmittelbarem Anschluss an Versuch Nr. 8 vorgenommene Änderung der Nahrung - an Stelle von Reis wurden $\mathrm{Phaseolusradiatus-Bohnen} \mathrm{gereicht} \mathrm{-} \mathrm{hatte}$ 
zur Folge, dass die Bilanz durchweg eine stark positive wurde, was neben dem Kalk bei der Phosphorsäure am ausgesprochensten war. Eine erhebliche Zunahme des Körpergewichts ging bei beiden Versuchstauben biermit Hand in Hand (Versuche Nr. 9 und 10).

Bei dem Versuche Nr. 10 wurde festgestellt, welche Mengen von Phaseolusradiatus-Bohnen erforderlich sind, um eine Taube von etwa $340 \mathrm{~g}$ im Ernährungsgleichgewicht und auf Gewichtskonstanz zu erhalten. Die gefundene Menge betrug $21 \mathrm{~g}$ pro Tag. Der Energiewert dieser $21 \mathrm{~g}$ Phaseolus radiatus-Bohnen beträgt 60,87 Kalorien. $18,88 \mathrm{~g}$ geschliffenen rohen Reises weisen denselben Energiewert auf.

Es sei hier noch über zwei weitere S toff wechselversuche mit Kaninchen berichtet, deren Ergebnisse für die hier in Frage kommenden Verhältnisse recht lehrreich erseheinen.

Wie schon erwähnt, geben Kaninchen bei einseitiger Fütterung mit Ma is nach einiger Zeit unter starker Abmagerung und nach dem Auftreten von Lähmungen an den Beinen, Ausfall und Struppigwerden der Haare, Rarifikation der Knochen und unter zeitweilig einsetzenden heftigen Krampfanfällen zugrunde. Der Harn wird sehr bald nach dem Beginn der eirseitigen Maisfütterung sauer. Mais ist bekanntlich ein sehr kalkarmes Nahrungsmittel, und man hat daher vielfach die Erkrankung von ausschliesslich mit Mais genährten Kaninchen auf Kalkmangel zurückgeführt und eine hierdurch veranlasste Aci d o s e angenommen. Jedoch wird aber Mais dureh Zusatz von Kalziumkarbonat in reichlicher Menge nicht zu einem für Kaninchen vollwertigen Nahrungsmittel. Mit Mais und $\mathrm{CaCO}_{3}-\mathrm{Zusatz}$ ernährte Kaninchen gehen ebensowohl nach einiger Zeit unter starker $A b$ magerung zugrunde. Ein Beweis dafür, dass Kalk bei diesen Versuchen in reichlicher Menge resorbiert wurde, war die alkalische Reaktion des Harnes. Auch konnten bei den so verendeten Kaninchen keine Knochenveränderungen festgestellt werden. Diese bei mehreren Versuchen immer wieder gemachten Erfahrungen lassen es als ausser Frage stehend erscheinen, dass der Kalkmangel des Maiskornes all ein nicht dessen Insuffizienz bedingt, um so weniger, als Mais für Tauben ein suffizientes Nahrungmittel darstellt. Diese Befunde sprechen auch gegen die Annahme einer Säurevergiftung (Acidosis). Wie schon eine Anzahl früher ausgeführter Versuche ${ }^{1}$ ) erwiesen hatten, gediehen

1) H. Schaumann, Arch. f. Schiffs- n. Tropen-Hyg. Bd. 14 Beih. 8 S. 249 u. 250.1910. 
Kaninchen bei einseitiger Maisfütterung dagegen vorzüglich, wenn man dem Mais eine geringe Menge Hefe (etwa $5 \mathrm{~g}$ trockener Presshefe pro Tag) zusetzt. Bei dem verbältnismässig sehr hohen Gehalt der Hefe an organisch gebundener Phosphorsäure führt man dem Kaninchenorganismus durch den Hefezusatz eine erheblich grössere Menge von Anionen zu, als dies ohne einen solchen Zusatz der Fall ist.

Trotzdem gedeihen die Kaninchen vorzüglich und werden nicht krank, wie bei reiner Maisfütterung. Angesichts dieser Tatsachen erscheint die Annahme einer Säurevergiftung (Acidosis) als Ursache der Erkrankung von Kaninchen bei einseitiger Maisfüterung nichthaltbar. Der Anlass zur Erkrankung muss somit ein anderer sein.

Bei einseitiger Fütterung mit getrockneten gelben Erbsen bleiben Kaninchen dagegen gesund und magern hierbei im allgemeinen nicht ab. Nachstehend seien die Ergebnisse von drei derartigen Stoffwechselversuchen kurz aufgeführt. Über die Einzelheiten dieser Versuche muss auf die Originalveröffentlichung verwiesen werden ${ }^{\mathbf{1}}$ ). Die $\mathrm{zu}$ diesen Stoffwechselversuchen verwandten Nahrungsmittel (Mais und Erbsen) lieferten bei den ausgeführten Doppelanalysen nachstehende Werte:

$$
\text { Gehalt an: } \quad \text { Mais } \quad \text { (Qualität A): Erbsen : }
$$

1. Wasser (Feuchtigkeit) . . $13,85 \% \quad 15,50 \%$

2. Ásche . . . . . . $1,19 \%$

3. Stickstoff . . . . . . $\quad 1,57 \%$

4. Phosphorsäure $\left(\mathrm{P}_{2} \mathrm{O}_{5}\right)$. . $0,77 \% \quad 0,98 \%$

5. Schwefelsäure $\left(\mathrm{SO}_{3}\right)$. . . $0,45 \% \quad 0,47 \%$

6. Kalk $(\mathrm{CaO})$. . . . . $0,09 \%$

7. Magnesia $(\mathrm{MgO})$. . . . $0,12 \% \quad 0,15 \%$

Die zu dem Stoffwechselvereuch Mais $+5 \mathrm{~g}$ entfettete getrocknete Hefe verwandten Qualitäten Mais und Hefe enthielten:

$\begin{array}{lcc} & \text { Mais (Qual. B) : } & \text { entfettete Hefe: } \\ \text { Stickstoff . . . . } & 1,65 \% & 10,72 \% \\ \text { Phosphorsäure }\left(\mathrm{P}_{2} \dot{\mathrm{O}}_{5}\right) \cdot & 0,64 \% & 5,24 \%\end{array}$

1) H. Schaumann, Die Ätiologie der Beriberi. II. Arch. f. Schiffs- u. Tropen-Hyg. Bd. 18 Beih. 6 S. 97-99 u. S. 101. 1914. 
Beitrag zur Kenntnis von organischen Nahrungsstoffen mit spezif. Wirkung. 55

St offwechselversuch I.

Versuchstier: ein gesundes, kräftiges Kaninchen.

Nabrung: Mais, Qualität A (Analyse vorstehend).

$\mathrm{Zug}$ a be: keine.

Versuchsdauer: 25 Tage.

Köpergewicht: Anfangsgewicht $3120 \mathrm{~g}$, Endgewicht $2700 \mathrm{~g}$. Bilanz:

$\begin{array}{llllll}\text { In 25 Tagen: } & \mathrm{N} & \mathrm{P}_{2} \mathrm{O}_{5} & \mathrm{SO}_{3} & \mathrm{CaO} & \mathrm{MgO}\end{array}$

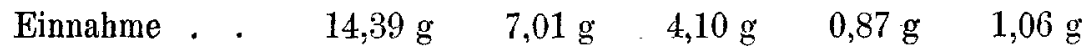
Ausgabe in Kot

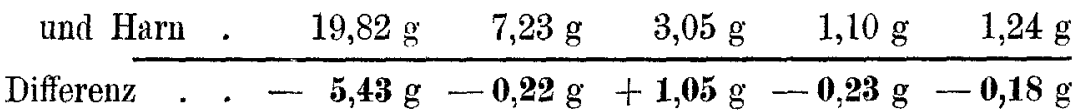

Stoffwechselversuch II.

Versuchstier: ein gesundes, kräftiges Kaninchen.

Nabrung: getrocknete gelbe Erbsen (Analyse vorstehend).

Versuchsdauer: 25 Tage.

Körpergewicht: Anfangsgewicht 2730 g, Endgewicht $2660 \mathrm{~g}$. Bilanz:

$\begin{array}{llllll}\text { In 25 Tagen: } & \mathrm{N} & \mathrm{P}_{2} \mathrm{O}_{5} & \mathrm{SO}_{3} & \mathrm{CaO} & \mathrm{MgO}\end{array}$ Einnahme . . $\quad 28,65 \mathrm{~g} \quad 8,38 \mathrm{~g} \quad 3,99 \mathrm{~g} \quad 0,15 \mathrm{~g} \quad 1,26 \mathrm{~g}$ Ausgabe in Kot

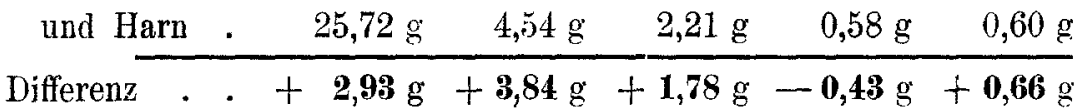

St offwechselversuch III.

Versuchstier: ein gesundes, kräftiges Kaninchen.

Nahrung: Mais, Qualität B (Analyse vorstehend).

Zugabe: $5 \mathrm{~g}$ trockene entfettete Hefe pro Tag.

Versuchsdauer: 11 Tage.

Körpergewicht: Anfangsgewicht $2245 \mathrm{~g}$, Endgewicht $2280 \mathrm{~g}$. Bilanz:

In 11 Tagen: $\quad \mathrm{N} \quad \mathrm{P}_{2} \mathrm{O}_{5}$

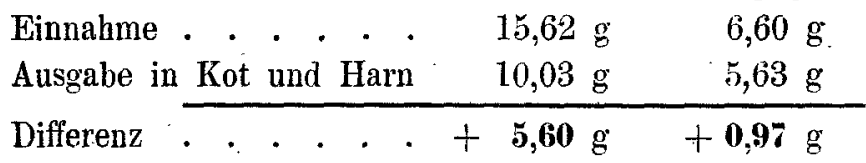


Die angeführten Werte zeigen einen augenfälligen Unterschied: Während bei ausschliesslicher Ernährung mit Mais ein erhebliches Defizit an $\mathrm{N}, \mathrm{P}_{2} \mathrm{O}_{5}, \mathrm{CaO}$ und $\mathrm{MgO}$ eintrat und nur für $\mathrm{SO}_{3}$ ein positiver Wert sich ergab, war bei einseitiger Fütterung mit Erbsen die Bilanz bis auf ein Manko an CaO durchweg positiv. Das Kalkdefizit war offenbar durch den aussergewöhnlich niedrigen Kalkgehalt der Erbsen, welcher nur $0,02 \%$ betrug, veranlasst. Ebenso ergaben sich bei einseitiger Maisfütterung unter Zugabe ron $5 \mathrm{~g}$ Hefe pro Tag für $\mathrm{N}$ und $\mathrm{P}_{2} \mathrm{O}_{5}$ beträchtliche positive Werte. Dies alles deutet darauf hin, dass beim Phosphorstoffwechsel nicht die zugefühte Menge ron Phosphorsäure allein ausschlaggebend ist, sondern dass bier noch andere Faktoren in Betracht kommen müssen. Entweder verhalten sich die verschiedenartigen, in der Nahrung enthaltenen Phosphorsäureverbindungen bei der Resorption und Assimilation verschieden, oder es spielen hierbei noch andere bislang unbekannte Nahrungsbestandteile eine vermittelnde Rolle. Diese sind vielleicht in bestimmten organischen Phosphorsäureverbindungen der Nahrung selbst enthalten.

Die soeben erörterten Beobachtungen stehen keineswegs vereinzelt da. So fand $\mathrm{Weiser^{1 }}$ ), dass einseitige Maisfütterung bei Schweinen ein erhebliches Defizit an $\mathrm{N}$ und $\mathrm{P}_{2} \mathrm{O}_{\overline{5}}$ in der Stoffwechselbilanz nach sich zog, während bei einseitiger Fütterung mit Gerste dies nicht eintrat. Ferner stellten Underhill und Bogert ${ }^{2}$ ) fest, dass nach einseitiger Hafer-und Korn- (Mais-) fütterung die Phosphorausscheidung im Kaninchenharn erheblich gesteigertwirdund bei weitem die Aufnahmeübertrifft. Die genannten Autoren deuten dies ebenfalls als ein Hilfsmittel des Kaninchenorganismus, um sein Basensäuregleichgewicht aufrechtzuerhalten. Dieser Deutung widersprechen indessen die vorstehend erörterten Beobachtungen.

Zum Schlusse sei hier noch über neue Versuche mit Ratten und Sperlingen (Protokolle S. 159 u. 160) berichtet. Erstere, seit

1) S. We is er, Über den Ca-, $\mathrm{Mg}$-, P- und $\mathrm{N}$-Umsatz des wachsenden Schweines. Biochem. Zeitschr. Bd. 44 S. 279. 1912.

2) Frank P. Underhill und L. Jean Bogert, Änderung in der Menge gewisser Harnbestandteile als Folge von Änderungen des Charakters der Nahrung. Journ. of Biol. Chem. vol. 27 p. 161. 1916. Ref. Chem. Zentralbl. Bd. I. S. 967. 1917. 
mehreren Jahren von $\Lambda$ bderhalden durchgeführt, sind noch nicht abgeschlossen. Sie hatten bislang folgende Ergebnisse:

Bei $R$ atten, die sich viel besser als Mäuse zu derartigen Experimenten eignen, wurden die Dauerversuche mit einseitiger $\mathrm{Er}$ nährung bis über ein Jahr ausgedehnt. Am besten vertragen wurde Roggen. Es folgen dann Weizen und Hafer, Sojabohnen und Gerste. Bei einseitiger Ernährung mit $\mathrm{Natalma}$ is konnten die Ratten bis zu 200 Tagen am Leben erhalten werden. Bei aus. schliesslicher Fütterung mit g e w öh nl i che m Ma is (Zea-Mais) starben die Versuchstiere schon nach 150 Tagen. Meistens traten vor dem Tode Krämpfe und bierauf Lähmungen auf. Mit sogenannten Pferdebohnen oder geschältem Reis als einziger Nahrung lebten die Ratten ebenfalls im Durchschnitt 150 Tage lang.

Mit Ausnahme der Roggentiere traten bei allen Ratten nach Verlauf eines mehr oder weniger langen Zeitraums trotz sorgfältiger Pflege und Reinlichkeit mehr oder weniger schwere Schädigungen des Integuments auf: struppiges Fell, Haarausfall. Am Schwanz und auf der Nase bildeten sich in der Folge kleine Knötchen, die durch Wucherung, besonders an der Nase, schliesslich zu grossen "Hörnern" auswuchsen. Spezifisch waren diese Erscheinungen für keine der gewählten Nahrungsmittelarten. Es scheint, als ob die Haut an Widerstandsfähigkeit gegen Infektionen abnimmt. Die Ratten liessen auch bald in der Pflege des Felles nach.

Bei einseitiger Reis- und Maisfütterung wurden besonders oft-Fälle von schwerer Konjunktivitis beobachtet. Auch traten bei dieser Ernährung besonders oft Lähmüngen und Krämpfe auf. Der Tod trat bald unerwartet ohne besondere Vorzeichen, bald im Gefolge von Krämpfen ein. Führten diese Krämpfe nicht zum Tode, so zeigten sich im Auschluss an sie Lähmungen, an denen besonders die hinteren Extremitäten beteiligt waren. Auch wurden Fälle beobachtet, bei denen es u u r zu Lähmungen kam. Hochinteressant ist die Feststellung, dass durch Zusatz geringer Mengen von frischem Gemüse und von Extrakten aus solchen die Lebensdauer ganz beträchtlich verlängert wurde. Es gelang ferner, durch insuffiziente Ernährung still gestelltes Wachstum durch Hefe, Extrakte aus grünen Pflanzen und aus Keimlingen wieder in Gang zu bringen ${ }^{1}$ ).

1) Über diese Versuche wird der eine von uns (Abderhalden) noch ans. ausführlich an Hand der Protokolle berichten. 
Sperlinge sind weniger geeignet zu den hier in Betracht kommenden Versuchen. Ein grosser Bruchteil der Tiere geht in der Gefangenschaft schon nach einjgen Tagen zugrunde. Immerhin ist es uns gelungen, bei einigen Sperlingen durch einseitige Fütterung mit geschliffenem Reis alimentäre Dystrophie hervorzurufen. Die Krankheit trat schon nach verhältnismässig kurzer Zeit, nach 10 bis 14 Tagen, auf. Sie äusserte sich durch Paralyse der Beine und der Flügel, wodurch die Tiere vollkommen ausserstande waren, zu laufen und zu fliegen. Hierbei waren sie aber teilweise noch sebr munter und bissen vereinzelt sogar sehr energisch um sich, wenn man sie in die Hand nahm. Opisthotonus und Krämpfe wurden in keinem Falle beobachtet. Die meisten der mit geschliffenem Reis gefütterten Tierc gingen aber schon sebr bald und ehe es zu nervösen Störungen kam. plötzlich und ohne Vorzeichen des nahen Todes zugrunde. Es mag sein, dass man bei Sperlingen bei einseitiger Verfütterung anderer Nahrungsmittel, wie z. B. kleiearmen Weizenbrots u. dgl. m., leichter und sicherer Erkrankungen an alimentärer Dystrophie hervorrufen kann. Die Photographie Nr. 32 zeigt einen durch einseitige Fütterung mit geschliffenem Reis an Beinen und Flügeln schwer gelähmten, sonst aber noch sehr munteren Sperling.

\section{Ist die alimentäre Dystrophie bzw, die Beriberi des Mensehen auf die Wirkmng eines exogenen oder endogenen Giftes zurïck- zuführen?}

Diese Frage ist häufig und eingehend von den verschiedensten Seiten und Gesichtspunkten aus erörtert worden. Auch heute noch spielt die "Intoxikationstheorie" insofern eine Rolle, als die schädliche Wirkung insuffizienter Nahrung, im besonderen die des geschliffenen Reises, letzten Endes als eine Giftwirkung aufgefasst wird.

Es leuchtet wohl ein, dass die Definition des Begriffes "Gift" an sich schon gewisse Schwierigkeiten bietet. Zunächst ist er ja an und für sich ein insofern relativer, als irgendeine Substanz für eine Tierart giftig, für eine andere dagegen ungiftig sein kann. Das Gift bestimmter Schlangenarten ist zum Beispiel auch für viele andere Schlangenarten sehr giftig, dagegen für eine bestimmte, an sich ungiftige Schlangenart, die den betreffenden Giftschlangen nachstellt, völlig ungefährlich. Man hat von der Giftigkeit reiner Salzlösungen 
und sogar des destillierten Wassers gesprochen. Diese im allgemeinen sicherlich nicht als "giftig" angesehenen Flüssigkeiten sind es zweifellos für eine Reihe von Salzwassertieren und -Pflanzen, die durch die Veränderung der osmotischen Vorgänge in reinem Wasser oder andersartigen Salzlösungen schnell zugrunde gehen. Ferner ist es schwierig, bei Substanzen, die irgendwie, aber erst nach grösserer oder länger anhaltender Zufuhr, schädigend auf den Organismus wirken, die Grenze zu ziehen, von wann an man die durch sie hervorgerufenen Störungen als "Giftwirkung" bezeichnen will. Schliesslich spielt die Menge der einwirkenden Stoffe eine grosse Rolle. Gerade dieser Punkt mahnt zur Vorsicht bei der Beurteilung der Wirkung bestimmter Substanzen. Adrenalin zum Beispiel erweist sich in grösseren Dosen entschieden als ein schweres Gift. Im normalen Organismus wird es zweifellos in genau abgestuften, sehr kleinen Mengen zur Wirkung gebracht, wobei sicherlich schädliche Einflüsse ausgeschlossen sind. Es wäre verkehrt, diese Substanz deshalb als schädlich und "giftig" anzusprechen, weil wir mit ihr schwere Störungen hervorrufen können. Erkennen wir bei einer Substanz im Tierversuch schädliche Wirkungen, dann müssen wir uns stets die Frage vorlegen, ob sie unter natürlichen Verhältnissen in so grossen Mengen auftritt, dass solche möglich sind. Diese allgemeinen Gesichtspunkte erscheinen uns auch bei dem hier zu behandelnden Sonderfalle als wichtig, weil es sich bei ihm offènbar um sehr verwickelte, mit schweren Störungen verknüpfte Vorgänge handelt. Die Folgeerscheinungen kann man dann aus den angeführten Gründen mit mehr oder weniger Recht auf eine "Vergittung." des Organismus zurückführen.

Man hat früher die Schädlichkeit des Reises, im besonderen des geschliffenen Reises, bypothetischen Giften zugeschrieben, die er entbalten sollte. Abgesehen davon, dass es nie gelungen ist, im Reis irgendwelche derartigen Gifte aufuninden, widerspricht diese Auffassung auch den gemachten und bei diesem Nahrungsmittel doch auch besonders reichen Erfahrungen. Wie schon mehrfach betont, treten nur dann Folgeerscheinungen auf, wenn der geschliffene Reis die ausschliessliche oder doch überwiegende Nahrung bildet. Sobald ihm eine geeignete Zukost von Fleisch, Gemüsen, Obst u. a. m. beigegeben wird, so ist er durchaus bekömmlich und unschädlich. Man müsste hier also schon eine Zuflucht zu der Voraussetzung nehmen, dass die als Zukost verzehrten Nahrungsmittel hypothetische Gegengifte ent- 
hielten. Auch hierfür liegen keine experimentellen Anhaltspunkte vor. Auch bei anderen Nahrungsmitteln (Konserven verschiedenster Art), nach deren Genuss Segelschiff-Beriberi aufgetreten war, hat man wiederholt, aber ganz erfolglos, auf Gifte, d. h. auf solche Substanzen, die schon in kleinen Gaben merkliche Sehädigungen oder gar den Tod von Tieren nach sich ziehen, gefahndet. Die Annahme e x o ge ner Gifte, auf welche die schädliche Wirkung des geschliffenen Reises und ähnlich wirkender Nahrungsmittel zurückzuführen wäre, scheint auf Grund dieser Beobachtungen und Erfahrungen auch so gut wie allgemein verlassen worden $\mathrm{zu}$ sein.

In der Literatur stösst man aber sehr oft auf die Deutung des schädlichen Einflusses insuffizienter Nahrungsmittel als einer endog enen Giftwirkung. Um zu der Lösung dieser Frage beizutragen, haben wir eine Anzahl von Tierversuchen unternommen und auch einige Untersuchungen ausgeführt, deren Ergebnisse nachstehend mitgeteilt werden sollen.

Zuvor aber möchten wir auf einige schon früher nach dieser Richtung hin vorgenommene Nachforschungen eingehen:

Wiederholt ist die Annahme gemacht worden, dass die schädliche Wirkung einseitiger oder vorwiegender Ernährung mit geschliffenem Reis auf Gifte zurückzuführen wäre, die bei der intraintestinalen Zersetzung dieses Nahrungsmittels entstehen sollten. Man hat in diesem Zusammenhange vor allem an Alkohol, Milchsäure und Oxalsäure gedacht und ferner an die hierbei vorausgesetzte Bildung organischer Säuren die Vorstellung einer Störung des Säurebasengleichgewichts, der Entstehung einer Acidose geknüpft. Die Annahme einer durch Gärung des Reischymus im Darm entstehenden grösseren Menge von Alkohol, durch den eine Alkoholneuritis hervorgerufen werden könnte, ist wohl durch die Versuche von Vedder und diejenigen von $\mathrm{C}$ o oper entkräftet.

V edde $r^{1}$ ) fütterte Hühner mit ungeschliffenem Reis und flösste ihnen täglich je $4 \mathrm{ccm} \mathrm{Alkohol} \mathrm{von} 95 \%$ mit $10 \mathrm{~cm}$ destillierten Wassers verdünnt ein. Trotzdem diese Versuche 45 Tage lang durchgeführt wurden, entwickelte sich bei keinem der Hühner Neuritis.

1) E. B. Vedder, A fourth contribution to the etiology of Beriberi. The Philipp. Journ. of Science B. vol. 7. p. 415. 1912. 
Cooper ${ }^{1}$ ) gab Tauben, die mit geschliffenem Reis ernährt wurden, täglich dreimal je $0,5 \mathrm{ccm}$ Al ko hol ein. Bei diesen Tauben entwickelte sich alimentäre Dystrophie (Polyneuritis) nicht früher als bei den mit geschliffenem Reis (ohne Alkoholzugabe) gefütterten Tauben.

Auch Milchsäure hatte keinen Einfluss. Dies war auch wohl kaum anders zu erwarten, da doch dem Organismus noch andere Mittel zur Ausschaltung organischer Säuren zur Verfügung stehen als deren Absättigung durch Basen. Wir denken dabei an ibren Abbau durch Spaltung.

Von Maurer ${ }^{2}$ ) ist schon vor Jahren angegebeu worden, er habe bei Hühnern durch fortgesetzte $\mathrm{O} x \mathrm{a}$ l s $\mathrm{s}$ u $\mathrm{r}$ e $\mathrm{g}$ a b e $\mathrm{n}$ eine der alimentären Dystrophie (Polyneuritis gallinarum) gleichartige Krankheit hervorgerufen. Treutlein ${ }^{3}$ ) schloss sich dieser Auffassung auf Grund seiner Tierversuche an und behauptete, auch in dem Harne von Beriberikranken pathologische Mengen von Oxalsäure gefunden zu haben. Die von einem von uns (Schaumann) schon vor Jahren vorgenommenen Nachprüfungen ergaben folgendes: In den Harnen von sieben verschiedenen Beriberikranken wurden in fünf Fällen nur Spuren von Oxalsäure gefunden; in zwei Fällen betrug die quantitativ bestimmte Menge $2,7 \mathrm{mg}$, sie war also minimal. In dem Inhalt vou Kropf, Magen und Darm von drei, längere Zeit hindurch mit geschliffenem Reis gefütterten Tauben fand sich überhaupt keine Oxalsäure. Über weitere nach dieser Richtung hin von uns aus angestellte Nachforschungen soll in der Folge noch berichtet werden.

Eingehend haben sich mit der Frage nach der Bildung von toxisch wirkenden Stoffen im Darmkanal auch Abderhalden und Ewal d ${ }^{4}$ ) beschäftigt. Es wurde der Kot von an alimentärer Dystrophie leidenden Tauben an gesunde Tiere verfüttert. Es gelang nicht, die

1) E. A. Cooper, The preparation from animal tissues of a substance which cures Polyneuritis in birds produced by diets of polished rice. Biochem. Journ. vol. 7 p. 268.1913.

2) G. Maurer, 'Die Ätiologie der Beriberi. Geneesk. Tijdschr. vor Nederl. Indie 1908.

3) A. Treutlein, Über chronische Oxalsäurevergiftung an Hühnern und deren Beziehung zur Ätiologie der Beriberi. Würzburg 1906.

4) Emil Abderhalden u. Gottfried Ewald, Zeitschr. f. experim. Med. Bd. 5 S. 1. 1916. 
Erscheinungen der erwähnten Krankheit hervorzurufen. Es glückte ferner nicht, durch Tierkohle, die bekanntlich mancherlei Stoffe durch Adsorption aus dem Darminhalt entfernt, das Auftreten der Erscheinungen an alimentärer Dystrophie hintanzuhalten oder gar zu verhindern. Auch der Versuch, durch vergleichende Untersuchungen des Kotes von gesunden und kranken Tauben besondere, für die alimentäre Dystrophie charakteristische Stoffe zu gewinnen, schlugen fehl. Diese Untersuchungen waren unternommen worden, weil bei der experimentellen alimentären Dystrophie sehr häufig schwere Erscheinungen von seiten des Darmkanals zu beobachten sind. Es war denkbar, dass diese durch im Chymus enthaltene Stoffe bedingt sind. Die gemachten Erfahrungen sprechen jedoch nicht für diese Ansicht.

Über etwaige Toxinbildung im Organismus bei menschlicher Beriberi und alimentärer Dystrophie von Tieren liegen eine Reihe von Untersuchungen vor, bei denen durchweg nur negative Ergebnisse zu verzeichnen waren.

Grijns und de Haan ${ }^{1}$ ) untersuchten Blut von Beriberikranken sowie Blut und Organextrakte von Hühnern, die an alimentärer Dystrophie (Polyneuritis) erkrankt waren, auf die Gegenwart von Antigenen und Antist offen. Die Resultate waren sämtlich negativ.

Auch die Versuche von Shiga und $\mathrm{K}$ u s a ma ${ }^{2}$ ), durch Komplementbindung und Einspritzen von Beriberikranken entnommenem Serum in Kaninchen und Meerschweinchen sowie durch Injektion des Blutes von Tauben, die an alimentärer Dystrophie erkrankt waren, in gesunde Tauben etwaige Toxine nachzuweisen, zeitigten nur negative Resultate.

$\mathrm{Funk}{ }^{3}$ ) spritzte das alkoholische, durch Ausziehen von Tauben, welche an alimentärer Dystrophie eingegangen waren, gewonnene Extrakt ebenso erkrankten Tauben ein. Diese genasen dem Autor zufolge, ohne dass irgendwelche Giftwirkung bemerkbar gewes $\mathrm{en}$ wäre

1) G. Grijns u. J. de Haan, Over het outbreken van antigeen en zogenamde antistoffen bij Beriberi en bij kippenneuritis. Geneesk. Tijdschr. v. Nederl. Indie Bd. 49 H. 23. 1909.

2) K. Shig a und Sh. Kus ama, Über die kakke-(beriberi-)ähnliche Krankheit der Tiere (Studien über das Wesen der Kakke). Arch. f. Schiffs- u. Tropenhyg. Bd". 15 Beih. 3. 1911.

3) C. Funk, Studien über Beriberi. X. Mitteilung. Experimenteller Beweis gegen die toxische Theorie der Beriberi. Zeitschr.f. physiol. Chemie Bd.89 S.373. 1914. 
Allerdings will Sawazaki ${ }^{1}$ ) bei Hähnern durch Einspritzen der Milch beriberikranker Frauen Lähmungen hervorgerufen haben.

Andrews ${ }^{2}$ ) beobachtete bei jungen Hunden, die von beriberikranken Frauen gesäugt worden waren, pathologisch-anatomische Veränderungen und klinische Erscheinungen, wie sie bei der alimentären Dystrophie aufzutreten pflegen: Schwäche der Extremitäten, die sich in mehreren Fällen zu vollkommener Paralyse der Hinterbeine steigerte, Ödeme des Unterhautgewebes und geringe Degeneration peripherer Nerven. Bei einem dieser Hunde war eine ausgesprochene Erweiterung und Hypertrophie des rechten Herzens bemerkenswert. Andrews nimmt allerdings an, dass diese pathologischen Veränderungen und Erscheinungen auf den Mangel der Milch an gewissen, bislang wenig bekannten lebenswichtigen Nährstoffen und nicht auf Toxine zurüekgeführt werden müssten ${ }^{3}$ ).

Von Abderhalden und Ewald ${ }^{4}$ ) sind Versuche mit Methylimidazol und Imidazolyläthylamin angestellt worden, um festzustellen, ob etwa diese Körper, die beim intermediären Stoffwechsel, zum Beispiel beim Abbau des Histidins, entstehen könnten, hier eine Rolle spielen. Abderhalden und Ewald fassen die Ergebnisse ihrer nach dieser Richtung hin angestellten Versuche dahin zusammen, dass die Annahme einer Substanz, die im Darmkanal oder anderswo im Organismus bei Fütterung von geschältem Reis entsteht und die Ursache der eigenartigen Erscheinungen, die dieser Fütterungsart folgen, sein könnten, weder genügend gestützt noch auch ganz widerlegt. ist. Die Beobachtung, dass Methylimidazol zum Teil ähnliche Erseheinungen hervorruft, wie sie der ausschliesslichen Verabreichung von geschältem Reis folgen, beweise natürlich noch nichts. für eine in beiden Fällen gleiche Ursache.

1) K. S a wa za ki, Über den paralytischen Zustand bei Hühnern, welcher durch die Injektion der Milch von Kakkekranken entsteht. Mitteil. d. Med. Gesellsch. zu Tokio 1913 H. 3. Ref. Arch. f. Schiffs- u. Tropenhyg. Bd. 18 S. 102.1914.

2) V. L. Andrews, Infantile Beriberi. The Philipp. Journ. of Science B. vol. 7 p. 67.1912.

3) In hohem Maasse zu berücksichtigen wäre hier vor allem die ganz verschiedene Zusammensetzung von Frauen- und Hundemilcb. So beträgt u. a. zum Beispiel der $\mathrm{P}_{2} \mathrm{O}_{5}$-Gehalt von Frauenmilch nur $0,0585 \%$, von Hundemilch dagegen $0,5078 \%$, also etwa das Neunfache.

4) E. Abderhalden u. G. Ewald, Gibt es lebenswichtige, bisher unbekannte Nahrungsstoffe? Zeitschr. f. d. ges. experim. Med. Bd. 5 H. 1/2. S. 1. 1916. 
Neuerdings sind von Eijk $\mathrm{man}^{\mathbf{1}}$ ) Versuche mit Hühnern angestellt worden, die zum Teil gar keine Nahrung, sondern nur destilliertes Wasser bekamen. Eine zweite Gruppe von Hühnern wurde einseitig mit geschliffenem Reis gefüttert, und eine dritte Gruppe erhielt ausser destilliertem Wasser nur $5 \mathrm{~g}$ Presshefe pro Tag und Huhn. Da bei vollkommener Nahrungsentziehung ebenfalls alimentäre Dystrophie (Polyneuritis) bei Hühnern auftrat, so folgerte Eijkman hieraus, dass eine von der Nahrung ausgehende Giftwirkung als Ursache der Polyneuritis gallinarum ausgeschlossen und eine endogene Giftbildung unwahrscheinlich sei sowie, dass letztere Annahme durch diese Versuche Eijkman's nicht an Wahrscheinlichkeit gewonnen babe.

Was andere von Eijkman hier aus seinen Versuchsergebnissen gezogene Schlussfolgerungen betrifft, so werden wir auf diese an anderer Stelle (S. 122) zurückkommen, weil Eijkman's Versuche uns auch nach anderer Richtung hin bemerkenswert erscheinen.

Wie schon vorstehend (S. 54) erwähnt, hat man wiederholt geglaubt, die alimentäre Dystrophie bei Tieren auf eine Störung des Basensäuregleichgewichts im Organismus, auf eine Acidos is zurückfübren zu können. Wir haben bereits unsere Gründe gegen eine solche Auffassung geltend gemacht und hervorgehoben, dass man bei Zufuhr von Hefe, die viel mehr Anionen als Kationen enthält, einen schnelleren und heftigeren Ausbruch der Krankheit gewärtigen müsste als obne eine solche Zugabe. Es geschieht in Wirklichkeit genau das Gegenteil: Die Krankheit ẻntwickelt sich überhaupt nicht. Auch die Versuche Eijkman's, bei denen nur $5 \mathrm{~g}$ Hefe täglich ausser destilliertem Wasser gereicht wurden, ergaben, dass wohl starke $\mathrm{Ab}$ magerung erfolgte, wie dies nicht anders zu erwarten war, dagegen keine Lähmungen auftraten.

Zum Schluss haben wir noch unsere eigenen nach dieser Richtung hin unternommenen Versuche und Untersuchungen zu besprechen.

Zunächst haben wir bei den beiden Versuchen Nr. 1 und 2 (S. 160 und 161) geprüft, ob Oxalsäurezufuhr bei Tauben ein der alimentären Dystrophie ähnliches Krankheitsbild zu erzeugen vermag.

1) C. Eijkman, Über den Einfluss der Ernährung und der Nahrungsentziehung auf die Erkrankung an Polyneuritis gallinarum. Virchow's Arch. f. pathol. Anat. u. Physiol. u. f. klin. Med. Bd. 222 S. 301. 1916. 
Beitrag zur Kenntnis von organischen Nahrungsstoffen mit spezif. Wirkurg. 65

Die erste der zu diesen Versuchen verwandten Tauben bekam täglich bei Ernährung mit gemischtem Taubenfutter die ersten 20 Tage lang $0,05 \mathrm{~g}$, dann weitere 9 Tage lang $0,1 \mathrm{~g}$ Oxalsäure mit einem Überschuss von Natriumkarbonat in Pillenform. Das Tier nahm während der ersten 9 Tage um $61 \mathrm{~g}=15,6 \%$ an Körpergewicht $\mathrm{ab}$, um dann während der letzten 21 Tage wieder um $58 \mathrm{~g}=17,6 \%$ zuzunehmen, so dass es am Schlusse des Versuches annähernd dasselbe Körpergewicht wie zu Beginn desselben aufwies. Irgendwelche Gesundheitsstörungen, im besonderen solche nervöser Art; wurden nicht beobachtet. Die Taube war im Gegenteil während der ganzen Versuchsdauer sehr munter und beweglich.

$\mathrm{Zu}$ dem zweiten Versuche wurde eine junge, etwa 2 Monate alte weisse Taube gewählt. Erfahrungsmässig sind weisse und besonders junge Tauben gegen Schäligungen durch eine insuffiziente Nahrung besonders empfindlich. Die Versuchstaube erhielt bei Ernährung mit gemischtem Taubenfutter täglich während der ersten 43 Tage $0,05 \mathrm{~g}$, während der nächstfolgenden 12 Tage $0,10 \mathrm{~g}$ und während der letzten 20 Tage $0,15 \mathrm{~g}$ Oxalsäure mit einem Überschuss von Natriumkarbonat, um Ätzwirkung auszuschalten, in Pillenform. Das Körpergewicht der Taube schwankte während des ganzen 75 Tage währenden Versuches innerhalb mässiger Grenzen hin und her und betrug am Schlusse des Versuches nur $9 \mathrm{~g}$ weniger als zu Beginn desselben. Auch die wiederholt gemessene Körpertemperatur war schwankend: Minimum $38,4^{\circ} \mathrm{C}$., Maximum $41,0^{\circ} \mathrm{C}$. Im übrigen war die Taube während des ganzen Versuchesdurchaus munter. Nervöse Störungen irgendwelcher Art traten nicht auf.

Bei allen von uns verwandten Tauben, die nach dem Auftreten alimentärer Dystrophie zur Sektion kamen, wurde eine intensive Grünfärbung der Hornhaut des Muskelmagens beobachtet. Der Farbstoff liess sich durch Alkohol leicht ausziehen. Wurde dieser Auszug abfiltriert, der Alkohol abgedampft und der so erhaltene Rückstand in destilliertem Wasser gelöst, so gab diese Lösung stark positive Gmelin'sche Reaktion. Offenbar handelt es sich um eine besonders starke Gallensekretion. Hierauf deutete auch die zuweilen vorhandene ikterische Färbung anderer Gewebe hin. Um zu ergründen, ob diese vermehrte Gallenabsonderung einen Einfluss auf das Ent- 
stehen der Frscheinungen der alimentären Dystrophie haben konnte, wurden bei dem Versuche Nr. 3 (S. 161) einer Taube 1 Monat lang bei Erährung mit gemischtem Taubenfutter Tagesgaben von 0,1 bis $0,3 \mathrm{~g}$ getrocknete Rindergalle in Pillenform eingeflösst. Das Körpergewicht der Taube nahm hierbei anfangs um $60 \mathrm{~g}=+20,79 \%$ zu, dann bei den erhöhten Gaben, die etwas abführend zu wirken schienen, wieder um $22 \mathrm{~g}=-8,22 \%$ ab. Am Schlusse des Versuches wog die Taube noch $36,5 \mathrm{~g}=+16,15 \%$ mehr als am Anfange desselben. Sie war während der ganzen Dauer des Versuches durchaus munterund wieskeinerlei abnorme Erscheinungen a f.

Es wurde schliesslich in Fortsetzung der S. 61 erwähnten Untersuchungen noch der Kot von Tauben untersucht, die einseitig mit geschliffenem Reis gefüttert worden waren. Der Gang dieser Untersuchung ist auf S. 199-203 genau angegeben. Di e Prüfungen auf die Anwesenheit von Oxalsäure oder von anderen organischen Giften hattenallenurnegative Ergebnisse. Auch die mit den verschiedenen Auszügen angestellten Tierversuche lieferten keinerlei Anhaltspunkte fürdie Anwesenbeit von irgendeinem Gift.

Quantitative Bestimmungen in dem bei $105^{\circ} \mathrm{C}$. getrockneten Kot von Tauben, die mit gemischtem Taubenfutter ernährt worden waren, und im Kote von solchen, die nur geschliffenen Reis als Futter erhalten hatten, ergaben nachstehende Werte (vgl. S. 200, 201):

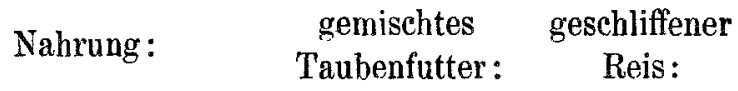

1. Stickstoff . . . . . $6,29 \%$. $8,72 \%$

2. Asche . . . . 9, $9,12 \% \quad 7,34 \%$

3. Phosphorsäure $\left(\mathrm{P}_{2} \mathrm{O}_{5}\right) \quad 2,76 \% \quad 2,52 \%$

Berücksichtigt man, wie gering die Zufuhr von Stickstoff, mineralischen Bestandteilen und Phosphorsäure bei einseitiger Ernährung mit geschliffenem Reis ist, so deuten auch diese Zahlen auf eine Verarmung des Taubenorganismus an den genannten Stoffen hin, wie dies auch sehon durch die bereits besprochenen Stoffwechselversuche (S. 45 u. ff.) erwiesen ist. Dagegen haben die vorstehend besprochenen, von uns angeführten Versuche und Untersuchungen ebenso wie alle früherenderartigen Nachforschungen nicht den geringsten Anhalt für eineendo- 
gene Giftbildung bei einseitiger Ernährung von Tauben mit geschliffenem Reis erbracht.

\section{Die Eutonine.}

Für die organischen Basen, welchen in besonders hohem Masse die Fähigkeit zukommt, die im Gefolge der alimentären Dystrophie auftretenden Störungen und Ausfallerscheinungen nervöser Art zu beseitigen bzw. derem Auftreten vorzubeugen, haben wir die Bezeichnung „Eutonine" (źvoovos $=$ nervenstärkend) gewählt. Dieser Name erschien uns aus den bereits angeführten und anderen Gründen (S. 11) bezeichnender als die bisher, für derartige Substanzen, vielfach auch in weiterem und wenig scharf umschriebenem Sinne gebrauchten Ausdrücke (Vitamine, antineuritisches Prinzip, Oryzanin, Torubin u. a. m.). Selbstverständlich sind wir uns bewusst, dass das Auftreten der nervösen Störungen nur ein Teilsymptom der ganzen Erscheinungen der alimentären Dystrophie darstellt. Sie fallen am meisten in die Augen. Auch sind die Wirkungen bestimmter Stoffe an ihnen am leichtesten zu verfolgen. Die Eutonine könnten ausser der Wirkung auf nervöse Symptome noch andere Wirkungen entfalten. Weitere Forschungen müssen hierüber noch Klarheit geben. Es sind von_dem einen von uns (Abderhalden) Versuche an überlebenden Organen (Herz, Darm usw.) in Angriff genommen, um die Wirkung der einzelnen Stoffe genauer $z u$ differenzieren. Vor allem muss noch geprift werden, $o b$ der Sympathicus nicht beeinflusst wird ${ }^{1}$ ).

Als Sammelname für alle die zum grossen Teil noch sehr wenig oder doch nicht genauer bekannten Nahrungsbestandteile, die ausser den bekannten Nährstoffen (Kohlehydraten, Eiweiss, Fetten und anorganischen Nahrungsstoffen) die Vollwertigkeit der Nahrung bedingen, schlagen wir den Namen "Nutramine" vor. Dieser ist kürzer als die bislang häufig gebrauchte Bezeichnung "akzessorische Nährstoffe“. Soweit es sich bis jetzt übersehen lässt, handelt es sich bei allen derartigen Stoffen um stickstoffhaltige, aus komplizierteren Verbindungen dureh mehr oder weniger energische Eingriffe losgelöste Spaltprodukte, welche Stickstoff in Form von Amino- $\left(\mathrm{NH}_{2}\right)$ oder Imino-( $\left.\mathrm{NH}\right)$ Gruppen

1) Die Durchführung dieser Versuche, die schon vor 4 Jahren in Angriff genommen waren, hat sich aus naheliegenden Gründen stark verzögert. 
enthalten oder als methylierte Abkömmlinge von Aminosäuren resp. Aminen (Betain- und Cholingruppe) aufgefasst werden können. Weitere Forschungen werden wohl bald einen tieferen Einblick in die chemische Konstitution der hierher gehörigen Körper ermöglichen und so zu genaueren, dem chemischen Aufbau derselben besser Rechnung tragenden Bezeichnungen führen.

Die überraschend schnelle und starke Wirkung, welche bestimmten, natürlich vorkommenden Stoffen (Reiskleie, Hefe, Stierhoden usw.) schon in relativ geringen Gaben als Heil- und Vorbeugungsmittel gegen die alimentäre Dystrophie, im besonderen gegen die des Geflügels, zukommt und sie u. a. auch dazu befähigt, die im Gefolge dieser Krankheit auftretenden nervösen Störungen rasch und sicher zu beseitigen, legte den Gedanken nahe, dass als Träger dieser Eigenschaften besondere Bestandteile der betreffenden natürlich vorkommenden Stoffe in Frage kämen.

Einer von uns (Schaumann) suchte diese Stoffe unter den organischen Phosphorverbindungen, welche sich in fast allen Nahrungsmitteln, wenn auch in sehr verschiedenen Mengenverhältnissen, in ausserordentlich hohem Maasse aber in den gegen alimentäre Dystrophie wirksamsten Stoffen finden.

In der Folge wurden dann von verschiedenen Forschern Versuche angestellt, um durch Ausziehen von Reiskleie (und einigen anderen besonders wirksamen Stoffen) mit verschiedenen Lösungsmitteln wirksame Extrakte herzustellen. Diese Versuche waren insofern von Erfolg, als es gelang, durch Ausziehen von Reiskleie mit verdünnter Salzsänre, vor allem aber mit $96 \%$ igem Alkohol [Fraser und Stanton ${ }^{1}$ )] Auszüge zu bereiten, die sich als geeignet erwiesen, um die bei alimentärer Dystrophie auftretenden nervösen Störungen (Lähmungen, Streckkrämpfe, Opisthotonus, Konvulsionen) zu beseitigen. Durch Hydrolyse der alkoholischen Extrakte mit verdünnter Schwefelsäure und nachträgliches Ausfällen der Schwefel- und in Freiheit gesetzten Phosphorsäure mit Barythydrat, Abfiltrieren von dem entstandenen Niederschlage und Eindampfen bei niedriger Temperatur glückte es weiter, zu einem in dem genannten Sinne wirksamen Präparat zu gelangen. Dieses war nicht nur bei oraler, sondern auch

1) H. Fraser and A. T. Stanton, The etiology of Beriberi. Studies from the Institute for medical Research. Federadet Malay States Singapore 1911 Nr. 12. 
bei parenteraler Anwendung (Eijkman) wirksam. Es enthielt, wie es bei dem zu seiner Bereitung in Anwendung gebrachten Verfahren nicht anders zu erwarten war, nur noch sehr geringe Mengen von Phosphorsäure. Aus diesem Befunde schloss man dann, dass die von Schauman nertretene Auffassung irrig sein müsste.

Funk ${ }^{1}$ ) gelang es dann bekanntlich, auf diesen Vorarbeiten fussend, durch Anwendung des gebräuchlichen Fällungsverfahrens mit Phosphorwolframsäure einen Niederschlag $\mathrm{zu}$ erhalten, aus dem sich durch Zerlegung mit Barythydrat und weitere Reinigung des Filtrats eine sehr wirksame Substanz gewinnen liess. Diese bezeichnete Funk später als "Vitamin“. Wie Funk bei seiner ersten Veröffentlichung angab, war die von ihm dargestellte Substanz gegen die bei TaubenDystrophie auftretenden nervösen Störungen in Mengen, die $4 \mathrm{mg}$ Stickstoff enthielten, wirksam. Die von Funk für den von ihm als rein und einheitlich bezeichneten Körper auf Grund einer Elementaranalyse aufgestelite Formel lautete: $\mathrm{C}_{17} \mathrm{H}_{18} \mathrm{O}_{4} \mathrm{~N}\left(\mathrm{HNO}_{3}\right)$; die gefundene Menge $\mathrm{N}$ betrug $7,68 \%$. Es war demnach für den genannten Erfolg eine Gabe von etwas mehr als $0,05 \mathrm{~g}$ "Vitamin" erforderlich. Wie wir später zeigen werden, übersteigt diese Gabe um das Zebnfache diejenige, welche zu dem gleichen Erfolge von dem zuerst von $\mathrm{Edie}^{2}$ ) und seinen Mitarbeitern und dann auch von uns aus Hefe dargestellten Produkt erforderlich ist.

Funk sprach die Vermutung aus, dass das von ihm dargestellte "Vitamin" in die Reihe der Pyrimidinbasen gehöre, ohne indessen zur Stütze einer solchen Mutmaassung geeignete Gründe auszuführen.

Unabhängig von Funk und ungefähr gleichzeitig mit ihm hatten Suzuki, Shimamura und $0 \mathrm{dake}^{3}$ ) aus Reiskleie eine ebenso wie Funk's "Vitamin" wirkende Substanz dargestellt, die sie „Oryzanin" nannten. Die von diesen Autoren durch Fällung mit Pikrin-

1) Casimir Funk, On the chemical nature of the substance, which cures polyneuritis in birds produced by a diet of polished rice. Journ. of Physiol. vol. 43 p. 378 . Nov. 1911.

2) E. S. Ědie, W. H. Evans, B. Moore, C. C. Simpson and A. Webster, The antineuritis bases of vegetable origin in relationship to Beri-Beri, with a method of isolation of Torubin, the antineuritis base of yeast. Annals of Tropic Med. and Parasitol vol. 6 p. 235. 1912 and Bjochem. Journ. vol. 6 p. 234. 1912.

3) Suzuki, Shimamura and Odake, Oryzanin in Beriberi. Ref. Journ. of Tropic Med. and Hyg. vol. 15 p. 352. 1912. 
säure gewonnenen Mengen waren indessen zu gering, un neben den angestellten Tierversuchen auch noch die Ermittlung der chemischen Zusammensetzung des "Oryzanins" zuzulassen.

Von Edie ${ }^{1}$ ) und seinen Mitarbeitern, wurde bald darauf aus Bierhefe nach einem anderen Verfahren eine Substanz gewonnen, welche schon in Mengen von $6 \mathrm{mg}$ die bei der alimentären Dystrophie der Tauben auftretenden Lähmungen und Krampfanfälle zum Verschwinden brachte. Die genannten Autoren stellten für diese von ihnen "T o r u b in " genannte Substanz die empirische Formel $\mathrm{C}_{7} \mathrm{H}_{16} \mathrm{NO}_{2}\left(\mathrm{HNO}_{3}\right)$ auf und sprachen die Vermutung aus, dass die Konstitutionsformel des salpetersauren Salzes $\mathrm{N}(\mathrm{CH})_{3} \mathrm{C}_{4} \mathrm{H}_{7} \mathrm{O}_{2}\left(\mathrm{HNO}_{3}\right)$ sein könnte. Diese Vermutung gründete sich auf die Beobachtung, dass bei der Zerlegung des Phosphorwolframsäure-Niederschlages durch Barythydrat Trimethylamin entsteht.

Inzwischen war von einem von uns nach einem dritten Verfahren aus der Reiskleie ebenfalls eine in kleinen Gaben und in derselben Weise wirksame Substanz dargestellt worden ${ }^{2}$ ).

In der Folge wurden dann noch aus Stierhoden [Schaumann $\left.{ }^{3}\right)$ und aus Pferdefleisch [Cooper $\left.\left.{ }^{4}\right)\right]$ derartig wirkende Substanzen gewonnen, die allerdings anch in kleinen Mengen wirksam waren, aber keinen Anspruch auf Reinheit erheben konnten.

Funk ${ }^{5}$ ) hat angegeben, er habe auch aus 0 chsenhirn, Milch und Zitronensaft "Vitamine" dargestellt. Über die Wirksamkeit sowobl, wie anch uber die chemischen Eigenschaften dieser "Vitamine" fehlen indessen bislang verbürgte Angaben.

Neuerdings hat D. J. $\mathrm{Hulshoff} \cdot \mathrm{Pol}^{6}$ ) versucht, aus der Bohne

1) a. a. 0. 8. 69 .

2) H. Schaumaun, C̈ber die Darstellung und Wirkungsweise einer der in der Reiskleie enthaltenen gegen experimentelle Polyneuritis wirksamen Substanzen. Arch. f. Schiffs- u. Tropenhyg. Bd. 16 S. 349. 1912.

3) H. Schaumann, Die Ätiologie der Beriberi. II. Arch. f. Schiffs- a. Tropenhyg. Bd. 18 Beih. 6 S. 36 u. 78.1914.

4) E. A. Cooper, The preparation from animal tissues of a substance which cures Polyneuritis in birds induced by diets of polished rice. Biochem. Journ. vol. 7 p. 268.1913.

5) C. Funk, The preparation from yeast and certain foodstuffs of the substance the deficiency of which in diet occasions Polyneuritis in birds. Journ. of Physiol. vol. 45 p. 75. 1912.

6) D. J. Huls h off-Pol, X-Säure als Heilmittel bei Polyneuritis und Beriberi. Journ. of Physiol. vol. 51 p. 432. 1917. Ref. Chem. Zentrallbl. 1918 Bd. 1 S. 562. 
Beitrag zur Kienntnis von organischen Nahrungsstoffen mit spezif. Wirkung. 71

Katjang hidjoe (Phaseolus radiatus) das wirksame Prinzip zu gewinnen. Er bezeichnet das in seiner Zusammensetzung noch unbekannte Produkt als "X-Säure“.

Über die von Funk an die Entdeckung des "Vitamins" und dessen physiologischen Eigenschaften geknüpfte "Vitamintheorie" und von den "Avitaminosen" ist schon an anderer Stelle die Rede gewesen (S. 11 u. ff.).

Abderhalden und Ewald ${ }^{6}$ ) haben dann eine Reihe von Versuchen mit Tauben angestellt, die mit geschliffenem Reis gefüttert wurden und als Zugaben "Vitamin" in wässeriger Lösung erhielten. Diese Versuchsreibe wurde angestellt, um festzustellen, ob geschliffener Reis durch Zusatz von "Vitamin" wirklich, wie vielfach angenommen wurde, zu einem vollwertigen Nahrungsmittel ergänzt würde, d. h., ob die Insuffizienz des geschliffenen Reises nur auf dessen geringen Gehalt an „Vitamin" zurückzuführen wäre.

Bei Füterung mit geschliffenem Reis und oraler Anwendung des „Vitamins" gingensämtliche Versuchstauben innerhalb von 29-129 Tagen (im Durchschnitt von acht derartigen Versuchen nach 54 Tagen) unter starker Abmagerung ein. Bei parenteraler Anwendung von "Vitamin" bei 5 Tauben betrug die Lebensdauer zwischen 17 und 62 Tagen, im Durchschnitt 29,8 Tage. Nervöse Störungen (Lähmungen, Opisthotonus, Streckkrampf, Konvulsionen) traten bei kontinuierlicher Anwendung von "Vitamin" allerdings nicht auf.

Abderhalden und $E$ wald bemerken zu diesen Versuchen: "In keinem Falle gelang der Nachweis, dass geschälter Reis plus Vitamin ein vollwertiges Nahrungsmittel darstellt. Sicher bewiesen ist, dass der alkoholische Auszug aus Reiskjeie in den meisten Fällen imstande ist, Anfälle, die im Gefolge der ausschliesslichen Verfütterung von geschältem Reis auftreten, aufzuheben. Schwer erkrankte Tiere erholen sich vollständig. Immer ist dies freilich nicht der Fall. Dieser Umstand erscheint uns nicht unwichtig. Ebenso ist bedeutsam, dass nach dem Aussetzen der Vitaminzufuhr die Anfälle oft sehr rasch wiederkehrten."

6) E. Abderhalden und G. Ewald, Gibt es lebenswichtige, bisher unbekannte Nahrungsbestandteile? Zeitschr. f. d. ges. exper. Med. Bd. 5 H. 1/2 S. 1. 1916. 


\section{Ferner :}

„Betrachtet man die Gewichte der Versuchstiere, dann erkennt man in vielen Fällen eine günstige Einwirkung der Vitaminzufuhr auf das Körpergewicht. Im allgemeinen fällt es während der Reisfütterung von Tag zu Tag. Die individuellen Unterschiede siud auch hier beträchtlich."

\section{Und weiter:}

"Sehr schwere Fälle nervöser Störuugen können rasch vollständig behoben werden, während in anderen Fällen im Gefolge scheinbar ganz leichter. Erscheinungen, die schon nach kurzer Zeit der Verabreichung von Reis aufgetreten sind, trotz Vitaminzufuhr der Tod eintritt."

Wie schon erwähnt, bewirken die aus Hefe und Reiskleie gewonnenen salzsauren und alkoholischen Extrakte eine Steigerung der Fresslust, wodurch v or überge hend ein besserer Ernährungszustand erzielt werden kann. Im ganzen aber sinkt das Körpergewicht der Versuchstiere bei Fütterung mit geschliffenem Reis trotz kontinuierlicher Zufuhr derartiger Extrakte ständig. Die Abnahme betrug:

\begin{tabular}{|c|c|c|}
\hline bei täglicher Zufuhr von & innerhalb von & $\begin{array}{c}\left.\text { Gewichtsabnahme }{ }^{1}\right) \\
\% \%\end{array}$ \\
\hline 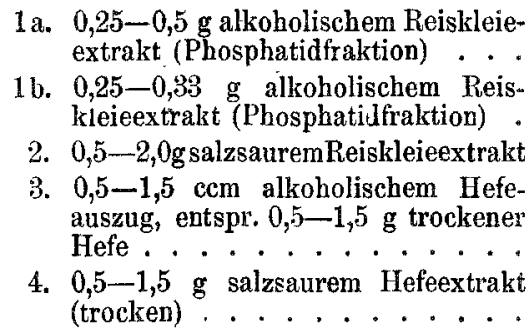 & $\begin{array}{r}87 \text { Tagen } \\
112 " \\
42 " \\
42 " \\
58\end{array}$ & $\begin{array}{l}-41,6 \\
-20,4 \\
-41,2 \\
-26,0\end{array}$ \\
\hline
\end{tabular}

Salzsaure Extrakte sind, wie die vorstehend angefübrten Zahlen erweisen, erheblich wirksamer als alkoholische Auszuge. Alle diese Präparate bleiben aber doch schon an Stärke und Vielseitigkeit der Wirkung weit hinter den Ausgangsprodukten (Reiskleie und besonders Hefe) zurück, welche, wie die betreffenden Versuche immer wieder gezeigt haben, den geschliffenen Reis zu einem vollwertigen Nahrungsinittel auch bei relativ geringen Zugaben zu ergänzen vermögen.

1) Siehe Tabellen S. 47 und 48. 
Beitrag zur Kenntnis von organischen Nahrungsstoffen mit spezif. Wirkung. 73

Von einem von uns [Schaumann $\left.\left.{ }^{1}\right)\right]$ ist ferner ein Parallelversuch ausgeführt worden, bei welchem von zwei Taubenpaaren das eine mit geschliffenem Reis allein, das andere mit geschliffenem Reis derselben Qualität und Zusammensetzung plus einer Tageszugabe von $0,0116 \mathrm{~g}$ „Vitamin" aus Reiskleie ernährt wurde. Das Vitaminpräparat war sehr weit gereinigt und hatte sich bei vier Vorversuchen bei oraler Anwendung von nur $0,01 \mathrm{~g}$ als sehr wirksam erwiesen. Die Stoffwechselbilanz gestaltete sich folgendermaassen (s. S. 50):

Einnahme in 20 Tagen.

\begin{tabular}{ll|c|c|c|c|c}
\hline \multicolumn{2}{c|}{ Geschliffener Reis } & $\begin{array}{c}\mathrm{N} \\
\mathrm{g}\end{array}$ & $\begin{array}{c}\mathrm{P}_{2} \mathrm{O}_{5} \\
\mathrm{~g}\end{array}$ & $\begin{array}{c}\text { Asche } \\
\mathrm{g}\end{array}$ & $\begin{array}{c}\mathrm{CaO} \\
\mathrm{g}\end{array}$ & $\begin{array}{c}\mathrm{MgO} \\
\mathrm{g}\end{array}$ \\
\hline ohne Vitaminzufuhr & . . . & 2,129 & 0,358 & 0,669 & 0,0081 & 0,0043 \\
mit &. & 3,051 & 0,513 & 0,959 & 0,0118 & 0,0059
\end{tabular}

Ausgabe in 20 Tagen.

\begin{tabular}{ll|c|c|c|c|c}
\hline \multicolumn{2}{c|}{ Geschliffener Reis } & $\begin{array}{c}\mathrm{N} \\
\mathrm{g}\end{array}$ & $\begin{array}{c}\mathrm{P}_{2} \mathrm{O}_{5} \\
\mathrm{~g}\end{array}$ & $\begin{array}{c}\text { Asche } \\
\mathrm{g}\end{array}$ & $\begin{array}{c}\mathrm{CaO} \\
\mathrm{g}\end{array}$ & $\begin{array}{c}\mathrm{MgO} \\
\mathrm{g}\end{array}$ \\
\hline ohne Vitaminzufuhr & . . . & 3,071 & 0,791 & $\mathbf{1 , 6 7 7}$ & 0,0219 & 0,0018 \\
mit & . . . & 3,009 & 0,807 & $\mathbf{1 , 5 6 9}$ & 0,0100 & 0,0017 \\
\end{tabular}

Bilanz nach 20 Versuchstagen.

\begin{tabular}{|c|c|c|c|c|c|c|c|c|c|}
\hline \multirow{2}{*}{$\begin{array}{c}\text { Geschliffener } \\
\text { roher Reis } \\
\text { derselben } \\
\text { Qualität }\end{array}$} & \multirow{2}{*}{$\begin{array}{c}\text { Spontan } \\
\text { auf- } \\
\text { genon- } \\
\text { mene } \\
\text { Nah- } \\
\text { rung in } \\
\text { Gramm }\end{array}$} & \multirow{2}{*}{$\begin{array}{c}\text { Ka- } \\
\text { lorien- } \\
\text { zahl }\end{array}$} & \multirow{2}{*}{$\begin{array}{c}\text { Ab- } \\
\text { nahme } \\
\text { des } \\
\text { Körper- } \\
\text { ge- } \\
\text { wichts } \\
\text { in Proz. }\end{array}$} & \multirow{2}{*}{$\begin{array}{c}\text { Verhält- } \\
\text { nis des } \\
\text { Kotes zur } \\
\text { Nahrung } \\
\text { (trocken) } \\
\text { in } \\
\text { Prozent }\end{array}$} & \multicolumn{5}{|c|}{$\begin{array}{l}\text { Differenz von Einnahme und Ansgabe } \\
\text { in Gramm }\end{array}$} \\
\hline & & & & & $\mathrm{N}$ & $\mathrm{P}_{2} \mathrm{O}_{5}$ & Asche & $\mathrm{CaO}$ & $\mathrm{MgO}$ \\
\hline $\begin{array}{l}\text { ohno Vitamin- } \\
\text { zufuhr : } \\
\text { mit Vitamin- } \\
\text { zufuhr. . }\end{array}$ & $\begin{array}{l}204,30 \\
295,14\end{array}$ & $\begin{array}{l}658,7 \\
951,6\end{array}$ & $\begin{array}{r}-20,70 \\
-\quad 9,14\end{array}$ & 11,47 & $-0,942$ & $\begin{array}{l}-0,433 \\
-0,294\end{array}$ & $-0,610$ & $-0,0138$ & $+0,0042$ \\
\hline
\end{tabular}

Die angeführten Werte zeigen sehr bemerkenswerte Unterschiede. Bei Vitaminzufubr war die Fresslust erheblich reger und die spontane Nahrungsaufnahme entsprechend grösser, die Abnahme des Körpergewichtes wesentlich geringer und das Verhältnis von Kot zur auf-

1) H. Schaumann, Die Ätiologie der Beriberi. II. Arch. f. Schiffs- u. Tropenhyg. Bd. 18 Beih. 6 S. 104 u. 114. 1914. 
genommenen Nahrung günstiger, Alles dies deutet (bei Vitaminzufuhr) nicht nur auf einen regeren hmsatz, sondern auch auf eine bessere Ausnutzung der Nahrung hin, wie dies auch bei der Bilanz der einzelnen Nahrungsbestandteile seinen Ausdruck findet. Nichtsdestoweniger waren die $\mathrm{N}-, \mathrm{CaO}$ - und $\mathrm{MgO}$ - Bilanzen nur sehr wenig positiv, während sich für $\mathrm{P}_{2} \mathrm{O}_{5}$ und auch für die Aschebestandteile negative Werte ergaben. Dass ein solches nicht unbeträchtliches Manko bei einem so wichtigen Nahrungsbestandteil, wie es hier besonders die Phosphorsäure ist, auf die Dauer nicht ohne Schädigungen des Organismus ertragen werden kann, steht wohl ausser jedem $Z$ weifel.

Schon länger bekannt ist, dass auch andere Substanzen die bei alimentärer Dystrophie auftretenden Erscheinungen nervösen Ursprungs (Lähmungen, Opisthotonus, Krämpfe) wenigstens vorübergehend zu beseitigen vermögen. Vor allem kommt diese Eigenschaft der $\mathrm{He}$ e nukleinsäure zu, die nach dieser Richtung hin, wie von einem von uns (Schaumann) festgestellt worden ist, zuweilen eine ebenfalls überraschende Wirksamkeit äussert. Diese hängt allerdings in hohem Maasse vou der Sorgfalt ab, mit der die Nukleinsäure bereitet ist. Verwendung starker Alkalilauge und Erwärmen bei der Herstellung scheinen die Wirksamkeit sehr zu beeinträchtigen oder ganz aufzuheben ${ }^{1}$ ). Merkwürdigerweise wirkt die Hefenukleinsäure aber nur so günstig bei ihrer erstmaligen Anwendung und versagt bei wiederholten Gaben. Funk ${ }^{2}$ ) berichtete, dass Thymusnukleinsäure ebenso wirksam wäre wie Hefenukleinsäure und will auch bei Verwendung von Purin-und Pyrimidinbasen eine, wenn auch erheblich schwächere Wirkung als bei Nukleinsäure beobachtet haben.

Nach Cooper ${ }^{3}$ ) sollen auch $\mathrm{Chinin}$ und Cinchonin eine vorübergehende Wirkung gegen die genannten nervösen Störungen entfalten. Strychningaben sollen nach Angaben desselben Forschers das Auftreten der Anfälle verzögern.

1) Als am wirksamsten erwies sich bei diesen Versuchen eine von der Firma C. F. Boehringer \& Söhne in Mannheim dargestellte Nukleinsäure aus Hefe.

2) C. Funk, Further experimental studies on Beriberi. The action of certain purine- and pyrimidine-derivates. Journ. of Physiol. vol. 45 Nr. 6. 1913.

3). C. A. Cooper, On the protective and curative properties of certain foodstuî̀s against Polyneuritis induced in birds by a diet of polished rice. Journ. of Hyg. vol. 12 Nr. 4 a. 5. 1913 (s. a. Biochem. Journ. Bd. 7 S. 268.1913. 
Von Abderbalden und Ewald (l. c.) sind auch Versuche mit Pilokarpin und Atropin angestellt worden. Dem Anscheine nach vermochte letzteres die Anfälle nervöser Art zu mildern und auch zu beseitigen.

Dies war in den Hauptzügen der Stand der Forschung auf diesem speziellen Gebiete, als wir die vorliegende gemeinschaftliche Arbeit begannen. In der Folge soll noch von einigen aus der Hefe durch Hydrolyse von uns gewonnenen Abbauprodukten (s. Abschnitt X) berichtet werden, denen ebenfalls eine Wirksamkeit gegen die bei alimentärer Dystrophie auftretenden nervősen Störungen zukommt. Ferner sind noch hierher gehörige Versuche mit synthetisch dargestellten Abkömmlingen des Pyridins und der Nikotinsäure zu erwähnen. Auf diese letzteren werden wir noch zurückkommen. $\mathrm{Zu}$ nächst seien hier jedoch unsere neueren in den Protokollen auf S. 164 und 255 aufgeführten Versuche besprochen:

Zur Darstellung der zu diesen Versuchen verwandten Eutoninpräparate wurden hydrolysierte Reiskleie, vor allem aber hydrolysierte Hefe verwandt. Die Darstellung der Präparate in ihren Einzelheiten ist auf S. 214 u. ff. der betreffenden Protokolle angegeben. Sowohl bei den durch zehnmal wiederholtes Lösen in Alkohol und Wiedereindampfen wie auch bei den durch Acetonfällung gewonnenen Extrakten handelte es sich um hochwertige Eutoninpräparate, die ausser diesem kaum andere wirksame Bestandteile enthalten konnten.

Über den Verlauf der hier zu besprechenden Versuche geben die Protokolle auf S. 168 u. ff. und S. 255 u. ff. mit Rücksicht auf alle bemerkenswerten Einzelheiten Aufschluss. Es seien hier deshalb nur die für unsere Untersuchungen wichtigen Ergebnisse noch einmal kurz zusammengefasst:

Die Wirksamkeit der angewandten Eutoninpräparate war durch geeignete Vorversuche festgestellt worden. Die weitgehende Wirksamkeit des Acetonniederschlages, welcher aus dem alkoholischen Extrakt hydrolysierter Hefe gewonnen war, erweisen die anf S. 216 u. 218 aufgeführten Versuche sowie die Photographien Nr. 2-5.

Das als Hefepräparat A bezeichnete Erzeugnis war durch Erhitzen von Hefe mit $2 \%$ iger Natronlauge auf dem Wasserbade während 4 Stunden und nachträgliches Eindampfen auf dem Wasserbade gewonuen (Darstellungsmethode S. 162). Es war auf diese Weise seiner Wirksamkeit gegen die bei alimentärer Dyștrophie auftretenden Läh- 
mungen vollkommen beraubt und vermochte als einzige Zugabe zu gesehliffenem Reis Tauben weder gesund noch am Leben zu erhalten, und ebensowenig die bei alimentärer Dystrophie auftretenden nervösen Störungen zu beseitigen, wie die auf $\mathrm{S}$. $214 \mathrm{u}$. ff. aufgeführten Versuche zeigen.

Bei allen unseren neueren gemeinschaftlichen Versuchen wurde die bereits gemachte Erfahrung bestätigt, dass Eutonin allein als Zugabe zu geschliffenem Reis diesen nicht zu einer vollwertigen Nahrung zu ergänzen vermag: Sämtliche Versuchstiere magerten stark ab und gingen nach einem bald längeren, bald kürzeren Zeitraum zugrunde. In einzelnen Fällen traten trotz Zufuhr der Eutoninpräparate auch Störungen nervöser Art (Lähmungen, Krämpfe) auf, obschon diese bei Eutoninzufuhr in der Regel ausbleiben oder unterdrückt werden. Letzteres ist das wahrscheinlichere, weil eine Unterbrechung der Zufubr von Eutonin (Vitamin), auch nur auf kurze Zeit, schnell wieder Anfälle (Lähmungen, Opisthotonus, Krämpfe) nach sich zu zieben pflegt, wie auch ein Teil dieser Versuche wiederum zeigte.

Es ist allerdings nicht zu verkennen, dass bei fortgesetzter Eutoninzufuhr die Lebensdauer der Versuchstiere durchschnittlich eine erheblich längere ist als bei der Fütterung mit geschliffenem Reis ohne Entoninzugabe. Der auf S. 73 angeführte Stoffwechselversuch zeigt, wieviel besser die Nahrung im. ersteren Falle ausgenützt wird, so dass lierdurch der günstige Einfluss des Eutonins auf die Versuchstiere schon eine Erklärung findet.

Schon frühere von uns unabbängig voneinander ausgeführte Versuche hatte ngezeigt, dass weder Zugaben von Asche (Hefe-, Reiskleie-, Taubenasche), noch solche von Salzmischungen, noch auch solche von Eiweiss allein die Insuffizienz des geschliffenen Reises aufzuheben vermögen. Auch die gleichzeitige Zufuhr von Eutoninen (nebst den vorgenannten Zugaben) änderte an diesen Verhältnissen wenig. Die Versuchstiere magerten schnell ab und gingen schliesslich, wenn sie keine vollwertige Nahrung bekamen, ein.

Dieser Befund wurde durch die auf S. 255 u. 256 aufgeführten Versuche Nr. 24 und 25 bestätigt. Bei den zu diesen Versuchen verwandten, nach längerer einseitiger Fütterung mit geschliffenem Reis stark abgemagerten Tauben vermochte ein sehr wirksames Eutoninpräparat (Acetonniederschlag) weder allein noch zusammen mit Hefe- 
Beitrag zur Kenntnis von organischen Nahrungsstoffen mit spezif. Wirkung. 77

asche bzw. Hefeasche + Betainchlorbydrat und ebensowenig in Gemeinschaft mit Rinderblutkörperchen eine Gewichtszunahme und Besserung der Versuchstiere zu bewirken. Sie gingen beide nach relativ kurzer Zeit (20 bzw. 26 Tagen) ein. Erscheinungen nervöser Art traten allerdings vor dem Tode nicht ein.

Bei dem Dauerversuch Nr. 9 (S. 168) schwanden bei einer bereits an alimentärer Dystrophie erkrankten Taube nach fortgesetzter Zufuhr eines sehr wirksamen Eutoninpräparates (Acetonniederschlag aus hydrolysierter Hefe) zwar die nervösen Erscheinungen schnell, aber die Taube nahm trotzdem an Gewicht ständig ab. Gleichzeitige Zufuhr eines Gemisches von Aminosäuren (s. S. 168) bewirkte eine geringe, aber keineswegs eine in die Wage fallende Zunahme des Körpergewichtes. Erst Tagesgaben von $1 \mathrm{~g}$ getrockneter Hefe bei fortgesetzter Füterung mit geschliffenem Reis führten eine anfangs langsame, dann schnellere Zunahme des Körpergewichtes herbei. Dieses nahm dann bei der Ernährung mit gemischtem Taubenfutter und einer Tagesgabe von 1-2 g getrockneter Hefe nur noch sehr wenig zu. Dieses Verhalten der Versuchstiere kann aber gar nicht anders gedeutet werden, als dass geschliffener Reis + Eutonin ebenso wie geschliffener Reis + Eutonin + Hefeasche oler + Rinderblutkörperchen (Eiweiss) keine vollwertige Nahrung ist, während geschliffenerReis durcheinenrelativgeringen Hefezusatz ein vollkommensuffizientes Futter für Tauben (undeine Reihe anderer Tiere) wird. Die nachstehende Übersicht (S. 78) lässt die augenfälligen Unterschiede bei beiden Fütterungsarten deutlich hervortreten.

Bei anschliessender Ernährung mit gemischtem Taubenfutter unter täglicher Zugabe von $2 \mathrm{~g}$ getrockneter Hefe konnte nur noch eine Gewichtszunahme von $5 \mathrm{~g}=2,4 \%$ erzielt werden.

Wie schon vorstehend erwähnt, war das durch Erhitzen von trockener Bierhefe mit Natronlauge gewonnene Hefepräparat A alle in vollkommen ausserstande, sowohl die im Gefolge der alimentären Dystrophie auftretenden nervösen Störungen zu beseitigen, wie auch bei fortgesetzter Zugabe zu geschliffenem Reis die Versuchstauben gesund, auf Gewichtskonstanz und am Leben zu erhalten. Die Tierversuche auf S. 162 und 163 können hierüber nicht im Zweifel lassen.

Andererseits hatten alle unsere Versuche ausnahmslos erwiesen, dass Eutoninpräparate allein als Zusätze zu geschliffenem Reis 
Übersicht (s. a. S. 169).

Bei Frnährung mit geschlifienem rohen Reis.

\begin{tabular}{|c|c|c|c|}
\hline $\begin{array}{l}\text { Tägliche } \\
\text { Zugaben }\end{array}$ & $\begin{array}{l}\text { Daner } \\
\text { der } \\
\text { Periode }\end{array}$ & $\begin{array}{l}\text { Weitere Zu- } \\
\text { bzw. Abnahme des } \\
\text { Körpergewichts }\end{array}$ & $\begin{array}{c}\text { Gesundheitszustand } \\
\text { des } \\
\text { Versuchstieres }\end{array}$ \\
\hline $\begin{array}{l}20 \text { Tropfen der kon- } \\
\text { zentrierten Lösung d. } \\
\text { Acetonniederschlags }\end{array}$ & 19 Tage & $-14 \mathrm{~g}=-7,0^{\circ} \%$ & $\begin{array}{l}18 \text { Tage. lang munter. } \\
\text { Am 19. Tage schwer } \\
\text { krank. Durch Fin- } \\
\text { spritzung von } 0,15 \mathrm{~g} \\
\text { Acetonniederschlag } \\
\text { wieder hergestellt }\end{array}$ \\
\hline Ebenso & 5 & $-2 \mathrm{~g}=-1,2 \%$ & $\begin{array}{c}\text { Bis zum } 24 \text {. Versuchs- } \\
\text { tage munter, dann apa- } \\
\text { thisch }\end{array}$ \\
\hline $\begin{array}{l}20 \text { Tropfen Aceton-" } \\
\text { niederschlag, 5Pillen } \\
\text { A minosäuregemisch }\end{array}$ & 3 & $+7 \mathrm{~g}=+4,1 \%$ & $\begin{array}{l}\text { Verschlimmerung. Am } \\
27 \text {. Versuchstage } \\
\text { moribund }\end{array}$ \\
\hline $\begin{array}{l}20 \text { Tropfen Aceton- } \\
\text { niederschlag }+1 \mathrm{~g} \\
\text { getrocknete Bierhefe }\end{array}$ & $\begin{array}{l}8 \\
8\end{array}$ & $\begin{array}{l}+13 \mathrm{~g}=+7,5 \% \\
+21 \mathrm{~g}=+11,7 \%\end{array}$ & $\begin{array}{l}\text { Am 28. Versuchstage } \\
\text { wieder sehr munter. }\end{array}$ \\
\hline $\begin{array}{l}20 \text { Tropfen Aceton- } \\
\text { niederschlag }+2 \mathrm{~g} \\
\text { getrocknete Hefe }\end{array}$ & 22 & $+4 \mathrm{~g}=+1,9 \%$ & $\begin{array}{l}\text { Yon da an immer sehr } \\
\text { munter }\end{array}$ \\
\hline
\end{tabular}

ebenfalls nicht vermögen, Tauben auf die Dauer auf Gewichtskonstanz und lebensfähig zu erhalten.

Gibt man aber beide Präparate zusammen, so erzielt mansofortnicht nurein Zurückgehen allernervösen Erscheinungen, sondern es erfolgt gleichzeitig eine relativ schnelle Zunahme des Körpergewichts, wie der Versuch Nr. 10 (S. 170) deutlich zeigt. Hefenukleoproteid, von dem im nächsten Abschnitt die Rede sein wird, scheint mit dem Hefepräparat A zusammen allerdings noch wirksamer zu sein als der Acetonniederschlag aus hydrolysierter Hefe plus Hefepräparat A. Noch wirksamer ist freilich getrocknete Hefe selbst. Die Übersicht auf S. 171 lässt diese bemerkenswerten Unterschiede klar hervortreten.

Aus diesem Versucheergibtsich, dass geschliffener Reis durch Eutonin plus Hefepräparate A zu einem wenigstens annähernd, wenn nicht völlig suffizienten Nahrungsmittel ergänzt werden kann, während weder Eutonin allein noch Hefepräparat A allein hierzu imstande sind. Es müssen also in dem Hefepräparat $A$ ebenfalls lebenswichtige Stoffe vorbanden sein, und zwar solche, die gegen die 
Beitrag zur Kenntnis von organischen Nahrungsstoffen mit spezif. Wirkung. 79

Einwirkung von Alkalien und gegen Temperaturen bis $\mathrm{zu} 100^{\circ} \mathrm{C}$. hinauf viel widerstandsfähiger sind als Eutonin. Da Eutoninpräparate von hohem Wirkungswert weder mit Asche noch mit Eiweiss noch auch (wie frühere Versuche erwiesen haben) mit Fett zusammen eine solche oder auch nur ähnliche Wirkung wie das Hefepräparat A auszuäben vermögen, so kann es sich bei den Substanzen, welche die Wirksamkeit des Hefepräparates A veranlassen, um die soeben genannten Stoffe nicht handeln. Welcher Art die hier wirksamen Bestandteile der Hefe bzw. des Hefepräparates A sind, muss sich aus weiteren Nachforschungen ergeben, die wir uns vorbehalten.

Wie lange trotz fortgesetzter Anwendung starkwirkender Eutoninpräparate die Lähmungen anhalten können, welche bei alimentärer Tauben-Dystrophie auftreten, zeigt der Versuch Nr. 5 (S. 257). Hier dauerte es 25 Tage, bis die Paresen bei dem betreffenden Versuchstiere vollkommen beseitigt waren.

Bei weiterer Reinigung nach dem auf S. 216 u. ff. beschriebenen Verfahren nahm die Wirksamkeit des Hefe-Eutonins (Präparat I A, I A 1, I-A 2 und I N. 5) ständig zu. Die Wirkung war am stärksten bei dem Präparat I N. 5. Dieses vermochte schon in einer Gabe von $5 \mathrm{mg}$ bei intramuskulärer Einspritzung alle nervösen Störungen bei einer typisch erkrankten Taube (Paralyse der Beine und Flügel, Opisthotonus, Streckkrampf der Beine, Konvulsionen) für relativ lange Zeit zu beseitigen (S. 258, Photographien Nr. 30 und 31).

In der Regel wirken alle hochwertigen Eutoninpräparate bei Tauben sehr schnell; mitunter sind schwere nervöse Störungen schon nach einer Stunde so gut wie beseitigt. Individuelle Unterschiede sind aber auch hier sehr ausgesprochen. Die Art der Erkrankung, d. h. die verschiedenen Formen, welche die alimentäre TaubenDystrophie aufweist, spielt hier zweifellos auch eine Rolle. Der Typus III (S. 36) scheint im allgemeinen derjenige zu sein, bei welchem die Beseitigung der nervösen Störungen am leichtesten gelingt.

Sehr bemerkenswert ist die zuweilen beobachtete lange Wirkungsdauer sehr geringer Gaben von Eutoninpräparaten. Bei dem vorstehend bereits erwăhnten Versuche mit Hefe-Eutonin (Präp. I N. 5 , S. 258) hielt die Wirkung einer einmaligen Gabe von $5 \mathrm{mg} 19$ Tage lang an. Allerdings ist dies eine Ausnahme. In der Regel pflegen so kleine Gaben Schutz vor neuen Anfällen bei weitem nicht solange zu gewähren. Vorher schon mehrere Male an alimentärer Dystrophie 
erkrankte, dann durch vollwertige Ernährung wiederhergestellte Tiere pflegen neuen Anfällen leichter ausgesetzt zu sein als Tauben, die nur von einem erstmaligen Anfall durch Eutoninbebandlung wiederhergestellt sind.

Man hat wiederholt die Ansicht ausgesprochen, der tierische Organismus verfüge über einen bestimmten Vorrat an Eutonin, der, wenn die Zufuhr von Eutonin mit der Nahrung aufhört, zur Bestreitung des Bedarfs herangezogen würde. Zur Beschaffung des Eutoninbedarfs des Organismus sollte dieser, einer solchen Auffassung zufolge, Körpergewebe einschmelzen, und die nervösen Störungen sollten erst dann einsetzen, wenn die Eutoninreserven völlig erschöpft wären. Hiermit ist jedoch schon die häufiger gemachte Erfahrung, dass auch relativ noch wohlgenährte Tiere ebenfalls an typischen nervösen Störungen, und zwar zuweilen schon sehr bald nach Beginn der insuffizienten Ernährung erkranken, nicht in Einklang zu bringen.

Es spricht alles dagegen, dass sich Eutonine als solche, d. h. im freien $Z \mathbf{Z}$ ustande, in einer den momentanen Bedarf wesentlich übersteigenden Menge im tierisclen Organismus finden. Wie wir sehen werden (S. 92), sind die Eutonine in den vegetabilischen Lebensmitteln, also in pflanzlichen Organen in der Hauptsache, vielleicht überhaupt nur in Form von komplexen Verbindungen entbalten. Vieles spricht dafür, dass die Verbältnisse im tierischen Organismus ähnliche sind, und dass immer nur kleiue, dem zeitweiligen Bedürfnisse angemessene Mengen abgespalten werden. Wie die Tierversuche lehren, vermag der tierische Organismus eine solche Abspaltung leicht zu bewerkstelligen. Auch ist sein Bedarf an freiem Eutonin, wie ebenfalls aus Tierversuchen zu schliessen ist, relativ sehr gering. Schliesslich wirken grosse Mengen freien Eutonins, wie der Tierversuch S. 258 zeigt, giftig. Es liegen hier allem Anschein nach ähnliche Verhältnisse vor wie bei dem Cholin, welches ebenfalls aus komplexen Verbindungen, wie zum Beispiel aus dem Lecithin, nur allmählich in Freiheit gesetzt wird.

Wir sind u. a. auch der Frage nachgegangen, ob Eutonin oder Eutoninverbindungen in nachweisbarer Menge in das Blut übergehen.

Bei früheren, von einem von uns (Schaumann) nach dieser Richtung hin unternommenen Versuchen wurde folgendes beobachtet: 
Beitrag zur Kenntnis von organischen Nahrungsstoffen mit spezif. Wirkung. 81

Frisch entnommenes, defibriniertes Taubenblut sowie frisehes Kaninchenserum bewirkten bei gelähmten Tauben ein wirkliches, aber weder vollkommenes noch auch mehr als 2 Tage lang anhaltendes Zurüekgeheı der Lühmungen. Meerschweinblut war wirkungslos.

Von Derks ${ }^{1}$ ) sind später Versuche mit Pferdeblut sowie auch mit Pferdeserum und Pferdeblutkörperchen bei Hühnern angestellt worden, die an alimentärer Dystrophie erkrankt waren und typische nervöse Störungen aufwiesen. In keinem Falle wurde bei diesen Versuchen eine günstige Wirkung beobachtet.

$\mathrm{Zu}$ unseren Tierversuchen verwandten wir getrocknete Rinderblutkörperchen und getrocknetes sowie enteiweisstes Rinderserum, ferner getrocknete Hühner- und Taubenblutkörperchen sowie getrocknetes Hühnerserum.

Bei dem Dauerversuch mit Rinderblutpräparaten Nr. 12 (S. 172) war in keinem Falle ein günstiger Einfluss zu bemerken. Sämtliche Versuchstauben erkrankten nach 16-31 Tagen unter mebr oder weniger starker Abmagerung an typischer alimentärer Dystrophie.

Hühnerblutkörperchen äusserten bej einer gelähmten Taube ebensowenig eine nennenswerte Wirkung wie Hühnerserum.

Nach oraler Anwendung von Taubenblutkörperchen bei zwei an alimentärer Dystropłie erkrankten Tauben war in einem der Fälle keinerlei Besserung zu verzeichnen. Bei der zweiten Taube war eine merkliche, aber sehr vorübergehende günstige Wirkung zu beobachten.

Es scheint so, als ob nur sehr geringe Mengen von Eutoninbzw. Eutoninverbindungen im Blutezirkulieren. Es stände dies auch im Einklang mit den bei anderen für den tierischen Organismus wichtigen Körpern (Inkreten) gemachten Beobachtungen.

Freies Eutonin ist eine ausserordentlich labile und, wie schon länger bekannt, gegen Wärme und besonders gegen Alkalien sehr empfindliche Verbindung. Erheblich grösser ist die Widerstandsfähigkeit gegen Säuren, mit denen es Salze bildet. In den Muttersubstanzen sind es mit grösster Wahrscheinlichkeit organische Phosphorsäureverbindungen (Glyzerylphosphorsäure, Nukleinsäure und vielleicht andere mehr), an denen das Eutonin bängt. Diese Verhältnisse sollen im nächsten Abschnitt eingehender erörtert werden.

1) Th. J. G. Derks, Bijdrage tot de Kennis der Polyneuritis gallinarum in verband met het Beriberivraagstuk. Inaugur.-Dissert. Utrecht 1916. 
Es leuchtet wohl ohne weiteres ein, dass den in Lebensmittein vegetabilischen Ursprungs, also in pflanzlichen Organen, vorkommenden Eutouinen bzw. Eutoninverbindungen a priori eine pflanzenphysiologische Bedentung zukommt. Von diesen Gesichtspunkten aus geben die folgenden Untersuchungen vielleicht einen Fingerzeig.

Bottomley ${ }^{1}$ ) machte in dem Botanischen Garten von Kew bei London folgende Beobachtungen: Sphagmum-Torf wurde durch ein Gemisch von aeroben Bakterien zum Teil in lösliche Humate verwandelt. Der so behandelte Torf war, auch nach seiner Sterilisation, ein vorzüglicher Nährboden für Pflanzen und förderte, wenn auch nur kleine Mengen davon gewöhnlicher Pflanzennahrung zugesetzt wurden, das Wachstum höherer Pflanzen in bemerkenswerter Weise, Das wirksame Prinzip konnte dem Torf in seinem ursprünglichen Zustande weder durch Wasser noch durch Sodalösung entzogen werden. Nach Einwirkung der Bakterien hingegen konnten aus dem Torf durch Ausziehen mit Wasser und Alkohol sehr wirksame Extrakte gewonnen werden. Es war daher anzunehmen, dass die auf das Wachstum beschleunigend wirkeude Substanz erst durch die Bakterien aus dem Torf gebildet (bzw. in Freiheit gesetzt) wird. Durch Phosphorwolframsäure wurde der wirksame Stoff gefällt und konnte nach Zerlegung dieses Niederschlages mit Barythydrat aus dem Filtrate mittels Silbernitat-Baryt-Fällung niedergeschlagen werden.

Bottomley nannte die in dieser Weise wirksamen Substanzen

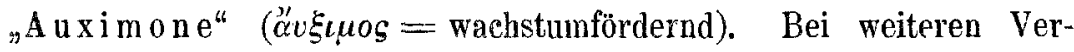
suchen fand er, dass mineralischen Nährsalzlösungen, welche allein das Wachstum von Lemna minor nicht zu unterhalten vermögen, durch Zusatz sehr geringer Mengen der wässerigen Extrakte aus bakterisiertem Torf $(0,368 \%)$ hierzu befähigt wurden. Die Vermehrung der Pflanzen betrug im Vergleich mit reinen Salzlösungen (Kontrollversuchen) das 20 fache in der Zahl und das 62 fache im Gewicht der zur Fntwicklung gelangten Pflanzen. Noch günstigere Resultate ergaben das alkoholische Extrakt und die aus dem wässerigen

1) W. B. Bottomley, Einige unterstützende Faktoren bei Wachstum und Ernährung der Pflanzen. Proc. Royal Soc. London Ser. B vol. 88 p. 237. 1914. Ref. Chem. Zentralbl. 1915 Bd. 2 S. 908 . - Derselbe, Einige Wirkungen organischer wachstumfördernder Substanzen (Auximone) auf das Wachsen von Lemna minor in mineralischen Nährlösungen. Proc. Royal Soc. London Ser. B vol. 89 p. 481. Ref. Chem. Zentralbl. 1917 Bd. 2 S. 690. 
Beitrag zur Kenntnis von organischen Nahrungsstoffen mit spezif. Wirkung.

Extrakt gewonnene Phosphorwolframsäurefraktion bzw. die durch Zerlegung derselben gewonnene Flüssigkeit.

Diese Beobachtungen wurden im wesentlichen durch die Versuchsergebnisse von Mockeridg $\mathrm{e}^{1}$ ) bestätigt.

Von $\mathrm{Maze}^{2}$ ) wurde über folgende auch für die hier vorliegenden Verhältnisse bedeutsame Beobachtung berichtet: Beim Fehlen yon Mangan im Nährboden wurden Maispflanzen chlorotisch. Diese Chlorose konnte durch nachträgliche Zufuhr von Mangansalzen nicht mebr behoben werden. Dagegen gelang dies bei gleichzeitigem Zusatz des Exsudates normaler Maisblätter oder eines aus diesen durch Ausziehen mit destilliertem Wasser bereiteten Extraktes. Es liess sich in diesem eine organische Substanz von spezifischer Wirkung nachweisen, die in Wasser und Alkohol löslich, dagegen in Äther unlöslich war. Kurzem Erhitzen auf $100^{\circ} \mathrm{C}$. widerstand dieses Agens.

Für die naheliegende Auffassung, dass die Nutramine und speziell auch die Eutonine bzw. deren Muttersubstanzen vom Pflanzenorganismus für seine eigenen Zwecke erzeugt werden, und dass sie daher in erster Linie eine pfianzenphysiologische Bedeutung haben, liefert der Einfluss des alkoholischen, aus hydrolysierter Hefe gewonnenen Extraktes sowie des aus einem solchen Extrakt ausgefällten Acetonniederschlages auf die Hefegärung eine weitere wichtige Stätze. Dieser Einfluss äusserte sich, wie später eingehend ausgeführt werden soll, in der erheblichen Beschleunigung, welche die Vergärung durch Bierhefe von Fruchtzucker, Traubenzucker, Galaktose, Maltose, Rohrzucker und Brenztraubensäure durch Zusatz geringer Mengen der genannten, aus hydrolysierter Hefe gewonnenen Präparate erfubr. Wie schon dargelegt, kommt diesem Präparate eine sehr ausgesprochene Wirksamkeit gegen die bei der alimentären Taubendystrophie auftretenden nervösen Störungen zu, welche nur auf ihren Gehalt an. Eutonin

1) Florence A. Mockeridge, Einige Wirkungen wachstumfördernder Substanzen (Auximone) auf die Bodenorganismen bezüglich des Stickstoff'stoffwechsels. Proc. Royal Soc. London Ser. B vol. 89 p. 508. Ref. Chem. Zentralbi. 1917 Bd. 2 S. 691. - Vgl. auch G. Davis Buchner und Joseph H. Kastle, Wachstum von isolierten Pflanzenembryonen. Journ. of biol. Chem. vol. 29 p. 209. 1917. Ref. Chem. Zentralbl. Bd. 2 S. 753. 1917.

2) P. Mazé, Recherches de Physiologie végétale. Influences respectives des élements de la solution minérale sur le développement du mais. Annales de l'Inst. Pasteur t. 28 p. 21.1914. 
zurückgeführt werden kann. Wir kommen auf diese Versuche noch zurück.

Auch für Insekten scheinen Eutonine bzw. deren Muttersubstanzen unentbehrliche Nahrungsbestandteile zu sein.

So konnte zum Beispiel $\mathrm{G}$ u yén ot ${ }^{1}$ ) nacìweisen, dass sterile Fliegen, die bei Fütterung mit sterilisierten Kartoffeln schnell zugrunde gingen, bei Zugabe von Hefezellen, lebenden oder abgetöteten, zu den sterilisierten Kartoffeln hingegen vorzüglich gediehen.

Loeb und Northrop ${ }^{2}$ ) fanden ebenfalls, dass sterile Bäckerhefe mit sterilisiertem Wasser und Zitronensäure gemischt das brauchbarste Nahrungsmittel für sterile Fliegen ist. Durch intensives Auszieben mit Alkohol wurde die Hefe für sterile Fliegenzucht unbrauchbar.

Was die Verfahren zur Darstellung von wirksamen St offen angeht, so sind verschiedene Methoden hierfür zur Anwendung gelangt. Das von Funk angewandte Verfahren, welches bekanntlich schon seit langem vielfach besonders zur Abscheidung von basischen Aminosäureverbindungen Verwendung findet, beruht auf der Fällung der hydrolysierten Phosphatidfraktion mit Phosphorwolframsäure, Zerlegung des Phosphorwolframsäureniederschlages mit Barythydrat und weiterer Reinigung durch Silbernitrat-Barythydrat-Fällung. Die Methode hat den grossen Nachteil, dass bei der Behandlung mit Barythydrat ein grosser Bruchteil des wirksamen Prinzips zersetzt wird. F u n k erhielt seinen Angaben zufolge aus $100 \mathrm{~kg}$ getrockneter Hefe nach dem von ihm befolgten Verfahren nur $2,5 \mathrm{~g}$ und aus $350 \mathrm{~kg}$ Reiskleie ebensoviel Rohvitamin.

Von Edie und seinen Mitarbeitern (1. c.) wurde ein durch Ausziehen mit Methylalkohol aus Hefe gewonnenes Extrakt nach dem Abdampfen des Lösungsmittels bei niedriger Temperatur mit Gipsmehl gemischt. Das getrocknete und gemahlene Gemisch wurde nochmals in der Schüttelmaschine mit Methylalkohol ausgezogen. Der so erhaltene Auszug wurde nach dem. Abdampfen des Methylalkohols in Wasser gelöst, dann mit Bleiessig im Überschuss versetzt. Der entstandene Niederschlag wurde abfiltriert und als unwirksam nicht weiter berücksichtigt. Das Filtrat wurde durch Einleiten von Schwefelwasserstoff von Blei befreit und der PbS-Niederschlag abfiltriert. Das

1) Guyénot, Compt. rend. de la Soc. de Biol. t. 97 p. 178. 1913.

2) Jacques Loeb und J. H. Northrop, Ernährung and Entwicklung. Journ. of Biol. Chem. vol. 27 p. 309. 1916. Ref. Chem. Zentralbl. 1917 Bd. 2. S. 787. 
Filtrat wurde bei $38^{\circ} \mathrm{C}$ eingedampft und der Rückstand mit absolutem Alkohol behandelt. Die filtrierte alkoholische Lösung wurde von Alkohol befreit, der Rückstand mit Wasser aufgenommen und mit Silbernitrat und Barythydrat versetzt. Der abfiltrierte Niederschlag wurde in Wasser suspendiert und durch Schwefelwasserstoff zerlegt, Der $\mathrm{Ag}_{2} \mathrm{~S}-$ Niederschlag wurde abfiltriert und das Filtrat bei $38^{\circ} \mathrm{C}$. zur Trockene verdampft. Es blieb eine geringe Menge eines braunen, klebrigen und hygroskopischen Rückstandes zurück, der dann durch Behandlung mit Alkohol weiter gereinigt wurde. Hierdurch wurde schliesslich eine aus federförmigen Kristallen bestehende Substanz (Torulii) erbalten.

Die auch von uns zur Ausfällung der gröbsten Verunreinigungen verwandte Fällung mit Bleiessig ist für diesen Zweck sehr empfehlenswert, besonders bei den aus Reiskleie dargestellten Aúszügen. Im übrigen war die von $\mathrm{Edi}$ e und seinen Mitarbeitern verwandte Methode auch nicht sehr ausgiebig.

Noch weniger gute Ausbeute scheint das von Suzuki, Shimamura und $O d a k e$ (l. c.) benutzte und auf die Fällung des Reiskleie-Oryzanins mit Pikrinsäure gegründeten Verfahrens zu liefern. Auch wir hatten bei einem Versuche, Hefe-Eutonin auf diese Weise auszufällen, nur einen sehr unbefriedigenden Erfolg.

Ferner hat man Versuche angestellt, um durch Ausfällung mit Tannin die wirksamen Stoffe zu gewinnen; aber auch hier entsprachen die Resultate keineswegs den gehegten Erwartungen.

Cooper ${ }^{1}$ ) (l. c.) empfahl, die primären konzentrierten alkoholischen Auszüge zunächst mit Äthyläther zu versetzen und den hierdurch entstehenden Niederschlag dann in geeigneter Weise zu reinigen. Diese Methode soll aber nicht allgemein anwendbar sein.

In neuerer Zeit sind auch Versuche angestellt worden, um die wirksamen Stoffe durch Adsorption zu gewinnen. Seidel1 ${ }^{2}$ ) berichtete, dass beim Schütteln des Filtrats von autolysierter Bierhefe mit Lloyd's Reagens (kolloidem Aluminiumsilikat) oder Tonerde (Fullers earth) das gesamte in der Lösung enthaltene "Vitamin" von diesen Adsorbentien fixiert würde. Autolysierte Hefe war wesentlich wirksamer als nicht autolysierte. Aus dem $\mathrm{N}$-Gehalt des mit Vitamin

1) Biochem. Journ. Bd. 7 S. 268. 1913.

2) A therton Seidell, Der Vitamingehalt der Brauereihefe. Journ. of Biol. Chem. vol. 29 p. 145. 1917. Ref. Chem. Zentralbl. 1917 Bd. 2 S. 819. 
beladenen Tones berechnete Seidell den Gehalt von $100 \mathrm{ccm}$ des Filtrats zu $0,18 \mathrm{~g}$ "Vitamin" und den täglichen Vitaminbedarf einer Taube zu $1 \mathrm{mg}$.

Die von uns befolgte, auf S. $214 \mathrm{ff}$. in allen ihren Einzelheiten angegebene und in der Hauptsache auf die Fällung des Eutonins mit Quecksilberchlorid in alkoholischer Lösung gegründete Methode liefert von allen bisher bekannten Verfahren zweifellos die bei weitem grössere Ausbeute. Es werden allerdings (bei Verarbeitung von Hefe) mit dem Eutonin auch grössere Mengen von Betainchlorhydrat als $\mathrm{HgCl}_{2}$ Doppelsalz ausgefällt, deren Entfernung jedoch nach dem beschriebenen Verfahren gelingt.

Neuerdings sind auch Versuche gemacht worden, um auf synthetischem Wege Präparate von gleicher oder ähnlicher Wirkung herzustellen, wie sie den Eutoninen zukommt, obschon solche Versuche wenig aussichtsreich erscheinen, solange die Konstitution der natürlich vorkommenden Eutonine unbekannt ist.

Williams ${ }^{1}$ ) hatte bei seinen erfolglosen Versuchen, die von Funk zur Vitamindarstellung benutzte Methode zu verbessern, gefunden, dass die Funk'sche Substanz mit dem bei $233^{\circ} \mathrm{C}$. liegenden Schmelzpunkt ("Vitamin") im wesentlichen aus Nikotinsäure bestand. Williams ${ }^{1}$ ) prufte deshalb zunächst die Wirkung von dieser sowie von einigen ihr verwandten Verbindungen (Trigonellin, Nikotinsäuremethylester und $\beta$-Oxynikotinsäure) an Vögeln, die an alimentärer Dystrophie erkrankt waren. Nur der Ester rief eine deutliche, aber vorübergehende Besserung hervor. Trigonellin und $\beta$-0xynikotinsäure vermochten dem Autor zufolge nur eine gewisse Verlängerung der Lebensdauer herbeizuführen. Bessere Erfolge wurden mit undefinierten Kondensationsprodukten der Nikotinsäure erzielt, welche durch Finwirkung von Phosphorpentoxyd bzw. Essigsäureanhydrid auf diese entstanden.

Williams ${ }^{2}$ ) hat ferner Cinchomeronsäure, 6-Oxynikotinsäure, Chinolinsäure, Citrazinsäure, $\alpha$-Oxypyridin, Glutazin, 2-, 4-, 6-Trioxypyridin und dessen Anhydrid, Tetraoxypyridin und 2-, 3-, 4-Trioxy-

1) Robert R. Williams, Die Chemie der Vitamine. The Philipp. Journ. of Science A vol. 11 p. 49. 1916. Ref. Chem. Zentralbl. 1917 Bd. 1 S. 251.

2) Robert R. Williams, Die chemische Natur der Vitamine. I. Antineuritische Eigenschaften der Oxypyridine. Journ. of Biol. Chem. vol. 25 p. 437. 1916. Ref. Chem. Zentralbl. 1917 Bd. 1 S. 101. 
Beitrag zur Kenntnis von organischen Nahrungsstoffen mit spezif. Wirkung. 87

pyridin auf ihre Wirksamkeit gegen die bei alimentärer Dystrophie auftretenden nervösen Störungen untersucht. Eine deutliche Wirkung soll dem Autor zufolge dem $\alpha$-Oxypyridin, 2-, 3-, 4-Trioxypyridin und 2-, 4-, 6-Trioxypyridin zukommen. Frische Präparate waren wirksam, büssten aber diese Wirksamkeit allmählich und schliesslich vollkommen ein. Williams meint, dass eine innere Umlagerung $z \mathfrak{u}$ einer tautomeren Form die Ursache dieser Inkonstanz der Wirkung sein könnte, und weist darauf hin, dass von den genannten Verbindungen je eine Enol- und Ketoform bekannt sind, denen verschiedene Wirksamkeit zuzukommen schiene.

Harden und Zilva ${ }^{1}$ ) konnten bei der Nachprüfung der Versuchsergebnisse von Williams dessen Angaben über die Wirksamkeit von $\alpha$-0xypyridin gegen die bei alimentärer Taubendystrophie auftretenden nervösen Störungen nicht bestätigen. Als ebensowenig gegen diese wirksam bezeichnen dieselben Autoren, im Gegensatz zu den Angaben von Williams und Seidell' ${ }^{2}$ ), sowohl reines Adenin wie auch solches, welches vorher mit Natriumäthylat behandelt worden ist.

Ob die aus verschiedenen Ausgangsprodukten gewonnenen Eutonine in ihrem chemischen Aufbau sowie mit Rücksicht auf ihre physikalischen und physiologischen Eigenschaften Verschiedenheiten aufweisen, ist bei dem gegenwärtigen Stande unseres Wissens nicht zu entscheiden. Es ist anzunehmen, dass derartige Verschiedenheiten vorhanden sind, weil schon jetzt Substanzen bekannt sind, die eine ähnliche, wenn auch lange nicht so intensive und anhaltende Wirkung äussern wie die Eutonine, von diesen aber in ihrem chemischen Aufbau sebr verschieden sind. Über die von uns aus Bierbefe durch deren hydrolytischen Abbau usw. dargestellten Eutoninpräparate finden sich eingehende Angaben im Abschnitt X. Um Wiederholungen tunlichst zu

1) Arthur Hardén und Sylvestre Salomon Zilva, Die angeblichen antineuritischen Eigenschaften von $\%$-Oxypyridin und Adenin. Biochem. Journ. vol. 11 p. 172. 1917. Ref. Chem. Zentralbl. 1917. Bd. 2 S. 319. - Vgl. auch Carl Voegtlin und George F. White, Kann Adenin antineuritische Eigenschaften annehmen? Journ. Pharm. Therap. vol. 9 p. 155. 1916. Ref. Chem. Zentralbl. 1917 Bd. 1 S. 1014.

2) Robert R. Williams und Atherthon Seide11, Die chemische Natur der "Vitamine". II. Isomerieerscheinungen bei den natürlichen antineuritischen Substanzen. Journ. of Biol. Chem. vol. 26 p. 431. 1916. 
vermeiden, verweisen wir auf diese. An dieser Stelle sei nur bemerkt, dass alle diese Eutoninpräparate sich als ausserordentlich wirksam erwiesen, um die bei der alimentären Dystrophie der Tauben auftretenden nervösen Störungen schnell und sicher zu beseitigen. Von dem am weitesten gereinigten derartigen Präparate (I N 5) genügte, wie schon gesagt, eine einmalige intramuskuläre Einspritzung von $5 \mathrm{mg}$, um die von einem schweren Anfalle ergriffene Versuchstaube (Photographie Nr. 30) restlos von allen nervösen Störungen zu befreien. Bei fortgesetzter Ernährung mit derselben Qualität geschliffenen Reises, mit welcher die Taube vorher gefüttert worden war, hielt die Wirkung 19 Tage lang an. Von den Zwischenprodukten (I A, I A 1 und IA 2), deren Reinigung weniger weit getrieben war, waren Gaben von $0,01 \mathrm{~g}$ ausreichend, um bei intramuskulärer Anwendung innerhalb weniger Stunden das Verschwinden aller nervösen Störungen bei den Versuchstauben $\mathrm{zu}$ bewirken (Photographien Nr. 10-12).

\section{Einfluss des mit Alkohol aus hydrolysierter Hefe hergestellten Extraktes und ferner der aus diesem gewonnenen hochwertigen Eutoninpräparate auf die Wirkung von Hefefermenten.}

Eine besondere, von uns ausgeführte Arbeit ${ }^{1}$ ), welche die Beeinflussbak keit der Wirkung bestimmter Hefefermente durch alkohollösliche Bestandteile hydrolysierter Hefe zum Gegenstand hatte, scheint auch für die hier in Betracht kommenden Verhältnisse wichtige Aufschlüsse erbracht zu haben. Es seien daher die hierher gehörigen Ergebnisse in diesem Zusammenhang kurz erörtert.

Zur Darstellung des hauptsächlich zur Verwendung gelangten Präparates wurde Bierhefe nit der zehnfachen Menge 10\% iger Schwefelsäure 24 Stunden lang im Wasserbade auf $50^{\circ} \mathrm{C}$. erwärmt. Der gelöste Anteil wurde dann abfiltriert und die Schwefelsäure quantitativ mit Barythydrat gefällt. Der $\mathrm{BaSO}_{4}$-Niederschlag wurde abgenutscht und das Filtrat bei $40^{\circ} \mathrm{C}$. unter vermindertem Druck zur Trockene verdampft. Hierbei wurden von Zeit zu Zeit der einzudampfenden Flüssigkeit Stichproben entnommen, um festzustellen,

1) E. Abderhalden und H. Schaumann, Studien übẹr die Beeinflussbarkeit der Wirkung einiger Fermente der Hefe durch Stoffe, die sich durch Alkohol aus der Hefezelle abtrennen lassen. Zeitschr. f. Fermentforsch. Bd. 2 S. 120. 1918. 
ob die Reaktionen auf Baryt und Schwefelsäure auch in der konzentrierten Lösung noch negativ ausfielen. War dies nicht der Fall, so wurde ein Überschuss der einen oder anderen der genannten Verbindungen quantitativ aus der gesamten Lösung entfernt, ehe mit ihrem Konzentrieren fortgefahren wurde. Es handelt sich hierbei um eine unbedingt nötige Vorsichtsmaassregel, weil es leicht vorkommen kann, dass in der stark verdünnten Lösung geringe Mengen von Baryt resp. Schwefelsäure übersehen werden. Der beim Eindampfen verbleibende Trockenrückstand wurde nun mit der zebnfachen Menge seines Eigengewichtes an absolutem Alkohol übergossen -und dann auf dem Wasserbade aufgekocht. Diese Operation wurde fünfmal nạcheinander wiederholt. Die vereinigten, alkoholischen Auszüge wurden hierauf unter vermindertem Druck bei $30^{\circ} \mathrm{C}$. möglichst weit eingedampft und noch dreimal mit je $500 \mathrm{ccm}$ absolutem Alkohol abgedampft. Der schliesslich verbleibende Rückstand wurde nochmals mit siedendem absolutem Alkohol ausgezogen und die Lösung von dem erheblichen in Alkohol unlöslichen Rückstande abfiltriert. Das Filtrat wurde dann zum dritten Male bei $30^{\circ} \mathrm{C}$ unter vermindertem Drucke eingedampft und der Rüekstand wiederum mit absolutem Alkohol aufgenommen. Bis auf einen geringfügigen unlöslichen Anteil, der abfiltriert wurde, ging nunmehr alles in Lösung.

Dieses alkoholische Extrakt enthielt $8,95 \%$ Trockensubstanz, $0,87 \%$ Asche, $0,19 \%$ Stickstoff und $0,093 \%$ Phosphor. Es war sehr wirksam gegen die bei alimentärer Dystrophie von Tauben anftretenden nervösen Störungen, entfaltete aber ausserdem eine sehr bemerkenswerte Eigenschaft insofern, als es die Wirksamkeit von auf Kohlehydrate eingestellten Hefefermenten gegen eine Anzahl verschiedener Substrate in erheblichem Maasse zu steigern vermochte. Vorläufig ist nur die Wirkung der auf Kohlehydrate eingestellten Fermente geprüft worden. Versuche über die Einwirkung auf Proteasen, Peptasen, Polypeptitasen und Lipasen werden folgen.

Unter Hinweis auf die Originalveröffentlichung seien an dieser Stelle vornehmlich die von uns befolgte Methodik sowie die für das vorliegende Problem wichtigen Versuchsergebnisse erörtert und eirige Erwägungen an diese geknüpft.

Für die Vergärung der verschiedenen von uns untersuchten Substrate wurden sowohl frische Presshefe wie auch trockene Bierhefe verwandt. Zur Feststellung der Wirksamkeit des alkoholiseben Hefe- 
extraktes wurden Parallelversuche angestellt, bei deuen in beiden Fällen ein und dasselbe Substrat mit derselben Hefeart, und zwar einmal ohne, das andere Mal mit Hefeextrakt unter Einhaltung der gleichen sonstigen Versuchsbedingungen vergoren wurde. Durch besondere Versuche wurde festgestellt, dass die beobachtete beschleunigende Wirkung des Hefeextraktes nicht auf die in ihm enthaltene geringe Menge von Phosphorsäure zurückzufübren ist und auch nicht auf die sonst vorhandenen Aschebestandteile. Der Verlauf des Gärungsprozesses wurde durch Gewichtsbestimmung der entweichenden Kohlensäure auf der von einem von uns (A bderhalden) beschriebenen automatischen und selbstregistrierenden Wage ${ }^{1}$ ) verfolgt.

Die bei Verwendung verschiedener Substrate erhaltenen Ergebnisse waren folgende:

Milchzucker wurde in keinem Falle, auch nicht bei Zusatz von alkoholischem Hefeextrakt, angegriffen.

Rohrzucker und Maltose wurden bei Anwesenbeit von Hefeextrakt bedeutend rascher gespalten, und die hierbei entstehenden Monosaccharide, Trauben- und Fruchtzucker, wurden auch viel schneller vergoren als bei Abwesenheit von Hefeextrakt.

Ganz bedeutend war auch die Beschleunigung der Gärung der Galaktose.

Die beschleunigende Wirkung des alkoholischen Hefeextraktes beschränkte sich jedoch nicht auf den Komplex der Z y mase, sondern sie erstreckte sich auch auf die von Neuberg entdeckte und ebenfalls in der Bierhefe enthaltenen Karbox y lase.

Brenztraubensaures Kali um wurde bei Zusatz von alkoholischem Hefeextrakt viel schneller zerlegt, als dies ohne einen solchen Zusatz erfolgte.

Bei Versuchen mit Traubenzucker erwies sich der durch die Dialyse gereinigte Niederschlag, welcher sich durch Acetonzusatz zu dem aus hydrolysierter Hefe gewonnenen alkoholischen Extrakt ausfallen lässt (S. 166), ebenfalls als sehr wirksam.

Diese Versuche weisen das gemeinsame Ergebnis auf, dass in das alkoholische, nach dem beschriebenen

1) E. Abderhalden, Stoffwechselversuche mit einer neuen Wage, die automatisch Gewichtsab- und -zunahme registriert. Skand. Arch. f. Physiol. Bd. 29 S. 75.1916 . 
Verfahrengewonnene Hefeextrakt ein Stoffodermehrere Stoffe übergehen, welche die Wirksamkeit von Hefefermenten erheblich zu steigen vermögen.

Dasselbe weitgereinigte Hefeextrakt vermochte demnach sowoh] eine stark beschleunigende Wirkung auf den fermentativen Abbau einer Reihe von Substraten auszuüben wie auch die bei alimentärer Dystrophie auftretenden nervösen Störungen zu beseitigen. Wieweit man aus diesem Zusammentreffen Schlüsse auf die Rolle des Eutonins im Organismus der höheren Tiere ziehen kann, soll im Schlusswort erörtert werden.

Im vorigen Abschnitt ist bei Besprechung der sogenannten Auximone schon darauf hingewiesen worden, dass die Pflanzen derartige Stoffe offenbar für ihre eigenen Zwecke herstellen. Auch hier ist daher die Annabme berechtigt, dass dem in das alkoholische Hefeextrakt übergehenden wirksamen Stoffe (bzw. den wirksamen Stoffen) ursprünglich im Haushalt der Hefezelle wichtige Aufgaben zufallen. Berücksichtigt man, dass die Stoffwechselvorgänge in den verschiedensten Zellarten auf bestimmte gemeinschaftliche Grundlinien zurückgefübrt werden können, so ist es nicht ausgeschlossen, dass Stoffe, wie sie hier in Frage kommen, im tierischen Organismus dieselben oder doch ähnliche Funktionen auszuüben vermögen wie im pflanzlichen.

Sollte sich diese Vermutung mit Rücksicht auf das Eutonin bestätigen, so würden die besprochenen Gärversuche auch als geeignet erscheinen, um den Wirkungswert von Eutoninpräparaten gegen die bei alimentärer Dystrophie auftretenden nervösen Störungen schnell und bequem durch Gärversuche festzustellen. Man wäre dann bierzu nicht mehr wie bisher auf umständliche und zeitraubende Tierexperimente angewiesen. Selbstverständlich liessen sich die Versuche durch Anwendung gewöhnlicher Gärungsröhrchen vereinfachen.

Wiederbolt ist die Vermutung ausgesprochen worden, dass zwischen der mit der Nahrung aufgenommenen Menge von Kohlehydraten und dem Auftreten alimentärer Dystrophie (Polyneuritis) bei Hühnern urd Tauben Wechselbeziehungen beständen: Je grösser die Zufuhr von Kohlehydraten in einer insuffizienten Nahrung wäre, desto schneller sollte die Krankheit zum Ausbruch kommen. Hierauf hat man u. a. auch das Verhalten von Tauben und Hünern zurückgefürt, die zwangsweise mit geschliffenem Reis gefüttert wurden und in demselben Maasse schneller erkrankten, wie die tägliche Reiszufuhr erhöht wurde. 
Bradden und Cooper ${ }^{1}$ ) fanden, dass sehr geringe Zusätze von getrockneter Hefe zu geschliffenem Reis genügten, um das Auftreten nervöser Störungen bei Hühnern und Tauben erheblich zu verzögern, und ferner, dass, um die gleiche Wirkung zu erzielen, die zugeführte Menge getrockneter Hefe in demselben Verhältnisse wie die zwangsweise zugeführte Menge geschliffenen Reises erhöht werden musste, wie nachstehende Aufstellung es zeigt.

\begin{tabular}{|c|c|c|c|}
\hline \multirow{2}{*}{$\begin{array}{l}\text { Täglich verfütterter } \\
\text { geschliffener Reis } \\
\text { pro Taube }\end{array}$} & \multirow{2}{*}{$\begin{array}{l}\text { Hefezugaben pro } \\
\text { Tag und Taube }\end{array}$} & \multicolumn{2}{|c|}{$\begin{array}{c}\text { Auftreten von alimentärer } \\
\text { Dystrophie }\end{array}$} \\
\hline & & $\begin{array}{l}\text { Gegenwerte } \\
\text { nach }\end{array}$ & $\begin{array}{l}\text { Durchschnitt } \\
\text { nach }\end{array}$ \\
\hline $\begin{array}{l}1 / 25 \text { des Körpergewichts } \\
1 / 10 " n \\
1 / 20 " \\
1 / 10 " n\end{array}$ & $\begin{array}{l}1 / 2500 \text { des } \\
1 / 2500 \text { Körpergewichts } \\
1 / 3500 " \\
1 / 3500 " n\end{array}$ & $\begin{array}{l}39-59 \text { Tagen } \\
22-46 " \\
32-44 " \\
15-22 "\end{array}$ & $\begin{array}{l}49 \text { Tagen } \\
34 " n \\
38 " \\
18 "\end{array}$ \\
\hline
\end{tabular}

Die dieser Erscheinung zugrundeliegenden Stoffwechselvorgänge stehen möglicherweise zu der beschleunigenden Wirkung in Beziehung, welche ein bestimmter in der Hefe entbaltener alkohollöslicher Stoff oder mehrere solche Stoffe auf den fermentativen Abbau von Kohlehydraten (Mono- und Disachariden) auszuüben vermögen. Ob tatsächlich ein solcher Zusammenhang besteht, muss selbstverständlich erst durch weitere hierauf bezügliche Nachforschungen genügend sichergestellt werden.

\section{Die Muttersubstanzen der Eutonine.}

Wie wir bereits betont haben, handelt es sich bei den Eutoninen um sehr labile Verbindungen, die gegen Alkalien und auch gegen den Einfluss von Wärme (Temperaturen über $50^{\circ} \mathrm{C}$.) sehr empfindlich sind. Wesentlich grösser ist die Widerstandsfähigkeit der Eutonine gegen Säuren, mit denen sie Salze bilden.

Diese geringe Stabilităt der Eutonine gegen Wärmeeinflüsse sowie ihre leichte Löslichkeit in Wasser standen von vornherein der Wahrscheinlichkeit entgegen, dass sie sich in Nahrungsmitteln und anderen

1) W. L. Bradden und E. A. Cooper, The influence of the total fuel value of a dietary upon the quantity of yitamin required to prevant Beriberi. Brit. Med. Journ. Nr. 2790 p. 134 8. 1914. 
natürlich vorkommenden, besonders in den gegen alimentäre Dystrophie wirksamsten Stoffen (Hefe, Kleie u. a. m.) in der Hauptsache oder aberhaupt in freiem, fertig gebildetem Zustande fänden. Wäre dies der Fall, so würden sie beim Lagern, Wässern, Kochen und anderen derartigen Eingriffen viel schneller und sorgfältiger ausgelaugt bzw. zerstört werden müssen, als dies in Wirklichkeit der Fall ist.

Die Vermutung, dass die Eutonine in den Nahrungsmitteln usw. hauptsäehlich oder überhaupt nur in anderer als freier Form vorkommen, wird auch durch das Verbalten der an Eutoninen reichsten Stoffe (Bierhefe, Reiskleie) gegen Lösungsmittel bestätigt. Alle bisher dargestellten freien Eutonine sind in Wasser und Alkohol leicht löslich. Wären sie also in den genannten Stoffen in freiem Zustande enthalten, so müssten sie sich aus ihnen durch die genannten Lösungsmittel leicht und voll $\mathrm{kommen}$ ausziehen lassen. Dies ist aber nicht der Fall. Sowohl durch Wasser wie auch durch Alkohol lässt sich auch bei häufig wiederholter Extraktion weder aus Hefe noch aus Reiskleie alles Eutonin ausziehen. Nur ein Bruchteil der Gesamtmenge geht hierbei in die genannten Lösungsmittel über. Die Hauptmenge wird hartnäckig zurückgehalten und kann dem nach vollkommenem Ausziehen mit Alkohol bzw. Wasser verbleibenden Rückstande durch Wasser oder Alkohol erst nach Hydrolyse mit Salz- oder Schwefelsäure entzogen werden. Dieses Verhalten vou

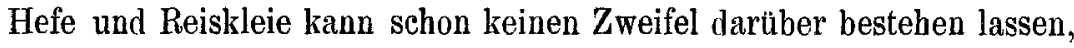
dass die Hauptmenge des Eutonins in ihnen nicht frei, sondern in einer Form enthalten sein muss, welche in Wasser und Alkohol unlöslich ist. Es käme also nur in Frage, ob sich jene Menge Eutonin, die ohne vorausgehende Hydrolyse in die wässerigen und alkoholischen Auszüge der genannten Stoffe (Hefe und Reiskleie) übergeht, als Base oder einfaches Salz findet.

Es ist nun vorerst der Frage nachzugehen, welcher Art die Verbindungen sein können, in denen die Eutonine entbalten sind. Sie können einfacherer oder aber sehr komplizierter Art sein. Ferner besteht die Möglichkeit, dass sie Bausteine einer für sich bestehender Gruppe sind, oder aber sie gehören bereits bekannten Verbindungen an. Schliesslich muss auch der Gedanke erwogen werden, ob nicht die Eutonine in einer durch Säurespaltung leicht umwandelbaren Form in den Nahrungsmitteln enthalten sind. Es ist nicht ohne weiteres 
erwiesen, dass sie Bausteine von bestimmten Verbindungen sind. Es sei zum Beispiel an Diketopiperazine der Dipeptide resp. Aminosäuren erinnert. Diese baben zum Teil ganz andere Eigenschaften als ihre Bausteine und die ihnen entsprechenden Dipeptide. Sie sind zum grossen Teil sehr schwer löslich in Wasser. Durch Alkali und Säuren lassen sie sich leicht spalten. Derartige Beispiele liessen sich leicht häufen. Immerhin machen die ganzen Beobachtungen mehr den Eindruck, dass sie aus zusammengesetzten Verbindungen hervorgehen. Wir wollen deshalb in erster Linie dieser Spur folgen.

Von bekannten Gruppen von Verbindungen kommen in Frage: die sogenannten Phosphatide, die Nukleoproteide und die Eiweissstoffe. Was zunächst die erstere Gruppe von Verbindungen anbetrifft, so kennen wir ihre Zusammensetzung nur in allgemeinen Zügen ${ }^{1}$ ). Als stickstoffhaltiger Baustein sind Cholamin = Oxyäthylamin und Cholin aufgefunden worden. Mehrfach ist schon der Vermutung Ausdruck gegeben worden, dass noch andere stickstoffhaltige Verbindungen Bausteine von Phosphatiden sein könnten. Leider ist die Forschung auf diesem Gebiete nicht recht vorwärtsgekommen, offenbar deshalb nicht, weil diese Verbindungen sehr leicht zersetzbar sind. Es fehlen noch geeignete Methoden zur Isolierung. Dazu kommen noch die folgenden Schwierigkeiten. Die zur Gruppe der Phosphatide hinzugerechneten Verbindungen sind sehr schwer zu isolieren. Sie sind vielfach schon gegen Licht empfindlich. Die Methoden ihrer Isolierung gestatten ihrer Art nach nicht zu entscheiden, ob die gewonnenen Produkte einheitliche Verbindungen darstellen. Der Befund von neuen stickstoffhaltigen Basen kann auf Verunreinigungen bezogen werden. Isoliert man aus Hefe oder Reiskleie usw. Phosphatide, und beweist man mittels des Tierversuches, dass diesen die Wirkungen des Eutonins eigen sind, dann bleibt die Vermutung unwiderlegt, dass das Eutonin im Phosphatid als Beimengung enthalten ist. Phospbatide aus Reiskleie sind von Tri e ${ }^{2}$ ) untersucht worden. Er fand neben den dieser Gruppe von Verbindungen charakteristischen Bausteinen noch

1) Vgl. bierzu: Emil Abderhalden, Lehrbuch der physiologischen Chemie, 3. Aufl., S. 233 ff. 1914.

2) G. Trier, Über die nach den Methoden der Lecithindarstellung aus Pflanzensamen erhältlichen Verbindungen. IV. Mitteilung. Zeitschr. f. physiol. Chemie Bd. 68 S. 407. 1913. 
Beitrag zur Kenntnis von organischen Nahrungsstoffen mit spezif. Wirkung. 95

reichliche Mengen eines Glukosids und ferner eine zerebrosidartige Verbindung. Wir müssen es nach dem Stande der ganzen Forschung dahingestellt sein lassen, ob die Eutonine als Baustein von bestimmten Phosphatiden in Frage kommen. Manches spricht dafür, jedoch reichen die bisherigen Befunde zu einer bestimmten Schlussfolgerung nicht aus. Es ist besser, alle Möglichkeiten offen zu _lassen, solange ein bestimmter Beweis für eine bestimmte Körperklasse nicht vorliegt.

In diesem Zusammenhange sei der folgenden Versuche gedacht. Vedder und Will i a ms ${ }^{1}$ ) beobachteten, dass alkoholisches Reiskleicextrakt, welches unverändert ohne Schaden in grossen Mengen gegeben werden kann, durch Hydrolysieren mit Salz- oder Schwefelsäure sebr giftig wird. Diese Wahrnehmung ist dann auch von anderen Seiten bestätigt worden. Um den hierbei vorliegenden Verhältnissen weiter nachzugehen, haben wir einen hierauf bezüglichen Versuch (Nr. 17, S. 177) in Ermangelung von Reiskleie mit dem aus Weizenkleje gewonnenen "Phosphatidgemisch" ausgeführt.

Bei diesem Versuche (S. 177) bekam eine und dieselbe Taube zu verschiedenen Zeiten zuerst $3 \mathrm{~g}$ des "Phosphatidgemisches", so wie es gewonnen worden war, dann $3 \mathrm{~g}$ des Pbosphatids nach vorhergegangener Trypsinverdauung und schliesslich $3 \mathrm{~g}$ des Phosphatids nach erfolgter hydrolytischer Zerlegung mit verdünnter Schwefelsäure unter Einhaltung derselben Zeitintervalle bei den einzelnen Gaben derselben Fraktion. Alle drei Fraktionen wurden erst gegeben, nachdem die durchweg mit derselben Qualität geschliffenen Reises einseitig gefütterte Versuchstaube nervöse Störungen aufwies, wie sie bei alimentärer Dystrophie aufzutreten pflegen. Zwischen der Behandlung mit der zweiten (mit Trypsin verdauten) und der dritten (hydrolysierten) Phosphatidfraktion war eine Pause eingeschaltet worden, während der die Taube ausser geschliffenem Reis einige Zeit lang täglich $1 \mathrm{~g}$ Bierhefe bekam. Erst nachdem die Taube sich hierbei völlig erholt hatte, wurde die Bierhefe wieder fortgelassen. Die bydrolysierte Phosphatidfraktion war vollkommen frei von Schwefelsäure und Baryt.

1) C. B. Vedder and R. R. Williams, Concerning the Beriberi preventing substances or vitamines contained in rice polishings. The Philipp. Journ. of Science B vol. 8 p. 175.1913. 
Die Wirkung sowohl bei der ersten (unverändert gebliebenen) wie auch bei der zweiten (mit Trypsin verdauten) Phosphatidfraktion äusserte sich in einer schnellen und restlosen Beseitigung aller nervösen Störungen ohne irgendwelche schädliche Nebenwirkung. Die Wirkung der dritten, vorher der Hydrolyse unterworfenen Fraktion war dagegen die eines Giftes. Sehr bald schon äusserte sich dies in deutlichster Weise, und die Taube war, als ihr die letzten Pillen eingeflösst wurden, bereits moribund.

Berbicksichtigt man, dass die zweite (mit Trypsin verdaute, heilsam wirkende) und die dritte (durch Hydrolyse zerlegte, giftig wirkende) Phosphatidfraktion in genau einander entsprechenden Gaben und unter Einhaltung derselben Zeitintervalle zwischen den einzelnen Gaben der Versuchstaube eingefiösst wurden, so ergibt sich, dass die Säurehydrolyse zu anderen Stoffen geführt hat als die Fermentspaltung.

Es entsteht nun die Frage, ob man aus diesen Beobachtungen den Schluss ableiten darf, dass im Magendarmkanal das verfütterte Produkt weniger weit zerlegt wird, als es durch Kochen mit Säure der Fall ist. Nur eine eingehende chemische Untersuchung der Spaltprodukte könnte eine eindeutige Grundlage für die Beantwortung dieser Frage geben. Zunächst bleibt der Einwand, dass die Säurehydrolyse zu seḳundären Veränderungen der Spaltstücke geführt hat. Selbst dann, wenn erwiesen würde, dass bei der Hydrolyse mit Säure ausschliesslich die Bausteine der Phosphatide entstanden wären und somit einem oder mehreren von diesen die giftige Wirkung zukäme, wäre damit noch nicht bewiesen, dass im Magendarmkanal der Abbau nicht bis zu den Bausteinen führt. Es bliebe der Finwand, dass der normale Abbau durch die Fermente des Magendarmkanals stufenweise vor sich geht, so dass immer nur Spuren von Bausteinen auf einmal zugegen sind. Damit soll nicht gesagt sein, dass eine Zerlegung der zusammengesetzten Nahrungsstoffe unbedingt bis zu den Bausteinen erfolgen muss. Auf der anderen Seite sei daran erinnert, dass man aus vielen Beobachtungen schliessen muss, dass auch jenseits des Darmes in den Zellen eine Auflösung von Phosphatiden in die Bausteine erfolgt, ohne dass sich Vergiftungen zeigen! Der Befund von Cholin im Nervengewebe spricht schon fur einen solchen Abbau. Der Organismus arbeitet überall im Zwischen- 
Beitrag zur Kenntnis von organischen Nahrungsstoffen mit spezif. Wirkung. 97

stoffwechsel 'mit Spuren. Sie entstehen und sind schon im nächsten Augenblicke umgesetzt.

Wie schon erwähnt, halten Hefe und Reiskleie einen grossen Teil ihres Eutoningehaltes beim Ausziehen mit Alkohol unả Wasser hartnäckig in Form von Verbindungen zurück, die in diese Lösungsmittel nicht überzuführen sind. Wir haben versucht, festzustellen, welcher Art diese eutoninhaltigen, in Wasser und besonders in Alkohol unlöslichen Verbindungen sind, und haben zu diesem Zwecke eine Reihe von Versuchen mit Bierhefe ausgeführt, die auf S. 179-189 genauer beschrieben sind. Es sollen deshalb hier nur die Hauptergebnisse kurz zusammengestellt und die aus ihnen sich ergebenden Schlussfolgerungen gezogen werden:

Durch Ausziehen von getrockneter Bierhefe mit eiskalter, verdünnter (2,5\% iger) Ammoniakflüssigkeit und angeschlossene Filtration lässt sich ein klarer Auszug darstellen, in welchem bei sofortiger Übersättigung mit verdünnter Schwefelsäure ein flockiger Niederschlag entsteht. Wird dieser Niederschlag zunächst durch Zentrifugieren und Auswaschen mit destilliertem Wasser, dann durch weiteres anhaltendes

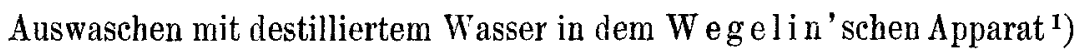
von allen wasserlöslichen Beimischungen soweit befreit, dass das Waschwasser nicht mehr die geringste Reaktion mit Silbernitrat (auf Cl) und Bariumchlorid (auf $\mathrm{SO}_{4}$ ) gibt, so erhält man eine Substanz, welche alle charakteristischen Eigenschaften eines Nuikleoproteids aufweist, wie dies unten noch weiter ausgeführt werden soll.

Um weiter zu ermittelń, ob durch das hierbei befolgte Verfahren die in der Hefe enthaltenen Eutoninverbindungen dieser v $011 \mathrm{k} \mathrm{o} \mathrm{m} \mathrm{m} \mathrm{en}$ entzogen würden, und ob die anderen hierbei als Nebenprodukte erhaltenen Fraktionen etwa auch noch wirksam wären, wurden mit diesen ebenfalls einige Versuche angestellt. Ferner wurde durch längere Einwirkung von Pepsinsalzsäure bei $37^{\circ} \mathrm{C}$. auf das Hefenukleoproteid die hierbei als Pepton in Lösung gehende, locker gebundene Eiweisskomponente desselben abgespalten. Sowohl diese wie auch das hierbei entstehende Hefenuklein wurden ebenfalls auf ihre chemischen und physiologisehen Eigensehaften untersucht, wie dies in der Folge eingehender ausgeführt ist.

1) G. Wegelin, Über eine neue Art der Reinigung kolloider Lösungen. Kolloid-Zeitschr. Bd. 18 S. 225. 1916.

Pflüger's Archiv für Physiologie. Bd. 172. 
Die Beziehungen der einzelnen Fraktionen zueinander werden durch folgendes Schema veranschaulicht:

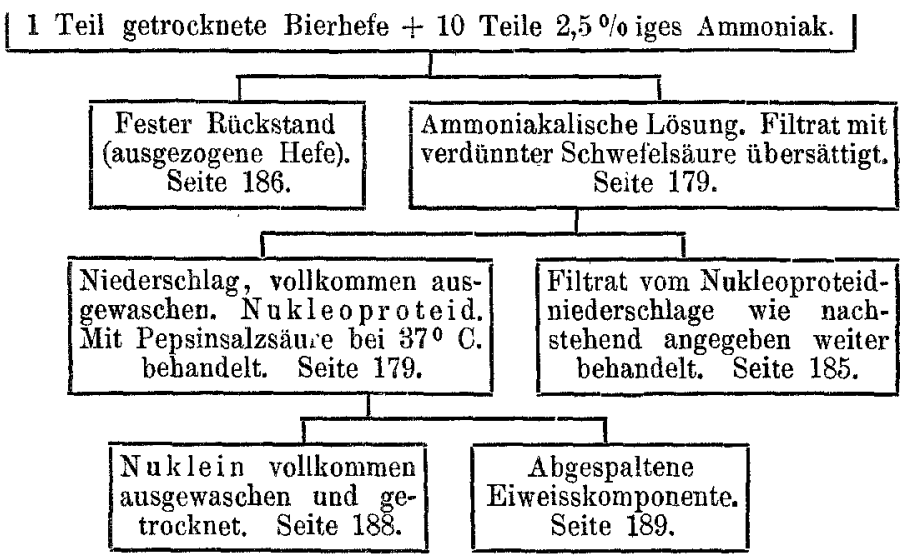

Hefenukleoproteid. In frischem Zustande (feucht) bildete das Präparat eine bräunlich gefärbte Pasta, die in verdünnter Natronlauge leicht löslich war und aus dieser Lösung durch einen geringen Überschuss von Essigsäure wieder ausgefällt wurde. Die alkalisehe Lösung gab starke Biuretreaktion. Die Reaktion mit Millon's Reagens, die Xanthoproteinprobe sowie die Schwefelbleiprobe waren positiv. Die Reaktionen auf Stickstoff (mit Natronkalk) und auf $\mathrm{P}_{2} \mathrm{O}_{5}$ (mit Ammomolybdat nach der nassen Verbrennung mit Salpeterschwefelsäure) fielen ebenfalls positiv aus. Durch Hydrolyse mit verdünnter Schwefelsäure und angeschlossene Fällung mit Natriumbisulfit-Kupfersulfat usw. liess sich aus der Substanz ein mikrokristallinischer Rückstand gewinnen, der, wie die auf S. 181 angegebenen Reaktionen zeigen, aus Purinbasen bestand.

Das nach dem Wegelin'sehen Verfahren vollkommen ausgewaschene, dann bei $105^{\circ} \mathrm{C}$. getrocknete und zerriebene Präparat bildete ein bräunliches, spezifisch schweres Pulver von ausgesprochenem Quellungsvermögen beim Benetzen mit Wasser. Quantitative Bestimmungen (s. S. 208) ergaben als Gehalt an:
1. Asche . . . . . . . . . $2,24 \%$
2. Phosphorsäure $\left(\mathrm{P}_{2} \mathrm{O}_{5}\right) \cdot \ldots 4,14 \%$
3. Stickstoff . . . . . . . $13,46 \%$

Es handelt sich bei diesem Hefepräparat demnach zweifellos um ein Nukleoproteid oder um ein Gemenge 
Beitrag zur' Kenntnis von organischen Nahrungsstoffen mit spezif. Wirkung. 99

mehrerer voneinander verschiedener Nukleoproteide. Eine weitere Bestätigung fand dies durch sein noch zu besprechendes Verhalten gegen Pepsinsalzsäure.

Die physiologische Prüfung dieses Nukleoproteids (bzw, dieser Nukleoproteide) ergabweiter, dassihm(bzw. ihnen) eine ausgesprochene und zuverlässige Wirkung gegen die bei der alimentären Dystrophie der Tauben auftretenden nervösen Störungen zukommt.

Bei Tauben, welche alle die im Gefolge der alimentären Dystrophie auftretenden typischen nervösen Störungen (Lähmungen, Streckkrampf der Beine, Opisthotonus und Konvulsionen) aufwiesen, genügte eine einmalige Gabe von $1 \mathrm{~g}$ des Hefenukleoproteids, um alle diese Erscheinungen innerbalb von $17-20$ Stunden vollkommen zu beseitigen. Die Tauben waren sämtlich nach Verlauf eines solchen Zeitraumes wieder vollkommen munter und imstande, behende zu laufen und $\mathrm{zu}$ fliegen. Die bei einem dieser Versuche aufgenommenen Photographien Nr. 14 und 15 veranschaulichen die Wirksamkeit. Zwischen den beiden Aufnahmen lag ein Zwischenraum von 18 Stunden. Bei einem dieser Versuche betrug die Wirkungsdauer einer einmaligen Gabe von $1 \mathrm{~g}$ Hefenukleoproteid (bei fortgesetzter einseitiger Fütterung mit geschliffenem Reis) 9 Tage.

Noch augenfälliger und vielseitiger als bei den soeben besprochenen Versuchen äusserte sich die Wirksamkeit des Hefenukleoproteids bei dem Dauerversuche Nr. 18 (S. 182). Die Versuchstaube blieb hier, solange sie bei einseitiger Fütterung mit geschliffenem Reis eine tägliche Zugabe von 0,5 g des Hefenukleoproteids bekam (70 Tage lang), nicht nur von Lähmungen verschont, sondern nahm auch verhältnismässig wenig an Körpergewicht ab. Die Photographie Nr. 16 zeigt die Taube bei Beginn des Versuches, die Photographie Nr. 17 nach 60 tägiger Versuchsdauer. Erst nachdem die tägliche Zugabe von Hefenukleoproteid auf die Hälfte $(0,25 \mathrm{~g}$ pro Tag) herabgesetzt worden war, magerte die Taube stärker ab und wurde am 78 . Versuchstage von typischen nervösen Störungen befallen (Photographie Nr. 18), die aber durch eine einmalige Gabe von $1,25 \mathrm{~g}$ des Hefenukleoproteids schnell und vollkommen wieder beseitigt wurden (Photographie Nr. 19).

Die vorstehend besprochenen Versuchsergebnisse dürften es wobl ausser $Z$ weifel stellen, dass die ver- 
wendete Substanz Eutonin enthielt. Es ist wach der Art ihrer Gewinnung höchstwahrscheinlich, dass dieses oder auch mehrere solcher Verbindungen gebunden in den Nukleoproteiden enthalten sind. Da vorläufig nicht bewiesen ist, dass die von uns angewandten Nukleoproteide "rein" waren, müssen wir uns in unseren Schlussfolgerungen noch bescheiden. - Wir nennen im Folgenden mit dem hier gemachten Vorbehalte das wirksame Produkt Nukleoproteid.

Bemerkenswert bei diesem Versuche mit Hefenukleoproteid war die relativ geringe Abnahme des Körpergewichtes der Versuchstaube. Diese Abnahme pflegt bei Verwendung gereinigter Eutoninpräparate viel grösser zu sein und schneller einzutreten, wie die betreffenden Versuche (S. 47 u. 165) zeigen. Die bei der Darstellung des Hefenukleoproteids erzielte Ausbeute von rund $5 \%$ des Ausgangsmaterials (Hefe) liess darauf schliessen, dass der grösste Teil des Eutonins sich in der Hefe in Beziehung zum Nukleoproteid oder zu mehreren solchen findet, da selbstverständlich mit der Möglichkeit gerechnet werden muss, dass das von uns der Einfachheit wegen als Hefenukleoproteid bezeichnete Präparat ein Gemenge von mehreren Nukleoproteiden ist, deren Trennung voneinander zurzeit mangels hierzu geeigneter Verfahren nicht durchführbar ist. Das von uns angewandte Verfahren ermöglicht offenbar auch keine vollkommene Extraktion des Nukleoproteids aus der Hefe, wie dies unten noch erörtert werden soll.

Sehr lehrreich gestaltete sich die Fortsetzung des soeben besprochenen Versuches, welcher der Übersichtlichkeit wegen gleich hier besprochen werden soll.

Bei diesem soeben erörterten unmittelbar angeschlossenen Versuche (Nr. 19, S. 183) erhielt eine Versuchstaube bei fortgesetzter Fütterung mit geschliffenem Reis täglich $0,5 \mathrm{~g}$ Hefenukleoproteid und ausserdem noch $1 \mathrm{~g}$ des Hefepräparates $\mathrm{A}^{\boldsymbol{1}}$ ).

Dieses durch längeres Erhitzen von Hefemit Natronlauge bereitete Präparat war hierdurch gegen die im Gefolge der alimentären Dystrophie a utretenden nervösen Störungen vollkommen unwirksam geworden. Auch vermochte es, als einzige Zugabe bei einseitiger Fütterung mit geschliffenem Reis gereicht, Taubn

1) Wie spätere Versuche zeigten, büsst Hefe bei lang em Erhitzen mit Natronlauge ihre Wirksamkeit vollkommen ein. 
Beitrag zur Kenntnis von organischen Nahrungsstoffen mit spezif. Wirkung. 101

weder aufGewichtskonstanz noch am Lebenzuerhalten, wie dies aus den mit ihm angestellten Versuchen (S. 162) in unzweideutiger Weise hervorgeht. Es handelt sich bei diesem Versuche um die Feststellung, ob diesem Präparate (A) nicht etwa dennoch eine, wenn auch nach einer anderen Richtung hin liegende günstige Wirkung auf den Stoffwechsel zukäme. Diese Vermutung erwies sich auch hier (ebenso wie bei dem Acetonniederschlag aus hydrolysierter Hefe S. 170) als richtig. Wie aus dem Protokoll (S. 183) zu ersehen ist, nahm die Versuchstaube sofort nach der Zufuhr von Hefepräparat A (neben der des bis dahin schon verabreichten Hefenukleoproteids) erheblich an Körpergewicht zu. Diese Zunahme betrug im Laufe von 18 Tagen $38 \mathrm{~g}=19,9 \%$.

Die Versuchstaube hatte bis dahin, d. h. vom 29. Januar bis 9. Mai, also im Verlaufe von 100 Tagen, erhalten:

71 Tage lang $0,50 \mathrm{~g}$ Hefenukleoproteid

$8 \%$ " $" 0,25 \mathrm{~g}$ Hefenukleoproteid, erkrankt

1 Tag " 1,25 g Hefenukleoproteid, wiederhergestellt

20 Tage $\quad "\left\{\begin{array}{rl}0,50 & \mathrm{~g} \text { Hefenukleoproteid } \\ +1,00 & \mathrm{~g} \text { Hefepräparat } \mathrm{A} .\end{array}\right.$

Innerhalb dieses Zeitraumes hatte die Versuchstaube, die einmal nach zu geringer Zufubr von Hefenukleoproteid erkrankt war, sich aber nach vermehrter Zufuhr desselben sofort wieder erholt hatte, im ganzen $56,5 \mathrm{~g}=19,8 \%$ des Anfangsgewichtes eingebüsst, befand sich aber sonst in vorzüglichem Zustande, wie dies die am 9. Mai aufgenommene Photographie Nr. 20 zeigt.

Dieses Ergebnis zeigt, dass durchgleichzeitige Zufuhr des Hefepräparates A die an sich schon weitgehende Wirksamkeit des Hefenukleoproteids noch eineweitere Steigerung erfährt. Diese günstige Wirkung des Hefepräparates $A$, welches alleingegeben eine Wirksamkeit gegen die alimentäre Dystrophie der Tauben nicht er kennen lässt, kann nur auf die Gegenwart von Substanzenzurückgeführt werden, welche gegen Alkalien und Hitze eine grössere Widerstandsfähigkeit besitzen und die bei der günstigen Wirkung der Hefe ebenfalls eine Rolle spielen. Auch hierzeigteessichwieder, wie unbegründet es ist, die Wirkung gegen alimentäre Dy strophie heilsamer Stoffe auf ihren Gehalt an einer ein- 
zigen wirksamen Substanz ("Vitamin" alleín) zurück$\mathrm{zu}$ üuhren. In Frage kommen in erster Linie Bausteine der Nukleoproteide, die als Material zum Aufban von Kernen dienen können. Es besteht jedoch die Möglichkeit der Wirksamkeit noch anderer. bisher unbekannter Produkte.

Im weiteren Verlauf des letztbesprochenen Versuches erhielt die Versuchstaube zunächst weitere 2 Tage lang ausser dem Hefenukleoproteid und dem Hefepräparat A täglich $0,2-0,4 \mathrm{~g}$ Weizenkleiephosphatid und dann noch weitere 12 Tage lang nur $1 \mathrm{~g}$ getrocknete Bierhefe bei fortgesetzter einseitiger Fütterung mit geschliffenem rohen Reis. Es wurde während dieser zwei Perioden von zusammen 33 Tagen nur noch eine Zunahme des Körpergewichtes von insgesamt $21,5 \mathrm{~g}=9,43^{\circ}$ \% erzielt, wie es unter anderem auch die Übersicht auf S. 185 zeigt.

Filtrat vom Hefenukleoproteid. Diese Fraktion erwies sich als giftig. Durch das auf S. 186 angegebene Verfahren konnte aus ihr eine kristallinische Substanz gewonnen werden, die sich bei eingehender Prüfung als Cholinchlorhydrat erwies. Fine kleine Menge in Wasser gelöst und einer Maus subkutan eingespritzt, führte deren Tod nach kaum einer Minute herbei. Die giftige Wirkung dieser Fraktion dürfte demnach wohl auf ibren Gehalt an Cholin zurückzuführen sein.

Mit verdüntem Ammoniak ausgezogene Hefe (Rückstand). Um festzustellen, ob und eventuell in welchem Umfange dieser Rückstand noch wirksam wäre, wurden mit ihm zwei Versuche angestellt, die folgenden Verlauf nahmen:

Bei dem ersten Versuche Nr. 20 (S. 186) nahm die mit geschliffenem rohen Reis einseitig ernährte Versuchstaube bei täglicher Zugabe von $0,6 \mathrm{~g}$ des Rückstandes während der ersten 18 Tage um $90 \mathrm{~g}=31,58 \%$ an Körpergewicht ab. Während der nächstfolgenden 49 Tage nahm dieses aber wieder um $38 \mathrm{~g}=19,49 \% \mathrm{zu}$, so dass die Taube am Schlusse der im ganzen 67 Tage umfassenden Versuchsperiode $52 \mathrm{~g}=18,25 \%$ des Anfangsgewichtes verloren hatte.

Bei dem zweiten Versuche Nr. 21 (S. 186) trat ebenfalls im Verlaufe der ersten 26 Tage eine Verminderung des Körpergewichtes um $69 \mathrm{~g}=20,09^{\circ} \%$ ein. Es blieb dann aber bis zum Schlusse der im ganzen 45 Tage umfassenden Versuchsperiode ziemlich konstant. 
Beide Tauben befanden sich während der ganzen Dauer des Versuches durchaus wohl.

Diese beiden Versuche zeigen, dass es bei dem befolgten Verfahren nichtgelingt, getrockneter Bierhefe allegegen die bei alimentärer Dystrophieauftretenden nervösen Störungen wirksamen Bestandteile (vor allem wohl die Muttersubstanzen der Eutonine) restlos zu entziehen. Ein erheblicher Teil der in der Hefe enthaltenen wirksamen Substanzen wird von ihr zurückgehalten. Es scheint so, als ob zu vollkommener Extraktion eine längere Einwirkung oder ein höherer $\mathrm{NH}_{3}$-Gehalt der Ammoniaklösung erforderlich sind. Hierbei liegt dann allerdings die Gefahr vor, dass das aus der Hefe ausgezogene Nukleoproteid eine Zerstörung erfährt und unwirksam wird.

Dưrch Einwirkung von Pepsinsalzsäure hei $35^{\circ} \mathrm{C}$. lassen sich aus dem Hefenukleoproteid Eiweisskomplexe abspalten, die als Peptone in Lösung gehen und sich so von dem unlöslichen Rückstand trennen lassen, wie dies mit allen Einzelheiten auf S. 188 angegeben ist. Man erhält auf diese Weise einen in Wasser und verdünnten Säuren unlöslichen Rückstand (Hefenuklein) und eine Lösung, welche die abgespaltene Fiweisskomponente enthält. Letztere wurde, wie dies nachstehend angegeben ist, weiter behandelt und auf ihre Wirksamkeit geprüft.

Man hat für das Verhalten der Nukleoproteide im Magendarmkanal unter dem Einfluss der hier auf sie einwirkenden Fermente auf Grund der vorliegenden Beobachtungen bekanntlich folgendes Schema aufgestellt:

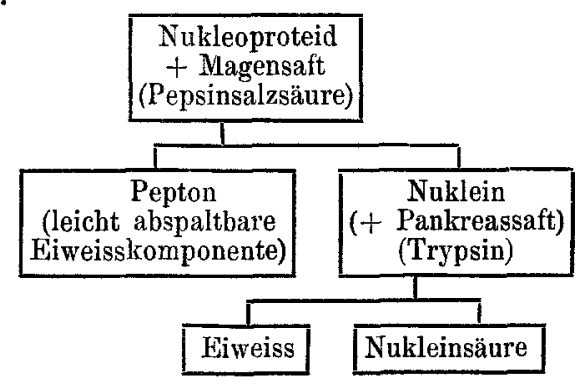

Dieses Schema gibt ohne Zweifel nur einen ganz rohen Einblick in die Zusammensetzung der Nukleoproteide ${ }^{1}$ ).

1) Vgl. hierzu: Emil Abderhalden, Lehrbuch der physiologischen Chemie, 3. Aufl, S. 654. 1914. 
Bei dem durch Magensaft bzw. Pepsinsalzsäure leicht abspaltbaren Eiweisskomplex handelt es sich um eine locker in das Gesamtmolekül der Nukleoproteide eingefügte Proteinkomponente, die unter der Einwirkung des Magensaftes gleichzeitig in Pepton übergeführt wird. Eine weitere Aufspaltung des auf die beschriebene Weise gewonnenen Hefenukleins in eine $z$ weite Eiweisskomponente und Nukleinsäure wäre insofern von Bedeutung, als es hierdurch möglich sein würde zu entscheiden, ob das Eutonin einen integrierenden Bestandteil der Hefenukleinsäure bildet oder nicht. Die Ausführung dieses Gedankens stiess indessen auf so viele praktische Schwierigkeiten, dass wir vorläufig hiervon absehen mussten.

Hefenuklein. Das auf die vorstehend angegebene Weise gewonnene Hefenuklein bildete nach dem vollkommenen Auswaschën nach dem Wegelin'schen Verfahren, dem Trocknen bei $105^{\circ} \mathrm{C}$. und Zerreiben ein dunkelbraunes, spezifisch schweres Pulver, welches beim Benetzen mit Wasser ein starkes Quellungsvermögen zeigte. In frischem (feuchtem) Zustande war das Präparat in 10\% iger Natronlauge leicht löslich und wurde aus dieser Lösung durch Zusatz von Essigsäure in geringem Überschusse wieder ausgefällt. Die alkalische Lösung gab starke Biuretreaktion. Die Prüfungen auf N (mit Natronkalk) und auf P (mit Ammonmolybdat nach der nassen Finäscherung mit Salpeterschwefelsäure) liessen über die Gegenwart reichlicher Mengen von Stickstoffverbindungen und Phosphorsäure keinen Zweifel. Die mit dem bei $105^{\circ} \mathrm{C}$. getrockneten Pulver ausgeführten quantitativen Bestimmungen (S. 208) ergaben folgende Werte:

1. Asche . . . . . . . . . . $4,68 \%$

2. Phosphorsäure $\left(\mathrm{P}_{2} \mathrm{O}_{5}\right)$. . . . . $6,86 \%$

3. Stickstoff . . . . . . . . 12,90\%.

Der aus dem Hefenukleoproteid durch Einwirkung von Pepsinsalzsäure bei $37^{\circ} \mathrm{C}$. gewonnene feste Rückstand wies demach alle die den Nukleinen eigentülichen und für sie charakteristischen Eigenschaften auf.

Diesem Hefenuklein kam ebenfalls eine sehr ausgesprochene Wirksamkeit zu, wie dies aus den auf S. 188 protokollierten Tierversuchen hervorgeht.

Bei dem ersten der angeführten Versuche gentugte schon eine Gabe von $0,25 \mathrm{~g}$, um bei einer schwer erkrankten Taube (Photographie Nr. 21) innerhalb von 17 Stunden eine augenfällige Besserung 
Beitrag zur Kenntnis von organischen Nahrungsstoffen mit spezif. Wirkung. 105

herbeizuführen (Photographie Nr. 22). Eine zweite Gabe von $0,25 \mathrm{~g}$ zog vollkommene Wiederherstellung nach sich (Photographie Nr. 23).

Bei einer anderen von schweren nervösen Störungen befallene Taube (Photographie Nr. 24) wichen alle diese Frscheinungen restlos nach einer einmaligen Gabe von $0,5 \mathrm{~g}$ Nuklein innerhalb von 16 Stunden (Photographie Nr. 25).

Die Ergebnisse dieser Versuche lehren, dass auch dem Hefenuklein eine weitgehende Wirksamkeit gegen die im Gefolge der alimentären Dystrophie der Tauben a uftretenden nervösen Störungen zukommt. Diese Wirksamkeit übertrifft die des Hefenukleoproteidserheblich. Das Hefenuklein steht daher ebenfalls zu den Muttersubstanzendes Hefeeutoninsindirekteroderindirekter Beziehung und scheint die wirksamste der in der Hefe enthaltenen eutoninhaltigen Substanzen zu sein.

Es ist natürlich nicht ausgeschlossen, dass ausser den genannten Verbindungen, deren Wirksamkeit festgestellt ist, und welche bei der Schutz- und Heilwirkung der Hefe offenbar die ausschlaggebende Rolle spielen, auch noch anderen in ihr enthaltenen Stoffen eine Bedeutung zukommt. Hierauf lassen der bei Zugabe des (für sich allein unwirksamen) Hefepräparates A erzielte bessere Ernährungszustand der Versuchstauben, ferner die in Abschnitt $\mathrm{X}$ behandelten, mit Abbauprodukten der Hefe erzielten Ergebnisse sowie auch die bessere Wirkung der Hefe selbst schliessen.

Von dem Hefenukleoproteid durch Einwirkung von Pepsinsalzsäure bei $37^{\circ} \mathrm{C}$. abgespaltene Eiweisskomponente (S. 189). Die bei der Verdaung des Hefenukleoproteids mit Pepsinsalzsäure gewonnene und filtrierte klare Lösung wurde nach dem Neutralisieren mit verdünnter Natronlauge und nach Zusatz von etwas Alkohol und Toluol auf flachen Porzellantellern im FaustHeim'schen Apparat zur Trockene verdampft. Es hinterblieben klare, gelblich gefärbte hygroskopische Lamellen, die nach dem vollkommenen Trocknen zu Pulver zerrieben wurden. Dieses Pulver war in Wasser leicht und k]ar löslich. Die Biuretreaktion war stark positiv und zeigte die den Peptonen eigentümliche rötliche Färbung. Die quantitative Bestimmung nachstehender Bestandteile in dem über Chlorkalzium getrockneten Pulver ergaben folgende Werte (S. 209): 
1. Wasser (Feuchtigkeit) . . . . 7,00\%

2. Stickstoff . . . . . . . 10,57\%

3. Protein (berechnet) . . . $64,87 \%$

4. Phosphorsäure $\left(\mathrm{P}_{2} \mathrm{O}_{5}\right)$. . . $0,49 \%$.

Beachtenswert ist hier folgendes: Das zu dem fermentativen Abbau verwandte Nukleoproteid war in dem W ege el in 'schen Apparat vorher vollkommen ausgewaschen worden. Das letzte Waschwasser gab nicht mehr die geringste $\mathrm{Cl}$ - und $\mathrm{SO}_{4}$-Reaktion und enthielt in einem Liter nur $0,00482 \mathrm{~g} \mathrm{P}_{2} \mathrm{O}_{5}$. Es handelte sich daher bei der durch Pepsinsalzsäure abgespaltenen Eiweisskomponente entweder um ein phosphorhaltiges Protein, oder aber es war die Phosphorsäure gleichzeitig mit Eiweiss aus einer anderen Bindung losgelöst worden.

Bei zwei Tierversuchen (S. 190) zogen orale Gaben von je $1 \mathrm{~g}$ dieses Präparates in einem Falle bei einer unter typischen nervösen Störungen erkrankten Taube eine ausgesprochene Besserung nach sich, die über die Wirksamkeit des Präparates keinen Zweifel lassen konnte. In einem zweiten Falle wurde kein Erfolg erzielt. Es handelte sich hier allerdings um eine extrem abgemagerte und heruntergekommene Taube, bei der wahrscheinlich auch andere stärker wirkenden Präparate versagt hätten. Immerhin stand auch bei dem mit Frfolg behandelten ersten Falle die Wirksamkeit der abgespaltenen Eiweisskomponente hinter der ihrer Muttersubstanz (des Nukleoproteids) merklich zurück.

Vergleicht man nun den Gehalt an Asche, Phosphorsäure und Stickstoff der als Ausgangsmaterial verwandten Hefe und der verschiedenen aus ihr gewonnenen und vorstehend besprochenen Präparate (sämtlich bei $105^{\circ} \mathrm{C}$. getrocknet) miteinander, so erhält man folgendes Bild:

\begin{tabular}{|c|c|c|c|c|}
\hline Gehalt an & $\begin{array}{c}\text { Bierhefe } \\
\%\end{array}$ & $\begin{array}{c}\text { Hefenukleo- } \\
\text { proteid } \\
\%\end{array}$ & $\begin{array}{l}\text { Hefenuklein } \\
\quad \% \\
\end{array}$ & $\begin{array}{c}\text { Aus Hete- } \\
\text { nukleoproteid } \\
\text { abgespaltene } \\
\text { Eiweiss- } \\
\text { komponente } \\
\%\end{array}$ \\
\hline $\begin{array}{l}\text { 1. Asche } \\
\text { 2. Phosphorsäure } \\
\text { 3. Stickstoff }\end{array}$ & $\begin{array}{r}10,84 \\
6,65 \\
10,20\end{array}$ & $\begin{array}{r}2,24 \\
4,14 \\
13,46\end{array}$ & $\begin{array}{r}4,68 \\
6,86 \\
12,90\end{array}$ & $\begin{array}{r}\overline{0,58} \\
11,16\end{array}$ \\
\hline
\end{tabular}

Nach dem Stutzer'schen Verfahren bestimmt, entfallen von der in der Hefe enthaltenen Gesamtphosphorsäure 48,48\% auf an-

1) Organisch gebundene $P_{2} O_{5}$ ca. $3,33 \%$. 
organisch und 51,52\% auf organisch gebundene Phosphorsäure. In der untersuchten Hefe würde demnach rund die Hälfte der gesamten $\mathrm{P}_{2} \mathrm{O}_{5}$, also $3,33 \%$ auf organisch gebundene Phosphorsäure zu beziehen sein. Bei den besprochenen Hefepräparaten konnte nach dem befolgten Darstellungsverfahren kaum andere als organisch gebundene Phosphorsäure in Betracht kommen, so dass sich folgende Steigerung ergibt:

Organisch gebundene $\mathrm{P}_{2} \mathrm{O}_{5}$

Aus Hefenukleoproteid abgespaltenes Eiweiss $0,53 \%$

Bierhefe . . . . . . . . . . . . . $3,33 \%$

Hefenukleoproteid . . . . . . . . 4,14\%

Hefenuklein . . . . . . . . . . $6,86 \%$

Bei diesen Hefepräparaten stieg also, wie sich aus vorstehender Zusammenstellung und dem Vergleich mit ihnen durch Tierexperimente festgestellten Wirkungswert ergibt, die Wirlssamkeit proportional mit dem $\mathrm{P}_{2} \mathrm{O}_{5}$-Gehalt.

Als wirksamstes Präparat erwies sich das Hefenuklein mit dem höchsten $\mathrm{P}_{2} \mathrm{O}_{5}$-Gehalt. Im ungeschälten Reis sind es erfahrungsmässig die Fruchthäute, welche diesem hauptsächlich die Schutzwirkung gegen Beriberi verleiben. Auch hier (in der Reiskleie) scheinen es neben Phosphatiden vor allem Nukleine zu sein, welche als die Träger dieser Schutzwirkung zu betrachten sind. Dies ist aus dem Verhalten der Reishleie gegen Alkohol zu schliessen, das ihr nur einen Teil der wirksamen phosphorhaltigen Bestandteile zu entziehen vermag, während ein grosser, vielleicht wie bei der Hefe der grösste Teil, hartnäckig zurückgehalten wird. Diese Verhältnisse liefern auch die einfachste Erklärung für die immer wieder gemachte Beobachtung, dass der Phosphorgehalt des Reises einen relativ zuverlässigen Maassstab für dessen Bekömmlichkeit als ausschliessliches oder stark vorwiegendes Nahrungsmittel liefert: Je höher der Phosphorgehalt einer bestimmten Reissorte ist, um so geringer. ist die Gefabr, dass sie Beriberi nach sich zieht. Da aber die hier in Betracht kommenden wirksamen und phosphorreichen organischen Verbindungen hauptsächlich in den Fruchthäuten (dem Perikard) enthalten sind, während der Kern (das Endosperm) an diesen organischen wie an Phosphorsäureverbindungen überhaupt sehr arm ist, so folgt hieraus, dass je nach der mehr oder minder weit getriebenen Ent- 
fernung der Samenhüllen (Fruchtbäute) parallel mit dem Phosphorsäuregehalt auch die Schutzwirkung gegen Beriberi abnehmen muss.

Die soeben besprochene Beziehung zwischen dem $\mathrm{P}_{2} \mathrm{O}_{5}$-Gehalt verschiedener Reissorten und ihrer mehr oder minder ausgesprochenen Schutzwirkung gegen alimentäre Dystrophie bzw. Beriberi, die bei Reissorten mit sehr niedrigem $\mathrm{P}_{2} \mathrm{O}_{5}$-Gehalt (unter $0,4 \%$ ) völlig versagen kann, ist demnach keineswegs eine zufällige, wie man dies wiederholt behauptet hat. Dasselbe gilt sicherlich auch für eine Anzahl anderer Lebensmittel, zum Beispiel für viele Hülsenfrüchte, deren relativ hoher Phosphorgehalt mit ibren beriberiverhütenden Eigenschaften ebenfalls im Einklange steht. Ich nemne hier als nach dieser Richtung hin durch zahlreiche Versuche erprobte Hülsenfrüchte Katjang-idjoe, Erbsen und Linsen, deren $\mathrm{P}_{2} \mathrm{O}_{5}$-Gehalt um $1 \%$ herum sich bewegt. Dieser Maasstab ist selbstverstandlichkein absoluter, schon deshalb nicht, weil anorganische Phosphate von vornherein als unwirksam ausscheiden.

Als sehr verfehlt erscheint $e s$, an die Stelle des $\mathrm{P}_{2} \mathrm{O}_{5}$-Gehaltes als Wertmesser den der Asche setzen zu wollen, wie dies vorgeschlagen worden ist. Das Verhältnis von Asche : $\mathrm{P}_{2} \mathrm{O}_{5}$ kann in versehiedenen Reissorten ein sehr stark schwankendes sein, wie dies unter anderem auch der auf $\mathrm{S}$. 210-211 aufgeführte Gehalt an $\mathrm{P}_{2} \mathrm{O}_{\tilde{a}}$ und Asche von drei verschiedenen Reissorten zeigt. Hier betrug der Gehalt an:

$\begin{array}{cccc}\text { Reissorte } & \text { Asche } & \mathrm{P}_{2} \mathrm{O}_{5} & \text { Asche : } \mathrm{P}_{2} \mathrm{O}_{\tilde{5}} \\ \mathrm{~A} & 5,02 \% & 0,48 \% & 9,56 \% \\ \mathrm{~B} & 1,40 \% & 0,27 \% & 19,28 \% \\ \mathrm{C} & 0,93 \% & 0,27 \% & 29,03 \%\end{array}$

$\mathrm{Ob}$ es sich bei dem auffallend hohen Aschegehalt der Reissorte A, welche während des Krieges beschafft werden musste, um künstlich zugesetzte Beimengungen bandelte, musste dahingestellt bleiben.

Überdies ist die titrimetrische $\mathrm{P}_{2} \mathrm{O}_{5}$-Bestimmung eipe viel lejchter, bequemer und schneller auszuführende Operation als eine genaue Aschebestimmung. Die erstere hat ausserdem den Vorzug grösserer Genauigkeit und ist mit einer sehr einfachen Operation ausführbar.

Reiskleie und Hefe scheinen sich allerdings auch insofern voneinander zu unterscheiden, als erstere eine erheblich grössere Menge als letztere von Phosphatiden enthält, während die Bierhefe an wirksamen Nukleoproteiden bzw. Nukleinen reicher zu sein scheint. 
Wie schon angedeutet worden ist, kann der Gesamtphosphorgehalt irgendeines Nahrungsmittels allein keinen absolut zuverlässigen Maassstab für dessen Insuffizienz in dem bier in Betracht kommenden Sinne abgeben. Dagegen kann, wie schon gesagt, der Phosphorgehalt bestimmter Nahrungsmittel (wie zum Beispiel der verschiedener Reissorten) zweifellos gute und bequeme Anhaltspunkte für deren Bewertung nach der hier in Frage kommenden Richtung hin liefern.

Es bleibt natürlich dahingestellt, ob die Phosphorsäure als solche eine besondere Rolle im ganzen Problem der Entstehung, Heilung und Verhütung der alimentären Dystrophie spielt. Einstweilen lässt sich nur soviel aussagen, dass sie im gerissen Sinne ein Reagens auf den Gehalt an wirksamen Stoffen sein kann. Die Eutonine, die wir geprüft haben, waren frei von Phosphorsäure und wirkten dennoch. Somit ist diese nicht direkt an der Wirkung beteiligt. Es scheint uns vorläufig die Annahme am wahrscheinlichsten, dass die Eutonine in Kombination mit Phosphorsäure beständig sind und durch sie geschützt werden. Auch im Organismus dürften auf diesem Wege Eutonine vor weiterer Zerlegung und vor Umwandlungen geschützt werden. Schau mann ${ }^{1}$ ) hat somit mit seiner von ihm immer wieder verfochtenen Anschauung, dass Beziehungen zwischen organischen phosphorhaltigen Verbindungen und der Wirksamkeit von Substanzen, die Beriberi günstig beeinflussen oder ihr Entstehen verhindern können, vorbanden sind, im genannten Sinne recht behalten. Der weiteren Forschung bleibt es vorbehalten, sie vollständig aufzuklären. Immer wieder stört bei diesen Überlegungen der Umstand, dass weder Phosphatide noch Nukleoproteide noch Nukleine wohl definierte, in ihrer Zusammensetzung und vor allem in ihrer Einheitlichkeit klar erkannte Produkte sind. Infolgedessen möchten wir uns in unseren Schlussfolgerungen nicht fester legen, als die Tatsachen es zulassen. Wir betrachten vielmehr diese Untersuchungen als Leitpunkte für weitere Forschungen.

$\mathrm{Ob}$ bei der Beriberi infolge stark vorwiegender Ernährung mit sehr phosphorarmen Nahrungsmitteln (geschliffenem Reis, Sago, kleiearmem Weizenbrot u. a. m.) die sehr geringe $\mathrm{P}_{2} \mathrm{O}_{5}$-Zufuhr nicht auch eine Rolle spielt, ist vorläufig unentschieden. Zweifellos aber ist, dass bei den genannten Krankheiten die ausserordentlich geringe $\mathrm{P}_{2} \mathrm{O}_{5}$-Ausscheidung, besonders mit dem Harn, auf einen gestörten

1) Arch. f. Schiffs- u. Tropenhyg. Bd. 14 Beih. 8 S. 241. 1910. 
Phosphorstoffwechsel so stark hindeutet, dass dieser Umstand sicherlich alle Beachtung verdient.

Die Entdeckung des Eutonins (Vitamins) in der Reiskleie und. der Nachweis seiner „antineuritischen" Wirkung verlieren hierdurch selbstverständlich keineswegs an Bedeutung für die Lösung des vorliegenden Problems, welches jedoch viel verwickelter ist, als man vielfach anzunebmen scheint. Es erscheint daher auch als verfehlt, die Bedeutung der "Vitamine" zu überschätzen, wie dies auf Grund der vorliegenden Versuche schon an anderer Stelle begründet worden ist. Hier sei nur noch einmal hervorgehoben, dass Hefe- und Reiskleieeutonin (Vitamin) alle in weder imstande sind, ein insuffizientes Nahrungsmittel wie geschliffener Reis zu einem vollwertigen zu ergänzen, noch auch dieselbe Wirkung entfalten wie die betreffenden Muttersubstanzen.

Es ist wiederholt in diesem Zusammenhange auch behauptet worden, Sojabohnen wären trotz ihres hohen Phosphorgehaltes für Hühner und Tauben ein insuffizientes Nahrungsmittel. Diese angebliche Insuffizienz hat uns $\mathrm{zu}$ einem Tierversuch veranlasst, bei welchem Tauben einseitig mit Sojabohnen gefüttert wurden. Wie aus dem Analysenergebnis auf S. 212 hervorgeht, enthielten die zu den Tierversuchen verwandten Sojabohnen $1,28 \% \quad \mathrm{P}_{\mathbf{9}} \mathrm{O}_{5}$.

Drei mit Sojabohnen einseitig gefütterte Tauben befanden sich nicht nur während der ganzen 35 Tage umfassenden Versuchsdauer vorzüglich, sondern hatten im Durchschnitt am Schlusse des Versuches noch um 4,14\% an Körpergewicht zugenommen. Eine der Versuchstauben wies kei Beendigung des Versuchs sogar eine Zunahme des Körpergewichts von. $55 \mathrm{~g}=15,99 \%$ des Anfangsgewichts auf.

Es wurden dann noch verschiedene Präparate aus Sojabohnen auf ihre Wirksamkeit geprüft. Zur Darstellung dieser Präparate war Sojabohnenmehl nacheinander mit Aceton, Alkohol, verdünnter Salzsäure und Pepsinsalzsäure behandelt worden, wie dies auf S. 191 eingehend beschrieben ist.

Die mit den verschiedenen Fraktionen angestellten Tierversuehe lieferten folgende Ergebnisse:

Sowohl der durch Ausziehen mit verdünnter Salzsäure und Eindampfen des neutralisierten Auszuges zur Trockene gewonnene, wie auch der schliesslich verbleibende Sojabohneumehlrückstand erwiesen sich als unwirksam, um an alimentärer Dystrophie erkrankte Tauben 
Beitrag zur Kenntnis von organischen Nahrungsstoffen mit spezif. Wirkung. 111

wiederherzustellen. Eine deutliche, aber nicht sehr ausgesprochene und wenig anhaltende Wirkung kam dem zur Trockene verdampften Pepsinsalzsäureauszug zu. Am stärksten wirkte die "Phosphatidfraktion", von welcher eine Gabe von $0,7 \mathrm{~g}$ bei oraler Anwendung genügte, um eine unter schweren nervösen Störungen erkrankte Taube von diesen innerhalb von 15 Stunden vollkommen zu befreien.

Diese Phosphatidfraktion enthielt $1,54 \% \mathrm{P}_{2} \mathrm{O}_{5}$, während der $\mathrm{P}_{2} \mathrm{O}_{5}$ Gehalt des bei $105^{\circ} \mathrm{C}$. getrockneten Pepsinsalzsäureauszuges $0,72 \%$ und derjenige der Sojabohnen selbst $1,28 \%$ betrug.

DieseVersucheerweisen, dass Sojabohnen für Tauben keineswegs ein insuffizientes Nahrungsmittel sind, wie dies verschiedentlich behauptet worden ist. Ferner zeigen sie, dass dem aus Sojabohnen gewonnenen „Phosphatid"(mit dem S.94ff.mitgeteilten Vorbehalte)gegen die bei deralimentären Dystrophieder Tauben auftretenden nervösen Störungen einestarke und dem durch fermentative Einwirkung von Pepsinsalzsäureauf Sojabohnenmehl gewonnenen Extrakte eine unverkennbare, wenn auch erheblich geringere Wirkung als dem Phosphatid $\mathrm{zukommt}$.

Hühner fressen, wie ein Versuch lehrte, Sojabohnen sehr ungern, was bei Tauben nicht der Fall ist. Leider konnten Fütterungsversuche mit Hühnern während der Kriegszeit wegen der unzureichenden Mengeu von Sojabohnen nicht durchgeführt werden.

Schliesslich haben wir noch Versuche mit Erbsenpräparaten angestellt. Erbsen selbst haben sich sowohl bei der alimentären Dystrophie der Tauben (Axel Holst) wie auch neuerdings bei der mensehlichen Beriberi ${ }^{1}$ ) als ein gutes Heil- und Vorbeugungsmittel erwiesen.

Es wurde zunächst aus Erbsenmehl mit 2,5\% iger Ammoniaklösung ein Auszug dargestellt und der aus diesem durch verdünnte Schwefelsäure ausgefällte, dann gut ausgewaschene Niederschlag auf seine Wirksamkeit geprüft. Bei der Darstellung wurde ebenso verfahren wie dies bereits bei der Gewinnung der Nukleoproteide aus

1) D. J. Hulsh off-Pol, Bericht üler Versuche bei Beriberipatienten mit getrockneten Erbsen und Hafergriess. Norske Magazin for Lägerwidenskaben 1916 Nr. 1. Ref. Münch. Med. Wochenschr. 1916 Nr. 24 S. 869. 
Hefe (S. 179) beschrieben ist. Das so erhaltene Präparat unterschied sich indessen insofern wesentlich von dem aus Hefe gewonnenen, als es bei der Behandlung mit Pepsinsalzsäure bei $37^{\circ} \mathrm{C}$. bis auf einen sehr geringfügigen Rest in Lösung ging. Es konnte sich demnach nicht wie bei der Hefe um ein Nukleoproteid handeln. Dieser Befund deckt sich auch mit den von E. Schulze und seinen Mitarbeitern ${ }^{2}$ ) gemachten Angaben, denen zufolge der Nukleingehalt von Erbsen nur 1,14-1,91\% ausmacht und der Lecithingehalt derselben ebenfalls sehr gering $(0,81-1,21 \%)$ ist. Das Präparat erwies sich dann auch bei einem Taubenversuche (S. 193) als unwirksam.

Es wurden weiter feingemablene gelbe Erbsen nacheinander mit absolutem Alkohol, dann mit Pepsinsalzsäure ausgezogen. Der Rückstand des alkoholischen Auszuges war zu gering, als dass mit ihm Tierversuche angestellt werden konnten. Auch konnte dieser Fraktion in Anbetracht der sehr geringen Ausbeute, selbst im besten Falle, ein wesentlicher Anteil an der Wirksankeit des Ausgangsmaterials (der Erbsen) nicht zufallen. Dagegen erwies sich eine Tagesgabe von $1 \mathrm{~g}$ des neutralisierten und dann zur Trockene eingedampften Pepsinsalzsäureauszuges als recht wirksam. Eine der Versuchstauben, welche ausgesprochene Paresen der Beine aufwies und bei Beginn des Versuchs sehr hinfällig war, wurde in kurzer Zeit von den Lähmungen vollkommen befreit und nahm in 17 Tagen um $27 \mathrm{~g}=16,4 \%$ an Körpergewicht zu. Mit dem nach dem Ausziehen mit Alkohol und Pepsinsalzsäure verbliebenen Rückstand konnte keine merkliche Wirkung erzielt werden.

Die Ergebnisse der soeben besprochenen Versuche mit Sojabohnen und gelben Erbsen lassen darauf schliessen, dass die Muttersubstanzen der Eutonine in diesen Hülsenfrüchten in der Hauptsache wahrscheinlich andere sind als die Muttersubstanzender Hefe-und Reiskleieeutonine.

Zum Schluss seien die wesentlichen Ergebnisse der in diesem Absehnitte besprochenen Versuche und die aus ihnen sich ergebenden Schlussfolgerungen kurz wiederholt:

2) J. Koenig, Die menschlichen Nahrungs- und Genussmittel Bd. 1 S. 607 a. Bd. 2 S. 787. Julius Springer, Berlin 1904. 
Beitrag zur Kenntnis von organischen Nahrungsstoffen mit spezif. Wirkung. 113

Als Muttersubstanzen der Eutonine kommen sehr wahrseheinlich verschiedene Verbindungen in Betracht, deren Qualität und Quantität in verschiedenen Nahrungsmitteln sehr wechseln kann. Soweit die vorliegenden Ergebnisse ein Urteil darüber zulassen, scheint es sich bei den Muttersubstanzen der Eutonine hauptsächlich, wenn nicht ausschliesslich um organisehe Phosphorverbindungen (Phosphatide, Nukleoproteide, Nukleine usw.) zu handeln. Möglicherweise schützt die stark saure Phosphorsäure hier die gegen Alkalien sehr empfindlichen Eutonine vor Zersetzung. Sichergestellt ist, dass sich in der Hefe wenigstens ein, wenn nicht eine Mehrzahl von solchen gegen alimentäre Dystrophie sehr wirksamen Nukleoproteiden findet, welches sich durch Pepsinsalzsäure in ein noch wirksameres Nuklein und ein phosphorsäurehaltiges Peptongemisch von erheblich geringerer Wirksamkeit spalten lässt. Als wichtige, eutoninbaltige Substanzen kommen ferner zu der Gruppe der Phosphatide gehörende Produkte aus verschiedenen Kleiearten, aus Bierhefe und Sojabohnen (und wahrscheinlich einer ganzen Reihe von Pflanzensamen) in Betracht. Als sichergestellt erscheint ferner, dass in verschiedenen Nahrungsmitteln und anderen natürlich vorkommenden Stoffen pflanzlichen und tierisehen Ursprungs die Muttersubstanzen der Eutonine ibrer Natur und Menge nach grosse Verschiedenheiten aufweisen. Bald stehen, wie bei der Hefe, Nukleoproteide im Vordergrunde, bald scheinen es vorzugsweise Phosphatide oder phosphorhaltige Eiweissstoffe zu sein. Die Frage, ob auch in anderen, nicht phosphorhaltigen Substanzen (Proteinen, Koblebydraten, Fetten) als integrierende Bestandteile ihrer Moleküle Eutonine vorkommen; muss vorläufig offen bleiben. Irgendwelche Beweise oder Anhaltspunkte hierfür liegen bislang nicht vor. Ebensowenig ist bekannt, ob Eutonine in Tieren und Pflanzen in nennenswerter Menge in frei em Zustande vorkommen. Eine Reihe von (bereits angeführten) Gründen spricht gegen eine solche Annabme.

Werden die Eutonine durch eine unzweckmässige Darstellungsweise oder Behandlung aus dem Gesamtmolekül dieser Verbindungen herausgerissen und hierbei entfernt oder zerstört, so geht die Wirksamkeit des zurückbleibenden Anteils ganz oder doch zum grössten Teil verloren. Andererseits ist aber die Wirksamkeit dieser organischen Verbindungen nicht auf ihren Gehalt an Eutonin allein zurückzuführen. Hiergegen spricht' erstens, dass es nicht gelingt, dureh Zufuhr von Eutoninen allein oner durch Zufuhr von Eutonin + Eiweiss + KohlePfIñger's Archiv für Physiologie. Bd. 172. 
hydraten (oder Fetten) + Nährsalzen (Hefe- oder Reiskleieasche) Tauben auf Gewichtskonstanz und am Leben zu erbalten, und zweitens der Umstand, dass Reiskleiephosphatid, vor allem aber Hefenuklein eine viel weitergehende und vielseitigere Wirkung entfalten als die betreffenden Eutonine allein. Allem Anschein nach handelt es sich hier um eine synergetische Wirkung versehiedener Komponenten der Muttersubstanzen. Eine Stütze findet diese Mutmaassung in der ausgesprochenen, wenn auch bei wiederholter Anwendung versagenden Wirkung der Nukleinsäuren aus Hefe und Thymusdrüse.

Es ist wohl selbstverständlich, dass man die Wirksamkeit organischer Phosphorverbindungen nur dann richtig einwerten kann, wenn man gleichzeitig für eine ausreichende Zufuhr der Hauptnährstoffe (Kohlehydrate oder Fette, Eiweiss und Nährsalze) Sorge trägt. Die wesentliche Bedeutung der Muttersubstanzen der Eutonine erscheint ebensowohl wie die der Eutonine selbst, nur in höherem Grade und in vielseitigerer Weise, in einer Vermittlerrolle beim intermediären Stoffwechsel zu liegen. Welcher Art diese anscheinend recht vielseitige Wirkungsweise ist, wird durch weitere Forschungen aufzuklären sein. Die im Abschnitt V, S. 88 behandelte Einwirkung der Eutonine auf fermentative Vorgänge liefert hierfür vielleicht den ersten brauchbaren Fingerzeig. Als bedeutungsvoll könnte man es bezeichnen, dass es vorzüglich Phosphatide und Nukleine zu sein scheinen, denen eine so grosse Wirksamkeit gegen die bei alimentärer Dystrophie auftretenden Stoffweehselstörungen zukommt. Die in den Molekülen dieser Substanzen zusammengefügten heterogenen Bausteine, die den verschiedensten am Aufbau und Betriebe der Zellen beteiligten Gruppen (Kohlehydraten, Fetten, Eiweisskörpern, Phosphorverbindungen usw.) entnommen sind, sôwie die hierdurch ermöglichte grosse, durch Verschiedenartigkeit des Aufbaues und der Kombination ermöglichte Mannigfaltigkeit lassen diese Verbindungen ja auch für die verschiedenartigsten Funktionen und für Vermittlerrollen als besonders geeignet erscheinen.

\section{Versuche mit Aminosäuren.}

Von einigen Autoren ist die Existenz von Eutoninen (Vitaminen) in Abrede gestellt worden. Besonders bat $\mathrm{Röhmann}^{1}$ ) sich in einer

1) F. Röhmans, Über künstliche Ernährung und Vitamine. Die Biochemie in Einzeldarstellungen. Gebrüder Bornträger, Berlin 1916. 
umfangreichen Abhandlung in diesem Sinne ausgesprochen und dahin geäussert, dass keine Beweise für das Vorhandensein von „Vitaminen“ vorlägen. Núr unter bestimmten Umständen seien "Ergänzungsstoffe" in der Nahrung notwendig, nämlich bei der Ernährung mit unvollständigen Eiweissstoffen. Als "Ergänzungsstoffe" bezeichnet $\mathrm{R}$ öh mann "Stoffe, welche in ganz bestimmter chemischer Beziehung zu einem bestimmten Eiweissstoffe der Nahrung stehen". Als Ergänzungsstoffe wären aber "Vitamine", die allverbreitete Katalysatoren sein sollten, nicht anzusprechen.

Röhmann's Ausführungen, die sich nicht auf ejgene Untersuchungen auf diesem Gebiete stützen, ist leider nicht zu entnehmen, wie man sich diese "bestimmten chemischen Beziehungen" vorzustellen hat und welcher Art die bestimmten Eiweissstoffe sind, zu welchen diese Beziehungen unterhalten werden.

Unter unvollständigen Fiweissstoffen versteht man bekanntlich im allgemeinen solche, denen bestimmte Aminosäuren fehlen, welche sich der tierische Organismus durch Autosynthese nicht zu verschaffen vermag, die aber für sein Fortbestehen unerlässlich sind (zum Beispiel Tryptophan). Wie wir bereits ausgeführthaben, kann Insuffizienz unter anderem auch durch das Fehlen bestimmter Aminosäuren im Eiweiss der Nahrung veraulasst sein. Um der Frage nachzugehen, ob dieser Umstand etwa auch beim geschliffenen Reis vorliege, haben wir die auf S. 175 u. ff. aufgeführten Tierversuche und die auf S. 203 in allen Einzelheiten beschriebenen Untersuchungen mit dem aus geschliffenem Reis gewonnenen Protein (Pepton) ausgeführt.

Bei unseren Versuchen mit Aminosäuren wurden zunächst Tauben, welche die bei alimentärer Dystrophie auftretenden typischen Erscheinungen aufwiesen, mit einzelnen Aminosäuren (Histidin, Tryptophan, Arginin) behandelt. Die Lösung der beiden erstgenannten Aminosäuren wurde den Tauben in den. Brustmuskel eingespritzt. Es konnte bei Histidin und Tryptophan nur eine vorübergehende und keineswegs tiefgreifende Besserung, wie sie als Regel die Einspritzung von Eutoninpräparaten nach sich zieht, beobachtet werden. Arginin, welches der betreffenden Versuchstaube in den Kropf eingespritzt wurde, äusserte überhaupt keine Wirkung.

Diese wenigen Vorversuche konnten selbstverständlich nicht als ausreichend für die Entscheidung der vorliegenden Frage angesehen 
werden. Es wurde desbalb ein Dauerversuch (Nr. 16, S. 176) mit zwei Tauben angeschlossen, welche bei einseitiger Ernährung mit geschliffenem Reis täglich zwei Pillen eines Aminosäuregemisches bekamen. Die Tagesgabe für jede Taube betrug an Tryptophan $5 \mathrm{mg}$, Tyrosin $15 \mathrm{mg}$, Histidinchlorhydrat $15 \mathrm{mg}$, Arginin $15 \mathrm{mg}$, Leuzin $50 \mathrm{mg}$, Glutaminsäure $50 \mathrm{mg}$, Cystin $10 \mathrm{mg}$, Glukosaminehlorhydrat $10 \mathrm{mg}$. Eine der Tauben bekam das Aminosäuregemisch sofort bei Beginn des Versuches, die andere Taube erst nach voraufgegangener zehntägiger Fütterung mit geschliffenem Reis allein. Appetit sowie Körpergewicht beider Versuchstauben nahmen ebenso wie bei der Fütterung mit geschliffenem Reis allein ab. Die Taube Nr. 7 wurde daher von dem 8 . Versuchstage an zwangsweise mit $20 \mathrm{~g}$ geschliffenem Reis pro Tag gefüttert. Sie nahm trotzdem ständig an Körpergewicht $\mathrm{ab}$ und wies am 33. Versuchstage Lähmungen der Beine nnd Flügel, Opisthotonus, Krämpfe und besonders ausgesprochene Reflexe (Photographien Nr. 26, 27 und 28) auf. Eine intramuskuläre Einspritzung des von der Eutoninfraktion befreiten Acetonniederschlages (s. S. 236) bewirkte nur eine teilweise Besserung, wie die $3^{1 / 2}$ Stunden nach der Einspritzung aufgenommene Photographie Nr. 39 zeigt. Krämpfe und Opisthotonus waren geschwunden, auch erschien die Taube munterer, aber Streckkrampf und Lähmungen der Beine blieben unverändert. Die Einspritzung eines sehr wirksamen Eutoninpräparates beseitigte zwar den Streckkrampf, aber die Taube war bereits so matt und hinfällig, dass sie bald darauf starb.

Die zweite Versuchstaube (Nr. 8) erkrankte schon am 22. Versuchstage unter schweren Lähmungen der Beine (Photographie Nr. 2). Nach Einspritzung von 15 Tropfen eines sehr wirksamen Eutoninpräparates (dialysierter Acetonniederschlag aus hydrolysierter Hefe) waren die Lähmungen schon nacb $1^{1 / 2}$ Stunden beseitigt (Photographie Nr. 3). Am nächsten Tage war die Taube wieder ganz munter. Die Wirkung hielt 8 Tage lang an. Es stellten sich alsdann wieder Lähmungen der Beine, Opisthotonus und Krämpfe ein (Photographie Nr. 11), die nach Einspritzung von 0,01 g eines kristallisierten, aus Hefe gewonnenen Eutoninpräparates und nach Verlauf yon $3^{1 / 2}$ Stunden wiederum gewichen waren (Photog raphie Nr. 12). Am nächsten Tage war die Taube trotz hochgradiger Abmagerung wieder imstande behende zu laufen und zu fliegen.

Diese Versuche zeigen einmal, dass die Zufuhr von 
Beitrag zur Kenntnis von organischen Nahrungsstoffen mit spezif. Wirkung. 117

Aminosäuren, wie sie in dem von uns verwandten Gemisch enthalten waren, keinen Einfluss auf den gewöhnlichen Verlauf der alimentären Dystrophie auszüuben vermag. Fortschreitende Abmagerung und typische Erscheinungen nervöser Art boten das gewöhnliche Bild der alimentären Dystrophie. Auch eine Verzögerung beim Auftreten der nervösen Störungen sowie bei der Abnabmedes Körpergewichtes waren nicht zu verzeichnen. Dagegen wurden die ersterendurch Anwendung von Eutoninpräparaten schnell und für längere Zeit vollkommen beseitigt.

Zur weiteren Vervollständigung dieser Ergebnisse haben wir dann noch eine Untersuchung des Proteins aus geschliffenem Reis ausgeführt (S. 203).

Mit einem Teil des aus $500 \mathrm{~g}$ feingemahlenen geschliffenen Reises durch Einwirkung von natürlichem Magensaft bei einer Temperatur von $37^{\circ} \mathrm{C}$., Abseihen usw. gewonnenen Peptons wurden die üblichen Eiweissreaktionen (Biuret- und Xanthoproteinreaktion), ferner die Reaktionen mit Mill on's Reagens, Glyoxylsäure, alkalischer Bleilösung und Diazobenzolsulfosäure ausgeführt. Sie gaben sämtlich positive Ergebnisse. Es war hiermit der Nachweis der Gegenwart von Tryptophan, Tyrosin und Cystin erbracht, d. h. von solchen Aminosäuren, von denen die biologische Wertigkeit eines Proteins nach den bicherigen Kenntnissen in erster Linie abhängt.

Ein anderer Teil der Peptonlösung wurde der Hydrolyse mit konzentrierter Salzsäure unterworfen. Das Hydrolysat wurde durch Eindampfen im Vakuum bei $37^{\circ} \mathrm{C}$. von Salzsäure möglichst befreit, mit Natriumkarbonat neutralisiert und nach dem Versetzen mit Tierkohle filtriert. Mit dem eingeengten Filtrat, aus welchem sich Tyrosinkristalle gewinnen liessen, wurden die schon genannten Eiweissreaktionen nochmals angestellt. Auch hier fielen sie sämtlich positiv aus, bis auf die Xanthoproteinreaktion. Bei letzterer ist der negative Ausfall wohl dadurch zu erklären, dass die Hauptmenge des Tyrosins beim Eindampfen des Hydrolysats sich bereits ausgeschieden hatte und filtriert worden war. Der negative Ausfall der Reaktion mit Bromwasser auf Tryptophan war zu erwarten, weil Tryptophan der Einwirkung starker Salzsäure in der Hitze in Gegenwart anderer Verbindungen nicht widersteht. 
Boruttau ${ }^{1}$ ) berechnete bei seinen Versuchen an Hunden die biologische Wertigkeit des Eiweisses im Reis nach den Thomas. schen Formeln und fand hierbei folgende Werte:

für geschliffenen Reis:

nach der ersten Formel . . . . . 61,0\%

" zweiten $"$. . . . . $93,8 \%$

für ungeschliffenen Reis:

nach der ersten Formel . . . . 50,2\%

" zweiten " . . . . 81,5\%

Die Zahlen sind an sich ja recht hoch. Merkwürdigerweise übertraf die biologisehe Wertigkeit des Proteins im geschliffenen Reis, der ja für die meisten bisher zu Versuchen herangezogenen Tieratten insuffizient ist, diejenige des Proteins im ungeschliffenen Reis, welcher bekanntlich für Geflügel als voll rertige Nahrung zu betrachten ist.

Bei zwei in gleicher Weise aus geschliffenem und ungeschliffenem Reis durch möglichst weitgehende Entfernung von Kohlehydraten gewonnenen und auf diese Weise angereicherten Eiweisspräparaten wurden bei Versuchen an Hunden als biologisehe Wertigkeit folgende Zahlen gefunden:

für das Eiweisspräparat aus geschliffenem Reis: nach der ersten Formel . . . . . 96,1\% $"$ "zweiten $" . . . .107,3 \%$

für das Eiweisspräparat aus ungeschliffenem Reis: nach der ersten Formel . . . . . 73,7\% $"$ "zweiten. $n$. . . . . $79,0 \%$

Anch hier war demnach die biologische Wertigkeit des aus geschliffenem Reis gewonnenen Eiweisspräparates höher als die eines aus ungeschliffenem Reis in analoger Weise dargestellten Präparates.

Die vorstehend besprochenen Tierversuche und chemischen Untersuchungen haben demach ebensowenig wie frühere derartige Untersuchungen den geringsten Anhaltspunkt dafür erbracht, dassdie Insuffizienz des geschliffenen Reises auf die Unvollständigkeit des in ihm enthaltenen Proteins bzw. auf den

1) H. Boruttau, Beiträge zur Frage: Wie wird pflanzliches Eiweiss im 'Tierkörper verwertet? II. Mitteilung. Biochem. Zeitschr. Bd. 82 S. 96.1917. 
Beitrag zur Kemntnis von organischen Nahrungsstoffen mit spezif. Wirkung. 119

Mangel des letzteren an unentbehrlichen Aminosäuren zurückzuführen wäre. Sie weisen vielmehr auf das Gegenteil hin.

\section{Versuche mit vollständig abgebauten, Inkrete} liefernden Organen (Optonen).

Wiederholt ist die Vermutung ausgesprochen worden, dass Wechselbeziehungen beständen zwischen der Wirkung von denjenigen Substanzen, welche bei der alimentären Dystrophie heilend und vorbeugend wirken, und der Funktion endokriner Drüsen.

Funk. und Douglas ${ }^{1}$ ) berichteten, sie hätten bei Tauben, die an alimentärer Dystrophie (Beriberi) erkrankt waren, eine starke Grössenabnahme innersekretorischer Drüsen (Thymus, Hypophyse, Schilddrüse, Nebenniere, Ovarium, Hoden, Niere, Leber, Pankreas, Milz) gefunden. Die ausgesprochenste Atrophie hätte hierbei die Thymusdrüse gezeigt. Die genannten Autoren folgerten hieraus, dass der Mangel der Nahrung an "Vitaminer" eine Dysfunktion und eine Atrophie dieser Organe verursache.

Williams und $\mathrm{Crowel1}{ }^{2}$ ) fanden bei Tauben und Hübnern nach längerer einseitiger Fütterung mit geschliffenem Reis, dass die Thymussdrüse in vielen Fällen völlig verschwunden, in anderen Fällen merklich atrophiert und nur in einer Minderzahl von Fällen unverändert geblieben war. Die genannten Autoren meinten, das Alter der betreffenden Vögel habe hiermit nichts zu tun, da die Veränderungen der Thymus sowohl bei jungen wie bei ausgewachsenen Tieren beobachtet wurden. 'Zugabe von frischer Milch bei einseitiger Fütterung mit geschliffenem Reis hätte der Atrophie der Thymusdrüse vorgebeugt. Zugaben von Schafthymus und alkoholischem Extrakt aus solchem hätten zwar den Ausbruch der alimentären Dystrophie nicht verhindert, aber verzögert, und die Versuchstiere wären nicht so stark abgemagert. Getrocknete Schafthymus bei menschlicher Beriberi wäre ebenfalls nur von vorübergehender und unsicherer Wirkung gewesen.

Es ist bei den Sektionen von Tauben, die an alimentärer Dystrophie eingegangen waren, bei einer ganzen Reihe von Tieren auf das Ver-

1) C. Funk and M. Douglas, Studien über Beriberi. Journ. of Physiol. vol. 47 p. 475 . Ref. Chem. Zentralbl. 1914 Bd. 1 S. 1453.

2) B. B. Williams and B. C. Crowell, Thymus gland and Beriberi. The Philipp. Journ. of Science Sect. B, vol. 10 p. 121. 1915. 
halten der Thymus- und der Schilddrüse geachtet worden. Zum Vergleiche wurden Tiere herangezogen, die gehungert hatten. Die Ergebnisse waren nicht einheitlich, $d . h$. wir fanden, dass bei der alimentären Dystrophie, hervorgebracht durch ausschliessliche Verfütterung von geschliffenem Reis, keine charakteristischen Veränderungen der genannten Organe vorhanden waren. Sie waren wobl oft klein, jedoch war das auch in einigen Fällen bei Tieren der Fall, die keine Nahrung bekommen hatten.

Um Missverständnissen vorzubeugen, sei noch ausdrücklich bemerkt, dass selbstverständlich Störungen einzelner Organe vorhanden sein können, ohne dass dies in der Grösse zum Ausdruck zu gelangeu braucht. Auch kann ein Organ verkleinert sein, ohne dass seine iunersekretorische Funktion beeinträchtigt ist.

$\mathrm{Zu}$ diesen Untersuchungen waren wir gekommen, weil die Vermutung nahelag, dass jene Stoffe, die imstande sind, die Erscheinungen der alimentären Dystrophie günstig zu beeinflussen resp. ihr Auftreten auszuschliessen, das Baumaterial für bestimmte Stoffe jener Organe sein könnten, die Inkrete abgeben. Würde dieses fehlen, dann könnten auch diese für den gesamten Haushalt des Organismus" so wichtigen Stoffe nicht gebildet werden. Die Folge müssten schwere Störungen sein. Die unten (S. 195) mitgeteilten Versuche haben nicht ergeben, dass die von uns angewandten Präparate im gleichen Sinne wirksam waren wie die aus Hefe isolierten Stoffe. Das beweist natürlich durchaus nicht, dass die Annahme, wonach die Stoffe der Hefe in Beziehung zu Inkreten stehen könnten, zu verwerfen ist; wohl aber ist bewiesen, dass in den angewandten, vollständig abgebauten Organen jene Stoffe nicht vorhanden sind, die die gleiche Wirkung entfalten wie die aus Hefe isolierten. Uns erscheint das besonders wichtig, weil vielfach die Behauptung aufgetreten ist, als würden die die Erscheinungen der alimentären Dystrophie beeinflussenden Stoffe ganz allgemein verbreitet sein. Nach unseren Erfahrungen ist das durchaus nicht bewiesen.

Optone sind die nach dem von einem von uns (Abderhalden) ausgearbeiteten Verfahren aus Inkrete liefernden Organen durch deren vollkommenen Abbau mit Verdauungsfermenten gewonnene Präparate. Diese Präparate haben sich nach einer anderen Richtung hin als wirksam erwiesen (vgl. S. 26) ${ }^{1}$ ). $\mathrm{Zu}$ bemerken ist, dass die Wirkung

1) Emil Abderhalden, Pflüger's Arch. Bd. 162 S. 99.1915. 
der.gesamten Drüsensubstanzen selbst zum Teil eine andere als die jenige der aus ihnen gewonnenen reinen oder gereinigten Präparate (Adrenalin, Thyroidin, Pitnitrin usw.) ist, und dass man daher die Wirkungen der letztgenannten Erzeugnisse nicht mit denen der entsprechenden Optone in eine Linie stellen darf.

Versucht wurden die Optone aus Corpus lnteum, Thymus, Thyroidea, Testes und Hypophyse. Mit Ausnahme von einem Falle (Thyroidea-Opton), in welchem das Versuchstier vorher einging, wurden alle anderen $\mathrm{zu}$ diesen Versuchen verwandten Tauben nachträglich mit getrockneter Bierhefe oder wirksamen Hefepräparaten behandelt. In allen diesen Fällen wurde eine schnelle Besserung oder Wiederherstellung erzielt. Durch diese erfolgreich verlaufenen Gegenproben erscheint die Schlussfolgerung berechtigt, dass den genannten Optonen zum mindesten keine schnelle und ausgesprochene Wirksamkeit gegen die bei alimentärer Dystrophie auftretenden nervösen Störungen zukommt. Gegen diese Störungen ist übrigens Adrenalin schon früher von Abderhalden und Lampé erfolglos angewandt worden. Dieses Ergebnis schliesst nicht die Möglichkeit aus, dass den Inkreten dennoch eine Rolle bei der Pathogenese der alimentären Dystrophie zufällt. Aus diesem Grunde und auch wegen der geringen Anzahl von Versuchen, die wir bei dem Mangel an Versuchstieren sebr einschränken mussten, erscheint uns ein abschliessendes Urteil nach dieser Richtung hin vorläufig noch als verfrüht.

\section{Prüfung der Sera von einseitig mit geschliffenem Reis ernährten Tauben auf Abwehrfermente.}

Wie bereits von uns an anderer Stelle hervorgehoben worden ist, bildet die starke Abmagerung von Hühnern und Tauben bei einseitiger Fütterung mit geschliffenem Reis eine so gut wie durchstehende Erscheinung. Bei Säugetieren (Hunden, Katzen, Meerschweinchen, Kaninchen, Affen und anderen mehr) beobachtet man dasselbe, wenn sie mit einem insuffizienten Nahrungsmittel gefüttert werden. Nur sehr vereinzelt kommen bei Tauben Fälle vor, in denen schon nach verhältnismässig geringer Abnahme des Körpergewichts schwere nervöse Störungen (Lähmungen, Opisthotonus, Krämpfe) einsetzen. Bei zahlreichen von uns ausgeführten Versuchen an Tauben, die mit ge- 
schliffenem Reis oder Graupen oder Weizenhartbrot oder Kartoffein einseitig ernährt worden waren, betrug die Gewichtsabnahme durehschnittlich $40 \%$ des Anfangsgewichts. Von Eijk man ${ }^{1}$ ) sind neuerdings zahlreiche Versuche mit Hühnern ausgeführt worden, deren Zitsammenstellung folgende Verbältnisse zeigt.

\begin{tabular}{|c|c|c|c|}
\hline Ernährung bzw. Behandlung & $\begin{array}{l}\text { Anzahl } \\
\text { der } \\
\text { Hühner }\end{array}$ & $\begin{array}{c}\text { Gewichts- } \\
\text { abnahme } \\
\%\end{array}$ & $\begin{array}{c}\text { Alimentäre } \\
\text { Dystrophie } \\
\text { nach }\end{array}$ \\
\hline 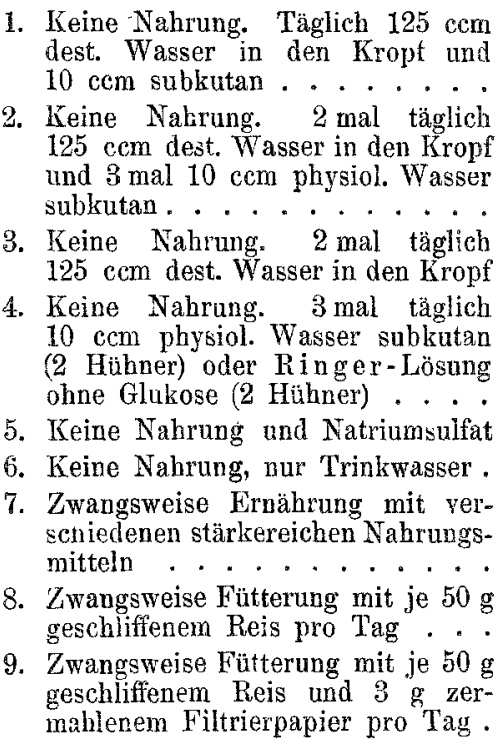 & $\begin{array}{l}4 \\
2 \\
6\end{array}$ & $\begin{array}{l}43,8 \\
44,7 \\
44,7 \\
23,1\end{array}$ & $\begin{array}{l}31,0 \\
26,0 \\
29,7 \\
20,0 \\
27,2 \\
19,3\end{array}$ \\
\hline
\end{tabular}

Wie sich aus vorstehender Aufstellung ergibt, erkranken Hühner an alimentärer Dystrophie bei völliger Nahrungsentziebung etwa nach der gleichen Gewichtsabnahme, wenn auch schneller wie Tauben, wemn letztere einseitig mit geschliffenem Reis ernährt werden. Bei den zahlreichen von Eijkman in dieser Abbandlung veröffentlichten Versuchen betraf die geringste Abnahme des Körpergewichts die mit ge= schliffenem Reis + zermablenem Filtrierpapier gefütterten Hübner. Unter diesen, erkrankte ein Huhn schon nach einer Gewichtsabnahme

1) C. Eijkman, Über den Finfluss der Ernährung und der Nahrungsentziehung auf die Erkrankung an Polyneuritis gallinarum. Virchow's Arch. f. pathal. Anat. u. Physiol. u. f. klin. Med. Bd. 222 S. 301. 1916. 
Beitrag zur Kenntnis von organischen Nahrungsstoffen mit spezif. Wirkung. 123

von nur 2,2\% und ein anderes nach einer solchen von 6,0\%. Bei allen anderen so ernährten Hühnern schwankte die Abnahme des Körpergewichts zwischen 13,2 und $21 \%$, war aber immerhin noch erheblich trotz der Zwangsfütterung. Diese ist aber auch nicht ausreichend, um die Hühner auf Gewichtskonstanz zu erhalten, obschon sie ja einen gewaltsamen Eingriff in den natürlichen Verlauf der Krankheitsentwicklnng darstellt. Bei der alimentären Dystrophie ist die allmählich sich einstellende Appetitlosigkeit gegen insuffiziente Nahrung eine so durchstehende Erscheinung, dass man diesen Faktor unmöglich für die Pathogenese dieser Krankheit als nebensächlich betrachten kann, um so weniger, als die oben angeführten Eijkman'schen Versuche lehren, dass auch völlige Nahrungsentziehung zu alimentärer Dystrophie (Polyneuritis gallinarum) führen kann.

Diese Erwägungen haben uns dazu veranlasst, Sera von Tauben auf die Anwesenheit von proteolytischen Fermenten zu präfen. Wir haben versucht, hierbei festzustellen, ob sich im Serum einseitig mit geschliffenem Reis ernährter Tauben Proteasen finden, und zu diesem Behufe die Einwirkung solcher Sera auf verschiedene Organe geprüft.

Die Herstellung der zu diesem Zwecke aus verschiedenen Organen gewonnenen Substrate sowie der Taubensera ist auf S. 196 u. ff. eingehend beschriehen. Auf S. 199 findet sich eine Übersicht über die bei diesen Versuchen erzielten Ergebnisse. Wir können uns daher hier auf eine Erörtelung der Hauptergebnisse beschränken.

Bei sämtlichen mit Sera gesunder Tauben ausgeführten Dialysierversuchen war keinerlei Abbau der verschiedenen bierzu verwandten Organsubstrate (Gehirn, Herzmuskel, Brustmuskel, Leber von Tauben, mensehliches Gehirn und Rückenmark) zu verzeichnen.

Der Befund bei Sera von Tauben, die an manifester alimentärer Dystrophie erkrankt waren, wechselte sehr. In zwei von acht Fällen wurde Taubengehirn sehr stark, in einem Falle nur in mässigem Umfange abgebaut; Herzmuskel und Brustmuskel erfuhren je einmal einen mässigen Abbau.

Viel einheitlicher waren die Resultate bei der Verwendung der Sera von Tauben, die nur $10-15$ Tage lang einseitig mit geschliffenem Reis gefüttert worden waren. Von diesen Sera wurde 
der Brustmuskel von Tauben in allen Fällen in mässigem, aber deutlich wahrnehmbarem Umfange abgebaut. Gehirn von Tauben lieferte in drei von vier Fällen und Herzmuskel in allen drei zur Prüfung herangezogenen Fällen positive Ergebnisse. Bei Taubenleber fiel die Prüfung in zwei von drei Fällen positiv, in einem dritten Falle negativ aus. Bei der oft sehr geringen Menge von Serum, die von einer einzeluen Taube zu gewinnen war, konnten in vielen Fällen nicht alle der genannten Substrate in den Kreis der Untersuchung einbezogen werden. Leider stand auch die grosse Schwierigkeit, während des Krieges geeignete Tauben zu beschaffen, der Ausführung zablreicherer Versuche hindernd im Wege.

Soweit die angeführten Versuchsergebnisse Schlussfolgerungen zulassen, scheint sich aus ihnen folgendes zu ergeben: Bei Tauben, die nach vorangegangener, sehr starker Abmagerung an alimentärer Dystrophie erkrankt sind, scheinen sich nur noch ausnahmsweise Abwehrfermente im Serum $\mathrm{zu}$ finden. Dagegen scheint dies in viel umfangreicherem und häufigerem Maasse bei solchen Tauben der Fall zu sein, die sich nach einseitiger Fütterung mit geschliffenem Reis in einer Periode starker Abmagerung befinden. Bei diesen Tieren, die noch genügende Mengen eigenen Körpergewichtes zuzusetzen haben, scheint die Bildung von Abwehrfermenten dem Einschmelzen von Gewebe parallel zu gehen.

Sehr erwünscht wären weitere derartige Untersuchungen bei menschlicher Beriberi, welche möglicherweise weitere Aufschlüsse über die Pathogenese dieser Krankheit liefern und vielleicht anch für diagnostische $Z$ wecke verwendbar sein würden.

Bei den von uns ausgeführten Untersuchungen konnte es sich selbstverständlich nur um den Nachweis von proteolytischen Fermenten, von Protearen, handeln. Ebenso wichtig wäre es natürlich, auch auf die Gegenwart von anderen Fermentarten bzw. Vorstufen von solchen zu fahnden. In Anbetracht der degenerativen Prozesse in peripheren Nerven sowie im Rückenmark würden sich diese Nachforschungen auf das etwaige Auftreten von Nukleasen und Phosphatidasen sowie Lipasen im Serum von an alimentärer Dystrophie erkrankten Tieren oder von Beriberipatienten zu erstrecken haben. Leider sind die Methoden, welche zum Nachweis derartiger Fermente bislang zur Verfügung stehen, noch nicht genügend ausgebildet, um zuverlässige Ergebnisse zu verbürgen. 
Beitrag zur Kenntnis von organischen Nahrungsstoffen mit spezif. Wirkung. 125

\section{Versuehe mit einer Reihe durch Hydrolyse aus Bierhefe gewonnener Abbauprodukte.}

Wie alle bislang vorliegenden Versuche immer wieder dargetan haben, kommt der Bierhefe unter den bekannten, natürlich vorkommenden Frgänzungsstoffen (für geschliffenen Reis und eine Reihe anderer insuffizienter Nahrungsmittel) zweifellos die grösste Wirksamkeit gegen alimentäre Dystrophie zu. An anderer Stelle ist bereits nachgewiesen worden, dass alle die bisher aus Hefe gewonnenen und durch Tierversuche geprüften Präparate weder dieselbe relative Stärke noch dieselbe Vielseitigkeit der Wirkung zu entfalten vermögen wie die Hefe selbst. Zwar genügen schon ausserordentlich geringe Gaben des Hefeeutonins (Vitamins), um die im Gefolge der alimentären Dystrophie von Hühnern und besonders von Tauben auftretenden nervösen Störungen zu beseitigen, wenn diese nicht durch tiefergehende degenerative Veränderungen peripherer Nerven oder des Rückenmarks veranlasst sind. Dieser sehr in die Augen fallende, man könnte sagen sensationelle Effekt des Eutonins steht indessen ganz im Vordergrunde seiner Wirksamkeit. Die bei Eutoninzufuhr zugleich auftretende. Steigerung der Fresslust und der anregende Einfluss des Eutonins auf den Stoffwechsel treten dagegen erheblich zurück und halten keinen Vergleich mit der Wirksamkeit der Hefe selbst aus. Sehr ähnlich liegen die Verbältnisse bei der Reiskleie. Andere bisher aus der Hefe gewonnene Präparate, wie Hefenukleinsäure, sowie aus dieser dargestellte Purin- und Pyrimidinbasen entwickeln eine zu einseitige und vorübergehende Wirkung, als dass man ihnen allein eine hervorragende Rolle bei der Gesamtwirkung der Hefe einräumen könnte. Wirksamer ist schon die Phosphatidfraktion der Hefe. Am wirksamsten von allen bislang dargestellten Hefepräparaten ist unstreitig das von uns gewonnene Nukleoproteid bzw. Nuklein, deren Wirksamkeit schon eine viel grössere Vielseitigkeit aufweist als alle anderen bekannten Hefepräparate. Wie aber die im Abschnitt IV besprochenen Versuche erweisen, kann die Wirksamkeit des Hefenukleoproteids noch weiter gesteigert werden dureh Zugabe des durch Erhitzen ton Hefe mit $2 \%$ iger Natronlange gewonnenen Hefepräparates $A$, welches all ein weder imstande ist, die im. Gefolge der alimentären Dystrophie auftretenden nervösen. Störungen zu beseitigen bzw. ihnen vorzubengen, noch auch einseitig mit geschliffenem Reis 
ernährte Tauben auf Gewichtskonstanz und am Leben zu erhalten. Es müssen daher in dem Hefepräparat $A$ noch andere supplementär wirkende Stoffe enthaiten sein, welche dem Hefenukleoproteid bzw. Nuklein mangeln. Diese sowie eine Reihe anderer bereits erörterter Beobachtungen lassen keine andere als die Schlussfolgerung zu, dass der Gesamteffekt der Hefe als die Resultante einer Mehrzahl von Komponenten zu betrachten und nicht auf die Wirkung eines einzigen in ihr enthaltenen Körpers (Eutonin) zurückgeführt werden kann. Dasselbe trifft natürlich für alle anderen natürlich vorkommenden Stoffe zu, die eine aus reinen Hauptnährstoffen - Kohlehydraten, Fetten, Protein und anorganischen Salzen - bestehende Nahrung zu einer vollwertigen zu ergänzen vermögen, und ebenso für alle von Haus aus suffizienten Nahrungsmittel.

Derartige Erwägungen haben uns veranlasst, zu versuchen, durch bydrolytischen Abbau der Hefe den bei ihrer Kollektivwirkung beteiligten einzelnen Substanzen auf die Spur zu kommen. Zwar waren hier von vornherein zwei Umstände nicht ausser acht zu lassen: Erstens war selbstverständlich damit zu rechnen, dass etwaige in der Hefe enthaltene Stoffe von labiler, chemischer Konstitution bei den zu ibrer Isolierung erforderlichen Eingriffen schon weitgebende Veränderungen erleiden und ihre ursprünglichen physiologischen Eigenschaften hierdurch einbüssen könnten. Und zweitens war wohl zu beachten, dass es schwer, wenn nicht unmöglich sein würde, aus dem Verhalten der Versuchstiere bzw, dem Einfluss, welchen einzelne der hier aus dem Gesamtkomplex herausgérissenen Körper beim Tierexperiment übten, zu erkennen, ob den betreffenden Körpern bei dem Zusammenspiel mit anderen in der Hefe enthaltenen Stoffen überhaupt eine Rolle zufiele bzw. welcher Art diese wäre. Trotz dieser Bedenken, und obschon es uns von vornherein klar war, dass es sich hierbei zunächst nur um eine für weitere Nachforschungen grundlegende Orientierung handeln köunte, haben wir uns die Durchführung dieser Arbeit angelegen sein lissen. Die Beschreibung der hierbei angewandten Verfahren, der chemischen und physikalischen Eigenschaften der isolierten Produkte und die mit diesen bei Tierversuchen erzielten Ergebnisse sind mit allen erforderlichen Einzelheiten auf $\mathrm{S} .214$ u. ff. und S. 255 u. ff. angegeben. Wir können uns daher hier auf die Erörterung der wesentlichen Ergebnisse beschränken. Bei dem von uns angewandten Verfahren wurde aus dem Hefe- 
Beitrag zur Kenntnis von organischen Nahrungsstoffen mit spezif. Wirkung. 127

hydrolysat zunächst ein alkoholisches Extrakt dargestellt. Dieses wurde dann bis zur Sirupkonsistenz eingedampft und nun mit Aceton versetzt, bis keine Fällung mehr erfolgte. Dieser primäre Acetonniederschlag wurde nochmals iń möglichst wenig ,Alkohol gelöst uud die konzentrierte Lösung wiederum mit Aceton gefällt. Dieselbe Operation wurde dann zum dritten Male ausgeführt. Bei dem Behandeln der Acetonniederschläge mit absolutem Alkohol blieb in allen Fällen ein unlöslicher Rückstand zurück, der bei dem primären Acetonniederschlag erheblich, bei dem sekundären Acetonniederschlag wesentlich geringer und bei dem tertiären Acetonniederschlag sehr gering war. Durch Dekantation bzw. Filtration wurden auf diese Weise aus dem ursprünglichen alkoholischen Auszuge drei versebiedene Fraktionen gewonnen, nämlich :

I. tertiärer Acetonniederschlag;

II. in absolutem Alkohol des Handels (99\% igem) unlöslicher Anteil der Acetonniederschläge;

III. in Aceton löslicher Anteil des primären alkoholischen Extrakts. Diese drei Fraktionen wurden dann in der im experimentellen Teil genau beschriebenen Weise weiterbehandelt. Hierbei wurde eine Reihe verscbiedener Präparate gewonnen, deren Beziehung zueinander mit Rücksicht auf ihre Herkunft durch die auf S. 217 und 236 aufgezeichneten Schemata veranschaulicht wird. $\mathrm{Zu}$ Tierversuchen wurden auch wiederholt Zwischenprodukte verwandt. Diese konnten selbstverständlich auf Reinheit und Einheitlichkeit keinen Anspruch machen. Die Prüfung dieser Zwischenprodukte erschien uns aber schon deshalb als zweckmässig, weil sie möglicherweise wichtige Anhaltspunkte für die physiologische Bedeutung einzelner Fraktionen liefern und so in gewissem Umfange als Wegweiser dienen konnte: Die im experimentellen Teil genauer angegebenen physikalischen und chemischen Eigenschaften der einzelnen Produkte sollen hier auch nur insoweit berücksichtigt werden, wie dies für die Feststellung ihrer chemischen $\mathrm{Zu}$ sammensetzung bzw. Konstitution oder für ihre Zugehörigkeit zu bestimmten Gruppen von Verbindungen dienlich erscheint. Inwieweit die Untersuchungsergebnisse hierfür die nötigen Grundlagen oder Anhaltspunkte geliefert haben, wird im Schlusswort erörtert werden. Bei einer Mehrzahl von Präparaten waren die gewonnenen Mengen allerdings für eine eingehendere chemische Untersuchung unzureichend. 
Dagegen konnten Tierversuche mit fast allen den dargestellten Präparaten vorgenommen werden.

\section{Tertiärer Acetonniederschlag und aus diesem dargestellte Präparate.}

(Siehe Schema S. 217 und Verzeichnisse S. 271 u. 272.)

1. Tertiärer Acetonniederschlag (S. 166 und S. 216 und S. 255). Das Präparat bildete nach dem Verdampfen des Alkohols unter vermindertem Druck ein dunkelbraunes, dickflussiges und klebriges Extrakt, welches in Wasser und Alkohol leicht löslich war. Es erwies sich als sehr wirksam, um die im Gefolge der alimentären Dystrophie bei Tauben auftretenden nervösen Störungen schnell und sicher zu beseitigen. Durch Dialyse liess sich aus einer Lösung in verdünntem Alkohol ein ebenso wirksames, wenn nicht noch wirksameres Präparat gewinnen. Als Beispiele für die Wirksamkeit seien hier zwei Fälle angeführt: Eine unter typischen nervösen Störungen erkrankte Taube (Photographie Nr. 2) war nach Einspritzung von 15 Tropfen einer konzentrierten Lösung des Acetonniederschlages schon nach $1^{1 / 2}$ Stunden soweit wiederhergestellt, dass sie wieder aufrechtzusitzen (Photographie Nr. 3) und umherzulaufen vermochte. Am nächstfolgenden Tage früh war sie völlig munter. Bei einer anderen, von schweren nervösen Störungen befallenen Taube (Photographie Nr. 4) genügte die intramuskuläre Finspritzung von $0,15 \mathrm{~g}$ (in 3 cem destillierten Wassers gelöst), um das Tier innerbalb einer Stunde so weit wiederherzustellen, wie dies die Photographie Nr. 5 veranschaulicht.

Dagegen erwies sich dasselbe Präparat als völlig unzureichend, un Tauben, die mit geschliffenem Reis einseitig gefüttert wurden, auf Gewichtskonstanz und am Leben zu erhalten, wie dies unter anderem auch die Versuche Nr. 9 (S. 168) sowie Nr. 24 und 25 (S. 255) erwiesen. Hieran änderte die gleichzeitige Zugabe von Aminosäuren bzw. Hefeasche, Rinderblutkörperchen und Betainehlorhydrat nichts Wesentliches. Die gleichzeitige Zugabe des Hefepräparates A, welches für sich allein einseitig mit geschliffenem Reis ernährte Tauben weder vor nervösen Störungen zu bewahren noch gesund zu erhalten vermochte, bewirkte dagegen eine erhebliche Besserung (Versuch Nr. 10, S. 170), wie dies an anderer Stelle schon eingehend erörtert worden ist. Als noch wirksamer erwies sich freilich die Zugabe von $0,5-2 \mathrm{~g}$ Bierhefe pro Tag. 
Auf dem Wege zur Darstellung von Präparat I N 5 (Hefeeutonin) durch Fällung mit Quecksilberchlorid usw. wurden unter anderem die Präparate I A, I A 1 und I A 2 als Zwischenprodukte erhalten. Alle diese Präparate gaben mit Quecksilberchlorid (in alkoholischer Lösung) mit Phosphorwolframsäure und mit Nessler's Reagens starke Niederschläge, mit Folin's Reagens nach Übersättigung mit Natriumkarbonatlösung intensive Blaufärbung. Die mit diesen Präparaten vorgenommenen Tierversuche ergaben folgendes:

2. Präparat IA. Intramuskuläre Einspritzungen von etwa $0,01 \mathrm{~g}$ des Präparates in wässeriger Lösung genügten, um schwere nervöse Störungen bei Tauben innerhalb von wenigen Stunden in drei Fällen zu beseitigen. Bei einem dieser Fälle war eine von schweren nervösen Störungen ergriffene Taube ( $\mathrm{Ph}$ ot $\mathrm{g} \mathrm{graph}$ ie Nr. 9) schon nach 2 Stunden von diesen so gut wie völlig befreit ( $\mathrm{Photo-}$ graphie Nr. 10). In einem anderen Falle (Photographie Nr. 11) war die Wirkung fast ebenso ausgesprochen. Nach $3^{1 / 2}$ Stunden war eine augenfällige Besserung eingetreten (Photographie Nr. 12), und am nächstfolgenden 'Tage erschien das Tier vollkommen gesund und war ganz frei von nervösen Störungen.

Bei einer vierten, ebenfalls von schweren nervösen Störungen befallesen Taube genügte eine Einspritzung von $0,005 \mathrm{~g}$ wohl, um das Tier vou diesen Störungen zu befreien. Diese traten aber schon nach Verlauf von 3 Tagen in heftiger Weise wieder auf.

Eine junge, an den Beinen schwer gelähmte Taube zeigte dagegen ein anderes Verhalten. Zwar vermochten zwei intramuskuläre Einspritzungen von $0,01 \mathrm{bzw} .0,015 \mathrm{~g}$ des Präparates I $\mathrm{A}$ in wässeriger Lösung einen Rückgang der Lähmungen zu bewirken, diese schwanden. aber keineswegs vollkommen. Erst nach 25 tägiger Behandlung zuerst mit Hefenuklein, dann mit sehr wirksamer getrockneter Bierhefe waren die Paresen der Beine völlig geschwunden. Die Photographie Nir. 13 zeigt die Taube nach neuntăgiger Behandlung. Auf dem Bilde sieht man, dass das rechte Bein nach vorn, das linke nach hinten ausgestreckt worden ist. Eine gesunde Taube würde in eine solche Stellung gar nicht zu bringen sein.

3. Präparat I A 1, welches aus Präparat I A durch wiederholte Fällung mit Quecksilberchlorid aus alkoholischer Lösung und Zerlegung des Niedersehlages gewonnen war, erwies sich in einer einmaligen intramuskulären Gabe von $0,01 \mathrm{~g}$ als sehr wirksam. Schwere 
nervöse Störungen wurden bei einer Taube hierdurch innerhalb von 3 Stunden fast restlos beseitigt.

4. Präparat I A 2 (aus Präparat I A 1 durch nochmalige Fällung mit Quecksilberchlorin aus alkoholischer Lösung dargestellt) bewirkte schon nach Einspritzung von zwei Gaben von je $0,0025 \mathrm{~g}$ in wässeriger Lösung eine ausgesprochene Befreiung von vorhandenen Ausfallserscheinungen.

5. Präparat I N 5 (Hefeeutonin). Dieser durch die zum vierten Male wiederholte Fällung mit Quecksilberchlorid und Zerlegung des Niederschlages mit Schwefelwasserstoff aus Präparat I A 2 gewonnenen sowie durch wiederholtes Auflösen mit 100\% igem Alkohol und anschliessende Filtration weiter gereinigten Substanz kam eine sehr grosse Wirksamkeit zu: Die einmalige intramuskuläre Einspritzung von $0,005 \mathrm{~g}$ in wässeriger Lösung war nicht nur ausreichend, um eine an alimentärer Dystrophie schwer erkrankte Taube (Photographie Nr. 30) von allen nervösen Störungen innerhalb von 16 Stunden ganz zu befreien (Photographie Nr. 31), sondern sie genügte auch, um das Tier 19 Tage lang frei von dem Wiederauftreten derartiger Störungen zu erhalten. Die Nahrung des Versuchstieres hatte während der ganzen Dauer des Versuches aus derselben Qualität geschliffenen Reises bestanden, so dass eine Beeinflussung durch veränderte Ernährung völlig ausgeschlossen war.

In grösseren Gaben erwies sich das Präparat als giftig. Die intramuskuläre Einspritzung von $0,15 \mathrm{~g}$ (in wässeriger Lösung) zog bei einer Taube fast unmittelbar nach der Einspritzung heftigen Streckkrampf des ganzen Körpers, wobei die Beine starr nach hinten standen, nach sich (wie auf Photographie Nr. 7). Eine Viertelstunde nach der Einspritzung verendete die Taube.

Das Präparat I N 5, bei welchem es sich um das chlorwasserstuffsaure Salz handelte, bildete nach dem Trocknen über Schwefelsäure im Vakuumexsikkator eine mit Kristallen dicht durchsetzte, bräunliche, äusserst hygroskopische und klebrige Substanz, die in Wasser und Alkohol leicht löslich, in Äther, Aceton, Essigäther und Chloroform dagegen unlöslich war. Beim Erhitzen für sich sowie mit Natronkalk entwickelte sie Dämpfe, die stark an Trimethylamin erinnerten und im letzteren Falle angefeuchtetes Lakmuspapier blau färbten. Die wässerige Lösung gab Niederschläge mit Phosphorwolframsäure (weiss), mit saurem Quecksilbersulfat (weiss), mit 
Nessler's Reagens (hellgelb) und mit Jodjodkalium (dunkelbraun). Die alkoholische Lösung gab mit Quecksilberchlorid einen starken weissen Niederschlag. Durch Versetzen mit Platinchlorid, Eindampfen bei niedriger Temperatur, Auswaschen mit Alkohol und Umkristallisieren aus Wasser gelang es, ein Platinchloriddoppelsalz darzustellen. Beim Kochen der wässerigen Lösung mit einigen Tropfen einer $1 \%$ igen Ninhydrinlösung trat starke Blaufärbung auf. Btim Versetzen der wässerigen Lösung mit Fol ins Reagens und Übersättigen $m$ it konzentrierter Natriumkarbonatlösung färbte sich das Reaktionsgemisch ebenfalls intensiv blau.

Bei der mikroskopischen Prüfung wurde folgendes beobachtet:

Das chlorwasserstoffsaure Salz bestand aus äusserst feinen, in der Luft zerfliesslichen Nädelchen. Beim Lösen des chlorwasserstoffsauren Salzes in einem Tröpfchen $1 \%$ iger Schwefelsäure und nach Eindampfen dieser Lösung auf einem Objektträger bei $37^{\circ} \mathrm{C}$. bildeten sich nadelförmige, zu Drusen oder Büscheln vereinigte Kristalle (Mikrophotographien Nr. 38 und 39). Diese Krystalle zeigten bei starker Vergrösserung im polarisierten Licht und bei gekreuzten Nicols das auf der Mikrophotographie Nr. 40 wiedergegebene Bild. Wurde das chlorwasserstoffsaure Salz mit wenig $1 \%$ iger Phosphorsäure versetzt und die hierbei entstehende Lösung langsam bei niedriger Temperatur eingedampft, so bildeten sich Kristalle, wie sie die Mikrophotographie Nr. 41 zeigt. Es erforderte jedoch zuweilen ziemlich viel Geduld und Mühe, um die Bildung lieser Kristalle hervorzurufen. Die Menge der zugesetzten Phosphorsäure sowie der beim Eindampfen der Lösung verstreichende Zeitraum und die hierbei einwirkende Temperatur scheinen für das Entstehen gut ausgebildeter Kristalle bestimmend zu sein. Das bereits erwähnte Platinchloriddoppelsalz lieferte beim langsamen Eindampfen in reiner wässeriger Lösung auf einem Objektträger die auf der Mikrophotographie Nr. 42 dargestellten Kristalle. Beim Versetzen von einem Tropfen der wässerigen Lösung des Präparates I N 5 mit Jodjodkaliumlösung auf einem Objektträger entstand sofort ein starker, aus mikroskopischen Kügelchen bestehender dunkelbrauner Niederschlag (Periodid), wie dies bei einigen der Verbindungen aus der Cholingruppe (Betain u. a. m.) ebenfalls erfolgt. Während aber bei letzterem aus diesem kugelförmigen Gebilde nach kurzer Zeit nadelförmige Kristalle zu entstehen pflegen, wurde dieser Vorgang bei 
Präparat I N 5 im Laufe einer Reihe von Versuchen in keinem Falle beobachtet.

Ein bemerkenswertes Verhalten zeigte die Lösung des Präparates $I N 5$ in $100 \%$ igem Alkohol. Die frischbereitete und anfangs vollkommen klare Lösung trübte sich schon nach einigen Stunden. Im Laufe von 8-10 Tagen entstand dann ein Niederschlag. Wurde dieser abfiltriert, mit stark verdünnter alkoholischer Natronlauge annähernd neutralisiert und dann mit einer gesättigten alkoholischen Pikrinsäurelösung versetzt, so bildeten sich sofort Kristalle, wie sie die Mikrophotographie $\mathrm{Nr} .43$ (schwächer vergrössert) und Nr. 44 (stärker vergrössert) zeigen. Diese Kristalle wiesen die grösste Ähnlichkeit mit denen des Betainpikrats auf, die auf der Mikrophotographie Nr. 45 wiedergegeben sind. Dies ist deshalb bemerkenswert, weil aus dem Acetonniederschlag auch erhebliche Mengen von Betainchlorhydrat (Präparat I R 1) gewonnen wurden. Man könnte darum denken, dass das Präparat I N 5 durch irgendeine Umwandlung (Umlagerung, Wasserzutritt) in Betainchlorhydrat übergeht. Leider waren die aus der alkoholisehen Lösung des Präparates I N 5 gewonnenen Mengen des Niederschlages für eine eingehende Untersuchung und eine auf diese sich stützende Entscheidung dieser Frage unzureichend.

Für das Platinsalz von I N 5 wurden folgende Werte gefunden:

1. $21,16 \% \mathrm{C}, 4,54 \% \mathrm{H}, 6,00 \% \mathrm{~N}, 28,68 \% \mathrm{Cl}, 34,16 \% \mathrm{Cl}$ und $28,38 \% \mathrm{Pt}$;

2. $20,95 \% \mathrm{C}, 4,40 \% \mathrm{H}, 33,96 \% \mathrm{Cl}$ und $28,45 \% \mathrm{Pt}$.

Das salzsaure Salz ergab, wie die S. 220 mitgeteilten Werte zeigen, auch keine bestimmten Anhaltspunkte.

Die Werte der Elementaranalyse lassen keine Formel berechnen. Der relativ hohe Aschengehalt störte. Ferner war die Substanz so hygroskopisch, dass sie kaum zur Gewichtskonstanz zu bringen war. Bei stärkerem Trocknen war die Gefahr einer Zersetzung gross. Allem Anschein nach gehört die so _ wirksame Substanz in die Gruppe der Betaine. Es wird unser nächstes Bestreben sein, dieses Produkt in reinem Zustand zu gewinnen. Die Vorbereitungen dazu sind schon im Gange.

6. Präparat I R 1. Bei Befolgung des auf S. 216 schematisch wiedergegebenen Verfahrens wurden aus dem Acetonniederschlage erhebliche Mengen dieses Präparates dargestellt. Seine 
Beitrag zur Kenntnis von organischen Nahrungsstoffen mit spezif. Wirkung. 133

Ausbeute übertraf bei weitem die aller anderen aus dieser Fraktion gewonnenen Präparate. Das durch wiederholtes Umkristallisieren gereinigte Produkt bildete eine weisse, aus farblosen Kristallen bestehende Substanz, die sich bei eingehender Untersuchung als Bet a inchlorhy drat erwies. Dieser Befund wurde durch das physikalische Verhalten des Präparates, durch die mit ihm angestellten Reaktionen, ferner durch die bei der Elementaranalyse gefundenen Werte für Kohlenstoff, Wasserstoff, Stickstoff und Chlor sowie schliesslich noch durch die Eigenschaften des aus dem salzsauren Salze gewonnenen Pikrats sichergestellt. Eingehende Angaben hierüber finden sich auf S. 221-223.

Die Elementaranalyse ergab für I R 1 :

1. $38,96 \% \mathrm{C}, 7,43 \% \mathrm{H}$ und $9,23 \% \mathrm{~N}$;

2. $39,20 \% \mathrm{C}, 7,51 \% \mathrm{H}, 9,19 \% \mathrm{~N}$ und $23,20 \% \mathrm{Cl}$.

Berechnet für Betainchlorhydrat: $\mathrm{C}_{5} \mathrm{H}_{12} \mathrm{NClO}_{2}: 39,10 \% \mathrm{C}, 7,82 \% \mathrm{H}$, $9,12 \% \mathrm{~N}$ und $23,10 \% \mathrm{Cl}$.

Es lag somit unzweifelhaft Betain vor.

Die mit diesem Präparat angestellten Tierversuche lieferten keine eindeutigen Ergebnisse. Fin Teil der im Gefolge der alimentären Dystrophie bei Tauben auftretenden nervösen Störungen schien allerdings durch intramuskuläre Einspritzungen von $0,05-0,25 \mathrm{~g}$ des Präparates günstig beeinflusst zu werden. Hierzu gehörten vor allem die häufig auftretenden Streckkrämpfe und Konvulsionen. Dagegen war in vier Fällen eine auf die Lähmung der Beine sich erstreckende günstige Wirkung nicht deutlich zu beobachten.

Ein Dauerversuch, bei welchem eine einseitig mit geschliffenem Reis ernährte Taube täglich eine Zugabe von $0,05 \mathrm{~g}$ des Präparates I R 1 per os bekam, liess auch eine günstige Beeinflussung des Verlaufes nicht erkennen: Die Versuchstaube nabm von Anfang des Versuchs an stark an Körpergewicht ab und erkrankte nach 33 Tagen unter Auftreten typischer nervöser Störungen.

Bei einer gesunden Taube wurde nach intramuskulärer Einspritzung von $0,2 \mathrm{~g}$ des Präparates in wässeriger Lösung keinerlei Wirkung beobachtet. Über die Wirkung des Betains auf höhere Tiere finden sich in der Literatur unter anderem nachstehende Angaben: Walter und Plimmer) wie auch Kohlrausch ${ }^{2}$ ) beob-

1) Proceedings Royal Society vol. 72 p. 345. 1903.

2) Zentralbl. f. Physiol. Bd. 23 S. 154. 1909. 
achteten nach intravenöser Einspritzung von Betain Speichelfluss, Blutdrucksenkung, Dyspnöe und Atemstillstand. Bei oraler Anwendung scheint Betain ein in Jifferenter Körper zu sein. Andrlik, Velich und Stánekl) gaben einer Kuh wochenlang $144 \mathrm{~g}$ Betain täglich in Form von Melasse mit der Nahrung, ohne dass hierbei irgendwelche abnorme Erscheiuungen beobachtet wurden.

$O b$ Betain in verhältnismässig so grosser Menge in der Hefe selbst ursprünglich enthalten ist oder erst durch die bei den zur Darstellung des Präparates I R 1 vorgenommenen chemischen Eingriffen aus anderen ihm nahestehenden Verbindungen gebildet worden war, muss vorläufig dahingestellt bleiben.

7. Präparat I R 2 (S. 224 u. 260). Die mit diesem Zwischenprodukt bei zwei Tierversuchen gemachten Erfahrungen liessen ebenfalls keine deutliche Einwirkung auf die nervösen Störungen, welche bei zwei an alimentärer Dystrophie erkrankten Tauben aufgetreten waren, erkennen. Zwar schwanden in einem Falle der Opisthotonus und die Krämpfe, auch war gesteigerte Fresslust zu beobachten, aber die Lähmungen der Beine blieben unverändert.

Nach dem Ergebnis der Elementaranalyse und besonders dem Verhalten beim Erhitzen der freien Substanz und des Kupfersalzes lag nicht ganz reines Prolin vor.

8. Präparat IR 3 (S. 230 u. 260). Dieses aus dem Präparat 1 R 2 gewonnene Präparat bestand in der Hauptsache ebenfalls aus Betainchlorhydrat, welches durch geringe Beimengung verunreinigt war. Eine weitere Reinigung war wegen der geringen Menge, die zur Verfügung stand, nicht durchführbar.

Die bei zwei Tierversuchen erzielten Ergebnisse deckten sich im wesentlichen mit denjenigen, welche bei Anwendung der Präparate I R 1 (reines Betainchlorhydrat) und Präparat I R 2 (unreines Betainchlorhydrat) erhalten worden waren.

9. Präparat I R 4 (S. 224). Die chemische Untersuchung ergab, dass auch dieses Prïparat in der Hauptsache aus Betainchlorhydrat bestand. Von weiteren Tierversuchen wurde deshalb Abstand genommen. Eine weitere Reinigung des Präparates war wegen der geringen zur Verfügung stehenden Menge auch hier nicht tunlich.

10. Präparat I B 3a (S. 226) erwies sich ebenfalls als fast

1) Zentralbl. f. Physiol. Bd. 16 S. 452.1902. 
reines Betainchlorhydrat. Von weiteren Tierversuchen wurde daher abgesehen.

11. Präparat I B 1 (S. 232 u. 261). Ein mit diesem unreinen Zwischenprodukt ausgeführter Tierversuch führte nicht zu eindeutigen Ergebnissen. Bei einer unter typischen nervösen Störungen (Streckkrampf, Opisthotonus, starken Reflexen) erkrankten Taube (Photog r a p h i e Nr. 26-28) gingen diese Erscheinungen nach intramuskulärer Einspritzung von $2 \mathrm{~g}$ des Präparates zwar zum grössten Teil zurück (Photographie Nr. 29), aber die Lähmung sowie der Streckkrampf der Beine blieben bestehen. Nach einer Einspritzung von $0,02 \mathrm{~g}$ des sehr wirksamen Präparates I A schwand allerdings der Streckkrampf der Beine; das Tier erbolte sich aber nicht weiter und ging einige Stunden später ein.

12. Präparat I B 2 (\$. 229 u. 262). Dieses aus mikroskopischen Kristallen bestehende Präparat, dessen physikalische und chemische Eigenschaften auf S. 229 näher angegeben sind, wirkte ähnlich wie Präparat I B 1. Die bei einer an alimentärer Dystrophie erkrankten Taube aufgetretenen - nervösen Störungen schwanden nach zweimaliger intramuskulärer Einspritzung von je $0,025 \mathrm{~g}$ in wässeriger Lösung nur zum Teil. Die Lähmung der Beine blieb unverändert. Da das Präparat nicht rein war, ist das Ergebnis der biologisehen Prüfung nicht eindeutig.

13. Präparat I B 3 c (S. 228 u. 262). Es handelt sich bei diesem Präparate um eine in der Hauptsache kolloide Substanz, in der sich nach längerem Stehen im Vakuumexsikkator über Schwefelsäure eine geringe Menge von Kristallen ausschied. Angaben über einige mit dieser Substanz angestellte Reaktionen finden sich im experimentellen Teil. Zu einer eingehenden chemischen Untersuchung waren die gewonnenen Mengen indessen zu gering. Es muss deshalb auch dahingestellt bleiben, ob die Substanz rein und einheitlich war. Bei drei mit diesem Präparate angestellten Tierversuchen war eine deutliche Wirkung gegen die nervösen Störungen bei den betreffenden, an alimentärer Dystrophie erkrankten Tauben nicht zu bemerken.

14. PräparatIR 6 (S. 227 u. 261). Die Ausbeute war sehr gering, so dass nur einige wenige chemische Reaktionen sowie zwei Tierversuche mit diesem Präparat angestellt werden konnten. Die Mikrophotographie Nr. 46 zeigt die Form der Kristalle, welche bei langsamem Eindampfen der wässerigen Lösung des Präparates auf 
einigen Objektträgern zurückblieben. Bei intramuskulären Einspritzungen der wässreigen Lösung von 0,025 bzw. $0,05 \mathrm{~g}$, welche bei zwei an alimentärer Dystrophie erkrankten Tauben vorgenommen wurden, erwies sich das Präparat als sehr giftig. In beiden Fällen trat unmittelbar wach den Einspritzungen heftiger Streckkrampf (s. Photographie Nr. 7) der Beine auf. Beide Tauben verendeten 10 bzw. 15 Minuten nach erfolgter Finspritzung.

\section{In absolutem Alkohol des Handels unlöslicher Anteil. des Acetonniederschlages (S. 232).}

Durch Auflösen in destilliertem Wasser, Filtrieren und Wiedereindampfen unter vermindertem Druck wurde aus dieser Fraktion eine dunkelbraune Substanz gewonnen, die einen intensiven, an Fleischextrakt erinnernden Geruch besass. Durch die im experimentellen Teil mit allen Einzelheiten angegebenen Verfahren konnten aus ihr Purinbasen sowie eine sehr geringe Menge einer kristallinischen organisehen Substanz (Mikrophotographie Nr. 47) gewonnen werden. Betainchlorhydrat, welches in den anderen Fraktionen (I und. III) in relativ grossen Mengen gefunden wurde, war hier nicht nachzuweisen.

Gegen die nervösen Störungen, wie sie im Verlaufe der alimentären Dystrophie bei Tauben aufzutreten pflegen, war die Substanz unwirksam. Sie enthielt demnach Hefeeutonin in irgendwelchen in Betracht kommenden Mengen nicht mehr.

Zwei an Tauben angestellte Dauerversuche ergaben beide, dass das Präparat bei einseitiger Ernährung der Versuchstiere mit geschliffenem Reis, in Zugaben von täglich $0,2-1,0 \mathrm{~g}$ gereicht, weder instande war, die Versuchstauben auf Gewichtskonstanz noch gesund zu erhalten. Bei diesen Versuchen (Nr. 27 u. 28, S. 262 u. ff.) erkrankten die betreffenden Tauben unter starker Abmagerung nach 45 bzw. 29 Tagen in typischer Weise an alimentärer Dystrophie.

Sehr auffallend war indessen, dass die Fresslust bei beiden Tauben in bemerkenswerter Weise erhalten blieb. Der Appetit pflegt ja sonst bei einseitiger Ernährung mit geschliffenem Reis sehr schnell nachzulassen. So betrug zum Beispiel bei zwei Versuchen, von denen der eine 35 , der andere 45 Tage währte, die spontan aufgenommene Reismenge im Durchsebnitt pro Tag 7,16 bzw. $6,45 \mathrm{~g}$. Bei den beiden vorstehend beschriebenen Versuchen Nr. 27 u. 28 beliefen sich dagegen 
Beitrag zur Kenntnis von organischen Nahrungsstoffen mit spezif. Wirkung. 137

die täglich spontan aufgenommenen Mengen von geschliffenem Reis auf durehschnittlich 19,3 bzw. $16,1 \mathrm{~g}$. Dies ergibt beim Vergleich beider Versuchsreihen im arithmetischen Mittel ein Verhältnis der spontan aufgenommenen Futtermengen von $6,8: 17,7$ oder von $100: 260$.

Sehr beachtenswert war bei diesen Versuchen auch, dass die Gewichtsabnahme beider Tauben trotz der verhältnismässig grossen Mengen, welche sie von dem geschliffenen Reis frassen, eine sehr erhebliche war. Dies ist um so bemerkenswerter, weil die von den Tauben verzehrten Mengen von geschliffenem Reis bei täglicher $\mathrm{Zu}$ fuhr von nur $0,5 \mathrm{~g}$ getrockneter Hefe vollkommen genügten, um Tauben ausreichend zu ernähren und gesund zu erhalten, wie dies der Versuch Nr: 29 erweist. Dieser Versuch ist deshalb sehr lehrreich, weil er in deutlichster Weise zeigt, in wie hohem Maasse durch geringe Hefemengen die Verwertung des aufgenommenen geschliffenen Reises beeinflusst wird.

\section{In Aceton löslicher Anteil des konzentrierten, primären alkoholischen Auszuges aus hydrolysierter Hefe (S. 235).}

Über die zahlreichen aus dieser Fraktion gewonnenen Präparate und über ihre genetischen Beziehungen zueinander gibt das Schema auf S. 236 eine allgemeine Übersicht. Auf S. 271 findet sich ferner ein Verzeichnis sämtlicher hierher gehörigen Präparate nebst Angabe der Seiten, auf welchen Eingehendes über die physikalischen und chemischen Eigenschaften der einzelnen Präparate berichtet ist. Ein Verzeichnis der mit diesen Präparaten vorgenommenen Tierversuche nebst Angabe der Seiten, auf denen diese Versuche beschrieben sind, findet sich auf S. 272. Wir können uns daher auch hier auf die Erörterungen der wesentlichen Ergebnisse beschräuken.

1. Präparat III $R$ (S. 237). Durch eingehende Untersuchung wurde festgestellt, dass dieses Präparat mit dem Präparate I $\mathbf{R} 1$ identisch (Betainchlorhydrat) war. Von weiteren Tierversuchen wurde aus diesem Grunde abgesehen.

2. Präparat III N 4 (S. 238). Die Menge, welche von diesem Präparate gewonnen werden konnte, war äusserst gering und sowohl für eine eingehendere chemische Untersuchung wie auch für Tierversuche unzureichend. 
3. Präparat III F 8 (S. 239 u. 266). Bei diesem Präparate handelte es sich offenbar nicht um eine einheitliche chemische Verbindung. Versuche, durch Anwendung verschiedener Lösungs- bzw. Fällungsmittel zu einer reinen Verbindung oder mehreren solchen zu gelangen, schlugen fehl.

Das Präparat erwies sich bei einem Versuche als recht wirksam, um die bei einer (an alimentärer Dystrophie erkrankten) Taube aufgetretenen Lähmungen der Beine zu beseitigen. Zur Anwendung kamen hierbei wiederholte intramuskuläre Einspritzungen von 0,05 $\mathrm{bzw} .0,1 \mathrm{~g}$ des Präparates in wässeriger Lösung.

4. Präparat III R 8 (S. 240 u. 266) wurde bei der eingehenden chemischen Untersuchung als reines oder doch fast reines Betainchlorhydrat erkannt. Da mit diesem bereits eine grössere Anzahl von Tierversuchen angestellt worden war, wurde von weiteren solchen Versuchen abgesehen.

5. Präparat III N 8 (S. 241) bestand aus schwach gelblich gefärbten Nadeln, die äusserst hygroskopisch waren und in wässeriger Lösung sich als optisch schwach aktiv erwiesen. Sowohl für sich, wie auch mit Natronkalk erhitzt, entwickelte die Substanz nach Trimethylamin riechende Dämpfe, die angefeuchtetes rotes Lackmuspapier blau färbten. Mit Silbernitrat gab die wässerige Lösung der Substanz einen starken, in Salpetersäure unlöslichen, in überschüssigem Ammoniak leicht löslichen Niederschlag. Es handelte sich bei ihr also um das Chlorhydrat einer stickstoffhaltigen organischen Substanz. In der wässerigen Lösung der Substanz entstanden ferner starke Niederschläge bei Zusatz der nachstehenden Reagenzien: Phosphorwolframsäure (weiss), N e s s l er's Reagens (gelblich-weiss), Quecksilberchlorid (weiss), Jodjodkaliumlösung (dunkelbraun).

Bei der mikroskopischen Prüung des nach Zusatz von Jodjodkaliumlösung entstandenen Niederschlages erwies sich dieser als aus kleinen Kügelchen bestehend. Eine nachträgliche Bildung von Kristallen, wie sie bei gleicher Behandlung von Cholin und Betain (Periodide) entstehen, wurde hier bei mehrfachen Versuchen nicht beobachtet.

Durch geeignete Behandlung mit Platinchlorid liess sich die Substanz in ein gut kristallisierendes Platinchlorid-Doppelsalz überführen. Die Photographie Nr. 53 zeigt seine Kristalle in natürlicher Grösse, die Mikrophotographie Nr. 54 den Rück- 
Beitrag zur Kenntnis von organischen Nahrungsstoffen mit spezif. Wirkung. 139

stand eines Tropfens der wässerigen, auf einem Objektträger langsam eingedunsteten Lösung des Platinchlorid-Dopppelsalzes bei stärkerer Vergrösserung. Dieses Platinchlorid-Doppelsalz schmolz unter Zersetzung bei $201^{\circ} \mathrm{C}$. und enthielt $31,63 \%$ Platin.

Aus dem Chlorhydrat liess sich nach dem im experimentellen Teil beschriebenen Verfahren ein in Nadeln kristallisierendes Pikrat (Mikrophotographie Nr. 52) darstellen, welches bei $231^{\circ} \mathrm{C}$. unter Zersetzung schmolz.

Die Elementaranalyse des Körpers III N 8 ergab:

1. Salzsaures Salz: $42,81 \% \mathrm{C}, 9,84 \% \mathrm{H}, 9,81 \% \mathrm{~N}$, $25,41 \% \mathrm{Cl}$;

2. Platinsalz: $19,52 \% \mathrm{C}, 4,54 \% \mathrm{H}, 4,62 \% \mathrm{~N}, 33,77 \% \mathrm{Cl}$ und $32,03 \%$ Pt;

3. Pikrat: $39,27 \% \mathrm{C}, 4,04 \% \mathrm{H}$ und $17,59 \% \mathrm{~N}$.

Die gefundenen Werte stimmen ziemlich gut auf eine Substanz der Zusammensetzung: $\mathrm{C}_{5} \mathrm{H}_{13} \mathrm{NO}$.

Es ergibt: $\mathrm{C}_{5} \mathrm{H}_{14} \mathrm{NOCl}$ :

$43,02 \% \mathrm{C}, 10,00 \% \mathrm{H}, 10,00 \% \mathrm{~N}, 11,49 \% \mathrm{O}$ und $25,42 \% \mathrm{Cl}$;

$\left(\mathrm{C}_{5} \mathrm{H}_{13} \mathrm{NO} \cdot \mathrm{HCl}\right)_{2} \cdot \mathrm{PtCl}_{4}$ ergibt:

$19,52 \% \mathrm{C}, 4,55 \% \mathrm{H}, 4,55 \% \mathrm{~N}, 34,60 \% \mathrm{Cl}$ und $31,25 \% \mathrm{Pt}$;

Pikrat: $\mathrm{C}_{5} \mathrm{H}_{13} \mathrm{NO} \cdot \mathrm{C}_{6} \mathrm{H}_{2}\left(\mathrm{NO}_{2}\right)_{3} \mathrm{OH}$ :

$$
39,76 \% \mathrm{C}, 4,82 \% \mathrm{H} \text { und } 16,90 \% \mathrm{~N} \text {. }
$$

Wir dachten zuerst, dass Neurin vorläge. Allein die gleich $\mathrm{zu}$ besprechenden physiologischen Untersuchungen zeigten, dass deren Ergebnisse nicht den Eigenschaften dieser Verbindung übereinstimmten. Herr Dr. Hans Lieb in Graz hatte die Freundlichkeit, die Anzahl der Methylimidgruppen mittels der mikroanalytischen Methode festzustellen. Die Bestimmung ergab, dass zwei $\mathrm{NH}_{3}$-Gruppen am Stickstoff sitzen. Gefunden: $22,07 \% \mathrm{CH}_{3}$, berechnet für $2 \mathrm{CH}_{8}: 21,52 \%$. Drei $\mathrm{CH}_{3}$-Gruppen würden $32,3 \%$ verlangen. Es liegt somit offenbar die folgende Verbindung vor:

$$
\mathrm{N}=\begin{aligned}
& \mathrm{CH}=\mathrm{CH} \cdot \mathrm{CH}_{3} \\
& \mathrm{CH}_{3} \\
& \mathrm{CH}_{3} \\
& \mathrm{Cl}
\end{aligned}+\mathrm{H}_{2} \mathrm{O}
$$

$=$ wasserhaltiges Hydrochlorid des Dimethyl-propenylamin (bzw. wasserhaltiges Dimethyl-propenyl-ammoniumchlorid). 
Mit der empirischen Formel $\mathrm{C}_{5} \mathrm{H}_{14} \mathrm{ONCl}$ stimmen auch die Hydrochloride der Verbindungen:

oder:

$$
\mathrm{N}=-\begin{aligned}
& \mathrm{CH}_{2} \cdot \mathrm{CH}(\mathrm{OH}) \cdot \mathrm{CH}_{3} \\
& \mathrm{CH}_{3} \\
& \mathrm{CH}_{3}
\end{aligned}
$$

$$
\mathrm{N}=-\underset{\mathrm{CH}_{2}}{\mathrm{CH}_{3}} \cdot \mathrm{CH}_{2} \cdot \mathrm{CH}_{2} \cdot \mathrm{OH}
$$

überein. Beide Basen sind von A. Lade $\mathrm{nburg}^{1}$ ) dargestellt worden. Der ersteren Formel entspricht das aus Dimethylamin und Propylenchlorliydrin: $\mathrm{CH}_{3}: \mathrm{CH}(\mathrm{OH}) \cdot \mathrm{CH}_{2} \mathrm{Cl}$ gewonnene Produkt und der zweiten das aus Dimethylamin und Äthylenchlorhydrin: $\mathrm{CH}_{2} \mathrm{Cl} \cdot \mathrm{CH}_{2} \mathrm{OH}$ dargestellte. Leider sind beide Verbindungen nur sehr kurz beschrieben, doch lässt sich erkennen, dass unsere Verbindung mit den beiden Basen in ihren Eigensehaften nicht übereinstimmt. Beide werden als Flüssigkeiten beschrieben. Das sogenannte Dimethylpropylalkin siedet bei 124,5 bis $126,5^{\circ}$ und bildet ein im Wasser sehr leichtlösliches Platinsalz, das in Prismen kristallisiert. Die zweite Verbindung, das Dimethyl-äthylalkin ist von $\mathrm{Lade}$ burg nicht in reinem Zustand erhalten worden. Die Base ging bei $130-134^{\circ}$ über. Das Goldsalz zeigte seidenglänzende Nadeln. Das Platinsalz ist in Wasser leicht löslich und bildet prachtvolle Prismen. Unsere Base entfärbt in wässriger Lösung Kaliumpermanganatlösung in der Kälte sofort, ferner wird Brom anfgenommen. Es scheint, dass ein schwer lösliches Additionsprodukt entsteht. Infolge Mangel an Material konnte dieses Produkt noch nicht ausreichendi untersucht werden. Ebenso konnte das freie Amin in seinen Eigenschaften noch nicht genügend studiert werden. Wird das Hydrochlorid mit der berechneten Menge Natronlauge versetzt und der Auszug eingedampft, dann erstarrt der Rückstand zu einer mikrokristalinischen Masse, die offenbar hygroskopisch ist.

Wir konnten in der Literatur die Verbindung Dimethylpropenyl-amin nicht auffinden. Herr Prof. Jacobsohn hatte die grosse Freundlichkeit, uns mitzuteilen, dass ihm die Verbindung auch neu erscheine. Wir hätten somit ein bisher unbekanntes

1) Vgl. A. Ladenburg, Berichte d. D. Chem. Ges. Jahrg. 1914 S. 240708. (1881.) 
Beitrag zur Kenntnis von organischen Nahrungsstoffen mit spezif. Wirkung. 141 methyliertes Amin aufgefunden. Der Base selbst, dem Dimethyl-propenyl-amin, kommt die Formel:

$$
\begin{aligned}
& \mathrm{CH}=\mathrm{CH} \cdot \mathrm{CH}_{3} \\
& \mathrm{CH}_{3} \\
& \mathrm{CH}_{3} \\
& \mathrm{OH}
\end{aligned}
$$

zu. Die Synthese dieser Verbindung und ihr Vergleich mit dem von uns isolierten Produkte wird erst ein endgültiges Urteil über die Richtigkeit der angenommenen Struktur geben. Woher diese Verbindung stammt, d. h. ob sie frei in der Hefe vorkommt oder aber als Baustein einer żusammengesetzten Verbindung aufzufassen ist, muss zur Zeit dahingestellt bleiben. Ihre Herkunft soll weiter studiert werden. Es ist das neue Amin auch in physiologischer Hinsicht noch eingehend zu studieren. Die Verbindung sei Aschamin genannt.

Bei Tierversuchen wurde durch intramuskuläre Einspritzungen wässeriger Lösung von $0,02-0,08 \mathrm{~g}$ des Präparates III N 8 eine Wirkung gegen die bei der alimentären Dystrophie der Tauben auftretenden nervösen Störungen nicht beobachtet. Bei zwei unter derartigen Erscheinungen erkrankten Tauben riefen Einspritzungen wässeriger Lösung von $0,02 \mathrm{~g}$ bzw. $0,08 \mathrm{~g}$ des Präparates dagegen heftige Streckkrämpfe hervor. Bei einer dieser Tauben, die für alimentäre Dystrophie typische Symptome anfwies (Photographie Nr. 6), stellte sich der Streckkrampf sehr bald nach Einspritzung einer wässerigen Lösung von $0,02 \mathrm{~g}$ des Präparates (Photographie Nr. 7) ein. Er schwand in diesem Falle aber schon nach etwa einer halben Stunde. Nach einer zweiten ebensolchen Einspritzung drohte die Taube einzugehen. Ihr wurde deshalb $1 \mathrm{~g}$ getrocknete Hefe in Pillenform eingegeben. Am nächsten Morgen war das Tier wieder recht munter (Photographie Nr. 8) und erholte sich im Laufe des Tages völlig. Bei einer zweiten, ebenfalls an alimentärer Dystrophie erkrankten Taube rief die Einspritzung einer wässerigen Lösung von $0,08 \mathrm{~g}$ fast sofort s̀ehr heftigen Streckkrampf hervor. Die Taube erschien hierbei moribund und erhielt deshalb eine Einspritzung von Hefeeutonin. Obwohl der Streckkrampf etwa 3 Stunden lang anhielt, erholte sich die Taube, nachdem er geschwunden war, sehr schnell und war 4 Stunden nach der Einspritzung des Präparates III N. 8 wieder recht munter. Merkwürdigerweise vertrugen dagegen gesunde Tauben Ein- 
spritzungen von $0,02-0,04 \mathrm{~g}$, ohne dass diese irgend welche besonderen Erscheinungen hervorriefen. Die Vergiftungserscheinungen bei den beiden kranken Tauben hatten grosse Ähnlichkeit mit denen, welche nach intramuskulärer Einspritzung von Cholinchlorhydràt aufzutreten pflegen. Während von diesem intramuskuläre Einspritzungen von $0,0015-0,002 \mathrm{~g}$ bei gesunden Tauben schon schwere Vergiftungserscheinungen nach sich zogen, wie frühere Versuche zeigten ${ }^{1}$ ), wurden von dem Präparat III N 8 die 20 fache Menge von gesunden Tauben gut vertragen.

6. Präparat III R 2 (S. 245 u. 267). Das Präparat bildete eine weisse mikrokristallinische Substanz, die auf Platinblech erhitzt verbrannte, ohne einen Rückstand zu hinterlassen. Mit Natronkalk erhitzt, entwickelte sie Dämpfe, die feuchtes, rotes Lakmuspapier blau färbten. Die wässerige Lösung des Präparates gab mit Phosphorwolframsäure und mit Mill on's Reagens starke weisse Niederschläge und beim Kochen mit einigen Tropfen einer $1^{\circ}, 0$ igen Ninhydrinlösung starke Blaufärbung. Durch Kochen einer wässerigen Lösung des Präparates mit frischgefälltem Kupferoxyd und angeschlossene Filtration wurde eine blaue Lösung erhalten, aus der sich beim langsamen Eindampfen ein dunkelblaues Kupfersalz in blättehenförmigen Kristallen ausschied. Das Präparat III R 2 schmolz bei 201-202 ${ }^{\circ} \mathrm{C}$. unter Zersetzung. Seine wässerige Lösung erwies sich als rechtsdrehend $[\alpha]_{D}=+7,3^{\circ} \mathrm{C}$.

Elementaranalysen, welche mit dem über das Silbersalz noch weiter gereinigten Präparate vorgenommen wurden, ergaben Werte, die auf ein Gemisch schliessen liessen. Die weitere Reinigung durch fraktionierte Kristallisation zeigte, dass das Präparat Glutaminsäure, ferner Valin und vielleicht Betain enthielt. Die Analyse des nach Abscheidung der Glutaminsäure als salzsaures Salz verbleibenden, von Salzsäure durch Kochen mit gelbem Bleioxyd befreiten Produktes ergab:

Analyse 1: $51,64 \% \mathrm{C}, 9,11 \% \mathrm{H}\}$ " 2: $52,57 \% \mathrm{C}, 9,30 \% \mathrm{H}$

$11,62 \% \mathrm{~N}$

Mit Salzsäure versetzt, bildete das nicht gereinigte Präparat III R 2 ein salzsaures Salz, welches bei $172^{\circ} \mathrm{C}$. unter Zersetzung schmolz. Die wässerige Lösung dieses Salzes erwies sich optisch viel stärker aktiv als das Präparat III $\mathrm{R} 2$ selbst: $[\alpha]_{D}=+15,66^{\circ} \mathrm{C}$. Bei dén mit dem salzzsauren Salz vorgenommenen quantitativen Bestimmungen

1) H. Schaumann, Die Ätiologie der Beriberi. II. Arch. f. Schiffs- u. Tropenhyg. Bd. 18 Beih. 6 S. 34. 1914. 
Beitrag zur Kenntnis ron organischen Nahrungsstoffen mit spezif. Wirkung. 143

(als Durchschnitt von je zwej, gut untereinander stimmenden Analysen) wurden als Gehalt an Chlor 18,11\% und als Gehalt an Stickstoff $9,66 \%$ gefunden. Beim Verdunsten eines Tröpfchens der wässerigen Lösung des salzsauren Salzes auf einem Objektträger schieden sich die auf den Mikrophotographien Nr. 48 and 49 wiedergegebenen Kristalle aus.

Die mit dem nicht gereinigten Präparate III $R 2$ sowie mit dessen salzsaurem Salze an Tauben vorgenommenen Versuche ergaben folgendes: Nach intramuskulären Einspritzungen von $0,025 \mathrm{bzw}, 0,05 \mathrm{~g}$ wurde in der Mehrzahl der Fälle eine ausgesprochene Besserung der für alimentäre Dystrophie bei Tauben charakteristischen nervösen Störungen beobachtet. Auch stellte sich wiederholt nach den Einspritzungen lebhafte Fresslust geschliffenem Reis gegenüber ein. Dies Verhalten der Versuchstiere lässt darauf schliessen, dass dem Präparat. III $R 2$ bei der Gesamtwirkung der Bierhefe ebenfalls eine wichtige Rolle zufällt. Wahrscheinlich kommt dieser Wirkung eine Beimengung $\mathrm{zu}$, die wir nicht fassen konnten, oder aber das gesamte Gemisch hat die günstige Wirkung.

7. Präparat III R 3 (S. 246 u. 269). Die gewonnenen Mengen waren nur für eine oberflächliche chemische Untersuchung, eine Elementaranalyse und einen Tierversuch ausreichend. Erstere ergab, dass es sich um eine kristallisierende, stickstoff haltige, organische Sub$\operatorname{stanz}$ handelte, deren wässerige Lösung bei der Kochprobe mit Ninhydrinlösung sich nicht färbte. Bei dem Tierversuche, der mit einer an den Beinen geläbmten Taube vorgenommen wurde, war keinerlei günstige Wirkung za bemerken.

Die Elementaranalyse des Präparates ergab folgende Werte: $42,75 \% \mathrm{C}, 3,36 \% \mathrm{H}$ und $24,86 \% \mathrm{~N}$.

Die Werte stimmen gut auf Uracil. Auch die Eigenschaften des unkristallisierten Produktes machen es, sehr wahrscheinlich, dass dieser Verbindung vorlag.

8. Präparat III N 2 (S. 247 u. 269) bestand aus einer weissen mikrokristallinischen, stickstoffhaltigen, organischen Substanz, die bei $250^{\circ} \mathrm{C}$. unter Zersetzung schmolz. Ihre wässerige Lösung reagierte gegen Lakmuspapier sauer und gab mit Phosphorwolframsäure einen starken, weissen, mit Nes s l er's Reagenzien einen gelben Niederschlag. Die Ausbeute war auch hier eine recht geringe. Die mit der Substanz ausgeführten Elementaranalysen hatten folgendes Ergebnis: 
Analyse 1: $34,76 \% \mathrm{C}, 4,33 \% \mathrm{H}, 18,73 \% \mathrm{~N}$ und $15,87 \% \mathrm{H}_{2} \mathrm{SO}_{4}$.

$$
\begin{aligned}
& \text { 2: } 36,83 \% \mathrm{C}, 3,56 \% \mathrm{H} . \\
& 3: 35,36 \% \mathrm{C}, 3,65 \% \mathrm{H} . \\
& 21,68 \% \mathrm{~N} \text { und } 17,23 \% \mathrm{H}_{2} \mathrm{SO}_{4} .
\end{aligned}
$$

Die leider nicht von Asche ganz frei zu machende Substanz war offenbar nicht rein. Es lässt sich ubber die Natur der Substanz infolgedessen vorläufig nichts Genaues aussagen.

Leider war die zur Verfügung stehende Menge auch hier nur zu einem einzigen Tierversuch ausreichend, der folgendes Ergebnis hatte: Eine in typischer Weise an alimentärer Dystrophie erkrankte Taube wies nach zwei Einspritzungen einer wässerigen Lösung von je $0,05 \mathrm{~g}$ des Präparates eine unzweideutige Besserung auf: Opistothonus und Krämpfe, die vor der Einspritzung sehr ausgesprochen waren, hatten sich 24 Stunden nach der ersten Einspritzung vollkommen verloren. Die Lähmung der Beine war erheblich zurückgegangen und die Fresslust geschliffenem Reis gegenüber wieder sehr rege.

9. Prä parat III L 6 (S. 248 u. 269) betraf eine mikrokristallinische, in Wasser lösliche, in Alkohol fast unlösliche, stickstoffhaltige, bei 212-213 ${ }^{\circ} \mathrm{C}$. unter Zersetzung schmelzende organische Substanz. Ihre wässerige Lösung gab bei Zusatz von Phosphorwolframsäure eine starke weisse Fällung und bei der Kochprobe mit einigen Tropfen einer $1 \%$ igen Ninhydrinlösung starke Blaufärbung.

Die Elementaranalysen, welche mit dem Präparat ausgeführt wurden, lieferten folgende Werte:

$$
\begin{aligned}
& \text { Analyse 1: } 46,53 \% \mathrm{C}, 7,21 \% \mathrm{H} \text { und } 9,80 \% \mathrm{~N} \text {. } \\
& " \quad 2: 46,26 \% \mathrm{C} \text { und } 7,07 \% \mathrm{H} . \\
& " \quad 3: 45,78 \% \mathrm{C}, 6,63 \% \mathrm{H} \text { und } 10,46 \% \mathrm{~N} . \\
& " \quad 4: 46,27 \% \mathrm{C} \text { und } 6,92 \% \mathrm{H} .
\end{aligned}
$$

Diese Werte stimmen ziemlich gut auf eine Verbindung der $\mathrm{Zu}$ sammensetzung $\mathrm{C}_{5} \mathrm{H}_{9} \mathrm{NO}_{3}$. Fs könte somit $\mathrm{Oxy}$ prolin vorgelegen haben. Dafur spricht das Verhalten der Substanz beim Erhitzen. Es trat Geruch nach Pyrrolidin auf. Das im Eiweiss vorkommende Oxyprolin kann allerdings nicht vorgelegen haben, denn dieses zersetzt sich bei $270^{\circ} \mathrm{C}$.

Bei zwei mit diesem Präparat angestellten Tierversuchen wurde in einem Falle bei einer an den Beinen geläbmten Taube nach zwei Einspritzungen wässeriger Lösung von je $0,05 \mathrm{~g}$ eine mehrere Tage 
Beitrag zur Kenntnis von organischen Nahrungsstoffen nit spezif. Wirkung. 145

lang anhaltende wesentliche Besserung beobachtet. Die Lähmung der Beine ging erheblich zurück, und der vorher verschmähte geschliffene Reis wurde von der Taube wieder gerne genommen. Der zweite Fall betraf eine junge Taube. Junge Tauben sind ja erfahrungsmässig weniger widerstandsfähig und auch schwerer $\mathrm{zu}$ heilen als ausgewachsene Tiere. Hier war der Erfolg intramuskulärer Einspritzungeu von je $0,05 \mathrm{~g}$ des Hefepräparates auch weniger günstig. Der vor der Einspritzuug sehr ausgesprochene Opithotonus und die heftigen Krampfanfälle waren allerdings nach der zweiten Einspritzung geschwunden; die Lähmung der Beine hielt aber unverändert an.

Trotz Behandlung mit getrockneter, als sebr wirksam erprobter Bierhefe, die hier aber nur geringen Erfolg hatte, ging die Taube nach zwei Tagen ein.

10. Präparat III L 5 (S. 250 u. 270 ) bildete eine mikrokristallinische, bei $239-240^{\circ} \mathrm{C}$. unter Zersetzung schmelzende, stickstoff haltige Substanz, die in Wasser ziemlich leicht, in Alkohol sehr schwer löslich war. Die wässerige Lösung erwies sich auf Zusatz von Salzsäure als optisch aktiv, $[\alpha]_{D}=+12,6^{\circ} \mathrm{C}$. Sie gab mit Phosphorwolframsäure eine starke weisse und mit Nessler's Reagens eine gelblichweisse Fällung. Beim Kochen der wässerigen Lösung mit einigen Tropfen einer $1 \%$ igen Ninhydrinlösung nahm das Reaktionsgemisch eine dunkelblaue Farbe an. Kochte man die wässerige Lösung mit frischgefälltem Kupferoxyd und filtrierte, so konnten aus dem blaugefärbten Filtrate durch langsames tindampfen plättchenförmige Kristalle eines dunkelblauen Kupfersalzes gewonnen werden.

Eine Elementaranalyse- des Präparates III L 5 ergab als Gehalt an $\mathrm{C} 48,48 \%, \mathrm{H} 8,79 \%, \mathrm{~N} 11,57 \%$. Diese Zahlenverhältnisse lassen sich nicht auf eine einfache empirische Formel zurückführen. Der Versuch, die Substanz nochmals der Hydrolyse zu unterwerfen und dann weiter $\mathrm{zu}$ reinigen, scheiterte an der geringen zur Verfügung stehenden Menge. Möglicherweise handelte es sich bei diesem Präparat um ein Polypeptid. Ob diese Vermutung zutrifft, wäre natürlich erst nach Darstellung grösserer Mengen des Präparates durch Aufspaltung desselben und weitere Reinigung sowie Untersuchung der Spaltprodukte zu .entscheiden.

Zwei mit diesem Präparat angestellte Tierversuche lieferten keine eindeutigen Ergebnisse. Die verfügbare Menge des Präparates war leider zu weiteren Versuchen unzureichend. Es muss daher die Frage, 
ob und in welcher Weise dieses Präparat etwa wirksam ist, offen gelassen werden, bis weitere genügende Mengen davon zur Darstellung gelangt sind.

11. Präparat III N 3 (S. 252). Auch hier war die Ausbeute sehr gering. Das Präparat bestand aus einer weissen kristallinischen, stickstoffhaltigen Substanz, die in Wasser ziemlich leicht löslich war und bei $240^{\circ} \mathrm{C}$. unter Zersetzung schmolz. Ein Tropfen der wässerigen Lösung, auf einem Objektträger verdampft, hinterliess die auf der Mikrophotographie Nr. 50 bei etwa 220 facher Vergrösserung wiedergegebenen Kristalle. Für Tierversuche war die gewonnene Menge leider zu gering.

Die Elementaranalyse des salzsauren Salzes lieferte folgendes Ergebnis :

$$
32,53 \% \mathrm{C}, 3,63 \% \mathrm{H}, 15,85 \% \mathrm{Cl}, 37,94 \% \mathrm{~N} \text {. }
$$

Nach allen Figenschaften und den Analysenzahlen dürfte Guaninchlorhydrat vorgelegen haben.

12. Präparat III N 7 (S. 253). Die äusserst geringen Mengen, welche von diesem Präparate gewonnen werden konnten, betrafen eine weisse kristallinische, stickstoffhaltige Substanz. Die geringe Ausbeute ermöglichte weder eine genatere chemische Untersuchung noch die Ausführung von Tierversuchen.

13. Präparat III F 7 (S. 253 u. 270) betraf eine gelblich gefärbte ,kolloide organische Substanz, die stickstoffhaltig war und deren wässerige Lösung sich mit Folin's Reagens nach Übersättigung mit Natriumkarbonat stark blau färbte. Diese Substanz erwies sich bei einem Tierversuche, der mit einer an alimentärer Dystrophie unter schweren nervösen Störungen erkrankten Taube angestellt wurde, als recht wirksam: Der Opisthotonus und die Konvulsionen schwanden nach der ersten intramuskulären Einspritzung einer wässerigen Lösung von $0,05 \mathrm{~g}$ des Präparates. Nach einer zweiten ebensolchen Einspritzung ging auch die Lähmung der Beine bis auf einen geringen Rest zurück, und die Fresslust geschliffenem Reis gegenüber wurde wieder sehr rege. Die Wirkung hielt, soweit die Lähmung der Beine in Betracht kam, allerdings nur sehr kurze Zeit an. Eine eingebendere chemische Untersuchung liess' die geringe zur Verfügung stehende Menge nicht zu.

14. Präparat III F 2 (S. 254 u. 271) betraf ein unreines und offenbar keineswegs einheitliches Produkt. Die Versuche, aus ihm 
Beitrag zur Kenntnis von organischen Nahrungsstoffen mit spezif. Wirkung. 147

reine und einheitliche Substanzen zu gewinnen, waren erfolglos. Bei zwei Tierversuchen mit Tauben, die an alimentärer Dystrophie erkrankt waren, wurde nach Einspritzung einer wässerigen Lösung von $0,05-0,10 \mathrm{~g}$ des trockenen Präparates keinerlei Wirkung beobachtet.

Wir sind uns selbstverständlich bewusst, dass die Ergebnisse der vorstehend mitgeteilten Versuche ein abschliessendes Urteil über die Wirksamkeit und Wirkungsweise aller einzelnen von uns dargestellten Hefepräparate nicht zulassen. In der Mehrzahl der Fälle mussten wir uns bei den vorgenommenen Tierversuchen darauf beschränken, die Wirksamkeit der betreffenden Präparate gegen die nervösen Störungen zu prüfen, welche bei der alimentären Dystrophie der Tauben aufzutreten pflegen. Die grosșen Schwierigkeiten, welche mit der Beschaffung geeigneter Versuchstiere sowie mit der von geschliffenem Reis während des Krieges verknüpft waren, vor allem aber die geringe Ausbeute bei einer Reihe von Präparaten, liessen weitergehende chemische Untersuchungen und Tierversuche vielfach nicht zu. Die erwähnten nervösen Störungen bilden aber, wie dies an anderer Stelle schon betont worden ist, nur Teilerscheinungen in dem Gesamtbilde der alimentären Dystrophie, und die Unwirksamkeit bestimmter Hefepräparate gegen diese nervösen Störungen beweist natürlich noch nicht, dass die betreffenden Hefepräparate nicht etwa irgendwie an der vielseitigen Wirkung beteiligt sind, welche die Hefe erfahrungsmässig auszuüben vermag. Um diese Fragen zu entscheiden, dürften Dauerversuche mit einzelnen Hefepräparaten und mit verschiedenartigen Gemischen von solchen wohl die meisten Aussichten auf Erfolg bieten. Bei den vorstehend beschriebenen Nachforschungen konnte es sich, wie dies schon eingangs hervorgehoben worden ist, in der Hauptsache nur um eine grundlegende Orientierung handeln, bei der unser Bestreben dahin ging, durch mögliehst schonende Eingriffe eine Anzahl möglichst reiner Abbauprodukte aus der Hefe zu gewinnen und diese $z u$ einigen vorläufigen Prüfungen an Hand von Tierversuchen zu verwenden. Die von uns angewandten Methoden sind wahrscheinlich nach mancher Richtung hin der Verbesserung und Vervollkommnung zugänglich. Besonders dürfte dies mit Rücksicht auf die weitere Reinigung einzelner Präparate zutreffen.

Selbstverständlich müssen alle isolierten Präparate auch an überlebenden Organen geprüft werden. Versuche am überlebendem Darm 
sind von dem einen von uns (Abderhalden) schon vor längerer Zeit in Angriff genommen worden und ebenso Versuche zum Studium des Einflusses der Nutramine und speziell der Eutonine auf den Blutdruck und das Herz. Besonders wichtig ist auch die Beantwortung der Frage, ob das symathische Nervensystem für diese Substanzen Angriffspunkt ist. Leider sind die jetzigen Verhältnisse diesen Ver suchen nicht günstig. Es fehlt das Tiermaterial. Schon die Feststellung, dass die Eingabe voi Eutonin bei an alimentärer Dystrophie erkrankten Tieren nach ganz kurzer Zeit zu Nahrungsaufnahme führt, zeigt, dass eine Einwirkung auf die Fresslust vorhanden ist. Ferner beobachtet man an frisch sezierten Fällen Sekretion von Verdăuungssäften. Sie kommt kurze Zeit nach den Einspritzungen in Gang. Bei den an alimentärer Dystrophie zugrunde gegangenen Tieren hat man stets den Eindruck, als ob die Verdauungsdrusen ihre Funktion eingestellt hätten. Ferner beobachtet man oft unmittelba: nach der Zufuhr des Eutonins Darmentleerung. Es muss somit ein Einfluss auf die Darmperistaltik vorhanden sein. Pharmakologische und toxikologische Versuche an einzelnen Organen erhalten erst dam ihren vollen Wert, wenn Substanzen zur Verfügung stehen, die wenigstens nach ihrer Darstellung sich gleich bleiben. Auch in dieser Hinsicht sind unsere Untersuchungen wichtig. Es muss jeder Forseher auf diesem Gebiete die gleichen Produkte anwenden können, damit wirklich vergleichbare Versuche zustande kommen. Leider sind vielfach Versuche mit Präparaten mitgeteilt, die nicht genau genug beschrieben sind ${ }^{1}$ ).

Aus den oben ausgeführten Gründen betrachten wir die Aufgabe, die wir uns gestellt haben, hiermit keineswegs als vollkommen gelöst, soudern behalten uns weitere, nach den angegebenen Richtungen hin liegende Nachforschungen vor.

\section{XI. Übersicht iiber die gewonnenen Resultate und Sehluss- folgerungen.}

Es ist einwandfrei festgestellt, dass ausser den bereits bekannten, allgeinein in Betracht gezogenen Nahrungsstoffen noch solche eine bedeutsame Rolle im Stoffwechsel spielen, deren Bedeutung erst in

1) Soeben erscheint eine Arbeit von Fr. Uhlmann über: Beiträge zur Pharmakologie der Vitamine. Habilitationsschrift. R. Oldenbourg, Hünchen. 1918 and Zeitschr. f. Biologie Bd. 68 S. 419, 457. 1918. 
neuerer Zeit augenfällig geworden ist. Die Tatsache, dass bestimmte Krankheiten im Anschluss an in bestimmter Weise vorbereitete Nahrungsmittel entstehen, hat die Ernährungsforschung in neue Bahnen gelenkt. Besonders bedeutungsvoll ist der Umstand, dass es möglich ist, schwere Störungen durch Verabreichung bestimmter Nahrungsmittel hervorzurufen, deren Ausbruch man durch Zugabe bestimmter Produkte vermeiden kann. Ferner können bereits eingetretene Ausfallerscheinungen mit Erfolg durch solche Produkte beseitigt werden. Die.gegebene Aufgabe war nun, diese Produkte zu reinigen und das oder die wirksamen Produkte in reinem Zustande zu gewinnen. Dieses von uns angestrebte Ziel ist zurzeit noch nicht ganz erreicht. Immerhin haben wir Verbindungen aus Hefe isoliert, die wirksam sind und deren Natur wenigstens zum Teil erschlossen werden kann. Der Weg $\mathrm{zu}$ weiterer, sicherlich erfolgreicher Forschung ist gegeben. Besonders wichtig ist ohne Zweifel die Erkenntnis, dass die Wirkung der Hefe und des alkoholischen Hefeextraktes auf die Erscheinungen der alimentären Dystrophie mit grösster Wahrscheinlichkeit nicht auf eine einzige Verbindung zurückzuführen ist. Es handelt sich offenbar um mehrere Verbindungen mit versehiedener Wirkung, die zusammen einen vollwertigen Einfluss ausüben.

Es ergibt sich zunächst die fundamental wichtige Frage, $a b$ wir Stoffe vor uns haben, die sich einer der bekannten Gruppen von Nahrungsstoffen anreihen lassen oder aber, ob Nahrungsstoffe einer besonderen Klasse mit eigenartiger Bedeutung abzugrenzen sind. Jedenfalls handelt es sich um organische Verbindungen. Allem Anschein nach kommen sie in den Nabrungsmitteln mit Phosphorsäure direkt oder indirekt kombiniert vor. Die Wirkung ist jedoch nach unseren Erfahrungen nicht von der Kombination abbängig. Die Phosphorsäure spielt offenbar die Rolle eines Schutzes für die labilen, bezonders gegen Alkali sehr empfindlichen Verbindungen. Die organischen Nabrungsstoffe werden im allgemeinen in erster Linie vom Gesichtspunkt ihres Energiewertes aus betrachtet. Ferner wird ihnen eine Rolle als Baumaterial für Zellen zugesprochen. Der eine von uns (A bderhalden) hat in seinem Lehrbuch der physiologischen Chemie nachdrücklich darauf hingewiesen, dass aus jedem Baustein der organischen Nabrungsstoffe Verbindungen mit eigenartiger physiologischer Wirkung hervorgehen können. 
Der Organismus hat seinen gesamten Stoffwechsel in feinster Weise geregelt und abgestuft. Jede Zwischenstufe beim Abbau von organischen Verbindungen hat eine bestimmte Bedeutung und ist ein Rad im gesamten grossen Getriebe. Dieser Gedanke drängt sich ganz besonders auf, wenn man den komplizierten Abbau des Traubenzuckers, der Fettsäuren und vor allem auch der Aminosäuren überdenkt. Auch die stickstoffhaltige Base der Phosphatide, das Cholamin resp. das Cholin, hat sicherlich im Zellstoffwechsel eine gauz bestimmte Aufgabe. Wir müssen deshalb die Aufgaben auch der organischen Nahrungsstoffe weiterfassen, als es vielfach üblich war. Die auffallenden tiefen Störungen im Stoffwechsel nach Verabreichung von Eiweissstoffen resp. Eiweiss. bausteinen, denen das Tryptophan fehlt, zeigen schon, dass zum Beispiel diesem Baustein eine bedeutungsvolle Aufgabe zufällt.

Betrachten wir nun die Wirkungen der von uns Nutramine genannten Stofie. Sie wirken in sehr geringen Mengen. Somit kommen sie als Energieträger nicht in Frage. Dagegen lässt sich die Möglichkeit, dass sie wichtige Zellbausteine sind, nicht ohne weiteres ablehnen. Es ist denkbar, dass sie am Zellbau Anteil nehmen. Immerhin hält es schwer, ihre Bedeutung in dieser Hinsicht zu suchen. Man ist eher geneigt, ihnen eine andere Rolle zuzuerkennen. Wenn oben hervorgehoben wurde, dass die Bausteine der organischen Nahrungsstoffe mit all ihren mannigfaltigen Abbaustufen bis hinunter zu den Stoffwechselendprodukten im Gesamtstoffwechsel an irgendeiner Stelle eine wichtige und entscheidene Rolle spielen, so liegt es ganz besonders nahe, den Nutraminen eine solche Rolle zuzuschreiben.

Wir möchten zunächst folgendes hierzu hervorheben. Wenn man die ersten Beobachtungen uber die Folgen der ausschliesslichen Ernährung von Tauben mit geschältem Reis anstellt, dann fällt in erster Linie das Auftreten von Appetitlosigkeit auf. Fast immer mageru die Tiere in kurzer Zeit stark ab. Vor dem Auftreten der charakteristischen Ausfallerscheinungen bemerkt man, dass die Tiere mit gesträubtem Gefieder dasitzen. Bei einiger Erfahrung kann man aus vielen Tauben heraus diejenigen erkennen, bei denen die Anfälle auftreten werden. Der Ausbruch der Erkrankung kann, wie schon früher betont, recht verschieden sein. Das Gewöhnliche sind Krämpfe oder Lähmungen orler beides zusammen. Seltener erfolgt der Tod, ohne dass äusserlich besondere Sympto me vorhanden waren. Diese Krämpfe 
können beschleunigt werden, wenn man die Tiere viel bewegt. Eine Taube, die zunächst einen noch sicheren Gang zeigt, die jedoch durch das Sich-Zurückziehen von ibren Kameraden, durch das Einziehen des Kopfes und das Aufblustern des Gefieders anzeigt, dass sie sich nicht wohl befindet, kann man oft durch Herumjagen zu einem unsicheren Gang bringen. Manchmal gelingt es direkt die typischen, schweren Krämpfe hervorzurufen.

Erhält nun ein erkranktes Tier Hefe, Hefeextrakt oder aus Hefe resp. Kleie isolierte Substanzgemische resp. bestimmte Produkte, dann fällt zunächst am meisten die Beobachtung auf, dass das Tier sofort frisst. Noch ehe es sich von seinem Zustand ganz erbolt hat, nimmt es Nahrung auf. Wir haben oft Fälle gesehen, bei denen die Nahrungsaufnahme wenige Minuten nach dem Einspritzen der Substanz erfolgte, nachdem das Tier oft mehrere Tage künstlich gefüttert worden war, weil es sonst nichts gefressen hätte. Ferner setzt zumeist auch sofort Kloakenentleerung ein. Überraschend schnell gehen dann die Lähmungen und Krämpfe zurück. Die Tiere schlafen meistens viel nach der Einspritzung, besonders wenn ihr Zustand ein schwerer war.

Diese Beobachtungen zeigen schon, dass die zugeführten Stoffe eine ganz bestimmte und ganz gewiss nicht einheitliche Wirkung gehabt haben. Man hat durchaus den Eindruck, als ob ein ganzer Komplex von Wirkungen vorliegt. Dass die Ausfallerscheinungen nicht einheitlich sind, zeigt die Beobachtung. Man könnte jedoch daran denken, dass das Versagen einer bestimmten, vom Vorbandensein einer gewissen Verbindung abhängigen Funktion nun sekundär im Laufe der Zeit zu weiteren Störungen führt. Es ist eine Funktion von der anderen abhängig. Versagt ein Rad im Getriebe, dann stehen viele vom Laufen dieses einen Rades abhängige andere Räder still. Es wäre in diesem Falle nicht ohne weiteres verständlich, weshalb die Zufuhr bestiminter Verbindungen fast mit einem Schlage wenigstens äusserlich - so erstaunliche Besserungen zahlreicher Ausfallerscheinungen bedingen kann. Man würde vielmehr erwarten, dass zunächst ein Symptom sich bessert und nach und nach eine Funktion nach der anderen wieder ins Geleise kommt.

Nach unseren Beobachtungen kann man die bei der künstlich herbeigeführten Erkrankung durch einseitige Verfütterung bestimmter Nahrungsmittel auftretenden Erscheinungen nicht so auffassen, als wäre wenigstens zunächst nur eine bestimmte Ausfallerscheinung vor- 
handen und nur ein Organsystem betroffen. Der Name "Polyneuritis" wird den ganzen Ausfallerscheinungen nicht gerecht. Wir haben deshalb den Namen alimentäre Dystrophie gewählt und jede Organbezeichnung vermieden.

Wir kommen somit zu der Anschauung, dass speziell bei der Verabreichung von geschliffenem Reis an Tauben zahlreiche Ausfallerscheinungen gleichzeitig auftreten, die durch das Fehlen mehrerer Stoffe in der Nahrung bedingt $\sin d$.

Die von uns isolierten Stoffe waren nicht so wirksam wie die Hefezelle selbst. Es gelang nicht, mit gereinigten Stoffen Tauben vollständig zu ernähren, wenn man diese zu einer unzureichenden Nahrung, zum Beispiel geschliffenem Reis, zulegte. Wenn auch die Ausfallerscheinungen glatt versehwanden, d. $\mathrm{h}$. wenigstens die äusserlich sichtbaren, so blieb doch ein Ausfall. Das Körpergewicht nahm nicht oder doch nicht wesentlich zu, und nach einiger Zeit trat der Tod ein. Es konnte sogar vorkommen, dass trotz der Zufuhr der erwähnten Stoffe wieder Krämpfe oder Lähmungen sich einstellten. Gab man jedoch Hefe oder, was besonders wichtig ist, Nukleoproteid resp. Nuklein aus Hefe, dann stieg das Körpergewicht der erkrankten Tiere an. Man hatte durchaus den Eindruck, dass sie wieder ganz normal wurden. Je reiner die isolierten Stoffe wurden, um so mehr verloren sie ihre augenfällige Wirkung. Damit soll durchaus nicht gesagt sein, dass sie überhaupt ihre Wirksamkeit einbüssten. Es ist sehr wohl möglich, dass sie wirksam blieben, dass die Wirkung jedoch erst mittels besonderer Methoden und Untersuchungen zutage gefördert werden kann. Die weit überlegene Wirkung der Hefezellen selbst, d. h. des Inhaltes dieser Zellen, führen wir darauf zurück, dass der ganze Komplex aller jener Stoffe mit ihnen verabreicht wird, der notwendig ist, um den Stoffwechsel in allen seinen vielfach verzweigten Anteilen in normalen Babnen ablaufen zu lassen. Verabreichen wir isolierte, gereinigte Verbindungen, dann genügt ihre Wirkung nicht, um den Komplex der Ausfallerscheinungen $\mathrm{zu}$ beseitigen. Es sprechen alle unsere Beobachtungen dafür, dass nicht eine einzelne Verbindung als Träger bisher unbekannter Wirkungen in Frage kommt, sondern eine Mehrzahl von solchen. In dieser Hinsicht ist der auf S. 162 geschilderte Versuch besonders bedentungsvoll. Es wurde Hefe 
mit Natronlauge erhitzt. Sie verlor die Eigenschaft, die im Gefolge der alimentären Dystrophie auftretenden nervösen Störungen günstig zu beeinflussen, vollkommen. Wurde dieses Produkt mit geschliffenem Reis zusammen verabreicht, dann war keine Behinderung des eintretenden Gewichtsverlustes festzustellen. Gleichzeitige Zufubr des erwähnten, mit Natronlauge vorbehandelten Hefepräparates und von Hefenukleoproteid steigerte die günstige Wirkung des letzteren Produktes deutlich. Es wird die Aufgabe der weiteren Forschung sein, diese Stoffe im reinen Zustand zu gewinnen und von jedem einzelnen seine Wirkung zu studieren. Von allergrösstem Interesse wird es dann sein, festzustellen, welche Wirkungen bestimmte Kombinationen der einzelnen Verbindungen hervorbringen.

Wegleitend für die Beurteilung der Bedeutung der Nutramine muss die Tatsache sein, dass sie nach allen Erfahrungen nicht für jere Tierart die gleichen sind. Dieser Umstand ist ohne Zweifel von der allergrössten Bedeutung. Eine Nahrung, die für Tauben ungenügend ist, braucht es nicht auch für Kaninchen usw. zu sein. Man kann mit geschliffenem Reis nicht bei jeder Tierart die Symptome der alimentären Dystrophie hervorrufen. Man hat es auch nicht in der Hand, bei jeder Tierart auf dem gleichen Wege skorbutähnliche Erkrankungen hervorzubringen. Es liegt wahrscheinlich auch hier nicht eine Tatsache vor, die ganz überraschend ist. Freilich hat man allgemein die Vorstellung verbreitet, dass der Stoffwechsel, von wenigen Besonderheiten abgesehen, bei allen Tieren gleichartig verlaufe. Es ist sehr leicht möglich, dass diese Annahme sich weiter von der Wirklichkeit entfernt, als man anzunehmen geneigt ist. Gewiss sind in den Grundzügen die Stoffwechselvorgänge in allen Zellen gleichartige. Dagegen können besonders in der Bildung von Stoffwechselzwischenprodukten Besonderheiten vorhanden sein. Es können auch die syathetischen Leistungen versehiedenartige sein. Man muss jedenfalls die Frage offen lassen, ob nicht jeder Tierart im Stoffwechselgetriebe Eigentümlichkeiten von entscheidender Bedeutung zukommen. Das von dem einen von uns ( $\mathrm{b}$ d erhald en) begonnene systematische Studium der Wirkung der einzelnen Abbaustufen der Bausteine der einzelnen Nahrungsstoffe wird vielleicht weiterführen.

Der Umstand, dass wir nieht zum Ausdruck bringen können, zu den bisher bekannten Nahrungsstoffen tritt eine bestimmte in sich geschlossene Gruppe von Verbindungen mit besonderer Wirkung binzu, 
kompliziert die ganze Forschung und vor allem auch die Beurteilung der Bedeutung und der Wirkung dieser Stoffe. Hätte man ganz einfach noch eine oder auch mebrere Verbindungen entdeckt, die unentbehrlich sind, und zwar für jede Tierart, dann wäre es viel einfacher gewesen, bestimmte Vorstellungen über ihre Stellung im Stoffwechsel zu entwickeln.

Es drängt sich uns zunächst folgender Gedankengang auf. Es hat die Art der Nahrung auf unseren Stoffwechsel in gewissem Sinne einen entscheidenden Einfluss. Der Darmkanal mit seinen Einrichtungen, seinen Drüsen und schliesslich alle Organe stellen sich auf jene Zufuhr an Stoffen ein, die immer wieder zur Aufnahme gelangen. Man könute in weitestem Sinne von einer Art von Symbiose der gesamten Organismenwelt sprechen. Die Pflanze erzeugt in sich bestimmte Stoffe, die in ihrem Stoffwechsel eine ganz bestimmte Bedeutung haben. Vielleicht hat auch sie Inkrete, die unentbebrlich sind. Diese Stoffe kommen in den Darmkanal jenes Tieres, das sich von der betreffenden Nahrung ernährt. Sie werden übernommen und entfalten im Stoffwechselgetriebe eine oder mehrere Wirkungen. Es handelt sich um eine Art von Anpassung und Gewöbnung, die sich im Laufe vieler Generationen herausgebildet hat. Feblen diese Stoffe, dann kommt es zu Störungen. Der Organismus ist gewohnt, mit ihnen zu rechnen und zu arbeiten. Der Fleischfresser, der immer Fleisch aufnimmt, müsste in diesem Falle ganz andere Stoffe notwendig haben als der Pflanzenfresser, wenn man nicht annehmen will - was ja auch möglich ist -, dass der Fleischfresser mit dem Fleisch des Pflanzenfressers, das er verzehrt, sich auch jene Stoffe aus der Pflanze aneignet.

Vielleicht darf man auf folgende Beobachtungen zurückgreifen. Niedere Tiere, wie z. B. Insekten, - um ein Beispiel aus der grossen Zahl berauszugreifen - sind auf ein sehr eng begrenztes Gebiet von Nahrungsmitteln angewiesen. Dis Raupe des Wolfsmilehschwärmers frisst z. B. Wolfsmilch und davon nicht einmal jede Art. Auf anderen Pflanzen verhungert sie. Die Raupe des Ligusterschwärmers muss Ligusterblätter zur Ernährung haben usw. Es gelingt $a b$ und zu, eine Raupe an andere Nahrung zu gewöhnen. Es ist dies jedoch sehr schwer. Man könnte in diesem Falle daran denken, dass die Anpassung zwischen Tier und Nahrung auf eine bestimmte Beschaffenheit der Fresswerkzeuge zurückzuführen ist. 
Das kann jedoch nicht das Bestimmende sein. Es ist naheliegender, an engste Beziehungen zwischen der Art der Nahrung und bestimmten Stoffwechselvorgängen der Wirte zu denken. In der Tat hat man beobachtet, dass die Art der Nahrung auf Raupen und speziell auf die aus ihnen hervorgehenden Schmetterlinge Einfluss haben kann. Jedenfalls haben wir bei dieser Tiergruppe engstes Angewiesensein auf ein ganz bestimmtes Futtermittel. Steigen wir in der Tierreihe empor, dann finden wir, dass ein so enges Begrenztsein auf nur eine bestimmte Nahrung mehr und mehr fortfällt. Der Pflanzenfresser kann sich von sehr vielen verschiedenartigen Pflanzen nähren. Eine gewisse Auswahl treffen wir allerdings vielfach auch an. Der Fleischfresser beschränkt sich auch nicht auf nur eine Tierart. Der Allesfresser hat den weitesten Bereich. Man kann nicht so ohne weiteres einen Pflanzenfresser zum Fleischfresser machen und umgekehrt. Der praktische Versuch zeigt, dass das schwierig ist.

Gehen wir von diesen Gedanken aus, dann könnte man sich folgende Vorstellung zu eigen machen. Wir wissen, dass der tierische Organismus in bestimmten Organen Sekrete und Inkrete bereitet. Beide werden von den Zellen abgegeben. Beide enthalten Stoffe mit bestimmter Wirkung. Beide werden nicht immer abgegeben, sondern nur auf bestimmte Reize hin. Bei der Nahrungsaufnahme werden an den Organismus gewaltige Aufgaben gestellt. Es sollen ganz fremdartige Produkte zusammengesetzter Natur in eine Form gebracht werden, in der der Organismus sie für seine Zwecke verwenden kann. Es ist ein weitgehender Abbau und Umbau notwendig. Diesen Aufgaben dienen die Verdauungssekrete. Es wäre nun sehr gut denkbar, dass die Nutramine oder einzelne davon die Aufgabe haben, die Verdaungsdrüsen zu einer bestimmten Tätigkeit anzuregen. Wir hätten in ihnen Stoffe mit ähnlichen Aufgaben, wie wir sie den Inkreten zuschreiben. Wir kommen zu einer solchen Vermutung, weil man ganz den Eindruck hat, als würden bei Tauben, die ausscltliesslich mit geschliffenem Reis ernährt worden sind, die Funktionen der Verdauungsdrüsen allmählich ganz still stehen. Die Reiskörner liegen ohne erkennbare Veränderung im Kropf. Er wird nicht entleert. Man findet weder im Magen noch im Darm Anzeichen von Sekretion. Hierzu ist allerdings zu bemerken, dass diese Erscheinungen auch sekundärer Art sein könnten. Sie könnten zum Beispiel die Folge der mangelnden Nahrungsaufnahme sein. 
Wir haben schon erwähnt, dass es auffällig ist, dass mit der Zufuhr der Nutramine der Appetit zurückkehrt. Sie müssen somit in irgendeiner Weise anregend sein. Lejder können wir den Appetit als solchen nicht als Funktion eines bestimmten Organes lokalisieren. Auch kann sein Auftreten sekundär durch die Wiederaufnahme anderer Funktionen bedingt sein.

Eine andere, an sich sehr wahrscheinliche Möglichkeit der Wirkung der Nutramine ist, dass sie im $Z$ wischenstoffwechsel in den Zellen eine bestimmte Rolle spielen. Für diese Ansicht ist anzuführen, dass bewiesen werden konnte, dass die Gärung von Monosacchariden und des brenztraubensauren Kaliums durch aus der Hefe isolierte Stoffe beträchtlich gesteigert wird. Vielleicht gibt diese Beobachtung einen Fingerzeig für die Art der Wirkung der Nutramine. Sie wirken vielleicht beschleunigend auf bestimmte Reaktionen ein. Jedenfalls wird man in Zukunft die Abhängigkeit des Zellstoffwechsels von bestimmten Stoffen eingehend zu berücksichtigen haben. Es liegt hier ein grosses Arbeitsgebiet vor. Der eine von uns (Abderhalden) hat bereits mit Stoffwechselversuchen in dieser Richtung begonnen.

Wir müssen noch einer anderen Möglichkeit gedenken. Die Erfahrung hat gezeigt, dass offenbar alle Organe imstande sind, besondere Stoffe hervorzubringen, die für andere Zellarten unentbehrlich sind. Diese Inkrete müssen ohne $Z$ weifel eine ganz besonders geartete Struktur und Konfiguration haben. Es ist wahrscheinlich, dass bestimmte Aminosäuren das Baumaterial für bestimmte Stoffe einzelner solcher Inkrete abgeben. Vielleicht sind einzelne Gewebe auf ein ganz besonderes Baumaterial der Nahrung angewiesen. Wird es in dieser nicht zugeführt, dann fällt eine wichtige Funktion aus, und es kommt zu Störungen.

Wir möchten diese Möglichkeiten der Bedeutung der Nutramine nur als Arbeitshypothesen betrachtet wissen. Man soll sich nicht dưrch bestimmte, vorgefasste Meinungen die Freibeit der Forschung verbauen. Die Tatsachen müssen wegleitend sein. Unser Beitrag zu dem ganzen Probleme einer neuen Gruppe organiseher Nahrungsstoffe mit besonderen Aufgaben im tierischen und auch im Pflanzenorganismus baut sich, wie in der Einleitung zu der ganzen Arbeit mitgeteilt und belegt ist, auf vorhandene Arbeiten auf. Sie will nichts anderes als ein weiterer Baustein auf dem ganzen, so wichtigen Forschungsgebiete sein. Obwohl die Fortsetzung der ganzen Forschung dureh die Zeit- 
verhältnisse stark erschwert ist, wird sie fortgefübrt. Die Reindarstellnng der bereits isolierten Stoffe ist das nächste Ziel. Ferner sind noch mancherlei Beobachtungen vorbanden, die vertieft werden müssen. Von manchem Stoffe sind nur so kleine Mengen in unseren Händen gewesen, dass es unmöglich war, auch nur Reaktionen durchzuführen. Nicht genug kann hervorgehoben werden, wie ausserordentlich wertvoll die Mikroelementaranalyse von Fritz Pregl für unsere Arbeit gewesen ist. Ohne sie würden wir nicht imstande gewesen sein, alle isolierten Körper zur Analyse zu bringen. Die Mikroelementaranalysen hat Herr Dr. Hans Lieb in Graz ausgeführt. Es sei ibm auch an dieser Stelle gedankt.

Der Mikroanalyse verdanken wir vor allem die rasche Aufklärung der Zusammensetzung und der Konstitution des neu entdeckten Amins, des von uns als Aschamin bezeichneten Dimethyl-propenylamins. Diese Verbindung hatte keine beilende Wirkung auf die äusserlich in Erscheinung tretenden Symptome der alimentären Dystrophie. Interessanterweise vertrugen normale Tauben Dosen von $0,02 \mathrm{~g}$ ohne jede äusserlich erkennbare Erscheinung, während an alimentärer Dystrophie leidende Tauben Streckkrämpfe aufwiesen. Es ist von grösstem Interesse, diesen Beobachtungen weiter nachzugehen. Es ist nicht ausgeschlossen, dass das Aschamin in die Reihe der notwendigen Nutramine gehört. Dass methylierte Amine den Eutoninen nahe stehen, resp. dass diese Substanzen in die Klasse der von $\mathrm{Gu} g \mathrm{~g}$ en heim biogene Amine genannten Verbindungen zu rechnen sind, dafür sprechen manche Beobachtungen. Die grosse Bedeutung dieserGruppe von Verbindungen fürden Stoffwechsel würde damit noch eine ganz bedeutungsvolle Erweiterung erfahren.

Eines geht ganz klar auch aus unseren Untersuchungen hervor. Die biologische Wertigkeit einer Nahrung lässt sich nicht ausschliesslich auf Grund ihres Kalorieninhaltes ersehliessen. Ei we is $\mathrm{s}$, Kohlehydrate, Fette, Mineralst offe, Wasser und Sa uerst off - diese klassischen Gruppen von Nahrungsstoffen - genügen nicht, um den Stoffwechsel in all seinen Feinheiten aufrechtzuerhalten. Praktisch liegen die Verhältnisse so, dass bei der Zugrundelegung der Kalorienmenge als Maassstab für den Wert einer Nahrung ohne unser besonderes Zutun Mineralstoffe und auch Nutramine mit Einschluss der Eutonine in ge- 
nügender Menge zugegen sind, weil ja praktisch nur Nahrungsmittel und nicht die reinen Nahrungsstoffe zur Ernährung herangezogen werden. Wollen wir alimentäre Dystrophie bewirken, dann müssen wir besondere Bedingungen schaffen. Wir suchen uns als ausschliessliche Nahrung, Nahrungsmittel aus, die möglichst arm bis frei von Nutraminen sind. Dieser Hinweis ist vielleicht nicht ganz unangehracht, weil gegen die Zugrundelegung des Kalorieninhaltes der Nahrung als Ausdruck für ihren Wert im einzelnen Falle vielfach Einsprüche erhoben wurden, besonders unter dem Hinweis, dass die sogenannte Kalorienlehre die Mineralstoffe nicht berücksichtige ${ }^{1}$ ).

Die Feststellung, dass die Nutramine den Appetit, die Darmtätigkeit und vor allem auch die Tätigkeit der Verdaungrsdrüsen sichtlich beeinflusst, und ohne Zweifel larüber hinaus die ganze Verwertung der Nahrungsstoffe innerhalbderGewebe und Zellen starkvon ihrer Anwesenheit abhängt, führt von selbst zu der Forderung, den Stoffwechsel von Zellen, Geweben und ganzen Organismen mit und ohne ihren Einfluss gründlich zu studieren. Auch dieser Aufgabe werden wir uns zuwenden. Es liegt ein gewaltig grosses Forschungsgebiet vor, das noch reiche Früchte verspricht.

Die Mittel zur Durchführung der Arbeit stammten zum Teil aus den Mitteln, die die Kaiser-Wilhelm-Gesellschaft zur Verfügung gestellt hat. Es sei ihr auch an dieser Stelle gedankt.

\section{B. Experimenteller Teil.}

\section{Versuche mit ausgezogenen Graupen.}

Graupen wurden mit der fünffachen Menge ihres Eigengewichts an Leitungswasser zweimal je 24 Stunden lang unter häufigem Umrühren ausgezogen und das Waschwasser jedesmal möglichst vollständig abgegossen. Die ausgezogenen Graupen wurden dann in einen Spitzbeutel gebracht und nach dem Abtropfen der letzten Mengen Waschwasser, welches erhebliche Mengen Phosphorsäure anfgenommen hatte, wie die Prüfung einer Probe lehrte, nochmals mit Wasser nachgewaschen. Die Graupen wurden dann in dünner Schicht ansgebreitet und zuerst bei Zimmmertemperatur, hierauf bei $37^{\circ} \mathrm{C}$. gut getrocknet und so verfüttert.

1) Vgl. hierzu: Emil A bderhalden, Die Grundlagen unserer Ernährung. 2. Auflage. S. 95 ff. J. Springer, Berlin. 1916. 
Tauben, welche mit den so zubereiteten Graupen einseitig ernährt wurden, magerten unter allmählicher Abnahme der Fresslust stark ab. Ein Teil der Versuchstauben erkrankte innerhalb von 30-60 Tagen in typischer Weise an alimentärer Dystrophie, doch geschah dies in verhältnismässig geringerem Verhältnis als bei der einseitigen Ernährung mit geschliffenem Keis. Die Mehrzahl der Tauben ging ein oder erkrankte, ohne daș es zu den charakteristischen nervösen Störungen - Lähmung der Beine und Flügel, Streckkrampf der Beine, Opisthotonus und Konvulsionen - kam. Extreme Abmagerung, bei welcher sich die Versuchstauben zuweilen noch wenige Stunden vor dem Tode leicht und behende bewegten, wurde in allen Fällen beobachtet. Oft gesellte sich zu den übrigen Störungen noch eine heftige Enteritis mit schleimigen, dünnflüssigen Entleerungen.

\section{Versuche mit getrockneten Kartoffeln.}

Verwendet wurden $\mathrm{zu}$ diesen Versuchen frische, in feine Scheiben geschnittene, dann zunächst bei Zimmertemperatur und weiter bei $37^{\circ} \mathrm{C}$. getrocknete Kartoffeln. Die so konservierten Kartoffeln wurden täglich in gerade. ausreichender Menge mit wenig Wasser gekocht und sofort nach dem Erkalten verfüttert.

Von den mit derartig zubereiteten Kartoffeln ernährten Tauben ging die Mehrzahl unter hochgradiger Abmagerung, zu welcher sich häufig ein Magen-Darmkatarrh gesellte, zugrunde. Bei einer Minderzahl traten typische Symptome alimentärer Dystrophie - Paralyse der Beine und Flügel, Streckkrampf der Beine, Opisthotonus, Krämpfe - auf.

Eine der auf diese Weise gefütterten Tauben wies bei starker $A b$ magerung und Beinlähmung auch hochgradige Ödeme der Füsse, insbesondere der Zehen, auf (Photographie Nr. 34, 12. April 1917). Nach siebentägiger Fütterung mit Sojabohnen und gemischtem Taubenfutter und einer Tagesgabe von $1 \mathrm{~g}$ Hefe war ein deutliches Abschwellen der Füsse, hauptsächlich des rechten Fusses, bemerkbar (Photographie.Nr. 35, 19. April 1917); doch dauerte es noch $1 \frac{1}{2}$ Monat, bis beide Füsse wieder normal waren. Ein geringer Unterschied zwischen dem rechten und linken Fusse, welcher auch dann noch etwas stärker war, blieb bestehen (Photographie Nr. 36, 26. Juni 1917). Auch die Lähmung der Beine schwand bei dieser Taube langsamer als gewöhnlich bei der Behandlung mit Hefe bzw. vollwertiger Nahrung und war erst nach etwa 8 Tagen beseitigt.

Photographie Nr. 33: Normale Taubenfüsse.

\section{Versuche uiber einseitige Ernährung an Ratten.}

Seit einer Reihe von Jahren sind Versuche im Gange, um den Einfluss der Ernährung mit einer bestimmten Lebensmittelart festzustellen. Sie sind noch nicht abgeschlossen. Einmal sollte geprüft werden, wie lange Zeit es möglich ist, ein Tier mit einer einzigen, bestimmten Nahrungsmittelart ohne wahrnehmbare Störungen zu ernähren. Ferner sollten Studien über die Nachkommenschaft von solchen Tieren und deren weiteres Schicksal gemacht werden. Dazu gehören jahrelange 
Erfahrungen, um alle Zufälligkeiten auszuschliessen. Vor allem muss ein sehr grosses Tiermaterial herangezogen werden.

Im Zusammenhang mit den Versuchen an Vogelarten (Tauben und Sperlingen) seien die folgenden Ergebnisse hervorgehoben: Mäuse eignen sich wenig zu Dauerversuchen; sie erliegen sehr leicht. Viel geeigneter sind Ratten. Es gelang, solche bis zu einem Jahre zu beobachten. Am besten vertragen wurde der Roggen. Dann folgen Weizen und Hafer, Sojabohnen, Gerste. Mit Natalmais glückte es, die Versuchstiere bis zu 200 Tagen am Leben zu erhalten. Bei ausschliesslicher Verabreichung von gewöhnlichem Mais (Zea-Mais) starben die Tiere nach etwa 150 Tagen. Meistens traten vor dem Tode Krämpfe und darauf folgende Lähmungen auf. Mit sogenanntef Pferdebohnen lebten die Ratten durchschnittlich 150 Tage und ebensolange mit geschältem Reis.

Mit Ausnahme der "Roggentiere" traten bei allen Ratten nach mehr oder weniger langer Zeit trotz sorgfältigster Pflege und grösster Reinlichkeit mehr oder weniger schwere Erscheinungen am Integument auf. Die Haare fingen an, struppig zu werden; sie fielen aus. Bald zeigten sich kleine Knötchen am Schwanz und auf der Nase. Die im Anschluss daran auftretenden Wucherungen führten, besonders an der Nase, zuweilen zu ganz grossen "Hörnern". Spezifisch waren diese Erscheinungen für keine der gewählten Nahrungsmittelarten. Man gewinnt den Eindruck, als ob die Haut gegen Infektionen an Widerstand abnimmt. Die Tiere werden auch in der Pflege des Felles nachlässig.

Bei der Reis- und Maisfütterung wurde besonders oft schwere Konjunktivitis beobachtet. Ferner zeigten sich besonders oft Krämpfe und Lähmungen. Der Tod trat bald unerwartet ohne besondere Vorzeichen ein, bald traten Krämpfe auf, in deren Gefolge der Tod eintrat, oder aber es zeigten sich im Anschluss an die Kämpfe Lähmungen. Besonders waren die hinteren Extremitäten beteiligt. Endlich sind Fälle beobachtet, bei denen ausschliesslich Lähmungen auftraten.

\title{
IV. Versuche über einseitige Ernährung an Sperlingen.
}

Sperlinge, die mit geschliffenem Reis einseitig gefüttert wurden, erkrankten ebenfalls, jedoch nicht immer an alimentärer Dystrophie. Die Mehrzahl der Sperlinge ging in der Gefangenschaft schon nach wenigen Tagen, meistens plötzlich und unerwartet zugrunde. Bei einigen Sperlingen kam es nach verhältnismässig kurzer Zeit (10-14 Tagen) schon zu manifester alimentärer Dystrophie. Die Erkrankung äusserte sich durch ansgesprochene Paralyse der Beine und Flügel. Die sonst meistens noch recht kräftigen und munteren Tiere waren infolgedessen vollkommen ausserstande, zu laufen und zu fliegen (Photographie Nr. 32). Opisthotonus und Konvulsionen wurden in keinem Falle beobachtet. Die Mehrzahl der Sperlinge ging jedoch, ehe es zu nervösen Störungen kam, ein.

\section{Versuche mit 0xalsäure (Nr. 1 und 2).}

\author{
Versuch Nr. 1.
}

Versuchstier: Eine gesunde kräftige Taube.

Beginn des Versuchs: 20. Juli 1916. 
Beitrag zur Kenntnis von organischen Nahrungsstoffen mit spezif. Wirkung. 161.

Abschluss des Versuches: 19 . August 1916.

Nahrung: Gemischtes Taubenfutter.

$\mathrm{Zugaben:}$ Vom 20. Juli bis 10. August $0,05 \mathrm{~g}$ Oxalsäure pro Tag, "11. bis $19 . \quad 0,10 \mathrm{~g} "$ "

Die Oxalsäure wurde in Pillen von nachstehender Zusammensetzung gegeben: Reine Oxalsäure $\mathbf{2 , 5} \mathrm{g}$, reines wasserfreies Natriumkarbonat $5,0 \mathrm{~g}$, reine Weizenstärke $5,0 \mathrm{~g}$, reines Dextrin $3 \mathrm{~g}$ wurden gemischt, dann mit dest. Wasser bis zur Bildung einer plastischen Masse in einer Reibschale durchgeknetet und in 50 Pillen eingeteilt.

Körpergewichteder Taube:

\begin{tabular}{cc|cc} 
Datum 1916 & Gewicht & Datum 1916 & Gewicht \\
20. Juli & $391 \mathrm{~g}$ & 5. August & $350 \mathrm{~g}$ \\
22. & $359 \mathrm{~g}$ & 12. & $368 \mathrm{~g}$ \\
29. & $330 \mathrm{~g}$ & 19. & $388 \mathrm{~g}$ \\
1. August & $336 \mathrm{~g}$ & &
\end{tabular}

Verhalten des Versuch stieres: Anfangs Abnahme des Körpergewichtes um $61 \mathrm{~g}$, entsprechend - 15,6\% des Körpergewichtes innerhalb der ersten 9 Versuchstage, dann Wiederansteigen des Körpergewichtes bis nahezu zum Anfangsgewicht. Die Taube war während der ganzen Versuchsdauer sehr munter und erschien durchaus gesund.

\section{Versuch Nr. 2.}

Versuchstier: Eine junge, weisse Taube (etwa zwei Monate alt). Beginn des Versuches: 3. September 1917.

Abschluss des Versuches: 17. November 1917.

Nahrung: Gemischtes Taubenfutter.

Tägliche Zugaben:

Vom 3. September bis 15. Oktober $0,05 \mathrm{~g}$ Oxalsäure, $\begin{array}{lll}16 . \text { Oktober } & \text { 27. November } 0,15 \mathrm{~g}, & 0,10 \mathrm{~g}\end{array}$

Die Oxalsäure wurde in Pillenform wie bei Versuch Nr. 1 verabreicht. Körpergewichte:

\begin{tabular}{|c|c|c|c|c|c|}
\hline Datum 1917 & Gewicht & Datum 1917 & Gewicht & Datum 1917 & Gewicht \\
\hline 3. September & $256,0 \mathrm{~g}$ & 29. September & $272,0 \mathrm{~g}$ & 27. Oktober & 274,0 \\
\hline 8. & $270,0 \mathrm{~g}$ & 6. Oktober & $273,0 \mathrm{~g}$ & 3. November & 277 \\
\hline 5. & $272,0 \mathrm{~g}$ & 13. & $275,0 \mathrm{~g}$ & 10. & 240 \\
\hline 2. & $245,0 \mathrm{~g}$ & 20. & $267,0 \mathrm{~g}$ & 17. & \\
\hline
\end{tabular}

Verhalten des Versuchstieres: Die Taube war während der ganzen Versuchsdauer durchaus munter. Von irgendwelchen abnormen Erseheinungen, im besonderen von nervösen Störungen, wie Lähmungen, Krämpfen und dergl. $m$. war nichts zu bemerken. Die Körpertemperatur schwankte zwischen 38,4 und $41,0^{\circ}$ C. (5. Sept. $38,4^{\circ}$, 14. Sept. $41,0^{\circ}$, 5. Okt. $40,0^{\circ}$, 3. Nov. $40,3^{\circ}$ C.).

VI. Versuch mit Rindergalle (Nr. 3).

Versuchstier: Eine gesunde, kräftige Taube.

Beginn des Versuches: S. Januar 1917.

Pflüger's Arehiv für Physiologie. Bd, 172. 
Abschluss des Versuches: 3. Februar 1917.

Nahrung: Gemischtes Taubenfutter.

Tägliche Zugaben:

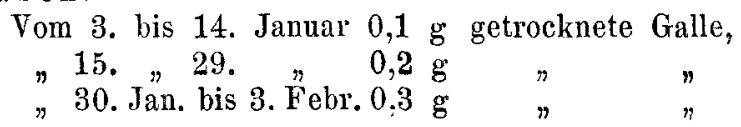

Die getrocknete Rindergalle wurde folgendermaassen bereitet: Frische Rindergalle wurde nach dem Filtrieren auf dem Wasserbade unter Umrühren zur Trockne verdampft. Der Rückstand wurde nach dem Zerreiben zu einem feinen Pulver mit etwas reiner Weizenstärke, reinem Dextrin und destilliertem Wasser zu einer plastischen Masse verarbeitet, aus der Pillen hergestellt werden, von denen jede $0,1 \mathrm{~g}$ trockene Rindergalle enthielt.

Körpergewichte:

\begin{tabular}{|c|c|c|c|}
\hline Datum 1917 & Gewicht & Datum 1917 & Gewicht \\
\hline 3. Januar & $226,0 \mathrm{~g}$ & 20. Januar & $286,0 \mathrm{~g}$ \\
\hline 6. $\quad \eta$ & $256,0 \mathrm{~g}$ & & $274,0 \mathrm{~g}$ \\
\hline 13. & $\mathbf{2 7 3 , 0} \mathrm{g}$ & 3. Februar & $262,5 \mathrm{~g}$ \\
\hline
\end{tabular}

Verhalten des Versuchstieres: Während der ersten 17 Tage Zunahme des Körpergewichts um $60 \mathrm{~g}$, entsprechend $+20,97 \%$ des Anfangsgewichtes, dann bei erhöhter Gabe, die abführend zu wirken schien, Abnahme um $22 \mathrm{~g}$, entsprechend $-8,22 \%$ des Höchstgewichtes innerhalb der letzten 13 Versuchstage. Am Schlusse wog die Taube noch $365 \mathrm{~g}$, entsprechend $+16,15 \% \mathrm{mehr}$ als am Anfange des Versuches. Die Taube war während der ganzen Versuchsdauer durchaus munter und erschien vollkommen gesund.

\section{Hefepräparat A.}

Darstellung.

$50 \mathrm{~g}$ Bierhefe Qual. I (siehe S. 206), $250 \mathrm{ccm}$ dest. Wasser und $\breve{g}$ g Natriumbydroxyd wurden am Rückflusskühler anf dem kochenden Wasserbade 4 Stunden lang erhitzt, wobei eine erhebliche Menge von Ammoniak entwich. Die Mischung wurde nach erfolgter Neutralisation mit Salzsäure auf dem Wasserbade bis zur Konsistenz einer dicken Pillenmasse eingedampft und in 300 Pillen eingeteilt. Je sechs Pillen entsprachen demnach $1 \mathrm{~g}$ des Ausgangsproduktes (Hefe).

Die verwandte Hefe hatte sich bei zahlreichen Versuchen an typisch erkrankten Tauben als sehr wirksam erwiesen.

Tierversuche.

I. Heilungsversuche.

Bei vier verschiedenen Versuchen an Tauben, welche in typischer Weise an alimentärer Dystrophie erkrankt waren, erwiesen sich Gaben von 1 bis $1^{1 / 2} \mathrm{~g}$ als vollkommen unwirksam gegen die durch Hefe und bestimmte Hefepräparate mit seltenen Ausnahmen leicht und sicher zu beseitigenden Lähmungen und anderen nervösen Erscheinungen (Opisthotonus, Krämpfe). 
Beitrag zor Kenntnis von organischen Nahrungsstoffen mit spezif. Wirkung. 163

II. Prophylaxe. Versuch Nr. 4 .

Versuchstier: Eine gesunde, kräftige Taube.

Beginn des Versuches: 30. März 1917.

Schluss des Versuches: 25. Mai 1917.

Nahrung: Geschliffener roher Reis Sorte B. Gehalt an:

1. Stickstoff . . . . . . . 1,22\%

2. Stickstoff-Substanz (Protein) . . . 7,62\%

3. Asche . . . . . . . . . 1,40\%

4. Phosphorsäure $\left(\mathrm{P}_{2} \mathrm{O}_{\bar{a}}\right)$. . . . . $0,27 \%$

Tägliche Zugaben:

Vom 30. März bis 14. April $1 \mathrm{~g}$ Hefepräparat A (6 Pillen),

"15. April , 28. \# keine Zugabe,

$" 28.20 " 25$. Mai 1 g Hefepräparat $A$.

Körpergewichte:

\begin{tabular}{cc|ccc|cc} 
Datum 1917 & Gewicht & Datum 1917 & Gewicht & Datum 1917 & Gewicht \\
30. März & $139,5 \mathrm{~g}$ & 21. April & $251,0 \mathrm{~g}$ & 12. Mai & $213,5 \mathrm{~g}$ \\
7. April & $330,0 \mathrm{~g}$ & 28. M" & $219,0 \mathrm{~g}$ & 19. & \\
14. & 288,0 & g. Mai & $222,0 \mathrm{~g}$ & 25. & $198,5 \mathrm{~g}$ \\
& & 5. & $195,0 \mathrm{~g}$
\end{tabular}

Übersicht.

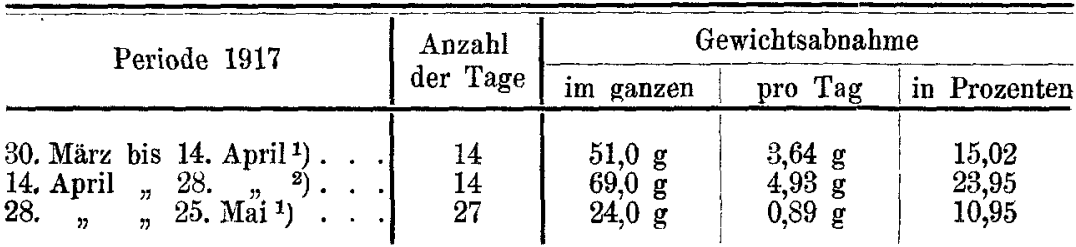

Vexhalten des Versuchstieres: Während des Versuches bis auf die letzten drei Tage war die Taube sehr munter. Fresslust gegen Ende des Versuches geringer. Am 24. Mai nachmittags: Paresen der Beine, stolperiger Gang, sonst keine nervösen Störungen. Am 25. Mai früh tot.

\section{Versuch Nr. 5.}

Versuchstier: Eine gesunde, kräftige Taube,

Beginn des Versuches: 26. Mai 1917.

Schluss des Versuches: 26. April 1917.

Nahrung: Geschliffener roher Reis Sorte B (S. 211).

Tägli che Zugabe: 1 g (6 Pillen) des Hefepräparates A (S. 162).

Körpergewichte:

Datum 1917

30. März

Gewicht

Datum 1917

Gewicht

7. April

$280,0 \mathrm{~g}$

$245,5 \mathrm{~g}$

14.

$223,5 \mathrm{~g}$

21. April

$216,0 \mathrm{~g}$

26. " $186,0 \mathrm{~g}$

Gewichtsabnahme im ganzen: $94,0 \mathrm{~g}=33,57 \%$.

1) 1 g Hefepräparat 1 pro Tag.

2) Keine Zugabe. 
Verhalten des Versuchstieres: Bis zum 25. April trotz starker Abmagerung sehr munter. Am 26. April früh Paresen der Beine, stolperiger Gang. Das Tier drehte sich im Kreise um sich selbst and machte den Eindruck, schwindlig zu sein. Sonst keine nervösen Erscheinungen.

Die Taube wurde nun zu dem Versuche Nr. 10 (s. S, 170) verwandt.

\section{Versuche mit Präparaten aus hydrolysierter Bierhefe und Reiskleie.}

\section{Alkoholische Extrakte.}

Versuche Nr. 6-8.

Darstellung des Präparates: Reiskleie oder Bierhefe wurden 24 Stunden lang auf dem Wasserbade mit der zehnfachen Menge ihres Eigengewichtes $10 \%$ iger. Schwefelsäure erwärmt. Die Schwefe]säure wurde dann sehr sorgsam mit Baryt entfernt. Es wurde hierbei vermieden, dass die Lösung einen Überschuss von Baryt erhielt. Vom schwefelsauren Baryt wurde abfiltriert, und das Filtrat unter vermindertem Druck zur Trockne verdampft. Der Rückstand wurde mit viel absolutem Alkohol ausgezogen. Das alkoholische Extrakt wurde wieder unter vermindertem Druck eingedampft und der Rückstand wiederum mit absolutem Alkohol ausgezogen. Dieser Prozess wurde zehnmal wiederholt. Jedesmal blieb ein erheblicher Teil des Verdampfungsrückstandes ungelöst.

Das. so erhaltene Extrakt wurde auf seine physiologische Wirksamkeit an Tauben geprüft, die an alimentärer Dystrophie (sogenannter Tanben-Beriberi) litten. Es war sehr wirksam. Die verwendete Lösung war etwa $1 \%$ ig.

$$
\text { Versuch Nr. 6. Taube Nr. } 1 .
$$

Nahrung: Roher geschliffener Reis.

\begin{tabular}{|c|c|c|c|}
\hline Tag & $\begin{array}{c}\text { Körper- } \\
\text { gewicht } \\
\text { g }\end{array}$ & Zugaben & Bemerkungen \\
\hline $\begin{array}{l}1 . \\
\text { 2. bis } 8 \text {. } \\
9.16 . \\
17 .\end{array}$ & $\begin{array}{l}275,0 \\
285,0 \\
250,0 \\
245,0\end{array}$ & 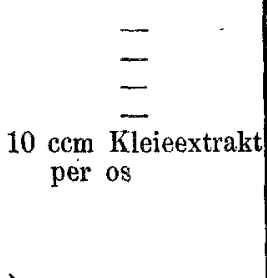 & $\begin{array}{l}\text { Frisst viel. } \\
\text { Nimmt immer weniger Nahrung auf. } \\
\left\{\begin{array}{l}\text { Sitzt mit gesträubtem Gefieder im } \\
\text { Käfig. Ganz paretisch. Nach } \\
\text { wenigen Stunden immer mehr zu- } \\
\text { nehmend. } 6 \text { Stunden nach Eingabe } \\
\text { des Kleieextraktes ist das Tier } \\
\text { munter und frisst. }\end{array}\right.\end{array}$ \\
\hline $\begin{array}{lll}18 . & & 26 . \\
27 . & & 40 . \\
40 . & 60 . \\
61 . & 80 . & 80 . \\
& 85 .\end{array}$ & $\begin{array}{l}250,0 \\
262,0 \\
260,0 \\
250,0 \\
234,0\end{array}$ & $\begin{array}{l}\text { Täglich } 10 \mathrm{ccm} \\
\text { Kleieex trakt }\end{array}$ & Nach kurzem Krampfstadium tot. \\
\hline
\end{tabular}


Beitrag zur Kenntnis von organischen Nahrungsstoffen mit spezif. Wirkung. 165 Versuch Nr. 7. Taube Nr. 2.

Nahrung: Geschliffener roher Reis.

\begin{tabular}{|c|c|c|c|}
\hline Tag & $\begin{array}{l}\text { Körper- } \\
\text { gewicht } \\
\mathbf{g}\end{array}$ & Zugaben & Bemerkungen \\
\hline $\begin{array}{r}1 . \\
5 . \\
10 . \\
15 . \\
20 . \\
22 .\end{array}$ & $\begin{array}{l}308 \\
315 \\
310 \\
290 \\
280 \\
275\end{array}$ & $\begin{array}{l}10 \mathrm{cem} \text { Hefeextrakt } \\
\text { per os } \\
10 \text { ccm Hefeextrakt } \\
\text { per os } \\
10 \text { ccm Hefeextrakt } \\
\text { per os } \\
10 \text { ccm Hefeextrakt } \\
\text { per os }\end{array}$ & $\begin{array}{l}\text { Frisst gat. } \\
\text { Apathisch. Gesträubtes Gefieder. } \\
\text { Starker Anfall. Opisthotonus. } \\
\text { Das Tier erholt sich rasch und frisst } \\
\text { spontan. } \\
\text { Munter. } \\
\text { Apathisch. Streckkrämpfe schwerster } \\
\text { Art. } \\
\text { Nach } 6 \text { Stunden frisst das Tier spontan. } \\
\text { Munter. } \\
\text { Lähmung des rechten Beines. } \\
\text { Das Tier frisst spontan. } \\
\text { Lähmung etwas gebessert. } \\
\text { Lähmung bleibt. } \\
\text { Das Tier wird tot im Käfig gefunden. }\end{array}$ \\
\hline
\end{tabular}

Versuch Nr. 8. Taube Nr. 3.

\begin{tabular}{|c|c|c|c|}
\hline Tag & $\begin{array}{c}\text { Körper- } \\
\text { gewicht } \\
\mathrm{g}\end{array}$ & Zugaben & Bemerkungen \\
\hline $\begin{array}{c}\text { 1. } \\
\text { 2. bis } 8 . \\
16 . \\
24 . \\
25 . \\
26 . \\
27 . \\
90 . \\
40 . \\
45 . \\
46 . \\
50 . \\
55 . \\
60 . \\
65 . \\
70 . \\
75 . \\
80 . \\
85 . \\
86 .\end{array}$ & $\begin{array}{l}260 \\
270 \\
255 \\
245 \\
\\
248 \\
258 \\
265 \\
280 \\
275 \\
270 \\
265 \\
265 \\
262 \\
253 \\
248 \\
240 \\
225 \\
220 \\
213 \\
205\end{array}$ & $\begin{array}{c}\bar{Z} \\
10 \mathrm{ccm} \text { Hefeextrakt } \\
\text { per os } \\
" \\
" \\
" \\
" \\
" \\
" \\
" \\
" \\
" \\
" \\
" \\
25 \text { ccm Hefeextrakt } \\
\text { per os }\end{array}$ & $\begin{array}{l}\text { Munter. } \\
\text { Schwerer Krampfaufall. Frisst nicht } \\
\text { mehr. } \\
\text { Nach 4 Std. gebessert. Frisst spontan. } \\
\text { Ganz munter. } \\
" \\
"\end{array}$ \\
\hline
\end{tabular}


Emil Abderhalden und H. Schaumann:

Versuch Nr. 8 (Fortsetzung).

\begin{tabular}{|c|c|c|c|}
\hline Tag & $\begin{array}{l}\text { Körper- } \\
\text { gewicht } \\
\mathrm{g}\end{array}$ & Zugaben & Bemerkungen \\
\hline $\begin{array}{l}87 . \\
90 . \\
95 \\
100 . \\
110 . \\
120 . \\
130 . \\
140 . \\
150 . \\
160 . \\
170 . \\
180 . \\
190 . \\
193 .\end{array}$ & $\begin{array}{l}202 \\
200 \\
198 \\
190 \\
185 \\
180 \\
182 \\
175 \\
170 \\
173 \\
170 \\
154 \\
150\end{array}$ & $\begin{array}{c}25 \mathrm{ccm} \text { Hefextrakt } \\
\text { per os } \\
" \\
" \\
" \\
" \\
" \\
" \\
" \\
" \\
"\end{array}$ & $\begin{array}{l}\text { Voliständig zum Skelett abgemagert } \\
\text { Tot im Käfig gefunden. }\end{array}$ \\
\hline
\end{tabular}

\section{Acetonniederschlag aus dem alkoholischen Auszuge des Hefehydrolysates.}

A. Darstellung.

$5 \mathrm{~kg}$ zunächst bei Zimmertemperatur, dann bei $37^{\circ} \mathrm{C}$. getrockneter Presshefe wurden mit 13 Litern $10 \%$ iger Schwefelsäure 18 Stunden lang in einem emaillierten Topf gekocht. Nach dem Abkühlen der Flüssigkeit wurde die Hauptmenge der Schwefelsäure mit Kalkmilch abgestumpft bzw. ausgefällt. Hierauf wurde in Wasser aufgeschwemmtes Kalziumkarbonat zugesetzt und unter häufigem Umrühren stehengelassen. Nach 12 Stunden wurde der Niederschlag durch Sackleinewand möglichst abgeseiht, dann ausgepresst. Die Kolatur wurde 18 Stunden lang ruhig stehengelassen und die überstehende Flüssigkeit dann durch Dekantieren und Abnutschen von dem Bodensatz getrennt. Letzterer wurde gut ausgewaschen. Filtrat und Waschwasser, die noch ziemlieh sauer waren, wurden so lange mit Barythydrat versetzt, bis Kongopapier danach blau gefärbt wurde. Der Niederschlag wurde wieder abgenutscht und gut ausgewaschen. Das Filtrat wurde mit Bleiessig versetzt, bis keine Fällung mehr erfolgte, der entstandene Niederschlag abgenutscht und ausgewaschen. Filtrat und Waschwasser wurden mit verdünnter Schwefelsäure in geringem Überschusse versetzt. Der Bleisulfatniederschlag wurde abgenutscht und das Filtrat im Vakuum bei $40^{\circ} \mathrm{C}$. stark eingeengt; dann mit 6 Litern absoluten Alkohols versetzt. Nach 24 Stunden wurde der gebildete Niederschlag abgenutscht. Das Filtrat wurde wiederum bei $30-40^{\circ} \mathrm{C}$. unter vermindertem Druck stark eingedampft und der Rückstand nochmals mit 6 Litern absoluten Alkohols aufgenommen. Nach 48 Stunden wurden Niederschlag und Lösung durch Filtrieren getrennt. Das Filtrat wurde nun zunächst im Vakuum, dann im Fa ustHe im'schen Trockenapparat bei $35-40^{\circ} \mathrm{C}$. bis zur Extraktkonsistenz eingedampft. Den Extrakt wurde unter Rühren and Durchkneten so viel gebranntes Gipsmehl zugesetzt, bis die Hauptmenge der Flüssigkeit gebunden war, und das Gemisch zunächst bei Zimmertemperatur, dann bei $37^{\circ} \mathrm{C}$. getrocknet. Hierauf wurde es fein gemahlen, durch ein fein- 
maschiges Sieb geschlagen und nochmals bei $37^{\circ} \mathrm{C}$. getrocknet. Das so gewonnene Mehl wurde nun dreimal hintereinander in geeigneten Mengen mit absolutem Alkohol durch Schütteln in der Schüttelmaschine (je 3 Stunden lang) ausgezogen. Die alkoholischen Auszüge wurden durch Abnutschen von dem Gipsmehl getrennt, dann bei $37^{\circ} \mathrm{C}$. unter vermindertem Druck zunächst in einem Kolben, hierauf in einer Porzellanschale stark eingeengt. Der Rückstand wurde in wenig absolutem Alkohol gelöst, mit Salzsäure bis zur deutlich sauren Reaktion versetzt und die Lösung unter Druck filtriert. Das Filtrat wurde mit Aceton solange versetzt, bis keine Fällung mehr eintrat. Von dem anfangs flockigen, dann zu einer dunklen extraktartigen Masse sich zusammenballenden Niederschlage, der an den Wandungen des zur Fällung benutzten Glashafens fest haftete, wurde die überstehende Flüssigkeit dekantiert und der Rest des Acetons durch Durchsaugen von Luft entfernt. Dieser primäre Acetonniederschlag wurde nochmals in möglichst wenig absolutem Alkohol gelöst und filtriert, das Filtrat nochmals wie verher mit Aceton versetzt, bis keine Fällung mehr eintrat: Der so gewonnene sekundäre Acetonniederschlag wurde wiederum mit absolutem Alkohol aufgenommen, dann filtriert. Das Filtrat wurde im Vakuum bei $37^{\circ} \mathrm{C}$. möglichst weit eingedampft, der Rückstand wiederholt mit absolutem Alkohol aufgenommen und dieser wieder im Vakuum abgedampft. Der so gewonnene dickflüssige Rückstand wurde dann in $100 \%$ Alkohol (durch Digerieren von absolutem Alkohol des Handels zuerst mit gebranntem Kalk, 'dann mit entwässertem Kupfersulfat und Destillieren gewonnen) gelöst und filtriert. Das Filtrat wurde durch Pergamentschlauch gegen $50 \%$ igen Alkohol so lange dialysiert, bis die wiederholt erneuerte Aussenflüssigkeit nur noch schwach gefärbt wurde. Die vereinigten Dialysate wurden schliesslich im Vakuum bei $37^{\circ} \mathrm{C}$. bis zur Extraktkonsistenz eingedampft. Das auf diese Weise erhaltene Präparat bildete eine dunkelbraune zähe Masse von eigentümlichem, an Fleischextrakt erinnernden Geruch. Ihre wässerige Lösung gab mit Folin's Reagens einen Niederschlag, der in überschüssiger Natriumkarbonatlösung mit blauer Farbe löslich war. Die wässerige Lösung lieferte mit Phosphorwolframsäure und die alkoholische Lösung mit Quecksilberchlorid starke weisse Niederschläge.

Der mit Quecksilberchlorid aus der alkoholischen Lösung des Acetonniederschlages gefällte Niederschlag wurde durch Einleiten von Schwefelwasserstoff zerlegt, das ausgefällte $\mathrm{HgS}$ abgenutscht und ausgewaschen. Filtrat und Waschwasser wurden durch Durchsaugen von Luft vom Schwefelwasserstoff befreit, dann bei $37^{\circ} \mathrm{C}$. im Vakuum möglichst weit eingedampft. Der Rückstand wurde wiederholt mit absolutem Alkohol des Handels aufgenommen und letzterer im Vakuum wieder abgedampft. Es hinterblieb ein kristallinischer, sehr hygroskopischer und dabei sehr leicht klebrig werdender gelblicher Rückstand, der sich als äusserst wirksam erwies. Über die näheren Eigenschaften dieser Substanz soll nachstehend (s. S. 214 u. ff.) eingehend berichtet werden.

Ein Teil des sekundären Acetonniederschlages diente zu Vorstudien, die bei der später (s. S. 216) zu beschreibenden gründlicheren Untersuchung der hydrolytischen Abbauprodukte der Hefe verwertet wurden. 
B. Tierversuche.

1. Heilung. Bei einer ganzen Reihe von Versuchen an Tauben, die in typischer Weise an alimentärer Dystrophie erkrankt waren, erwies sich der dialysierte Acetonniederschlag als sehr wirksam gegen die hierbei auftretenden nervösen Störungen. Gaben von $0,05-0,15 \mathrm{~g}$ in wässeriger Lösung intramuskulär eingespritzt oder per os in Pillenform verabreicht, äusserten eine oft üherraschende Wirksamkeit. Als Beispiele seien hier der bereits auf S. 177 (Taube Nr. 8) beschiriebene sowie noch ein weiterer Versuch angeführt.

a) Einer erkrankten Taube mit typischen Lähmungserscheinungen (Photographie Nr. 2, s. Versuch Nr. 16) wurden 15. Tropfen einer konzentrierten Lösung des Acetonniederschlages mit $3 \mathrm{ccm}$ dest. Wasser verdünnt in den Brustmuskel eingespritzt. Schon nach $1^{1 / 2}$ Stunde war das Tier instande, sich wieder zu erheben und umherzulaufen (Photograhie Nr. 3), und am nächsten Tage völlig munter. Auch die Fresslust gegen geschliffenen Reis war wiedergekehrt.

b) Einer an alimentärer Dystrophie typisch erkrankten Taube (Photographie Nr. 4; Lähmung von Beinen und Flügeln, Opisthotonus, heftige Konvulsionen) wurden $0,15 \mathrm{~g}$ des Acetonniederschlages in $2 \mathrm{ccm}$ dest. Wassers gelöst in den Brustmuskel eingespritzt. Nach Verlauf einer Stunde waren alle nervösen Erscheinungen so gut wie völlig beseitigt (Photographie Nr. 5). Nach 24 Stunden ersehien das Tier vollkommen gesund, war sehr munter und nahm auch wieder reichliche Mengen des kurz vorher verschmähten geschliffenen Reises spontan auf.

Dauerversuche. Versuch Nr. 9.

Versuchstier: Eine nach längerer Fütterung mit geschliffenem Reis an alimentärer Dystrophie typisch erkrankte, dann mit Tagesgaben von 20 Tropfen einer konzentrierten Lösung des sekundären, dialysierten Acetonniederschlages 3 Tage lang vorbehandelte Taube. Das Tier war bei Beginn des Versuches von allen nervösen Störungen wieder frei und imstande, sich leicht und behende zu bewegen.

Beginn des Versuches: 28. Juni 1917.

Schluss des Versuches: 9. September 1917.

Nahrung: Vom 28. Juni bis 18. August geschliffener roher Reis. Vom 19. August bis 9. September gemischtes Taubenfutter.

Tägliche Zugaben: Vom 28. Juni bis 18. August 20 Tropfen der zur Vorbehandlung mit Erfolg angewandten, konzentrierten wässerigen Lösung des Acetonniederschlages. Ausserdem:

Am 8. Juli intramuskuläre Einspritzung von $0,15 \mathrm{~g}$ des Acetonniederschlages in $5 \mathrm{ccm}$ dest. Wassers gelöst.

Am 22., 23. und 24. Juli je 5 Pillen des Aminosäuregemisches (s.S.176).

Vom.24. Juli bis 9. August $1 \mathrm{~g}$ getrocknete Hefe Qual. I (s. S. 206) in Pillenform.

Vom 10. August bis 9. Septbr. $2 \mathrm{~g}$ getrocknete Hefe Qual. I (s. S.206).

Körpergewichte:

\begin{tabular}{cc|cc|cc} 
Datum 1917 & Gewicht & Datum 1917 & Gewicht & Datum 1917 & Gewicht \\
28. Juni & $184,0 \mathrm{~g}$ & 8. Juli & $170,0 \mathrm{~g}$ & 22. Juli & $168,0 \mathrm{~g}$ \\
5. Juli & $178,5 \mathrm{~g}$ & $15 . \quad$, & $174,5 \mathrm{~g}$ & $24 . \quad "$ & $175.0 \mathrm{~g}$
\end{tabular}


Beitrag zur Kenntnis von organischen Nahrungsstoffen mit spezif. Wirkung. 169

\begin{tabular}{|c|c|c|c|c|c|}
\hline Datum 1917 & Gewicht. & Datum 1917 & Gewicht & Datum 1917 & Gewicht \\
\hline 26. Juli & $185,0 \mathrm{~g}$ & 5. August & $198,0 \mathrm{~g}$ & 26. Angust & $218,0 \mathrm{~g}$ \\
\hline 29. & $182,0 \mathrm{~g}$ & 9. & $209,0 \mathrm{~g}$ & 2. September & 223,0 \\
\hline 1. August & $188,0 \mathrm{~g}$ & $\begin{array}{l}12 . \\
19 .\end{array}$ & $\begin{array}{l}210,0 \mathrm{~g} \\
213,0 \mathrm{~g}\end{array}$ & 9. & 218,0 \\
\hline
\end{tabular}

Verhalten der Taube: Nach anfänglichem Wohlbefinden traten am 8. Juli wieder schwere nervöse Störungen auf: Paralyse der Beine und Flügel, Opisthotonus und Krämpfe. Eine Einspritzung in den Brustmuskel von $0,15 \mathrm{~g}$ des extraktförmigen Acetonniederschlages in $5 \mathrm{ccm}$ dest. Wassers gelöst beseitigte diese Erscheinungen nach Verlauf von etwa einer Stunde so gut wie vollkommen. Die Taube war dann bis zum 22. Juli munter. An diesem Tage wurde sie plötzlich sehr hinfällig und apathisch, ohne dass indessen Lähmungen oder andere nervöse Störungen bemerkbar waren. Sie bekam nun 3 Tage lang neben der Tagesgabe des Acetonniederschlages je fünf Pillen des Aminosäuregemisches (s. S. 176) und wurde mit geschliffenem rohen Reis (10 g pro. Tag) künstlich gefüttert. Am 24. Juli nachmittags stellten sich wieder Lähmung der Beine, Opisthotonus und Konvulsionen ein. Gegen Abend lag die Taube vollkommen apathisch mit geschlossenen. Augen und anscheinend moribund da. Sie bekam nun $1 \mathrm{~g}$ getrocknete Bierhefe in Pillenform. Am nächsten Morgen (25. Juli) war das Tier wieder munter und lief behende umher. Sie bekam nun täglich $1-2 \mathrm{~g}$ getrocknete. Hefe und erholte sich bei dieser Behandlung nicht nur sichtlich, sondern nahm auch, anfangs langsamer, dann schneller an Körpergewicht zu. Die vom 19. August an begonnene Fütterung mit gemischtem Taubenfutter (statt des geschliffenen Reises) hatte nur noch eine sehr geringe Gewichtszunahme zur Folge. Nachstehende Übersicht veranschaulicht die einzelnen Phasen des Versuches.

Übersicht.

\begin{tabular}{|c|c|c|c|c|c|}
\hline \multirow[t]{2}{*}{ Periode 1917} & \multirow[t]{2}{*}{ Nahrung } & \multirow[t]{2}{*}{ Tägliche Zugaben } & \multicolumn{2}{|c|}{$\begin{array}{l}\mathrm{Zu}-\text { bzw. Abnahme } \\
\text { desKörpergewichts }\end{array}$} & \multirow{2}{*}{$\begin{array}{l}\text { Gesundheits- } \\
\text { zustand }\end{array}$} \\
\hline & & & absolute & relative & \\
\hline 28.Juni bis 17.Juli & $\begin{array}{l}\text { Geschliff. } \\
\text { roher Reis }\end{array}$ & $\begin{array}{l}\text { Acetonniederschlag } 20 \text { Tropfen } \\
\text { (der konzentrierten Lösung) } \\
\text { per os }\end{array}$ & $-14 \mathrm{~g}$ & $-7,6 \%$ & Munter \\
\hline 8. Juli. . . & $"$ & $\begin{array}{l}\text { Acetonniederschlag } 20 \text { Tropfen } \\
\text { per os, } 0,15 \mathrm{~g} \text { intramuskulär }\end{array}$ & - & - & Schwerkrank \\
\hline 8. bis 22. Juli . & $n$ & A cetonniederschlag 20 Tropfen & $-2 \mathrm{~g}$ & $-1,2 \%$ & Munter \\
\hline 22. bis 24. Juli. & $n$ & \begin{tabular}{|} 
Acetonniederschlag 20 Tropfen \\
Aminosäuregemisch 5 Pillen
\end{tabular} & $+7 \mathrm{~g}$ & $+4,1 \%$ & Apathisch \\
\hline 24. Juli . . & $n$ & $\begin{array}{c}\text { Acetonniederschlag } 20 \text { Tropfen } \\
\text { Getrocknete Bierhefe } 1 \mathrm{~g}\end{array}$ & - & - & Moribund \\
\hline 25. Juli bis 1. Aug. & $"$ & $\begin{array}{l}\text { Acetonniederschlag } 20 \text { Tropfen } \\
\text { Getrocknete Bierhefe } 1 \mathrm{~g}\end{array}$ & $+13 \mathrm{~g}$ & $+7,5 \%$ & \\
\hline & $"$ & $\begin{array}{l}\text { Acetonniederschlag } 20 \text { Tropfen } \\
\text { Getrocknete Bierhefe } 1 \mathrm{~g}\end{array}$ & $+21 \mathrm{~g}$ & $+11,7 \%$ & \\
\hline 10. bis 18. Ang. & " & $\begin{array}{l}\text { A cetonniederschlag 20 Tropfen } \\
\text { Getrocknete Bierhefe } 2 \mathrm{~g}\end{array}$ & $+4 \mathrm{~g}$ & $+1,9 \%$ & Selhr munter \\
\hline 19. Aug. bis 9. Sept. & $\begin{array}{l}\text { Gemischtes } \\
\text { Taubenfutt. }\end{array}$ & Getrocknete Bierhefe $2 \mathrm{~g}$ & $+5 \mathrm{~g}$ & $+2,4 \%$ & \\
\hline
\end{tabular}


Versuch Nr. 10 (Fortsetzung des Versuches Nr. 5, S. 163).

Versuchstier: Die zu dem Versuche Nr. 5 (S. 163) verwandte Taube nach ihrer Wiederherstellung (s, nachstehend).

Beginn des Versuches: 26. April 1917.

Schluss des Versuches: 16. Juni 1917.

Nahrung: Geschliffener roher Reis.

Tägliche Zugaben: Vom 28. April bis 1. Mai: $0,6 \mathrm{~g}$ des Hefepräparates A (s. S. 162) und $0,1 \mathrm{~g}$ des Acetonniederschlages aus hydrolysierter Hefe (s. S. 166).

Vom 2. bis 5. Mai: $0,6 \mathrm{~g}$ des Hefepräparates $\mathrm{A}$ und $0,15 \mathrm{~g}$ des Acetonniederschlages aus hydrolysierter Hefe.

A m-6. und 7. Mai: $0,6 \mathrm{~g}$ des Hefepräparates A, 0,2 g des Acetonniederschlages aus hydrolysierter Hefe und 2 Aminosäurepillen (s. S. 176).

Vom 8. bis 22. Ma i: $0,6 \mathrm{~g}$ des Hefepräparates A, $0,5 \mathrm{~g}$ Hefenukleoproteid (s. S. 179) und 2 Aminosäurepillen (s. S. 176).

Vom 23. bis 28. Mai: $0,6 \mathrm{~g}$ des Hefepräparates $\mathrm{A}$ und $0,5 \mathrm{~g}$ Hefentkleoproteid (s. S. 179).

Vom 29. Mai bis 16. Juni: $1 \mathrm{~g}$ getrocknete Bierhefe Qual. I (s. S. 206).

Körpergewichte:

\begin{tabular}{|c|c|c|c|c|c|}
\hline Datum 1917 & Gewicht & Datum 1917 & Gewicht & Datum 1917 & Gewicht \\
\hline 28. April & $185,0 \mathrm{~g}$ & 19. Mai & $204,5 \mathrm{~g}$ & 7 Juni & $224,0 \mathrm{~g}$ \\
\hline & $188,0 \mathrm{~g}$ & 26. & $187,0 \mathrm{~g}$ & & $223,0 \mathrm{~g}$ \\
\hline 3. Mai & $187,0 \mathrm{~g}$ & 29. & $202,0 \mathrm{~g}$ & 13. & $235,0 \mathrm{~g}$ \\
\hline $\begin{array}{r}5 . \\
12 .\end{array}$ & $\begin{array}{l}187,5 \mathrm{~g} \\
190,5 \mathrm{~g}\end{array}$ & 2. Juni & $201,5 \mathrm{~g}$ & 16. & 242,0 \\
\hline
\end{tabular}

Aufgenommener geschliffener Reis:

Datum 1917 Gewicht Datum 1917 Gewicht Datum 1917 Gewicht \begin{tabular}{ll|lll|l} 
28./29. April $20,0 \mathrm{~g}$ & $14 . / 15$. Mai & $10,3 \mathrm{~g}$ & $1 . / 2$. Juni $15,7 \mathrm{~g}$
\end{tabular}

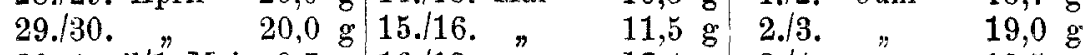

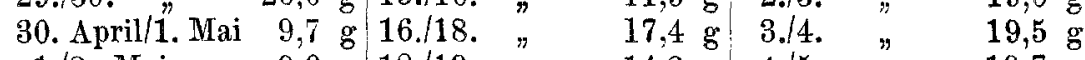
$\begin{array}{lrlllllll}\text { 1./2. Mai } 9,0 \mathrm{~g} & 18 . / 19 . & & 14,2 \mathrm{~g} & 4 . / 5 . & & & 19,7 \mathrm{~g}\end{array}$ $2 . / 3$. $3 . / 4$." " 4.15 . " 5.16 . " $6.17 . "$ 7.18." "

8.19.

9./10. " \begin{tabular}{ll|l|l}
13,0 & $\mathrm{~g}$ & $19 . / 20 . "$
\end{tabular} \begin{tabular}{ll|l|l}
9,0 & $\mathrm{~g}$ & $20 . / 21$.
\end{tabular} \begin{tabular}{ll|l|l}
9,2 & $\mathrm{~g}$ & $21 . / 22 . "$
\end{tabular} $13,2 \mathrm{~g}$ 22./23. " $6,7 \mathrm{~g} 23.24$. " \begin{tabular}{ll|l}
$6,1 \mathrm{~g}$ & $24.25 .$,
\end{tabular} \begin{tabular}{ll|l|l}
$11,4 \mathrm{~g}$ & $25 . / 26$. &
\end{tabular} 10.11." 11./12." 12./13, " 13./14. " \begin{tabular}{rr|l|l}
8,8 & $\mathrm{~g}$ & $26 . / 28$. & $"$ \\
11,2 & $\mathrm{~g}$ & $28 . / 29$. & $"$ \\
9,7 & $\mathrm{~g}$ & $29 . / 30$. & $"$ \\
12,4 & $\mathrm{~g}$ & $30 . / 31$. & $"$ \\
13,4 & $\mathrm{~g}$ & $\mathbf{3 1 .}$ Mai/1. Juni
\end{tabular} $7,8 \mathrm{~g}$ $14,9 \mathrm{~g}$ $25,7 \mathrm{~g}$ $1,2 \mathrm{~g} \quad 7.18 . \quad " \quad 24,3 \mathrm{~g}$ \begin{tabular}{l|lll}
8,9 & $\mathrm{~g}$ & $8 . / 9 . \quad \% \quad 30,0 \mathrm{~g}$
\end{tabular} $13,2 \mathrm{~g} \quad 9 . / 10 . \quad$ " $30,0 \mathrm{~g}$ $11,0 \mathrm{~g} 10.111 . \quad, \quad 30,0 \mathrm{~g}$ $10,7 \mathrm{~g}$ 11./12. " $\quad 39,7 \mathrm{~g}$ \begin{tabular}{ll|lll}
20,0 & $\mathrm{~g}$ & $12.133 . \quad " \quad 39,7 \mathrm{~g}$
\end{tabular} $17,0 \mathrm{~g}: 13 . / 14$. " $\quad 38,8 \mathrm{~g}$ \begin{tabular}{ll|lll}
$6,0 \mathrm{~g}$ & $14.115, \#$ & $47,7 \mathrm{~g}$
\end{tabular} $\begin{array}{lllll}18,6 \mathrm{~g} & 15.116 . \quad \# \quad 34,0 \mathrm{~g}\end{array}$

Verhalten des Versuchstieres: Die bei Abschluss des Versuches. Nr. 5 (s. S. 163) an alimentärer Dystrophie schwer erkrankte Taube bekam am 26. April 1917 um $11 \mathrm{Uhr}$ vorm. eine intramuskuläre Einspritzung von $0,025 \mathrm{~g}$ des Acetonniederschlages (s. S. 166) in dest. 
Beitrag zur Kenntnis von organischen Nahrungsstoffen mit spezif. Wirkung. 171

Wasser gelöst. Nach 2 Stunden merkliche Besserung. Taube, die sich vorher im Kreise um sich selbst drehte, als ob sie schwindlig wäre, lief wieder ziemlich behende geradeaus. Um $4 \mathrm{Uhr}$ nachm. wurden ihr $0,05 \mathrm{~g}$ und um $6 \mathrm{Uhr}$ weitere $0,075 \mathrm{~g}$ des Acetonniederschlages in den Kropf gespritzt. Um $7 \mathrm{Uhr}$ nachm. war das Tier erheblich munterer und am nächsten Tage (27. April) früh wieder ganz munter und versuchte, behende umherzulaufen. Die Taube blieb nun während des ganzen Versuches gesund und war stets sehr munter.

Übersicht.

\begin{tabular}{|c|c|c|c|c|c|c|}
\hline \multirow{2}{*}{$\begin{array}{c}\text { Periode } \\
1917\end{array}$} & \multirow{2}{*}{$\begin{array}{c}\text { Anzahl } \\
\text { der } \\
\text { Tage }\end{array}$} & \multirow[t]{2}{*}{ Tägliche Zugaben } & \multicolumn{2}{|c|}{$\begin{array}{l}\text { Aufgenommener } \\
\text { geschliffener Reis }\end{array}$} & \multicolumn{2}{|c|}{$\begin{array}{l}\text { Zunahme des } \\
\text { Körpergewichts }\end{array}$} \\
\hline & & & imganzen & pro Tag & absolute & I relative \\
\hline $\begin{array}{l}\text { 28. April } \\
\text { bis 7. Mai }\end{array}$ & 9 & $\begin{array}{l}0,6 \mathrm{~g} \text { Hefepräparat } \mathrm{A} \\
0,1 \text { bis } 0,2 \mathrm{~g} \text { Acetonnieder- } \\
\text { schlag } \\
3 \times 2 \text { Aminosäurepillen }\end{array}$ & $109,8 \mathrm{~g}$ & $12,2 \mathrm{~g}$ & $+22,5 \mathbf{g}$ & $+13,6 \%$ \\
\hline $\begin{array}{c}\text { 7. Mai } \\
\text { bis } 22 . \text { Mai }\end{array}$ & 15 & $\begin{array}{l}0,6 \mathrm{~g} \text { Hefepräparat } \mathrm{A} \\
0,5 \mathrm{~g} \text { Hefenukleoproteid } \\
2 \text { Aminosäurepillen }\end{array}$ & $150,3 \mathrm{~g}$ & $10,0 \mathrm{~g}$ & $+14,5 \mathrm{~g}$ & $+78 \%$ \\
\hline $\begin{array}{l}\text { 22. Mai } \\
\text { bis } 28 . \text { Mai }\end{array}$ & 6 & $\begin{array}{l}0,6 \mathrm{~g} \text { Hefepräparat } \mathrm{A} \\
0,5 \mathrm{~g} \text { Hefenukleoproteid }\end{array}$ & $63,8 \mathrm{~g}$ & $10,6 \mathrm{~g}$ & & \\
\hline $\begin{array}{c}\text { 28. Mai } \\
\text { bis 16.Juni }\end{array}$ & 19\{ & $\begin{array}{l}1,0 \text { g getrocknete Bierbefe } \\
\text { Qual. I }\end{array}$ & $497,8 \mathrm{~g}$ & $26,2 \mathrm{~g}$ & $+40,0 \mathrm{~g}$ & $+19,8 \%$ \\
\hline
\end{tabular}

3. Versuche mit dem aus hydrolysierter Hefe gowonnenen Acetonniederschlage und mit dem aus einer alkoholischen Lösung desselben durch Quecksilberchlorid gefällten, dann durch

Schwefelwasserstoff zerlegten Niederschlage (s. S. 235 u. ff.).

Versuch Nr. 11. Einer schon mehrere Tage lang gelähmten, an alimentärer Dystrophie schwer erkrankten Taube (Opisthotonus, Paralyse der Beine und Flügel, Krämpfe, extreme Abmagerung) wurden am 11. M a i 1917 $0,025 \mathrm{~g}$ des zerlegten $\mathrm{HgCl}_{2}$-Niederschlages in dest. Wasser gelöst in den Brustmuskel eingespritzt. Bis $3 \mathrm{Uhr}$ nachm. keine merkliche Besserung. Einspritzung einer grösseren Menge des zerlegten $\mathrm{HgCl}_{2}$-Niederschlages (Gewicht war nicht festgestellt worden) in wässeriger Lösung. Nach einer Viertelstunde trat heftiger Streckkrampf (wie auf Photographie Nr. 7) auf, wie er sonst nicht bei alimentärer Dystrophie, wohl aber nach Einspritzung grösserer Gaben Cholins (die dann als Regel nach kurzer Zeit zum Tode führten) beobachtet wird. Nach einer weiteren halben Stunde erholte sich die Taube wieder und erschien gebessert. Am nächsten Tage früh keine weitere Besserung, obschon die Taube inzwischen wieder geschliffenen rohen Reis gefressen hatte. Um 101/4 Uhr vorm. Einspritzung von $0,02 \mathrm{~g}$ des Acetonniederschlages in dest. Wasser gelöst. Nach ein paar Stunden merkliche Besserung. Opisthotonus und Krampfanfälle traten nicht mehr auf. Um $11^{1 / 4} \mathrm{Uhr}$ vorm. weitere intramuskuläre Einspritzung von $0,04 \mathrm{~g}$ des Acetonniederschlages in $2 \mathrm{ccm}$. dest. Wassers gelöst. Keine merkliche weitere Besserung bis 12 Uhr 50 Min. nachm. 
Um 1 Uhr und 4 Uhr nachm. wurden nun dem Tiere je $0,2 \mathrm{~g}$ Acetonniederschlag in dest. Wasser gelöst in den Kropf mittels einer an einer Spritze angebrachten dünnen Schlundsonde (Urethra-Sonde) eingespritzt. Am 13. Mai 9 Uhr vorm. sichtliche Besserung. Die Taube war viel munterer, doch traten zuweilen wieder Krämpfe auf. Einspritzung von $1 \mathrm{~g}$ des Acetonniederschlages in wässeriger Lösung (in zwei Malèn innerhalb einer halben Stunde) in den Kropf. Am 14. Mai 9 Uhr vorm. bedeutende Besserung: Keine Krämpfe, Opisthotonus völlig geschwunden, Paresen der Beine noch vorhanden, ausserdem grosse Mattigkeit und anscheinend Schwindelanfälle. Um $10 \mathrm{Uhr}$ vorm. und $7 \mathrm{Uhr}$ nachm. Einspritzung yon je $0,2 \mathrm{~g}$ des Acetonniederschlages in wässeriger Lösung in den Kropf. Am 15. Mai früh weitere Besserung. Die Taube war viel munterer, frass wieder geschliffenen Reis und vermochte umherzulaufen; doch waren die Paresen der Beine noch immer sehr ausgesprochen. Das Tier bekam nun bei fortgesetzter Futterung mit geschliffenem rohen Reis täglich $1 \frac{1}{2}-2 \mathrm{~g}$ getrocknete Bierhefe Qual. I (s. S. 206), bis der Gang wieder völlig normal erschien. Dies war erst am 2. Juni, also 22 Tage nach der ersten Behandlung am 11. Mai, der Fall.

Körpergewichte: 15. Mai $171,5 \mathrm{~g}, 26$. Mai 172,5 g, 2. Juni $217,0 \mathrm{~g}, 19$. Juni $171,5 \mathrm{~g}, 29$. Juni $202,0 \mathrm{~g}$.

\section{Versuche mit Rinderblut (Nr. 12).}

Bereitung der Rinderblutpräparate.

Frisches Rinderblut wurde nach dem Gerinnen mehrere Tage lang bei Temperaturen unter $0^{\circ} \mathrm{C}$. sich selbst überlassen, bis sich eine geniïgende Menge Serum ausgeschieden hatte, welches vom Blutkuchen abgegossen und wie unter 2. nachstehend angegeben weiterbehandelt wurde.

1. Der Blutkuchen wurde gut zerkleinert, bis alle Klümpchen möglichst beseitigt waren, und dann auf einem Koliertuche mit physiologischer Kochsalzlösung gut ausgewaschen. Die auf dem Tuche zurückgebliebenen Blutkörperchen. wurden auf grossen Tellern in möglichst dünner Schicht ausgebreitet und bei $37^{\circ} \mathrm{C}$. unter Zusatz von etwas Tolnol getrocknet. Der nach 24 Stunden getrocknete Ruckstand wurde dann durch Mahlen, Zerreiben und Sieben in ein feines Pulver verwandelt. Von diesem wurden $30 \mathrm{~g}$ mit $5 \mathrm{~g}$ reiner Weizenstärke, $5 \mathrm{~g}$ reiner löslicher Stärke, $2 \mathrm{~g}$ Glyzerin und genügend viel Wasser zu einer plastischen Masse verarbeitet, aus der 120 Pillen hergestellt wurden. Jede Pille enthielt demnach $0,25 \mathrm{~g}$ trockene Blutkörperchen.

2. Das Rinderblutserum wurde sofort nach dem Abgiessen vom Blutkuchen zentrifugiert. $320 \mathrm{ccm}$ des reinen Serums wurden danu vorsichtig mit verdünnter Salzsäure versetzt, bis sich der nach jedem Zusatz entstehende Niederschlag gerade wieder löste und die Reaktion gegen blaues Lakmưspapier schwach sauer war. Die Flüssigkeit wurde dann nach Zusatz von etwas Toluol in dünner Schicht auf flachen Tellern bei $37^{\circ} \mathrm{C}$. getrocknet, wozu 36 Stunden erforderlich waren. Der trockene Rückstand wurde nun von den Tellern abgekratzt und fein zerrieben. 
Beitrag zur Kenntnis von organischen Nahrungsstoffen mit spezif. Wirkung. 173

Die Ausbeute betrug $26 \mathrm{~g}$, welche mit $5 \mathrm{~g}$ reinem Dextrin, $8 \mathrm{~g}$ reiner Weizenstärke, $2 \mathrm{ccm}$ Glyzerin gemischt und mit einer genügenden Menge destillierten. Wassers $\mathrm{zu}$ einer plastischen Masse verarbeitet und in 130 Pillen eingeteilt wurde. Jede Pille entsprach demnach annähernd $2,5 \mathrm{ccm}$ frischen und genau $0,2 \mathrm{~g}$ getrockneten Serums.

3. Enteiweisstes Rinderserum. $200 \mathrm{ccm}$ frischen Rinderserums wurden mit einem Tropfen Eisessig versetzt und dann unter häufigem Umschwenken einmal aufgekocht. Die ausgefällten Eiweissstoffe wurden durch eine dicke Lage zerzupften und angefenchteten Filtrierpapiers abgenutscht und ausgewaschen. Das klare Filtrat wurde nunmehr auf flachen Tellern bei $37^{\circ} \mathrm{C}$. getrocknet. Der trockene Rückstand wurde von den Tellern möglichst abgekratzt, der Rest in wenig Wasser gelöst und die Gesamtmenge dann unter Zusatz von reiner Weizenstärke, reinem Dextrin und etwas Glyzerin zu einer knetbaren Masse verarbeitet, aus der 120 Pillen hergestellt wurden. Jede Pille entsprach annähernd $0,5 \mathrm{ccm}$ enteiweissten Serums. and 6 .

Versuchsti e re: Vier gesunde kräftige Tauben, Nr. 4, 5, 5 a

Beginn des Versuches: 3. April 1916.

Abschluss des Versuches: 18. Mai 1916.

Nahrung: Geschliffener roher Reis.

Zugaben pro Tag: Vom 3. bis 6. April nur geschliffener roher Reis. Vom 7. April an nachstehende Zugaben.

Ta u be Nr. 4: Vom 7. bis 26. April 0,5 g (2 Pillen) trockener Rinderblutkörperchen. Vom 27. April an $1 \mathrm{~g}$ (4 Pillen).

Ta u be Nr. 5 bzw. 5a: 0,4 g (2 Pillen) getrockneten Rinderblutserums.

T a u b Nr. 6: 2 Pillen entsprechend 3 ccm enteiweissten Rinderblutserums.

Körpergewichte:

\begin{tabular}{|c|c|c|c|c|c|}
\hline Datum & 1916 & $\begin{array}{c}\text { Taube Nr. } 4 \\
g\end{array}$ & $\begin{array}{c}\text { Taube } \mathrm{Nr} .5 \\
\mathrm{~g}\end{array}$ & $\begin{array}{c}\text { Taube } \mathrm{Nr}_{n} 5 \mathrm{a} \\
\mathrm{g}\end{array}$ & $\begin{array}{c}\text { Taube Nr. } 6 \\
g\end{array}$ \\
\hline 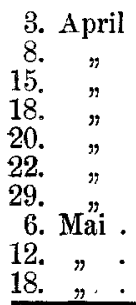 & $\begin{array}{l}\therefore \\
\therefore \\
\therefore \\
\therefore \\
\therefore \\
\therefore \\
\therefore \\
\therefore\end{array}$ & $\begin{array}{c}349,5 . \\
305,0 \\
325,0 \\
- \\
- \\
270,0 \\
263,5 \\
252,0 \\
217,0 \\
195,0\end{array}$ & $\begin{array}{l}306,5 \\
292,0 \\
295,0 \\
247,0 \\
= \\
= \\
= \\
-\end{array}$ & $\begin{array}{l}\text { 二 } \\
\text { 二 } \\
2 \overline{-}, 0 \\
300,0 \\
266,5 \\
241,0 \\
222,0 \\
-\end{array}$ & $\begin{array}{l}305,0 \\
292,0 \\
285,0 \\
- \\
258,5 \\
234,5 \\
230,0 \\
202,5 \\
- \\
-\end{array}$ \\
\hline
\end{tabular}

Verhalten der Versuchstiere:

T a u be Nr. 4 (Rinderblutkörperchen). Am 27. April sitzt die Taube mit eingezogenem Kopfe und gesträubtem Gefieder áuf der Stange, kann nicht mehr gut fliegen, läuft aber behende. Am 28. und 29. April nach 
Verdopplung der Gabe Blutkörperchen Besserung. Am 30. April Verschlimmerung. Am 2. Mai ausgesprochene Lähmung, Unfähigkeit zù fliegen und zu laufen. Verwendung zu einem anderen Versuche. Typische Erkrankung nach 29 Tagen.

T a a be Nr. 5 (Rinderblutserum). Am 18, April gelähmt. Typische Erscheinungen alimentärer Dystrophie. Bekommt $1 \mathrm{~g}$ Rinderblutkörperchen. Am 19. April keinerlei Besserung. Nochmals $1 \mathrm{~g}$ Rinderblutkörperchen und $1 \mathrm{~g}$ Pankreatin am 19. April morgens. Abends ist die Taube sehr krank. Bekommt 2,5 g Hefe in Pillen. Am nächsten Morgen (20. April) sehr munter. Erkrankung nach 16 Tagen.

Ta ube Nr. 5a (Rinderblutserum). Am 15. Mai erste Anzeichen der Erkrankung: Eingezogener Kopf, geduckte Haltung, gesträubtes Gefieder, Zittern. Am 17. Mai ausgesprochene Symptome alimentärer Dystrophie. Erkrankung nach 26 Tagen.

T a u be Nr. 6 (enteiweisstes Rinderblutserum). Am 29. April erste Krankheitssymptome. Am 3. Mai typische alimentäre Dystrophie: Lähmung der Beine und Flügel, Opisthotonus. Wird zu einem anderen Versuche verwandt. Erkrankung nach 31 Tagen.

\section{Versuche mit Hïhner- und Taubenblut.}

\section{A. Darstellung der Blutpräparate.}

In reinen Gefässen aufgefangenes Hühner- bzw. Taubenblut wurde nach dem Gerinnen durch Stehenlassen in der Kälte von Serum möglichst befreit. Letzteres wurde, wie nachstehend angegeben, weiter behandelt.

Der Blutkuchen wurde möglichst fein zerteilt und mit physiologischer Kochsalzlösung auf einem Koliertuch gut ausgewaschen. Der so gewonnene Rückstand von Blutkörperchen wurde in einer flachen Schale mit etwas Toluol versetzt und gut umgerührt, dann bei $37^{\circ} \mathrm{C}$. getrocknet and fein zerrieben.

Das Serum wurde unter Zusatz von etwas Toluol auf flachen Porzellantellern bei $37^{\circ} \mathrm{C}$. eingetrocknet, der Rückstand von den Tellern abgekratzt und nach nochmaligem Trocknen im Vaknum-Exsikkator über Schwefelsäure fein zerrieben, dann in einem gut verschlossenen Glase verwahrt.

\section{B. Tierversuche.}

1. Taubenblutkörperchen.

a) Eine an alimentärer Dystrophie typisch erkrankte Taube erhielt am 10. Mai 1917 um 6 Uhr nachm. $1 \mathrm{~g}$ Taubenblutkörperchen (mit Glyzerinstärkekleister gut durchsetzt und in 10 Pillen eingeteilt). Am 11. Mai war weder morgens noch im Laufe des Tages eine Wirkung bzw. Besserung festzustellen.

b) Einer typisch und sehr schwer an alimentärer Dystrophie erkrankten Taube (Lühmung und Streckkrampf der Beine nach vorne, Opisthotonus) wurden 2,3 g trockene Taubenblutkörperchen (mit Glyzerinsträrkekleister gemischt und in 30 Pillen eingeteilt) am 30. Oktober um $6 \mathrm{Uhr}$ nachm. eingeflösst. Am nächsten Tage war die Taube wieder 
Beitrag zur Kenntnis von organischen Nahrungsstoffen mit spezif. Wirkung. 175

munter und frei von nervösen Erscheinungen; der Gang war indessen noch immer etwas behindert. Nahrung nach wie vor geschliffener Reis. Am 1. November früh sehr munter, Gang noch immer paretisch, nachmittags plötzlich Opisthotonus and Streckkrampf der Beine. Die Taube erhielt nun $1 \mathrm{~g}$ alkoholischen Extrakts ans hydrolysierter Hefe (s. S. 164) in intramuskulärer Einspritzung, nach 2 Stunden noch 0,05 g Acetonniederschlag aus hydrolysierter Hefe (s. S. 166) und $1 \mathrm{~g}$ Hefe per os. Am 2. November früh keine Besserung. Die Taube erschien völlig gelähmt und konnte sich nicht mehr erheben, machte aher keinen apathischen Eindruck. Sie erhielt noch eine Gabe von $0,1 \mathrm{~g}$ des Acetonniederschlages aus hydrolysierter Hefe und $1 \mathrm{~g}$ getrocknete Bierhefe Qual. I per os. Eine Besserung trat im Verlaufe des Tages nicht mehr ein. Am 3. November früh wurde das Tier tot im Käfig gefunden.

Bei der Sektion wurde ein schwerer Darmkatarrh festgestellt.

$\mathrm{H}$ ü h n e r blut. Einer schwer gelähmten Taube (Paralyse der Beine und Flügel, starke Abmagerung, kein Opisthotonus, keine Krämpfe, Temperatur unter $36^{\circ} \mathrm{C}$.) wurden am 2. November $191710 \mathrm{Uhr}$ vorm. $2 \mathrm{~g} \mathrm{Hühnerblutkörperchen} \mathrm{in} \mathrm{Pillenform} \mathrm{(mit} \mathrm{reinem} \mathrm{Glyzerin-}$ stärkekleister bereitet) eingeflösst. Um $3^{1 / 2} \mathrm{Uhr}$ nachm. schien eine geringe Besserung eingetreten zu sein. Es wurden ihr weitere $3 \mathrm{~g}$ Hühnerblutkörperchen (60 Pillen) eingegeben. Am nächsten Tage (3. Ncvember) 10 Uhr vorm. war eine Besserung nicht eingetreten. Sie bekam nun 1,6 g getrocknetes $\mathrm{H} \ddot{u}$ h n er s e r u m (30 Pillen, ebenfalls mit Glyzerinstärkekleister bereitet). Am 3. November früh Verschlimmerung: Opisthotonus, Streckkrampf. Der Taube wurden um $11 \mathrm{Uhr}$ vorm. $1 \mathrm{~g}$ getrocknete Hefe Qual. I (in 6 Pillen) eingeflösst und $5 \mathrm{ccm}$ einer $10 \%$ igen Lösung von Natriumsulfat in den Kropf gespritzt. Am nächstfolgenden 'Tage früh wurde die Taube tot'im Käfig vorgefunden.

\section{Versuche mit Aminosäuren (Nr. 13-16).}

\section{Versuch Nr. 13: Histidin.}

Einer in charakteristischer Weise an alimentärer Dystrophie erkrankten Taube wurden am 23. Juni $191611 \mathrm{Uhr}$ vorm. $5 \mathrm{ccm}$ einer $1 \%$ igen Histidinlösung in den Brustmuskel eingespritzt. Nach einer Stunde merkliche Besserung. Opisthotonus geschwunden. Am Nachmittage Verschlimmerung. Einspritzung von weiteren $5 \mathrm{ccm}$ derselben Histidinlösung bewirkte auch nur eine vorübergehende, bis zum nächsten Morgen anhaltende Besserung.

\section{Versuch Nr. 14: Tryptophan.}

Der zu vorstehendem Versuche verwandten Taube, die am 24. Juni 1916 früh wieder typische Erscheinungen alimentärer Dystrophie (Beinlähmung, Opisthotonus, Krämpfe) aufwies, wurden $5 \mathrm{ccm}$ einer $21 / 2 \%$ igen Tryptophanlösung in den Brustmuskel eingespritzt: Vorübergehende Besserung, die aber nur bis zum nächsten Tage früh anhielt. Nochmalige Einspritzung von $5 \mathrm{ccm}$ der $21 / 2 \%$ igen Tryptophanlösung. Unwesentliche, vorübergehende Besserung. Am 26. Juni war die Taube wieder sehr krank (Beinlähmung, Opisthotonus, Krämpfe) (Photographie Nr. 9). Sie 
bekam nun eine Einspritzung von $1 \mathrm{ccm}$ einer Lösung des Acetonniederschlages aus hydrolysierter Hefe (s. S. 166). Nach 2 Stunden wesentliche Besserung (Photographie Nr, 10). Eine zweite intramuskuläre Finspritzung von $2 \mathrm{ccm}$ derselben Lösung beseitigte nach drei weiteren Stunden sämtliche nervösen Erscheinungen.

Versuch Nr. 15: Arginin.

Einer typisch an alimentärer Dystrophie erkrankten Taube wurden an 1. Juli $191611 \mathrm{Uhr}$ vorm. $3 \mathrm{ccm}$ einer $1 \%$ igen Argininlösung $(0,05 \mathrm{~g})$ in den Kropf gespritzt. Am 2. Juli früh wesentliche Verschlimmerung.

Die Taube bekam nun 20 Tropfen einer Lösung des Acetonniederschlages aus hydrolysierter Hefe (s. S. 166) per os. Am 3. Juli früh keine wesentliche Besserung. Auch eine Gabe von 1,5 g Nukleoproteid brachte keine Besserung und die Taube ging nachmittags ein.

Die Sektion des Tieres ergab, dass eine schwere Enteritis vorlag.

Versuch Nr. 16: Aminosäurengemisch.

Versuchstiere: Zwei gesunde, kräftige und ausgewachsene Feldtauben.

Beginn des Versuches: 30. Juni 1916.

Schluss des Versuches: 1. Angust 1916.

Nahrung: Geschliffener, roher Reis.

Zugaben: Taube Nr. 7 bekam von Anfang des Versuches an täglich zwei Pillen eines Aminosäurengemisches von nachstehender $\mathrm{Zu}$ sammensetzung.

Ta u be Nr. 8 erhielt während der ersten zehn Versuchstage keine Zugabe, dann täglich zwei Aminosäurepillen (ebenso wie Taube Nr. 7).

Bereitung der Aminosäurepillen: Aus nachstehender Mischung verschiedener Aminosäuren wurde unter Zusatz von ausreichenden Mengen reiner Weizenstärke, reinen Dextrins und dest. Wassers eine plastische Masse dargestellt, aus der 160 Pillen geformt wurden.

In 160 Pillen In 2 Pillen

1. Tryptophan . . . . . 0,4

2. Tyrosin . . . . . . $1,2 \mathrm{~g}$

3. Histidinchlorhydrat . . . , 1,2 g

4. Arginin . . . . . . . 1,2 g

5. Leucin . . . . . . . . 4,0 g

6. Glutaminsäure . . . . . $4,0 \mathrm{~g}$

7. Cystin . . . . . . . $0,8 \mathrm{~g}$

8. Glukosaminchlorhydrat . . $0,8 \mathrm{~g}$

9. Natriumbikarbonat . . . $0,8 \mathrm{~g}$ (tägliche Zugabe)

Körpergewichte:

Datum 1916 Taube Nr. 7 Taube Nr. 8 30, Juni $437,0 \mathrm{~g}$

5. Juli $395,0 \mathrm{~g}$

8. $375,0 \mathrm{~g}$ 15. " $315,0 \mathrm{~g}$ $310,0 \mathrm{~g}$ $308,0 \mathrm{~g}$ $279,5 \mathrm{~g}$

Datum 1916 Taube Nr. 7 Taube Nr. 8 22. Juli 29. $0,005 \mathrm{~g}$ $0,015 \mathrm{~g}$ $0,015 \mathrm{~g}$ $0,015 \mathrm{~g}$ $0,050 \mathrm{~g}$ $0,050 \mathrm{~g}$ $0,010 \mathrm{~g}$ $0,010 \mathrm{~g}$ $0,010 \mathrm{~g}$ 
Beitrag zur Kenntnis von organischen Nahrungsstoffen mit spezif. Wirkung. 177

A boname des Körpergewichtes:

$$
\begin{gathered}
\text { Taube Nr. 7: } 145 \mathrm{~g}=33,1 \% \\
n \quad \text { 8: } 131 \mathrm{~g}=41,6 \% .
\end{gathered}
$$

Verhalten der Versuchstauben:

Ta abe Nr. 7 wurde vom 8. Juli an täglich zwangsweise mit geschliffenem rohen Reis gefüttert. Am 31. Juli Lähmung der Beine. Am 1. Angust Zunahme der Lähmung. Am 2. August typische Symptome alimentärer Dystrophie: Lähmung der Beine und Flügel, Opisthotonus, Krämpfe, ausgesprochene Reflexe (Photographien Nr. 26, 27 u. 28). Das Tier erhielt eine intramuskuläre Einspritzung des von $\mathrm{Hg}$ befreiten, durch $\mathrm{HgCl}_{2}$ in alkoholischer Lösung nicht fällbaren Anteils des Acetonniederschlages aus hydrolvsierter Hefe (s. S. 236). Krämpfe und Opisthotonus schwanden hierauf, dagegen blieben die Lähmung und der Streckkrampf der Beine bestehen, obschon die Taube sonst wesentlich munterer erschien (Photographie Nr. $29-3^{1 / 2}$ Stunden nach der ersten Einspritzung). Am 3. August früh Lähmung der Beine unverändert. Einspritzung von $0,02 \mathrm{~g}$ des durch $\mathrm{HgCl}_{2}$ - Fällung aus dem Acetonniederschlage (s. S. 256) gewonnenen Präparates. Der Krampf der Beine schwand nach $1 \frac{1}{2}$ Stunden; die Taube war aber so matt und hinfällig; dass sie um 5 Uhr nachm. starb.

Sektionsbefund: Starke Abmagerung. Die Muskel der Oberschenkel bis auf einen geringfügigen Rest geschwunden. Der Kropf mit Reis prall gefiullt, obschon die Taube in den letzten 24 Stunden keinen Reis mehr bekommen hatte.

Zur weiteren Untersuchung entnommene und in Müller'sche Lösung eingelegte Organe: Gehirn, Rückenmark, Nervus ischiadicus, andere periphere Nerven, Lungen, Leber, Herz, Nieren, Darm, Pankreas, Brustmuskel.

Taube Nr. 8. Am 22. Juli schwer gelähmt. Gewichtsabnahme bis dahin $78 \mathrm{~g}=25,7 \%$ (Photographie Nr. 2). Einspritzung in den Brustmuskel von 15 Tropfen des dialysierten Acetonniederschlages aus hydrolysierter Hefe (s. S. 167), mit $3 \mathrm{ccm}$ dest. Wassers verdünnt. Nach $1 \frac{1}{2}$ Stunden waren die Lähmungen so gut wie völlig beseitigt (Photographie Nr.'3). Die Taube war am nächsten Morgen (23. Juli) wieder ganz munter. Wohlbefinden hielt bis zum 30. Juli trotz fortschreitender Abmagerung an. Dann wieder typische nervöse Störungen: Beinlähmung, Opisthotonus, Krämpfe (Photographie Nr. 11). Einspritzung von $0,01 \mathrm{~g}$ des durch $\mathrm{HgCl}_{\mathrm{g}}$-Fällung aus der alkoholischen Lösung des Acetonniederschlages gewonnenen kristallisierten Präparates, in $5 \mathrm{ccm}$ dest. Wássers gelöst. Nach $31 / 2$ Stunden wesentliche Besserung (Photographie Nr. 12). Am nächsten Tage 9 Uhr vorm. vermochte die Taube wieder behende zu laufen und zu fliegen.

\section{Versuche mit dem Phosphatid aus Weizenkleie} (Nr. 17 A, B und C).

Bereitung des Phosphatids. Weizenkleie wurde mit der funffachen Gewichtsmenge absoluten Alkohols 8 Tage lang bie $37^{\circ} \mathrm{C}$. unter häufigem Umschütteln digeriert. Der alkoholische Auszug. wurde 
dann durch ein Koliertuch abgeseiht und der Rückstand stark ausgepreßt. Die Kolatur wurde nach vorgenommener Filtration bei $37^{\circ} \mathrm{C}$. im Vakuum eingedampft und der Rückstand mit Aceton vollkommen ausgezogen, sodann durch Erwärmen im Vakuum auf $40^{\circ} \mathrm{C}$. von Aceton vollkommen befreit. Gelblich gefärbtes, klares, sehr konsistentes Extrakt, das mit Natronlauge leicht verseifbar war und nach A. Ne uman n verbrannit mit Ammonmolybdat starke $\mathrm{P}_{2} \mathrm{O}_{5}$-Reaktion gab.

\section{Versuch A.}

$3 \mathrm{~g}$ des Phosphatids wurden mit reiner. löslicher Stärke und reinem Dextrin in einer Reibschale unter Zusatz von dest. Wasser gut dureh geknetet, bis eine plastische Masse entstand, die auf einer Pillenmaschine in 60 gleiche Pillen eingeteilt wurde. Einer nach etwa vierwöchiger einseitiger Fütterung mit geschliffenem rohen Reis an alimentärer Dystrophie typisch erkrankten Taube (Beinlähmung, Opisthotonus, Krämpfe) wurden am 12. Januar 1917 um 4 Uhr nachm. 20 Pillen, um 7 Uhr nachm. weitere 20 Pillen and am nächsten Tage um $10 \mathrm{Uhr}$ vorm, die letzten 20 Pillen eingeflösst.

Schon am 13. Januar früh vor dem Eingeben der letzten 20 Pillen war die Taube vollkommen munter, lief und flog behende. Sie erholte sich noch weiter im Laufe des Tages und blieb bei fortgesetzter Fütterung mit geschliffenem rohen Reis 12 Tage lang gesund. Nebenerscheinungè unerwünschter Art, im besonderen Giftwirkung, blieben aus.

$$
\text { Versuch B. }
$$

a $\mathrm{g}$ des Extraktes (Phosphatids) wurden mit $30 \mathrm{~g}$ Trypsinogenum naturale "Phaomakon" (A.-G. P ha omakon, St. Petersburg) gut verrieben, ein Stück frischen, ausgespülten und zerkleinerten Taubendarmes zur Aktivierung des Ferments zugegeben und in einem Erl enmeyer-Kölbchen mit einer Toluolschicht bedeckt 3 Tage lang bei $37^{\circ} \mathrm{C}$. digeriert. Nach erfolgter Verdauung wurde, die ein wenig trübe, gelblich gefärbte Flüssigkeit zur Entfernung der Darmpartikel zunächst durch feinmaschige Gaze durchgeseiht, dann vom Toluol im Scheidetrichter getrennt und nach dem Filtrieren im Vakuum bei $37^{\circ}$ C. möglichst weit eingedampft. Aus dem konzentrierten Rückstande wurden unter Zusatz von reiner Weizenstärke und reinem Dextrin 90 gleichgrosse Pillen hergestellt.

Die zu dem Versuche Nr. 17 A verwandte Taube war am 25. Januar 1917 wieder schwer gelähmt. Sie bekam nun von dem in vorstehend angegebener Weise bereiteten Präparat am 25. Januar um $10^{1 / g}$ und $11^{3} / 4$ Uhr vorm., dann um 1 Uhr nachm. je 10 Pillen, um $3^{3 / 4}$ und 5 Uhr nachm. je 15 Pillen, um 7 Uhr nachm. 20 Pillen und am 26. Januar um 9 Uhr vorm. die letzten 10 Pillen.

Schon am Nachm. des 25. Januar wies die Taube wesentliche Besserung auf und konnte wieder laufen. Am 26. Januar früh war sie wieder sehr munter und lief und flog behende. Keine schädlichen Nebenerscheinungen, keine Giftwirkung.

\section{Versuch $\mathrm{C}$.}

$3 \mathrm{~g}$ des in der auf S. 177 angegebenen Weise dargestellten Extraktes (Phosphatids) wurden mit $50 \mathrm{ccm}$ dest. Wassers gut verrieben. Die 
hierbei entstandene EmuIsion warde mit $2^{1 / 2} \mathrm{ccm}$ konzentrierter Schwefelsäure versetzt und im kochenden Wasserbad am Rückflusskühler 6 Stunden lang erhitzt. Das so gewonnene Hydrolysat wurde nach dem Erkalten durch vorsichtigen Zusatz von Barytwasser von $\mathrm{H}_{2} \mathrm{So}_{4}$ vollkommen befreit. Der Bariumsulfatniederschlag wurde durch ein dichtes, mit einer dünnen Schicht Tierkohle bedecktes Filter abgenutscht und gat ausgewaschen. Filtrat und Waschwasser wurden nun im Vakuum bei $37^{\circ} \mathrm{C}$. bis auf ein geringes Volumen eingedampft. In einer Próbe dieses Rückstandes wurde nochmals die völlige Abwesenheit von $\mathrm{H}_{2} \mathrm{So}_{4}$ sowie Bariumsalzen festgestellt, sodann wurde der gesamte Rückstand in einer Schale und im Vakuum bei $37^{\circ} \mathrm{C}$. bis zur Extraktkonsistenz eingedampft und nach Zusatz genügender Mengen reiner Weizenstärke und reinen Dextrins anf einer Pillenmaschine in 90 gleichgroße Pillen eingeteilt.

Die zu den Versuchen Nr. $7 \mathrm{~A}$ and B verwandte Taube bekam, da sie stark abgemagert war, bis zum 31. Januar bei fortgesetzter Fütterung mit geschliffenem Reís täglich $1 \mathrm{~g}$ getrocknete, sehr wirksame Bierhefe, wobei sie sich vollkommen erholte und an Körpergewicht zunahm. Vom 1. Februar an erhielt sie nur geschliffenen Reis. Am 6. März 1917 war die Taube wieder dentlich gelähmt. Sie bekam nun unter genatuer Einhaltung der Zeitintervalle wie bei Versuch $B$ am $10^{1 / 2}$ und $11^{3 / 4}$ Uhr vorm. sowie um 1 Uhr nachm. je 10 Pillen des durch Hydrolyse gewonnenen Präparates, um $33 / 4$ und 5 Uhr nachm. je 15 und um 7 Uhr nachm. 20 Pillen. Um 4 Uhr nachm. schon stellten sich schwere Vergiftungserscheinungen ein (Streckkrampf der Beine und starrkrampfartige Symptome), die sich bei jeder weiteren Gabe steigerten. Am 7. März früh war die Taube schwer krank und hinfällig. Es wurden ihr dann noch die letzten 10 Pillen eingeflösst. Um $10 \mathrm{Uhr}$ vorm. starb sie.

Sektionsbefund: Der Darm ist mit grünem, dünnflüssigem Inhalt angefüllt. - Vor dem Tode entleerte das Tier grünen, dünnflüssigen Kloakeninhalt. Hornschicht des Muskellmagens grün gefärbt. An der Grenze gegen den eigentlichen Magen zahlreiche Ekchymosen. In der Leber alte Herde. Herz schlaff. Lungen gebläht, zahlreiche Infarkte, die zum Teil frisch, zum Teil mehrere Stunden alt sind.

\section{Nukleoproteid aus Hefe.}

\section{A. Darstellung und Untersuchung.}

Nach verschiedenen Vorversuchen wurde nachstehendes Verfahren als das geeignetste beibehalten: Je $50 \mathrm{~g}$ einer bei $50^{\circ} \mathrm{C}$. getrockneten Bierhefe Qual. Nr. I [Gehalt an $\mathrm{H}_{2} 0: 6,95 \%, \mathrm{~N}: 9,49 \%, \mathrm{P}_{2} \mathrm{O}_{5}: 6,18 \%$ und Asche : $10,09^{\circ}{ }_{0}^{1}$ )] wurden mit einer eiskalten Mischung von $50 \mathrm{ccm}$ Ammoniak von $25 \%$ und $450 \mathrm{ecm}$ dest. Wassers in einer Porzellanreibschale gat verrieben. Das Gemisch wurde 2 Stunden lang unter öfterem Umschütteln in Eis gestellt, sodann auf Filter, die vorher mit, Tierkohle beschickt worden waren (Photographie Nr. 37), gebracht. Das

1) Analyse s. S. 206 . 
klare Filtrat wurde in einer Flasche aufgefangen, in der sich $200 \mathrm{ccm}$ einer 10\% igen Schwefelsäure befanden, und durch einen bis auf den Grund der Flasche reichenden Trichter für eine schnelle Mischung des Filtrats mit der Säure Sorge getragen. Es scheidet sich hierbei ein voluminöser Niederschlag aus. Nachdem die Flüssigkeit möglichst vollständig abfiltriert war, wurde der Inhalt der Vorlage in ein hohes Zylinderglas gegossen und in der Kälte etwa 12 Stunden lang ruhig stehengelassen, sodann die überstehende Flüssigkeit von dem Sediment vorsichtig dekantiert und filtriert (s. S. 185). Letzteres wurde nunmehr in Zentrifugierröhrchen umgefüllt, durch Zentrifugieren von dem Rest der Flüssigkeit befreit, und durch häufig wiederholtes Aufsehwemmen in dest. Wasser und anschliessendes Zentrifugieren so lange ausgewaschen, bis Kongopapier durch das Waschwasser nicht mehr gebläut wurde. Der Rückstand wurde zum Teil gleich auf flache Teller ausgebreitet und bei $37^{\circ} \mathrm{C}$. getrocknet, zum anderen Teil in noch feuchtem Zustande mit dest. Wasser aufgeschwemmt und nach dem von $\mathrm{W}$ e g e l in ${ }^{1}$ ) angegebenen Verfahren solange ausgewaschen, bis das Waschwasser vollkommen frei von Chlor und Schwefelsäure war. Es wurden dann noch weitere $1000 \mathrm{ccm}$. Waschwasser durchgetrieben, gesondert aufgefangen und auf ihren Gehalt an $\mathrm{P}_{2} \mathrm{O}_{\tilde{5}}$ untersucht. Dieser betrug $0,00482 \mathrm{~g}^{1}$ ). Das ausgewaschene Präparat wurde nun durch Durchnutschen auf einem gehärteten Filter gesammelt, zuerst mit einem Gemisch von gleichen Teilen Aceton und Alkohol, dann mit reinem Aceton nachgewaschen, bei gelinder Wärme getrocknet und zerrieben.

Untersuchung des Präparates. Das nach vorstehend angegebenem Verfahren gewonnene Präparat bildete ein braunes, spezifisch schweres Pulver. Die Ausbeute betrug etwa 4,5\% der angewandten Bierhefe. In frischem Zustande war das Präparat in Natronlauge leicht löslich and wurde aus dieser Lösung zum grössten Teil durch einen geringen Überschuss von Essigsäure wieder ausgefällt. Die alkoholische Lösung zeigte starke Biuretreaktion. Die Reaktion auf $\mathrm{P}_{2} \mathrm{O}_{5}$ nach der nassen Verbrennung mit Salpeterschwefelsäure war stark positiv. Die angestellten Eiweissrealtionen hatten folgendes Ergebnis:

Millon's Reagens: +

Xanthoproteinreaktion: +

Alkalische Bleilösung (Kochprobe): +

Glyoxylsäurereaktion : -

Bromwasserreaktion (nach der Verdauung mit Pankreatin):

Zur Prüfung anf Purinbasen wurde das aus $200 \mathrm{~g}$ Hefe gewonnene Präparat in frischem Zustande mit $200 \mathrm{ccm}$ dest. Wassers gut verrührt, mit $4 \mathrm{ccm}$ reiner konzentrierter Schwefelsäure versetzt und im Kochsalzbade am Rückflusskühler 5 Stunden lang : auf $105^{\circ} \mathrm{C}$. erhitzt. Nach dem Abkühlen wurde das Hydrolysat mit Natronlauge schwach alkalisch gemacht, dann mit Essigsäure von $10 \%$ angesäuert und $15 \mathrm{Mi}$ nuten lang auf dem kochenden Wasserbade erwärmt. Der entstandene Niederschlag wurde abgenutscht and das klare Filtrat mit Natronlauge von $10 \%$ bis zur allalischen Realtion, dann mit $5 \mathrm{ccm}$ Natriumbisulfit-

1) G. Wegelin, Über eine nene Art der Reinigung kolloidaler Lösungen. Kolloid-Zeitschr. Bd. 18 \$. 225. 1916. 
Beitrag zur Kenntnis von organischen Nahrungsstoffen mit spezif. Wirkung. 181

lösung von $40 \%$ versetzt und zum Sieden erhitzt. Schliesslich wurden noch $20 \mathrm{ccm}$ Kupfersulfatlösung von $10 \%$ hinzugefügt. Nach 3 Minuten langem Sieden. wurde der entstandene Niederschlag durch ein gehärtetes Filter abgenutscht, mit heissem Wasser ausgewaschen und wieder in den gut ausgespülten, zur Fällung benutzten Kolben nach sorgsamer Verteilung and Aufschwemmung in dest. Wasser zurïckgegeben. Der Niederschlag wurde dann durch $\mathrm{H}_{2} \mathrm{~S}$ zerlegt, das ausgefällte $\mathrm{CuS}$ abgenutscht und ausgewaschen, das Filtrat durch Durchsaugen von Luft von $\mathrm{H}_{2} \mathrm{~S}$ befreit und die Schwefelsäure durch vorsichtigen Zusatz von Barytwasser quantitativ ausgefüllt. Das ausgefällte $\mathrm{BaSO}_{4}$ wurde abgenutscht und mit heissem Wasser gut ausgewaschen. Filtrat und Waschwasser wurden auf dem Wasserbade zur Trockene verdampft, der Rückstand mit heissem dest. Wasser und etwas Tierkohle aufgenommen, nochmals filtriert und eingedampft. Es hinterblieb ein aus mikroskopischen Kristallen bestehender weisser Rückstand. Mit diesem wurde nachstehende Prüfung vorgenommen:

1. Mit Natronkalk im Röhrchen erhitzt: Entwicklung von Dämpfen, die angefeuchtetes rotes Lakmuspapier blau färben.

2. Anf dem Platinblech erhitzt: ohne Rückstand verbrennbar.

3. In verdünntem Ammoniak gelöst and mit ammoniakalischer Silberlösung versetzt: kolloider, in Ammoniak unlöslicher weisser Niederschlag.

4. Mit Diazobenzolsulfosäure (Burian-Pauly'sche Lösung) nach vorhergegangenem Zusatz von $\mathrm{Na}_{2} \mathrm{CO}_{3}$-Lösung in geringem Uberschuss: sofortige intensive Rotfärbung.

Es handelte sich demnach bei dem so untersuchten Rückstande um Purinbasen.

Weitere nach den üblichen Methoden ausgeführte und gut untereinander stimmende Doppelanalysen ${ }^{1}$ ) ergaben folgende Werte:

\begin{tabular}{|c|c|c|}
\hline $\begin{array}{l}\text { Hefenukleoproteid } \\
\text { (nur zentritugiert) }\end{array}$ & lnfttrocken & bei $105^{\circ} \mathrm{C}$. getrocknet \\
\hline sser (Feuchtigkeit) & . $13,39 \%$ & $0,00 \%$ \\
\hline osphorsäure $\left(\mathrm{P}_{2} \hat{O}_{5}\right)$ & $\begin{array}{l}. \quad 5,23 \% \\
. \quad 3,00 \%\end{array}$ & $\begin{array}{l}6,04 \% \\
3,46 \%\end{array}$ \\
\hline
\end{tabular}

Für das nach dem Wegelin'schen Verfahren vollkommen a us ewaschene $\mathrm{Nukleoproteid}$ wurden nachstehende Werte gefunden, die sich auf das bei $150^{\circ}$, C. getrocknete Präparat beziehen ${ }^{1}$ ):

1. Asche . . . . . . . . . . . . . . 2, $24 \%$

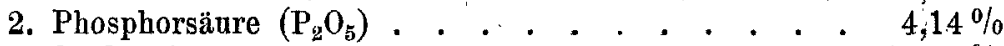

3. Stickstoff . . . . . . . . . . . . $13,46^{\%}$

Bei der unter besonders sorgsamer Beobachtung aller Kautelen erfolgten Verarbeitung von Hefe nach vorstehendem Verfahren wurden folgende Verhältniszahlen gefunden, die sich auf das bei $105^{\circ} \mathrm{C}$. getrocknete Ausgangsprodukt (Hefe) beziehen:

Mitverdünntem Ammoniak ausgezogene Hefe(trockner Rückstand) $62,83 \%$ Ausgefalltes Hefenukleoproteid bei $105^{\circ} \mathrm{C}$. getrocknet . . 4,84\% Filtrat zur Trockene verdampft (aus der Differenz berechnet) $32,33 \%$ Zusammen . $\overline{100,00 \%}$

1) Analysenbelege S. 207. 
A nm. Über Versuche, die mit dem nach Ausziehen der Hefe mit verdünntem Ammoniak zurückbleibenden Rückstande sowie mit dem Filtrate vom Nakleoproteidniederschlage angestellt wurden, ist auf S. 186 bzw. S. 185 berichtet.

\section{B. Tierversuche.}

I. Heilung von Tauben, die an alimentärer Dystrophie typisch erkrankt waren.

1. Einer schwer gelähmten Taube wurde am 23. Juli 1916 11 Uhr vorm. $1 \mathrm{~g}$ Hefenukleoproteid in Pillenform (mit Glyzerinstärkekleister bereitet) eingeflösst. Am nächsten Tage (24. Juli) 9 Uhr vorm. war die Taube wieder vollkommen munter und imstande, behende zu laufen.

2. Einer typisch erkrankten Taube (Lähmung der Beine und Flügel, Streckkrampf der Beine, Opisthotonus, Konvulsionen) wurde am 2. August 19164 Uhr nachm. $1 \mathrm{~g}$ Hefenukleoproteid in Pillenform eingeflösst. Um 7 Uhr nachm. waren die Krämpfe beseitigt. Das Tier lag ruhig und somnolent da. Am nächsten Tage war die extrem abgemagerte Taube wieder vollkommen munter und vermochte behende umherzulaufen (Photographien Nr. 14 und 15).

3. Eine schwer erkrankte Taube (Beinlähmung, Opisthotonus, Streckkrampf der Beine, Konvulsionen) bekam am 6. Januar 191712 Uhr mittags $1 \mathrm{~g}$ Hefenukleoproteid in Pillenform. Am 7. Januar früh wesentliche Besserung. Opisthotonus und Krämpfe waren geschwunden, Paresen der Beine noch vorhanden. Am 7. Januar 4 Uhr nachm. nochmals $1 \mathrm{~g}$ Nukleoproteid. Am nächsten Tage früh war die Taube wieder sehr munter und bewegte sich mit Leichtigkeit.

Bei dem unter 1 . angefithrten Versuche hielt die Wirkung von $1 \mathrm{~g}$ Hefenukleoproteid bis zum 1. August, also 9 Tage lang an. An diesem Tage machten sich wieder nervöse Störungen bemerkbar. Am 2. Augnst war die Taube wieder schwer gelähmt.

$\mathrm{Zu}$ vorstehenden Versuchen wurde teils das nur durch Zentrifugieren, teils das durch angeschlossene weitere Reinigung nach dem Wegelinschen Verfahren gewonnene Nukleoproteid verwandt. Die Wirkung liess keine merkbaren Unterschiede in beiden Fällen erkennen.

II. Prophylaxe.

$$
\text { Versuch Nr. } 18 .
$$

Versuchstier: Eine gesunde kräftige Taube (Photographie Nr.16).

Beginn des Versuches: 29. Januar 1917.

Schluss des Versuches: 19. April 1917 (bzw. 2. Juni 1917 s. Fortsetzung).

Nahrung: Geschliffener roher Reis, und zwar: vom 29. Januar bis 30. März 1917 Reissorte A, "31. März "19. April 1917, B.
2. Stickstoffsubstanz (Protein) - . . . $7,90 \% \quad \mathbf{7 , 6 2} \%$
3. Asche . . . . . . . . . $5,02 \% \quad 1,40 \%$
4. Phosphorsäure $\left(\dot{\mathrm{P}}_{2} \mathrm{O}_{5}\right) .+. \quad . \quad . \quad . \quad 0,48 \% \quad 0,27 \%$ Sorte A Sorte $\mathrm{B}^{1}$ )

1) Analysenbelege S. $210-211$. 
Beitrag zur Kenntnis von organischen Nahrungsstoffen mit spezif. Wirkung. 183

Zugaben pro Tag:

vom 29. Januar bis 19. April: 0,50 $\mathrm{g}$ Hefenukleoproteid, 11. April $" 18$. $" 0,25 \mathrm{~g}$ " am 19. April $1,25^{n} \mathrm{~g}$ Hefenukleoproteid und $1 \mathrm{~g}$ "Hefepräparat $\mathrm{A}$ (s. S. 162).

Das Nukleoproteid wurde in Pillen verabreicht, die durch Zusatz von Glyzerinstärkekleister zum Nukleoproteid und genaue Dosierung auf einer Pillenmaschine hergestellt waren.

Körpergewichte:

\begin{tabular}{|c|c|c|c|c|c|}
\hline Datum 1917 & Gewicht & Datum 1917 & Gewicht & Datum 1917 & Gewicht \\
\hline 29. Januar & $285,0 \mathrm{~g}$ & 3. März & $229,9 \mathrm{~g}$ & 7. April & 222,0 \\
\hline 3. Februa & $249,5 \mathrm{~g}$ & 10. & $226,0 \mathrm{~g}$ & 11. " & 217,0 \\
\hline 10. & $254,0 \mathrm{~g}$ & 17. & $230,0 \mathrm{~g}$ & 14. & 206,0 \\
\hline 17. & $248,5 \mathrm{~g}$ & 24. & $228,5 \mathrm{~g}$ & 19. & $190,5 \mathrm{~g}$ \\
\hline 24. & $235,5 \mathrm{~g}$ & 30. & $225,0 \mathrm{~g}$ & & \\
\hline
\end{tabular}

Gewichtsabnahme:

Periode vom 29. Januar bis 10. April - 71 Tage $-68,0 \mathrm{~g}=23,8 \%$, $"$ "11. April $" 19 ., "-8,-26,5 \mathrm{~g}=12,8 \%$,

Verhalten des Versuchstieres: Das Tier war bis zum 18. April abends wohl und munter und befand sich in demselben Zustande, wie er auf dem am 30. März (nach 60tägiger Behandlung) aufgenommenen Lichtbilde (Photographie Nr. 17) veranschaulicht ist. Am 19. April traten plötzlich Lähmung der Beine, Opisthotonus und Krämpfe auf (Photographie Nr. 18). Die Taube bekam nun 1,25 g des durch Auswaschen nach dem W'egelin'schen Verfahren gereinigten Nukleoproteids und $1 \mathrm{~g}$ des Hefepräparates $A$, welchem keinerlei Wirkung a uf die nervösen Erscheinungen zukamen (s. Versuch Nr. 5, S. 162), am 19. April um $9 \mathrm{Uhr}$ vorm. Um 4 Uhr nachm. erhebliche Besserung: Lähmung der Beine zurückgegangen, Opisthotonus und Krämpfe völlig geschwunden. Am nächsten Tage war die Taube wieder vollkommen munter und imstande, behende zu fliegen und zu laufen (Photographie Nr. 19). Der Versuch wurde nun in der nachstehend beschriebenen Weise fortgesetzt.

\section{Versuch Nr. 19.}

(Fortsetzung des vorstehenden Versuches Nr. 18.) Taube.

Versuchstier: Die zu vorstehendem Versuche Nr. 18 verwandte

Beginn des Versuches: 20. April 1917.

Sehluss des Versuches: 2. Juni 1917.

Nahrung: Gesehliffener roher Reis, und zwar:

vom 20. April bis 20. Mai 1917 Reissorte B, "21. Mai "2. Juni 1917. " C. 


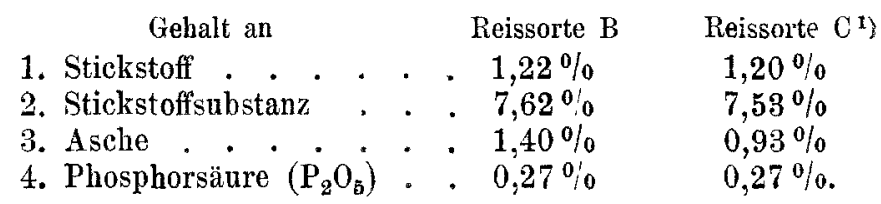

Tägliche Zugaben:

Vom 20. April bis 8. Mai $1917\left\{\begin{array}{l}0,5 \text { g Hefenulkleoproteid (s. S. 179). } \\ 1,0 \text { g Hefepräparat A (s. S. 162). }\end{array}\right.$

Vom 9. bis 12. Mai $1917 .\left\{\begin{array}{l}0,5 \mathrm{~g} \text { Hefenukleoproteid (s. S. 179). } \\ 1,0 \mathrm{~g} \text { Hefepräparat A (s. S. 162). } \\ 0,2 \mathrm{~g} \text { Weizenkleiephosphatid (s. S. } 177 \text { ). }\end{array}\right.$

Vom 13. bis 20. Mai $1917 \ldots\left\{\begin{array}{l}0,5 \mathrm{~g} \text { Hefenukleoproteid (s. S. 179). } \\ 1,0 \text { g Hefepräparat A (s. S. 162). } \\ 0,4 \text { g Weizenkleiephosphatid (s. S. 177). }\end{array}\right.$

Vom 21. Mai bis 2. Juni 1917 . 1,0 g Hefe (Qualität I) (s. S. 206).

Sämtliche Präparate wurden mit reiner Stärke und Stärkekleister zu einer plastischen Masse verarbeitet, auf einer Pillenmaschine in genau dosierte Pillen eingeteilt und in dieser Form der Versuchstanbe täglich zu derselben Zeit verabreicht. Für das Hefenukleoproteid erwies sich Glyzerinstärkekleister als das beste Bindemittel. Bei der Hefe genügte Zusatz von destilliertem Wasser, um eine plastische Pillenmasse herzustellen.

Körpergewichte:

\begin{tabular}{|c|c|c|c|c|c|}
\hline Datum 1917 & Gewicht & Datum 1917 & Gewicht & Datum 1917 & Gewicht \\
\hline 19. April & $190,5 \mathrm{~g}$ & 30. April & $223,5 \mathrm{~g}$ & 19. Mai & $239,5 \mathrm{~g}$ \\
\hline 21. & $194,0 \mathrm{~g}$ & 3. Mai & $224,5 \mathrm{~g}$ & 21. $n$ & 240,5 \\
\hline 23. & $203,0 \mathrm{~g}$ & 5. & $228,0, \mathrm{~g}$ & 26. & $247,0 \mathrm{~g}$ \\
\hline 25. & $207,0 \mathrm{~g}$ & 9 & $228,5 \mathrm{~g}$ & 2, Juni & $250,0 \mathrm{~g}$ \\
\hline 28. & $223,0 \mathrm{~g}$ & 12. & $228,5 \mathrm{~g}$ & & \\
\hline
\end{tabular}

A ufgenommene Futtermengen (geschliffener roher Reis):

\begin{tabular}{|c|c|c|c|c|c|c|}
\hline Datum 1917 & Gewicht & Datum 1917 & Gewicht & Datum & 1917 & Gewic \\
\hline 22./23. April & $12,3 \mathrm{~g}$ & 5./6. Mai & $9,5 \mathrm{~g}$ & $19 . / 20$ & Mai & 13,7 \\
\hline $3 . / 24 . \quad n$ & $15,0 \mathrm{~g}$ & $6 . / 7 . \quad n$ & $12,2 \mathrm{~g}$ & $20 . / 21$ & $"$ & 10,4 \\
\hline $4 . / 25$ & $12,6 \mathrm{~g}$ & $7 . / 8$ & $9,9 \mathrm{~g}$ & $21 . / 22$ & & 17,1 \\
\hline $5 . / 26$. & $12,2 \mathrm{~g}$ & $8 . / 9$ & $12,0 \mathrm{~g}$ & $22 . / 23$ & $n$ & 11,0 \\
\hline $6 . / 27$ & $17,4 \mathrm{~g}$ & $9 . / 10 . n$ & $6,5 \mathrm{~g}$ & $23 . / 24$ & $"$ & 15,6 \\
\hline $7 . / 28$ & $16,7 \mathrm{~g}$ & 10./11. & $13,0 \mathrm{~g}$ & $24 . / 25$ & & 15,9 \\
\hline $8 . / 29$ & $13,7 \mathrm{~g}$ & 11./12., " & $9,5 \mathrm{~g}$ & $25 . / 26$ & $n$ & 13,4 \\
\hline $9 . / 30$ & $11,7 \mathrm{~g}$ & $12 . / 13$ & $14,1 \mathrm{~g}$ & $26 . / 28$ & & 20,0 \\
\hline 0. April/1. Mai & $17,3 \mathrm{~g}$ & $13 . / 14$ & $7,0 \mathrm{~g}$ & $28 . / 29$ & $"$ & 13,9 \\
\hline 1./2. Mai & $8,0 \mathrm{~g}$ & 14.15 & $10,7 \mathrm{~g}$ & 29.30 & $n$ & 15,3 \\
\hline $2 . / 3$. & $15,2 \mathrm{~g}$ & $15 . / 16$ & $11,1 \mathrm{~g}$ & $30 . / 31$ & & 12,8 \\
\hline $3 . / 4$ & $12,0 \mathrm{~g}$ & $16 . / 18$ & $19,3 \mathrm{~g}$ & 31. Mai/ & /1. Juni & 15,3 \\
\hline $4 . / 5$. & $14,5 \mathrm{~g}$ & $18 . / 19$ & $12,7 \mathrm{~g}$ & 1./2. Jur & & 13,4 \\
\hline
\end{tabular}

1) Analysenbelege S. 210-211. 
Beitrag zur Kenntnis von organischen Nahrungsstoffen mit spezif. Wirkung. 185

Allgemeine Übersicht.

\begin{tabular}{|c|c|c|c|c|c|c|}
\hline \multirow{2}{*}{ Periode 1917} & \multirow{2}{*}{$\begin{array}{l}\text { Anzahl } \\
\text { der } \\
\text { Tage }\end{array}$} & \multirow{2}{*}{ Zugaben pro Tag } & \multicolumn{2}{|c|}{$\begin{array}{l}\text { Aufgenom- } \\
\text { mener Reis }\end{array}$} & \multicolumn{2}{|c|}{$\begin{array}{l}\text { Zunahme des } \\
\text { Körpergewichts }\end{array}$} \\
\hline & & & $\operatorname{in}_{\text {ganzen }}$ & pro Tag & absolute & relative \\
\hline 20. April bis 8. Mai & 18 & $\begin{array}{l}0,5 \mathrm{~g} \text { Hefenukleoproteid } \\
1,0 \mathrm{~g} \text { Hefepräparat A }\end{array}$ & $(\underset{16 \mathrm{Tage})}{210 \mathrm{~g}})$ & $13,1 \mathrm{~g}$ & $+38,0 \mathrm{~g}$ & $+19,0 \%$ \\
\hline 9. bis 12. Mai. & 4 & $\begin{array}{l}0,5 \mathrm{~g} \text { Hefenukleoproteid } \\
1,0 \mathrm{~g} \text { Hefepraparat A } \\
0,2 \mathrm{~g} \text { Weizenkleiephosphatid }\end{array}$ & $41,0 \mathrm{~g}$ & $10,2 \mathrm{~g}$ & $\pm 0,0 \mathrm{~g}$ & $\pm 0,0 \%$ \\
\hline 13. bis 20. Mai . & 8 & $\begin{array}{l}0,5 \mathrm{~g} \text { Hefenuklèoproteid } \\
1,0 \mathrm{~g} \text { Hefepräparat } \mathrm{A} \\
0,4 \mathrm{~g} \text { Weizenkléiephosphatid }\end{array}$ & $88,6 \mathrm{~g}$ & $11,1 \mathrm{~g}$ & $+11,0 \mathrm{~g}$ & $+4,8 \%$ \\
\hline 21. Mai bis 2. Juni & 13 & $1 ; 0 \mathrm{~g}$ Bierhefe Qual. I & $174,1 \mathrm{~g}$ & $13,1 \mathrm{~g}$ & $+10,5 \mathrm{~g}$ & $+4,4 \%$ \\
\hline
\end{tabular}

Verhaltendes Versuchstieres: Das Tier befand sich während des ganzen Versuches wohl und war durchaus munter. Die Photographie Nr. 20 veranschaulicht den Zustand der Taube am 9. Mai 1917.

\section{Filtrat von Hefenukleoproteid.}

Die. beim Dekantieren und Filtrieren (von dem aus ammoniakalischer Lösung durch Schwefelsäure ausgefällten Nukleoproteid [s. S: 179]) erhaltene Flüssigkeit wurde zunächst einige Tage lang der Ruhe 'überlassen. Es setzte sich hierbei noch eine geringe Menge eines Niederschlages $a b$, welche durch Abnutschen durch ein dichtes Filter beseitigt wurde. Das Filtrat wurde nun mit Barythydrat bis zur stark ammoniakalischen Reaktion versetzt, das ausgefällte $\mathrm{BaSO}_{4}$ abgenutscht und das Filter im Vakuum bei $37^{\circ} \mathrm{C}$. zur Trockene verdampft. Der Rückstand wurde in der Wärme mit absolutem Alkohol ausgezogen und der alkoholische Auszug nach dem Filtrieren mit konzentrierter alkoholischer Quecksilberchloridlösung versetzt, bis keine Fälluing mehr erfolgte. Der Niederschlag wurde auf der Nutsche gesammelt, mit absolutem Alkohol ausgewaschen, in dest. Wasser aufgeschwemmt und durch Einleiten von $\mathrm{H}_{2} \mathrm{~S}$ zerlegt. Das ansgefällte HgS wurde abgenutscht und mit warmem Wasser gut ausgewaschen. Filtrat und Waschwasser wurden durch Durchsaugen von Lnft von $\mathrm{H}_{\Omega} \mathrm{S}$ befreit, dann auf dem Wasserbade eingedampft. Der mit dest. Wasser aufgenommene Rückstand wurde mit Tierkohle versetzt und wach längerem Stehen unter häufigem Umschütteln filtriert. Das Filtrat warde wieder zur Trockene verdampft. Rückstand: Kristallnadeln, die, mit Platinchlorid versctzt, spiessige, gelblich-braune Kristalle lieferten. Durch Aùswaschen mit absolutem Alkohol und Umkristallisieren gereinigt, wurde ein. Teil im Tiegel verbrannt: $0,1757 \mathrm{~g}$ des Platinchloriddoppelsalzes hinterließen einen Rückstand (Platin) von $0,0567 \mathrm{~g}=32,27 \%$ Pt. Das Aussehen und übrige Verhalten des ursprünglich gewonnenen salzsauren Salzes denteten auf Cholinchlorhydrat. Die Richtigkeit dieser Vermutung wurde durch Bestimmung des Platingehaltes des $\mathrm{PtCl}_{4}$-Doppelsalzes [berechnet für $\left(\mathrm{C}_{5} \mathrm{H}_{14} \mathrm{NOCl}\right)_{2} \mathrm{PtCl}_{4} 31,64 \%$, gefunden $32,27 \%$ ] sowie durch den dem Cholinplatinchlorid eigentümlichen 
Dimorphismus erbracht: Das gewonnene Platinchloriddoppclsalz kristallisierte aus Wasser in langen, spiessigen Nadeln, aus einem Gemisch von vier Raumteilen dest. Wassers und fünf Raumteilen Alkoholdagegen in schön ausgebildeten 0ktaëdern. Das $\mathrm{PtCl}_{4}$-Doppelsalz gab, in kleiner Menge auf einem Objektträger mit Jodjodkaliumlösung versetzt, braune prismatische Kristalle, wie sie bei gleicher Behandlung von Cholinplatinchlorid entstehen.

Tierversuche: 1 . Ein Teil des nach dem vorstehend angegebenen Verfahren gewonnenen salzsauren Salzes wurde in dest. Wasser gelöst und einer Maus subkutan eingespritzt. Innerhalb einer Minute verendete das Tier unter Konvulsionen und Streckkrampf der Beine.

2. Eine Taube, die aus dem Rückstande des abgedampften Filtrats vom Hefenukleoproteid gefertigte Pillen bekam, starb nach kurzer Zeit unter heftigem Streckkrampf der Beine und der Halsmuskulatur.

\section{Rückstand der mit verdünntem Ammoniak ausgezogenen Hefe} (s. S. 179).

Der bei dem Filtrieren des ammoniakalischen Auszuges auf den Filtern zurückbleibende Heferückstand wurde noch zweimal mit dest. Wasser ausgewaschen. Nach vollkommenem Ablaufen des Waschwassers wurde der teigige Rückstand in möglichst dünner Schicht auf Porzellantellern ausgebreitet und bei $37^{\circ} \mathrm{C}$. so weit getrocknet, dass er sich mit Kieselgur gemischt zu einer Pillenmasse verarbeiten liess. Aus dem Rückstande von $50 \mathrm{~g}$ Hefe (etwa $30 \mathrm{~g}$ ) wurden 500 Pillen hergestellt. Jede Pille entsprach daher etwa $0,06 \mathrm{~g}$ des Rückstandes.

Tierversuche. Versuch Nr. 20.

Versuchstier: Eine ausgewachsene, gesunde und kräftige Taube.

Beginn des Versuches: 29. Mai 1917.

Schluß des Versuches: 4. August 1917.

Nahrung: Geschliffener roher Reis.

Tägliche Zugabe: 0,6 g (10 Pillen) des Rückstandes der mit verdünntem Ammoniak ausgezogenen Hefe.

Körpergewichte:

\begin{tabular}{ccc|cc|cc|} 
Datum 1917 & Gewicht & Datum 1917 & Gewicht & Datum 1917 & Gewicht \\
29. Mai & $285 \mathrm{~g}$ & 30. Juni & $\mathbf{2 1 2} \mathrm{g}$ & $\mathbf{2 1 . ~ J u l i}$ & $\mathbf{2 2 7} \mathrm{g}$ \\
2. Juni & $248 \mathrm{~g}$ & 7. Juli & $214 \mathrm{~g}$ & $\mathbf{2 8 .}$ & $\mathbf{2 3 6} \mathrm{g}$ \\
9. & $194 \mathrm{~g}$ & 14. Juli & $\mathbf{2 2 3} \mathrm{g}$ & 4 . August & $233 \mathrm{~g}$ \\
16. & $195 \mathrm{~g}$ & & & & &
\end{tabular}

Verhalten des Versuchstieres: Während des ganzen Versuches sehr munter. Nahrungsaufnahme zeitweilig gering.

\section{Versuch Nr. 21.}

Versuchstier: Èine besonders kräftige und wohlgenährte Taube.

Beginn des Versuches: 11. Juni 1917.

Schluss des Versuches: 4. August 1917.

Nahrung: Geschliffener roher Reis Sorte C. Gehalt des lufttrockenen Reises an Stickstoff $1,20 \%$, [Protein 7,53\% ${ }^{1}$ )], Asche $0,93 \%$, Phosphorsäure $\left(\mathrm{P}_{2} \mathrm{O}_{5}\right) \quad 0,27 \%$.

1) Analyse s. S. 211. 
Beitrag zur Kenntnis von organischen Nahrungsstoffen mit spezif. Wirkung. 187

Tägliche Zugabe: $0,6 \mathrm{~g}$ (10 Pillen) des durch Ausziehen der Hefe mit verdünntem Ammoniak erhaltenen Rückstandes.

Körpergewichte:

\begin{tabular}{|c|c|c|c|c|c|}
\hline Datum 1917 & Gewicht & Datum 1917 & Gewicht & Datum 1917 & Gewicht \\
\hline 11. Jun & $343,5 \mathrm{~g}$ & 30. Juni & $290,0 \mathrm{~g}$ & 21. Juli & \\
\hline 16. , & $305,0 \mathrm{~g}$ & 7. Juli & $0 \mathrm{~g}$ & 28. " & \\
\hline 23. & $290,0 \mathrm{~g}$ & 14. & $276,0 \mathrm{~g}$ & 4. August & 278 \\
\hline
\end{tabular}

Aufgenommener geschliffener Reis:

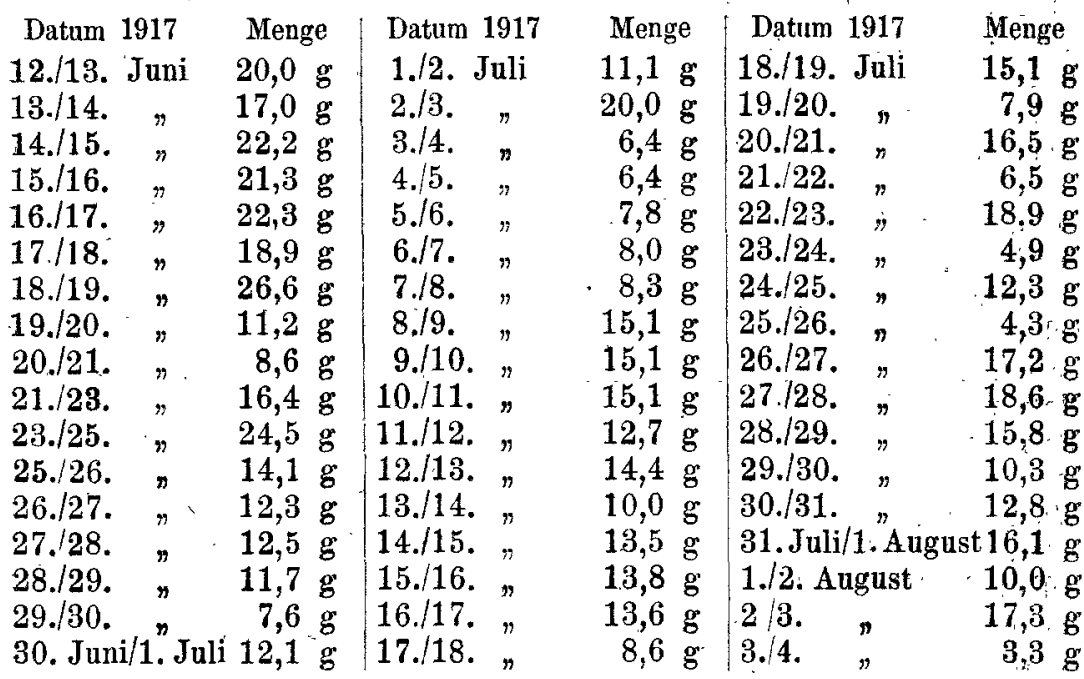

Verhalten des Versuchstieres: Die Taube war während der ganzen Versuchsdauer durchaus munter und wies keinerlei abnorme Erscheinungen auf, trotz des im ganzen $65,5 \mathrm{~g}=19,1 \%$ betragenden Verlustes an Körpergewicht.

Das Verhältnis von Nahrungsaufnahme in den einzelnen (mit Ausnahme der ersten) 7 Tagen betragenden Perioden zu dem Körpergewicht zeigt nachstehende Übersicht:

\begin{tabular}{|c|c|c|c|c|}
\hline \multirow{2}{*}{ Periode 1917} & \multicolumn{2}{|c|}{ Nahrungsaufnahme } & \multicolumn{2}{|c|}{$\begin{array}{c}\text { Körpergewicht } \\
\text { Ab- bzw. Zunahme }\end{array}$} \\
\hline & im ganzen & $\mid \begin{array}{c}\text { pro Tag } \\
\text { in Durehschnitt }\end{array}$ & absolute & relative \\
\hline 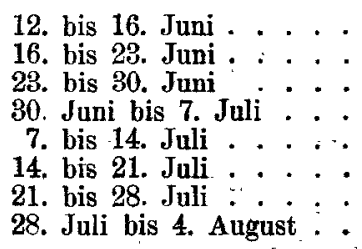 & $\begin{array}{rl}80,5 & \mathrm{~g} \\
125,3 & \mathrm{~g} \\
82,7 & \mathrm{~g} \\
70,8 & \mathrm{~g} \\
81,6 & \mathrm{~g} \\
89,0 & \mathrm{~g} \\
82,7 & \mathrm{~g} \\
85,3 & \mathrm{~g}\end{array}$ & $\begin{array}{ll}20,1 & \mathrm{~g} \\
17,9 & \mathrm{~g} \\
11,8 & \mathrm{~g} \\
10,1 & \mathrm{~g} \\
11,7 & \mathrm{~g} \\
12,7 & \mathrm{~g} \\
11,8 & \mathrm{~g} \\
12,1 & \mathrm{~g}\end{array}$ & $\begin{array}{r}-38,5 \mathrm{~g} \\
-\quad 5,0 \mathrm{~g} \\
-10,0 \mathrm{~g} \\
-16,0 \mathrm{~g} \\
+\quad 2,0 \mathrm{~g} \\
+1,0 \mathrm{~g} \\
+10,0 \mathrm{~g} \\
+9,0 \mathrm{~g}\end{array}$ & $\begin{array}{l}-11,2 \% \\
-\quad 1,1 \% \\
-\quad 3,3 \% \\
-\quad 5,5 \% \\
+\quad 0,7 \% \\
+\quad 0,4 \% \\
+\quad 3,6 \% \\
+\quad 3,2 \%\end{array}$ \\
\hline
\end{tabular}




\section{Nuklein ans Hefe.}

\section{A. Darstellung und Untersuchung.}

Eine nach dem auf S. 179 angegebenen Verfahren dargestellte Menge (ca. 4,5 g) Hefenukleoproteid wurde nach ausgiebigem Auswaschen in noch feuchtem Zustande mit einer Lösung von $0,1 \mathrm{~g}$ Pepsin in $50 \mathrm{ccm}$ dest. Wassers, dem 5 Tropfen einer $25 \%$ igen Salzsäure zugesetzt worden waren, in einer Reibschale gut verrieben. Die Mischung wurde dann 14 Stunden lang bei $37^{\circ} \mathrm{C}$. digeriert, wobei ein nicht unerheblicher Teil des Nukleoproteids durch Verdauung in Lösung ging. Durch Zentrifugieren und gründliches Auswaschen wurde nunmehr der ungelöste Rückstand A (Nuklein) von dem in Lösung gegangenen Anteil B getrennt. Letzterer wurde nach dem auf S. 189 geschilderten Verfahren weiterbehandelt.

Der ungelöste Rückstand wurde auf flachen Porzellantellern ausgebreitet und bei $37^{\circ} \mathrm{C}$. getrocknet, dann in einer Reibschale fein zerrieben.

Das so gewonnene Präparat bildete ein dunkelbraunes, spezifisch schweres Pulver, welches ein ausgesprochenes Quellungsvermögen beim Benetzen mit Wasser aufwies. In frischem Zustande war es in $10 \%$ iger Natronlauge leicht löslich und konnte aus dieser Lösung durch Zusatz von Essigsäure in geringem Überschusse wieder ausgefällt werden. Die Binretreaktion war positiv. Mit Salpeterschwefelsäure verbrannt, dann mit Wasser verdünnt und mit Ammoniumnitrat in genügender Menge versetzt, entstand bei Zusatz von Ammonmolybdat ein starker, zitronengelber, in Alkalien löslicher Niederschlag $\left(\mathrm{P}_{2} \mathrm{O}_{5}\right)$. Die quantitative Untersuchung des Präparates, deren Einzelheiten. auf S. 208 angegeben sind, ergab folgende Werte:

$$
\text { Rückstand A lufttrocken bei } 105^{\circ} \mathrm{C} \text {. getrocknet }
$$

1. Wasser (Feuchtigkeit) . . $7,43 \%$

2. Stickstoff . . . . $11,94 \%$

3. Asche . . . . . . . $4,33 \%$

4. Phosphorsäure $\left(\mathrm{P}_{2} \mathrm{O}_{5}\right)$. . 6,35\%

$$
\begin{array}{r}
12,90 \% \\
4,68 \% \\
6,86 \%
\end{array}
$$

Es handelte sich also um ein Nuklein, wie es nach der Art der Darstellung zu erwarten war.

\section{B. Tierversuche.}

1. Eine schwer gelähmte weisse Tanbe (Photographie Nr. 21) bekam am 29. Mai $19174^{1 / 2} \mathrm{Uhr}$ nachm. 0,25 g Hefenuklein (mit reinem Glyzerinstärkekleister gemischt und in 10 Pillen eingeteilt). Eine halbe Stunde später Opisthotonus und heftige Krämpfe. Am nächsten Tage (30. Mai) $9 \mathrm{Uhr}$ vorm. Opisthotonus, Lähmung und Krämpfe geschwunden. Die Taube vermochte wieder auf der Sprungstange zu sitzen, war aber noch matt und niclit recht munter (Photographie Nr. 22). Nochmals $0,25 \mathrm{~g}$ Hefenuklein per os. Um 6 Uhr nachm. war das Tier wieder viel munterer and lief ohne Schwierigkeit. $A \mathrm{~m}$ zweitnächsten Tage (31. Mai) $9 \mathrm{Uhr}$ vorm. war die Taube wieder ganz munter, lief und flog behende (Photographie Nr. 28). Fresslust wiederhergestellt. Die 
Beitrag zur Kenntnis von organischen Nahrungsstoffen mit spezif. Wirkung. 189

Nahrung bestand, wie stets bei unseren derartigen Versuchen, ausschliesslich aus demselben geschljffenen rohen Reis, der vor der Erkrankung gereicht worden war.

2. Einer an alimentärer Dystrophie typisch erkrankten Taube (Lähmung der Beine und Flügel, Opisthotonus) (Photographie Nr. 24) wurde am 3. August $191751 / 4$ Uhr nachm. $0,5 \mathrm{~g}$ (in 10 mit reinem Glyzerinstärkekleister bereiteten Pillen) eingeflösst: Am nächsten Morgen (4. August 1917) 9 Uhr vorm, waren alle nervösen Erscheinungen (Lähmung, Krampf) völlig geschwunden. Die Taube erschien noch etwas benommen und war nicht ganz so munter wie gesunde Tauben zu sein pflegen, bewegte sich aber ohne Schwierigkeit. Am zweitnächsten Tage (5. August) früh war das Tier ohne jede weitere Behandlung wieder völlig munter (Photographie Nr. 25), lief und flog behende und zeigte wieder lebhafte Fresslust. Nahrung war geschliffener roher Reis.

\section{Von dem Hefenukleoproteid durch Einwirkung von Pepsin= salzsäure bei $37^{\circ}$ C. abgespaltene Eiweisskomponente (s. S. 188).}

\section{A. Darstellung und Untersuchung.}

Die durch fermentative Einwirkung von Pepsinsalzsäure (künstliche Magenverdaung) auf Hefenukleoproteid bei $37^{\circ} \mathrm{C}$. gewonnene Lösung B (s. S. 188) wurde nochmals filtriert. Das klare Filtrat wurde mit verdünnter Natronlauge (etwa $4 \%$ ) genau neutralisiert, dann mit einer Mischung yon einigen ccm Alkohol und Toluol gut durchgeschüttelt und auf flachen Porzellantellern bei $37^{\circ} \mathrm{C}$. langsam zur Trockene verdampft. Die gelblich gefärbten, klaren Lamellen, welche hierbei zurückblieben, wurden in einem angewärmten Torellanmörser fein zerrieben. Das so erhaltene Pulver wurde über $\mathrm{CaCl}_{2}$ im Brühkocher nachmals getrocknet im Exsikkator nochmals getrocknet und in einem gutverschlossenen Glase verwahrt.

Eine Untersuchung des Pulvers ergab, dass es leicht und klar in dest. Wasser löslich, in Alkohol unlöslich war. Die Biuretreaktion war stark positiv. Eine kleine Menge mit Salpeterschwefelsäure verascht gab nach Verdünnung mit Wasser und Versetzen mit Ammonnitratlösung auf Zusatz von Ammonmolybdatlösung einen zitronengelben, in Alkalien löslichen Niederschlag $\left(\mathrm{P}_{2} \mathrm{O}_{5}\right)$. Quantitative Bestimmungen, deren Einzelheiten auf S. 208 angegeben sind, ergaben nachstehende Werte:

Abgespaltene Eiweisskomponente über $\mathrm{CaCl}_{2}$ getrocknet bei $105^{\circ} \mathrm{C}$. getrocknet

1. Wasser (Feuchtigkeit . . 7,00\%

2. Stickstoff . . . . . $10,37 \%$

3. Protein . . . . . . 64,87\%

4. Phosphorsäure - . . . $0,49 \% \quad 0,53 \%$

Die Substanz bestand demnach in der Hauptsache aus einem durch $\mathrm{NaCl}$ (entstanden durch Neutralisation der zugefügten $\mathrm{HCl}$ mit $\mathrm{NaOH}$ ) verunreinigten Protein. Da anorganische gebundene Phosphorsäure durch die vorausgegangene Behandlung des Nukleoproteids und gründliches Auswaschen desselben beseitigt war, so war die im Peptongemisch enthaltene Phosphorsäure bei der Verdauung in Freiheit gesetzt worden. 


\section{B. Tierversuche.}

1. Eine an alimentärer Dystrophie (Lähmung der Beine und Flügel, Opisthotonus, Krämpfe) erkrankte Taube bekam am -15. Juli 1917 $4^{1 / 2}$ Uhr nachm. $1 \mathrm{~g}$ des aus Hefenukleoproteid abgespaltenen, getrockneten Eiweisskörpers (mit wenig dest. Wasser bis zur Bildung einer plastischen Masse durchgeknetet und in 10 Pillen eingeteilt). Die Taube, welche während der Ernährung mit geschliffenem Reis auch eine starke Bindehautentzündung bekommen hatte, war am nächsten Tage 9 Uhr vorm. frei von allen nervösen Erscheinungen und lief ohne Schwierigkeit umher, war aber nicht so munter und lebhaft, wie dies nach der Behandlung ebenso erkrankter Tauben mit dem Hefenukleoproteid bzw. Hefenuklein der Fall war. Die Konjunktivitis -schwand nach Einträufelung einer Zinksulfatlösung $(0,05 \mathrm{~g}: 10 \mathrm{ccm}$ dest. Wassers) in wenigen Tagen völlig.

2. Einer zweiten an alimentärer Dystrophie schwer erkrankten Taube (Paralyse der Beine und Flügel, Opisthotonus) wurde am 22. August um 9 Uhr 50 Min. vorm. $1 \mathrm{~g}$ des aus Hefenukleoproteid durch Pepsinsalzsäure abgespaltenen Eiweisskörpers in Pillenform eingegeben. Im Laufe des Tages trat keine merkliche Besserung ein. Am nächsten Morgen wurde die Taube tot vorgefunden.

\section{Versuch mit Sojabohnen (Nr. 22).}

Versuchstiere: Drei gesunde, kräftige Tauben, Nr. 1, 2 und 3. Beginn des Versuches: 1. Februar 1916.

Abschluss des Versuches: 7. März 1916.

Nahrung: Sojabohnen (Soja hispida. -- Gelbe Varietät: Soja turnida). Vom 1. bis 3. Februar geschrotene Bohnen, vom 3. Februar bis 7. März ganze Sojabohuen. Diese enthielten 7,62\% Wasser (Feuchtigkeit) und 1,28\% $\mathrm{P}_{2} \mathrm{O}_{5}$.

Körpergewichte:

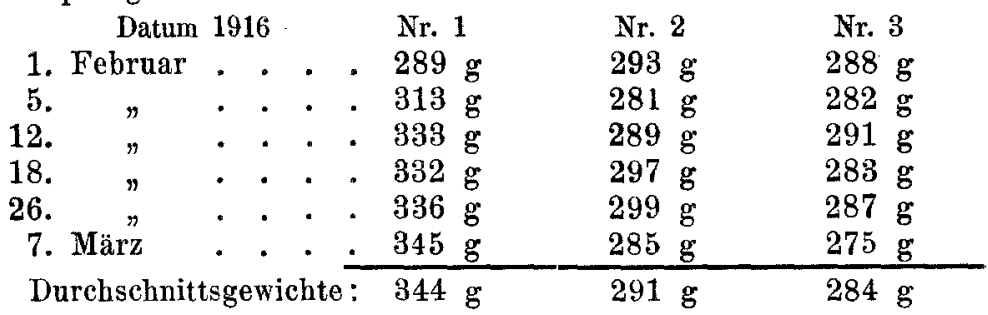

Durchschnittsgewichte der drei Versuchstauben:

bei Anfang des Versuches: $290 \mathrm{~g}$;

beim Schluss des Versuches: $302 \mathrm{~g}$. Zunahme $12 \mathrm{~g}=4,14 \%$; während des Versuches: $306 \mathrm{~g}, \quad, \quad 16 \mathrm{~g}=5,52 \%$.

Verhalten der Versuchstiere: Sowohl während wie bei Abschluss des Versuches so gesund und manter wie bei Beginn desselben. Sie nahmen geschrotene Sojabohnen nur widerwillig, frassen die ganzen Bohnen aber gerne. 
Beitrag zur Kenntnis von organischen Nahrumgsstoffen mit spezif. Wirkung. 191

\section{Versuche mit Präparaten aus Sojabohnen.}

\section{A. Darstellung und Untersuchung der. Präparate.}

$100 \mathrm{~g}$ dureh Mahlen und Durchschlagen durch ein feinmaschiges Sieb gepulverte Sojabohnen wurden im Soxhlet-Apparat mit Aceton 24 Stunden lang ausgezogen.

1. Acetonausug. Der Auszag wurde durch Abdestillieren im Vakuum bei $37^{\circ} \mathrm{C}$. befreit. Es hinterblieb ein brauner, in Äther zum bei weitem grössten Teile löslicher Rürckstand. Der in Äther lösliche Anteil, welcher nach dem Filtrieren und Abdestillieren des Äthers verblieb, bildete ein braunes, leicht verseifbares fettes Öl. Ausbeute: 13,6 g.

1. Alkoholiseher Auszug (Phosphatidfraktion). Das mit Aceton ausgezogene Sojabohnenmehl wurde zunächst durch längeres Stehenlassen an der Luft unter häufigerem Umrïhren von Aceton völlig befreit, dann zweimal hintereinander mit je $300 \mathrm{ccm} 99 \%$ igen Alkohols unter häufigem Schütteln bei einer Temperatur von $37^{\circ} \mathrm{C}$. ausgezogen. Die Auszüge wurden jedesmal durch Abseihen und Ausp̋ressen von dem Rückstande getrennt, dann filtriert. Das Filtrat wurde bei $37^{\circ} \mathrm{C}$. unter vermindertem Druck eingedampft. Der Rückstand wurde mit $50 \%$ igem Alkohol aufgenommen, die Lösung filtriert und bei $37^{\circ} \mathrm{C}$. in einem Schälchen langsam eingedampft. Der Rückstand wurde im Vakuumexsikkator über Schwefelsäure getrocknet. Ausbeute: $0,8 \mathrm{~g}$.

Das Präparat bildete eine braune, hygroskopische Masse, die mit Natronlauge leicht verseifbar und in Alkohol löslich war. Die Substanz bildete mit dest. Wasser verrührt eine schleimige, etwas trübe Emulsion und verbrannte, auf Platienblech erhitzt, bis auf einen äusserst geringfügigen Rückstand. Eine kleine Menge, mit Salpeterschwefelsäure verascht, dann nach Verdünnung mit dest. Wasser und Zusatz von Ammonnitrat erwärmt und mit einer Ammonmolybdatlösung versetzt, gab einen starken zitronengelben Niederschlag von Ammoniumphosphomolybdat: $\mathrm{P}_{2} \mathrm{O}_{5}$. Gehalt: $1,54^{\theta} / 0^{1}$ ).

3. Salzsaurer Auszug. Das bereits mit Aceton, hierauf mit Alkohol ausgezogene Sojabohnenmehl wurde zunächst bei $37^{\circ} \mathrm{C}$. getrocknet, dann mit $100 \mathrm{ccm} 99 \%$ igen Alkohols gut durchfeuchtet und mit einer Mischung von $100 \mathrm{ccm}$ Salzsäure von $10 \%$ und $800 \mathrm{ccm}$ dest. Wassers versetzt. Unter häufigem Umschütteln wurde das Gemisch 4 Stunden lang bei Zimmertempératur mazeriert. Die Lösung wurde hierauf von dem Rückstande abgenutscht und letzterer mit dest. Wasser wiederholt ausgewaschen. Filtrat und Waschwasser wurden mit schwacher Natronlauge neutralisiert, dann im $\mathrm{Fau}$ s $\mathrm{t}-\mathrm{H}$ e i m' schen Trockenapparat bei $50^{\circ}$ C. möglichst weit eingedampft. Der Rückstand wurde bei $37^{\circ} \mathrm{C}$. getrocknet, von den Wandungen der zum Abdampfen benutzten flachen Schalen abgekràtzt und in einer erwärmten Reibschale fein gepalvert. Eine nähere Untersuchung (s, S. 212) ergab folgenide Werte für das bei $105^{\circ} \mathrm{C}$. getrocknete Pulver:

Asche (einschliesslich $\mathrm{NaCl}$ ) . . $58,81 \%$

Asche (ausschliesslich $\mathrm{NaCl}$ ) . . 23,60\%

Phosphorsäure $\left(\mathrm{P}_{2} \mathrm{O}_{5}\right)$. . . . . 1,51\%

1) $\mathrm{P}_{2} \mathrm{O}_{5}$, Bestimmung s. $\mathrm{S} .213$. 
4. Pepsinsalzsäureauszug. Der nach Abnutschen des salzsauren Auszugs zurückbleibende, gut ausgewaschene Rückstand, der noch genügend salzsauer war, wurde mit einer Lösung von $1 \mathrm{~g}$ Pepsin und $400 \mathrm{ccm}$ dest. Wassers versetzt, gut umgeschüttelt und 15 Stunden lang bei $37^{\circ} \mathrm{C}$. digeriert. Der flüssige Anteil wurde nun von dem festen Rückstande abgenutscht und letzterer mit destilliertem Wasser wiederholt ausgewaschen. Filtrat und Waschwasser wurden mit schwacher Natronlauge neutralisiert, dann im $\mathrm{F}$ aust-Heim'schen Trockenapparat bei $50^{\circ} \mathrm{C}$. möglichst weit eingedampft. Der Rückstand wurde bei $37^{\circ} \mathrm{C}$. getrocknet, von den zum Abdampfen benutzten Schalen abgekratzt und in einem angewärmten Mörser fein zerrieben.

Das Präparat bildete ein hellgelbes, in Wasser leicht lösliches Pulver. Die wässerige Lösung gab starke Binretreaktion. Eine eingehendere Untersuchung lieferte nachstehende Werte für das bei $105^{\circ} \mathrm{C}$. getrocknete Präparat (s. S, 213):

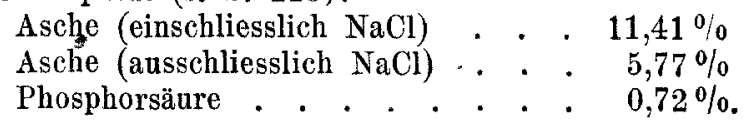

5. A u sgezogener $\mathbf{R} u ̈ \mathbf{c k s t a n d . ~ D a s ~ n a c h e i n a n d e r ~ m i t ~ A c e t o n , ~}$ Alkohol, Salzsäure and Pepsinsalzsäure ausgezogene Sojabohnenmehl wurde bei $37^{\circ} \mathrm{C}$. getrocknet. Der bei $105^{\circ} \mathrm{C}$. vollends getrocknete Rückstand enthielt (s. Analysen S. 214) an: Asche 2,26\% Phosphorsäure $\left(\mathrm{P}_{2} \mathrm{O}_{5}\right) \quad 0,98 \%$.

\section{B. Tierversuche.}

1. Alkoholischer Auszug (Phosphaditfraktion). Finer typisch erkrankten Taube (Beinlähmung, Opisthotonus, Streckkrampf der Beine) wurden am 9. November 1917 um $5 \frac{3}{4}$ Uhr nachm. $0,7 \mathrm{~g}$ mit $5 \mathrm{ccm}$ dest. Wassers gut verrieben mittels einer kleinen, an einer Spritze angebrachten Sonde aus weichem Gummi in den Kropf eingespritzt. Am nächsten Tage 9 Uhr vorm. war die Taube wieder sehr munter und lief behende umher.

2. Salzsaurer A uszug. a) Einer mit dem Pepsinsalzsäureauszug (s. 3. nachstehend) mit nur vorübergehendem Erfolge behandelten Taube, bei der wieder Lähmungen der Beine und Flügel, Opisthotonus und Krämpfe aufgetreten waren, wurde am 24. August $1917 \mathrm{um} \mathrm{6/2} \mathrm{Uhr}$ nachm. $1 \mathrm{~g}$ des trockenen Salzsäureauszuges in Wasser gelöst in den Kropf eingespritzt. Die Taube wurde am nächisten Morgen tot im Käfig gefunden.

b) Einer an den Beinen schwer gelähmten Taube wurden am 5. Dezember 1917 um 41/2 Uhr nachm. $2 \mathrm{~g}$ des trockenen Salzsäureanszuges in Wasser gelöst in den Kropf eingespritzt, Am 6. Dezember früh wurde die Taube tot aufgefunden.

3. Pepsinsalzsäureauszug. a) Einer typisch erkrankten Taube (Beinlähmung, Opisthotonus, Krämpfe) wurde am 23. August 1917 um $4 \mathrm{Uhr}$ nachm. $1 \mathrm{~g}$ des trockenen Pepsinsalzsäureauszuges in Pillenform eingegeben. Am 24. August 9 Uhr vorm. merkliche Besserung. Opisthotonus und Krämpfe geschwunden. Paresen der Beine noch sehr ausgesprochen. Die Taube bekam um $10 \mathrm{Uhr}$ vorm. noch weitere $2 \mathrm{~g}$ des Pepsinsalzsäureauszuges. Im Lanfe des Nachmittags traten wieder 
Opisthotonus und Krämpfe auf. Die Taube wurde nun zu dem Versuche mit dem salzsauren Auszuge aus Sojabohnen verwandt.

b) Eine sehr stark abgemagerte Taube mit ausgesprochenen Paresen der Beine bekam am 26. Angust 1917 um 11 Uhr vorm. $1 \mathrm{~g}$ des trockenen Pepsinsalzsäureauszuges in Pillenform. Am nächsten Tage frühmorgens waren die Paresen merklich zurückgegangen. Die Taube war viel munterer. Sie bekam nun bis zum 31. August täglich $1 \mathrm{~g}$ des Pepsinsalzsäureauszuges in Pillen. Am 28. August war die Taube sehr munter und lief behende umber. Sie erhielt sich so bis zum 31. August. An diesem Tage sass das Tier mit eingezogenem Kopf und gesträubtem Gefieder bedrückt da. Temperatur $36^{\circ} \mathrm{C}$. Um 7 Uhr nachm. wurde sie sehr hinfällig and bekam nun $1,5 \mathrm{~g}$ getrocknete Bierhefe Qual. I in Pillenform sowie einige gekochte gelbe Erbsen. Am 1. September um 9 Uhr vorm. war die Taube wieder sehr munter und lief behende umher. Temperatur $36,1^{\circ} \mathrm{C}$. Bei Fütterung mit gemischtem Taubenfutter und Hefetherapie erholte sich das Tier nun schnell.

'4. Ausgezogener Rückstand. Einer besonders grossen und kräftigen, an den Beinen schwer gelähmten Taube wurden am 9. November 1917 um 53/4 Uhr nachm. $2,5 \mathrm{~g}$ des Rückstandes in mit Glyzerinstärkekleister bereiteten Pillen (30 Stïck) eingegeben. Am 10. November um 9 Uhr vorm. keinerlei Besserung. Um $10 \mathrm{Uhr}$ nochmals 2,5 $\mathrm{g}$ des Rückstandes in 30 Pillen. Verschlimmerung im Laufe des Nachmittags. Bekam noch $1 \mathrm{~g}$ trockene Hefe per os, wurde aber trotzdem am nächsten Morgen tot aufgefunden.

\section{Versuche mit Präparaten aus gemahlenen gelben Erbsen.}

Die zur Darstellung nachstehender Präparatè verwandten gelben Erbsen enthielten in 100 Gewichtsteilen:

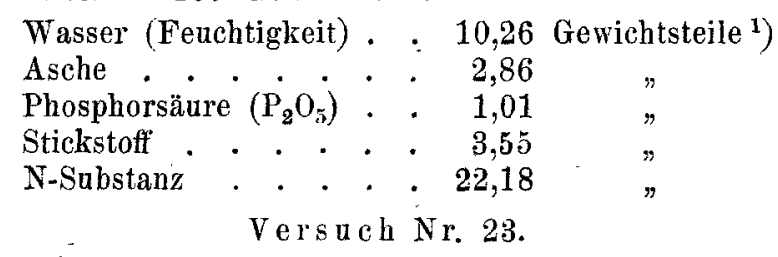

Durch verdünnte Schwefelsäure a a ammoniakalischem Erbsenauszug gefällter Niederschlag.

Bereitung des Präparates: $100 \mathrm{~g}$ feingesiebtes, frisch gemahlenes Erbsenmehl wurden mit einer Mischung von $100 \mathrm{ccm}$ Ammoniak von $25 \%$ und 1 Liter eiskalten dest. Wassers unter Eiskühlung und häufigem Umschütteln 3 Stunden lang stehengelassen. Der flüssige Anteil wurde dann durch Filter, die mit Tierkohle beschickt waren (Filtrierapparat Abb. 37), abfiltriert und das Filtrat in einer mit $100 \mathrm{ccm}$ verdünnter Schwefelsäure von $20 \%$ beschickten Flasche aufgefangen. Der sich ausscheidende voluminöse Niederschlag wurde durch Zentrifugieren gesammelt und so lange mit dest. Wasser ausgewaschen, bis Kongopapier durch das Waschwasser nicht mehr gebläut wurde, dann

1) Analyse s. S. 204.

Prlı̄ger's Archiv für Physiologie. Bd. 172. 
auf flachen Tellern in dünner Schicht ausgebreitet und bei $37^{\circ} \mathrm{C}$. getrocknet. Ausbeute: 5,9 .g.

Schweres, bräunlich gefärbtes, hygroskopisches Pulver, welches $8,97 \%$ Wasser (Feuchtigkeit) und $0,613 \% \mathrm{P}_{2} \mathrm{O}_{5}$ enthielt. Das Präparat in frischgefälltem Zustande war in $10 \%$ iger Natronlauge vollkommen löslich und wurde aus dieser Lösung durch Zusatz von Essigsäure in geringem Überschusse wieder ausgefällt. Die alkalische Lösung gab starke Biuretreaktion. Durch Pepsinsalzsäure (Pepsin $0,1 \mathrm{~g}, \mathrm{HCl}$ von $25 \% 5$ Tropfen, dest. Wasser $50 \mathrm{ccm}$ ) wurde das frischgefällte Präparat innerhalb von 16 Stunden bis auf einen geringfügigen Rückstand vollkommen gelöst.

Tierversuch: Einer an alimentärer Dystrophie typisch elkrankten Taube wurde am 9. Mai 1917 um 6 Uhr nachm. $1 \mathrm{~g}$ des Präparates in Pillenform eingegeben. Am 10. Mai früh keine Besserung. Um 10 Uhr vorm. zweite Gabe von $2 \mathrm{~g}$ des Präparates. Bis 4 Uhr nachm. keine günstige Wirkung bemerkbar. Durch Anwendung wirksamer Hefepräparate schwanden die nervösen Erscheinungen dagegen in kurzer Zeit.

Versuch Nr. 24.

Pepsinsalzsäureauszug aus gemahlenen gelben Erbsen.

Bereitung: $50 \mathrm{~g}$ feingemahlene Erbsen von der auf S. 204 angegebenen Zusammensetzung wurden zunächst mit $300 \mathrm{ccm}$ absoluten Alkohols bei $37^{\circ} \mathrm{C}$. unter häufigem Umschütteln 10 Tage lang digeriert. Der alkoholische Extrakt wurde dann von dem ausgezogenen Mehl abgenutscht und dieses mit absolutem Alkohol gut ausgewaschen.

A. Alkoholischer Extrakt. Der alkoholische Auszug wurde bei $37^{\circ} \mathrm{C}$. im Vakuum zur Trockne verdampft, der Rückstand mit Aceton wiederholt ausgezogen. Hierbei ging in den Acetonauszug vor allem fettes öl über (im ganzen etwa $0,5 \mathrm{~g}$ mit einem $\mathrm{P}_{2} \mathrm{O}_{5}$-Gehalt von nur $0,00165 \mathrm{~g}$, entsprechend $0,33 \%$ ). Das mit Aceton ausgezogene alkoholische Extrakt wurde durch Durchsaugen von Luft von Aceton befreit, in absolutem Alkohol aufgenommen, filtriert und durch $\mathrm{Ab}$ dunstenlassen von Alkohol befreit. Rückstand $0,51 \mathrm{~g}$.

B. Pepsinsalzsäureextrakt. Das durch Ausziehen mit Alkohol von der Phosphatidfraktion befreite Erbsenmehl wurde mit einer Mischung von $0,6 \mathrm{~g}$ Pepsin, 15 Tropfen Salzsäure von 25\% und $300 \mathrm{ccm}$ dest. Wassers 48 Stunden lang bei $37^{\circ} \mathrm{C}$. digeriert. Der feste Rückstand wurde nun von dem flüssigen Anteil durch Abnutschen getrennt und mit warmem Wasser gut ausgewaschen, dann zunächst im Vakuum bei $37^{\circ} \mathrm{C}$. eingedampft, mit verdiunnter Natronlauge neutralisiert und hierauf in flachen Schalen bei $37^{\circ} \mathrm{C}$. zur Trockne eingedampft. Der von den Schalenwandungen abgekratzte feste Extrakt wurde nochmaIs im Vakuum über Schwefelsäure getrocknet und schliesslich in einer angewärmten Reibschale zu einem feinen Pulver zerrieben. Ausbeute: 10,8 g.

Das in dünnen Lamellen vollkommen klare und durchsichtige Extrakt gab in wässeriger Lösung starke Biuretreaktion. Es enthielt: $7,84 \%$ Wasser, 7,38\% Stickstoff, entsprechend $46,12 \%$ Protein, and $1,35 \% \quad \mathrm{P}_{2} \mathrm{O}_{5}$ (Analyse s. S. 205). 
Beitrag zur Kenntnis von organischen Nahrungsstoffen mit spezif. Wirkung. 195

Tierversuche: 1. Einer an alimentärer Dystrophie (Lähmung der Beine und Flügel, Opisthotonus, Krämpfe) erkrankten Taube wurde am 17. Juni 1917.1 g des Pepsinsäureextraktes in Pillenform eingeflösst. Am 18. Juni 9 Uhr vorm. waren alle nervösen Erscheinungen (Lähmung der Beine, Opisthotonus, Krämpfe) geschwunden, und die Taube vermochte wieder behende zu laufen; dagegen war das Tier nicht so munter, wie dies bei anderen wirksamen Präparaten der Fall zu sein pflegt, und frass auch wenig von dem ihm vorgesetzten geschliffenen Reis.

2. Eine nach längerer Fütterung mit geschliffenem Reis am 29. August 1917 an alimentärer Dystrophie (ausgesprochene Paresen der Beine, grosse Hinfälligkeit) erkrankte, stark abgemagerte Taube bekam von diesem Tage an täglich $1 \mathrm{~g}$ Pepsinsalzsäureextrakt in Pillenform (ohne Zusatz). Nahrung: geschliffener roher Reis.

30. A u g ust: Taube wieder sehr munter, vermag behende zu laufen and za fliegen. Körpergewicht: $160 \mathrm{~g}$.

1. September: ebenso. Temp. $38,6^{\circ} \mathrm{C}$. Körpergewicht $165 \mathrm{~g}$.

4.

5

14 .

15 .

$$
\begin{aligned}
& \Rightarrow \quad 38,0^{\circ} \mathrm{C} \text {. } \\
& \text { " } 38,5^{\circ} \mathrm{C} \\
& \Rightarrow \quad \text { " } \quad 183 \mathrm{~g} \text {. }
\end{aligned}
$$

C. Mit Alkoholund Pepsinsalzsäure ausgezogenes Erbsenmehl. Der Rückstand $(34,55 \mathrm{~g})$, welcher nach dem Ausziehen mit Alkohol und Pepsinsalzsäure verblieb, enthielt an Wasser 10,34\%, Stickstoff $2,27 \%$, entsprecbend $14,21 \%$ Protein, und $0,66 \% \mathrm{P}_{2} \mathrm{O}_{5}$.

Tierversuch: Einer stark abgemagerten, an den Beinen schwer gelähnten Taube (Temp. 37, $6^{\circ}$ C.) wurden am 19. September 1917 $2 \mathrm{~g}$ des ausgezogenen Erbsenmehles (mit Glyzerinstärkekleister in Pillenform gebracht) eingefösst. Nahrung: geschliffener roher Reis, wie bis dahin. Körpergewicht: $143 \mathrm{~g}$.

20. Septem ber: Keine Besserung. Nochmals $2 \mathrm{~g}$ ausgezogenes Erbsenmehl.

21. $" \quad$ Keine Besserung. Paralyse der Beine zugenommen. Temp. $36,9^{\circ} \mathrm{C}$.

22. "Keine Besserung. Körpergewicht 145 g. Temp. $36,9^{\circ} \mathrm{C}$. Trotz Anwendung wirksamer Hefepräparate geht die Taube ein.

\section{Versuche mit vollständig alogebauten, Inkrete liefernden Organen (Optonen).}

\section{Corpus Inteum.}

Einer bereits zu einem anderen erfolglos verlaufenen Versuche (mit Präparat I R 1 [S. 259, Nr. 3]) verwandten Taube, welche typische nervöse Störungen (Beinlähmung, Opisthotonus, Krämpfe) aufwies, wurden am 3. Oktober 1917 um 101/2 Uhr vorm. 0,06 g (1 Ampulle) Corpus luteum-Opton in den Brustmuskel eingespritzt. Da bis 6 Uhr nachm. keinerlei Besserung, sondern erhebliche Verschlimmerung eingetreten war, bekam die Versuchstaube $1 \mathrm{~g}$ trockene Bierhefe Qual. I. Am nächsten Morgen war das Tier sehr munter und fast vollkommen wiederhergestellt. 


\section{Thymus.}

Einer typisch erkrankten Taube (Paralyse der Beine, Opisthotonus, keine Krämpfe) wurde am 22. Oktober 1917 um 4/2 Uhr nachm. der Inhalt einer Ampulle $(0,06 \mathrm{~g})$ Thymus - Opton in den Brustmuskel eingespritzt. Am nächsten Morgen (23. Oktober) 9 Uhr vorm. Opisthotonus geschwunden, Beinlähmung und sonstiger Zustand der Versuchstaube unverändert. Sie bekam nun $1,5 \mathrm{~g}$ getrocknete Bierhefe Qual. I. Am nächsten Morgen (24. Oktober) war die Taube wieder sehr munter. Die Lähmung der Beine war ebenfalls sehr erheblich zurückgegangen, schwand aber bei fortgesetzter einseitiger Reisfütterung mit Hefetherapie erst nach 16 Tagen (9. November) völlig.

\section{Thymoidea.}

Einer paretischen Taube (kein Opisthotonus, keine Krämpfe) wurde am 24. Oktober 1917 um 12 Uhr mittags der Inhalt einer Ampulle $(0,10 \mathrm{~g})$ Thyroidea-Opton in den Brustmuskel eingespritzt. Bis 7 Uhr nachm. keine Besserung. Am nächsten Morgen früh wurde die Taube tot in Käfig aufgefunden.

\section{Testes.}

Einer schwer gelähmten Taube wurden am 17. Dezember 1917 um $11^{1 / 2}$ Uhr vorm. $0,10 \mathrm{~g}$ Testes - Opton in den Brustmuskel eingespritzt. Das Tier erschien unmittelbar nach der Einspritzung viel munterer, doch war diese Wirkung nicht von längerer Dauer. Die Lähmung der Beine war bis um 5 Uhr nachm. unverändert. Nochmalige Einspritzung von $0,1 \mathrm{~g}$ Testes-Opton. Das Tier erschien vorübergehend munterer. Am nächsten Tage (18. Dezember) 9 Uhr vorm. keinerlei Besserung.

Die Taube bekam nun $1,5 \mathrm{~g}$ getrocknete Hefe und war am nächsten Tage (19. Dezember) wieder munter und so gut wie frei von Lähmungen.

\section{Hypophyse.}

Einer typisch erkrankten Taube (Beinlähmung, Opisthotonus, Krämpfe) wurde am 30. Dezember 1917 um 10/4 Uhr vorm. der Inhalt einer Ampulle $(0,06 \mathrm{~g})$ Hypophysen-Opton in den Brustmuskel eingespritzt. Bis zum nächsten Tage (31. Dezember) um 91/2 Uhr vorm. war keinerlei Besserung bemerkbar.

Der Versuchstaube wurden nun 20 Tropfen des dialysierten Acetonniederscllages aus hydrolysierter Hefe und $3 \mathrm{ccm}$ dest. Wassers verdümt in den Brustmuskel eingespritzt. Schon nach einer Stunde war eine grosse Besserung eingetreten: 0pisthotonus und Krämpfe waren geschwunden, die Lähmung der Beine war wesentlich zurückgegangen. Nach weiteren 3 Stunden war die Taube wieder sehr munter und die Lähmung der Beine bis anf einen sehr geringen Rest beseitigt.

\section{Prüfung der Sera von einseitig mit gesehliffenem Reis ernährten Tauben auf Abwehrfermente.}

\section{Bereitung der Substrate.}

A. Menschliche Organe. Die zu nachstehend beschriebenen Versuchen verwandten Organe - Gehirn und Rückenmark - wurden 
unmittelbar nach der Entnahme von Blutgerinnsel durch Abspülen, sodann von den Häuten mechanisch befreit. Sie wurden nun mit dem Messer fein zerschnitten, hierauf durch eine Fleischhackmaschine geschickt. Der so gewonnene Organbrei wurde auf einem feinmaschigen Metallsiebe gut ausgewaschen, dann, nach dem Ablaufen des Waschwassers, in einer Reibschale unter Zusatz von Kochsalz fein zerrieben und mít Wasser in einem hohen, nicht zu weiten Glaszylinder gespült. Nach dem Absetzen wurde das Waschwasser durch ein Koliertuch dekantiert und unter Zusatz von neuen Portionen Wasser das Auswaschen so lange fortgesetzt, bis das Sediment eine weisse Farbe angenommen hatte und frei von Blut war. Nach dem Dekantieren des letzten Waschwassers wurde der Rückstand mit absolutem Alkohol übergossen, gut umgeschüttelt und nach dem Absetzenlassen die überstehende Flüssigkeit dekantiert. Diese Operation wurde so oft. wiederholt, bis der Organbrei seine schleimige Beschaffenheit eingebüsst hatte. Er wurde nummehr auf einem Koliertuche durch Abseihen and anschliessendes Auspressen von Alkohol möglichst befreit. Der Presskuchen wurde hierauf nochmals mit absolutem Alkohol übergossen, in diesem möglichst fein verteilt und mehrere Stunden lang mazeriert. Durch Abseihen und Auspressen wurde der feste Anteil wiederum von der alkoholischen Flïssigkeit möglichst befreit, dann mit Äther übergossen und fein verteilt mehrere Stunden lang unter hüufigem Umschätteln mazeriert. Nach dem Abseihen des Äthers und Auspressen wurde der Rückstand auf Hachen 'Tellern in dünner Schicht ausgebreitet und nach dem Verdunsten des Äthers im Trockenschrank bei etwa $50^{\circ} \mathrm{C}$. getrocknet. Die so getrockneten Substanzem wurden in einer Reibschale fein zerrieben und nun im Soxhlet-Apparat durch genügend lange fortgesetztes Ausziehen mit Tetrachlorkohlenstoff von Lipoiden befreit. Nach dem Verdunsten des Tetrachlorkohlenstoffes wurde das ausgezogene Pulver in einem Emailletopf bzw, in einem Erlenmeyer-Kolben mit dest. Wasser ausgekocht und das Kochwasser durch ein Koliertuch abgeseiht. Dies wurde so oft wiederholt, bis eine Probe von 20 ccm des Kochwassers nach dem Filtrieren durch ein gehärtetes Filter und nach anschliessendem Eindampfen auf $2 \mathrm{ccm}$ mit $1 \mathrm{ccm}$ einer $1 \%$ igen Ninhydrinlösung beim Kochen während 1 Minute weder sofort noch nach 1 Stunde auch nicht mebr die geringste Blaufärbung erkennen liess.

B. Ta u benorgane (Gehirn, Herz, Leber, Brustmuskel). Die Gehirne gesunder Tauben wurden sofort nach der Entnahme mit Wasser gut abgespült und dann in einer Reibschale unter Zusatz von etwas reinem Kochsalz gut zerrieben. Nach dem Aufschwemmen in dest. Wasser wurde zentrifugiert, das Waschwasser abgegossen und der Rückstand wiederum mit dest. Wasser aufgeschwemmt. Dies wurde so oft wiederholt, bis alles Blut entfernt war. Die Taubengehirne wurden dann genau so weiter behandelt, wie dies vorstehend für menschliche Organe angegeben ist.

Herzmuskel, Brustmuskel und Leber wurden nach der Entnahme sofort mit Wasser gut ausgespült, mit der Schere fein zerschnitten und weiter in einer kleinen Fleischhackmaschine gut zerkleinert. Der Organbrei wurde nun mit Kochsalz fein zerrieben und dann durch Auf- 
schwemmen in dest. Wasser und anschliessendes Zentrifugieren so lange ausgewaschen, bis ailes Blut entfernt war. Die weitere Behandlung entsprach genau derjenigen, wie sie vorstehend für menschliche Organe beschrieben ist.

\section{Gewinnung des Taubenserums.}

Den Tauben, deren Serum geprüft werden sollte, wurde durch vorsichtiges Ausrupfen der- Federn der Hals freigelegt. Die Haut der kahlgemachten Stellen wurde dann durch Abreiben mit Baumwollbäuschehen, die mit Ätheralkohol getränkt waren, von Fett und Unreinlichkeiten möglichst befreit. Hierauf wurde durch einen Einschnitt die Karotis freigelegt und durchschnitten. Das ausströmende Blut wurde in einem Porzellanschälchen aufgefangen. Nach dem Gerinnen wurde der Blatkuchen auf einen paraffinierten, am Grunde mit einem Porzellansiebchen versehenen Glastrichter gebracht und nach dem Bedecken des Trichters mit einem Uhrschälchen bei mässiger Temperatur $\left(10-15^{\circ} \mathrm{C}\right.$.) so lange steliengelassen, bis kein Serum mehr in die unter dem Trichter aufgestellten Zentrifugierröhrchen abtropfte, was etwa 24 Stunden dauerte. Es wurde dann sofort zentrifugiert, das auf diese Weise geklärte Serum von dem meistens sehr geringen Sedimente abgegossen und ohne Zeitverlust zum Ansetzen der Dialysierversuche verwandt. Hämolytisches Serum wurde stets verworfen.

\section{Methodik des Dialysierverfahrens und Prüfung der Dialysate.}

Hierbei wurden die von $A b d e r h a l d e n$ angegebenen Weisungen und Regeln (s. Emil Abderhalden, Abwehrfermente des tierischen Organismus, Vierte Auff. Julius Springer, Berlin 1914) streng eingehalten.

\section{Versuchstiere.}

$\mathrm{Zu}$ den hier in Betracht kommenden Versuchen wurden ausschließlich Tauben, und zwar ausgewachsene, kräftige, vorzugsweise dunkelgefärbte Tiere verwandt. Von den im Handel befindlichen Tauben sind die meisten Bastarde verschiedener Rassen. Bei unseren Versuchen haben sich als die geeignetsten Bastarde von anderen Taubenarten mit sogenannten Pagadetten erwiesen, die sich durch ihre Grösse, Widerstandsfähigkeit und kräftige Muskulatur auszeichnen und an dem kräftig gebauten, geraden Schnabel und stärker entwickelten Höckern an den Nasenlöchern zu erkennen sind.

\section{Ernährung der Versuchstauben.}

Ein Teil der Versuchstauben, bei welchen es auf die Entnahme gesunder, zur Bereitung von Substraten geeigneter Organe und auf die Gewinnung normalen Taubenserums ankam, wurde mit gemisclitem gutem Taubenfutter ernährt.

Ein anderer Teil der Versuchstauben wurde ausschliesslich mit rohem geschliffenen Reis gefüttert. Diese Tiere wurden teils schon nach 10-15 tägiger Reisfütterung, teils erst dann getötet, wenn sie an alimentärer Dystrophie in typischer Weise erkrankt waren. Die Blutentnahme erfolgte dann in der unter II. geschilderten Weise. 
Beitrag zur Kenntnis von organischen Nahrungsstoffen mit spezif. Wirkung. 199

\section{Ergebnisse ${ }^{1}$ ).}

\section{A. Gesunde Tauben.}

1. Serum (allein)

$\begin{array}{llllll}\text { Taube: } & \text { Nr. } 1 & \text { Nr. } 2 & \text { Nr. } 3 & \text { Nr. } 4 & \text { Nr. } 5\end{array}$

2. Gehirn (Taube)

3. Herzmuskel

4. Brustmuskel,

5. Leber

6. Gehirn (Mensch)

7. Rückenmark ,

B. Tauben, die 10-15 Tage lang mit rohem geschliffenen Reis gefüttert worden waren.

$\begin{array}{llllll}\text { Taube: } & \text { Nr. } 6 & \text { Nr. } 7 & \text { Nr. } 8 & \text { Nr. } 9 & \text { Nr. } 10\end{array}$

Fütterungsdauer: - 10 Tage 11 Tage 12 Tage 18 Tage 15 Tage

1. Serum (allein)

2. Gehirn (Taube). . . . + +

3. Herzmuskel " . • . • +

4. Brustmuskel " $"$. . . +

5. Leber

6. Gebirn (Mènsch) .

C. Tauben, die an manifester alimentärer Dystrophie erkrankt waren.

Taube: Nr. 11 Nr. 12 Nr. 13 Nr. 14 Nr.15 Nr.16 Nr. 17 Nr.18

1. Serum (allein)

2. Gehirn (Taube)

3. Herzmuskel,

4. Brustmuskel"

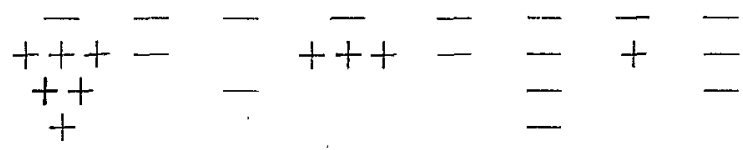

Anm.: Sämtliche zu dieser Versuchsreihe $\mathrm{C}$ verwandten Tauben befanden sich im letzten Stadium der Krankheit und waren stark abgemagert.

\section{Untersuchung von Taubenkot.}

A. Kot von Tauben, die mit gewöhnlichem gemischtem Tanbenfutter ernährt worden waren.

Der gesammelte Kot wurde bei $37^{\circ} \mathrm{C}$. getrocknet, dann in einer Reibschale fein zerrieben und durch ein feinmaschiges Sieb gegeben. Das so gewonnene Pulver diente zu nachstehenden Bestimmungen.

1. Wasser (Feuchtigkeit): 1,0014 g Kotpulver verloren beim Trocknen bei $105^{\circ}$ C. $0,0922 \mathrm{~g}$, bis Gewichtskonstanz erreicht war. Diese Gewichtsabnahme entspricht: $9,21 \%$ Wasser.

2. Phosphorsäure $\left(\mathrm{P}_{2} \mathrm{O}_{5}\right)$, nach dem Verfahren von $\mathrm{A}$. Ne $\mathrm{N}$ mann mit der von H. Schaumann ${ }^{2}$ ) angegebenen Apparatur bestimmt.

1) Die zuweilen sehr geringe Ausbeute an Serum gestattete in vielen Fällen nicht, Versuche mit allen Substraten auszuführen.

2) Archîv f. Schiffs - $\mathfrak{u}$. Tropenhygiene Bd. 14 Beih. 8 S. 147. 
Je $0,2 \mathrm{~g}$ bei $37^{\circ} \mathrm{C}$. getrocknetes Kotmehl mit Salpeterschwefelsäure verbrannt.

Titration (Faktor 0,001268).

$\begin{array}{ccccc}\text { Probe } & 1 / 2 \mathrm{n} \mathrm{NaOH} & 1 / 2 \mathrm{n} \mathrm{HCl} & \text { Differenz } & \mathrm{P}_{2} \mathrm{O}_{5} \\ \mathrm{Nr} .1 & 10,1 \mathrm{ccm} & 6,1 \mathrm{ccm} & 4,0 \mathrm{ccm} & 0,0050720 \mathrm{~g}=2,536 \% \\ \mathrm{Nr} .2 & 10,1 \mathrm{ccm} & 6,2 \mathrm{ccm} & 3,9 \mathrm{cem} & 0,0049452 \mathrm{~g}=2,473 \%\end{array}$
$\mathrm{P}_{2} \mathrm{O}_{5}$ Gehalt des bei $37^{\circ} \mathrm{C}$. getrockneten Kotes im Mittel: 2,504\% $\mathrm{P}_{2} \mathrm{O}_{5}$ " $" 105^{\circ} \mathrm{C}$. $" \quad " 2,758 \%$.

3. Stickstoff (nach Kjeldahl) mit der von E. Abderhatden und A. Fodor $\mathrm{r}^{1}$ angegebenen Abänderung für Mikrobestimmungen.

Je $0,2 \mathrm{~g}$ Kotpulver.

Verbraucht an 1/10 n. $\mathrm{H}_{2} \mathrm{SO}_{4}$ (Faktor 0,001401).

1. $7,7 \mathrm{cem}$, entsprechend $0,0107877 \mathrm{~g}$ oder $5,394 \% \mathrm{~N}$;

2. $8,6 \mathrm{ccm}, \quad 0,0120486 \mathrm{~g} " 6,024 \% \mathrm{~N}$.

N-Gehalt des bei $37^{\circ}$ C. getrockneten Kotes im Mittel: 5,709\% ;

N-Gehalt " $\quad 105^{\circ} \mathrm{C}$. $\quad " \quad$ " $\quad 6,288 \%$.

Anm.: Bei Verwendung von 1/10 n. Schwefelsäure und entsprechend grösseren Mengen von der Substanz, deren N-Gehalt bestimmt werden soll, ist ein Erhitzen des $\mathrm{Kjeldahl-Kolbens,} \mathrm{in} \mathrm{welchem} \mathrm{die} \mathrm{Austreibung}$ des Ammoniaks erfolgt, notwendig.

4. Asche. $0,9970 \mathrm{~g}$ des Kotmehles lieferten nach vollkommener Veraschung $0,0826 \mathrm{~g}$ Rückstand, entsprechend $8,28 \%$ A s che in dem bei $37^{\circ} \mathrm{C}$. getrockneten und $9,12 \%$ Asche in dem bei $105^{\circ} \mathrm{C}$. getrockneten Kot.

Zusammenstellung.

Taubenkot getrocknet bei : $\quad 37^{\circ} \mathrm{C}$

1. Wasser (Feuchtigkeit) . . 9,21\%

2. Stickstoff . . . . . . 5,71\% $6,29 \%$

3. Asche . . . . . . $8,28 \% \quad 9,12 \%$

4. Phosphorsäure $\left(\mathrm{P}_{2} \mathrm{O}_{5}\right)$. $\quad 2,50 \% \quad 2,76 \%$

B. Kot von Tauben, die ausschliesslich mit geschliffenem rohen Reis gefiut tert worden waren.

Der Kot war in derselben Weise, wie dies vorstehend angegeben ist, vorbereitet worden.

1. Wasser (Feuchtigkeit): 0,9966 g Kotpulver verloren beim Trocknen bei $105^{\circ} \mathrm{C}$., bis Gewichtskonstanz erreicht war, $0,0962 \mathrm{~g}$, entsprechend $9,65^{\circ}$ : Wass e r.

2. Phosphorsäure $\left(\mathrm{P}_{2} \mathrm{O}_{5}\right)$ nach A. Neumann. Je $0,2 \mathrm{~g}$ des Kotpulvers mit Salpeterschwefelsäure verbrannt.

Titration (Faktor 0,001268).

\begin{tabular}{lcccc} 
Probe & $1 / 2 \mathrm{n} . \mathrm{NaOH}$ & $\mathbf{1} / \mathbf{2}$ n. MCl & Differenz & \multicolumn{2}{c}{$\mathrm{Q}_{2} \mathrm{O}_{5}$} \\
$\mathrm{Nr} .1$ & $5,2 \mathrm{cem}$ & $\mathbf{1}, 7 \mathrm{ccm}$ & $\mathbf{3 , 5} \mathrm{ccm}$ & $0,0044380 \mathrm{~g}=2,219 \%$ \\
$\mathrm{Nr} .2$ & $5,2 \mathrm{ccm}$ & $\mathbf{1 , 5} \mathrm{ccm}$ & $\mathbf{3 , 7} \mathrm{ccm}$ & $0,0046916 \mathrm{~g}=2,346 \%$
\end{tabular}

1) Zeitschrift f. Physiol. Chemie Bd. 98 S. 190. 1917. 
Beitrag zur Kenntnis von organischen Nahrungsstoffen mit spezif. Wirkung. 201

$\mathrm{P}_{2} \mathrm{O}_{5}$-Gehalt des bei $37^{\circ} \mathrm{C}$. getrockneten Kotes im Mittel: 2,282\% $\mathrm{P}_{2} \mathrm{O}_{5}^{-} " \# " 105^{\circ} \mathrm{C}$. " " $" 2,525 \%$.

3. Stickstoff nach Kjeldahl (Mikromethode von Abderhalden und Fodor s. S. 200). Für je 0,2 g Kotpulver verbraucht an $1 / 10$ n. $\mathrm{H}_{2} \mathrm{SO}_{4}$ (Faktor 0,001401).

1. $11,1 \mathrm{ccm}$ entsprechend $0,0155511 \mathrm{~g}$ oder $7,78 \% \mathrm{~N}$;

2. $11,4 \mathrm{ccm} \quad 0,0159714 \mathrm{~g} " 7,98 \% \mathrm{~N}$.

$\mathrm{N}$-Gehalt des bei $37^{\circ}$ C. getrockneten Kotes im Mittel $7,88 \%$;

$\mathrm{N}-" \quad n 105^{\circ} \mathrm{C}$. $\quad " \quad$ " $\quad, 72 \%$.

4. Asche: 1,0024 g des Kotpulvers lieferten nach vollkommener Veraschung einen Rückstand von $0,0665 \mathrm{~g}$, entsprechend $6,63 \% \mathrm{Asch}$ e in dem bei $37^{\circ} \mathrm{C}$. getrockneten bzw. $7,34 \% \mathrm{Asche}$ in dem bei $105^{\circ}$ C. getrockneten Kote.

\section{$\mathrm{Zusammenstellung.}$}

Taubenkot getrocknet bei : $\quad 37^{\circ} \mathrm{C}$.

1. Wasser (Feuchtigkeit) . . $9,65 \%$

2. Stickstoff . . . . . . 7,88\%

3. Asche . . . . . . $6,63 \% \quad 7,34 \%$

4. Phosphorsäure $\left(\mathrm{P}_{2} \mathrm{O}_{5}\right)$. . $2,28 \% \quad 2,52 \%$

\section{Prüfung auf Oxalsäure.}

$20 \mathrm{~g}$ trockener, fein gemahlener und durch ein feinmaschiges Sieb geschlagener Kot wurden mit $60 \mathrm{ccm}$ absoluten Alkohols fein zerrieben. Dem Gemisch wurde dann so viel Salzsäure zugesetzt, bis Kongopapier deutlich geblänt wurde. Nach zweistündigem Mazerieren unter häufigem Schütteln wurde die alkoholische Lösung abgenutscht und der Rückstand mit absolutem Alkohol gut ausgewaschen. Das durch Gallenfarbstoff (durch die Gmelin' sche Reaktion nachgewiesen) intensiv grün gefärbte Filtrat wurde mit $20 \mathrm{cem}$ dest. Wassers versetzt und auf dem Wasserbade bis auf einen geringen Rückstand eingedampft. Dieser wurde mit dest. Wasser aufgenommen, die Lösung filtriert und der unlösliche Anteil auf dem Filter gut ausgewaschen. Filtrat und Waschwasser, zusammen etwa $60 \mathrm{ccm}$, wurden nun dreimal hintereinander mit je $50 \mathrm{ccm}$ Äther gut ansgeschüttelt. Die mittels Scheidetrichter abgesonderten Ätherauszüge wurden nach dem Absetzenlassen filtriert, mit $20 \mathrm{ccm}$ dest. Wassers versetzt ${ }^{*}$ und der $\ddot{A}$ ther abdestilliert. Der Rückstand wurde in wenig dest. Wasser gelöst, dann mit Ammoniak bis zur alkalischen Reaktion versetzt und filtriert. Das Filtrat wurde nun mit einer konzentrierten wässerigen Gipslösung versetzt. Eine sehr geringe Trübung, die nach zweitägigem Stehenlassen des Reaktionsgemisches benutzbar war, verschwand auf Zusatz von etwas überschüssiger Essigsäure. Auch nach anhaltendem Zentrifugieren war keine Spur eines Niederschlages (Kalziumoxalat) weder makroskopisch noch mikroskopisch aufzufinden: Abwesenheit von Oxalsäure.

Präfung auf die Anwesenheit anderer organischer Gifte. $50 \mathrm{~g}$ bei $37^{\circ} \mathrm{C}$. getrockneter und fein gemahlener Taubenkot wurden mit $150 \mathrm{ccm}$ absoluten Alkohols verrieben, dann in einen Kolben gebracht, mit alkoholischer Weinsäurelösung deutlich angesäuert und 
15 Minuten lang am Rückflusskühler und auf dem Wasserbade zum Sieden erhitzt. Die alkoholische Lösung wurde dann abgenutscht und der feste Rückstand nochmals mit $150 \mathrm{ccm}$ absoluten Alkohols wie vorher 15 Minuten lang ausgekocht, hierauf der alkoholische Auszug wiederum abgenutscht. Die durch Gallenfarbstoffe (Gmelin'sche Probe positiv) intensiv grün gefärbten Auszüge wurden nach dem völligen Abkühlen nochmals filtriert. Das Filtrat wurde auf dem Wasserbade zur Trockne verdampft, der Rückstand mit $150 \mathrm{ccm}$ absoluten Alkohols aufgenommen und filtriert. Der durch Abdampfen des Filtrats gewonnene Rückstand wurde nun mit $50 \mathrm{ccm}$ warmen dest. Wassers aufgenommen und durch ein feinporiges angefeuchtetes Filter so oft filtriert, bis die Flüssigkeit klar durchlief. Dieses Filtrat wurde nun zu nachstehenden Ausschüttelungen verwandt.

1. Ausschüttelung der sauren Lösung mit $\ddot{A} t h e r$. Der saure, vorstehenden Angaben gemäss bereitete Auszug wurde dreimal hintereinander mit je 50 ccm Äther jedesmal 1 Stunde lang in der Schüttelmaschine ausgeschüttelt. Die mittels Scheidetrichters abgetrennten, durch $\mathrm{CaCl}_{2}$-Zusatz entwässerten, dann filtrierten Ätherauszüge wurden langsam bei etwa $37^{\circ} \mathrm{C}$. eingedampft. Im Rückstande waren weder makroskopische noch mikroskopische Kristalle zu entdecken.

Der Rückstand wurde nun in 5 ccm dest. Wassers gelöst und filtriert. 2 ccm dieser Lösung wurden einer Taube intramuskulär eingespritzt. Als nach 3 Stunden keinerlei Wirkung bemerkbar war, wurden die übrigen $3 \mathrm{ccm}$ derselben Taube mittels Schlundsonde in den Kropf eingespritzt: Weder sofort noch bis zum folgenden Tage war irgendeine Wirkung festzustellen.

2. A usschüttelung der alkalischen Lösung mit $\ddot{A}$ ther. Der saure, mit Äther ausgeschüttelte wässerige Auszug wurde mit schwacher Natronlauge deutlich alkalisch gemacht, dann ebenso wie vorher mit Äther ausgeschüttelt und weiter verfahren. Im Rückstande der gut entwässerten und filtrierten Ätherauszüge waren ebenfalls weder makroskopische noch mikroskopische Kristalle aufzufinden. Der Rückstand wurde in 5 ccm dest. Wassers gelöst, die Lösung filtriert und einer Taube intramuskulär auf einmal eingespritzt. Es war weder sofort noch bis zum folgenden Tage irgendeine Wirkung bemerkbar.

3. Chloroformauszug der ammoniakalischen Lösung. Der zu den Ausschüttelungen mit Äther verwandte Auszug wurde zuvächst mit Salzsäure schwach angesäuert, dann mit Ammoniak in geringem Überschusse versetzt und dreimal hintereinander mit je $50 \mathrm{ccm}$ Chloroform jedesmal 1 Stunde lang in der Schüttelmaschine ausgeschüttelt. Die mittels Scheidetrichters abgesonderten, dann durch $\mathrm{CaCl}_{2}$ - Tusatz entwässerten und filtrirten (hloroformauszüge wurden bei etwa $37^{\circ} \mathrm{C}$. zur Trockne verdampft. Auch hier, konnten weder makroskopische noch mikroskopische Kristalle aufgefunden werden.

Der in dest. Wasser gelöste und filtrierte, dann einer Taube intramuskulär eingespritzte Rückstand äusserte innerhalb von 24 Stunden keinerlei Wirkung.

4. Wässerige Lösung. . Die mit"Äther, dann mit Chloroform ausgeschüttelte wässerige Lösung wurde schliesslich auf dem Wasserbade 
Beitrag zur Kenntnis von organischen Nahrungsstoffen mit spezif. Wirkung. 203

stark eingedampft, dann durch Zusatz von Weizenstärke, Dextrin und Tragantgummi zu einer plastischen Masse verarbeitet, die in Pillenform einer Taube innerhalb von 3 Stundén eingegeben wurde, ohne dass indessen innerhalb der nächsten 24 . Stunden irgendeine Wirkung bemerkbar gewesen wäre.

\section{Untersuchung des Proteins aus geschliffenem Reis.}

$500 \mathrm{~g}$ fein gemahlener, geschliffener Reis, $190 \mathrm{cem}$ natürlicher Magensaft and $190 \mathrm{ccm}$ 1/10 n. Salzsäure wurden 4 Tage lang unter häufigem Umsehütteln im Brutofen bei $37^{\circ} \mathrm{C}$. digeriert, dann.. noch weitere $50 \mathrm{ccm} 1 / 10 \mathrm{n}$. Salzsäure hinzugefügt. Die Flässigkeit wurde nun darch ein Tuch geseiht und der Rückstand nach kräftigem Auspressen mit $300 \mathrm{~cm}$ dest. Wassers gut verrihrt und nochmals ausgepresst. Die gesamte Kolatur wurde nach mehrstündigem Stehen von dem Satz dekantiert, dann durch eine Schicht feinzerzupften Filtrierpapiers durchgenutscht. Die ersten trübe durchgehenden Anteile des Filtrats wurden so oft zurückgegeben, bis die ablaufende Flüssigkeit vollkommen klar war. Diese wurde dann so lange mit sehr verdünnter Natronlauge verzehrt, bis sich $\mathrm{der}^{2}$ bei jedem neuen Zusatz entstehende Niederschlag beim Umschütteln gerade noch wieder löste und die Reaktion nur noch schwach sauer war. Mit einem kleinen Teil dieser Flüssigkeit wurden nun nachstehende Reaktionen angestellt:

1. Biuretreaktion: +++

2. Xantheproteinreaktion: ++

3. Millon's Reaktion: +++

4. Glyoxylsä̈urereaktion: ++

5. Alkalisches Bleiacetat (Kochprobe): +++

6. Diazobenzolsulfosäurerealition: +++

Die Hauptmenge der Verdaungsflüssigkeit wurde nun mit Chlorwașserstoffgas gesättigt, am Rückflusskühler hydrolysiert und dann im Vakuum bei $37^{\circ}$ C. bis fast zur Trockne eingedampft. Nach jedesmaligem Zusatz von. dest. Wasser wurde das Eindampfen im Vakuum wiederholt, um die Salzsäure möglichst zu entfernen. Der letzte Rückstand des Hydrolysats wurde nun mit dest. Wasser aufgenommen, mit Sodalösung neutralisiert, mit etwas Tierkohle versetzt und filtriert.

Ein -Teil dieser Flüssigkeit wurde im Vakuum bei $37^{\circ} \mathrm{C}$. stark eingeengt. Hierbei schieden sich Kristalle aus, die nach dem $\mathrm{Ab}$ filtrieren und Auswaschen mit kaltem Wasser durch Erhitzen ihrer Lösung mit Mill o n's Reagens als Tyrosin erkannt wurden (Rotfärbung).

Mit einem anderen Teile des neutralisierten Hydrolysats wurden nachstehende Reaktionen ausgeführt:

1. Biuretreaktion: +

2. Xanthoproteinreaktion: +

3. Millon's Reaktion: +

4. Alkalisches Bleiacetat (Kochprobe): +

5. Glyoxylsäurereaktion: +

6. Diazobenzolsulfosäurereaktion : +

7. Bromwasserreaktion (auf freies Tryptophan): - 


\section{Analysen.}

\section{Gelbe Erbsen.}

Getrocknete gelbe Erbsen, die zur Darstellung der verschiedenen auf S. 193 genannten Erbsenpräparate Verwendung fanden, worden fein gemahlen und durch ein feinmaschiges Sieb geschlagen. Das so gewonnene Mehl wurde zu nachstehenden Bestimmungen verwandt:

1. Wasser (Feuchtigkeit): 0,9976 g lufttrockenes Erbsenmehl verlor beim Trocknen bei $105^{\circ} \mathrm{C}$. bis " zur Gewichtskonstanz $0,1024 \mathrm{~g}$, entsprechend $10,26 \%$ Wasser.

2. Stickstoff nach Kjeldahl unter Verwendung der Mikromethode von E. Abderhalden and A. Fod or ${ }^{1}$ ).

A n m.: Bei dieser wie bei allen anderen in der Folge ausgeführten Stickstoffbestimmungen wurden von den zu analysierenden Substanzen grössere Mengen verwandt, als dies zu Mikrokjeldahlbestimmungen mit 1/10u n.-Lösungen erforderlich oder zweckmässig ist. Anstatt der 1/100 n.Lösungen wurde $1 / 10 \mathrm{bzw} .1 / 20 \mathrm{n}$. Schwefelsäure und ebensolche Natronlauge benutzt. Wiederholtes längeres Aufkochen des alkalisierten Reaktionsgemisches beim Austreiben des Ammoniaks ist bei dieser Modifikation der Methode jedoch erforderlich. Im übrigen verfährt man den Vorschriften der unten angegebenen Originalveröffentlichung entsprechend.

Verwandt: Probe Nr. 1: 0,1000 g lufttrockenes Mehl;

Bei der Titration "verbraucht an ${ }^{1 / 10}$ "n. $\mathrm{H}_{2} \mathrm{SO}_{4}$ " (Faktor "0,001401):

Probe Nr. 1: 2,5 ccm, entsprechend 0,0035025 g N $=3,50 \% \mathrm{~N}$;

Nr. 2: 2,6 cem $\quad 0,0036426 \mathrm{~g} N=3,61 \% \mathrm{~N}$.

$3,55 \%$ N-Gehalt (arithmetisches Mittel) in dem Iufttrockenen Mehl.

3. A s che: 0,9994 g lufttrockenes Erbsenmehl binterliessen nach vollkommener Veraschung einen Rückstand von $0,0286 \mathrm{~g}$, entsprechend $2,86 \%$ Asche.

4. Phosphorsäure $\left(\mathrm{P}_{2} \mathrm{O}_{5}\right)$ nach $A$. Neumann. Zur Verbrennung mit Salpeterschwefelsäure verwandt je $0,5 \mathrm{~g}$ lufttrockenes Erbsenmehl.

Titration (Faktor 0,001268).

\begin{tabular}{|c|c|c|c|c|}
\hline obe & $1 / 2$ n. $\mathrm{NaOH}$ & $1 / 2 \mathrm{n} . \mathrm{HCl}$ & Differenz & $\mathrm{P}_{2} \mathrm{O}_{5}$ \\
\hline & $10.3 \mathrm{ccm}$ & & $4,0 \mathrm{ccm}$ & $5072 \mathrm{~g}=$ \\
\hline & $\mathrm{ccm}$ & $\begin{array}{l}6,3 \mathrm{ccm} \\
\mathrm{P}_{9} \mathrm{O}_{5}-\mathrm{Ge}\end{array}$ & $\begin{array}{r}4,0 \mathrm{ccm} \\
\text { lit: } 1,014\end{array}$ & $0,005072 \mathrm{~g}=1,014$ \\
\hline
\end{tabular}

$\mathrm{Zusammenstellung.}$

Erbsenmehl

1. Wasser (Feuchtigkeit) . . . 10,26\%

2. Stickstoff . . . . . . . $3,55 \%$

3. Stickstoffsubstanz . . . . . $22,18 \%$

4. Phosphorsäure (Protein) $\left(\mathrm{P}_{2} \mathrm{O}_{5}\right), \quad 1,01 \%$

5. Asche . . . . . . 2, $2,86 \%$ bei $105^{\circ} \mathrm{C}$. getrocknet

$11,43 \%$

$3,96 \%$

$24,72 \%$

$1,13 \%$

$3,19 \%$

1) E. Abderhalden und A. Fodor, Mikrokjeldahlmethode. Zeitschr. f. physiol, Chemie Bd. 98 S. 190.1917. 
Beitrag zur Kenntnis von organischen Nahrungsstoffen mit spezif. Wirkung. 205

2. Pepsinsalzsäureauszug aus gelben Erbsen (s. S. 194).

Das nach dem auf S. 194 angegebenen Verfahren bereitete, zu einem feinen Pulver zerriebene Präparat ergab bei nachstehenden Bestimmungen folgende Werte:

1. Wasser (Feuchtigkeit). Es verlbren beim Trocknen bei $105^{\circ} \mathrm{C}$. bis zur Gewichtskonstanz:

$$
\begin{aligned}
& \text { 1. } 0,0973 \mathrm{~g} \text { des Präparats } 0,0077 \mathrm{~g}=7,91 \% \\
& \text { 2. } 0,0981 \mathrm{~g} \% \text { " } 0,0076 \mathrm{~g}=7,77 \% \text {. } \\
& \text { Arithmetisches Mittel: } 7,84 \% \mathrm{~W} \text { as ser. }
\end{aligned}
$$

2. Stickst off nach Kjeldahl (Mikromethode von E. Abderhalden und A. Fodor s. S. 204) in der bei $105^{\circ} \mathrm{C}$. getrockneten Substanz:

Verbraucht an $1 / 10$ n. $\mathrm{H}_{2} \mathrm{SO}_{4}$ (Faktor 0,001401) für:

1. $0,0896 \mathrm{~g}$ Substanz 5,1 cem entsprechend $0,0071451 \mathrm{~g} N=7,97 \%$; 2. $0,0905 \mathrm{~g} \quad " \quad 5,2 \mathrm{ccm} \quad$ " $0,0072852 \mathrm{~g} \mathrm{~N}=8,05 \%$. N-Gehalt:" $8,01 \mathrm{~g}$.

3. Phosphorsäure $\left(\mathrm{P}_{2} \mathrm{O}_{5}\right)$ nach A. Neumann.

Zur Verbrennung mit Salpeterschwefelsäure verwandt:

Probe Nr. 1. $0,1833 \mathrm{~g}$ bei $105^{\circ} \mathrm{C}$. getrocknete Substanz

Titration: (Faktor 0,001268).

$$
\begin{array}{ccclc}
\text { Probe } & 1 / 2 \mathrm{n} . \mathrm{NaOH} & 1 / 2 \mathrm{n} . \mathrm{HCl} & \text { Differenz } & \mathrm{P}_{2} \mathrm{O}_{5} \\
\text { Nr. 1. } & 10,2 \mathrm{ccm} & 8,1 \mathrm{ccm} & 2,1 \mathrm{ccm} & 0,0026628 \mathrm{~g}=1,45 \% \\
\text { 2. } & 10,2 \mathrm{ccm} & 8,0 \mathrm{ccm} & 2,2 \mathrm{ccm} & 0,0027896 \mathrm{~g}=1,50 \%
\end{array}
$$

\section{Zusammenstellung.}

Pepsinsalzsäureextrakt bei $37^{\circ} \mathrm{C}$. getrocknet bei $105^{\circ} \mathrm{C}$. getrocknet

1. Wasser (Feuchtigkeit) . . . $7,84 \%$

2. Stickstoff . . . . . . $7,38 \% \quad 8,01 \%$

3. Stickstoffsubstanz (Protein) . . 46,12\% $50,06 \%$

4. Phosphorsäure $\left(\mathrm{P}_{2} \mathrm{O}_{5}\right) \quad$. . . $1,35 \% \quad \mathbf{1 , 4 7 \%}$.

\section{Rückstand des mit Alkohol und Pepsinsalzsäure ausgezogenen} Erbsenmehls (s. S. 195).

Das nach dem auf S. 195 angegebenen Verfahren erhaltene Präparat ergab bei nachstehenden Bestimmungen folgende Werte:

1. Wasser (Feuchtigkeit): $0,9952 \mathrm{~g}$ bei $37^{\circ} \mathrm{C}$. getrocknetes Mehl verloren beim Trocknen bis zur Gewichtskonstanz bei $105^{\circ} \mathrm{C}$. $0,1029 \mathrm{~g}$, entsprechend $10,34 \%$ Was ser.

2. Stickst off nach Kjeldahl (Mikromethode von E. Abderhalden und A. Fodor s. S. 204).

Verwandt: je $0,2 \mathrm{~g}$ bei $37^{\circ} \mathrm{C}$. getrocknetes Mehl.

Verbraucht an 1/10 n. $\mathrm{H}_{2} \mathrm{SO}_{4}$ (Faktor 0,001401):

1. $2,95 \mathrm{ccm}$, entsprechend $0,00213295 \mathrm{~g} \cdot \mathrm{N}=2,17 \% \mathrm{~N}$;

2. $3,40 \mathrm{ccm} \quad 0,0044634 \mathrm{~g} \mathrm{~N}=2,38 \% \mathrm{~N}$.

$\mathrm{N}$ - Gehalt 2,27\% (arithmetisches Mittel), entsprechend an N-Substanz (Protein) 14,21\% (Faktor 6,25). 
3. As che: $0,9937 \mathrm{~g}$ bei $37^{\circ} \mathrm{C}$. hinterliessen nach vollkommener Veraschung $0,0043 \mathrm{~g}$, entsprechend $9,43 \%$ Asche.

4. Phosphorsäure $\left(\mathrm{P}_{2} \mathrm{O}_{5}\right.$ nach A. Neumann.

Verwandt je $1 \mathrm{~g}$ bei $37^{\circ} \mathrm{C}$. getrockneten Mehles.

Titration (Faktor 0,001268).

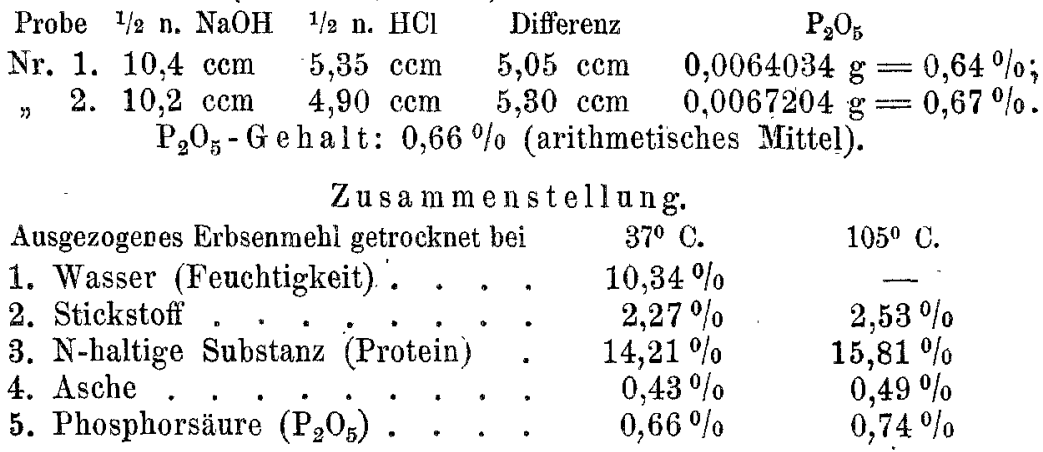

\section{Bierhefe Qual. Nr. I.}

Diese bei $50^{\circ} \mathrm{C}$. getrocknete, dann feingemahlene Hefe lieferte bei nachstehenden Bestimmungen folgende Werte:

1. Wasser (Feuchtigkeit): $0,9974 \mathrm{~g}$ bei $50^{\circ} \mathrm{C}$. getrockneter Hefe verloren beim Trocknen bei $105^{\circ} \mathrm{C}$. bis zur Gewichtskonstanz $0,0693 \mathrm{~g}$, entsprechend $6,95 \%$ Wasser.

2. Stickstoff nach Kjeldahl (Mikromethode von E. Abderhalden und A. Fod or s. S. 204).

Verwandt: je $0,2 \mathrm{~g}$ bei $50^{\circ} \mathrm{C}$. getrockneter Hefe.

Verbraucht an 1/10 n. $\mathrm{H}_{2} \mathrm{SO}_{4}$ (Faktor 0,001401):

1. $13,7 \mathrm{ccm}$, entsprechend $0,0191973 \mathrm{~g} \mathrm{~N}=9,597 \% \mathrm{~N}$;

2. $13,4 \mathrm{ccm} " 0,0187734 \mathrm{~g} \mathrm{~N}=9,387 \% \mathrm{~N}$.

$$
\text { N-Gebalt: } 9,49 \% \text { (arithmetisches Mittel). }
$$

3. A sche: $0,4993 \mathrm{~g}$ Hefe (bei $50^{\circ} \mathrm{C}$. getrocknet) hinterliessen nach vollkommener Veraschung einen Rückstand von 0,0504 g, entsprechend 10,09\% Asche.

4. Phosphorsäure $\left(\mathrm{P}_{2} \mathrm{O}_{5}\right)$ nach $A$. Neumann.

Verwandt: je $0,2 \mathrm{~g}$ bei $50^{\circ} \mathrm{C}$. getrockneter Hefe.

Titration (Faktor 0,001268).

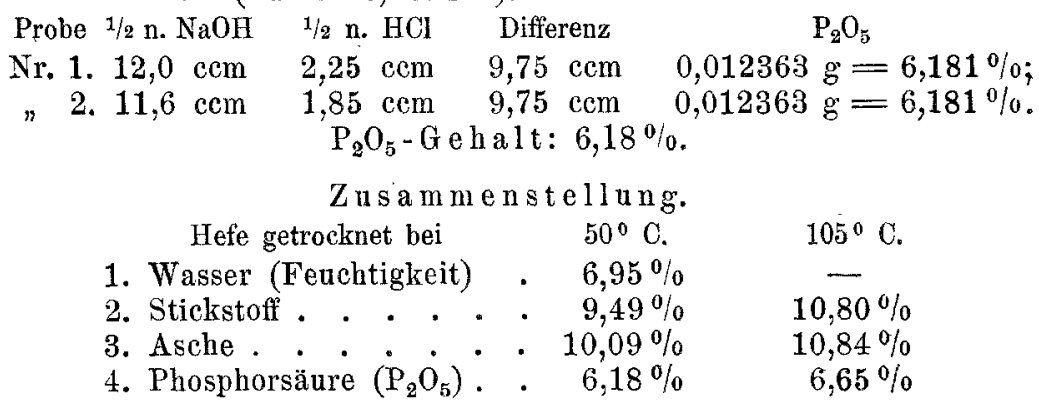


Beitrag zur Kenntnis von organischen Nahrungsstoffen mit spezif. Wirkung. 207

5. Bierhefe Qual. Nr. II.

1. Wasser (Feuchtigkeit): 0,9989 g Hefe verloren beim Trocknen bei $105^{\circ} \mathrm{C}$. bis zur Gewichtskonstanz $0,0536 \mathrm{~g}$, entsprechend $5,37 \%$ Wasser in der lufttrockenen Hefe.

2. Phosphorsäure $\left(\mathrm{P}_{2} \mathrm{O}_{\tilde{5}}\right)$ nach $A$. Neumann.

Verwandt: je $0,2 \mathrm{~g}$ lufttrockener Hefe.

Titration (Falstor 0,001268).

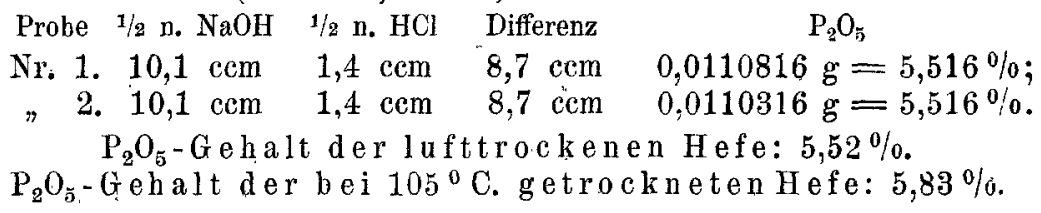

\section{Nukleoproteid aus Hefe.}

\section{A. Durch Zentrifugieren ausgewaschenes Präparat.}

1. Wasser (Feuchtigkeit): $1,0078 \mathrm{~g}$ des lufttrockenen Hefenukleoproteids verloren beim Trocknen bei $105^{\circ} \mathrm{C}$. bis zur Gewichtskonstanz $0,1350 \mathrm{~g}$, entsprechend $13,39 \% \mathrm{~W}$ a s s e $\mathrm{r}$ in dem lufttrockenen Präparat.

2. A s che: 1,0028 g lufttrockenen Nukleoproteids lieferten nach vollkommener Veraschung einen Rückstand von $0,0525 \mathrm{~g}$, entsprechend $5,23 \%$ As che.

3. Phosphorsäure $\left(\mathrm{P}_{2} \mathrm{O}_{5}\right)$ nach A. Neumann.

$0,8728 \mathrm{~g}$ des bei $105^{\circ} \mathrm{C}$. getrockneten Nukleoproteids mit Salpeterschwefelsäure verbrannt. Rückstand mit dest. Wasser auf $100 \mathrm{ccm}$ aufgefüllt.

Verwandt: je 25 ccm vorstehender Lösung, entsprechend $0,2182 \mathrm{~g}$ bei $105^{\circ} \mathrm{C}$. getrockneten Nukleoproteids.

Titration (Faktor 0,001268).

Probe $1 / 2 \mathrm{n} \mathrm{NaOH} \quad 1 / 2 \mathrm{n} \mathrm{HCl}$ Differenz $\quad \mathrm{P}_{2} \mathrm{O}_{5}$

Nr. 1. $10,1 \mathrm{ccm} \quad 4,1 \mathrm{ccm} \quad 6,0 \mathrm{ccm} \quad 0,007608 \mathrm{~g}=3,487 \%$;

"2. $15,1 \mathrm{ccm} \quad 9,2 \mathrm{ccm} \quad 5,9 \mathrm{ccm} \quad 0,0074812 \mathrm{~g}=3,429 \%$.

$\mathrm{P}_{2} \mathrm{O}_{5}-\mathrm{Gehalt}$ des bei $105^{\circ} \mathrm{C}$. getrockneten Hefenukleoproteids: $3,46 \%$, entsprechend $3,00 \%$ in dem lufttrockenen Nukleoproteid.

Zusammenstellung.

Hefenukleoproteid (zentrifugiert) luftrocken bei $105^{\circ} \mathrm{C}$, getrocknet

1. Wasser (Feuchtigkeit) . $13,39 \%$

2. Asche . . . . . $5,23 \%$

3. Phosphorsäure . . . . $3,00 \% \quad 3,46 \%$.

A 1 m. In der Asche war neben Phosphorsäure vor allem Ca nachweisbar.

\section{B. Nach dem Wegelin'schen Verfahren vollkommen ausgewaschenes Nukleoproteid ans Hefe.}

1. Wasser (Fe uchtig k e it): 1,9842 g des lufttrockenen Präparates verloren beim Trocknen bei $105^{\circ} \mathrm{C}$. bis zur Gewichtskonstanz $0,1863 \mathrm{~g}$ entsprechend, $9,39 \%$ W a s s e r. 
2. Stickst off nach Kjeldahl (Mikroverfahren ron E. Abderhalden und A. Fodor s. S. 204).

Verwandt von dem bei $105^{\circ} \mathrm{C}$. getrockneten Nukleoproteid für: Probe Nr. 1: 0,0959 g; Probe Nr. 2:0,0998 g.

Verbraucht an $1 / 10 \mathrm{n}$. $\mathrm{H}_{2} \mathrm{SO}_{4}$ (Faktor 0,001401):

Probe Nr. 1: 9,2 ccm, entsprechend 0,0128892 $\mathrm{g} \mathrm{N}=13,44 \%$;

" $\quad 2: 9,6 \mathrm{~cm} \quad 0,0134496 \mathrm{~g} \mathrm{~N}=13,49 \%$.

$\mathrm{N}-$ Gehalt des bei $105^{\circ} \mathrm{C}$.getrockneten Nukleoproteids (arithmetisches Mittel): $13,46 \%$, des lufttrockenen Präparates: $12,20 \%$.

3. A sche: Nach vollkommener Veraschung hinterliessen an Rückstand: Probe Nr. 1: 1,0061 g lufttrockene Substanz, 0,0205 $\mathrm{g}=2,04 \%$ Asche

$$
\begin{aligned}
& \text { 2: } 0,4956 \mathrm{~g} \\
& \text { A schegehalt:" 2,03\% (arithmetisches Mittel). }
\end{aligned}
$$

4. Phosphorsäure $\left(\mathrm{P}_{2} \mathrm{O}_{\tilde{a}}\right)$ nach $\mathrm{A}$. Neumann.

Verwandt an lufttrockener Substanz: Probe Nr. 1: $0.10 \mathrm{~g}$; Probe Nr. 2: 0,1927 g. Probe Nr. 3: 0,2051 g.

Titration (Faktor 0,001268).

\begin{tabular}{|c|c|c|c|}
\hline Probe $1 / 2 n \mathrm{NaOH}$ & $1 / 2 \mathrm{n} \mathrm{HCl}$ & Differenz & $\mathrm{P}_{2} \mathrm{O}_{5}$ \\
\hline Nr. 1. $15,8 \mathrm{ccm}$ & $12,9 \mathrm{ccm}$ & $2,9 \mathrm{~cm}$ & $0,0036772 \mathrm{~g}=3,677^{\circ}{ }^{\circ}$ \\
\hline $10,1 \mathrm{ccm}$ & $-4,5 \mathrm{ccm}$ & $5,6 \mathrm{ccm}$ & $0,0071008 \mathrm{~g}=3,685^{\circ}$ \\
\hline$" 3.10,5 \mathrm{ccm}$ & $4,2 \mathrm{ccm}$ & $6,3 \mathrm{ccm}$ & $0,0079884 \mathrm{~g}=3,895 \%$ \\
\hline
\end{tabular}
Nukleoproteids: $3,75 \%$.

$\mathrm{P}_{2} \mathrm{O}_{5}$-Gehalt des bei $105^{\circ} \mathrm{C}$. getrockneten Nukleoproteids: $4,14 \%$.

\section{Zusammenstellung.}

Völlig ausgewaschenes Nukleoproteid luftrocken bei $105^{\circ} \mathrm{C}$.getrocknet

1. Wasser (Feuchtigkeit) . . . 9,39\%

2. Stickstoff . . . . . $12,20 \% \quad 13,47 \%$

3. Asche . . . . . . . . 2,03\% 2,24\%

4. Phosphorsäure $\left(\mathrm{P}_{2} \mathrm{O}_{5}\right)$. . . $\quad 3,75 \% \quad 4,14 \%$

A nm.: Der grösste Teil der anwesenden Phosphorsäure war offenbar in organischer Bindung und wurde beim Glühen als $\mathrm{HPO}_{3}$ vergast.

Waschwasser. Die letzten $1000 \mathrm{ccm}$ Waschwasser, welche beim Auswaschen des Nukleoproteids nach dem Wegelin'schen Verfahren durch das Filter durchgetrieben worden waren, wurden bis auf etwa $10 \mathrm{ccm}$ auf dem Wasserbade eingedampft. Dieser Rückstand wurde mit Salpeterschwefelsäure nach $A$. Neumann verascht und weiter behandelt. Das in dem ausgefällten Niederschlag von Ammoniumphosphomolybdat enthaltene $\mathrm{NH}_{3}$ entsprach bei der Titration $3,8 \mathrm{ccm} 1 / 2 \mathrm{n} . \mathrm{HCl}$ (Faktor 0,001268) and demnach $0,00482 \mathrm{~g} \mathrm{P}_{2} \mathrm{O}_{5}$.

7. Nuklein aus Hefe (Rückstand A, s. S. 188).

Das nach dem auf $\mathrm{S}$. 188 beschriebenen Verfahren gewonnene Xuklein ergab bei der quantitativen Untersuchung der nachstehenden Bestandteile folgende Werte: 
Beitrag zur Kenntnis von organischen Nahrungsstoffen mit spezif. Wirkung. 209.

1. Wasser (Feuchtigkeit): 0,2045 g lufttrockener Substanz verloren beim Trocknen bei $105^{\circ} \mathrm{C}$. bis zur Gewichtskonstanz $0,0152 \mathrm{~g}$ $\doteq 7,43 \%$ Wasser.

2. Stickst off (Mikrokjeldahl-Verfahren von E. A b derhalden und A. Fod or's. S. 204).

Verwandt von der lufttrockenen Substanz für Probe Nr. 1: 0,1041 g, für Probe Nr. 2: 0,1024 g.

Bei der Titration verbraucht an $1 / 10$ n. $\mathrm{H}_{2} \mathrm{SO}_{4}$ (Faktor 0,001401).

Probe Nr. 1: $9,0 \mathrm{ccm}$ entsprechend $0,012609 \mathrm{~g} \mathrm{~N}=12,11 \% \mathrm{~N}$;

$" \quad 2: 8,6 \mathrm{ccm} \quad \Rightarrow \quad 0,0120486 \mathrm{~g} \mathrm{~N}=11,77 \% \mathrm{~N}$.

N-Gehalt (arithmetisches Mittel) des lufttrockenen Nukleins: $11,94 \%$.

3. Asche: $0,2045 \mathrm{~g}$ lufttrockener Substanz hinterliessen nach vollkommener Veraschung einen Rückstand von $0,00885 \mathrm{~g}$, entsprechend $4.33 \%$ Asche.

4. Phosphorsäure $\left(\mathrm{P}_{2} \mathrm{O}_{5}\right)$ nach $A$. Neumann.

Verwandt von der lufttrockenen Substanz für Probe Nr. 1: 0,1047 g, für Probe Nr. 2: 0,1030 g.

Titration (Faktor 0,001268).

Probe $1 / 2$ n. NaOH $1 / 2$ n. HCl Differenz $\dot{\mathrm{P}}_{2} \mathrm{O}_{5}$

Nr. 1. $10,25 \mathrm{ccm} \quad 2,0 \mathrm{ccm} \quad 5,25 \mathrm{ccm} \quad 0,0066570 \mathrm{~g}=6,358 \%$;

"2. $10,15 \mathrm{ccm} 5,0 \mathrm{ccm} 5,15 \mathrm{ccm} \quad 0,0065302 \mathrm{~g}=6,340 \%$.

$\mathrm{P}_{2} \mathrm{O}_{5}$-Gehalt der luftrockenen'Sübstanz: 6,3490/0 (arithmetisches Mittel).

\section{$\mathrm{Zus}$ ammenstellung.}

Hefenuklein

1. Wasser (Feuchtigkeit)

2. Stickstoff' . . . .

3. Asche

4. Phosphorsäure $\left(\mathrm{P}_{2} \mathrm{O}_{5}\right)$. . lufttrocken

$$
7,43 \%
$$$$
11,94 \%
$$$$
4,33 \%
$$$$
6,35 \%
$$

bei $105^{\circ}$ C. getrocknet

$$
\begin{gathered}
12,90 \% \\
4,68 \% \\
6,86 \%
\end{gathered}
$$

\section{Durch Verdauung mit Pepsinsalzsäure von dem Hefenukleo- proteíd abgespaltene Eiweisskomponente."}

Bei der Untersuchung dieses nach dem auf S. 189 angegebenen Verfahren gewonnenen Präparates wurden nachstehende Verhältniszahlen gefunder :-

1. Wasser (Feuchtigkeit): Beim Trocknen bei $105^{\circ} \mathrm{C}$. bis zur Gewichtskonstanz verloren von der (bei $37^{\circ} \mathrm{C}$. getrockneten) Substanz:
a) $0,5092 \mathrm{~g}$ Substanz
b) $0,3996 \mathrm{~g}$.
$0,0353 \mathrm{~g}=6,92 \%$ Wasser
$0,0283 \mathrm{~g}=7,08 \%$ " "
Arithmetisches Mittel; 7,00\% Wasser.

2. Stickstoff (Mikrokjeldahl-Verfahren von E. A hiderhalden and A. Fodor. s. S..204).

Verwandt ,von der bei $105^{\circ}$ C. getrockneten Substanz für- jede Bestimmung: 0,18565 $\mathrm{g}$. 
Verbraucht bei der Titration an 1/10 n. $\mathrm{H}_{2} \mathrm{SO}_{4}$ (Faktor 0,001401): Probe Nr. 1: $14,9 \mathrm{ccm}$, entsprechend $0,0208749 \mathrm{~g} \mathrm{~N}=11,24 \% \mathrm{~N}$ " 2: $14,7 \mathrm{~cm}, \quad 0,0205947 \mathrm{~g} \mathrm{~N}=11,09 \% \mathrm{~N}$ Arithmetisches Mittel: $11,16 \% \mathrm{~N}$.

3. Protein: $11,16 \%$ Stickstoff entsprechen $69,75 \%$ Protein (Faktor 6,25) in der bei $105^{\circ}$ C. getrockneten Substanz.

4. Phosphorsäure $\left(\mathrm{P}_{2} \mathrm{O}_{5}\right)$ nach $\mathrm{A}$. Neumann.

Verwandt von der bei $105^{\circ} \mathrm{C}$. getrockneten Substanz für Probe Nr. 1: $0,23695 \mathrm{~g}$, für Probe Nr. 2: 0,16700 g.

Titration (Faktor 0,001268).

\begin{tabular}{rlllll} 
Probe & $1 / 2 \mathrm{n} . \mathrm{NaOH}$ & $1 / 2 \mathrm{n} . \mathrm{HCl}$ & Differenz & \multicolumn{2}{l}{$\mathrm{P}_{2} \mathrm{O}_{5}$} \\
Nr. 1. $5,1 \mathrm{ccm}$ & $4,1 \mathrm{ccm}$ & $1,0 \mathrm{ccm}$ & $0,001268 \mathrm{~g}=0,535 \%$ \\
2. $5,2 \mathrm{ccm}$ & $4,5 \mathrm{ccm}$ & $0,7 \mathrm{ccm}$ & $0,0008876 \mathrm{~g}=0,531 \%$.
\end{tabular}
Substanz.

Arithmetisches Mittel : $0,533^{\circ} \% \mathrm{P}_{2} \mathrm{O}_{5}$ in der bei $105^{\circ} \mathrm{C}$. getrockneten Zusammenstellung.

Abgespaltene Eiweisskomponente, getrocknet bei: $37^{\circ} \mathrm{C} . \quad 105^{\circ} \mathrm{C}$.

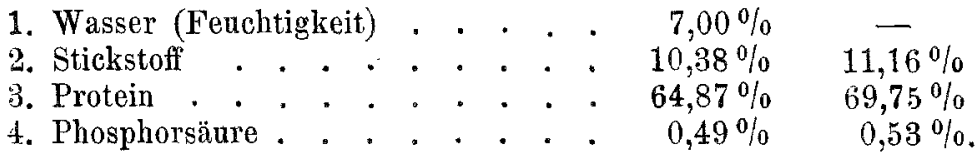

9. Geschliffener Reis (Sorte A, B und C).

Die zur Untersuchung verwandten Proben wurden der Hauptmenge, nach gutem Mischen derselben, entnommen und durch Mahlen und Durchsieben in ein feines Pulver verwandelt, welches in gut verschlossenen Gläsern verwahrt wurde.

\section{Sorte A.}

1. Stickstoff (Mikrokjeldahl-Verfahren von E. Abderhalden und A. Fod or s. S. 204).

Verwandt von lufttrockenem Reismehl für Probe Nr. 1: 0,2981 g, für Probe Nr. 2: 0,3002 g).

Bei der Titration verbraucht an $1 / 10$ n. $\mathrm{H}_{2} \mathrm{SO}_{4}$ für (Faktor 0,001401 ):

Probe Nr. 1: $2,7 \mathrm{ccm}$, entsprechend $0,0037827 \mathrm{~g} \mathrm{~N}=1,27 \% \mathrm{~N}$;

$$
\text { " } \quad 2: 2,7 \mathrm{~cm}, \quad 0,00037827 \mathrm{~g} N=1,26 \% \mathrm{~N} \text {. }
$$

2. Protein: 1,265\% N. entsprechen 7,90\% Protein (Faktor 6,25).

3. Asche: Bei der vollkommenen Veraschung hinterliessen an Rückstand:

1. $0,9945 \mathrm{~g}$ lufttrockenes Reismehl $0,0488 \mathrm{~g}=4,91 \%$ Asche

2. $0,4993 \mathrm{~g} " 0,0246 \mathrm{~g}=5,13 \%$ " Asch" : $5,02 \%$ (arithmetisches Mittel).

4. Phosphorsäure $\left(\mathrm{P}_{2} \mathrm{O}_{5}\right)$ nach $A$. Neumanu.

Verwandt: je $0,5 \mathrm{~g}$ lufttrockenes Reismehl. 
Beitrag zur Kenntnis von organischen Nahrungsstoffen mit spezif. Wirkung. 211

Titration (Faktor 0,001268).

Probe $1 / 2$ n. $\mathrm{NaOH} 1 / 2$ n. $\mathrm{H}_{2} \mathrm{SO}_{4}$ Differenz

Nr. 1. $10,35 \mathrm{ccm} \quad 8,50 \mathrm{ccm} 1,85 \mathrm{ccm} \quad 0,00234580 \mathrm{~g}=0,469 \%$

"2. $10,15 \mathrm{ccm} 8,20 \mathrm{ccm} \quad 1,95 \mathrm{ccm} \quad 0,00247260 \mathrm{~g}=0,494 \%$. $\mathrm{P}_{2} \mathrm{O}_{5}$ - Gehalt: $0,48 \%$ (arithmetisches Mittel).

Zus ammenstellung.

Lufttrockener Reis Sorte A.

1. Stickstoff . . . . . . . . . $1,26 \%$

2. Protein . . . . . . . . 7,90\%

3. Asche . . . . . . . . $5,02 \%$

4. Phosphorsäure $\left(\mathrm{P}_{2} \mathrm{O}_{5}\right)$. . . . $0,48 \%$.

\section{Sorte B.}

1. Stickst off (Mikrokjeldahl-Verfahren von E, A bderhalden und A. Fod or s. S. 204).

Verwandt: je $0,5 \mathrm{~g}$ lufttrockenes Reismehl.

Bei der Titration verbraucht an $1 / 10 \mathrm{n}, \mathrm{H}_{2} \mathrm{SO}_{4}$ (Faktor 0,001401):

Probe Nr. 1: 4,6 ccm, entsprechend 0,0064446 $\mathrm{g}=1,29 \%$;

n $\quad 2: 4,1 \mathrm{ccm}, \quad 0,0057441 \mathrm{~g}=1,15 \%$.

"N-Gehalt: $1,22 \%$ (arithmetisches Mittel).

2. Protein: 1,22\% Stickstoff entsprechen $7,62 \%$ Protein (Faktor 6,25).

3. Asche: Bei der vollkommenen Veraschung hinterliessen an Rückstand:

1. $0,9995 \mathrm{~g}$ lufttrockenes Reismehl $0,0146 \mathrm{~g}=1,46 \%$ Asche;

2. $1,0059 \mathrm{~g}$

Asche: $1,40 \%$ "(arithmetisches Mittel).

4. Phosphorsäure $\left(\mathrm{P}_{2} \mathrm{O}_{5}\right)$ nach A. Neumann.

Verwandt: je $1 \mathrm{~g}$ lufttrockener Reis.

Titration (Faktor 0,001268).

Differenz $\quad \mathrm{P}_{2} \mathrm{O}_{5}$

Nr. 1. $10,15 \mathrm{ccm} \quad 8,00 \mathrm{ccm} \quad 2,15 \mathrm{ccm} \quad 0,0027262 \mathrm{~g}=0,273 \%$;

n. 2. $10,20 \mathrm{ccm} \quad 8,05 \mathrm{ccm} \quad 2,15 \mathrm{ccm} \quad 0,0027262 \mathrm{~g}=0,273 \%$. $\mathrm{P}_{2} \mathrm{O}_{5}-$ Ge halt: $0,25 \%$.

Zusammenstellung.

Lufttrockener Reis Sorte B.

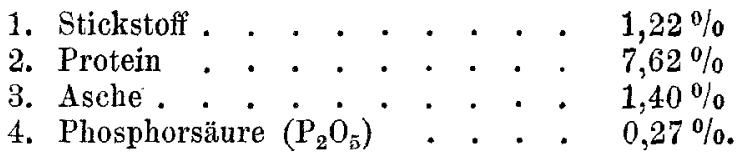

Sorte C.

1. Stickst off (Mikrokjeldahl-Verfahren von E. Abderhalden und A. Fodor s. S. 204).

Verwandt: je $0,5 \mathrm{~g}$ lufttrockenes Reismehl. 
Bei der Titration verbraucht an $1 / 10 \mathrm{n} . \mathrm{H}_{2} \mathrm{SO}_{4}$ (Faktor 0,001401): Probe Nr. 1: $4,3 \mathrm{ccm}$; entsprechend $0,0060243 \mathrm{~g} \mathrm{~N}=1,205 \% \mathrm{~N}$; $\Rightarrow \quad 2: 4,3 \mathrm{~cm}, \quad 0,0060243 \mathrm{~g} \mathrm{~N}=1,205 \% \mathrm{~N}$. $\mathrm{N}-\ddot{G}$ ehalt $1,20 \%$.

2. Protein: $1,205 \%$ Stickstoff entsprechen $7,53 \%$ Protein (Faktor 6,25).

3. A s c he: Bei der vollkommenen Veraschung hinterliessen $1,0016 \mathrm{~g}$ lafttrockenes Reismehl einen Rückstand von $0,0093 \mathrm{~g}=0,93 \%$ A sche.

4. Phosphorsäure $\left(\mathrm{P}_{2} \mathrm{O}_{5}\right)$ nach $\mathrm{A}$. Neumann.

Verwandt: je 1,0 g lufttrockenes Reismehl.

Titrati,on (Faktor 0,001268).

Probe $1 / 2$ n. $\mathrm{NaOH}$ 1/2 n. $\mathrm{HCl}$ Differenz $\mathrm{P}_{2} \mathrm{O}_{5}$

Nr. 1. $10,35 \mathrm{ccm} \quad 8,1 \mathrm{ccm} \quad 2,25 \mathrm{ccm} \quad 0,0028550 \mathrm{~g}=0,285 \%$;

"2. $10,20 \mathrm{ccm} \quad 8,1 \mathrm{ccm} \quad 2,10 \mathrm{ccm} \quad 0,0026628 \mathrm{~g}=0,266 \%$. $\mathrm{P}_{2} \mathrm{O}_{5}$-Gehalt: $0,27 \%$ (arithmetisches Mittel).

Zusammenstellung.

Lufttrockener Reis Sorte C.

1. Stickstoff . . . . . . . . . $1,20 \%$

2. Protein . . . . . . . . . $7,53 \%$

3. Asche . . . . . . . . $0,93 \%$

4. Phosphorsäure $\left(\mathrm{P}_{2} \mathrm{O}_{5}\right)$. . . . $0,27 \%$.

\section{Sojabohnen.}

1. Wasser (Feuchtigkeit): $1,0042 \mathrm{~g}$ feingemahlenc, lufttrockene Sojabiohnen verloren beim Trocknen bei $105^{\circ} \mathrm{C}$. bis zur Gewichtskonstanz $0,0765 \mathrm{~g}$, entsprechend $7,62 \% \mathrm{~W}$ as ser. $\operatorname{mann})$.

2. Phosphorsäure (alkalimetrisches Verfahren nach A. Neu.

Verwandt: je 0,5 g feingemahlene, lufttrockene Sojabohnen.

Titration (Faktor 0,001268).

\begin{tabular}{|c|c|c|c|}
\hline robe $1 / 2 n .1$ & 1/2 n. $\mathrm{HCl}$ & Differenz & $\mathrm{P}_{2} \mathrm{O}_{5}$ \\
\hline Nr. 1. 10,1 & $5,3 \mathrm{ccm}$ & $4,8 \mathrm{ccm}$ & $0,0060864 \mathrm{~g}=1,2$ \\
\hline
\end{tabular}

\section{Präparate aus Sojabohnen.}

A. Salzsaures Extrakt (s. S. 191).

1. W a s s e r ( $\mathrm{Fe} \mathrm{u} \mathrm{ch} \mathrm{t} \mathrm{ig} \mathrm{k} \mathrm{e} \mathrm{it):} 0,9966 \mathrm{~g}$ verloren beim Trocknen bei $105^{\circ} \mathrm{C}$. bis zur Gewichtskonstanz $0,0832 \mathrm{~g}$, entsprechend $8,35 \% \mathrm{~W}$ a s s e r.

2. Asche: $1,0055 \mathrm{~g}$ luftrockenes (bei $37^{\circ} \mathrm{C}$. getrocknetes) Extrakt hinterliessen nach vollkommener Veraschung einen Rückstand von 0,5420; entsprechend einem Aschegehalt:

in dem bei $37^{\circ} \mathrm{C}$. getrockneten Extrakt von $53,90 \%$;

$" \quad " 105^{\circ} \mathrm{C}$. $\quad " \quad 58,81 \%$.

Bei der Bestimmung des Chlorgehalts von $0,5420 \mathrm{~g}$ der Asche nach $\nabla$ olhard wurden verbraucht: $55,5 \mathrm{ccm} 1 / 10 \mathrm{n} . \mathrm{AgNO}_{3}-\mathrm{L}$ Lösung, 
Beitrag zur Kenntris von organischen Nahrungsstoffen mit spezif. Wirkung. 213

entsprechend $0,196803 \mathrm{~g}$ Chlor $=26,31 \%$ und $0,324453 \mathrm{~g} \cdot \mathrm{NaCl}$ $=59,86 \% \mathrm{NaCl}$ in der Asche.

In dem salzsauren Extrakt bei $37^{\circ} \mathrm{C}$. getrocknet bei $105^{\circ} \mathrm{C}$. getrocknet

Asche insgesamt . . $\quad 53,90 \% \quad 58,81 \%$

Chlornatrium $\cdot \cdots \cdot \cdot \frac{32,27 \%}{21,63 \%} \quad \frac{35,12 \%}{23,60 \%}$

3. Phosphorsäure $\left(\mathrm{P}_{2} \mathrm{O}_{5}\right)$ : Alkalimetrisches Verfahren nach A. Neumann.

Verwandt: je $0,5 \mathrm{~g}$ des bei $37^{\circ} \mathrm{C}$. getrockneten Extrakts.

Titration (Faktor 0,001268).

Probe $1 / 2 \mathrm{n} . \mathrm{NaOH} \quad 1 / 2 \mathrm{n}$. HCl Differenz $\mathrm{P}_{2} \mathrm{O}_{5}$

Nr. 1. $10,4 \mathrm{ccm} \quad 4,8 \mathrm{ccm} \quad 5,6 \mathrm{ccm} \quad 0,0071008 \mathrm{~g}=1,420 \%$;

» 2. $10,6 \mathrm{ccm} \quad 5,3 \mathrm{ccm} \quad 5,3 \mathrm{ccm} \quad 0,0067204 \mathrm{~g}=1,344 \%$. Arithmetisches Mittel: $1,38 \%$.

$\mathrm{P}_{2} \mathrm{O}_{5}$-Gehalt in dem bei $37^{\circ} \mathrm{C}$. getrockneten Extrakt: $1,38 \%$;

$\mathrm{P}_{2} \mathrm{O}_{5^{-}} \quad " \quad n \quad " 105^{\circ} \mathrm{C}$. $\quad " \quad 1,51 \%$.

B. Pepsinsalzsäureextrakt (s. S. 192).

1. Wassex (Feuchtigkeit): $0,4976 \mathrm{~g}$ des bei $37^{\circ} \mathrm{C}$. getrockneten Extrakts verloren bei weiterem Trocknen bei $105^{\circ} \mathrm{C}$. bis zur Gewichtskonstanz 0,0394 $\mathrm{g}$, entsprechend $7,92 \%$ W a s e r.

2. Asche: 0,4968 g bei $37^{\circ} \mathrm{C}$. getrockneten Extrakts hinterliessen nach vollkommener Veraschung einen Rückstand von $0,0522 \mathrm{~g}$, entsprechend einem Aschegehalt:

in dem bei $37^{\circ} \mathrm{C}$. getrockneten Extrakt von 10,51\%;

$$
105^{\circ} \mathrm{C} \text {. " " } " 11,41 \% \text {. }
$$

Bei "der "Chlorbestimmung nach Volhar"d wurden verbraucht für die salpetersaure Lösung von $0,0522 \mathrm{~g}$ Asche $4,4 \mathrm{ccm} 1 / 10 \mathrm{n}$. AgNO Lösung, entsprechend $0,0156024 \mathrm{~g} \mathrm{Cl}$ und $0,0257724 \mathrm{~g} \mathrm{NaCl}$.

In dem Pepsinsalzsäureextrakt bei $37^{\circ} \mathrm{C}$. getrocknet bei $105^{\circ} \mathrm{C}$. getrocknet Asche (insgesamt) . . 10,51\% 11,41\% Chlornatrium . . . . $\quad 5,19 \% \quad 5,64 \%$

Asche ohne $\mathrm{NaCl}$. . . $5,32 \% \quad 5,77 \%$.

3. Phosphorsäure $\left(\mathrm{P}_{2} \mathrm{O}_{5}\right)$ : Alkalimetrische Methode nach A. Neumann.

Verwandt: je 0,5 g des bei $37^{\circ} \mathrm{C}$. getrockneten Extrakts.

Titration (Faktor 0,001268).

Probe $1 / 2 \mathrm{n}$. NaOH $1 / 2 \mathrm{n}$. $\mathrm{HCl}$ Differenz $\mathrm{P}_{2} \mathrm{O}_{5}$

Nr. 1. $10,7 \mathrm{ccm} \quad 8,1 \mathrm{ccm} \quad 2,6 \mathrm{ccm} \quad 0,0032968 \mathrm{~g}=0,659 \%$;

"2. $10,2 \mathrm{ccm} \quad 7,6 \mathrm{ccm} \quad 2,6 \mathrm{ccm} \quad 0,0032968 \mathrm{~g}=0,659 \%$.

$\mathrm{P}_{2} \mathrm{O}_{5}$-Gehalt des bei $37^{\circ} \mathrm{C}$. getrockneten Extrakts: 0,66\%;

$\mathrm{P}_{2} \mathrm{O}_{5^{-}} " \quad$ " $105^{\circ} \mathrm{C}$. $" 0,72 \%$.

C. Rückstand des nacheinander mit Aceton, Alkohol, Salzsäure und Pepsinsalzsäure ausgezogenen, dann bei $37^{\circ} C$. getrockneten Sojabohnenmehls (s. S. 192).

1. Wasser (Feuchtigkeit): $0,9993 \mathrm{~g}$ des bei $37^{\circ} \mathrm{C}$. getrockneten Rückstandes verloren bei weiterem. Trocknen bis zur Gewichtskonstanz bei $105^{\circ}$ C. $0,0776 \mathrm{~g}$, entsprechend $7,77 \%$ Wasser. 
2. Asche: $1,0024 \mathrm{~g}$ des Rückstandes hinterliessen nach vollkommener Veraschung $0,0209 \mathrm{~g}$ Asche, entsprechend:

Asche in dem bei $37^{\circ} \mathrm{C}$, getrockneten Rückstande, 2,08\%;
$" n " \quad 105^{\circ} \mathrm{C}$.
"
$2,26 \%$.

3. Phosphorsäure $\left(\mathrm{P}_{2} \mathrm{O}_{5}\right)$ : Alkalimetrisches Verfahren nach A. Neumann.

Verwandt: je $1 \mathrm{~g}$ des bei $37^{\circ} \mathrm{C}$. getrockneten Rückstandes.

Titration (Faktor: 0,001268).
Probe $1 / 2$ n. NaOH
$1 / 2 \mathrm{n} . \mathrm{HCl}$
Differenz
$\mathrm{P}_{2} \mathrm{O}_{5}$
Nr. 1. $10,5 \mathrm{ccm} \quad 3,95 \mathrm{ccm} \quad 6,55 \mathrm{ccm} \quad 0,00830540 \mathrm{~g}=0,830 \%$
\#2. $10,9 \mathrm{ccm} \quad 3,20 \mathrm{ccm} \quad 7,70 \mathrm{ccm} \quad 0,0097636 \mathrm{~g}=0,976 \%$.
Arithmetisches Mittel : 0,$90 ; \%$.

$\mathrm{P}_{2} \mathrm{O}_{5}$-Gehalt des bei $37^{\circ} \mathrm{C}$. getrockneten Rückstandes, $0,903 \%$;

$$
\mathrm{P}_{2} \mathrm{O}_{5^{-}} " \text { " } " 105^{\circ} \mathrm{C} \text {. } \quad \text { " }
$$

Zusammenstellung.

Gehalt der bei $105^{\circ} \mathrm{C}$, getrockneten Sojabohnenpräparate an:

Salzsaures Extrakt Pepsinsalzsäureextrakt Rückstand

Asche (einschliesslich $\mathrm{NaCl}$ ) $\mathbf{5 8 , 8 1 \%}$

Asche (ausschliesslich $\mathrm{NaCl}$ ) $23,60 \%$

$11,41 \%$

$5,77 \%$ $2,26 \%$

Phosphorsäure . . . $1,51 \%$

$0,72 \%$

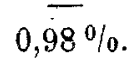

D. Alkoholisches Extrakt (Phosphadit-Fraktion s. S. 191).

Phosphorsäurebestimmung (nach A. Neumann). Substanz.

Verwandt: je $0,1585 \mathrm{~g}$ der über $\mathrm{H}_{2} \mathrm{SO}_{4}$ im Exsikkator getrockneten

Titration (Faktor 0,001268).

$\begin{array}{ccccc}\text { Probe } & 1 / 2 \mathrm{n} . \mathrm{NaOH} & 1 / 2 \mathrm{n} . \mathrm{HCl} & \text { Differenz } & \mathrm{P}_{2} \mathrm{O}_{5} \\ \text { Nr. 1. } 10,1 \mathrm{ccm} & 8,05 \mathrm{ccm} & 2,05 \mathrm{ccm} & 0,0025994 \mathrm{~g}=1,64 \% \\ \text { 2. } 10,4 \mathrm{ccm} & 8,60 \mathrm{ccm} & 1,80 \mathrm{~cm} & 0,0022804 \mathrm{~g}=1,44 \% \\ \text { Arithmetisches } & \text { Mittel : } 1,54 \% & \mathrm{P}_{2} \mathrm{O}_{5} .\end{array}$

\section{Darstellung von Abbauprodukten aus hydrolysierter Hefe sowie deren chemische und physiologisehe Untersuchung.}

$24 \mathrm{~kg}$ bei mässiger Temperatur getrockneter Bierhefe ${ }^{1}$ ) mit einem Wassergehalt von $5,37 \%$ und einem $\mathrm{P}_{2} \mathrm{O}_{5}$-Gehalt von $5,52 \%$ (Analysen S. 207) wurden in Portionen von 5 bzw. $4 \mathrm{~kg}$ mit der vierfachen Menge (je $20 \mathrm{bzw} .16 \mathrm{l}) 5 \%$ Schwefolsäure (5 Raumteile konzentrierter reiner $\mathrm{H}_{2} \mathrm{SO}_{4}$ auf 100 Raumteile Leitungswasser) 20-24 Stunden lang in einem emaillierten Topfe im lebhaften Sieden erhalten. Das abgedampfte Wasser wurde hierbei in nicht zu langen Zwischenräumen wieder zugesetzt. Es entstand hierbei eine trübe, dunkelgefärbte Flüssigkeit, welche keine gröberen festen Teilchen mehr enthielt. Nach dem

1) Die Bierhefe war vorher bei mehreren Versuchen an Tauben, die an typischer alimentärer Neuropathie erkrankt waren, versucht worden und hatte sich hierbei als sehr wirksam erwiesen. 
Beitrag zur Kenntnis von organischen Nahrungsstoffen mit spezif. Wirlung. 215

Erkalten wuxde die Flüssigkeit mit einer aus roliem gebranntem Kalk hergestellten, vorher durch ein Drahtsieb durchgeseihten Kalkmilch so lange versetzt, bis Kongopapier durch eine herausgeschöpfte und filtrierte Probe nur noch schwach blau gefärbt wurde. Es empfiehlt sich, die Kalkmilch, wenn die Hauptmenge der Schwefelsäure abgesättigt ist, in kleineren Portionen und längeren Zeitintervallen zuzusetzen, um sicher zu sein, dass eine alkalische Reaktion der Flüssigkeit niemals eintritt: Die Mischung wurde dann unter öfterem Prüfen der Reaktion, die gegen Lakmuspapier ansgesprochen, sauer bleiben muss, etwà 20 Stunden lang der. Ruhe überlassen. Der flüssige Anteil wurde nunmehr von dem Bodensatz durch vorsichtiges Dekantieren und Abnutschen getrennt. Die Rückstände von jeder Portion ( $5 \mathrm{~kg}$ Hefe entsprechend) wurden durch Übergiessen mit je 10 l Leitungswasser und Umrühren ausgewaschen und das Waschwasser durch Dekantieren und Abnutschen wiederum von dem festen Rückstande getrennt. 'Die gesamte Flüssigkeit wurde dann in langen viereckigen, innen mit Ölfarbe gestrichenen Schalen aus Zinkblech auf der Dampfheizung bei etwa $30-40^{\circ}$ C. bis zur dicken Sirupkonsistenz eingedampft. Der braune, sehr dickflüssige Rückstand wurde in angemessenen Portionen in einer grossen Reibschale mit gebranntem, gut bindendem Gipsmehl innig gemischt. Diese Mischung wurde in kleinen Klümpchen' auf Tischen, die mit Gipsmehl bestreut waren, zunächst bei Zimmertemperatur mehrere Tage lang getrocknet, dann zerkleinert tind auf Hürden bei $37^{\circ} \mathrm{C}$. so lange getrocknet, bis sie sich ohne Schwierigkeit in einem Mörser stossen liessen, ohne an dessen Wandungen festzukleben. Das so gewonnene grobe Pulver wurde nochmals bei $50^{\circ} \mathrm{C}$. getrocknet and dann durch Mahlen und Sieben in ein feines Pulver verwandelt, welches durch längeres Liegenlassen in gut schliessenden; bis zur Hälfte mit gutgebranntem Ätzkalk gefüllten Blechgefässen vollends getrocknet wurde. Das' so gewonnene Pulver wurde nun durch inniges Mischen mit absolntem Alkohol des. Handels gut durchfeuchtet, in grosse Blechperkolatoren gebracht und mit $97 \%$ igem Alkohol so lange ausgezogen, bis der abtropfende Auszug nur noch schwach gelb gefärbt war.

Das alkoholische Extrakt wurde nunmehr in grossen Destillierkolben unter vermindertem Druck bis zur Sirupkonsistenz eingedampft. Der dickflüssige braune Rückstand wurde mit $10 \%$ seines Volumens an $25 \%$ iger Salzsäure und dann so lange mit Aceton versetzt, bis keine Fällung mehr erfolgte. Der Niederschlag, welcher sich nach kurzer Zeit fest zusammenballte und an den Wandungen der Flaschen, welche zur Fällung benutzt worden waren, fest haftete, wurde durch Dekantieren der Acetonlösung getrennt. Es wurden auf diese Weise zunächst zwei Fraktionen erhalten:

1. Primärer Acetonniederschlag;

2. Acetonlöslicher Anteil des primären alkoholischen Extrakts.

Der primäre Acetonniederschlag wurde zunächst durch Durchsaugen von Luft durch das zur Fällung verwandte Gefäss von anhaftendem Aceton völlig befreit, hierauf mit 21 absoluten Alkohols des 
Handels übergossen und mit diesem unter häufigen Rühren und Lmschütteln in Beziehung gelassen. Nach etwà 12 Stunden wurde die alkoholische Lösung von dem ungelösten Rückstande dekantiert und filtriert und letztere nochmals mit absolutem Alkohol ausgezogen. Die alkoholischen Auszüge wurden vereinigt, im Vakuum bei $35^{\circ} \mathrm{C}$. bis zur Sirupkonsistenz eingedampft und der Rückstand nochmals so lange mit Aceton versetzt, bis keine Fällong mehr erfolgte. Der so erhaltene sekundäre Acetonniederschlag wurde noeh einmal wieder in absolutem Alkohol gelöst und die Lösung genau so, wie vorstehend angegeben, weiterbehandelt. Es érgaben sich aus diesem. Verfahren drei verschiedene Fraktionen, nämlich :

I. Tertiärer Acetonniederschlag (S. 216). Tierversuche (S. 255 u. ffi.);

II. In absolutem Alkohol des Handels (99\%) unlöslicher Anteil des primären und sekundären A'cetonniederschlages (S. 232);

III. In Aceton löslicher Anteil des primären alkoholisehen Extrakts aus hydrolysierter Hefe (S. 235).

\section{Tertiärer Acetonniederschlag ${ }^{1}$ ).}

Der tertiäre Acetonniederschlag wurde in etwa 11 absoluten Alkohols des Handels gelöst und mit Quecksilberchlorid in einer Reibschale verrieben, bis die Lösung ziemlich gesättigt war und weitere Zusätze von $\mathrm{HgCl}_{2}$ keine Fällung mehr hervorriefen. Der $\mathrm{Nieder-}$ schlag I A wurde nun von der Lösung I B 1 (S. 224) durch Abnutschen und Auswaschen mit etwas absolutem Alkohol getrennt.

Niederschlag I A wurde in einer Reibschale mit dest. Wasser gut verrieben und anfgeschwemmt, dann auf $50^{\circ} \mathrm{C}$. erwärmt und durch Einleiten von Schwefelwasserstoff zerlegt. Der HgS-Niederschlag wurde abgenutscht und zuerst mit kaltem, dann mit warmem dest. Wasser gut ausgewaschen. Filtrat und Waschwasser wurden durch Durchsaugen von Luft von $\mathrm{H}_{2} \mathrm{~S}$ befreit und im Vakuum bei $37^{\circ} \mathrm{C}$. eingedampft. Der Rückstand wurde, um die Salzsäure möglichst zu verjagen, wiederholt mit absolatem Alkohol aufgenommen und letzterer im Vakuum bei $37^{\circ} \mathrm{C}$. wieder abgedampft. Es hinterblieb ein gelb gefärbter, in der Hauptsache kristallinischer Rückstand, der mehrere Tage lang in einem mit gut gebranntem Ätzkalk und Natronkalk beschickten Valkuumexsikkator belassen wurde.

Ein Teil dieses Rückstandes wurde zu den auf S. 255 u. ff. beschriebenen Tierversuchen, bei denen er sich als sehr. wirksam erwies, verwandt.

Der über Ätzkalk getrocknete und von Salzsäure möglichst befreite Rückstand wurde in einer Reibschale mit $99 . \%$ igem Alkohol zerrieben. Er war in diesem nur zum Teil löslich. Der unlösliche Rückstand I R 1 (S. 255) wurde von der gelblich gefärbten alkoholischen Lösung durch Abnutschen und Auswaschen mit 99\% igem Alkohol getrennt. Filtrat und Waschflüssigkeit wurden zunächst bis auf etra

1) Verzeichnis sämtlicher Präparate nebst Seitenangabe S. 271. 
Beitrag zur Kenntnis yon organischen Nahrungsstoffen' mit spezif. Wirkung. 217

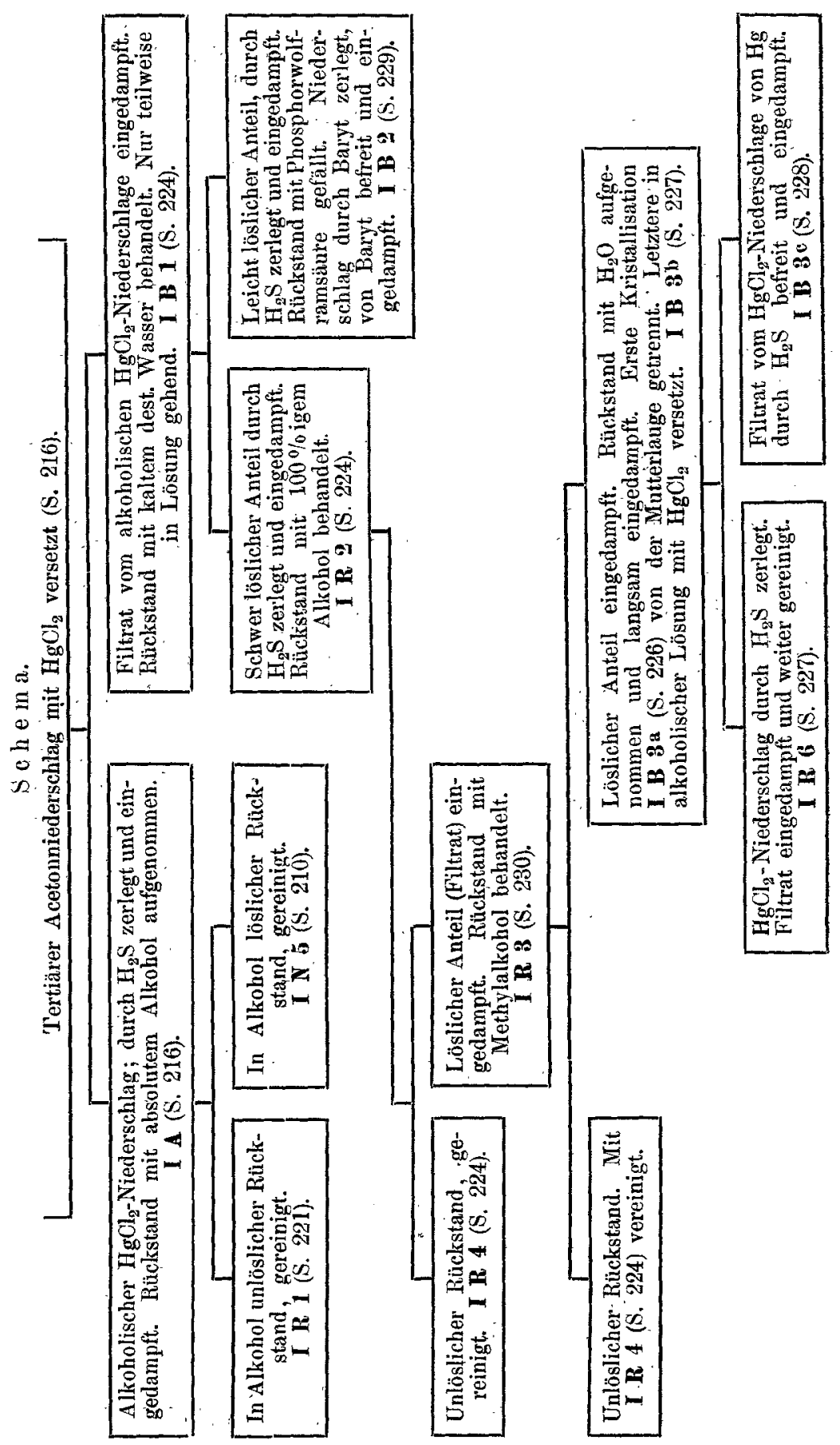


$250 \mathrm{ccm}$ im Vakuum bei $37 \% \mathrm{C}$. eingedampft, dann wiederum durch Verreiben mit Quecksilberchlorid gesăttigt. Der hierbei entstandene sekundäre $\mathrm{HgCl}_{2}$-Niederschlag I A 1 wurde abgenutscht and genau in derselben Weise zerlegt and weiterbehandelt, wie dies bei I A vorstehend angegeben ist. Der nach Eindampfen der Lösung erhaltene Rückstand wurde mehrere Tage lang im Vakuumexsikkator über Schwefelsäure und neben einem Schälchen mit konzentrierter Natronlauge getrocknet. $\mathrm{Lr}$ bildete eine gelbliche, in der Hauptsache kristallinische, klebrige Substanz, die sehr hygroskopisch war und mit Folin's Reagens einen starken weissen Niederschlag gab, der im Überschusse von Natriumkarbonatlösung mit blauer Farbe löslich war. Eine kleine Menge auf einem Objektträger mit einem Tropfen $1 \%$ iger Schwefelsäure versetzt und langsam eingedampft, lieferte gutausgebildete mikroskopische Nadeln (Tierversuch s. S. 256).

Das alkoholische Filtrat von I A 1 wurde mit $I R I$ (S. 223) vereinigt. Der getrocknete Rückstand, der durch Zerlegung von I A 1 gewonnen war, wurde nun mit 100\% igem Alkohol (durch Entwässern von absolutem Alkohol des Handels zuerst mit Ätzkalk, dann mit wasserfreiem $\mathrm{CaSO}_{4}$ und anschliessendes Abdestillieren gewonnen) in einer Reibschale gut verrieben. Es hinterblieb hierbei ein sehr geringer $\mathrm{R} u ̈ \mathbf{c k}$ stand I R 3 (S. 230), der durch Abfiltrieren von deralkoholisehen Lösung I A 2 getrennt wurde. Letztere wurde bei $37^{\circ} \mathrm{C}$. im Vakuum möglichst weit eingedampft, der Rückstand dann mit $50 \%$ igem Alkohol aufgenommen und diese Lösung langsam bei $37^{\circ} \mathrm{C}$. eingedampft. . Der so gewonnene Rückstand wurde im Vakuumexsikkator über Schwefelsäure und neben einem Schälchen mit starker Natronlauge getrocknet, dann mit reinem Methylalkohol aufgenommen. Die Lösung warde filtriert und das Filtrat nochmals bei $37^{\circ}$ C. eingedampft (Tierversuch mit 1 A 2 S. 258). Der Rückstand wurde wiederum mit 100\% igem Alkohol aufgenommen und unter Zusatz einer geringen Menge Tierkohle filtriert. Das Filtrat wurde noclmals mit Quecksilberchlorid gesättigt, der $\mathrm{HgCl}_{2}$-Niederschlag abgenutscht, mit wenig $100 \%$ igem Alkohol ausgewaschen, dann durch Einleiten von Schwefelwasserstoff zerlegt. Filtrat und Waschwasser vom HgS-Niederschlage wurden durch Durchsaugen von Luft von $\mathrm{H}_{2} \mathrm{~S}$ befreit und im Vakuum bei $37^{\circ} \mathrm{C}$. möglichst weit eingedampft. Der Rückstand wurde- wiederholt mit Alkohol aufgenommen nnd letzterer im Vakuum bei $37^{\circ} \mathrm{C}$. wieder eingedampft. Es hinterblieb ein gelber, kristallinischer, sehr hygroskopischer und ziemlich klebriger Rü $\mathrm{ck}$ stand I N 5 , der über Schwefelsäure und neben einer Schale mit NaOH 14 Tage lang im Vakuumexsikkator belassen wurde.

\section{Präparat I N ó.}

Das auf die vorstehend angegebene Weise gewonnene Präparat bildete eine gelblich-braune kristallinische, sehr hygroskopische und ziemlich klebrige Substanz, die in Alkohol und Wasser leicht, in Äther, Aceton und Essigäther nicht löslich war. Wurde der Körper in 100\% igem Alkohol gelöst und diese Lösung filtriert, so dass sie anfangs vollkommen klar war, so trülte sie sich nach wenigen Stunden. Diese Trübung nahm ständig zu, und nach einigen Tagen setzte sich ein kristallinischer 
Beitrag zur Kenntnis von organischen Nahrungsstoffen mit spezif, Wirkung. 219

Niederschlag $a b$, über dessen Untersuchung sich auf S. 221 weitere Angaben finden.

Mikroskopische Untersuchung des Präparats I N 5.

1. Eine kleine Menge des Präparats I N 5 (Chlorhydrat) auf einen Objekträger ìl dest. Wasser gelöst, dann im Exsikkator über $\mathrm{H}_{2} \mathrm{SO}_{4}$ langsam eingedampft, hinterliess einen aus sehr feinen Nädelehen bestehenden Rückstand.

2. Beim Auflösen einer geringen Menge in einem Tropfen $1 \%$ iger Schwefelsäure und nach langsamem Eindampfen dieser Lösung bei $37^{\circ} \mathrm{C}$. hinterblieb ein Rückstand, der aus langen stäbchenförmigen, oft zu Drusen vereinigten Kristallen oder seltener aus büschelförmig angeordneten Nädelchen bestand (Mikrophotographien Nr. 38 a. 39). Im polarisierten Licht bei gekreuzten Nisols zeigten die stäbchenförmigen Kristalle (Prismen) die auf dem Lichtbilde Nr. 40 wiedergegebenen Verdunkelungen an beiden Enden und in entgegengesetztem Sinne.

3. Löste man eine kleine Menge von $I N 5$ in sehr verdünnter Phosphorsäure, erwärmte den Objektträger schwach auf der Flamme und dampfte die Lösung dann im Exsikkator ein, sso erhielt man die auf dem Lichtbilde $\mathbf{N r}, 41$ dargestellten Kristalle. Ihre Bildung erfolgte nur unter geeigneten Bedingungen, die vorzüglich durch die richtige Menge der zugesetzten Phosphorsäure sowie durch das langsamere bzw. schnellere Eindampfen gegeben zu sein scheinen.

4. Die Lösung einer kleinen Menge des Präparats in einem Tröpfchen dest. Wassers gab mit Jodjodkaliumlösung einen braunen, aus kugelfôrmigen Gebilden bestehenden Niederschlag. Bei mehreren derartigen Versuchen wurde die Bildung eines $\mathrm{kr}$ istallis ierenden Perjodids nicht beobachtet.

5. Eine kleine Menge des Platindoppelsalzes (s. S. 220) in dest. Wasser auf einem Objektträger gelöst, dann wieder langsam eingedampft, ergab die auf der Mikrophotographie Nr. 42 wiedergegebenen Kristalle.

\section{Chemische Untersuchung von I N 5 .}

1. Reaktion der wässerigen Lösung: Saner.

2. Auf dem Platinblech erhitzt: Schmilzt schon bei gelindem Erwärmen unter Braunfärbung und Gasentwicklung. Bei stärkerem Erhitzen verbrennt die Substanz unter Entwicklung von Dämpfen, die nach Propylamin riechen, und unter Hinterlassung einer Spur Asche.

3. Mit Natronkalk gemiseht und im Glas röhrchen erhitzt: Entwicklung von Dämpfen, die nach Propylamin riechen und feuchtes, rotes Lakmuspapier blau färben.

4. Mit Natronlauge erwärmt: Entwicklung von Dämpfen, die feuchtes, rotes Lakmuspapier blau färben.

5. Reaktionen der wässerigen Lösung mit:

a) Silbernitrat: Weisser Niederschlag, in Salpetersäure unlöslich, in überschüssigem Ammoniak löslich:

b) Folin's Reagens: Weisser Niederschlag, der sich in ïberschüssiger Natriumkarbonatlôsung mit blauer Farbe löst. 
c) Phosphorwolframsäure: Starker weisser Niederschlag.

d) Quecksilberchlorid (gesättigte alkoholische Lösung): Starker, weisser Niederschlag.

e) Quecksilbersulfat (in saurer Lösung): Weisse Fällung.

f) Millon's Reagens: Kein Niederschlag, keine Färbung beim Kochen.

g) Nessler's Reagens: Starker, hellgelber Niederschlag.

h) Jodjodkaliumlös ung: Brauner Niederschlag.

i) Cadmiumehlorid: Keine Fällung.

k) Diazobenzolsulfosäure: Orangefärbung in der mit $\mathrm{Na}_{2} \mathrm{CO}_{3}$ übersättigten Lösung.

l) Ninhydrinlösung 1\% (Kochprobe): Starke Blaufärbung.

m) Basisches Bleiacetat: Keine Fällung.

Platinchloriddoppelsalz. Eine kleine Menge des Präparats (etwa $0,2 \mathrm{~g}$ ) wurde mit $10 \%$ iger Platinchloridlösung versetzt und bei $37^{\circ}$ C. langsam eingedampft. Der Rückstand wurde mit absolutem Alkohol aufgenommen, auf einem Filterchen gesammelt, mit absolutem Alkohol ausgewaschen, bis dieser farblos ablief, sodann in dest. Wasser gêlöst und langsam eingedampft. $\mathrm{E}_{\mathrm{s}}$ schieden sich gelbe Nädelchen aus; die im Vakuumexsikkator über $\mathrm{H}_{2} \mathrm{SO}_{4}$ und neben einem Schälchen mit $\mathrm{NaOH}$ getrocknet wurden. Schmelzpunkt (unk.): $145^{\circ}$ C. unter Zersetzung.

Elementaranalyse

(Chlorhydrat und $\mathrm{PtCl}_{4}$-Doppelsalz).

Substanz: I N 5:

1. PtCl $_{4}-$ Salz: Mikroskopisch.

a) $6,501 \mathrm{mg}: 1,845 \mathrm{mg}$ Rückstand $=\mathrm{Pt}=28,38 \% \mathrm{Pt}$. $5,045 \mathrm{mg} \mathrm{CO}_{2}: 2,64 \mathrm{mg} \mathrm{H}_{2} \mathrm{O}=\mathbf{2 1 , 1 6 \%} \mathrm{C}, 4,54 \% \mathrm{H}$.

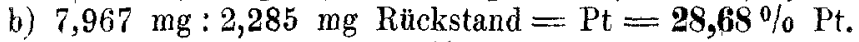
$11,00 \mathrm{mg} \mathrm{AgCl}=\mathbf{3 4 , 1 6 \%} \mathrm{Cl}$.

c) $5,935 \mathrm{mg}\left(729 \mathrm{~mm}, 14^{\circ}\right.$ C. $): 0,312 \mathrm{~cm} \mathrm{~N}=6,00 \% \mathrm{~N}$.

a) $5,195 \mathrm{mg}: 1,478 \mathrm{mg} \mathrm{Pt}=\mathbf{2 8 , 4 5} \% \mathrm{Pt}$. $3,99 \mathrm{mg} \mathrm{CO}+2,04 \mathrm{mg} \mathrm{H} \mathrm{H}_{2} \mathrm{O}=\mathbf{2 0 , 9 5} \% \mathrm{C}+\mathbf{4 , 4 0} \% \mathrm{H}$.

b) $5,452 \mathrm{mg}+1,490 \mathrm{mg} \mathrm{Pt}=\mathbf{2 7 , 3 3} \% \mathrm{Pt}$. $7,485 \mathrm{mg} \mathrm{AgCl}=\mathbf{3 3 , 9 6} \% \mathrm{Cl}$.

2. N 5 : HOl-Salz: äusserst hygroskopisch und aschehaltig:

$4,278 \mathrm{mg}: 0,186 \mathrm{mg}$ Asche (Glührückstand) $=4,35 \%$ Asche.

$6,005 \mathrm{mg} \mathrm{CO}: 3,07 \mathrm{mg} \mathrm{H}_{2} \mathrm{O}=\mathbf{4 0 , 0 2} \% \mathrm{C} ; \mathbf{8 , 4 0 \%} \mathrm{H}$ (berechnet auf aschefreie Substanz).

$5,225 \mathrm{mg}: 0,100 \mathrm{mg}$ Asche (etwas Ascheverlust durch Spritzen der Substanz beim Verbrennen).

$5,640 \mathrm{mg} \mathrm{AgCl}=\mathbf{2 6}, \mathbf{7 3} \% \mathrm{Cl}$.

$1,804 \mathrm{mg}$ (733 mm, $14^{\circ} \mathrm{C}$.) $0,170 \mathrm{ccm} \mathrm{N}=\mathbf{1 1 , 3 0 \%} \mathrm{N}$.

$4,105 \mathrm{mg}: 0,13 \mathrm{mg}$ Asche $=3,17 \%$ Asche.

$4,31 \mathrm{mg} \mathrm{AgCl}=\mathbf{2 5 , 9 7} \% \mathrm{Cl}$ (berechnet auf aschehaltige Substanz).

$5,710 \mathrm{mg}$ ergaben beim Veraschen und starken Glühen im Platintiegel $0,114 \mathrm{mg}$ Rückstand $=\mathbf{2 , 0 0} \%$ Asche. 
Beitrag zur Kenntnis von organischen Nahrungsstoffen mit spezif. Wirkung. 221

$5,088 \mathrm{mg}: 0,131 \mathrm{mg}$ Asche $=\mathbf{2}, \mathbf{5 8} \%$ Asche.

$7,26 \mathrm{mg} \mathrm{CO}$ and $3,90 \mathrm{mg} \mathrm{H}_{2} \mathrm{O}=\mathbf{3 8 , 9 2} \% \mathrm{C}, \mathbf{8 , 5 8} \% \mathrm{H}, 3,640 \mathrm{mg}$ (734 $\mathrm{mm} 17^{\circ}$ C.) $0,343 \mathrm{ccm} \mathrm{N}=10,71^{\circ} / 0 \mathrm{~N}$, berechnet auf aschehaltige Substanz.

Untersuchung des weissen Niederschlages, welcher sich aus einer Lösung von 1 N 5 in 100\% igem Alkohol bei längerem Stehenlassen ausschied. Die kleine zur Verfügung stehende Menge des Niederschlages wurde auf einem Filterchen gesammelt und mit $100 \%$ igem Alkohol gut ausgewaschen, dann in wenig dest. Wasser gelöst. Die weitere Untersuchung musste in Anbetracht der geringfügigen Menge auf nachstehende mikrochemische Reaktionen beschränkt werden :

1. Ein Tropfen der Lösung wurde auf einem Objektträger langsam eingedampft.' Die zurückbleibenden Kristalle zeigten die grösste Ähnlichkeit mit denen von I R 1 (Betainchlorhydrat s. S. 237).

2. Eine kleine Menge der wässerigen Lösung wurde in einem Uhrschälchen langsam eingedampft, der Rückstand mit schwacher alkoholischer Natronlange neutralisiert, filtriert und alkoholische Pikrinsäurelösung zugesetzt. Es entstand sofort ein starker Niederschlag, der mit absolutem Alkohol ausgewaschen, in dest. Wasser gelöst und dann wieder eingedampft wurde. Es hinterblieben gelbe, in Alkohol schwer lösliche lange Nadeln, die denen von Betainpikrat durchaus glichen (Mikrophotographien Nr. 43 a. 44).

3. Ein kleiner. Tropfen der wässerigen Lösung mit Jodjodkaliumlösung (1 Tröpfchen) versetzt, gab auf einem Objektträger sofort einen braunen, aus mikroskopischen Kügelchen bestehenden Niederschlag. Nach einigen Minuten schieden sich braune, lange, nadelförmige, oft kreuzweise gelagerte Kristalle aus, wie dies auch bei Betainchlorhydrat der Fall ist.

R ückstand I R 1. (s. S. 216). Er wurde in "dest. Wasser gelöst und mit Tierkohle versetzt.: Die Lösung wurde unter öfterem Umschütteln mehrere'Stunden lang stehengelassen, dann filtriert. Das Filtrat wurde im Vakuum bei $37^{\circ} \mathrm{C}$. eingedämpft. Es hinterblieb ein fast wẹisser, kristallinischer Rückstand, der beim Verbrennen auf Platinblech nur noch einen sehr geringen unverbrennlichen Rückstand hinterliess. Die Substanz wurde zunächst in Vakuumexsikkator über Ätzkalk und Natronkalk 14 Tage lang getrocknet und gleichzeitig von überschüssiger Salzsäure möglichst befreit. Sie wurde dann fein zerrieben, mit absolutem Alkohol gut ausgewaschen und nochmals in dest. Wasser gelöst. Die Lösung wurde mit Tierkohle versetzt und filtriert. Das nunmehr farblose Filtrat wurde im Vakuum bei $37^{\circ} \mathrm{C}$. zur Trockne verdampft, der Rückstand mit dest. Wasser aufgenommen und so oft umkristallisiert, bis der Schmelzpunkt (unkorr. bei $229^{\circ}$ C.) konstant war, dann im Vakuumexsikkator bei Zimmertemperatur und zuletzt bei $105^{\circ} \mathrm{C}$. im Trockenschrank getrocknet.

Untersuehung von Präparat I R 1.

Physikalische Eigenschaften. Weisse, aus farblosen Kristallen bestehende Substanz, die in Wásser leicht löslich, in Alkohol, 
Äther und Aceton unlöslich war. Unter dem Mikroskop beim Eindampfen der Lösung auf einem Objektträger eigenartige, spiess- und sägeförmig angeordnete Kristalle. Schmelzpunkt (unk.) $229^{\circ} \mathrm{C}$. Die wässerige Lösung war optisch įnaktiv.

Chemische Untersuchung.

1. Reaktion der wässerigen Lösung: Sauer.

2. Auf dem Platinblech erhitzt: Schmilzt zunächst unter Braunfärbung und Zersetzung, verbrennt dann unter Hinterlassung einer Spur Asche.

3. Im Glasröhrchen für sich erhitzt: Schmilzt unter Zersetzung und Entwicklung von Dämpfen, die nach Trimethylamin riechen.

4. Im Glasröhrchen mit Natronkalk erhitzt: Entwicklung von Dämpfen, die nach Trimethylamin riechen und feuchtes rotes Lakmuspapier blau färben.

5. Mit Natrium im Glasröhrchenerhizt (Lassaigne'sche Probe): Die mit dest. Wasser aufgenommene Schmelze gibt nach Zusatz einer Lösung von $\mathrm{FeCl}_{3}$ und $\mathrm{FeSO}_{4}$ und Übersättigung mit verd. $\mathrm{HCl}$ starke Blaufärbung.

6. Mit Natronlauge erhitzt: Entwicklung von Dämpfen, die feuchtes rotes Lakmuspapier schwach blau färben.

7. Reaktionen einer $2 \%$ igen Lösung mit:

a) Silbernitrat: Weisser Niedersehlag, in Salpetersäure unlöslich, in überschüssigem Ammoniak löslich.

b) Quecksilberchlorid (wässerige Lösung): Keine Fällung.

c) Basisches Bleiacetat: Keine Fällung.

d) Pikrinsäure (wässerige Lösung): Keine Fällung.

e) Nessler's Reagens: Gelblich weisse Fällung.

f) Ammonmolybdat: Weisse, mikrokristallinische Fällung.

g) Phosphorwolframsäure: Starker, weisser Niederschlag. Schon ausgebildete, an den Enden zugespitzte Nadeln $(\longrightarrow)$.

h) Ninhydrin 10 sung $1 \%$ (Kochprobe nach Neutralisation mit schwacher Natronlauge): Keine Blaufärbung.

i) Jodjodkaliumlösung: Starker, dunkelbrauner Niederschlag (s. a. Mikroskopische Prüfung).

k) Platinchlorid: Keine Fällung. Die eingedampfte Lösung hinterlässt einen Rückstand, der nach dem Auswaschen mit Alkohol and Umkristallisieren aus dest. Wasser wohlausgebildete federförmige Kristalle liefert.

1) Folin's $\mathrm{R}$ eage a $\mathrm{s}$ : Weisser Niederschlag; der in überschüssiger $\mathrm{Na}_{2} \mathrm{CO}_{3}$-Lösung schwer und ohne Färbung (Blaufärbung) löslich ist.

8. Mikroskopische Prüfung:

a) Ein Kriställchen in wenig dest. Wasser gelöst, dann mit einem Tröpfchen Jodjodkaliumlösung auf einem Objektträger versetzt, gibt sofort einen aus braunen Kügelchen bestehenden Niederschlag. Nach einigen Minuten entstehen lange dunkelbraune, nadelförmige Kristalle, die oft krenzweise gelagert sind. 
Beitrag zur Kenntnis von organischen Nahrungsstofien mit spezif. Wirkung. 223

b). Eine kleine Menge mit alkoholischer Natronlauge durch Verreiben in einem Uhrschälchen neutralisiert, dann durch ein Filterchen gegeben, liefert auf Zusatz konzentrierter alkoholischer Pikrinsäurelösung einen aus langen, feinen Nädelchen bestehenden Niederschlag (Mikrophotographie Nr. 45).

9. Elementaranalyse (Mikromethode von F. Pregl):

Das im Vakuumexsikkator längere Zeit hindurch äber Schwefelsäure und neben einem Schälchen mit Natriumhydroxyd getrocknete Präparat ergab, auf aschefreie Substanz berechnet, nachstehende Werte:

Substanz I R 1 ergab nach Pregl folgende Analysenwerte:

$4,388 \mathrm{mg}$ hinterliessen beim Verbrennen $0,020 \mathrm{mg}$ Asche und lieferten: $2,90 \mathrm{mg} \mathrm{H} \mathrm{H}_{2} \mathrm{O} ; 6,24 \mathrm{mg} \mathrm{CO}_{2}=\mathbf{7 , 4 3} \% \mathrm{H} ; \mathbf{3 8 , 9 6 \%} \mathrm{C}$.

$4,418 \mathrm{mg}$ hinterliessen beim Verbrennen $0,035 \mathrm{mg}$ Asche and lieferten: 2,94 $\mathrm{mg} \mathrm{H}_{2} \mathrm{O} ; 6,30 \mathrm{mg} \mathrm{CO}_{2}=\mathbf{7 , 5 1} \% \mathrm{H} ; \mathbf{3 9 , 2 0} \% \mathrm{C}$.

Die Prozentzahlen sind auf die as chefreie Substanz berechnet:

$4,871 \mathrm{mg}\left(738 \mathrm{~mm} ; 22^{\circ}\right.$. C. $): 0,400 \mathrm{ccm} \mathrm{N}_{2}=\mathbf{9 , 2 3 \%} \%$;

$5,975 \mathrm{mg}\left(739 \mathrm{~mm} ; 22^{\circ}\right.$ C. $): 0,488 \mathrm{ccm} \mathrm{N}_{2}=\mathbf{9 , 1 9} \% \mathrm{~N}$;

$7,230 \mathrm{mg}: 6.780 \mathrm{mg} \mathrm{AgCl}=\mathbf{2 3 , 2 0} \% \mathrm{Cl}$.

Berechnet für Betainchlorhydrat: $\mathrm{C}_{5} \mathrm{H}_{12} \mathrm{NClO}_{2}: 39,10 \% \mathrm{C}, 7,82 \% \mathrm{H}$, $9, \mathbf{1 2} \% \mathrm{~N}, \mathbf{2 3}, 10 \% \mathrm{Cl}$.

Ein Kriställchen der Substanz gab mit einem Tropfen Jodjodkaliumlösung die für Betain charakteristische Fällang eines kristallisierten dunkelbraunen Superjodids.

Die Formel $\mathrm{C}_{5} \mathrm{H}_{12} \mathrm{NO}_{2} \mathrm{Cl}$ entspricht der des Betainchlorhydrats. Zur weiteren Identifikation von Präparat I R 1 wurde schliesslich noch das Pikrat dargestellt.

12. Pikrat aus Präparat I R 1. 2 g der Substanz wurden mit $1 / 10 \mathrm{n}$. Natronlauge neutralisiert, dann bei $37^{\circ} \mathrm{C}$, im Vakuum zur Trockne verdampft. Der Rückstand wurde wiederholt mit absolutem Alkohol aufgenommen und dieser bei $37^{\circ} \mathrm{C}$. im Vakuum wieder abgedampft. Der Rückstand wurde mit absolutem Alkohol in einem Schälchen gat verrieben und die Lösung von dem unlöslichen Anteil (NaCl) abfiltriert. Das Filtrat wurde mit konzentricrter alkoholischer Pikrinsäurelösung versetzt. Es schied sich ein voluminöser gelber Niederschlag aus, der abgenutscht, mit absolutem Alkohol gründlich ansgewaschen und ans dest. Wasser umkristallisiert wurde: Gelbe, in Wasser leicht, in Alkohol sehr schwer lösliche Nadeln. Schmelzpunkt (unk.): $180^{\circ} \mathrm{C}$. unter Zersetzung. Betainpikrat schmilzt bei $180-181^{\circ} \mathrm{C}$. (Betainchlorhydrat bei $227-228^{\circ}$ C.)

Durch Übereinstimmang der empirischen Formeln des Präparates I R 1 mit der des Betainchlorhydrats, ferner durch Übereinstimmung der Schmelzpunkte sowohl des Chlorhydrats sowie auch des Pikrats von Präparat I R 1 mit den entsprechenden Verbindungen des Betains und schliesslich noch durch die physikalischen Eigenschaften und eine Anzahl chemischer Reaktionen wurde die Identität von Präparat I R 1 mit Betainchlorhydrat sichergestellt.

Tierversuches. S. 259 . 
Lösung I B 1 ${ }^{1}$ ) (S. 218). Filtrat von den alkoholischen $\mathrm{HgCl}_{2}$ Niedersehlägen I A u. I A 1 (Tierversuch s. S. 261). Das Filtrat wurde im Vakuum bei $37^{\circ}$ C. zur Trockne veräampft und der Rückstand dann mit kaltem dest. Wasser aufgenommen. Er war nur zum Teil leicht löslich. Der in Wasser schwerer lösliche Anteil I R 2 wurde von dem leichter löslichen Anteil I R 2 (S. 229) durch Abnutschen und Auswaschen mit etwas dest. Wasser getrennt,

Rückstand I R 2 (s. vorstehend). (Tierversuche s. S. 260.) Er wurde in dest. Wasser durch Verreiben in einer Reibschale aufgeschwemmt und durch Einleiten von $\mathrm{H}_{2} \mathrm{~S}$ zerlegt. Der HgS-Niederschlag wurde abgenutscht und gut ausgewaschen. Filtrat und Waschwasser wurden durch Durchsaugen von Luft von $\mathrm{H}_{2} \mathrm{~S}$ befreit, dann bei $37^{\circ} \mathrm{C}$. im Vakuum zur Trockne verdampft. Es hinterblieb ein gelblich gefärbter kristallinischer Rückstand, der in Wasser gelöst, mit Tierkohle versetzt und filtriert wurde. Das Filtrat wurde nochmals im Vakuum bei $37^{\circ}$ C. zur Trockne verdampft, der Rückstand wiederholt mit absolutem Alkohol aufgenommen und letzterer wiederum im Vakunm bei $37^{\circ} \mathrm{C}$. verdampft. Die hierbei zurückbleibende, noch immer gelblich gefärbte kristallinische Substanz wurde in wenig dest. Wasser gelöst und diese Lösung langsam bei $37^{\circ} \mathrm{C}$. eingedampft, dann im Vakuumexsikkator über $\mathrm{H}_{2} \mathrm{SO}_{4}$ und neben einem Schälchen mit $\mathrm{NaOH} 14$ Tage lang getrocknet. Der Rückstand wurde nun fein zerrieben und mit absolutem Alkohol ausgezogen. Der in Alkohol unlösliche Rückstand I R 4 (s. nachstehend) wurde von dem in Alkohol löslichen Anteil I R 3 (S. 230) durch Filtrieren und Auswaschen mit absolutem Alkohol getrennt.

Rückstand I R 4 (s. vorstehend). Er wurde. durch Behandeln mit Tierkohle und Umkristallisieren weiter gereinigt. Es hinterblieb schliesslich eine sehr geringe Menge.

\section{Untersuchung you Präparat I $R$ 4.}

Physikalische Eigenschaften. Weisse, kristallinische Substanz, die in Wasser leicht, in Äther, Aceton und Alkohol nicht löslich war. Schmelzpunkt (unk.) $225^{\circ} \mathrm{C}$.

Chemische Untersuchung.

1. Reaktion der wässerigen Lösung: Sauer.

2. A af dem Platinblech erhitzt: Schmilzt unter Braunfärbung und Gasentwicklung, verbrennt dann unter Hinterlassung eines sehr geringfügigen Rückstandes.

3. Mit Natronkalk im Glasröhrebenerhitzt: Entwicklung von Dämpfen, die nach Trimethylamin riechen und feuchtes, rotes Lakmuspapier blau färben.

4. Reaktionen der wässerigen Lösung mit:

a) Silbernitrat: Weisser Niederschlag, unlöslich in $\mathrm{HNO}_{3}$, leicht löslich in überschüssigem $\mathrm{NH}_{3}$.

1) Siehe auch S. 232 . 
Beitrag zur Kenntnis von organischen Nahrungsstoffen mit spezif. Wirkung. 225

b) Folin's Reagens: Keine Blaufärbung bei Zusatz überschüssiger $\mathrm{Na}_{2} \mathrm{CO}_{3}$-Lösung.

c) Phosphorwolf ram sän e: Weisser Niederschlag, in übẹrschüssiger $\mathrm{Na}_{2} \mathrm{CO}_{5}$-Lösung mit sehr schwach bläulicher Farbe löslich.

d) Nessler's Reagens: Orangerote Fällung:

e) Ninhydrinlösung 1\% (Kochprobe): Keine Blaufärbung.

f) Jodjodkalium: Brauner Niederschlag.

g) Pikrinsäure (wässerige Lösung): Keine Fällung.

5. Pikrat von Präparat I R 4. Einige kleine Kristalle wurden in einem Glasschälchen fein zerrieben, dann mit sehr veräünnter alkoholischer Natronlauge bis zur schwach alkalischen Reaktion, hierauf mit wenig absolutem Alkohol versetzt und durch ein Filterchen gegeben. Das Filtrat etwas eingedampft, gab auf Zusatz einer konzentrierten alkoholischen Pikrinsäurelösung sofort einen voluminösen gelben Niederschlag (s..a. Mikroskopișche Prüfung), der in Alkohol kaum löslich war.

6. Quecksilberchlorid-Verbindung von Präparat IR 4. Einige kleine Kristalle wurden ebenso wie vorstehend angegeben mit alkoholischer Natronlauge und absolutem Alkohol behandelt. Das eingeengte Filtrat gab mit konzentrierter alkoholischer $\mathrm{HgCl}_{2}$-Lösung sofort einen weissen Niederschlag (s. a. Mikroskopische Prüfung).

7. Mikroskopische Prüfung.

a) Ein Tröpfchen der wässerigen Lösủng auf einem Objektträger langsam eingedampft, lieferte einen aus Kristallen bestehenden Rückstand, die denen des Betainchlorhydrats durchaus gleichen.

b) Das auf vorstehend angegebene Weise dargestellte Pikrat bestand aus feinen gelben Nädelchen, die das charakteristische Aussehen des Betainpikrats hatten.

c) Die, wie vorstehend angegeben, dargestellte $\mathrm{HgCl}_{2}$-Verbindung bestand aus plättchenförmigen Kristallen.

d) Ein Kriställchen in einem Tröpfchen dest. Wassers gelöst, dann mit einem Tröpf́chen Jodjodkaliumlösung versetzt, gah einen zunächst aus dunkelbraunen Kügelchen bestehenden Niederschlag, in dem sich nach einiger Zeit lange, dunkelbraune, oft kreuzförmig gelagerte nadelförmige Kristalle bildeten, wie sie bei gleicher Behandlung von Betainchlorhydrat entstehen.

$\mathrm{Zu}$ weiteren quantitativen Bestimmungen war die zur Verfügung stehenàe Menge von Präparat I $\mathrm{R} 4: \mathbf{z}$. gering. Die angeführten Realitionen und das äbrige Verhalten des Präparats lassen aber kaum einen Zweifel darüber, dass es sich bei Prầparat $\mathrm{I}$ R (ebenso wie Präparat 1 R 1) in der Hauptsache : um Betainchlorhydrat hándelte. Ver unreinigungen 'mit Spuren von $\mathrm{NH}_{4} \mathrm{Cl}$ schienen die Orangefärbung mit Nessler's Reagens verursacht zu haben. Die, - ủbrigens äusserst schwache, Blaufärbung, die bei der Lösung des PhosphorwolframsäureNiederschlages in überschüssiger $\mathrm{Na}_{2} \mathrm{CO}_{3}-$ Lösung auftrat, mag auf Spuren des Präparats I N 5 zurückzuführien sein.

Pflüger's Archì fūr Physiologie. Bd. 172. 
Lösung I R 3 (Filtrat von I R 4 s. S. 224). Dieser in Alkohol löslicher Anteil von I R 2 (s. S. 224) wurde bei $37^{\circ}$ C. im Vakuum eingedampft. Der teils kolloide, teils kristallinische Rückstand wurde mit reinem Methylalkohol aufgenommen. Der unlösliche Rückstand, welcher kristallinisch war und dieselben Eigenschaften bei seiner Prüfung wie I R 4 aufwies, wurde abfiltriert, mit dieser Fraktion vereinigt und mit ihr zusammen weiter gereinigt. Die methylalkoholische, abfiltrierte Lösung wurde bei $37^{\circ} \mathrm{C}$. langsam eingedampft, der Rückstand mit dest. Wasser anfgenommen, nit Tierkohle versetzt and langsam bei $37^{\circ} \mathrm{C}$. eingedampft. Der hierbei sich ausscheidende kristallin is che Anteil I B $3^{a}$ wurde von dem kolloiden Anteil I B $3^{b}$ durch Abnutschen und Auswaschen mit 100\% igem Alkohol getrennt. Der kolloide Anteil I B $3^{b}$ wurde wie auf S. 227 angegeben weiterbehandelt.

Untersuchung des Präparats I $B$ 3 a (umkristallisiert).

Physikalische Eigenschaften. Weisse, kristallinische Substanz, die in Wasser leicht löslich, in Alkohol unlöslich war. Schmelzpunkt : $234-235^{\circ}$ C. unter Zersetzung.

\section{Chemische Untersuchung.}

1. Reaktion der wässerigen Lösung: Sauer.

2. Auf dem Platinblech erhitzt: Zersetzt sich zunächst unter Braunfärbung und Aufschäumen, verbrennt dann unter Entwicklung von Dämpfen, die nach Trimethylamin riechen, und unter Hinterlassung einer Spur Asche.

3. Mit Natronkalk im Glas öhrchenerhitzt: Entwicklung von Dämpfen, die nach Trimethylamin riechen und rotes feuchtes Lakmuspapier blau färben.

4. Reaktion der wässerigen Lösung mit:

a) Silbernitrat: Weisser Niederschlag, in $\mathrm{HNO}_{3}$ unlöslich, in überschüssigem $\mathrm{NH}_{3}$ leicht löslich.

b) Quecksilberchlorid (wässerige Lösung): Keine Fällung.

c) Saures Quecksilbersulfat: Keine Fällung.

d) Phosphorwolframsäure: Weisser Niedersehlag, in überschüssiger $\mathrm{Na}_{2} \mathrm{CO}_{3}$-Lösung farblos löslich.

e) Folin's Reagens: Keine Blaufärbung.

f) Nessler's Reagens: Schwach gelbliche Fällung.

g) Ninhydrinlösung 1\% (Kochprobe): Keine Blaufärbung.

5. Pikratvon Präparat I $3^{3}$. Eine kleine Menge von $I B 3^{a}$ wurde mit schwacher Natronlauge neutralisiert, dann bei $37^{\circ} \mathrm{C}$. zur 'Troekne verdampft. Der Rückstand.wurde mit absolutem Alkohol aufgenommen, filtriert und nach dem Einengen mit konzentrierter alkoholischer Pikrinsäurelösung versetzt: Voluminöser, gelber Niederschlag (s. a. Mikroskopische Prüfung), der in Alkohol schwer löslich war.

6. Mikroskopische Prüfun:

a) Ein Tropfen der wässerigen Lösung auf einem Objektträger langsam eingedampft, hinterlässt als Rückstand Kristalle, die denen von Betainchlorhydrat gleichen. 
Beitrag zur Kenntnis von organischen Nahrungsstoffen mit spezif. Wirkung. 227

b) Einige Kriställchen in einem Tröpfchen dest. Wassers auf einem Objektträger gelöst, dann mit Jodjodkalinmlösung versetzt: Bildung eines aus braunen Kügelchen bestehenden Niederschlages, in welchem nach einigen Minuten lange, dunkelbraune, nadelförmige Kristalle entstehen, wie Betainchlorhydrat sie auch bei gleicher Behandlung liefert.

c) Das, wie vorstehend angegeben, dargestellte Pikrat bestand aus langen, gelben, nadelförmigen Kristallen, die denen des Betainpikrats gleichen.

Chlorbestimmung nach Volhard.

Verwandt: $0,1142 \mathrm{~g}$ Substanz. Bei der Titration verbraucht $7,2 \mathrm{ccm} 1 / 10$ n. $\mathrm{AgNO}_{3}$-Lösung (Faktor 0,003546), entsprechend $0,0255312 \mathrm{~g} \mathrm{Cl}=22,36 \%$ Chlor (Betainchlorhydrat enthält $23,13 \% \mathrm{Cl}$ ). Sämtliche Reaktionen sowie die Resultate der mikroskopischen Prüfung deuteten darauf hin, dass das Präparat I B $3^{\text {a }}$ ebenfalls Betainchlorhydrat war. Der etwas höher als bei Betainchlorhydrat (Schmelzpunkt 227 bis $228^{\circ}$ C.) liegende Schmelzpunkt (234-235 ${ }^{\circ}$ C.) sowie der um - 0,77\% geringere Cl-Gehalt sind zweifellos auf Verunreinigungen zurückzuführen, welche in Anbetracht der geringen zur Verfügung stehenden Menge des Präparats nicht mehr zu beseitigen waren. Von Tierversuchen wurde, da solche schon mit I R 1 (Betainchlorhydrat) angestellt worden waren, abgesehen.

Lösung I B $3^{b}$ (Filtrat von I B $3^{a}$ s. S. 226). Nach langsamem Verdunsten des Lösungsmittels wurde ein brauner, zähflüssiger Rückstand erhalten. Dieser wurde mit 100\% igem Alkohol anfgenommen und filtriert. Das Filtrat wurde mit konzentrierter alkoholischer $\mathrm{HgCl}_{2}$ Lösung versetzt, wodurch ein Niederschlag entstand, der abgenutscht und mit wenig $100 \%$ igem Alkohol gewaschen, dann in Wasser suspendiert und durch Einleiten von $\mathrm{H}_{2} \mathrm{~S}$ zerlegt wurde. Nach dem $\mathrm{Ab}$ nutschen and Auswaschen des $\mathrm{HgS}-$ Niederschlages wurden Filtrat und Waschwasser durch Durchsaugen von Luft von $\mathrm{H}_{2} \mathrm{~S}$ befreit und dann in Vakuum bei $37^{\circ} \mathrm{C}$. eingedampft: Der Rückstand wurde durch wiederholtes Aufnehmen mit absolutem Alkohol und anschliessendes $\mathrm{Ab}$ destillieren desselben im Vakuum bei $37^{\circ} \mathrm{C}$. von $\mathrm{HCl}$ möglichst befreit, dann wiederholt mit dest. Wasser umkristallisiert. Die so gewonnene Menge dieses $\mathrm{Präparates} I \mathrm{R} 6 \mathrm{war}$ eine sehr geringe. Das Filtrat von de $\mathrm{HgCl}_{2}-\mathrm{Niederschlag} \mathrm{I} \mathrm{B} 3^{\text {c }}$ wurde in der auf S. 228 näher ausgeführten Weise weiterbehandelt.

Untersuchung von Präparat I R 6 (s. vorstehend).

Physjkalische Eigenschaften: Weisse, kristallinische Substanz: Bei 220 facher Vergrösserung gerade abgeschnittene, zu Drasen vereinigte Prismen (Mikrophotographie Nr. 46). Sehr hygroskopisch.

Chemische Untersuchung.

1. A uf dem Platinblech erhitzt: Verlrennt unter Hinterlassung eines sehr geringen Ascherückstandes. 
2. Mit Natronkalkim Glas röhrchen erhitzt: Entwicklung von Dämpfen, die feuchtes, rotes Lakmuspapier blau färben.

3. Reaktion der wässerigen Lösung: Sauer.

4. Reaktionen der wässerigen Lösung mit:

a) Silbernitrat: Weisser Niederschlag, in $\mathrm{HNO}_{3}$ unlöslich, in überschüssigem $\mathrm{NH}_{3}$ leicht löslich.

b) Folin's Reagens: Starker, weisser Niederschlag, der sich in überschüssiger $\mathrm{Na}_{2} \mathrm{CO}_{3}$-Lösung mit schwach blaner Farbe löst.

$\mathrm{Zu}$ einer weiteren und eingehenderen Prüfung war die gewonnene Menge des Präparats I P 6 zu gering.

Tierversuche s. S. 261.

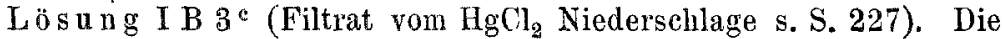
Lösung wurde durch Einleiten von $\mathrm{H}_{2} \mathrm{~S}$ von $\mathrm{Hg}$ befreit, der $\mathrm{HgS}$-Niederschlag abgenutscht und ausgewaschen. Filtrat und Waschwasser wurden zunächst von $\mathrm{H}_{\mathrm{a}} \mathrm{S}$ durch Durchsaugen ron Luft befreit, dann im Vakaum bei $37^{\circ} \mathrm{C}$. eingedampft. Der Rückstand wurde wiederholt mit Alkohol aufgenommen und letzterer bei $37^{\circ} \mathrm{C}$. im Vaknum wieder verjagt. 'Die so gewonnene Substanz wurde in dest. Wasser gelöst, mit wenig Tierkohle versetzt und filtriert. Das Filtrat wurde langsam bei $37^{\circ} \mathrm{C}$. eindampft. Es hinterblieb ein sehr geringer Rückstand.

\section{Untersuchung von Präparat I B $3 \mathrm{c}$.}

Kolloide, gelblich gefärbte Substanz, ans der sich bei längerem Stehen im Vakuumexsikliator eine geringe Menge von Kristallen ausschied. In Wasser und Alkohol löslich.

1. A uf dem Platinblech erhitzt: Verbrennt unter Hinterlassung einer geringen Menge Asche.

2. Mit Natronkalkim Glasröhrchen erhitzt: Entwicklung von Dämpfen, die feuchtes, rotes Lakmuspapier blau färben.

3. Reaktion der wässerigen Lösung: Saner.

4. Reaktionen der wässerigen Lösung mit:

a) Silbernitrat: Weisser Niederschlag, in $\mathrm{HNO}_{3}$ unlöslich, in überschüssigem $\mathrm{NH}_{3}$ löslich.

b) Nessler's Reagens: Gelber Niederschlag.

c) Folin's Reagens: Weisser Niederschlag, der in überschüssiger $\mathrm{Na}_{2} \mathrm{CO}_{3}$-Lösung mit bląuer Farbe löslich ist.

d) Quecksilberchlorid (wässerige Lösung): Weisse Trübung.

e) Phosphorwolframsäure: Weisser Niederschlag, in überschüssiger $\mathrm{Na}_{2} \mathrm{CO}_{3}$-Lösung mit blauer Farbe löslich.

f) $\mathrm{N}$ inhydrinlösung 1\% (Kochprobe): Blaufärbung.

g) Cadmiumchlorid: Keine Fällung.

$\mathrm{Zu}$ einer weiteren Untersuchung war die Ausbeute zu gering.

Tieiversuche s. S. 262.

Lösung I B 2. (In Wasser leichter löslicher Anteil von I B 1, s. S. 224.) Aus der wässerigen Lösung wurde durch Einleiten von 
$\mathrm{H}_{2} \mathrm{~S}$ das Quecksilber als $\mathrm{HgS}$ ausgefällt, abgenutscht und gut ausgewaschen. Filtrat und Waschwasser wurden durch Durchsaugen von Luft von $\mathrm{H}_{2} \mathrm{~S}$ befreit, damn im Vakuum bei $37^{\circ}$ C. zur Trockne verdampft. Der Rückstand, welcher noch starke Biuretreaktion gab, wurde in $100 \mathrm{ccm}$ dest. Wassers gelöst, mit $20 \mathrm{ccm}$ konzentrierter Schwefelsäure versetzt und am Rückflusskühler 20 Stunden lang in schwachem Sieden erhalten. Aus dem mit dest. Wasser verdünnten, dann filtrierten Hydrolysat wurde die Schwefelsäure durch genau bemessenen Zusatz von Barythydrat ausgefällt, der $\mathrm{BaSO}_{4}$-Niederschlag abgenutscht und gut ausgewaschen. Filtrat und Waschwasser wurden im Vaknum bei $37^{\circ} \mathrm{C}$. eingedampft. Der Rückstand wurde mit wenig dest. Wasser aufgénommen und diese Lösung durch vorsichtigen Zusatz von verdünnter Schwefelsäure von den noch vorhandenen Spuren von Baryt befreit, mit Tierkohle versetzt und filtrient. Das Filtrat warde wiederum bei $37^{\circ} \mathrm{C}$. in Vakuum eingedampft und nach wiederholten Versetzen mít absolutem Alkohol und Verjagen desselben mit absolutem Alkohol gut durchgerührt. Es hinterblieb ein weisser liristallinischer Rückstand, der abfiltriert wurde und der sich lei näherer Prüfung als Salmiak erwies. (Flüchtig beim Erhitzen auf Platinblech, Sublimation beim Erhitzen im Glasröhrchen, starker, ziegelroter Niederschlag mit Nessler's Reagens, weisser, käsiger in $\mathrm{HNO}_{3}$ unlöslicher, in $\mathrm{NH}_{3}$ Jöslicher Niederschlag mit $\mathrm{AgNO}_{3}$.) Die vom $\mathrm{NH}_{4} \mathrm{Cl}$ abfiltrierte alkoholische Lösung wurde im Vakaum bei $37^{\circ} \mathrm{C}$. eingedampft, dann im Vakuumexsikkator über $\mathrm{CaCl}_{2}$ längere Zeit stehengelassen. Es hinterblieb eine schwach gelblich gefärbte, dickflüssige Substanz. Sie wurde in $100 \mathrm{ccm}$ dest. Wassers gelöst, mit $5 \mathrm{ccm}$ konzentrierter Schwefelsäure und hierauf mit Phosphorwolframsäure versetzt, bis keine Fällung mehr erfolgte. Der Phosphorwolframsäureniederschlag wurde abgenutscht, mit $5 \%$ iger Schwefelsäure ausgewaschen und dann in der Kälte (Eiswasser) mit Barythydrat zerlegt. Der Nieder'schlag wurde abgenutscht und mit eiskaltem dest. Wasser nochmals aufgerührt und wieder abgenutscht. Filtrat und Waschwasser wurden vom Baryt durch quantitativ gerade ausreichenden Zusat' verdünnter Schwefelsäure befreit, Der $\mathrm{BaSO}_{4}$-Niederschlag wurde $\mathrm{ab}$ genutscht und gut ausgewaschen. Filtrat und Waschwasser wurden bei $37^{\circ} \mathrm{C}$. im Vakuum eingedampft. Der Rückstand wurde mit dest. Wasser aufgenommen, mit Tierkohle versetzt und filtriert. Das Filtrat wurde bei $37^{\circ} \mathrm{C}$. langsam eingedampft und der hierbei zurückbleibende kristallinische Rückstand wiederholt umkristallisiert. Die Ausbeute war auch hier recht gering.

\section{Untersuchung des Präparats I B q.}

Pltysikalische Eigenschaften. Kristallinischer, weisser Rückstand. Bei 220 facher Vergrösserung Tafeln sowie breite, an den Enden zugespitzte Nadeln, teils büschelförmig, teils drusenförmig aneinandergelagert. Schmelzpunkt (unkorr.): $250^{\circ} \mathrm{C}$. unter Zersetzung.

Chemische Untersuchung.

1. A uf dem Platinblech erhitzt: Verbremnt unter Entwicklung von Dämpfen, deren Geruch an den von Pyrrolidin erinnert. Ascherückstand minimal. 
2. Mit Natronkalk im Glasröhrehen erhitzt: Entwicklung von Dämpfen, die feuchtes, rotes Lakmuspapier blau färben.

3. Reaktion der wässerigen $L$ ösung: Schwach sauer.

4. Reaktionen der wässerigen Lösung mit:

a) Silbernitrat: Sehr geringe Trübung.

b) Phosphorwo If ram säure: Starker, weisser Niederschlag, der in überschüssiger $\mathrm{Na}_{2} \mathrm{CO}_{3}$-Lösung mit blauer Farbe löslich ist.

c) Folin's Reagens: Keine Blaufärbung.

d) Nessler's Reagens: Starker, gelber Niederschhlag.

e) Millon's Reagens: Kein Niederschlag, keine Färbung beim Erhitzen.

f) Alkalische Bleilosung: Kieine Färbung beim Kochen.

g) Ninhydrinlösung 1\% (Kochprobe): Blaufärbung.

Elementaranaly se.

I B 2: Hykroskopisch und aschehaltig.

$4,012 \mathrm{mg}: 0,267 \mathrm{mg}$ Asche $=6,66 \%$ Asche.

$6,955 \mathrm{mg} \mathrm{CO}+2,71 \mathrm{mg} \mathrm{H}_{2} \mathrm{O}=\mathbf{5 0 , 6 5} \% \mathrm{C}+\mathbf{8 , 1 0} \% \mathrm{H}$,

$4,342 \mathrm{mg}\left(7,36 \mathrm{~mm}, 14^{\circ} \mathrm{C}\right.$.) : $0,431 \mathrm{ccm} \mathrm{N}=\mathbf{1 2 , 2 5} \% \mathrm{~N}$ (berechnet auf aschefreie Substanz.

$10,080 \mathrm{mg}$ hinterliessen einen Glührückstand von $0,696 \mathrm{mg}=$ 6,90\% Asche.

$4,333 \mathrm{mg}: 0,284 \mathrm{mg}$ Asche $=\mathbf{6 , 5 5} \%$ Asche.

$7,46 \mathrm{mg} \mathrm{CO}+3,08 \mathrm{mg} \mathrm{H}_{2} \mathrm{O}=\mathbf{5 0 , 2 5} \% \mathrm{C}+\mathbf{8 , 5 1} \% \mathrm{H}$ (herechnet auf aschefreie Substanz).

Nach allen Reaktionen handelte es sich um unreines Piolin. (Berechnet für $\mathrm{C}_{5} \mathrm{HgO}_{2} \mathrm{~N}: \mathbf{5 2}, \mathbf{1 4} \%$ C, $7,88 \% \mathrm{H}+\mathbf{1 2 , 1 7} \% \mathrm{~N}$ ).

Die über das Kupfersalz gereinigte Substanz ergab 12,21\% $\mathrm{\Upsilon}$. Das Kupfersalz löste sich leicht in Alkohol. Beim Erhitzen der Substanz trat sehr deutlich ein Geruch nach Pyxrolidin auf.

I R 3. In Alkohol unlöslicker Rückstand von I A 1 (s. S. 218). Der geringe Rückstand wurde mit dest. Wasser aufgenommen, mit Tierkohle versetzt und filtriert. Das Filtrat wurde langsam bei $37^{\circ} \mathrm{C}$. eingedampft. Es hinterblieb ein fast weisser, kristallinischer Rückstand, der wiederholt unkristallisiert wurde.

\section{Untersuchung des Präparats I $\mathbf{R}$.}

Physikalische Eigen sehaften. Weisse, kristallinische Substanz, die in Wasser leicht, in Alkohol schwer löslich war. Schmelzpunkt (unk.) $237^{\circ} \mathrm{C}$. unter Zersetzung.

Chemische Untersuchung.

1. A uf dem Platinblech erhitzt: Schmilzt unter Zersetzung und Braunfärbung. Verbrennt dann unter Entwicklung von Dämpfen, die nach Trimethylamin riechen. Ascherückstand gering. 
Beitrag zur Kerntnis von organischen Nahrungsstoffen mit spezif. Wirkung. 231

2. Mit Natronkalk im Glas röhrchenerhitzt: Entwicking von Dämpfen, die nach Trimethylamin riechen und feuchtes, rotes Lakmuspapier blau färben.

3. Reaktion der wässerigen Lösung: Sauer.

4. Reaktionen der wässerigen Lösung mit:

a) Silbernitrat: Weisser Niederschlag, in $\mathrm{HNO}_{3}$ unlöslich, in überschüssigem $\mathrm{NH}_{3}$ löslich.

b) Phosphorwolframsäure: Weisser Niederschlag.

c) Nessler's Reagens: Gelblich-weisse Fällung.

d) Folin's Reagens: Keine Blaufärbung mit überschüssiger $\mathrm{Na}_{2} \mathrm{CO}_{3}$-Lösung.

e) Quecksilberchlorid (wässerige Lösung): Keine Fällung.

f) J o d jo d k a I i m lös u $\mathrm{g}$ : . Dunkelbrauner Niederschlag (s. a. Mikroskopische Prüfung).

Neutralisiert man einige Kriställchen mit alkoholischer Natronlauge durch Verreiben in einem Schälchen, verdünnt mit wenig absolutem Alkohol und filtriert, so gibt das Filtrat mit:

g) alkoholischer Pikrinsä u relös ung: Voluminösen, gelber Niederschlag (s. a. Mikroskopische Prüfung).

h) alkoholischer $Q u$ ecksilberchloridlösung (konzentriert): Weissen Niederschlag (s. a. Mikroskopische Prüfung).

5. Mikroskopische Prüfung.

a) Ein Tropfen der wässerigen Lösung auf einem Objektträger langsam verdunstet, hinterliess Kristalle, die denen des Präparats I R 1 (Betainchlorhydrat) durchaus glichen.

b) Das auf die vorstehend angegebene Weise dargestellte Pikrat bestand aus langen, gelben Nadeln, wie sie Betainchlorhydrat bei gleicher Behandlung ebenfalls liefert.

c) Die, wie vorstehend angegeben, dargestellte $\mathrm{HgCl}_{2}-\mathrm{Ver}-$ bindung bestand aus wohlausgebildeten, plättchenförmigen Kristallen.

d) Ein Tröpfchen der wässerigen Lösung auf einem Objektträger mit einem Tröpfchen Jodjodkaliumlösung versetzt, gab sofort einen aus dunkelbraunen Kügelchen bestehenden Niederschlag, in dem sich nach einigen Minuten lange, nadelförmige, dunkelbraune, oft kreuzweise gruppierte Kristalle ausschieden.

6. Chlorbestimmung nach Volhard (in der nur einmal umkristallisierten Substanz) (Faktor 0,003546).

Verwandt: $0,1044 \mathrm{~g}$ Substanz. Bei der Titration verbraucht an 1/10 11. $\mathrm{AgNO}_{3}$-Lösung: $6,3 \mathrm{ccm}$, entsprechend $0,0223398 \mathrm{~g} \mathrm{Cl}=$ $21,40 \%$ Chlor.

Die Kristallform, sämtliche Reaktionen sowie der Ausfall der mikroskopischen Prüfung liessen keinen Zweifel darïber, dass das Präparat I R 3 ebenfalls Betainchlorhydrat war.

Der etwas zu hohe Schmelzpunkt $\left(237^{\circ} \mathrm{C}\right.$. - Betainchlorhydrat $227-228^{\circ}$ C.) sowie der niedrigere Chlorgehalt (Betainchlorhydrat 
enthält $23,13 \% \mathrm{Cl}$ ) deuten auf Verumreinigungen hin, welche bei der geringen zur Verfügung stehenden Menge nicht mehr zu beseitigen waren.

Tierversuch s. S. 260.

Lösung I B 1 (s. S. 224). Ein Teil derselben wurde gleich durch Einleiten von $\mathrm{H}_{2} \mathrm{~S}$ von $\mathrm{Hg}$ befreit und der hierbei entstandene. $\mathrm{HgS}$ Niederschlag abgenutscht und ausgewaschen. Filtrat und Waschwasser wurden dann bei vermindertem Druck und bei $37^{\circ} \mathrm{C}$. möglichst weit abgedampft. Der Rückstand wurde wiederholt mit absolutem Alkohol aufgenommen und letzterer im Vakuum bei $37^{\circ} \mathrm{C}$. wieder abgedampft. Es hinterblieb schliesslich ein brauner, dickflüssiger Rückstand.

Tierversuch s. S. 261.

\section{In absolutem Alkohol des Handels (von 99\%) unlöslicher Anteil der Acetonniedersehläge (S. 217).}

Die vereinigten, in dest. Wasser gelösten, dann tiltrierten Rückstände der Acetonniederschläge bildeten eine dunkelbraune Flüssigkeit, die einen eigentümlichen, an den des Fleischextrakts erinnernden Geruch aufwies. Einige Tropfen mit dest. Wasser. verdünnt lieferten eine gelblichbraune Flüssigkeit. Wurde diese mit F olin's Reagens versetzt, so entstand ein Niederschlag, der sich leicht im Überschusse von Natriumkarbonatlösung auflöste. Die anfangs gelblichbraune Farbe des Gemisches ging dann allmählich über grün in blau über. Durch schwaches Erwärmen des Gemisches wurde dieser Übergang beschleunigt. Die wässerige Lösung wurde durch Quecksilberchlorid, Quecksilbersulfat und Phosphorwolframsäure gefällt. Die verdünnte, wässerige Lösung gab deutliche Biuretreaktion.

Tierversuche s. S. 262.

\section{A. Quecksilbersulfatniederschlag.}

Zur Beseitigung der Hauptmenge des Farbstoffs wurden in $1 \mathrm{l}$ der wässerigen Lösung der Rückstände (II) $20 \mathrm{~g}$ Kupfersulfat aufgelöst. In diese Lösung wurde dann $\mathrm{H}_{2} \mathrm{~S}$ eingeleitet, bis alles Kupfer als CuS ausgefällt war. Der CuS-Niederschlag wurde abgenutscht und gut ausgewaschen. Filtrat und Waschwasser, welche ncch gelblich gefärbt waren, wurden im Vakuum bei $37^{\circ} \mathrm{C}$. bis auf $250 \mathrm{ccm}$ Rückstand eingedampft und dann mit einer Lösung von 10\% Quecksilbersulfat in $5 \%$ iger Schwefelsäure so lange versetzt, bis hierdurch keine Fällung mehr hervorgerufen wurde.

Der Quecksilbersulfatniederschlag II $N$ wurde dureh Abnutschen und Auswaschen von der Lö sung II F (s. S. 238) getrennt, in dest. Wasser aufgeschwemmt und unter schwachem Erwärmen auf etwa $50^{\circ} \mathrm{C}$. durch Einleiten von $\mathrm{H}_{2} \mathrm{~S}$ zerlegt. Das Filtrat und Waschwasser von dem auf einer Nutsche gesammelten HgS-Niederschlage wurden von $\mathrm{H}_{2} \mathrm{~S}$ durch Durchsaugen von Luft befreit, dann bei $37^{\circ} \mathrm{C}$. im Vakuum ziemlich weit eingedampft. Der Rückstand wurde dann in einem Schälchen zuerst bei $37^{\circ} \mathrm{C}$, dann im Vakuumexsikkator über Schwefelsäure weiter eingeengt. Es hintẹrblieb eine dunkelbraune, zälhflüssige Substanz. Diese wurde mit absolutem Alkohol aufgenommen, 
wobei ein unlöslicher, aus mikroskopischen Nadeln bestehender Rückstand ungelöst blieb. Dieser wurde abfiltriert und mit absolutem Alkohol ausgewaschen. Er wurde bei näherer Prüfung als aus Kalziumsulfat bestehend erkannt. (Auf dem Platinblech unverbremnlich. Mit verdünnter $\mathrm{HCl}$ geschüttelt und filtriert: Das Filtrat gab einen weissen Niederschlag mit $\mathrm{BaCl}_{2}$ und nach Übersättigung mit $\mathrm{NH}_{3}$ einen weissen Niederschlag mit Ammonoxalat.) Der von $\mathrm{CaSO}_{4}$ bèfreite alkoholische Auszng wurde mit dest. Wasser verdünnt, mit Tierkoble versetzt, filtiert und bei $37^{\circ} \mathrm{C}$ : im Vakuum bis auf einen geringen Rückstand (etwa $100 \mathrm{ccm}$ ) eingeengt; daun vorsichtig mit Barytwasser versetzt, bis alle Schwefelsäure gerade ansgefällt war. Der $\mathrm{BaSO}_{4}$-Niederschlag wurde abgenutscht und gut ausgewaschen. Filtrat und Waschwasser wurden zuerst im Vakuum - bei $37^{\circ} \mathrm{C}$. eingeengt, dann in Vakuumexsikkator über Schwefelsäure völlig abgedampft. Es hinterblieb ein sehr geringer, gelblich gefärbter, kolloider Rückstand, dessen Menge zu einer weiteren Untersuchung. sowic zur Anstellung von Tierversuchen unzureichend war.

II F (Filtrat vom Quecksilbersulfatniederschlag, S. 232). Aus dem Filtrate wurde durch Einleiten von $\mathrm{H}_{2} \mathrm{~S}$ das Quecksilber als $\mathrm{HgS}$ ausgefällt. Der Niederschlag wurde abgenutscht und gut ausgewaschen. Filtrat and Waschwasser wurden im Valkum bei 50.0:C: ziemlich weit eingeengt, dann durch Barytzusatz zunächst von der Hauptmenge der Schwefelsäure befreit. Der BaSO-Niederschlag wurde abgenutșcht und gründlich ausgewaschen. Filtrat und Waschwasser wurden im Vakuum bei $37^{\circ} \mathrm{C}$. wiederum eingedampft. Es hinterblieb ein dickflüssiger brauner Rückstand. Dieser wurde mit ahsolutem Alkohol aufgenommen und längere Zeit in eine Kältemischung gestellt. Es schieden sich hierbei Kristalle aus, die von der Mutterlange abgenutscht, mit absolutem Alkohol gewaschen und aus Wasser umkristallisiert wurden. Bei näherer Prüfung erwiesen sie sich als Natriumsulfat. (Auf dem Platinblech erhitzt, nach dem Schmelzen und Entweichen von Wasserdampf unverbrennlicher Rückstand. Mit $\mathrm{BaCl}_{2}$ versetzt, starker, weisser, in $\mathrm{HCl}$ unlöslicher Rückstand. Starke Gelbfärbung der Bunsenflamme.) Die von dem $\mathrm{Na}_{2} \mathrm{SO}_{4}$ abfiltrierte alkoholische Lösung wurde nach einer Reihe von Vorversuchen mit konzentrierter Pikrinsäurelösung versetzt; die einen starken, an den Wandungen des zur Fällung benutzten Gefässses sich festsetzenden Niederschlag hervorrief. Der Niederschlag wurde durch Dekantieren der überstehenden Flüssigkeit und Auswaschen mit dest. Wasser von überschüssiger Pikrinsäure möglichst befreit, dann mit verdünnter Schwefelsäure übergossen und schwach erwärmt, wobei er in Lösung ging, hierauf filtriert. Das Filtrat wurde durch wiederholtes und anhaltendes Schütteln mit Äther in der Schüttelmaschine von Prikrinsäure befreit, dann nach Abscheidung des Ätherauszages und Abdunsten der, in Lösung gegangenen athermenge vorsichtig und unter Vermeidung eines Überschnsses mit Barytwasser so lange versetzt, bis alle Schwefelsäure gerade ausgefällt war. Der $\mathrm{BaSO}_{4}$-Niederschlag wurde abgenutscht und gut ausgewaschen. Filtrat and Waschwasser wurden zuerst bei $37^{\circ} \mathrm{C}$. im Vakuum, dann im Valuumexsikkator über Sehwefelsäure eingedampft. Es hinterblieb ein sehr geringer $R$ ückstand, II R 1, der a us sehiefabgeschnittenen, derben, 
mikroskopischen Prismen bestand (Mikrophotographie Nr. 47). Auf dem Platinblech erhitzt, verbrannte die Substanz bis auf einen geringen Ascherückstand.' Zur weiteren Reinigung und Untersuchung war die gewonnene Menge zu gering.

\section{B. Kupfersulfat-Natriumbisulfit-Niederschlag.}

$100 \mathrm{ccm}$ des in $99 \%$ igem Alkohol unlöslichen Anteils des Acetonniederschlages (II, S. 232) in konzentrierter wässeriger Lösung wurden mit $50 \mathrm{ccm}$ dest. Wassers, dann mit $10 \%$ iger Natronlauge bis zur deutlich alkalischen Reaktion versetzt. Die Lösung wurde dann mit $10 \%$ iger Essigsäure wieder angesäuert, auf dem kochenden Wasserbade kurze Zeit erhitzt und filtriert. Das durch $10 \%$ ige Natronlange wieder schwach alkalisch gemachte Filtrat wurde mit $10 \mathrm{cem} 40 \%$ iger Natriumbisulfitlösung und nach dem Erwärmen bis zum Sieden mit $15 \mathrm{ccm}$ einer $10 \%$ igen Kupfersulfatlösung versetzt, sodann 15 Minuten lang im Sieden erhalten. Der hierbei entstandene Niederschlag wurde durch ein gehärtetes Filter abgenutscht und mit dest. Wassers ausgewaschen, dann in einer Reibschale mit $100 \mathrm{ccm}$ dest. Wassers gut verrieben, in den zur Fällung benutzten Kolben zurückgegeben, mit eimigen Tropfen 10\% iger Schwefelsäure angesäuert und durch Einleiten von Schwefelwasserstoff zerlegt. Der CuS-Niederschlag wurde abgenutscht und gründlich ausgewaschen. Filtrat und Waschwasser wurden durch Durchsaugen von Luft von $\mathrm{H}_{2} \mathrm{~S}$ befreit, dann auf dem Wasserbade bis auf einen geringen Rückstand eingedampft. Der braungefärbte Rückstand wurde mit dest. Wasser aufgenommen, mit etwas Tierkohle versetzt und aufgekocht, dann fintriert, der Filterinhalt ausgewaschen. Filtrat und Waschwasser wurden nochmals bis auf einen geringen Rückstand eingedampit, der mit heissem Wasser anfgenommen wurde. Es blieb hierbei ein unlöslicher Anteil zurück, der sich nach den $A D$ filtrieren und Auswaschen bei näherer Prüfung als aus Kalziumsulfat bestehend erwies. (Mikroskopische Nadeln, auf dem Platinblech erhitzt, unverbrennlich. Mit verdünnter Salzsäure erwärmt, dann filtriert: Filtrat gibt mit $\mathrm{BaCl}_{2}$ einen weissen Niederschlag, mit Ammonoxalat nach Übersättigung mit $\mathrm{NH}_{3}$ ebenfalls einen weissen Niederschlag.) Das Filtrat von $\mathrm{CaSO}_{4}$ wurde bis fast zur Trockne verdampft. Es schieden sich Kristalle ans, die abgenutscht, mit etwas dest. Wasser gewaschen, dann mit absolutem Alkohol abgespült und im Exsikkator getrocknet wurden. Ihre nähere Untersuchung ergab folgendes:

1. Auf dem Platinblech erhitzt: Vollkommen verbrennbar.

2. Mit Natronkalk im Röhrehen erhitzt: Entwicklung von Dämpfen, die feuchtes, rotes Lakmuspapier blau färben.

3. Ein Tropfen der wässerigen Lösung auf einem Objektträger langsam eingedampft, hinterliess einen aus unregelmässigen Kristallen bestehenden Rückstand.

4. Eine Probe der wässerigen Lösung mit ammoniakalischer Silbcrlösung versetzt gab einen weissen, gallertartigen Niederschlag, der in übercshüssigem Ammoniak unlöslich war. 
Beitrag zur Kenntnis von organischen Nahrungsstoffen mit spezif. Wirkung. 235

๖. Eine andere Probe der wässerigen Lösung wurde mit Natriumkarbonatlösung bis zur alkalischen Reaktion, dann mit frisch bereiteter Diazobenzosulfosäurelösung versetzt : Intensive Rotfärbung.

Diese Reaktionen konnten keinen Zweifel darüber lassen, dass das gewonnene Präparat aus $\mathrm{Pur}$ in basen bestand.

\section{Quecksilberchloridniederschlag.}

Etwa $100 \mathrm{ccm}$ der konzentrierten wässerigen Lösung wurden mit dem doppelten Volumen absoluten Alkohols, hierauf mit einer konzentrierten alkoholischen Quecksilberchloridlösung versetzt, bis keine Fällung mehr erfolgte. Der entstandene Niederschlag wurde abgenutscht und mit absolutem Alkohol ausgewaschen, dann in dest. Wasser anfgeschwemmt und durch Einleiten von Schwefelwasserstoff zerlegt. Das ausgefällte HgS wurde abgenutscht und gut ausgewaschen, zuletzt mit heissem dest. Wasser. Filtrat und Waschwasser wurden im Vakuum bei $50^{\circ} \mathrm{C}$. bis auf einen geringen Rückstand eingedampft. Dieser wurde mit Tierkohle versetzt, einmal kurz aufgekocht und filtriert. Das Filtrat wurde mit Natronlauge neutralisiert und dann bei $37^{\circ} \mathrm{C}$. im Vakuum zur Trockne verdampft. Der Rückstand wurde nach wiederholtem Aufnehmen mit absolutem Alkohol und Wiederabdampfen desselben mit absolutem Alkohol bei etwa $50^{\circ}$ C. zu wiederholten Malen ausgezogen. Die alkoholischen Auszïge wurden vereinigt und im Vakuum bei $37^{\circ} \mathrm{C}$. stark eingeengt, dann nochmals filtriert. Eine Probe des Filtrats mit konzentrierter alkoholischer Pikrinsäure versetzt, gab auch nach längerer Abkühlung in Eiswasser keine Fällung (Abwesenheit von Betain).

Der Rest des alkoholischen Auszuges hinterliess nach dem Eindampfen bei $37^{\circ} \mathrm{C}$. und längerem Verweilen im Vakıumexsikkator über Schwefelsäure einen sehr geringen, gelblich gefärbten, kolloiden Rüekstand.

\section{In Aceton löslicher Anteil des konzentrierten, aus hydro- lisierter Hefe dargestellten alkoholischen Auszuges (s. S. 216).} (Schema anf S. 236.)

Die von den Acetonniederschlägen durch Dekantieren erhaltene Flüssigkeit wurde im Vakuum bei $37^{\circ} \mathrm{C}$. bis zar Sirupkonsistenz eingedampft, mit absolutem Alkohol aufgenommen, filtriert und mit konzentrierter alkoholischer Quecksilberchloridlösung so lange versetzt, bis keine Fällung mehr erfolgte.

Der Niederschlag III $\mathrm{N}$ wurde von der Lösung III L 1 (s. S. 244) durch Abnutschen und Auswaschen mit absolutem Alkohol getrennt. Niederschlag III N: Er wurde durch Verreiben in dest. Wasser aufgeschwemmt, dann durch Einleiten von $\mathrm{H}_{2} \mathrm{~S}$ zerlegt. Der HgS-Niederschlag wurde abgenutscht und gründlich ausgewaschen. Filtrat und Waschwasser wurden zunächst durch Durchsaugen von Luft von $\mathrm{H}_{2} \mathrm{~S}$ befreit, dann bei $37^{\circ} \mathrm{C}$. im Vakuum eingedampft. Der Rückstand wurde nach wiederholtem Aufnehmen mit absolutem Alkohol und Verjagen desselben im Vakuum bei $37^{\circ} \mathrm{C}$. mit absolutem Alkohol aufgenommen and verrieben. Es blieb hierbei ein unlöslicher $\mathrm{R}$ ü $\mathrm{ck}$ - 


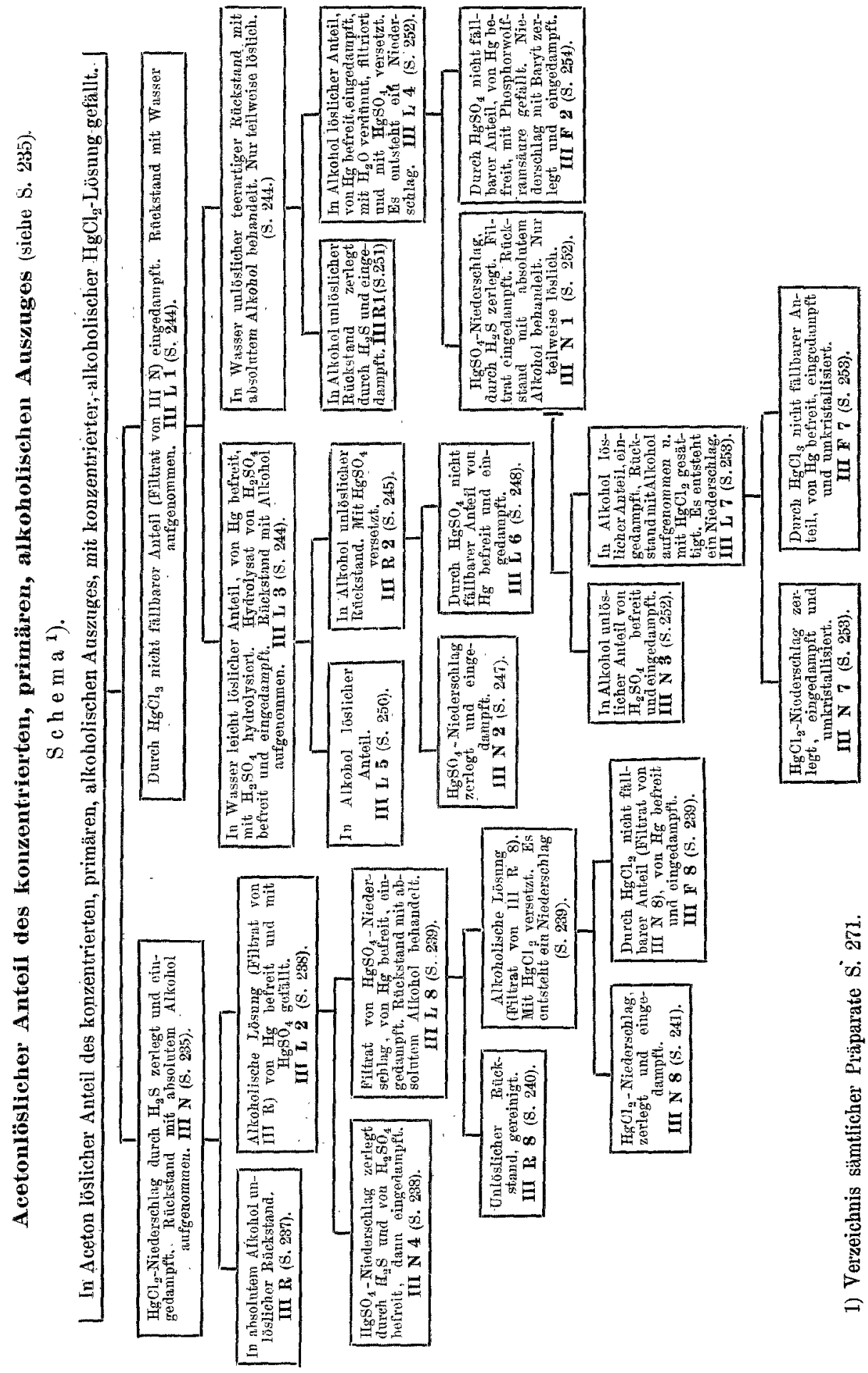


Beitrag zur Kenntnis von organischen Nahrungsstoffen mit spezif. Wirkung. 237

stand III R (s. S. 237) zurück, der durch Abnutschen und Auswaschen nit absolutem Alkohol von der Lösung III L 2 (s. S. 238) getrennt wurde.

Rückstand III R (s. S. 237). Er wurde in dest. Wasser gelöst, mit Tierkohle versetzt und die Lösung nach schwachem Erwärmen und Wiederabkühlen in Eiswásser filtriert. Das Filtrat wurde zunächst im Vakuum bei $37^{\circ}$ C. stark eingeengt, dann im Kristallisierschälchen bei $37^{\circ} \mathrm{C}$. langsam eingedampft: Es schied sich ein kristallinischer Rückstand aus, der im Vakuumexsikkator über Ätzkalk und Natronkalk mehrere Tage lang getrocknet, dann aus dest. Wasser wiederholt umkristallisiert wurde.

\section{Untersuchnng des Präparats III R.}

Physikalische Eigenschaften. Weisse, kiristallinische Substanz, die in Wasser leicht, in Alkohol, Äther und Aceton njeht löslich war. Schmelzpunkt (unk.): $230^{\circ}$ C. unter Zersefzung.

Chemische Untersuchung.

1. A uf dem Platinblech erhitzt: 'Schmilzt unter Braunfärbung und Gasentwickilung. Verbrennt dann unter Hinterlassung eines minimalen Ascherückstandes.

2. Mit Natronkalk im Glasröhrchenerhitzt: Entwicklung von Dämpfen, die nach Trimethylamin riechen und feuchtes, rotes Lakmuspapier blau färben.

3. Mit Natronlauge erwärmt: Entwicklung von Dämpfen, die feuchtes, rotes Lakmuspapier schwach blau färben.

4. Reaktion der wässerigen Lösung: Sauer.

5. Reaktionen der wässerigen Lösung mit:

a) Silbernitrat: Weisser Niederschlag, in $\mathrm{HNO}_{3}$ unlöslich, in überschüssigem $\mathrm{NH}_{3}$ leicht löslich.

b) Quecksilberchlorid (wässerige Lösung): Keine Fällung.

c) Nessler's Reagens: Gelblich-weisser Niederschlag.

d) Fol in's Reagens: Weisser Niederschlag, in überschüssiger $\mathrm{Na}_{8} \mathrm{CO}_{3}$-Lösung schwer und ohne Färbung löslich.

e) Phos phorwolframsäure: Starker, weisser Niederschlag.

f) Platinchlorid: Keine Fällung.

g) Jodjodkaliumlösung: Dunkelbrauner Niederschlag.

h) Ninhydrinlösung 1\% (Kochprobe): Keine Blaufärbung.

6. Mikroskopische Pritfung.

a) Ein Tröpfchen der Lösung auf einem Objektträger hinterlässt einen Rückstand von Kristallen, die denen von Präparat I R (Betainchlorhydrat) durchaus gleichen.

b) Ein Kriställchen in einem kleinen Tröpfchen dest. Wassers gelöst, gibt nach Zusatz von Jodjodkaliumlösung einen dunkelbraunen, aus kleinen Kügelchen bestehenden Niederschlag, in dem sich nach einigen Minuten lange, dunkelbraune, nadelförmige Kristalle ausscheiden. 
c) Das anf nachstehend angegebene Weise gewonnene Pikrat von Präparat III $R$ besteht aus Kristallen, die denen des Betrinpikrats gleichen.

7. Chlorbestimmung nach Volhard.

Verwandt: $0,1024 \mathrm{~g}$ Substanz. Verbraucht an $1 / 10 \mathrm{n}$. Silbernitratlösung (Faktor 0,003546): $6,5 \mathrm{ccm}$, entsprechend $0,023049 \mathrm{~g} \mathrm{Cl}=$ $22,50 \%$ Chlor.

8. Darstellung des Pikrats von III R.

$0,1 \mathrm{~g}$ des Chlorhydrats von III $\mathrm{R}$ wurden in dest. Wasser gelöst. Die Lösung wurde mit Natronlange neutralisiert und zur Trockne verdampft: Der Rückstand wurde mit absolntem Alkohol aufgenommen und filtriert. Das Filtrat wurde bis auf etwa $5 \mathrm{ccm}$ eingeengt und mit konzentrierter alkoholischer Pikrinsäurelösung versetzt. Es bildete sich ein voluminöser, gelber Niederschlag, der auf einem Filterchen gesammelt, mit absolutem Alkohol gründlich ausgewaschen und getrocknet wurde (mikroskopische Prüfung s. S. 222). Aus Wasser umkristallisiert, bildete das Pikrat lange, gelbe Prismen. Schmelzpunkt (unk.): $179-180^{\circ} \mathrm{C}$. (Betainpikrat $180-181^{\circ} \mathrm{C}$.).

Aus den vorstehenden Reaktionen und Bestimmungen ergibt sich zweifellos, dass Präparat III R mit PräparatIR (Betainchlorhydrat) identisch ist.

Tierversuche s. S. 259 (Präparat I R 1).

Lösung III L 2 (s. S. 238) (Filtrat von III R). Die Flüssigkeit wurde bei $37^{\circ} \mathrm{C}$. eingedampft. Es hinterblieb ein brauner, dickflüssiger Rückstand, in dem bei längerem Stehen im Vakuumexsikkator sich Kristalle ausschieden, deren Trennung von der dickflüssigen Mutterlange trotz wiederholter hierauf abzielender Versuche nicht gelang. Der Rückstand wurde deshalb wieder in dest. Wasser gelöst, mit Tierkohle versetzt und filtriert. Das Filtrat, in welchem durch $\mathrm{HgCl}_{2}, \mathrm{HgSO}_{4}$ und Pikrinsäure Fällungen hervorgerufen wurden, wurde mit Schwefelsäure bis zu einem Gehalt an dieser von $5 \%$ und dann mit $10 \%$ iger saurer Quecksilbersulfatlösung versetzt, bis keine Fällung mehr erfolgte. Der Quecksilbersulfatniederschlag III N 4 wurde von der Lösung III L 8 (s. S. 239) durch Abnutschen und Auswaschen mit etwas dest. Wasser getrennt.

$\mathrm{Ni}$ derschlag III N 4 (s. vorstehend). Er wurde in dest. Wasser suspendiert, auf etwa $50^{\circ} \mathrm{C}$. erwärmt und durch Durchleiten von $\mathrm{H}_{2} \mathrm{~S}$ zerlegt. Der HgS-Niederschlag wurde abgenutscht und gnt ausgewaschen. Filtrat und Waschwasser wurden zunächst von $\mathrm{H}_{2} \mathrm{~S}$ durch Durchsaugen von Luft und dann von $\mathrm{H}_{2} \mathrm{SO}_{4}$ durch Zusatz von Barytwasser bis auf eine geringe Menge befreit. Der $\mathrm{BaSO}_{4}$-Niederschlag wurde abgenutscht und ausgewaschen. Filtrat und Waschwasser wurden zuerst im Vakuum bei $37^{\circ} \mathrm{C}$. bis auf etwa $30 \mathrm{ccm}$ Rückstand eingeengt, dann im Kristallisierschälchen bei $37^{\circ} \mathrm{C}$. langsam eingedampft. Es hinterblieb ein sehr geringer Rückstand, der sich bei 220 facher Vergrösserung als aus stechapfelförmigen Kristallen bestehend erwies. Auf Platinblech erhitzt, verbrannte die Substanz bis auf einen sehr geringen Ascherückstand. Mit Natronkalk im Röhrchen erhitzt entwickelte sie Dämpfe, die rotes Lakmuspapier blau färbten. Mit $\mathrm{BaCl}_{2}$-Lösung gab der Körper einen 
Beitrag zur Kenntnis von organischen Nahrungsstoffen mit spezif. Wirkung. 239

weissen, in Salzsäure unlöslichen Rückstand. Es handelte sich hier demnach um das schwefelsaure Salz einer stickstoffhaltigen organischen Verbindung. Zur weiteren Reinigung und Tntersuchung sowie zur Anstellung von Tierversuchen war die gewonnene Menge zu gering.

Lös ung III L 8 (Filtrat vom $\mathrm{HgSO}_{4}$-Niederschlag III N 4 s. S. 238). Sie wurde durch Durchleiten von $\mathrm{H}_{2} \mathrm{~S}$ von $\mathrm{Hg}$ befreit. Der HgS-Niederschlag wurde abgenutscht und gut ausgewaschen. Filtrat nnd Waschwasser warden durch Durchsaugen von Luft von $\mathrm{H}_{2} \mathrm{~S}$ und durch genau bemessenen Zusatz von Baryt bzw. Barytwasser von $\mathrm{H}_{2} \mathrm{SO}_{4}$ befreit. Der $\mathrm{BaSO}_{4}$-Niederschlag wurde abgenutscht und gründlich ausgewaschen. Filtrat und Waschwasser wurden bei $37^{\circ} \mathrm{C}$. im Vakuum eingedampft. Der Rückstand wurde nach wiederholtem Aufnehmen mit Alkohol und Wiederabdampfen desselben. mit dest. Wasser aufgenommen, mit Tierkohle versetzt and filtriert. Das Filtrat wurde wiederum bei $37^{\circ} \mathrm{C}$. eingedampft, dann längere Zeit im Vakuumexsikkator über Schwefelsäure belassen. Es hinterblieb eine dickflüssige, braune, nach Fleischextrakt riechende Substanz. Sie wurde mit absolutem Alkohol aufgenommen. Hierbei blieb ein Teil ungelöst. Dieser in Alkohol unlösliche Rückstand III R 8 (s. S. 240) wurde abfiltriert und mit absolutem Alkohol ausgewaschen. Das Filtrat wurde durch Verreiluen mit Queck. silberchlorid gesättigt. Es entstand hierbei ein Niederschlag III N 8 (s. S. 241), der von der Lösung III F 8 (s. nachstehend) durch Abnutschen und Auswaschen mit absolutem Alkohol getrennt wurde.

Lös ung III F 8. (Filtrat von III N 8 s. vorstehend.) Sie wurde zunächst im Vakuum bei $37^{\circ} \mathrm{C}$. eingedampft. Der Rückstand wurde in dest. Wasser gelöst and diese Lösung durch Einleiten von $\mathrm{H}_{2} \mathrm{~S}$ von $\mathrm{Hg}$ befreit. Der HgS-Niederschlag wurde abgenutscht und sorgsam ausgewaschen. Filtrat und Waschwasser wurden nach dem Verjagen von $\mathrm{H}_{2} \mathrm{~S}$ durch Durchsaugen von Luft im Vakuum bei $37^{\circ}$ C. eingedampft. Der Rückstand wurde nach wiederholtem Aufnehmen mit absolutem Alkohol und Wiederabdampfen desselben in Wasser gelöst und mit Tierkohle versetzt. Die Lösung wurde filtriert, dann langsam bei $37^{\circ} \mathrm{C}$. eingedampft und schliesslich längere Zeit hindurch im Vakuumexsikkator über Schwefelsäure und neben einem Schälchen mit starker Natronlauge getrocknet.

\section{Untersuchung yon Präparat III F 8.}

Gelblich gefärbte, klare, in der Hauptsache kolloide Substanz, in der eine geringe Menge teils blättchen-, teils nadelförmiger Kristalle eingelagert war.

Chemische Untersuchung.

1. A uf Platinblech erhitzt: Bis auf einen sehr geringen Rückstand verbrennbar.

2. Mit Natronkalkim Glas röhrchen erhitzt: Entwicklung von Dämpfen, die feuchtes, rotes Lakmuspapier blau färben.

3. Reaktion der wässerigen Lösung: Sauer.

4. Reaktionen der wässerigen Lösung mit:

a) Silbernitrat: Woisser Niederschlag, in $\mathrm{HNO}_{3}$ unlöslich, in $\mathrm{NH}_{3}$ leicht löslich. 
b) Phos phorwolframsäure: Starker, weisser Niederschlag, in überschüssiger $\mathrm{Na}_{2} \mathrm{CO}_{3}$ - Lösung unter Blaufärbung löslich.

c) Folin's Reagens: Weisser Niederschlag, in überschüssiger $\mathrm{Na}_{2} \mathrm{Cl}_{3}$-Lösung mit hlauer Farbe löslich.

d) Nessler's Reagens: Hellgelber Niederschlag.

e) Quecksilberchlorid (wässerige Lösung): Keine Fällung.

f) Cadmiumchlorid: Keine Fällung.

g) Biuretreaktion: Sehr schwach positiv.

Von einer weiteren Untersuchung sowie einer Elementaranalyse musste abgesehen werden, weil für eine solche die Substanz nicht genügend rein erschien und die zur Verfügung stehende Menge für eine weitere Reinigung unzureichend war.

Tierversuch s. S. 266.

R ü ckstan d III R 8. (In Alkohol unlöslicher Anteil von III L 8 s. S. 239.) Der noch etwas gelblich gefärbte, geringe Rückstand wurde in dest. Wasser gelöst, mit Tíerkohle versetzt, filtriert und langsam bei $37^{\circ} \mathrm{C}$. eingedampft. Es hinterblieb eine geringe Menge einer weissen, kristallinischen Substanz.

\section{Untersuchung des Präparats III R 8.}

Physikalische Eigensehaften: Weisse, aus farblosen Kristallen bestehende, in Wasser leicht, in Alkohol unlösliche Substanz.

Chemische Untersuchung.

1. A uf den Platinblech erhitzt: Schmilzt unter Braunfärbung and Zersetzung, verbrennt dann unter Entwicklung von Dämpfen, die nach Trimethylamin riechen, und unter Hinterlassung einer Spur Asche.

2. Mit Natronkalkim Glasröhrchenerhitzt: Entwicklung von Dämpfen, die feuchtes, rotes Lakmuspapier blau färben.

3. Reaktion der wässerigen Lösung: Sauer.

4. Reaktionen der wässerigen Lösung mit:

a) Silbernitrat: Weisser Niederschlag, in $\mathrm{HNO}_{3}$ unlöslich, in überschüssigem $\mathrm{NH}_{3}$ leicht löslich.

b) Jodjodkalium: Brauner Niederschlag.

Eine kleine Menge des Rückstandes mit schwacher alkoholischer. Natronlauge neutralisiert, mit absolutem Alkohol verdünnt und filtriert. Filtrat auf ein kleines Volumen eingedampft und zu nachstehenden Reaktionen verwandt. Mit

c) Pikrinsäure(konzentriertealkoholische Lösung): Voluminöser, gelber Niederschlag (s. a. Mikroskopische Prüfung).

d) Quecksilberchlorid (konzentrierte alkoholische Lösung): Weisser Niederschlag.

5. Mikroskopische Prüfung.

a) Ein Tröpfchen der wässerigen Lösung auf einem Objektträger eingedampft, liefert einen aus Kristallen bestehenden Rückstand, die die charakteristischen säge- und spiessförmigen Formen des Betainchlorhydrats aufweisen. 
Beitrag zur Kenntnis von organischen Nahrungsstoffen mit spezif. Wirkung. 241

b) Ein Tröpfchen der wässerigen Lösung gibt beim Versetzen mit Jodjodkaliumlösung einen aus dunkelbraunen Kügelchen bestehenden Niederschlag, in dem sich nach einigen Minuten dunkelbraune, nadelförmige Kristalle ausscheiden, wie solche auch Betainchlorhydrat bei gleicher Behandlung liefert.

c) Das Pikrat von III R 8 (auf vorstehend angegebene Weise gewonnen) bestand aus langen, gelben, nadelförmigen $\mathrm{Kri}$ stallen, die denen des aus alkoholischer Lösung ausgefällten Betainpikrats durchaus gleichen.

d) Die, wie vorstehend angegeben, ausgefällte Quecksilberchloridverbindung von III $R \quad 8$ bestand aus plättchenförmigen Kristallen.

Die vorstehend angegebenen Eigenschaften und Reaktionen von III R 8 lassen es als zweifelsfrei erscheinen, dass auch dieses Präparat nichts anderes war als Betainchlorhydrat.

III N $8\left(\mathrm{HgCl}_{2}-\mathrm{Niederschlag}\right.$ aus III L 8 s. S. 239). Der Niederschlag wurde durch Einleiten von $\mathrm{H}_{2} \mathrm{~S}$ zerlegt, der HgS-Niederschlag abgenutscht und gründlich ausgewaschen. Filtrat und Waschwasser wurden nach dem Verdrängen des gelösten $\mathrm{H}_{2} \mathrm{~S}$ durch Durchsaugen von Luft im Vakuum bei $37^{\circ} \mathrm{C}$. eingedampft. Der Rückstand wurde mit Wasser aufgenommen und Tierkohle zugesetzt. Nach längerem stehenlassen, unter häufigem Umschütteln wurde die Lösung filtriert. Das Filtrat wurde wiederum bei $37^{\circ} \mathrm{C}$. im Vakuum ziemlich weit eingedampft. Der Rückstand wurde längere Zeit stehengelassen. Es schied sich hierbei noch eine kleine Menge von Kristallen aus, die sich bei näherer Prüfung als mit III R 8 (s. S. 266) identisch erwiesen. Sie wurden abfiltriert. Das Filtrat wurde nun in einem Kristallisierschälchen zunächst bei $37^{\circ} \mathrm{C}$, dann in Vakuumexsikkator über Schwefelsäure und veben einem Schälchen mit konzentrierter Natronlauge weiter eingedampft. Hierbei schieden sich lange, nadelförmige Kristalle aus, die sich als äusserst hygroskopisch erwiesen Sie wurden in einem mit einem Goldsiebchen und einer Filtrierpapierscheibe versehenen Allihnschen Röhrchen unter Zuführung getrockneter Luft mittels der Wasserstrahlluftpumpe abgenutscht und mit wenig $100 \%$ igem Alkohol, dann noch mit Äther ausgewaschen, schliesslich zweimal aus Wasser umkristallisiert.

Untersuchung des Präparats III N 8 (Hydrochlorid).

Physikalische Eigenschaften. Schwach gelblich gefärbte, lange, feine Nadeln. Sehr hygroskopisch und leicht löslich in Alkohol und Wasser. Die im unreinen Zustande schwach linksdrehende Substanz erweist sich gereinigt als optisch inaktiv.

\section{Chemische Untersuchung.}

1. A uf dem Platinblech erhitzt: Schmilat unter Zersetzung, verbrennt dann unter 'Entwicklung von Dämpfen, die aminartig riechen, und unter Hinterlassung einer Spur Asche.

2. Mit Natronkalk im Glasröhrchen erhitzt: Entwicklung von Dämpfen, die aminartig riechen und feuchtes, rotes Lakmuspapier blau färben. 
3. Wit Natronlauge erwärmt: Entwicklung von Dämpfen, die feuchtes, rotes Lakmuspapier blau fräben.

4. Reaktion der wässerigen Lösung: Sauer.

5. Reaktionen der wässerigen Lösung mit:

a) Silbernitrat: Weisser Niedersehlag, in $\mathrm{HNO}_{3}$ unlöslich, in überschüssigem $\mathrm{NH}_{3}$ leicht löslich.

b) Phosphorwolframsäure: Starker, weisser Niederschlag, in überschüssiger $\mathrm{Na}_{2} \mathrm{CO}_{3}$-Lösung mit bläulicher Farbe löslich.

c) Nessler's Reagens: Gelblich-weisser Niederschlag.

1) Folin"s Reagens: Starker, weisser Niederschlag, in überschüssiger $\mathrm{Na}_{2} \mathrm{CO}_{3}$-Lösung schwer löslich; Filtrat farblos.

e) Quecksilberchlorid (konzentrierte, wässerige Lösung): Weisser, kristallinischer Niederschlag.

5) Saures Quecksilbersulfat: Keine Fällung.

g) Jodjodkaliumlösung: Starker, dunkelbrauner Niederschlag.

h) Ninhydrinlösung 1\% (Kochprobe nach Neutralisation mit $\mathrm{NaOH}$ ): Keine Blaufärbung.

6. Mikroskop is che Prüfung.

a) Beim langsamen Abdampfen eines Tropfens der wässerigen Lösung im Vakuumexsikkator über Schwefelsäure hinterblieb ein Rückstand, welcher aus sehr langen, feinen Nadeln bestand and sich innerhalb sehr kurzer Zeit durch Wasseranziehung aus der Luft verflüssigte.

b) Ein Tröpfchen der wässerigen Lösung mit Jodjodkaliumlösung (ein Tröpfchen) versetzt, gab sofort einen aus kugelförmigen Gebilden bestehenden Niederschlag. Eine nachträgliche Bildung von Kristallen, wie sie unter anderem auch Cholin und Betain geben, wurde trotz mehrerer Versuche nicht beobachtet.

Die mit Natronlauge in Freiheit gesetzte Base erstarrt beim Eindampfen zu einer festen, hygroskopischen Masse, die aus mikroskopischen, undeutlichen Kriställchen besteht. Das Material reichte zu weiteren Kristallisationsversuchen nicht aus. Die wässerige Lösung entfärbte Kaliumpermanganatlösung in der Kälte sofort. Auf Zusatz von Bromwasser entsteht eine Trübung, die sich rasch absetzt, offenbar Additionsverbindung.

$$
\text { Elementaranalyse. }
$$

\section{Salzsaures Salz, sehr hygroskopisch:}

$4,845 \mathrm{mg}: 7,21 \mathrm{mg} \mathrm{CO} ; 3,96 \mathrm{mg} \mathrm{H}_{2} \mathrm{O}=\mathbf{4 2 , 8 1} \% \mathrm{C} ; \mathbf{9 , 8 4} \% \mathrm{H}$ (berechnet auf aschefreie Substanz).

$5,633 \mathrm{mg}: 0,026 \mathrm{mg}$ Rückstand $=0,46^{\circ} \%$ Asche.

$\mathbf{5 , 7 6} \mathrm{mg} \mathrm{AgCl}=\mathbf{2 5 , 4 1} \% \mathrm{Cl}$ (berechnet auf aschefreie Substanz). $7,00 \mathrm{mg}\left(729 \mathrm{~mm}, 14^{\circ}\right.$ C. $): 0,602 \mathrm{ccm} \mathrm{N}=\mathbf{9 , 8 1} \% \mathrm{~N}$.

$3,778 \mathrm{mg}: 0,013 \mathrm{mg}$ Asche. 
Beitrag zur Kenntnis ron organischen Nahrungsstoffen mit spezif. Wirkung. 243

$5,91 \mathrm{mg} \mathrm{CO}+3,31 \mathrm{mg} \mathrm{H}_{2} \mathrm{O}=\mathbf{4 2 , 8 1} \% \mathrm{C}+9,84 \% \mathrm{H}$ (berechnet auf aschefreie Substanz).

Berechnet für $\mathrm{C}_{5} \mathrm{H}_{14} \mathrm{NOCl}(139,45)$.

$\mathbf{4 3 , 0 2} \%$ C, $10,00 \%$ H, 10,00\% N, 11,49\% 0, 25,42\% Cl.

2. Platinsalz :

$5,822 \mathrm{mg}: 1,865 \mathrm{mg}$ Glührückstand $=\mathrm{Pt}=\mathbf{3 2 , 0 3} \% \mathrm{Pt}$.

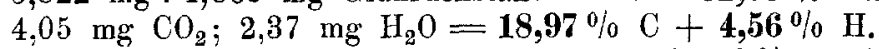

$7,890 \mathrm{mg} 2,560 \mathrm{mg}$ Glührückstand $=\mathrm{Pt}=\mathbf{3 1 , 6 9} \%$ Pt (geringer

Verlust durch Verspritzen der Substanz).

$11,02 \mathrm{mg} \mathrm{AgCl}=33,77 \% \mathrm{Cl}$.

$8,530 \mathrm{mg}\left(735 \mathrm{~mm}, 13^{\circ} \mathrm{C}.\right): 0,341 \mathrm{ccm} \mathrm{N}=\mathbf{4 , 6 2} \% \mathrm{~N}$.

Pt-Salz: 7,476 mg: 2,372 mg Pt $=31,73 \%$ Pt.

$5,35 \mathrm{mg} \mathrm{CO} 2+3,02 \mathrm{mg} \mathrm{H} \mathrm{CO}_{2} \mathrm{O}=19,52 \% \mathrm{C}+4,54 \% \mathrm{H}$.

(Berechnet für $\left.\mathrm{C}_{5} \mathrm{H}_{13} \mathrm{NO} \cdot \mathrm{HCl}\right)_{2} \cdot \mathrm{PtCl}_{4}(615,7)$.

19,52\% C, 4, $55 \%$ H, 4,55 \% N, 34,60\% Cl, 31,60\% Pt.

\section{Pikrat :}

$2,758 \mathrm{mg}\left(736 \mathrm{~mm}, 19,5^{\circ}\right.$ C.) : $0,402 \mathrm{ccm} \mathrm{N}=\mathbf{1 7 , 5 9} \%$ (berechnet auf aschefreie Substanz).

$4,645 \mathrm{mg}: 0,318 \mathrm{mg}$ Asche $=6,85 \%$ Asche.

$6,23 \mathrm{mg} \mathrm{CO}, 1,56 \mathrm{mg} \mathrm{H}_{2} \mathrm{O}=\mathbf{3 9 , 2 7} \% \mathrm{C}+\mathbf{4 , 0 4} \% \mathrm{H}$ (berechnet auf aschefreie Sulstanz).

Berechnet für $\mathrm{C}_{5} \mathrm{H}_{13} \mathrm{NO} \cdot \mathrm{ClH}_{2} \quad\left(\mathrm{NO}_{2}\right)_{3} \cdot \mathrm{OH} \quad(332) \quad \mathbf{3 9 , 7 6} \% \quad \mathrm{C}$, $4,82 \% \mathrm{H}, 16,90 \% \mathrm{~N}$.

\section{Methylimidbestimmung:}

$5,285 \mathrm{mg}: 18,23 \mathrm{mg}$ AgJ $=\mathbf{2 2 , 0 7 \%} \mathrm{CH}_{3}$.

Berechnet für $2 \mathrm{CH}_{3}$ in $\mathrm{C}_{5} \mathrm{H}_{14} \mathrm{NOCl}: \mathbf{2 1 , 5 2} \%$.

Platinchloriddoppelsalz von Präparat III $N 8$. Eine kleine Menge (etwa $1 \mathrm{~g}$ ) des Präparates III N 8 wurde in wenigen Kubikzentimetern dest. Wassers gelöst, dann mit 10\% iger Platinchloridlösung versetzt und hierauf langsam bei $37^{\circ} \mathrm{C}$. eingedampft. Der Rückstand wurde mit absolutem Alkohol gut verrieben, auf ein Filterchen gebracht und so lange mit absolutem Alkohol ausgewaschen, bis das Filtrat farblos war. Der Rückstand auf dem Filterchen wurde nun in warmem dest. Wasser gelöst und durch Abdampfen wieder zur Kristallisation gebracht. Es schieden sich lange, gelbe Nadeln (Photographie Nr. 53 und 54), daneben sechsseitige Tafeln aus. $0,1960 \mathrm{~g}$ des Platindoppelsalzes hinterliessen nach dem Verbrennen der organischen Substanz im Porzellantiegel $0,0620 \mathrm{~g}$ Platin, entsprechend $31,63^{\%} \%$. Schmelzpunkt (unk.): $201^{\circ} \mathrm{C}$. unter Zersetzung.

Pikrat von Präparat III N $8.0,5 \mathrm{~g}$ der Substanz wurden in absolutem Alkohol gelöst, dann durch vorsichtigen Zusatz von $4 \%$ iger alkoholiseher Natronlauge neutralisiert und filtriert. Das Filtrat wurde mit einem Überschuss von alkoholischer Pikrinsäurelösung versetzt und im Vakuum bei $37^{\circ} \mathrm{C}$. eingedampft. Der Rückstand wurde mit absolutem Alkohol aufgenommen, auf einem Filterchen gesammelt und auf diesem zuerst mit $100 \%$ igem Alkohol, dann mit Äther ausgewaschen and getrocknet. Der getrocknete Rückstand wurde in warmem Wasser- 
gelöst und durch langsames Abdampfen bei $37^{\circ} \mathrm{C}$. zur Kristallisation gebracht. Lange, gelbe Nadeln (Mikrophotographie Nr. 52). Schmelzpunkt (unk.): $231^{\circ} \mathrm{C}$. unter Zersetzung.

Tierversuche s. S. 267.

Lösung III L 1. (Filtrat von dem aus alkoholischer Lösung gefällten $\mathrm{HgCl}_{2}$-Niederschlage III $\mathrm{N}$ s. S. 235.) Die Lösung wurde im Vakuum bei $37^{\circ} \mathrm{C}$. möglichst weit eingedampft, dann mit dest. Wasser behandelt. Hierbei ging nur ein Teil des Rückstandes leicht in Lösung. Dieser in kaltem Wasser leicht lösliche Anteil III L 3 wurde von dem schmierigen, schwarzen Rückstande III R 1 (S. 251) durch Dekantieren und Abnutschen getrennt.

Lös ung III L 3 (s. vorstehend) wurde durch Einleiten von $\mathrm{H}_{2} \mathrm{~S}$ von $\mathrm{Hg}$ befreit. Der HgS-Niederschlag wurde abgenutscht und gründlich ausgewaschen. Aus dem Filtrat und Waschwasser wurde der gelöste $\mathrm{H}_{2} \mathrm{~S}$ durch Durchsangen von Luft verjagt. Die Flïssigkeit wurde nun im Vakuum bei $37^{\circ} \mathrm{C}$. möglichst weit eingedampft. Der Rückstand, welcher noch starke Biuretreaktion aufwies, wurde mit $500 \mathrm{ccm}$ dest. Wassers aufgenommen und $100 \mathrm{ccm}$ konzentrierter Schwefelsäure hinzugefügt. Das Gemisch wurde nun 16 Stunden lang auf dem Babeblech und am Rückflússkühler in gelindem Sieden erhalten. Das Hydrolysat wurde dann mit dest. Wasser verdünnt und filtriert. Aus dem Filtrat wurde zunächst durch Verreiben mit Barythydrat, dann durch vorsichtigen Zusatz von Barytwasser die Schwefelsäure quantitativ genau ausgefällt. Der $\mathrm{BaSO}_{4}$-Niederschlag wurde abgenutscht und gründlich ausgewaschen, indem er wiederholt mit warmem Wasser verrieben und wieder auf die Nutsche gebracht wurde. Filtrat und Waschwasser wurden im Vakuum bei $45-50^{\circ} \mathrm{C}$. möglichst weit eingedampft. Der braungefärbte, dickflüssige Rückstand wurde in $500 \mathrm{ccm}$ dest. Wassers unter schwachem Erwärmen gelöst, mit Tierkohle versetzt, einmal kurz aufgekocht und filtriert. Das noch immer sehr dunkelgefärbte Filtrat wurde nun mit $150 \mathrm{ccm}$ einer $10 \%$ igen $\mathrm{CuSO}_{4}$-Lösung versetzt und dann das $\mathrm{Cu}$ durch Einleiten von $\mathrm{H}_{2} \mathrm{~S}$ als $\mathrm{CuS}$ ausgefällt und gut ausgewaschen. Filtrat und Waschwasser wurden nach dem Austreiben der $\mathrm{H}_{2} \mathrm{~S}$ mittels Durchsaugens von Luft durch Zusatz von Barythydrat bzw. Barytwasser von $\mathrm{H}_{2} \mathrm{SO}_{4}$ quantitativ genau befreit. Der BaSO-Niederschlag wurde abgenutscht and gut ausgewaschen. Filtrat und Waschwasser wurden bei $50^{\circ} \mathrm{C}$. im Vakuum möglichst weit eingedampft. Der Rückstand wurde nach wiederholtem Aufnehmen mit absolutem Alkohol and Wiederabdampfen desselben mit absolutem Alkohol aufgenommen and gut durchgerührt. Es ging nur ein Teil in Lösung.

Der in Alkohol unlösliche Anteil III R 2 (s. nachstehend) wurde von dem in. Alkohol löslichen Anteil III L 5 (S. 250) durch Abnutschen und Auswaschen mit absolutem Alkohol getrennt.

R ückstand III R 2 (s. vorstehend). Die Hauptmenge wurde in dest. Wasser gelöst, mit Tierkohle versetzt und filtriert. Das schwach gelblich gefärbte-Filtrat wurde langsam bei $37^{\circ} \mathrm{C}$. eingedampft. Der Rückstand wurde mit kaltem dest. Wasser aufgenommen und geschättelt. Es hinterblieb ein kleiner, schwerer löslicher Anteil III R 3 (S. 246), der abfiltriert und mit kaltem Wasser etwas nachgewaschen 
Beitrag zur Kenntnis von organischen Nahrungsstoffen mit spezif. Wirkung. 245

wurde. Der leichter lösliche Anteil III R 2 (Filtrat) wurde bei $37^{\circ} \mathrm{C}$. eingedampft und der Rückstand aus dest. Wasser wiederholt umkristallisiert. Die bei der letzten Umkristallisation zuerst geronnene Substanzmenge wurde $z u$ nachstehenden Bestimmungen verwandt. Die zweitnächste Kristallisation wies einen um etwa $10^{\circ}$ C. höheren Schmelzpunkt auf.

\section{Untersuchung des Präparats III $\mathbf{R} 2$.}

Physikalische Eigenschaften. Weisse, kristallinische Substanz. Bei 220 facher Vergrösserung feine zu Drusen und Wärzchen vereinigte Nädelchen. In Wasser ziemlich leicht löslich. In Alkohol und Äther unlöslich. Schmelzpunkt (unk.): 201-202 ${ }^{\circ}$ C. unter Zersetzung $(\alpha)_{\mathrm{D}}=+7,3^{\circ} \mathrm{C}$. Die Mikrophotographien $\mathrm{Nr}$. 48 und 49 zeigen das salzsaure Salz.

Chemische Untersuchung.

1. A uf dem Platinblech erhitzt: Schmilzt unter Braunfärbung and Aufschäumen. Verbrennt dann vollständig.

2. Mit Natronkalk inı Glasrölurchen erhitzt: Entwicklung von Dämpfen, die feuchtes, rotes Lakmuspapier blau färben.

3. Mit Natronlauge erwärmt: Entwicklung von Dämpfen, die feuchtes, rotes Lakmuspapier nur sehr schwach und erst nach längere Einwirkung blau färben.

4. Reaktion der wässerigen Lösung: Sauer.

5. Reaktionen einer $2,5 \%$ Lösung mit:

a) Silbernitrat: Kaum wahrnehmbare Trübung.

b) Bariumchlorid: Keine Fällung bzw. Trübung.

c) Quecksilberchlorid (konzentrierte wässerige Lösung): Keine Fällung.

d) Saures Quecksilbersulfat: Keine Fällung.

e) Phosphorwolframsäure: Starker, weisser Niederschlag, in überschüssiger $\mathrm{Na}_{2} \mathrm{CO}_{3}$-Lösung mit bläulicher Farbe löslich-

f) Folin's Reagens: Keine Fällung. Nach Zusatz über. schüssiger $\mathrm{Na}_{2} \mathrm{CO}_{3}$-Lösung keine Färbung.

g) Millon's Reagens: Starker, weisser Niederschlag, beim Kochen keine Färbung.

h) Jodjodkaliumlösung: Keine Fällung.

i) $\mathrm{N}$ inhydrinlösung 1\% (Kochprobe): Starke Blaufärbung.

k) Nessler's Reagens: Geringe, weisse Trübung.

1) Basisches Bleiacetat: Keine Fällung.

m) Alkalische Bleilös ung (Kochprobe): Keinc Braunfärbung.

6. Kupfersalz von III $R 2$. $0,5 \mathrm{~g}$ des Präparats III $\mathrm{R} 2$ wurden mit einem Überschuss von frischgefälltem, vollkommen ausgewaschenem Kupferoxyd und etwa $10 \mathrm{ccm}$ dest. Wassers ungefähr 10 Minuten lang zum gelinden Sieden erhitzt, dann filtriert. Beim langsamen Eindampfen des blaugefärbten Filtrats schieden sich blättchenförmige blane Kristalle aus. 
Die ganzen Eigenschaften des Produktes wiesen auf Aminosäuren hin. Die Elementaranalyse bestätigte die Vermutung, dass ein Gemisch vorlag. Es enthielt Glutaminsäure und ferner, nach dem Ergebnis der Elementaranalyse zu urteilen, Aminovaleriansäure. Sie liess sich leicht durch Sublimieren reinigen. Die grobe Reinigung erfolgte in der folgenden Weise.

7. Silbersalz von III R2. Behufs weiterer Reinigung für die Elementaranalyse wurde das Präparat in möglichst wenig warmem, destilliertem Wasser gelöst und aus dieser Lösung das Silbersalz durch Zusatz einer konzentrierten ammoniakalischen Silberlösung (Silbernitratlösung, die mit Ammoniak so lange versetzt war, bis der entstandene Niederschlag gerade wieder in Lösung gegangen war) ausgefällt. Das Silbersalz wurde zuerst mit destilliertem Wasser, dann mit Alkohol gut ausgewaschen, hierauf in destilliertem Wasser suspendiert und durch Einleiten von Schwefelwasserstoff zerlegt. Der $\operatorname{Ag}_{2} \mathrm{~S}-$ Niederschlag wurde abgenutscht, das Filtrat von $\mathrm{H}_{2} \mathrm{~S}$ durch Durchsaugen von Luft befreit and dann unter vermindertem Druck bei $37^{\circ} \mathrm{C}$. zur Trockne verdampft. Der Rückstand wurde in warmem, destilliertem Wasser gelöst und nun langsam bei $37^{\circ} \mathrm{C}$. eingedampft, bis sich eine genügende Menge von Kristallen ausgeschieden hatte. Diese wurden abgenutscht, mit etwas Alkohol ausgewaschen und zuerst an der Luft bei Zimmertemperatur, hierauf bei $105^{\circ} \mathrm{C}$. getrocknet und zur Elementaranalyse verwandt.

Elemeutaranalyse.

$3,834 \mathrm{mg}\left(735 \mathrm{~mm}, 16^{\circ} \mathrm{C}.\right): 0,390 \mathrm{ccm} \mathrm{N}=11,62 \% \mathrm{~N}$.

$4,067 \mathrm{mg}: 7,70 \mathrm{mg} \mathrm{CO}, 3,31 \mathrm{mg} \mathrm{H}_{2} \mathrm{O}=51,64 \% \mathrm{C}, 9,11 \% \mathrm{H}$.

$4,342 \mathrm{mg}: 8,37 \mathrm{mg} \mathrm{CO}, 3,61 \mathrm{mg} \mathrm{H}_{2} \mathrm{O}=52,57 \% \mathrm{C}, 9,30 \% \mathrm{H}$.

Berechnet für Aminovaleriansäure: $\mathrm{C}_{5} \mathrm{H}_{11} \mathrm{NO}_{2}: 51,24 \% \mathrm{C}, 9,47 \% \mathrm{H}$, $11,96 \% \mathrm{~N}$.

Rückstand III R 3. (In Wasser schwer löslicher Anteil von III R 2; s. S. 245.) Der Rückstand wurde in warmem Wasser gelöst und wiederholt umkristallisiert. Er schrumpfte hierbei bis auf eine sehr geringe Menge zusammen, die für einen Tierversuch und zu nachstehender oberflächlicher Untersuchung sowie zu einer Mikroelementaranalyse gerade ausreichend war.

\section{Untersuchung des Präparats III $\mathbf{R}$ 3.}

Physikalische Eigenschaften. Weisse, kristallinische Substanz. Bei 220 facher Vergrösserung: warzenförmig zusammengelagerte Kristallnädelchen. Schmelzpunkt (unk.): $250^{\circ} \mathrm{C}$., unscharf und unter Zersetzung.

Chemische Untersuchung.

1. A uf dem Platinblech erhitzt: Verbrent unter Hinterlassung einer Spur Asche.

2. Mit Natronkalk im Glasröhrchenerhitzt: Entwicklung von Dämpfen, die feuchtes, rotes Lakmuspapier blau färben.

3. Reaktion der wässerigen Lösung: Sauer.

4. Reaktion mit Ninhydrinlösung $1 \%$ (Kochprobe): negativ. 
5. Elementaranalyse von III $\mathrm{R} 3$ :

$4,160 \mathrm{mg}: \mathbf{6 , 5 2} \mathrm{mg} \mathrm{CO} \mathrm{CO}_{2} ; 1,25 \mathrm{mg} \mathrm{H}_{2} \mathrm{O}=\mathbf{4 2 , 7 5} \% \mathrm{C}, \mathbf{3 , 3 6} \% \mathrm{H}$. $3,589 \mathrm{mg}\left(738 \mathrm{~mm}, 14,5^{\circ} \mathrm{C}, 0,779 \mathrm{ccm} \mathrm{N}=\mathbf{2 4 , 8 6} \% \mathrm{~N}\right.$.

Berechnet für $\mathrm{C}_{4} \mathrm{H}_{4} \mathrm{~N}_{2} \mathrm{O}_{2}=\mathrm{M}$ a cil: $42,82 \% \mathrm{C}, 3,59 \% \mathrm{H}+25,05 \% \mathrm{~N}$.

Rückstand III R 2 (s. S. 245). Ein Teil von III R 2 wurde in dest. Wasser gelöst und mit einer Lösung von 10\% Quecksilbersulfat in $5 \%$ iger Schwefelsäure versetzt. Es entstand ein Niederschlag III $\mathrm{N} 2$ (s. nachstehend), der von der Lösung III L 6 (s. S. 248) abgenutscht und mit $5 \%$ jger Schwefelsäure gut ausgewaschen wurde.

$\mathrm{Niederschlag}$ III $\mathrm{N} 2$ (s. vorstehend). Er wurde in warmem Wasser aufgeschwemmt und durch Einleiten von $\mathrm{H}_{2} \mathrm{~S}$ zerlegt. Der HgSNiederschlag wurde abgenutscht und gut ausgewaschen. Filtrat und Waschwasser wurden nach dem Austreiben von $\mathrm{H}_{2} \mathrm{~S}$ durch Durchsaugen von Luft und nach dem Ausfällen der Schwefelsäure durch genau bemessenen Zusatz von Barytwasser sowie anschliessendes Abnutschen und Auswaschen des $\mathrm{BaSO}_{4}$-Niederschlages im Vakuum bei $37^{\circ} \mathrm{C}$. zur Trockne verdampft. Der Rückstand wurde wiederholt mit Alkohol angefeuchtet und dieser im Vakuum bei $37^{\circ} \mathrm{C}$. wieder abgedampft. Er wurde dann mit dest. Wasser aufgenommen, mit Tierkohle versetzt und filtriert. Das Filtrat wurde langsam bei $37^{\circ} \mathrm{C}$. eingedampft. Es schied sich eine kleinkristallinische Substanz aus, die mehrere Male aus Wasser umkristallisiert wurde.

\section{Untersuchung des Präparats III N 2.}

Physikalische Eigenschaften. Weisse, kristallinische Substanz. Bei 220 facher Vergrösserung stechapfelförmige Kristalle. Schmelzpunkt (unscharf): bei $250^{\circ}$ C. unter Zersetzung.

Chemische Untersuchung.

1. A uf dem Platinblech erhitzt: Verbrennt unter Hinterlassung einer Spur Asche.

2. Mit Natronkalkim Glasröhrchen erhitzt: Entwicklung von Dämpfen, die feuchtes, rotes Lakmuspapier blau färben.

3. Reaktion der wässerigen Lösung: Sauer.

4. Reaktionen der wässerigen Lösung mit:

a) Phosphorwolframsäure: Starker, weisser Niederschlag.

b) Folin's Reagens: Keine Fällung, keine Blaufärbung bei Übersättigung mit $\mathrm{Na}_{2} \mathrm{CO}_{3}$-Lösung.

c) Nessler's Reagens: Gelber Niederschlag.

Elementaranalyse.

Substanz III N 2: hygroskopisch und aschehaltig.

1. $4,187 \mathrm{mg}: 0,205 \mathrm{mg}$ Rückstand $=4,90 \%$ Asche. 5,075 $\mathrm{mg} \mathrm{CO}_{2}$; $1,54 \mathrm{mg} \mathrm{H}_{2} \mathrm{O}=34,76 \% \mathrm{C} ; 4,33 \%$ (auf aschefreie $\mathrm{Sub}$ stanz berechnet).

$6,640 \mathrm{mg}\left(733 \mathrm{~mm}, 14^{\circ} \mathrm{H}.\right): 1,031 \mathrm{ccm} \mathrm{N}=18,73^{\circ} \% \mathrm{~N}$ (auf aschefreie Substanz berechnet). 
$11,668 \mathrm{mg}: 4,19 \mathrm{mg} \mathrm{BaSO}_{4}=15,87 \% \quad \mathrm{H}_{2} \mathrm{SO}_{4}$ (auf aschefreie Substanz berechnet).

$8,820 \mathrm{mg}: 0,428 \mathrm{mg}$ Glülirückstand $=4,85 \%$ Rückstand.

2. $4,285 \mathrm{mg}: 0,268 \mathrm{mg}$ Asche $=6,25 \%$ Asche.

$5,425 \mathrm{mg} \mathrm{CO} ; 1,29 \mathrm{mg} \mathrm{H}_{2} \mathrm{O}=\mathbf{3 4 , 5 3} \% \mathrm{C} ; \mathbf{3 , 3 7} \% \mathrm{H}$ (berechnet auf aschehaltige Substanz).

$36,83 \% \mathrm{C} ; 3,56 \% \mathrm{H}$ (berechnet auf aschefreie Substanz). $4,529 \mathrm{mg}: 0,215 \mathrm{mg}$ Asche $=4.75 \%$ Asche.

$5,595 \mathrm{mg} \mathrm{CO} ; 1,42 \mathrm{mg} \mathrm{H}_{2} \mathrm{O}=33,70 \% \mathrm{C} ; 3,51 \% \mathrm{H}$ (berechnet auf aschehaltige Substanz).

$35,36 \% \mathrm{C} ; 3,65 \% \mathrm{H}$ (berechnet auf aschefreie Substanz). $5,994 \mathrm{mg}\left(732 \mathrm{~mm}, 16^{\circ} \mathrm{C}.\right): 0,978 \mathrm{ccm} \mathrm{N}$

$=18,14 \% \mathrm{~N}$ (berechnet auf aschehaltige Substanz):

$=21,68 \% \mathrm{~N}$ (berechnet auf aschefreie Substanz).

$7,450 \mathrm{mg}: 0,312 \mathrm{mg}$ Asche $=4,19 \%$ Asche.

$2,920 \mathrm{mg} \mathrm{BaSO}_{4}$

$=16,47 \% \mathrm{H}_{2} \mathrm{SO}_{4}$ (berechnet auf aschehaltige Substanz); $=17,23 \% \mathrm{H}_{2} \mathrm{SO}_{4}$ (berechnet auf aschefreie Substanz).

Lös ung III I. 6 (Filtrat vom $\mathrm{HgSO}_{4}$-Niederschlag III N 2 s. S. 247). Aus der Lösung wurde zunächst alles $\mathrm{Hg}$ durch Einleiten von $\mathrm{H}_{2} \mathrm{~S}$ ausgefällt. Der HgS-Niederschlag wurde abgenutscht und gründlich mit warmem, dest. Wasser ausgewaschen. Aus dem Filtrat und Waschwasser wurde nach Verdrängung des gelösten $\mathrm{H}_{\mathrm{g}} \mathrm{S}$ durch Durchsaugen von Luft alle Schwefelsäure durch genau bemessenen Zusatz von Barytwasser ausgefällt. Der $\mathrm{BaSO}_{4}$-Niederschlag wurde abgenutscht und durch wiederholtes Aufrühren mit warmem, dest. Wasser und Wiederabnutschen ausgewaschen. Filtrat und Waschwasser wurden im Vakuum bei $37^{\circ} \mathrm{C}$. zur Trockne verdampft. Der Rückstand wurde nach wiederholtem Übergiessen mit absolutem Alkohol und Wiederabdampfen desselben mit dest. Wasser aufgenommen und filtriert. Das Filtrat wurde bei $37^{\circ} \mathrm{C}$. im Kristallisierschälchen langsam eingedampft. Der Rückstand wurde auf einem Filter gesammelt und mit Alkohol ausgewaschen. sodann getrocknet und aus dest. Wasser wiederholt umkristallisiert.

\section{Untersuchung des Präparats III $L$.}

Physikalische Eigenschaften. Weisse, kleinkristallinische Substanz. Bei 220 facher lin. Vergrösserung feine, büschelförmig angeordnete Nädelchen. In Wasser ziemlich leicht löslich, in Alkohol unlöslich. Schmelzpunkt (unk.): $212-213^{\circ}$ C. unter Zersetzung.

Chemische Untersuchung.

1. A f dem Platinblech erhitzt: Verbrennt unter Hinterlassung einer minimalen Menge Asche.

2. Mit Natronkalk im Glasröhrchenerhitzt: Entwicklung von Dämpfen, die feuchtes, rotes Lakmuspapier. blau färben.

3. Reaktion der wässerigen Lösung: Schwach sauer. 
Beitrag zur Kenntnis von organischen Nahrungsstoffen mit spezif. Wirkung. 249

4. Reaktionen der wässerigen Lösung mit:

a) Silbernitrat (in salpetersaurer Lösung): Kaum wahrnehmbare Trübung, auf Zusatz von überschüssigem $\mathrm{NH}_{3}$ sofort verschwindend.

b) Chlorbarium (in salzsaurer Lösung): Keine Fällung bzw. Trübung.

c) Phosphorwolframsäure: Weisser Niederschlag.

d) Quecksilberchlorid (konzentrierte wässerige Lösung): Keine Fällung.

e) Saures Quecksilbersulfat: Keine Fällung.

f) Pikrinsäure: Keine Fällung.

g) Nessler's Reagens: Geringe Trübung.

h) Pikrolonsäure: Keine Fällung.

i) Folin's Reagens: Keine Fällung, keine Blaufärbung nach Zusatz überschüssiger $\mathrm{Na}_{2} \mathrm{CO}_{3}$-Lösung.

k) Ninhydrinlösung 1\% (Kochprobe): Starke Blaufärbung.

5. Stickst off bestim m ung (Mikrokjeldahl-Methode von A bderh a lden und Fodor s. S. 204).

Verwandt: Probe Nr. 1: 0,1016 g; Probe Nr. 2: 0,1012 g.

Verbraucht an 1/20 n. Schwefelsäure: (Faktor: 0,0007005):

Probe Nr. 1: 15,1 ccm entsprechend, $0,01057755 \mathrm{~g} \mathrm{~N}=\mathbf{1 0 , 4 5} \% \mathrm{~N}$; $2: 14,9 \mathrm{ccm} \quad, \quad 0,01043745 \mathrm{~g} \mathrm{~N}=\mathbf{1 0 , 3 1} \% \mathrm{~N}$. Arithmetisches Mittel: $10,38 \%$ Stickstoff.

Behufs weiterer Reinigung für die Elementaranalyse wurde das Präparat in dest. Wasser gelöst. Diese Lösung wurde mit einer konzentrierten ammoniakalischen Silberlösung versetzt, bis keine Fällung mehr erfolgte. Das so ausgefällte Silbersalz wurde auf einer kleinen Nutsche gesammelt und zuerst mit dest. Wasser, dann mit Alkohol gut ausgewaschen, Es wurde nun in Wasser suspendiert und durch Finleiten von Schwefelwasserstoff zerlegt. Der Silbersulfitniederschlag wurde abgenutscht und gut ausgewaschen. Filtrat und Waschwasser wurden zunächst durch Durchsaugen von Luft von $\mathrm{H}_{2} \mathrm{~S}$ befreit und dann bei $37^{\circ} \mathrm{C}$. unter vermindertem Druck zur Trockne verdampft. Der Rückstand wurde in dest. Wasser gelöst und dann bei $37^{\circ} \mathrm{C}$. langsam eingedampft, bis sich eine genügende Menge von Kristallen ausgeschieden hatte. Diese wurden auf einer kleinen Nutsche gesammelt, zuerst mit dést. Wasser, dann mit Alkohol gewaschen und hierauf zunächst bei Zimmertemperatur und schliesslich bei $105^{\circ} \mathrm{C}$. getrocknet, um zur Elementaranalyse verwandt zu werden.

6. Elementaranalyse (von III L 6).

Substanz nicht hygroskopisch, aschefrei :

$$
\begin{aligned}
& 4,050 \mathrm{mg}: 6,91 \mathrm{mg} \mathrm{CO}_{2} ; 2,61 \mathrm{mg} \mathrm{N}_{2} \mathrm{O}=\mathbf{4 6 , 5 3} \% \mathrm{C} ; \mathbf{7 , 2 1} \% \mathrm{H} \text {. } \\
& 4,572 \mathrm{mg}: 7,755 \mathrm{mg} \mathrm{CO} ; 2,89 \mathrm{mg} \mathrm{N}_{2} \mathrm{O}=\mathbf{4 6 , 2 6} \% \mathrm{C} ; \mathbf{7 , 0 7} \% \mathrm{H} \text {. } \\
& 6,095 \mathrm{mg}\left(731 \mathrm{~mm}, 14^{\circ} \mathrm{C} \text {.) }: 0,522 \mathrm{ccm} \mathrm{N}=9,80 \% \mathrm{~N}\right. \text {. } \\
& 4,188 \mathrm{mg}: 7,03 \mathrm{mg} \mathrm{CO}_{2} ; 2,48 \mathrm{mg} \mathrm{H} \mathrm{H}_{2} \mathrm{O} .45,78 \% \mathrm{C} ; 6,63 \% \mathrm{H} \text {. } \\
& 2,497 \mathrm{mg}: 7,63 \mathrm{mg} \mathrm{CO}_{2} ; 2,78 \mathrm{mg} \mathrm{H}_{2} \mathrm{O} \text {. 46,27\% C; } 6,92 \% \mathrm{H} \text {. } \\
& 3,912 \mathrm{mg}\left(736 \mathrm{mg}, 17^{\circ} \mathrm{C} \text {.) : } 0,359 \mathrm{~cm} \mathrm{~N}=\mathbf{1 0 , 4 6 \%} \mathrm{N}\right. \text {. }
\end{aligned}
$$


Die Analysenwerte sowie das Verhalten der Substanz sprechen für eine Verbindung der Gruppe des Prolins.

Berechnet für Oxyprolin :

$$
\mathrm{C}_{5} \mathrm{H}_{9} \mathrm{NO}_{3}: 45,77 \% \mathrm{C}, 6,19 \% \mathrm{H} \text { und } 11,68 \% \mathrm{~N} \text {. }
$$

Tierversuche s. S. 269.

Lösung III L 5. (In Alkohol löslicher Anteil des eingedampften Hydrolysats von III L 3 s. S. 244.) Die alkoholische Lösung wurde durch Abdampfen im Vakuum bei $37^{\circ} \mathrm{C}$, von Alkohol befreit. Der Rückstand wurde in dest. Wasser gelöst und nochmals bei $37^{\circ} \mathrm{C}$. im Vakuum eingedampft. Es hinterblieb ein dickflüssiger, dunkler Rückstand, aus dem sich bei längerem. Stehen in einer Kältemischung eine nur sehr kleine Menge von Kristallen aussehied, deren Abscheidung von der dickflüssigen Mutterlauge sich als untunlich erwies. Der Rückstand wurde daher wieder in absolutem Alkohol gelöst und filtriert. Das Filtrat, welches noch sehr sauer reagierte, wurde mit alkoholischer Natronlauge versetzt, bis die Hauptmenge der Säure gesättigt war, dann mit wasserfreiem Natriumkarbonat im Überschuss versetzt und unter häufigem Umschütteln 24 Stunden lang stehengelassen, hierauf filtriert. Das Filtrat wurde im Vakuum bei $37^{\circ} \mathrm{C}$. eingedampft, der Rückstand in dest. Wasser gelöst und langsam bei $37^{\circ} \mathrm{C}$. in einem Kristallisierschälchen zur Trockne verdampft. Es blieb ein zum grössten Teil kristallinischer Rückstand zurück. Der braungefärbte Kristallbrei wurde abgenutscht, dann in dest. Wasser gelöst, mit 'Tierkohle versetzt, einmal kurz aufgekocht nnd nach dem Wiederabkühlen filtriert. Das noch etwas gelblich gefärbte Filtrat wurde im Vakuum bei $37^{\circ} \mathrm{C}$. wieder stark eingeengt, nochmals mit Tierkohle versetzt, aufgekocht und filtriert. Das nunmehr klare und beinahe farblose Filtrat wurde durch langsames Eindampfen bei $37^{\circ} \mathrm{C}$. so weit eingeengt, dass sich beim Abkühlen eine mässige Menge von Kristallen ausschied, die auf einem kleinen Filter gesammelt, mit etwas $100 \%$ igem Alkohol, dann noch mit Äther gewaschen und schliesslich getrocknet wurden.

\section{Untersuchung des Präparats III L o.}

Physikalische Eigenschaften. Weisse, kristallinische Sabstanz, aus feinen, zu Drusen und Wärzchen vereinigten mikroskopischen Kristallnädelchen bestehend. In Wasser ziemlich leicht, in Alkohol sehr schwer löslich. Schmelzpunkt (unk.): $239-240^{\circ} \mathrm{C}$. unter Zersetzung.

Die Lösung von Präparat III L 5 in dest. Wasser erwies sich als optisch inaktiv; nach Zusatz von Salzsäure war $[\alpha]_{\mathrm{p}}=+12,6^{\circ} \mathrm{C}$.

Chemische Untersuchung.

1. Auf dem Platinblech erhitzt: Verbrennt unter Hinterlassung einer minimalen Menge. Asche.

2. Mit Natronkalkim Glasröhrchen erhitzt: Entwicklung von Dämpfen, die feuchtes, rotes Lakmuspapier blau färben.

3. Reaktion der wässerigen Lösung: Schwach saucr.

4. Reaktionen der wässerigen Lösung mit:

a) Silbernitrat (salpetersaure Lösung): Äusserst geringe Trübung, bei Zusatz von überschüssigem $\mathrm{NH}_{3}$ sofort versehwindend. 
Beitrag zur Kenntnis von organischen Nahrungsstoffen mit spezif. Wirkung. 251

b) Chlorbarium (salzsaure Lösung): Keine Fällung bzw. Trübung.

c) Folin's Reagens: Keine Fällung, nach Zusatz überschüssiger $\mathrm{Na}_{2} \mathrm{CO}_{3}$-Lösung keine Blaufärbung.

d) Nessler's Reagens: Gelblich-weisse Fällung.

e) Phosphorwolframsäure: Starker, weisser Niederschlag.

f) Quecksilberchlorid (konzentrierte, wässerige Lösung): Keine Fällung.

g) Saures Quecksilbersulfat: Keine Fällung.

h) Cadmiumchlorid: Keine Fällung.

i) Ninhydrinlösung 1\% (Kochprobe): Starke Blaufärbung.

5. Kupfersalz: Mit frischgefälltem, gut ausgewaschenem Kupferoxyd gekocht, dann filtriert, gab III L 5 eine dunkelblaue Lösung, aus der sich beim Eindampfen dunkelblaue, plättchenförmige Kristalle ausschieden, die farnkrautartig aneinandergereiht waren.

6. Elementaranalys :

a) $0,0204 \mathrm{~g}$ Substanz gaben $0,036265 \mathrm{~g} \mathrm{CO}_{2}=0,00989 \mathrm{~g} \mathrm{C}=48,48 \% \mathrm{C}$. b) $0,0204 \mathrm{~g} " \quad$ " $0,01600 \mathrm{~g} \mathrm{H}_{2} \mathrm{O}=0,001794 \mathrm{~g} \mathrm{H}=8,79 \% \mathrm{H}$.

c) $0,03601 \mathrm{~g} " \quad " \quad 3,8 \mathrm{~cm} \mathrm{~N}$ bei $713 \mathrm{~mm}$ und $20^{\circ} \mathrm{C}=11,57^{\circ} \mathrm{C}$.

$$
\begin{aligned}
& \mathrm{C}: 48,48 \%, \\
& \mathrm{H}: 8,79 \%, \\
& \mathrm{~N}: 11.57 \% \text {. }
\end{aligned}
$$

Tierversuches. S. 270.

Rückstand III R 1. (In Wasser unlöslicher Anteil des Rückstandes von III L 1 s. S. 244.) Die schwarze, teerartige Substanz wurde mit absolutem Alkohol in einer Reibschale gut durchgerührt. Sie löste sich hierbei nur zum Teil. Es blieb eine graugefärbte pulverige Substanz III $R 1$ zurück, die von der sehr dunkelgefärbten alkoholischen Lösung III L 4 (s. S. 252) durch Abnutschen und Auswaschen mit absolntem Alkohol getrennt wurde. Sie wurde in dest. Wasser aufgeschwemmt und durch Einleiten von $\mathrm{H}_{2} \mathrm{~S}$ zerlegt. Der HgSNiederschlag wurde abgenutscht und gut ausgewaschen. Filtrat und Waschwasser wurden zunächst von $\mathrm{H}_{2} \mathrm{~S}$ durch Durchsaugen von Luft befreit, dann im Vakuum bei $37^{\circ} \mathrm{C}$. eingedampft. Der Rückstand wurde wiederholt mit absolutem Alkohol übergossen und nach dem Abdampfen desselben im Vakuum bei $37^{\circ} \mathrm{C}$. in dest. Wasser gelöst. Die Lösung wurde mit Tierkohle versetzt und filtriert, das Filtrat langsam bei $37^{\circ} \mathrm{C}$. in einem Kristallisierschälchen abgedampft. Die ausgeschiedenen Kristalle wurden schliesslich noch durch Umkristallisieren aus dest. Wasser gereinigt und über Natronkalk im Vakuumexsikkator getrocknet. Die Untersuchung des Präparats III R 1 ergab, dass es mit Präparat III R (s. S. 237), mit dem es ein durchaus gleiches Verhalten zeigte, identisch war. Es handelte sich demnach auch bei Präparat III R 1 um Betainchlorhydrat.

Tierversuches. S. 221 (Präparat I R 1). 
Lösung III I. 4. (In Alkohol löslicher Anteil des Rückstandes von III $\mathrm{R} 1$ s. vorstehend.) Nach Verdünnung der Lösung mit dest. Wasser wurde zunächst alles $\mathrm{Hg}$ aus derselben durch Einleiten von $\mathrm{H}_{2} \mathrm{~S}$ ausgefällt. Dieses wurde abgenutscht und gründlich ausgewaschen. Filtrat und Waschwasser wurden im Vakuum bei $37^{\circ} \mathrm{C}$. stark eingeengt. Die teerartige, schwarze Substanz, welche sich hierbei abschied, wurde abfiltriert. Das Filtrat wurde nun möglichst weit eingedampft, der Rückstand mit dest. Wasser aufgenommen. In der noch sehr dunkelgefärbten Lösung wurden nun $20 \mathrm{~g}$ Kupfersulfat aufgelöst und $\mathrm{H}_{2} \mathrm{~S}$ eingeleitet, bis alles Kupfer wieder ausgefällt war. Der CuS-Niederschlag wurde abgenutscht und gut ansgewaschen. Filtrat und Waschwasser wurden zunächst durch Durchsangen von Luft von $\mathrm{H}_{2} \mathrm{~S}$, dann durch Zusatz von Barythydrat von der Hauptmenge der Schwefelsäure befreit. Der $\mathrm{BaSO}_{4}$ Niederschlag wurde alfiltriert und gründlich ansgewaschen. Filtrat und Waschwasser wurden bei $37^{\circ} \mathrm{C}$. stark eingeengt, dann mit einer Lösung von $10 \% \mathrm{HgSO}_{4}$ in $5 \%$ iger Sehwefelsäure so lange versetzt, bis keine weitere Fällung mehr erfolgte ${ }^{1}$ ). Der so erhaltene $Q u e c k s i l b e r s u l f$ t niederschlag III N 1 (s. nachstehend) wurde von der Lösung III F 2 (s. S. 254) abgenutscht und ausgewaschen.

Quecksilbersulfatniederschlag III N 1. Er wurde durch Einleiten von $\mathrm{H}_{2} \mathrm{~S}$ zerlegt. Der HgS-Niederschlag wurde abgenutscht und gut ausgewaschen. Filtrat und Waschwasser wurden nach Verjagen des gelösten $\mathrm{H}_{2} \mathrm{~S}$ durch Durchsaugen von Luft in Valiuum bei $37^{\circ} \mathrm{C}$. eingedampft. Es blieb ein gelblich gefärbter, zum Teil kristallinischer Rückstand, der teilweise in Alkohol löslich war, zurück. Er wurde mit absolutem Alkohol gut durehgerührt. Der in absolutem Alkohol unlösliche Anteil III N 3 (s. nachstehend) wurde abfiltriert und gut mit absolutem Alkohol ausgewaschen. Der in Alkohol lösliche Anteil III L 7 wurde, wie auf S. 253 angegeben, weiterbehandelt.

Präparat III N 3 (s. vorstehend). (In Alkohol unlöslicher Anteil des zerlegten $\mathrm{HgSO}_{4}$-Niederschlages III N 1.) Die Substanz wurde in dest. Wasser gelöst, dann mit Barytwasser in genau bemessener Menge, so dass alle Schwefelsäure gerade ausgefällt war, versetzt. Die (auch von Barytverbindungen freie) Lösung wurde nun vom $\mathrm{BaSO}_{4^{-}}$ Niederschlag abgenutscht und letzterer sorgsam ausgewaschen. Filtrat und Waschwasser wurden zuerst im Vakuum bei $37^{\circ} \mathrm{C}$, dann bei $37^{\circ} \mathrm{C}$. langsam in einem Kristallisierschälchen eingedampft. Der sehr geringe $\mathrm{R} \ddot{\mathrm{c}} \mathrm{kstand}$ wurde noch einmal aus dest. Wasser umkristallisiert.

Untersuchung des Präparats III N 3 (Mikrophotographie Nr. 50).

Weisse, kristallinische Substanz. Bei 220 facher lin. Vergrösserung derbe, zu Drusen zusammengelagerte Kristalle. Schmelzpunkt: Zersetzt sich bei $240^{\circ} \mathrm{C}$. unter Abscheidang von Kohle.

$$
\text { Chemische Untersuchung. }
$$

1. A uf dem Platinblech erhitzt: Verbrennt unter Hinter lassung einer minimalen Menge Asche.

1) Der $\mathrm{HgSO}_{4^{-}}$Niederschlag schied sich nur sehr langsam aus. Erst nach mehreren Tagen war keine weitere Föllung mehr bemerkbar. 
Beitrag zur Kenntnis von organischen Nahrungsstoffen mit spezif. Wirkung. 253

2. Mit Natronkalk im Glasröhrehen erhitzt: Entwicklung von Dämpfen, die feuchtes, rotes Lakmuspapier blau färben. Zì weiteren Reaktionen war die zur Verfügung stehende Menge zu gering.

3. Elementaranalyse von III $\mathrm{N} 3$.

Die Substanz ist nicht hygroskopisch und aschefrei.

$4,250 \mathrm{mg}: 5,07 \mathrm{mg} \mathrm{CO}+1,38 \mathrm{mg} \mathrm{N}_{2} \mathrm{O}=\mathbf{3 2 , 5 3} \% \mathrm{C}+\mathbf{3 , 6 3} \% \mathrm{H}$.

$5,447 \mathrm{mg}: 3,49 \mathrm{mg} \mathrm{AgCl}=\quad \mathbf{1 5 , 8 5 \%}$ Cl.

2,032 mg (734 mm, $14^{\circ}$ C.) : 0,671 ccm $\mathrm{N}=\mathbf{3 7 , 9 4} \% \mathrm{~N}$.

Wahrscheinlich Guaninchlorhydrat:

Berechnet fürr $\mathrm{C}_{5} \mathrm{H}_{5} \mathrm{~N}_{5} \mathrm{O} \cdot \mathrm{HCl}: 32,00 \% \mathrm{C}, 3,20 \% \mathrm{~N}+37,35 \% \mathrm{~N}$.

Lösung III L. 7. (In Alkohol löslicher Anteil des $\mathrm{HgSO}_{4}$-Niederschlages III N 1 s. S. 252.) Die alkoholische Lösung wurde bei $37^{\circ} \mathrm{C}$. langsam eingedampft. Der Rückstand wurde mit dest. Wasser aufgenommen, mit Tierkohle versetzt und filtriert. Das Filtrat wurde bei $37^{\circ} \mathrm{C}$. zuerst im Vakuum, dann langsam bei $37^{\circ} \mathrm{C}$. eingedampft. Es hinterblieb ein dickflüssiger, gelber Rückstand, aus dem sich bei längerem Stehen im Exsikkator über $\mathrm{H}_{2} \mathrm{SO}_{4}$ Kristalle ausschieden, deren Trennung von dex zähflüssigen Mutterlauge nicht gelang. Der Rückstand wurde daher wieder in absolutem Alkohol gelöst und durch Verreiben mit Quecksilberchlorid in einer Reibschale mit diesem gesättigt. Es entstand ein Niederschlag III N 7 (s. nachstehend), der von der Lösung III F 7 (s. unten) abgenutscht und mit absolutem Alkohol ausgewaschen wurde.

Präparat III N 7. ( $\mathrm{HgCl}_{2}$-Niederschlag aus III L 7 s. vorstehend.) Der Niederschlag wurde in dest. Wasser aufgeschwemmt und durch Einleiten von $\mathrm{H}_{2} \mathrm{~S}$ zerlegt. Der HgS-Niederschlag wurde abgenutscht und gut ausgewaschen. Filtrat und Waschwasser wurden von $\mathrm{H}_{2} \mathrm{~S}$ durch Durchsaugen von Luft befreit, dann zuerst im Vakunm bei $37^{\circ} \mathrm{C}$, hierauf im Kristallisierschälchen (im Exsikkator über $\mathrm{H}_{2} \mathrm{SO}_{4}$ und neben einem Schälchèn mit $\mathrm{NaOH}$ ) eingedampft. Der sehr geringe Rü ckstand wurde noch einmal umkristallisiert.

\section{Untersuchnng des Präparats III $\mathbf{N} 7$.}

Weisser, kristallinischer Rückstand. Bei 220 facher lin. Vergrösserung derbe, unregelmässige Kristalle. Leicht löslich in Wasser. Zersetzt sich bei $170^{\circ} \mathrm{C}$. unter Kohleabscheidung, ohne zu schmelzen.

Chemische Untersuchung.

1. A uf dem Platinblech erhitzt: Verbrennt unter Hinterlassung eines geringen Ascherückstandes.

2. Mit Natronkalkim Glasröhrchen erhitzt: Entwicklung von Dämpfen, die rotes Lakmuspapier blau färben.

$\mathrm{Zu}$ weiteren Reaktionen war die gewonnene Menge nicht ausreichend.

Tierversuch s. S. 270.

Lösung III F 7. (Durch $\mathrm{HgCl}_{2}$ nicht fällbarer Anteil von III L 7 s. S. 252.) Die alkoholische Lösung wurde im Vakuum bei $37^{\circ} \mathrm{C}$. eingedampft. Der Rückstand wurde mit dest. Wasser aufgenommen und die Lösung durch Eiñleiten von $\mathrm{H}_{2} \mathrm{~S}$ von $\mathrm{Hg}$-befreit, Der HgS-Nieder- 
schlag wurde abgenutscht und sorgfältig ausgewaschen. Das Filtrat und Waschwasser wurden von $\mathrm{H}_{2} \mathrm{~S}$ durch Durchsangen von Luft befreit, dann bei $37^{\circ} \mathrm{C}$. zuerst im Vakuum, hierauf im Kristallisierschälchen eingedampft. Der Rückstand wurde mit 100\% igem Alkohol aufgenommen. Es hinterblieb ein aus mikroskopischen Nädelchen bestehender Rückstand, der als Calciumsulfat erkannt wurde (auf dem Platinblech erhitzt: unverbrennlich. Mit verdünnter $\mathrm{HCl}$ behandelt, dann filtriert: Das Filtrat gab mit $\mathrm{BaCl}_{2}$ einen weissen Niederschlag, mit $\mathrm{NH}_{3}$ übersättigt, dann mit Ammonoxalat versetzt ebenfalls einen weissen Niederschlag, der in Essigsäure unlöslich war). Die vom $\mathrm{CaSO}_{4}$ abfiltrierte alkoholische Lösung wurde langsam bei $37^{\circ} \mathrm{C}$. eingedampft, dann längere Zeit im Vakuumexsikkator über $\mathrm{H}_{2} \mathrm{SO}_{4}$ und neben einem Schälchen mit $\mathrm{NaOH}$ belassen. Es hinterblieb eine sehr geringe Menge eines gelblich gefärbten, kolloiden Rückstandes, der mit F olin's Reagens nach Übersättignng mit $\mathrm{Na}_{2} \mathrm{CO}_{3}$-Lösung starke Blaufärbung gab. Bei längeren Stehen im Valzuumexsikkator schieden sich in dem Rückstande Kristalle aus (Mikrophotographie Nr. 51). Auf dem Platinblech erhitzt: bis auf einen geringen Ascherückstand verbrennbar. Mit Natronkalk im Glasröbrchen erhitzt: Entwicklung von Dämpfen, die feuchtes, rotes Lakmuspapier blau färben.

Tierversuch s. S. 270 .

Lösung III F 2. (Filtrat vom $\mathrm{HgSO}_{4}$-Niederschlag III N 1 s. S.252.) Die Lösung wurde durch Einleiten von $\mathrm{H}_{2} \mathrm{~S}$ von $\mathrm{Hg}$ befreit, der $\mathrm{HgS}-$ Niederschlag abfiltriert und gut ausgewaschen. Filtrat und Waschwasser wurden, nach dem Verdrängen von gelöstem $\mathrm{H}_{2} \mathrm{~S}$ durch durchgesogene Luft, von $\mathrm{H}_{2} \mathrm{SO}_{4}$ durch genau bemessenen $\mathrm{Zusatz}$ von Barythydrat bzw. Barytwasser ausgefällt. Der $\mathrm{BaSO}_{4}$-Niederschlag wurde abgenutscht und gründlich ausgewaschen. Filtrat und Waschwasser wurden bei $37^{\circ} \mathrm{C}$. eingedampft. Es hinterblieb ein dickflüssiger, brauner Rückstand, der mit dest. Wasser aufgenommen und mit einer Losung von $25 \%$ Phosphorwolframsäure in $5 \%$ iger Schwefelsäure so lange versetzt wurde, bis keine Fällang mehr erfolgte. Der Phosphorwolframsäureniederschlag wurde abgenutscht, mit $5 \%$ iger Schwefelsäure gut ausgewaschen, in eiskaltem dest. Wasser aufgeschwemmt und unter Eiskühlung mit Bariumhydroxyd durch Verreiben in einer Reibschale zerlegt. Der Niederschlag wurde abgenutscht, in eiskaltem dest. Wasser wiederholt aufgeschwemmt und wieder auf die Nutsche gebracht. Das ständig unter Eiskühlung gehaltene Filtrat wurde durch vorsichtigen und genau bemessenen Zusatz verdünnter Schwefelsäure von Baryt befreit. Der $\mathrm{BaSO}_{4}$-Niederschlag wurde abgenutscht und gut ausgewaschen. Filtrat und Waschwasser wurden im Vakuum bei $37^{\circ} \mathrm{C}$. eingedampft. Es hinterblieb ein dickflüssiger, gelber Rückstand, der im Vakuumexsikkator über frischgebranntem Ätzkalk und Natronkalk eingetrocknet und dann in einer erwärmten Reibschale zu einem feinen Pulver zerrieben wurde.

Gelblich-weisses Pulver, sehr hygruskopisch und in Wasser leicht löslich. Beim Eindampfen eines Tropfens der wässerigen Lösung auf einem Objektträger im Vakuumexsikkator fanden sich im Rückstande mikroskopische Kristalle von der Gestalt sphärischer Zweiecke. 
Beitrag zur Kenntnis von organischen Nahrungsstoffen mit spezif. Wirkung. 255

Versuche, diese Kristalle zu isolieren, schlugen fehl. Die wässerige Lösung des Pulvers gab mit Folin's Reagens nach Übersättigung mit $\mathrm{Na}_{2} \mathrm{CO}_{3}$-Lösung schwache Blaufärbung. Biuretreaktion stark positiv (Peptonreaktion).

Tierversuches. S. 271.

\section{Tierversuche mit den aus hydrolysierter Hefe gewonnenen Abbauprodukten.}

I. Tertiärer Acetonniederschlag (S. 216).

(Siehe auch die Tierversuche mit dialysiertem Acetonniederschlag S. 128.)

Versuch Nr. 24.

Versuchstier: Eine junge, durch längere einseitige Fütterung mit rohem geschliffenën Reis extrem abgemagerte junge Taube ohne irgendwelche nervöse Störungen (keine Lähmungen, kein Opisthotonus, keine Krämpfe u. dgl. m.).

Beginn des Versuches: 29. Oktober 1917.

Schluss des Versuches: 18. November 1917.

Nahrung: Geschliffener roher Reis.

Tägliche Zugaben:

vom 29. Oktober bis 2. November: $0,05 \mathrm{~g}$ tertiärer Acetonniederschlag;

vom 3. bis 14 . November: $0,10 \mathrm{~g}$ tertiärer Acétonniedersehlag $+0,10 \mathrm{~g}$ Hefeasche (entsprechend der Asche aus $1 \mathrm{~g}$ Hefe);

vom 15. bis 17. November: $0,10 \mathrm{~g}$ tertiärer Acetonniederschlag $+0.10 \mathrm{~g}$ Hefeasche $+0,05 \mathrm{~g}$ des Präparats I R (Betainchlorhydrat).

Sämtliche Präparate wurden in Pillen verabreicht, die mit reiner Stärke und reinem Stärkekleister bereitet waren.

Körpergewichte:

Datum 1917

29. Oktober

2. November

3. "

7. $"$

Gewicht
$142 \mathrm{~g}$
$137 \mathrm{~g}$
$139 \mathrm{~g}$
$144 \mathrm{~g}$

Datum 1917

10. November 14 .

17.
Gewicht

$140 \mathrm{~g}$

$136 \mathrm{~g}$

$132 \mathrm{~g}$

Verhalten der Versuchstaube: Sie war bis zum 17. November munter und frass spontan, wenn auch nur geringe Mengen (ca. $8 \mathrm{~g}$ pro Tag). Lähmungen und andere nervöse Störungen traten nicht auf. Am 18. November früh starb die Taube plötzlich und ohne Vorzeichen des nahe bevorstehenden Todes.

\section{Versuch Nr. 25.}

Versuchstie $x$ : Eine junge, infolge längerer einseitiger Fütterung mit geschliffenem rohen Reis extrem abgemagerte Taube ohne Störungen nervöser Art (keine Lähmungen, kein Opisthotonus, keine Krämpfe und dergleichen mehr).

Beginn des Versuches: 29. Oktober 1917. 
Schluss des Versuches: 24. November 1917.

Nahrung: Geschliffener, roher Reis.

Tägliche Zugaben:

vom 29. Oktober bis 2. November $0,05 \mathrm{~g}$ tertiärer Acetonniederschlag;

vom 3 . bis 17 . November $0,10 \mathrm{~g}$ tertiärer Acetonniederschlag $+0,10 \mathrm{~g}$ Hefeasche (entsprechend der Asche aus $1 \mathrm{~g}$ trockener Hefe);

vom 18. bis 24. November: $0,10 \mathrm{~g}$ tertiärer Acetonniedersehlag $+0,10$ g Rinderblutkörperchen.

Sämtliche Präparate wurden in Pillen verabreicht, die mit reiner Stärke und reinem Stärkekleister dargestellt waren.

Körpergewich te:

\begin{tabular}{|c|c|c|c|}
\hline Datum 1917 & Gewicht & Datum 1917 & Gewicht \\
\hline 29. Oktober & $130 \mathrm{~g}$ & 10. November & $137 \mathrm{~g}$ \\
\hline 2. November & $130 \mathrm{~g}$ & $14 . \quad "$ & $135 \mathrm{~g}$ \\
\hline $3 . \quad \pi$ & $137 \mathrm{~g}$ & 17. & $137 \mathrm{~g}$ \\
\hline 7. & $145 \mathrm{~g}$ & 24. & - \\
\hline
\end{tabular}

Verhalten der Versuchstaube: Bis zum 24. November ziemlich munter. Lähmungen sowie andere Erscheinungen nervöser Art traten nicht auf. Am 25. November früh war die.Taube schwer krank und moribund. Trotz Einspritzung von $0,15 \mathrm{~g}$ dialysierten Acetonniederschlages und einer Gabe von $0,36 \mathrm{~g}$ Hefenuklein ging die Taube eine halbe Stunde später ein.

Präparat I A (S. 216).

(Zerlegter, primärer Quecksilberchlorid-Niederschlag.)

1. Einer erkrankten Taube (Lähmung der Beine und Flügel) wurde eine kleine (nicht gewogene) Menge, in $5 \mathrm{ccm}$ dest. Wassers gelöst, in zwei Malen innerhalb von 3 Stunden in den Brustmuskel eingespritzt. Nach Verlauf von 2 Stunden erhebliche Besserung. Nach weiteren 20 Stunden lief die Taube ohne merkliche Behinderung umher.

2. Einer schwer erkrankten Taube (Lähmung der Beine und Flügel, Opisthotonus, Krämpfe) (Photographie $\mathrm{Nr}$. 9) wurde eine etwas grössere (ebenfalls nicht gewogene) Menge, in $2 \mathrm{ccm}$ dest. Wassers gelöst, in den Brustmuskel eingespritzt. Nach 2 Stunden wesentliche Besserung: Opisthotonus und Krämpfe geschwunden (Photographie $\mathrm{Nr}, 10$ ). Nach weiteren 3 Stunden weitere Besserung. Am nächstfolgenden Tage war die Taube wieder sehr munter und imstande, sich behende zu bewegen.

3. Einer schwer gelähmten Taube (Photographie N'r. 11) wurde eine intramuskuläre Einspritzung von $0,01 \mathrm{~g}$, in $5 \mathrm{ccm}$ dest. Wassers gelöst, gemacht. Nach $3^{1 / 2}$ Stunden wesentliche Besserung ( $P$ h o to graph ie Nr. 12). Am nächsten Tage lief die Taube wieder behende umher.

4. Eine typisch erkrankte ju ng e Taube (Beinlähmung, Opisthotonus, Kränpfe) bekam am 12. Juni 1917 um 5/4 Uhr nachm. eine intramuskuläre Einspritzung von $0,005 \mathrm{~g}$, in $2 \mathrm{ccm}$ dest. Wassers gelöst. Um 7 Uhr nachm. waren Opisthotonus und Krämpfe geschwunden. Das 
Beitrag zur Kenntnis von organischen Nahrungsstoffen mit spezif. Wilkung. 257

'Tier war noch sehr matt und somnolent. Am nächsten Tage war die Taube wieder sehr munter und lief behende umher. Die Wirkung hielt indessen nur bis zum 15. Juni nachm. an. Es stellten sich dann wieder Lähmung und Streckkrampf der Beine sowie Opisthotonus ein.

5. Einer mit dem Präparat I R 2 mit nur teilweisem Erfolg vorbehandelten, an den Beinen gelähmten Taube wurden am 17. Juli 1917 um 11 Uhr vorm. $0,01 \mathrm{~g}$, in $3 \mathrm{ccm}$ dest. Wassers gelöst, in den Brustmuskel eingespritzt. Um $3 \mathrm{Uhr}$ nachm. Rückgang der Paresen der Beine bemerkbar. Um $3^{1 / 2}$ Uhr nachm. Einspritzung von weiteren $0,015 \mathrm{~g}$, in $4,5 \mathrm{ccm}$ dest. Wassers gelöst. Am 18. J uli früh Paresen der Beine noch sehr ausgesprochen, Gang stolprig und unsicher. Das Tier kippte beim Laufen häufig bald seitwärts, bald nach vorne um. Es bekam um $11 \mathrm{Uhr}$ vorm. $0,5 \mathrm{~g} \mathrm{Hefenuklein} \mathrm{in} \mathrm{Pillenform.}$ Am 19. Juli weiterer Rückgang der Paresen. Linksseitige Lähmung and ausgesprochene Fresslust gegen geschliffenen rohen Reis ebenso wie an dem vorhergehenden Tage vorhanden. Nochmals $0,5 \mathrm{~g} \mathrm{Hefe-}$ nuklein per os. Am 20. Juli weiterer, aber unerheblicher Rückgang der Paresen der Beine, die jetzt auf der rechten Seite ausgesprochener erschienen. Die Taube bekam nun täglich 1 g getrockneter Bier hefe Qual. I (s. S. 206) in 6 Pillen. Die Paresen waren bei sonstigem sehr gutem Allgemeinbefinden der Taube erst am 7. A u g u st 1917, also nach 25 tägiger Behandlung, vollkommen geschwunder. Über die vom 21. Juli ab aufgenommenen Mengen von geschliffenem Reis und die Zunahme des Körpergewichts der Taube geben nachstehende Tabellen Aufschluss:

Am 26. Ju.li 1917 wurde die Taube photographiert. Dies Bild veranschaulicht die trotz neuntägiger Behandlung mit sehr wirksamen Hefepräparaten noch sehr ausgesprochene Lähmungen der Beine (Photographie Nr. 13).

Körpergewichte:

\begin{tabular}{ll|ll} 
Datum 1917 & Gewicht & Datum 1917 & Gewicht \\
20. Juli & $206 \mathrm{~g}$ & 10. August & $242 \mathrm{~g}$ \\
28. & $200 \mathrm{~g}$ & $14 . \quad "$ & $247 \mathrm{~g}$ \\
4. August & $215 \mathrm{~g}$ & $18 . \quad "$ & $264 \mathrm{~g}$ \\
7. $"$ & $230 \mathrm{~g}$ & &
\end{tabular}

Gewichtszuna hme: vom 20. Juli bis 4. Angust - 15 Tage $-14 \mathrm{~g}=6,97 \%$ des Anfangsgewichts, $0,91 \mathrm{~g}$.pro Tag:

vom 4. bis 14. August -10 Tage $-32 \mathrm{~g}=15,91 \%$ des Anfangsgewichts, $3,20 \mathrm{~g}$ pro Tag;

vom 14. bis 18. August -4 Tage $-17 \mathrm{~g}=8,46 \%$ des Anfangsgewichts, $3,40 \mathrm{~g}$ pro Tag.

A ufgenommener geschliffener roher Reis:

Datum 1917 Gewicht Datum 1917 Gewicht Datum 1917 Gewicht

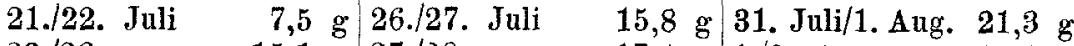

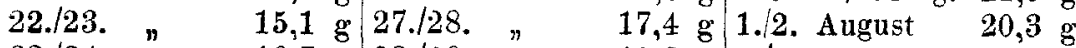

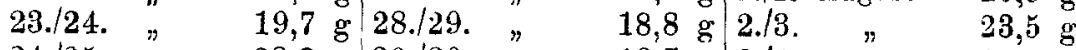
25./26. " $\quad \begin{gathered}14,0 \mathrm{~g} \mid 30 . / 31 . \\ \text { Durchschnittliche tägliche Aufnahme } 17,6 \mathrm{~g} .\end{gathered}$ 
Präparat 1 A 1 (S. 218).

(Zerlegter sekundärer Quecksilberchlorid-Niederschlag.)

Einer an alimentärer Dystrophie (Beinlähmung, Opisthotonus, Streckkrampf der Beine) typisch erkrankten Taube wurde am 25. Jun i $1917 \mathrm{um} 12$ Uhr mittags $0,01 \mathrm{~g}$, in $3 \mathrm{ccm}$ dest. Wassers gelöst, in den Brustmuskel eingespritzt. Um 3 Uhr uachm. waren die Lähmungen sowie alle nervösen Erscheinungen beseitigt. Das Tier vermochte wieder ohne Schwierigkeiten umherzulaufen, obschon es noch recht matt war.

Präparat I A 2 (S. 218).

(Zerlegter tertiärer Quecksilberehlorid-Niederschlag.)

Einer mit Präparat I R 1 mit unbefriedigendem Erfolge behandelten, an alimentärer Dystrophie (Beinlähmung) erkrankten Taube wurden am 7. A ugust 1917 um $91 / 4$ Uhr vorm. $0,0025 \mathrm{~g}$, in $1 \mathrm{ccm}$ dest. Wassers gelöst, intramuskulär eingespritzt. Bis $3 \mathrm{Uhr}$ nachm. keine merkliche Wirkung. Nochmalige intramuskuläre Einspritzung von $0,0025 \mathrm{~g}$, in 1 cem dest. Wassers gelöst. Am nächsten Tage (8. A u gu st) 9 Uhr vorm. ansgesprochene Besserung. Die Taube lief wieder ohne Schwierigkeit, erschien aber noch etwas matt und schwindlig. Weitere Einspritzung von $0,005 \mathrm{~g}$ in $2 \mathrm{ccm}$ dest. Wassers: Progressive Besserung während des Tages. Am zweitnächsten Tage (9. August) um 9 Uhr vorm: war die Taube wieder sehr munter und vermochte behende zu laufen und zu fliegen.

Präparat I N อ (S. 218).

(Hefeutonin.)

1. Einer an alimentärer Dystrophie (Paralyse der Beine und Flügel, Opisthotonus, Streckkrampf der Beine, Konvulsionen) erkrankten Taube (Photographie Nr. 30) wurden am 3. August 1917 um $4^{8 / 4}$ Uhr nachm. $0,005 \mathrm{~g}$, in $3 \mathrm{ccm}$ dest. Wassers gelöst, in den Brustmuskel eingespritzt. Am nächsten Tage (4. August) um $9 \mathrm{Uhr}$ vorm, war die Taube wieder munter and lief and flog mit grosser Leichtigkeit ( $\mathrm{P} \mathrm{h}$ o to graphie Nr. 31). Alle nervösen Erscheinungen waren verschwunden. Bei fortgesetzter Fütterung mit geschliffenem Reis und trotz fortbestehender starker Abmagerung (Körpergewicht $186 \mathrm{~g}$ ) blieb die Taube ohne jede weitere Behandlung bis zum 22. August, also 19 Tage $\mathrm{l} \mathrm{ang}$, munter und frei von allen bei alimentärer Dystrophie auftretenden uervösen Erscheinungen. Am genannten Tage erkrankte die Taube plötzlich wieder sehr heftig (Beinlähmung, Opisthotonus, Krämpfe). Sie wurde nun zu einem anderen Versuche mit dem aus dem Hefenukleoproteid durch Pepsimalsäure abgespaltenen Eiweisskörper (S. 189) verwandt.

2. Einer gelähmten Taube wurden $0,18 \mathrm{~g}$, in $5 \mathrm{ccm}$ dest. Wassers gelöst, in den Brustmuskel eingespritzt. Fast unmittelbar nach der Einspritzung heftiger Streckkrampf der Beine nach hinten (wie a uf $\mathrm{Ph}$ o to graphie Nr. 7), Nach etwa 15 Minuten verendete die Taube. 
Beitrag zur Kenntnis von organischen Nahrungsstoffen mit spezif. Wirkung. 259

Präparat I $\mathbf{R} 1$ (S. 221).

(Betainchlorhy drat.)

1. Einer gelähmten Taube (Beinlähmung, kein Opisthotonus, keine Krämpfe) wurden am 22. A u gu st 1917 um 12/2 Uhr nachm. 0,5 g, in 5 ccm dest. Wassers gelöst, in den Kropf eingespritzt. Nach 10 Minuten Opisthotonus und Streckkrampf der Beine nach vorne. Um $3^{1 / 2}$ nachm. war die Taube sehr matt und hinfällig und ging um 4 Uhr nachm. ein.

2. Einer typisch erkrankten Taube (Lähmung der Beine und Flügel, Opisthotonus) wurden am 22. A u g ust $1917 \mathrm{um} 7 \mathrm{Uhr}$ nachm. 0,25 g, in 4 cem dest. Wassers gelöst, in den Kropf gespritzt. Am nächsten Tage 9 Uhr vorm, geringe Besserung: Opisthotonus geschwunden, Pareseñ der Beine noch sehr ausgesprochen, Gang sehr behindert, Um $10 \mathrm{Uhr}$ vorm. nochmalige Einspritzung von $0,25 \mathrm{~g}$, in $4 \mathrm{ccm}$ dest. Wassers gelöst, in den Kropf. Keine weitere Besserung bis $4 \mathrm{Uhr}$ nachm. Die Taube wurde nun mit gutem Erfolge mit Hefe behandelt.

3. Einer an alimentärer Dystrophie erkrankten Taube (Beinlähmung, Opisthotonus, Krämpfe) wurden am 1. Oktober $19175 \%$ Uhr nachm. von einer $1 \%$ igen, vorher mit Natriumkarbonat neutralisierten Lösung $5 \mathrm{ccm}(0,05 \mathrm{~g})$ in den. Brustmuskel eingespritzt. Nach 2 Stunden Opisthotonus und Krämpfe geschwunden. Das Tier war munter und frass wieder geschliffenen Reis, die Beinlähmung war aber unverändert. Am nächsten Tage früh (2. Oktober) Opisthotonus zeitweilig wieder auftretend. In den Zwischenpausen pickte die Taube emsig geschliffenen rohen Reis auf. Nachmittags 5 Uhr nochmalige Einspritzung ron $5 \mathrm{ccm}$ der neutralisierten $1 \%$ igen Lösung $(0,05 \mathrm{~g})$. Fresslust hielt an. Am zweitnächsten Tage Verschlimmerung: Opisthotonus und heftige Krämpfe. Nach Verwendung zu einem anderen Versuche (Opton aus Corpus luteum), der erfolglos verlief, erholte sich die Taube bei Hefetherapie schnell und vollkommen.

4. Einer typisch erkrankten Taube (Opisthotonus; Paralyse der Beine) wurden am 3. A u g ast $1917 \mathrm{um} 9^{3} / 4$ Uhr vorm. $0,25 \mathrm{~g}$, in $5 \mathrm{ccm}$ dest. Wassers gelöst, in den Brustmuskel eingespritzt. Um 4 Uhr nachm. Opisthotonus und Krämpfe geschwunden, Lähmung der Beine unverändert. Nochmalige intramuskuläre Einspritzung einer Lösung von $0,25 \mathrm{~g}$ in 5 ccm dest. Wassers. Am nächsten Tage (4. A u gu st) 9 Uhr vorm.: Frei von Opisthotonus und Krämpfen. Die Taube erscheint schwindlig und scheut sich zu laufen, obschon die Lähmung der Beine zurückgegangen zu sein scheint. Durch Einspritzung von 2 Gaben von je $0,0025 \mathrm{~g}$ des Präparats I A 2 wurde die Taube in kurzer Zeit von allen nervösen Störungen vollkommen befreit.

5. Einer gesunden Taube wurden innerhalb von 4 Stunden $0,2 \mathrm{~g}$, in dest. Wasser gelöst, in den Brustmuskel eingespritzt. Irgendeine Wirkung, im besonderen eine Giftwirkung, wair nicht zu bemerken.

6. Dauerversuch Nr. 26.

Versuchstier: Eine gesunde, kräftige Taube.

Beginn des Versuchs: 10 Oktober 1917.

Schluss des Versuehs: 13. November 1917.

Nahrung: Geschliffener roher Reis. 
Tägliche Zugabe: $0,05 \mathrm{~g}$ des Präparats I R 1 (Betainchlorhydrat) in ciner Pille ( $3 \mathrm{~g}$ wurden mit Glycerinstärkekleister und reiner Stärke zu einer Pillenmasse verarbeitet, die in 60 gleiche Pillen eingeteilt wurde).

Körpergewichte:

Datum 1917

Gewicht

Datum 1917

Gewicht

10. Oktober

$340 \mathrm{~g}$

13. "

$352 \mathrm{~g}$

$20 . \quad "$

$292 \mathrm{~g}$

27.

$251 \mathrm{~g}$

2. November
$8 . " ~ " ~$
10.
$13 . \quad "$

$222 \mathrm{~g}$

$214 \mathrm{~g}$

$208 \mathrm{~g}$

$190 \mathrm{~g}$

Gewichtsverlust $150 \mathrm{~g}=-44,1 \%$ des Anfangsgewichts.

Verhalten des Versuchstieres: Bis zum 12. November trotz starker Abmagerung munter and anscheinend gesund. An diesem Tage sass die Taube mit gesträubtem Gefieder und eingezogenem Kopfe auf dem Boden des Käfigs. Am 13. November frühmorgens: Starke Paresen der Beine und Opisthotonus.

Die Taube wurde nun zu einem anderen Versuche (mit Präparat I R 6, S. 261) verwandt.

Präparat I R 2 (S. 224).

1. Einer vorher schon zu einem anderen Versuche (mit I A 1, S. 218) verwandten und von allen nervösen Erscheinungen befreiten, dann nach fortgesetzter einseitiger Fütterung mit geschliffenem rohen Reis wieder erkrankten Taube (Paresen der Beine) wurde am 2. Juli $1917 \mathrm{um}$ 6 Uhr nachm. eine Lösung von $0,1 \mathrm{~g}$ in $5 \mathrm{ccm}$ dest. Wassers in den Brustmuskel eingespritzt. Das äusserst stark abgemagerte Tier war schon eine halbe Stunde nach der Injektion äusserst matt und hinfällig und wurde am nächsten Morgen tot aufgefunden.

2. Einer typisch erkrankten jungen Taube (Paralysen der Beine und Flügel, Opisthotonus und Krämpfe, keine starke Abmagerung), wurde

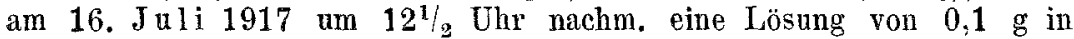
$5 \mathrm{ccm}$ dest. Wassers in den Brustmuskel eingespritzt. Bis $4 \mathrm{Uhr}$ nachm. keine merkliche Besserung. Nochmalige intramuskuläre Einspritzung von $0,1 \mathrm{~g}$, in $5 \mathrm{ccm}$ dest. Wassers gelöst. Am nächsten Tage (17. Ju li) Opisthotonus und Krämpfe geschwunden. Taube war viel munterer und nahm auch wieder spontan geschliffenen Reis auf. Lähmung der Beine unverändert.

Die Taube wurde nun zu dem Versuch 5 mit Präparat I \& (S. 216) verwandt.

Präparat I R 3 (S. 230).

1. Einer typisch erkrankten Taube (Beinlähmung, Opisthotonus, Strecklrampf der Beine nach vorne) wurden am 27. A ugust 1917 um $11 \mathrm{Uhr}$ vorm. 5 cem einer $1 \%$ igen Lösung in den Brustmuskel eingesspritzt. Um $3^{1 / 2}$ Uhr nachm. merkliche Besserung: Opisthotonus und Streckkrampf der Beine geschwunden. Die Taabe vermochte wieder zu laufen, obschon die Paresen der Beine nicht gehoben waren. Bis zum 31. August keine Ver'schlimmerang. Opisthotonus und Krämpfe traten nicht wieder auf, aber die Taube war sehr matt und hinfüllig ge- 
Beitrag zur Kenntnis von organischen Nahrungsstoffen mit spezif. Wirkung. 261

worden. Körpergewicht: $212 \mathrm{~g}$; Temperatur: $37^{\circ} \mathrm{C}$. Die Taube bekam num $1 \mathrm{~g}$ getrocknete Hefe und war am nächsten Tage wieder sehr munter und imstande, behende zu laufen und $\mathrm{zu}$ fliegen.

2. Einer typisch erkrankten Taube (Beinlährnung, Opisthotonus, heftige Krämpfe) wurden am 29. August 1917 um 6\% Uhr nachm. $0,05 \mathrm{~g}$, in $5 \mathrm{ccm}$ dest. Wassers gelöst, in den Brustmuskel eingespritzt. Am nächsten Morgen um $9 \mathrm{Uhr}$ vorm. waren Opisthotonus und Krämpfe greschwunden. Die Paresen dex Beine dagegen waren unverändert. Am Nachmittage machte sich plötzlich eine auffallende Mattigkeit bemerkbar (Körpertemperatur unter $35^{\circ} \mathrm{C}$.). Die Hinfälligkeit nahm schnell zu, und die Taube ging um $2 \mathrm{Uhr}^{\circ}$ nachm. ein.

\section{Präparat I $\mathbf{R} 6$ (S. 227).}

1. Der am Sehluss des Dauerversuches mit Präparat I R 1 (S. 221) typisch erkrankten Taube (starke Paresen der Beine, Opisthotonus) wurde am 13. November 1917 früh eine Lösung von $0,05 \mathrm{~g}$, in $5 \mathrm{ccm}$ dest. Wassers gelöst, in den Brustmuskel eingespritzt. Nach einer Viertelstunde war die Taube unter heftigem Streckkrampf der Beine nach hinten (s. Photographie $\mathrm{Nr}$. 7) verendet.

2. Einer erkrankten Taube (ausgesprochene Lähmung der Beine) warden am 15. November $1917 \mathrm{um} \mathrm{11/2}$ Uhr vorm. $0,025 \mathrm{~g}$, in $2,5 \mathrm{ccm}$ dest. Wassers gelöst, in den Brustmuskel eingespritzt. Unmittelbar darauf Streckkrampf der Beine nach hinten, dann Streckkrampf des ganzen Körpers. Nach 10 Minuten war das Tier tot.

\section{Präparat I B 1 (S. 232).}

Einer schwer gelähmten Taube (Lähmung der Beine und Flügel, Opisthotonus, sehr ausgesprochene Reflexe, Krämpfe (Photographien Nr. 26-28) wurden $2 \mathrm{~g}$ des Rückstandes, in 5 ccm dest. Wassers gelöst, in den Brustmuskel eingespritzt. Opisthotonus und Krämpfe waren nach 2 Stunden geschwunden, und das Allgemeinbefinden war sichtlich besser. Die Lähmung sowie der Streckkrampf der Beine blieben dagegen unverändert (Photographie $\mathrm{Nr}$. 29). Bis zum uächstfolgenden Tage um $9 \mathrm{Uhr}$ vorm. keine Veränderung.

Um $10 \mathrm{Uhr}$ vorm. intramuskuläre Einspritzung von $0,02 \mathrm{~g}$ des Präparates I A (S. 216). Der Streckkrampf der Beine schwand nach einer halben Stunde, doch war die Taube trotzden unfähig, sich zu erheben und zu stehen. Im Laufe des Nachmittags verschlimmerte sich der Zustand des sehr stark abgemagerten Tieres zusehends, und um 5 Uhr nachm. starb es.

Sektion der Taube. Starke Abmagerung. Der Kropf war noch mit Reis gefüllt, obschon die Taube mindestens innerhalb der ihrem Tode voranfgegangenen 24 Stunden keine Nahrung mehr zu sich genommen hatte.

In Müller'sche Lösung zur weiteren Untersuchung e ing e le g $\mathrm{t}$ : Lunge, Leber, Herz, Darm, Niere, Brustmuskel, Pankreas, Gehirn, Rückenmark, Nervus ischiadicus, verschiedene periphere Nerven. 
Präparat I B 2 (S. 229).

Einer typisch erkrankten Taube (Beinlähmung, Opisthotonus, Krämpfe) wurde am 2. Dezember 1917 um 11 Uhr vorm. 0,025 g, in $5 \mathrm{ccm}$ dest. Wassers gelöst, in den Brustmuskel eingespritzt. Um 4 Uhr nachm. Opisthotonus und Krämpfe geschwunden. Nochmalige intramuskuläre Einspritzung von $0,025 \mathrm{~g}$, in $5 \mathrm{ccm}$ dest. Wassers gelöst. Am 3. Dezember um $9 \mathrm{Uhr}$ vorm. keine weitere Besserung. Beinlähmung unverändert. Einspritzung von 15 Tropfen des dialysierten Acetonniederschlages $+2 \mathrm{ccm}$ dest. Wassers in den Brustmuskel. Am nächsten Tage (4. Dezember) um 9 Uhr vorm. wesentliche Besserung. Lebhafte Fresslust. Die Taube erholte sich bei Hefetherapie bald vollkommen.

Präpalat I B 3e (S. 228).

1. Einer typisch erkrankten Taube (Paralyse der Beine, Opisthotonus, Krämpfe) wurde am 7. November 1917 um 11/4 Uhr vorm. eine Lösung von $0,05 \mathrm{~g}$ in $3 \mathrm{ccm}$ dest. Wassers in den Brustmuskel eingespritzt. Im Laufe des Nachmittags keine Besserung. Am 8. Nove mber früh Opisthotonus und Krämpfe geschwunden. Die Beinlähmung war so weit zurückgegangen, dass die Taube wieder aufrechtstehen konnte. Das Tier ging dann plötzlich und unerwartet ein.

2. Einer an den Beinen schwer gelähmten Taube (kein Opisthotonus, keine Krämpfe) wurden am 4. Dezember $1917 \mathrm{um} \mathrm{101/4} \mathrm{Uhr}$ vorm. $0,05 \mathrm{~g}$, in $1 \mathrm{ccm}$ dest. Wassers gelöst, in den Brustmuskel eingespritzt. Am 5 . D e z e mber $9 \mathrm{Uhr}$ vorm. Beinlähmung stärker. Um $9^{3 / 4}$ Uhr vorm. Einspritzung von $0,15 \mathrm{~g}$ des Präparats I B $3+0,1 \mathrm{~g}$ des Präparats III F 2 (S. 254), in $6 \mathrm{ccm}$ dest. Wassers gelöst. Bis 4 Uhr nachm. keine Besserung. Intramuskuläre Einspritzung von $0,15 \mathrm{~g}$ des Präparats I B 3, in 3 cem dest. Wassers gelöst. Nach $10 \mathrm{Mi}$ nuten tot.

3. Einer typisch erkrankten Taube (Beinlähmung, Opisthotonus) am 6. Deze mber 1917 um $9^{1 / 2}$ Uhr vorm. $0,05 \mathrm{~g}$, in $3 \mathrm{ccm}$ dest. Wassers gelöst, in den Brustmuskel eingespritzt. Um 4 Uhr nachm. Verschlimmerung. Die Taube drohte einzugehen. Sie bekam daher $1 \mathrm{~g}$ getrocknete Hefe. Am 7. Dezember 9 Uhr vorm. war die Taube wieder ganz munter.

\section{In absolutem Alkohol unlöslicher Rüdkstand der Ac etonnieder- schläge (S. 232).}

1. Einer stark abgemagerten, an den Beinen gelähmten Taube wurden am 3. Juli 1917 um $6^{3} / 4$ Uhr nachm. $0,5 \mathrm{~g}$ des Räckstandes in $10 \mathrm{ccm}$ dest. Wassers mittels einer an einer Glasspritze befestigten Schlundsonde in zwei Malen in den Kropf eingespritzt. Am nächsten Tage früh geringe Besserung. Paresen der Beine etwas zurückgeganç en. Nochmalige Einspritzung von $0,5 \mathrm{~g}$ in den Kropf. Die Besserung hielt zunächst an. Der Gang war weniger behindert. Abmagerung extrem. Körpergewicht am 4. Juli $180 \mathrm{~g}$, am 7. Juli $178 \mathrm{~g}$. Trotz Hefetherapie und Zwangsfütterung ging die Taube am 10. Juli ein. 
Beitrag zur Kenntnis von organischen Nabrungsstoffen mit spezif, Wirkung. 263

Bei der Sektion der Taube wurden im Kropf, Magen und Darm unverdaute Reiskörner gefunden. Der Darm war mit schleimigem, übelriechendem Inhalt gefüllt und stark gereizt. Enteritis.

2. Dauerversuch Nr. 27.

Versuchstier: Eine kräftige ausgewachsene Taube.

Beginn des Versuches: 13. Juli 1917.

Schluss des Versuches: 15. September 1917.

Nahrung: Geschliffener roher Reis (bis zum 8. Sept.).

Tägliche Zugaben:

vom 13. Juli bis 26. August: $0,5 \mathrm{~g}$ des Rückstandes (5 Pillen);

vom 27. bis 29. August: 1,0 g des Rückstandes (10 Pillen);

vom 30. August bis 15. September: $1 \mathrm{~g}$ getrocknete Bierhefe.

Anmerkung: Der Rückstand wurde in dest. Wasser gelöst und diese Lösung filtriert. Das Filtrat wurde hierauf im Vakuum bei $37^{\circ} \mathrm{C}$. bis zur Extraktkonsistenz eingedampft. Aus $40 \mathrm{~g}$ des Rückstandes wurden dann nach genügendem Zusatz von reiner Weizenstärke und Kieselgur 400 gleichgrosse Pillen hergestellt.

\begin{tabular}{|c|c|c|c|c|c|c|}
\hline Datum 1917 & Gewicht & Datum 1917 & Gewicht & & 1917 & Gewicht \\
\hline 13. Juli & $311 \mathrm{~g}$ & 11. August & $244 \mathrm{~g}$ & 1. & ember & 201,5 \\
\hline 21. " & $284 \mathrm{~g}$ & 18. & $231 \mathrm{~g}$ & 5 . & " & 217,0 \\
\hline 28. " & $265 \mathrm{~g}$ & 25. & $215^{\circ} \mathrm{g}$ & 8. & $"$ & 233,0 \\
\hline 4. August & $252 \mathrm{~g}$ & 30. & $197 \mathrm{~g}$ & 15. & 'ו & 263,0 \\
\hline
\end{tabular}

Gewichtsabnahme vom 13. Juli bis 30. August:

$114 \mathrm{~g}=-36,66 \%$.

Gewichtszanahme vom 30. August bis 15. September: $76 \mathrm{~g}=+38,58 \%$.

Spontanaufgenommener roher Reis:

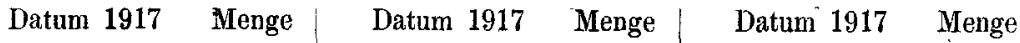
16./17. August $27,0 \mathrm{~g}$ 24./25. August $16,5 \mathrm{~g} / 1 . / 2$. September $30,0 \mathrm{~g}$ 17./18. " $\quad 17,7 \mathrm{~g}|25 . / 26 . \quad \# \quad 12,4 \mathrm{~g}| 2 . / 3 . \quad \# \quad 30,0 \mathrm{~g}$

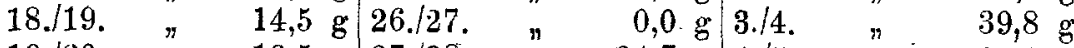

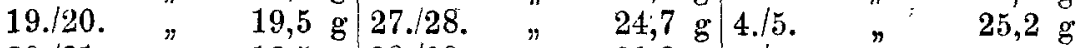
$\begin{array}{lllllllllll}20 . / 21 . & \# & 19,5 \mathrm{~g} & 28 . / 29 . & \# & 20,8 \mathrm{~g} & 5 . / 6 . & \# & 28,0 \mathrm{~g}\end{array}$

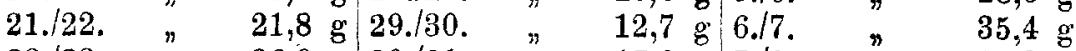

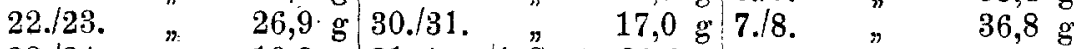
23./24. $\quad " \quad 19,8 \mathrm{~g} \mid 31$. Aug.1. Sept. $20,0 \mathrm{~g}$ |

Verhalten des Versuchstieres: Trotz fortschreitender Abmagerung bei lebhafter Fresslust (im Durchschnitt pro Tag 19,31 g) war die Taube bis zum 26. August sehr munter. An diesem Tag sass sie mit gesträubtem Gefieder und eingezogenem Kopfe apathisch da. Am 27. A ugust machten sich ausgesprochene Paresen der Beine bemerkbar. Die Zehen waren nach innen gekrümmt. Der Gang unsicher und unljehende. Dabei konnte, die Taube aber noch sehr gut fliegen. Bis zum 30. August blieb dieser Zustand unverändert.

Nach Zufuhr von Hefe allmähliches Zurückgehen der Paresen, die am 7. September völlig geschwunden waren. Fom 8. September an gemischtes Taubenfutter. Am 15. September war die Taube wieder sehr munter. 
Das Verhältnis der Abuahme bzw. Zunahme des Körpergewichtes zu den aufgenommenen Mengen geschliffenen Reises bei Zugabe des Rückstandes einerseits und Zugabe getrockneter Hefe anderseits veranschaulicht nachstehende Übersicht:

Übersicht.

\begin{tabular}{|c|c|c|c|c|}
\hline \multirow{2}{*}{$\begin{array}{c}\text { Perioden } \\
\text { von je sieben Tagen } \\
1917\end{array}$} & \multicolumn{2}{|c|}{$\begin{array}{l}\text { Aufnahme von } \\
\text { geschliffenem rohen Reis }\end{array}$} & \multicolumn{2}{|c|}{$\begin{array}{c}\text { A bnahme bzw. Zunahme } \\
\text { des Körpergewichts }\end{array}$} \\
\hline & in 7 Tagen & rro Tag & & \\
\hline 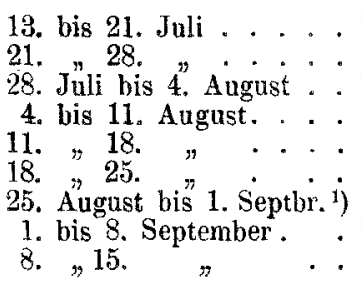 & $\begin{array}{c}\bar{Z} \\
\overline{-} \\
44,7 \mathrm{~g}(2 \mathrm{Tgg} \theta) \\
1.56,2 \mathrm{~g} \\
107,2 \mathrm{~g} \\
225,2 \mathrm{~g} \\
\text { Gemischtes . }\end{array}$ & $\begin{array}{l}\overline{-} \\
\overline{-} \\
22,3 \mathrm{~g} \\
22,3 \mathrm{~g} \\
15,4 \mathrm{~g} \\
32,2 \mathrm{~g} \\
\text { abenfutter }\end{array}$ & $\begin{array}{r}-27,0 \mathrm{~g} \\
-19,0 \mathrm{~g} \\
-13,0 \mathrm{~g} \\
-8,0 \mathrm{~g} \\
-13,0 \mathrm{~g} \\
-16,0 \mathrm{~g} \\
-13,5 \mathrm{~g} \\
+21,0 \mathrm{~g} \\
+30,5 \mathrm{~g}\end{array}$ & $\begin{aligned} &- 8,7 \% \% \\
&- 6,6 \% \\
&- 4,9 \% \\
&- 3,1 \% \\
&- 5,3 \% \\
&- 6,9 \% \\
&-\quad 6,0 \% \\
&+\quad 10,7 \% \\
&+13,1 \%\end{aligned}$ \\
\hline
\end{tabular}

3. Dauerversuch $\mathrm{Nr} .28$.

Versuchstier: Eine kräftige ausgewachsene Taube.

Beginn des Versuches: 29. September 1917.

Schluss des Versuches: 28. Oktober 1917.

Nahrung: Geschliffener roher Reis.

Tägliche Zugaben:

vom 29. September bis 13. Oktober: $0,2 \mathrm{~g}$ des Rückstandes II (2 Pillen);

vom 14. bis 28. Oktober: $0,5 \mathrm{~g}$ des Rückstandes II (5 Pillen).

Körpergewichte:

Datum 1917

29. September

6. Oktober

13.
Gewicht

$317 \mathrm{~g}$

$290 \mathrm{~g}$

$249 \mathrm{~g}$
Datum 1917

20. Oktober

27. $\quad$ "
Gewicht

$219 \mathrm{~g}$

$207 \mathrm{~g}$

Spontan aufgenommener rohergeschliffener Reis:

Datum 1917 Gewicht Datum 1917 Gewicht Datum 1917 Gewicht 29./30. Sept. $19,0 \mathrm{~g} \quad 9 . / 10$. Oktober $17,4 \mathrm{~g}$ 18./19. Oktober $18,9 \mathrm{~g}$

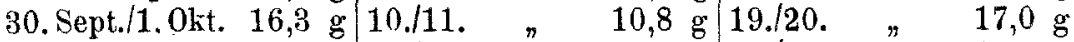

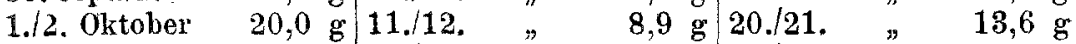

2./3. "

$3.44 . "$

4.15 . $"$

5.6 . "

$6 . / 7$.

7.18.

$8 . / 9$. "
$20,0 \mathrm{~g}$

$14,5 \mathrm{~g}$

$20,0 \mathrm{~g}$

$19,3 \mathrm{~g}$

$16,6 \mathrm{~g}$

$20,0 \mathrm{~g} / 17 . / 18$ $12,9 \mathrm{~g}$ \begin{tabular}{rr|llll}
8,9 & $\mathrm{~g}$ & $20 . / 21$, & & 13,6 & $\mathrm{~g}$ \\
16,9 & $\mathrm{~g}$ & $21 . / 22$. & & $\mathbf{2 1 , 9} \mathrm{g}$
\end{tabular}

$10,7 \mathrm{~g} / 22 . / 23 . \quad " \quad 16,1 \mathrm{~g}$

11,1 g $23 . / 24 . \quad$ " $\quad 21,6$ g

$20,0 \mathrm{~g}: 24.25 . \quad$; $\quad 14,2 \mathrm{~g}$

\begin{tabular}{ll|lll}
26,3 & $\mathrm{~g}$ & $25 . / 26 . \quad \#$ & $19,4 \mathrm{~g}$
\end{tabular}

$\begin{array}{lllll}18.7 \mathrm{~g} & 26 . / 27 . & & & 5,2 \mathrm{~g}\end{array}$

1) Vom 30. August bis 15. September täglich 1 g getrocknete Hefe. 
Beitrag zur Kenntnis von organischen Nahrungsstoffen mit spezif. Wirkung. 265

Verhalten des Versuchstieres. Bis zum 27. Oktober munter. Am 27. Oktober gesträubtes Gefieder, eingezogener Kopf, apathisch. Am 28. $0 \mathrm{ktober}$ ausgesprochene Paresen der Beine. Die Taube wurde nun zu dem unmittelbar angeschlossenen Vergleichsversuch Nr. 29 verwandt.

Übersicht.

\begin{tabular}{l|c|c|c|c|c|c}
\hline Periode 1917 & $\begin{array}{c}\text { Anzahl } \\
\text { der } \\
\text { Tage }\end{array}$ & \multicolumn{2}{|c|}{$\begin{array}{c}\text { Spontan aufgenommener } \\
\text { geschliffener Reis }\end{array}$} & \multicolumn{2}{|c|}{$\begin{array}{c}\text { Abnahme des } \\
\text { Körpergewichts }\end{array}$} \\
\cline { 3 - 7 } & im ganzen & pro Tag & absolute & relative \\
\hline 29. Sept. bis 6. Okt. & 7 & $129,1 \mathrm{~g}$ & $18,44 \mathrm{~g}$ & $-27 \mathrm{~g}$ & $-8,5 \%$ \\
6. bis 13. Oktober & 7 & $103,5 \mathrm{~g}$ & $14,78 \mathrm{~g}$ & $-41 \mathrm{~g}$ & $-\mathbf{1 4 , 1} \%$ \\
13. bis 20. & 7 & $122,7 \mathrm{~g}$ & $17,53 \mathrm{~g}$ & $-30 \mathrm{~g}$ & $-\mathbf{1 2 , 0} \%$ \\
20. bis 28. & 7 & 8 & $112,0 \mathrm{~g}$ & $14,00 \mathrm{~g}$ & $-12 \mathrm{~g}$ & $-5,5 \%$
\end{tabular}

Spontan aufgenommener geschliffener Reis:

während der 29 Versuchstage $467,3 \mathrm{~g}$;

im Durchschnitt pro Tag . . 16,1 g.

Gewichtsabnahme im ganzen. . - - $110 \mathrm{~g}=34,7 \%$. " im Durchschnitt pro Tag $-3,79 \mathrm{~g}=1,2^{\circ} \%$.

Vergleichsversuch $\mathrm{Nr} .29$.

(Fortsetzung des vorstehenden Versuches.)

Versuchstier: Die zu vorstehendem Versuche verwandte, an alimentärer Dystrophie erkrankte Taube.

Beginn des Versuches: 28. Oktober 1917 (in unmittelbarem Anschluss an vorstehenden Versuch).

Schluss des Versuches: 1. Dezember 1917.

Nahrung: Geschliffener roher Reis vond erselben Qualität, wie der $z \mathfrak{u}$ dem vorstehenden Versuch verwandte. Die Taube bekam am 28./29. Oktober $26,7 \mathrm{~g}$, am 29./30. Oktober $17,8 \mathrm{~g}$, am 30./31. Oktober $4,8 \mathrm{~g}$, am 31. Oktober 1 . November $10,7 \mathrm{~g}$, also während der ersten 4 Versuchstage im ganzen $60 \mathrm{~g}$, das ist durchschnittlich $15 \mathrm{~g}$ pro Tag, und vom 1. November ab täglich $15 \mathrm{~g}$, die sie regelmässig bis zum folgenden Morgen aufgefresser hatte.

Tägliche Zugabe: $0,5 \mathrm{~g}$ getrocknete Hefe Qual. I in 5 ohne irgendwelchen Zusatz, ausser dest. Wasser, bereiteten Pillen. Die getrocknete Hefe enthielt: Wasser 69,5\%, Stickstoff 9,49\%, Asche 10,09\%, $\mathrm{P}_{2} \mathrm{O}_{5} 6,18 \%$ (Analyse s. S. 206). Zufuhr pro Tag mit der Hefe: $\mathrm{N} 0.04745 \mathrm{~g}$, Asche $0,05045 \mathrm{~g} . \mathrm{P}_{2} \mathrm{O}_{5} 0,0309 \mathrm{~g}$.

Körpergew ichte :

Datum $1917 \quad$ Gewicht

$\begin{array}{rr}\text { 28. Oktober } & 203 \mathrm{~g} \\ \text { 3. November } & 228 \mathrm{~g} \\ 7 . \quad " \quad & 235 \mathrm{~g} \\ 10 . \quad " \quad & 243 \mathrm{~g}\end{array}$

Datum 1917

Gewicht

17. November

$252 \mathrm{~g}$

24. $\quad 267 \mathrm{~g}$

1. Dezember $\quad 267 \mathrm{~g}$

Gewichtszunahme in 26 Tagen: $+64 \mathrm{~g}=+31,5 \%$. 
Verhalten des Versuchstieres: Am 28. Oktober ausgesprochene Paresen der Beine, Apathie. Am 29. Oktober wieder sehr munter. Paresen der Beine indessen noch immer recht ausgesprochen. Am 30. Oktober Rückgang der Paresen. Taube setzte sich wieder auf die Sprungstange. Am 2. November Paresen der Beine vollkommen geschwunden. Die Taube war dann im weiteren Verlauf und bis zum Schlusse des Versuches durchaus munter und gesund.

\section{In Aceton löslicher Anteil des konzentrierten, primären, alko- holischen Auszuges aus hydrolysierter Hefe (S. 235).}

Präparat III $\mathbf{R}$ (S. 237) und III R 1 (S. 251).

Beide Präparate erwiesen, sich bei der näheren Untersuchung als identisch mit I R 1 (s. S. 221), d. h. als Betainchlorhydrat. Es sei daher auf die mit diesem Präparat angestellten Tierversuche (s. S. 259) verwiesen.

Präparat III N 4 (S. 288).

Die zur Verfügung stehende Menge war infolge der äusserst geringen: Ausbeute zur Anstellung von Tierversuchen zu gering.

Präparat III F 8 (S. 239).

Einer gelähmten, sonst noch recht kräftigen Taube (Paresen der Beine und Flügel, unsicherer Gang, bei dem das Tier bald vornüber. bald zur Seite fiel, Apathie, kein Opisthotonus, keine Krämpfe) wurden am 29. 0ktober 1917 um 12 Uhr mittags $2,5 \mathrm{ccm}$. einer $2 \%$ igen Lösung $(0,05 \mathrm{~g})$ in den Brustmuskel eingespritzt. Um $5 \mathrm{Uhr}$ nachm. Beinlähmung unverändert. Sehr rege Fresslust. Die Taube nahm gierig geschliffenen rohen Reis auf. Intramuskuläre Einspritzung von weiteren $5 \mathrm{cem}$ der $2 \%$ igen Lösung $(0,10 \mathrm{~g})$. Am 30 , $0 \mathrm{ktober}$ früh war die Taube sehr munter. Die Beinlähmung erschien aber unverändert. Um 11 Uhr vorm. nochmalige intramuskaläre Einspritzung von $5 \mathrm{ccm}$ der $2 \%$ igen Lösung $(0,10 \mathrm{~g})$. Um $5^{1 / 2} \mathrm{Uhr}$ nachm. merkliche Besserung. Einspritzung von $10 . \mathrm{ccm}$ der $2 \%$ igen Lösung in den Kropf. Am 31. Oktober früh weiterer Rückgang der Paresen. Am 2. November Paresen kaum noch bemerkbar. Die Taube, die seit dem 30. Oktober immer sehr munter war, blieb ohne weitere Behandlung und bei fortgesetzter Fütterung mit geschliffenem Reis bis zum 7. No$v$ ember frei von Lähmungen. An diesem Tage traten wieder Parasen auf. Am 9. November waren die Paresen wieder sehr ausgesprochen. Der Gang. wurde wiederum sehr unsicher. Die Taube erschien apathisch und vernachlässigte die Pflege ihres Gefieders.

Sie bekam nun getrocknete Hefe und war nach kurzer Zeit ganz wiederhergestellt.

Präparat III R 8 (S. 240).

Einer gelähmten Taube (Beinlähmung, kein Opisthotonus, keine Krämpfe) wurden am 26. Ok to ber 1917 um 111/2 Uhr vorm. $5 \mathrm{ccm}$ einer $1 \%$ igen Lösung $(0,05 \mathrm{~g})$ in den Brustmuskel eingespritzt. Um 
Beitrag zur Kenntnis von organischen Nahrungsstoffen mit spezif. Wirkung. 267

5 Uhr nachm. Verschlimmerung. Nochmalige Einspritzung von 5 ccm der $1 \%$ igen Lösung $(0,05 \mathrm{~g})$ in den Brustmuskel. Die Taube wurde am nächsten Morgen früh tot in Käfig aufgefunden.

Die noch zur Verfügung stehende Menge des Präparates war für weitere Versuche unzureichend.

Präparat III N S (S. 241).

1. Einer typisch erkrankten Taube (Beinlähmung, Opisthotonus) (Photographie Nr. 6) wurden am 12. Oktober $1917 \mathrm{um} \mathrm{10} / 2 \mathrm{Ohr}$ vorm. $0,02 \mathrm{~g}$, in $2 \mathrm{ccm}$ dest. Wassers gelöst, in den Brustmuskel eingespritzt. Nach 2 Minuten Streckkrampf der Beine nach hinten (Photographie Nr. 7), welcher nach 1/g Stunde wieder schwand. Opisthotonus blieb bestehen. Bis 5 Uhr nachm. keine Besserung. Nochmalige intramuskuläre Einspritzung von $0,02 \mathrm{~g}$, in $2 \mathrm{ccm}$ dest. Wassers gelöst. Um $6 \mathrm{Uhr}$ nachm. wesentliche Verschlimmerung.

Die Taube drohte einzugehen. Sie bekam deshalb $1 \mathrm{~g}$ getrocknete Hefe Qual. I und war am nächsten Morgen (19. Oktober) frei von Störungen nervöser Art and wieder munter (Photographie Nr. 8).

2. Einer gesunden Taube wurden innerhalb einer Stunde zweimal je 0,02, in dest. Wasser gelöst, in den Brustmuskel eingespritzt. Keine merkliche Wirkung, im besonderen keine Gif twi rkung. Nach 4 Stunden nochmalige intramuskuläre Einspritzung von $0,02 \mathrm{~g}$, in dest. Wasser gelöst: ke in e G if t w ir kung.

3. Einer zweiten, ebenfalls gesunden Taube wurden $0,04 \mathrm{~g}$, in dest. Wasser gelöst; auf einmal in den Brustmuskel eingespritzt. Ebenfalls keine Giftwirkung.

4. Einer an den Beinen erheblich gelähmten Taube wurde am 3. Januar 1918 um 12/4 Uhr nachm. eine Lösung von $0,08 \mathrm{~g}$ in $3 \mathrm{ccm}$ dest. Wassers in den Brustmuskel eingespritzt. Nach wenigen Minuten heftiger Streckkrampf (wie auf Photographie Nr. 7). Die Taube erschien moribund. Einspritzung von $1 \mathrm{ccm}$ alkoholischen Hefeextraktes um 11/4 Uhr nachm. Nur Streckkrampf hielt bis $3 \mathrm{Uhr}$ nachm. an. Um 4 Uhr, nachm. Streckkrampf völlig geschwunden. Die Taube war wieder munter, die Beinlähmung jedoch nicht merklich zurückgegangen. Am nächsten Tage 9 Uhr vorm. war die Taube sehr munter, doch waren die Lähmungen der Beine noch recht ausgesprochen.

Präparat III R 2 (S. 245).

1. Einer an alimentärer Dystrophie typisch erkrankten Taube (Paralyse der Beine und Flügel, Opisthotonus, Krämipfe; Körpertemperatur $37,3^{\circ}$ C.) wurde am 10 . September 1917 um 4 Uhr nachm, eine Lösung von $0,1 \mathrm{~g}$, in $5 \mathrm{ccm}$ dest. Wassers gelöst, in den Brustmuskel eingespritzt. Bis $7 \mathrm{Uhr}$ nachm. keine merkliche Besserung. Nochmalige intramuskaläre Einspritzung von $0,1 \mathrm{~g}$, in $5 \mathrm{ccm}$ dest. Wassers gelöst. Die Taube wurde am nächsten Morgen früh tot aufgefunden. (Die Gaben waren anscheinend $\mathrm{zu}$ gross.)

2. Einer typisch erkrankten Taube (Paralyse der Beine und Flügel, Opisthotonus, Krämpfe, Körpertemperatur $37,3^{\circ}$ C.) wurde am 11. S e ptember 1917 nm $9^{3 / 4}$ Uhr vorm. eine intramuskuläre Einspritzung 
von $0,025 \mathrm{~g}$ in $2,5 \mathrm{ccm}$ dest. Wassers (durch Zusatz von Natriumkarbonat neutralisiert) gemacht. Un $1 \mathrm{Uhr}$ nachm. wesentliche Besserung: Opisthotonus und Krämple beseitigt. Die Taube vermochte wieder zu laufen, wenn anch mit einiger Schwierigkeit. Bis 4 Uhr nachm. weitere Besserung. Die Taube hatte inzwischen wieder geschliffenen Reis gefressen. Um $6 \mathrm{Uhr}$ nachm. nochmalige intramuskuläre Einspritzung vọn $0,025 \mathrm{~g}$, in 2,5 ccm dest. Wassers gelöst. Am nächsten Morgen (12. September) war die Taube viel munterer. Der Gang war indessen noch immer paretisch, Vom 11. September nm 6 Uhr nachm. bis 12. September 9 Uhr vorm. hatte die Taube $17,5 \mathrm{~g}$ geschliffenen Reis gefressen. Körpertemperatur $38,3^{\circ} \mathrm{C}$. Um $10 \mathrm{Uhr}$ vorm. intramuskuläre Einspritzung von weiteren $0,04 \mathrm{~g}$ in $4 \mathrm{ccm}$ dest. Wassers. Am 13. September um 9 Uhr vorm. weitere Besserung. Die Taube lief wieder recht behende. Aufgenommener geschliffener Reis: 12,6 g. Körpertemperatur $38^{\circ} \mathrm{C}$. Um $10 \mathrm{Uhr}$ nachm. war die Taube wieder sehr munter and vermochte behende zu laufen.

Zur völligen Wiederherstellung und behufs Verwendung zu einem anderen Versuche bekam die Taube nun 1,5 g getrocknete Hefe und gemischtes Taubenfutter. Am nächsten Tage war das Tier wieder sehr munter und lebhaft (Körpertemperatur $39,8^{\circ}$ C.) und erholte sich in kurzer Zeit vollkommen.

3. Einer typisch erkrankten Taube (Paralyse und Streckkrampf der Beine nach vorne, Opisthotonus, heftige Krämpfe, sehr kalte Füsse) wurden am 5 . Oktober $1917 \mathrm{am} 3^{3} / 4$ Uhr nachm. $0,025 \mathrm{~g}$, in $2,5 \mathrm{ccm}$ dest. Wassers gelöst, in den Brustmuskel eingespritzt. Nach 2 Stunden Streckkrampf der Beine, Opisthotonus und Krämpfe geschwunden. Lähinung der Beine unverändert. Um $6^{3 / 4}$ Uhr nochmalige intramuskuläre Einspritzung einer Lösung von $0,025 \mathrm{~g}$ in 5 cem dest. Wassers. Am 6. $0 \mathrm{ktober} 9 \mathrm{Uhr}$ vorm. wesentliche Besserung: kein Opisthotonus, keine weiteren Krampfanfälle, Beinlälumung zurückgegangen. Die Taube war viel munterer und pickte eifrig geschliffenen Reis auf. Gang noch unsicher. Um 12 Uhr mittags nochmalige intramuskuläre Einspritzung einer Lösung von $0,025 \mathrm{~g}$ in $2,5 \mathrm{ccm}$ dest. Wassers. Am $7.0 \mathrm{ktober}$ früh weitere Besserung. Die Taube lief wieder schnell umher. Der Gang war aber immer noch ein wenig paretisch. Körpertemperatur $39,7^{\circ}$ C. Am 8. $0 \mathrm{kt}$ ob e r früh Paresen der Beine geschwunden. Die Taube lief wieder behende umher. Körpertemperatur $37,8^{\circ} \mathrm{C}$.

Präparat III R 2 (salzsaures Salz) ${ }^{\circ}$ (S. 245).

Einer stark abgemagerten Taube mit schwerer Lähmung: der Beine (kein Opisthotonus, keine Krämpfe) wurden am 7. De z e m b e r $1917 \mathrm{um} 10$ Uhr vorm. $0,025 \mathrm{~g}$, in $4 \mathrm{ccm}$ dest. Wassers, gelöst in den Brustmuskel eingespritzt. Am 8. Dezember früh wesentliche Bes* serung. Beinlähmung zurückgegangen. Die Taube war viel munterer und lief wieder behende umher. Rege Fresslust. Nochmalige intra. muskuläre Einspritzung von $0,05 \mathrm{~g}$, in $4 \mathrm{ccm}$ dest. Wassers gelöst. Die Taube war um $5 \mathrm{Uhr}$ nachm, noch sehr munter, wurde aber wider Erwarten am 9. Dezember früh tot im Käfig aufgefunden. 
Beitrag zur Kenntnis von organischen Nahrungsstoffen mit spezif. Wirkung. 269

Sektion: Magen und Eingeweide durch Gallenfarbstoffe stark grün gefärbt. Kropf mit spontan aufgenommenem geschliffenen Reis ziemlich gefüllt, Darm entzündet und mit sehr đünnflüssigem, schleimigem and übelriechendem Inhalt. Enteritis.

\section{Präparat III R 3 (S. 246).}

Einer schwer gelähmten Taube (Paralyse der Beine, kein Opisthotonus, keine Krämpfe) wurden am 5 . Novem ber 1917 um 118/4 Uhr vorm. $2,5 \mathrm{ccm}$ einer $1 \%$ igen Lösung $(0,025 \mathrm{~g})$ in den Brustmuskel eingespritzt. Bis 4 Uhr nachm. keine Besserung. Um $41 / 4$ Uhr nachm. intramuskuläre Einspritzung von $5 \mathrm{ccm}$ der $1 \%$ igen Lösung $(0,05 \mathrm{~g})$. Bis 7 Uhr nachm. keine Besserung. Am 6. November früh wurde die Taube tot im Käfig aufgefunden.

Präparat III N 2 (S. 247).

Einer an alimentärer Dystrophie typitsch erkrankten Taube (Beinlähmung, Opisthotonus, Konvulsionen) wurde am 13. 0ktober. $1917 \mathrm{um} \mathrm{10} / 4$ Uhr vorm. eine Lösung von $0,05 \mathrm{~g}$ in $5 \mathrm{ccm}$ dest. Wassers in den Brustmuskei eingespritzt. Bis $11 / 2$ Uhr vorm. keine merkliche Besserung. Nochmalige intramuskuläre Einspritzung von $5 \mathrm{ccm}$ der $1 \%$ igen Lösung $(0,05 \mathrm{~g})$. Am nächsten Tage $(14.0 \mathrm{k} \mathrm{to} \mathrm{b} \mathrm{e} \mathrm{r)}$ wesentliche Besserung: Opisthotonus und Krämpfe geschwunden. Die Taube war viel munterer und lief wieder behende umher. Fresslust sehr rege: Die Taube pickte emsig geschliffenen Reis auf. Am zweitnächsten Tage (15. Oktober) sehr munter. Paresen der Beine kaum noch zu bemerken.

$\mathrm{Zu}$ weiteren Versuchen war die zur Verfügung stehende Menge zu gering.

Prïparat III L 6 (S. 248).

1. Einer gelähmten Taube (ausgesprochene Paresen der Beine, kein Streckkrampf, kein Opisthotonus) wurde am 16. Oktober $1917 \mathrm{um}$ $10^{1 / 4}$ Uhr vorm. eine Lösung von $0,05 \mathrm{~g}$ in $5 \mathrm{ccm}$ dest. Wassers in den Brustmuskel eingespritzt. Die Taube war nachmittags sichtlich munterer und nicht so apathisch wie vorher. Paresen der Beine unverändert: $\mathrm{Um} \mathrm{3} / 4 \mathrm{Uhr}$ nachm. nochmalige intramuskuläre Einspritzung von $5 \mathrm{ccm}$ der $1 \%$ igen Lösung. Am nächsten Tage (17. Ok tob e r) wesentliche Besserung: Paresen zurückgegangen; Gang viel sicherer; lebhafte Fresslust. Der geschliffene rohe Reis wurde emsig aufgepickt. Bis zum 20. Oktober hielt die Besserung ohne weitere Therapie und bei fortgesetzter einseitiger Fütterung mit geschliffenem Reis an. Am 20. Oktober waren die Paresen wieder sehr ausgesprochen.

Die Taube erhielt nun 1,5 g getrocknete Hefe. Am 21.0k tober wesentliche Besserung, Gang jedoch noch immer merklich behindert. Nochmals 1,5 g getrocknete Hefe. Am 22. 0k tober früh Paresen so gut wie beseitigt.

2. Einer an alimentärer Dystrophie typisch erkrankten jungen Taube (Lähmung der Beine, Opisthotonus, Krämpfe). wurden am 22. Okto b e r 1917 um $12 \%$ Uhr nachm. 5 ccm einer $1 \%$ igen Lösung in den Brustmuskel eingespritzt. Um 4 Uhr nachm. geringe Besserung: 
Keine Konvulsionen mehr. Opisthotonus nur nach längeren Pausen und weniger stark auftretend. Nochmalige intramuskuläre Einspritzung von $5 \mathrm{ccm}$ der $1 \%$ igen Lösung $(0,05 \mathrm{~g})$. Am nächsten Tage (23. $0 \mathrm{k} \mathrm{tob} \mathrm{e} \mathrm{r)}$ $9 \mathrm{Uhr}$ vorm. geringe Besserung. Opisthotonus und Krämpfe geschwunden. Beinlähmung unverändert. Fresslust sehr gering.

Die Taube bekam nun, da sie extrem abgemagert war, 1,5 g getrocknete Hefe. Am 24. Oktober munterer. Beinlähmung zurückgegangen. Nochmals $1,5 \mathrm{~g}$ getrocknete Hefe. Am nächsten Tage (25. Oktober) früh wurde die Taube tot im Käfig gefunden. Die Sektion ergab eine schwere Enteritis.

\section{Präparat III L 5 (S. 250).}

1. Einer typisch erkrankten Taube (Beinlähmung, Opisthotonus, keine Konvulsionen) wurden am 27. November 1917 um $10^{2 / 4}$ Uhr vorm. $5 \mathrm{ccm}$ einer $1 \%$ igen Lösung $(0,05 \mathrm{~g})$ in den Brustmuskel eingespritzt. Um 5 Uhr nachm. Besserung: Opisthotonus geschwunden. Beinlähmung zurückgegangen. Am 28. No vember 9 Uhr vorm. Beinlähmung wieder ausgesprochen, kein Opisthotonus. Die Taube erschien sonst viel munterer.

Der Versuch, die Taube, die längere Zeit in einem dunklen Raum gestanden hatte, zwangsweise mit geschliffenem Reis zu füttern, führte leider plötzlich zum Tode durch Ersticken. Wie die Sektion ergab, waren ein paar Reiskörner in die Trachea gelangt und hatten sich dort festgesetzt.

2. Einer typisch erkrankten Taube (schwere Lähmung der Beine, Opisthotonus, heftige Konvulsionen) wurden am 30. November 1917 um $10^{8} / 4$ Uhr vorm. $5 \mathrm{ccm}$ einer $1 \%$ igen Lösung in den Brustmuskel eingespritzt. Um 4 Uhr nachm. ausgesprochene Besserung: Opisthotonus und Krämpfe geschwunden. Die Taube vermochte sich wieder zu erheben und zu laufen, doch war der Gang schwerfällig und behindert. Das Tier wurde am 1. Dezember frühmorgens tot im Käfig aufgefunden.

$\mathrm{Zu}$ weiteren Tierversuchen war die verfügbare Menge nicht ausreichend.

Präparat III N 3 (S. 252).

Bei der äusserst geringen Ausbeute war die verfügbare Menge für Tierversuche zu gering.

\section{Präparat III N 7 (S. 253).}

Die zur Verfügung stehende Menge war infolge sehr geringer Ausbeute sehr klein. Ein mit dieser unternommener Tierversuch missglückte leider.

Prảparat III F 7 (s. 258).

Einer typisch erkrankten Taube (Beinlähmung, Opisthotonus, Krämpfe) wurden am 2. Dezember um 11/4 Uhr vorm. 5 ccm einer $1 \%$ igen Lösung $(0,05 \mathrm{~g})$ in den Brustmuskel eingespritzt. Um 4 Uhr nachm. Opisthotonus und Krämpfe geschwunden. Paresen der Beine etwas zurückgegangen. Nochmalige intramuskuläre Einspritzung von $5 \mathrm{ccm}$ der $1 \%$ igen Lösung. Am 3. D e ze mber früh sehr ausgesprochene Besserung: Lebhafte Fresslust. Der geschliffene Reis wurde eifrig von der 
Beitrag zur Kenntnis von organischen Nahrungsstoffen mit spẹzif. Wirkung. 271

Taube aufgepickt. Beinlähmung sehr zurückgegangen. Am 4. D e z e m b er ohne weitere Behandlung erheblicher Fortschritt: Beinlähmung bis auf einen geringen Rest zurückgegangen. Fresslust sehr rege. Am 5. Dezember Beinlähmung wieder stärker. Das Tier war sonst munter und zeigte auch sonst lebhafte Fresslust.

Da die vorhandene Menge des Präparats aufgebraucht war und die Lähmungen wieder zunahmen, wurde die Taube mit getrockneter Hefe behandelt, wobei sie sich schnell und vollkommen erholte.

Präparat III F 2 (S. 254).

1. Einer gelähmten Taube (ausgesprochene Lähmung der Beine and Flügel, kein Opisthotonus, keine Krämpfe) wurden am 25. 0ktober $191711^{1 / 2}$ Uhr vorm. $5 \mathrm{ccm}$ einer $1 \%$ igen Lösung $(0,05 \mathrm{~g})$ in den Brustmuskel eingespritzt. Bis 5 Uhr nachm. keinerlei Besserung. Nochmalige Einspritzung von $5 \mathrm{ccm}$ der $1 \%$ igen Lösung. Nach Verlauf einer Stunde ging die Taube ein.

2. Einer typisch erkrankten Taube (Paralyse der Beine, Opisthotonus, keine Krämpfe) wurden am 5. Dezember $1917 \mathrm{um} 9^{3 / 4} \mathrm{Uhr}$ vorm. $0,1 \mathrm{~g}$, in $3 \mathrm{ccm}$ dest. Wassers gelöst, in den Brustmuskel eingespritzt. Bis 4 Uhr nachm. keine merkliche Besserung. Nochmals intramuskuläre Einspritzung von $0,1 \mathrm{~g}$, in $3 \mathrm{ccm}$ dest. Wassers gelöst. Am 6. Dezember früh keine Besserung.

Die Taube wurde nun zu dem Versuche 3 mit Präparat I B 3 (S. 262) verwandt.

\section{Verzeichnis der aus hydrolysierter Hefe gewonnenen Abbau- produkte.}

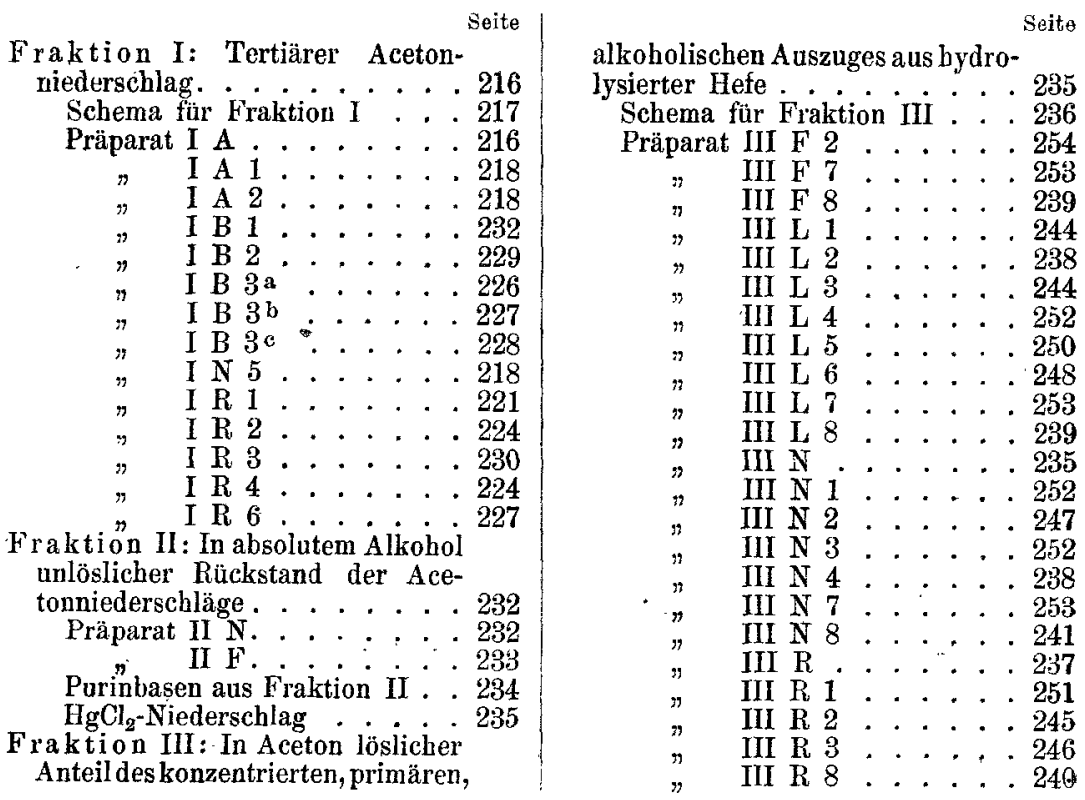




\section{Verzeichnis der Tierversuche mit den aus hydrolysierter Hefe gewonnenen Abbauprodukten.}

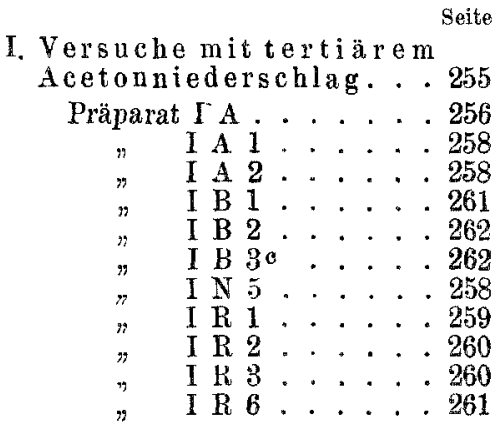

II. Versuch mit dem in absolutem Alkohol unlöslichen Rückstande der Aceton. niederschläge .... . 262
III. Im Aceton löslicher Anteil deskonzentriert., primären, alkoholischen Auszuges.

Präparat III F 2 . . . 271

III $\mathrm{F}_{7} \ldots 270$

III $5 \times 8 \ldots 266$

111 L $5 . .270$

III $\mathrm{L} 6 \ldots 269$

III $\mathrm{N}_{3} \ldots . .270$

III $\mathrm{N} 4 \ldots . .266$

III $\mathrm{N} 7 \ldots 270$

III N $8 \ldots 267$

III $\mathrm{R} . . .266$

III $\mathrm{R} 2 \ldots 268$

III R 2, salzsaures Salz 269

III R $3 \ldots . .266$

III $\mathrm{R} 8 \ldots 266$

III $\mathrm{N} 2 \ldots . .269$

\section{XXIX.}

1. Erläuterungen zu den Lichtbildern Nr. 1-37

(Tafel I bis III).

Nummer

1. Tauben bei einseitiger Fütterung mit geschliffenem Reis. Prodromalstadium vor dem Auftreten nervöser Störungen.

2. An alimentärer Dystrophie unter nervösen Störungen erkrankte Taube (S.168).

3. Dieselbe Taube $11 / 2$ Stunde nach intramuskulärer Einspritzung von 15 Tropfen einer konzentrierten Lösung des Acetonniederschlages aus hydrolysierter Hefe (S. 168).

4. An alimentärer Dystrophie unter schweren nervösen Störungen erkrankte Taube (S. 168).

5. Dieselbe Taube 1 Stunde nach Einspritzung von $0,15 \mathrm{~g}$ des Acetonniederschlags aus hydrolysierter Hefe, in $2 \mathrm{ccm}$ dest. Wassers gelöst (S. 168).

6. An alimentärer Dystrophie unter schweren nervösen Störungen erkrankte Taube (S. 267).

7. Dieselbe Taube: Streckkrampf 2 Minuten nach der intramuskulären Einspritzung einer wässerigen Lösung von $0,02 \mathrm{~g}$ des Präparats III N 8 (S. 267).

8. Dieselbe Taube nach der Behandlung mit $1 \mathrm{~g}$ getrockneter Hefe (S. 267).

9. An alimentärer Dystrophie typisch erkrankte Taube (S. 175).

10. Dieselbe Taube 2 Stunden nach der Einspritzung von $1 \mathrm{ccm}$ einer konzentrierten Lösung des Acetonniederschlages aus hydrolysierter Hefe (S. 176).

11. An alimentärer Dystrophie erkrankte Taube (S. 177).

12. Dieselbe Taube $3^{1 / 2}$ Stunden nach der intramuskulären Einspritzung von $0,01 \mathrm{~g}$ Eutonin aus hydrolysierter Hefe (S. 177).

13. Junge, an alimentärer Dystrophie unter starker Lähmung der Beine erkrankte Taube nach neuntägiger Behandlung mit getrockneter Hefe und sehr wirksamen Hefepräparaten. Die Lähmungen hielten hier trotz der erwähnten Behandlung 25 Tage lang an (S. 257). 
Beitrag zur Kenntnis von organischen Nahrungsstoffen mit spezif. Wirkung. 273 Nummer

14. An alimentärer Dystrophie typisch erkrankte Taube (S. 182).

15. Dieselbe Taube 17 Stunden nach Fingabe von $1 \mathrm{~g}$ Hefenukleoproteid (S. 182).

16-20. Dauerversuche mit Hefenukleoproteid Nr. 18 und 19 (S. 182).

16. Taube bei Beginn des Versuches (29. Januar 1917). S. 182.

17. Tambe nach 60tägiger einseitiger Fütterung mit geschliffenem Reis, bei täglicher Zugabe von 0,5 g Hefenakleoproteid (30. März 1917). S. 183.

18. Taube, 7 Tage nach der Herabsetzung der täglichen Zugabe von Hefenukleoproteid von $0,5 \mathrm{~g}$ auf $0,25 \mathrm{~g}$ an alimentärer Dystrophie typisch erkrankt (19. April 1917). S. 183.

19. Taube 24 Stunden nach einer einmaligen Gabe von $1,25 \mathrm{~g}$ Hefenukleoproteid +1 g Hefepräparat A (20. April 1917). S. 183.

20. Taube nach täglicher Zugabe von $0,5 \mathrm{~g}$ Hefenukleoproteid $+1 \mathrm{~g}$ Hefepräparat A bzw. nach 80 tägiger Zugabe von $0,5 \mathrm{~g}$ bzw. $0,25 \mathrm{~g}$ Hefenukleoproteid und 20 tägiger Zugabe von $0,5 \mathrm{~g}$ Hefenukleoproteid $+1 \mathrm{~g}$ Hefepräparat A pro Tag. S. 185.

21. An alimentärer Dystrophie erkrankte, schwer gelähmte Taube (S. 188).

22. Dieselbe Taube 17 Stunden nach einer Gabe von $0,25 \mathrm{~g}$ Hefenuklein (S. 188).

23. Dieselbe Taube 24 Stunden nach einer zweiten Gabe von $0,25 \mathrm{~g}$ Hefenuklein (S. 188).

24. An alimentärer Dystrophie unter schweren nervösen Stö́rungen erkrankte Taube (S. 189).

25. Dieselbe Taube 40 Stunden nach einer einmaligen Gabe von 0,5 g Hefenuklein (S. 189).

26. An alimentärer Dystrophie unter schweren nervösen Störungen erkrankte Taube (S. 261).

27.28. Reflexe beim Berühren des Rückens mit der Fingerspitze. (Sehr kurz belichtete Augenblicksaufnahmen.) (S. 261.)

29. Teilweise Besserung nach intramuskulärer Einspritzung einer wässerigen Lösung des Präparats I B 1 (S. 261).

30. An alimentärer Dystrophie unter schweren nervösen Störungen erkrankte Taube (S. 258).

31. Dieselbe Taube 16 Stunden nach der intranuskulären Einspritzung von $3 \mathrm{ccm}$ wässeriger Lösung von $0,005 \mathrm{~g}$ des Präparats I N 5 , Hefeeutonin (S. 258).

32. Infolge einseitiger Ernährung mit geschliffenem Reis an Beinen und Flügeln gelähmter Sperling (S. 160).

33. Füsse einer normalen Taube.

34. Ödematöse Füsse einer längere Zeit hindurch mit getrockneten Kartoffeln einseitig gefütterten Taube (S. 159).

35. Füsse derselben Taube nach teilweisem Schwinden der Ödeme, besonder's am rechten Fusse (S. 159).

36. Füsse derselben Taube nach dem völligen Schwinden der Ödeme (S. 159).

37. Apparat zum Filtrieren langsam durchgehender Hefeauszüge (S. 179).

2. Erläuterungen zu den Mikrophotographien Nr. 38-54 (Tafel IV und V).

Nummer

38./39. Präparat I N 5 (Hefeeutonin) mit einem Tropfen $1 \%$ iger Schwefelsäure langsam eingedampft (S, 219).

40. Einzelner Kristall des vorstehenden Präparats im polarisierten Licht stark vergrössert (S. 219).

41. Präparat I N 5 (Hefeeutonin) mit einem Tropfen 1\%iger Phosphorsäure langsam eingedampft (S. 219).

42. Platinchlorid-Doppelsalz des Präparats I N 5, Hefeeutonin (S. 219).

Pflüger's Archiv fúr Physiologie. Bd. 172. 
274 Emil Abderhalden und H. Schammann: Beitrag zur Kenntnis usw. Nummer

43./44. Pikrat der Substanz, welche bei längerem Stehen einer Lösung des Präparats I $\mathrm{N} 5$ (Hefeeutonin) in 100\% igem Alkohol ausfällt (S. 220). $\mathrm{Nr} .43$ schwächer, Nr. 44 stärker vergrössert.

45. Pikrat von Präparat I R 1, Betainpikrat (S. 225).

46. Präparat I K 6 (S. 227).

47. $n$ II R 1 (S. 234).

48./49. $\quad$ III R 2, salzsaures Salz (S. 245).

$50 . \quad " \quad$ III N 3 (S. 252).

51. $\quad " \quad$ III F 7 (S. 254).

52. $"$ III N 8, Pikrat (S. 244).

53.154. " " III N 8, Platinchlorid-Doppelsalz (S. 243). 
1921

d K1

(1)

$81 / 4$ 


$$
\begin{aligned}
& \text { IXst } \\
& \$ 1 \\
& \text { and } \\
& \text { Pek }
\end{aligned}
$$


Pflüger's Archiv f. d. ges. Physiologie. Bd. 172.

Tafel III.

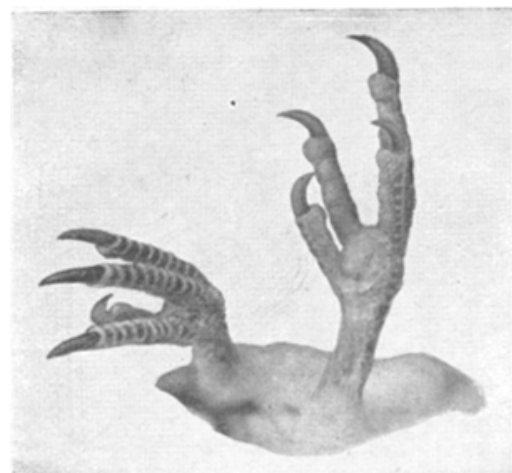

Abb. 33.

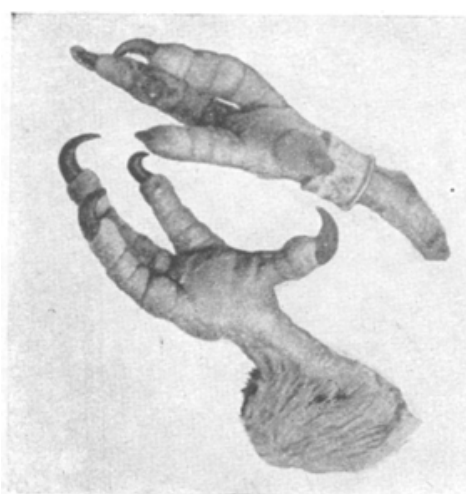

Abb. 34 .

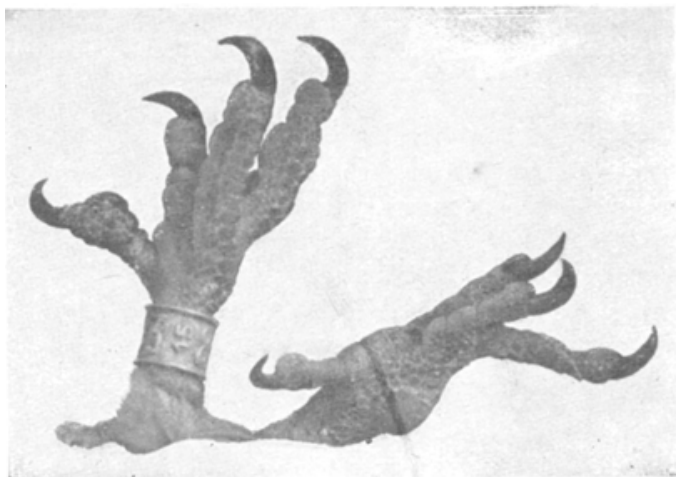

Abb. 35 .

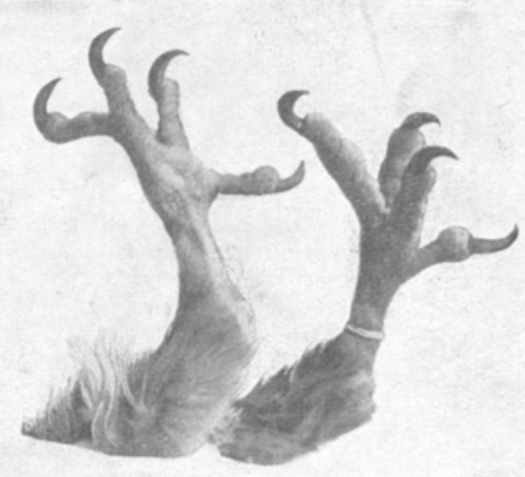

Abb. 36.

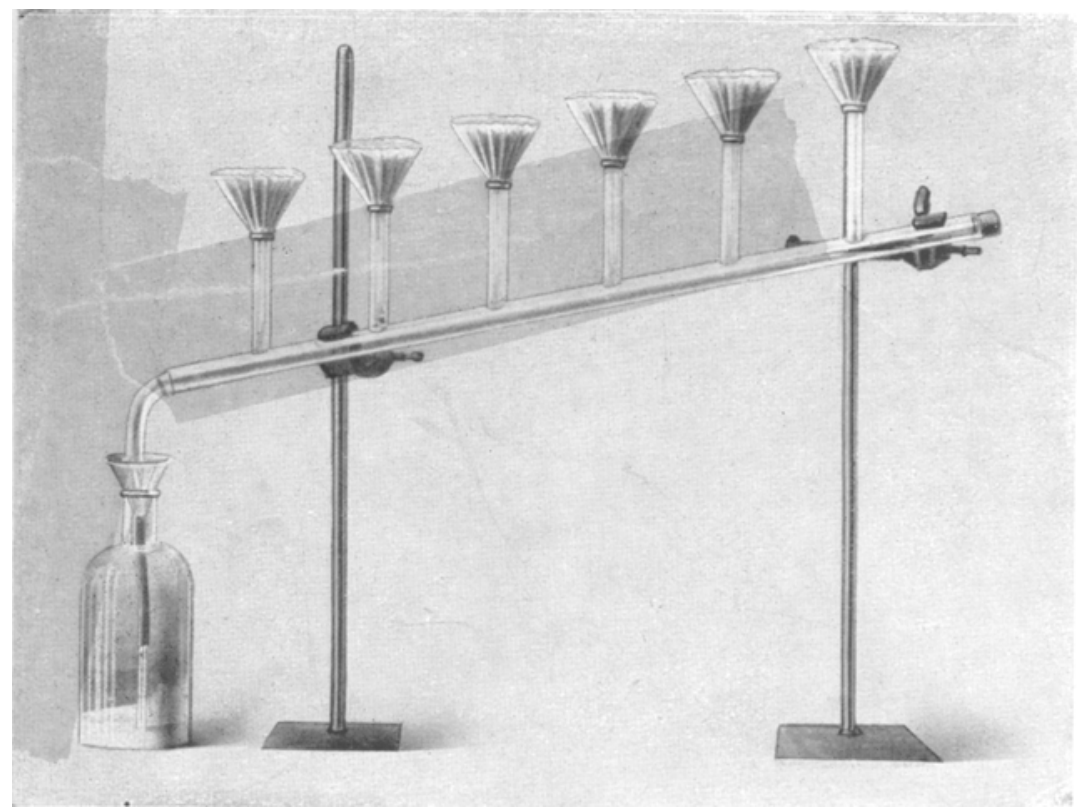

Abb. 37. 

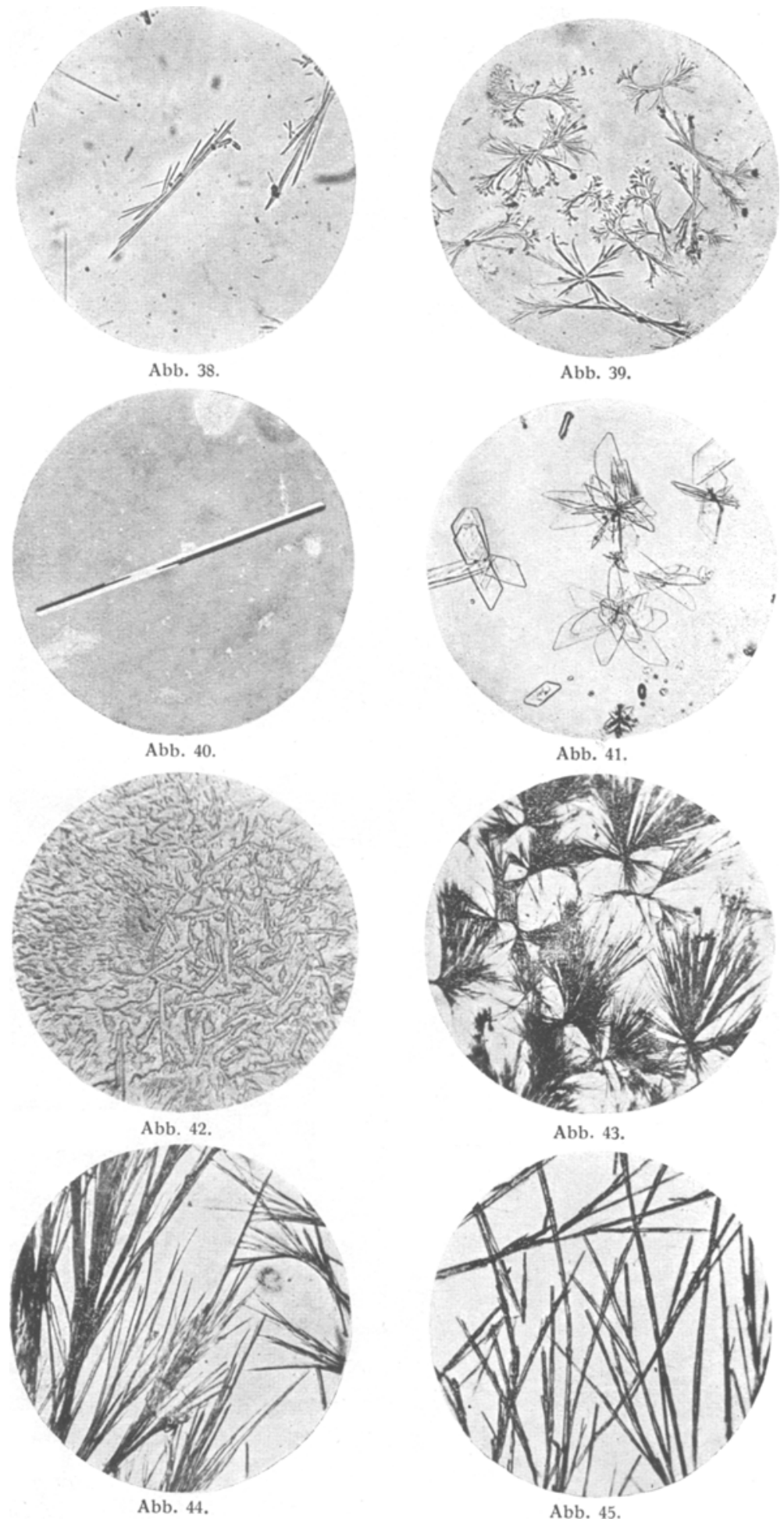

A vaerharden u. Schaumann, Kenntnis organ. Nahrungsstoffe. Verlag von Julius Springerin Berlin. 
Pflüger's Archiv f. d. ges. Physiologie. Bd. 172.

Tafel V.
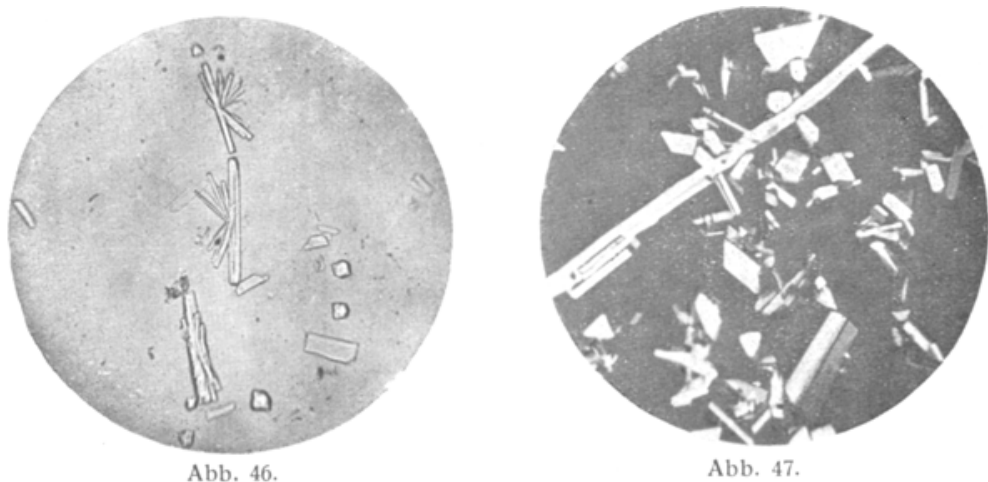

Abb. 47.
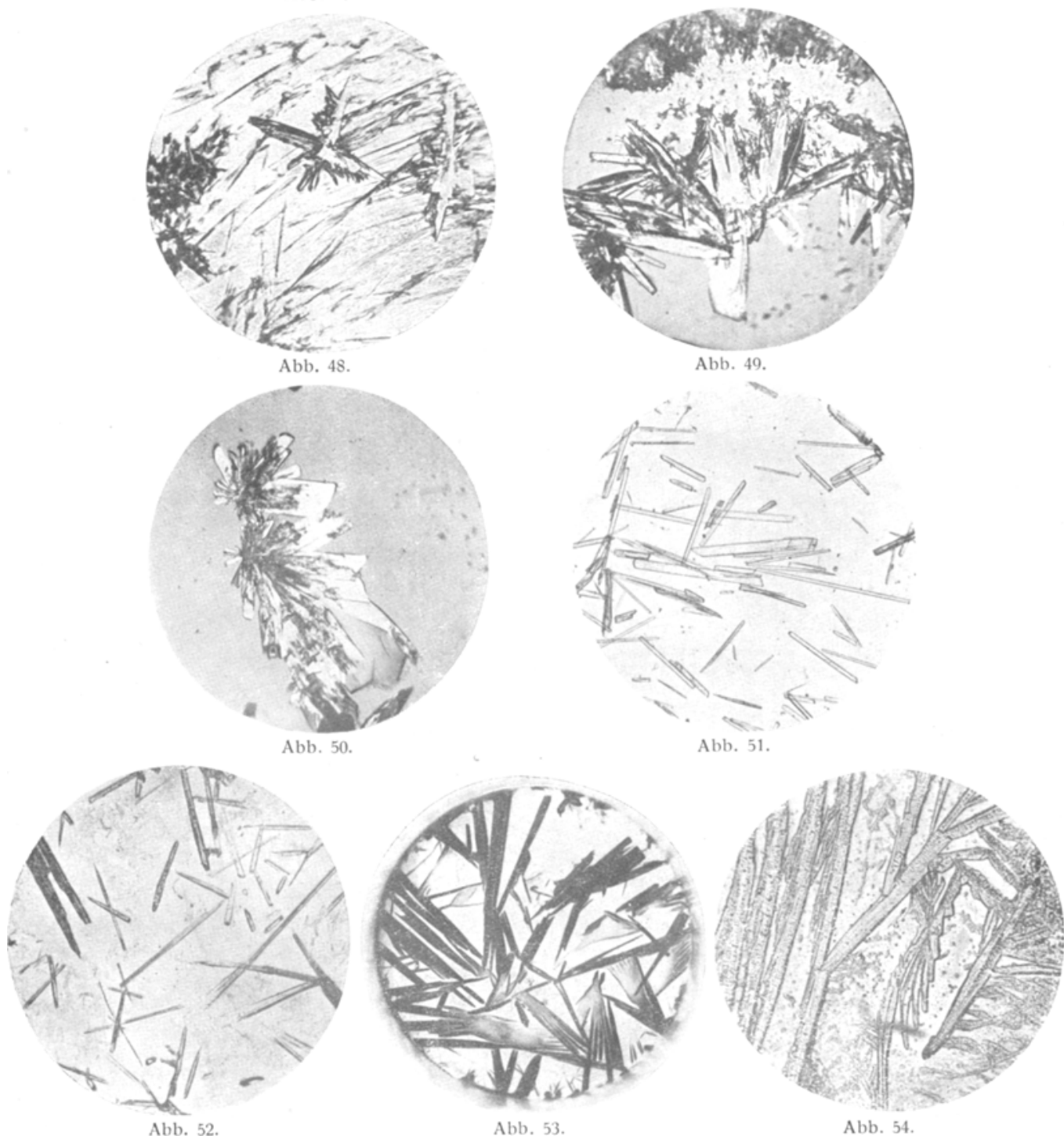

Abderhalden u. Schaumann, Kenntnis organ. Nahrungsstoffe. 